NIST GCR 15-1000

\title{
Risk-Informed Performance-Based Design Concepts and Framework
}

\author{
Brian J. Meacham \\ Alberto Alvarez-Rodriguez \\ Worcester Polytechnic Institute
}

This publication is available free of charge from: http://dx.doi.org/10.6028/NIST.GCR.15-1000

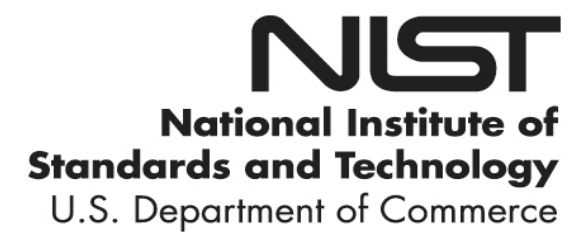




\title{
NIST GCR 15-1000
}

\section{Risk-Informed Performance-Based Design Concepts and Framework}

\author{
Prepared for \\ U.S. Department of Commerce \\ Engineering Laboratory \\ National Institute of Standards and Technology \\ Gaithersburg, MD 20899-8660
}

By

Brian J. Meacham

Alberto Alvarez-Rodriguez

Worcester Polytechnic Institute

This publication is available free of charge from:

http://dx.doi.org/10.6028/NIST.GCR.15-1000

March 2015

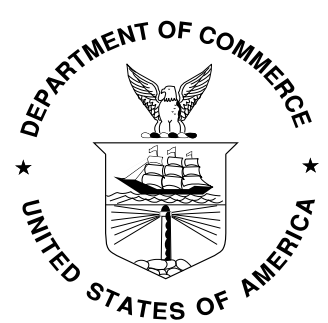

U.S. Department of Commerce

Penny Pritzker, Secretary

National Institute of Standards and Technology Willie May, Under Secretary of Commerce for Standards and Technology and Director 


\title{
Risk-Informed Performance-Based Design for Fire: Concepts and Framework
}

Final Report - NIST Award 60NANB10D228

\author{
Prepared by \\ Brian J. Meacham, Ph.D., P.E., FSFPE \\ Alberto Alvarez-Rodriguez, Ph.D.
}

Date

June 2014

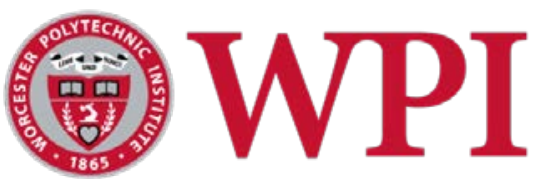

Department of Fire Protection Engineering Worcester Polytechnic Institute 100 Institute Road Worcester, MA 01609 USA http://www.wpi.edu/academics/fpe.html 


\begin{abstract}
A new framework for a risk-informed performance-based approach to fire safety analysis and design has been proposed. It is structured around a paradigm in which the performance analysis is conducted relative to the performance of a building-occupant system within a broader context of the managing risk of an acute event (e.g., fire) on the chronic state of the system. The role of risk characterization, targets and vulnerabilities, direct and in-direct impacts, and approaches for assessing and mitigating the likelihood of disruptive events on the desired performance of the building-occupant system are addressed. In addition, a test-bed environment, embodied within a web-based platform, has been proposed to facilitate a common location for data and information in support of risk-informed performance-based design. A key benefit will be the ability for practitioners, students and others to interactively use building geometries, data and analysis tools to gain and share experiences in the application of the new process. To support the test-bed environment, data have been collected and made available on heat release rate curves and associated information as part of a database on design fire curves, and a selection of building geometries for use fire effects, evacuation and other modeling and analysis have been compiled.
\end{abstract}




\section{Acknowledgements}

I would like to gratefully acknowledge the financial support provided by the National Institute of Standards and Technology (NIST) under award 60NANB10D228 which facilitated the research and outcomes as described herein. This award was used to support a large number of graduate students in the Department of Fire Protection Engineering who contributed to this effort.

I would like to especially acknowledge the significant effort and contributions from my co-author, Dr. Alberto Alvarez-Rodriguez, who through the course of his Ph.D. and post-doctoral studies developed the fundamental frameworks and components as described in this report and associated annexes. Dr. AlvarezRodriguez's work ultimately has provided a structure that can be used as a foundation for the next generation of risk-informed performance-based design for fire. I would also like to gratefully acknowledge other WPI graduate students who provided research in support of this effort: Manuel Hurtado, William Ivans, Jin-Kyung Kim, Matthew Ferreira, Arthur Gager, Kamal Aljazireh and Shane Cherney.

I would also like to acknowledge the contributions of Dr. Cornelius Albrecht, who illustrated during his post-doctoral research at WPI, how a reliability-based approach to risk-informed performance-based design which he developed during his Ph.D. studies fits into the overall framework and path forward for the future.

Finally, I would like to gratefully acknowledge the feedback and support of the NIST Technical Officer for this grant, Mr. Richard Peacock, for his guidance, feedback and facilitation of information interchange amongst the research team and researchers at NIST and elsewhere over the course of the project.

Brian J. Meacham

Project Principal Investigator

\section{Disclaimer}

All research, summaries, opinions, findings, conclusions and recommendations expressed in this report are those of the authors and do not necessarily reflect those of the National Institute of Standards and Technology or other sponsors, institutions, agencies or organizations which have supported this research. 


\section{Contents}

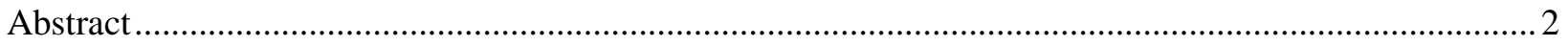

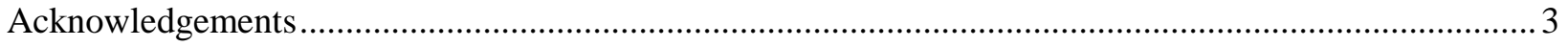

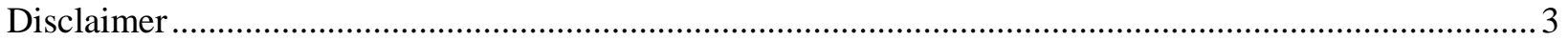

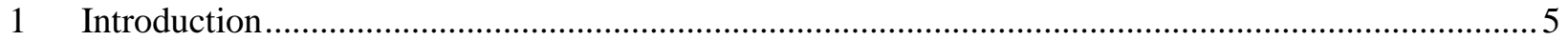

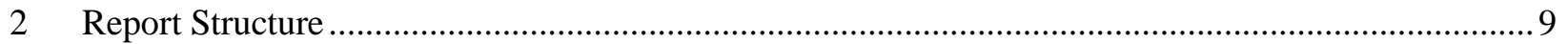

$3 \quad$ Need for New Performance-Based Design Approach .........................................................................11

4 Need for a Paradigm Shift to Accommodate New Approach............................................................. 13

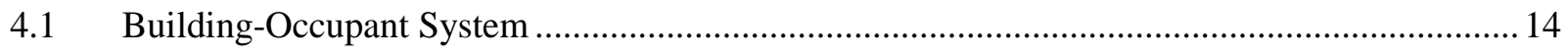

$4.2 \quad$ Chronic and Acute Operation ....................................................................................... 15

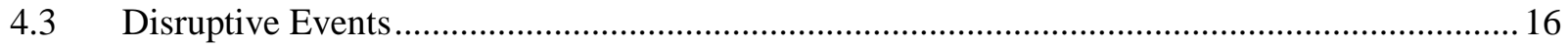

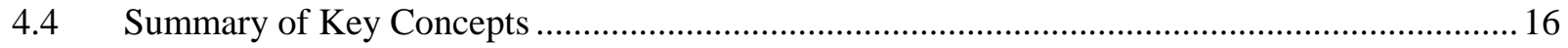

$5 \quad$ Framework for Risk-Informed Performance-Based Fire Design ........................................................... 18

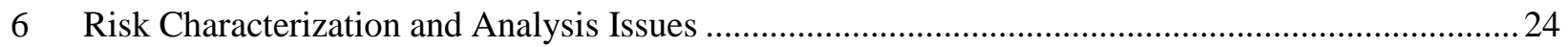

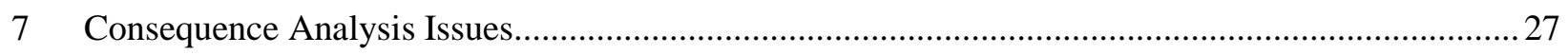

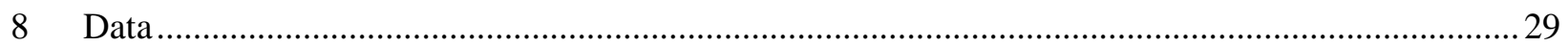

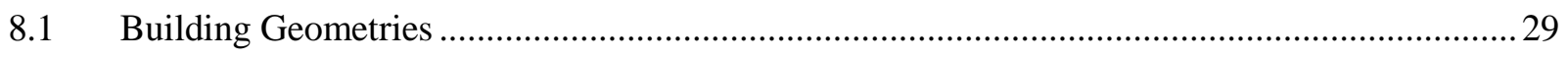

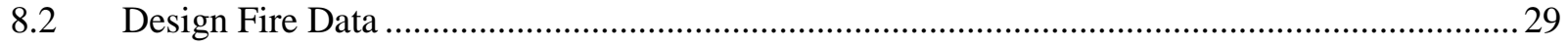

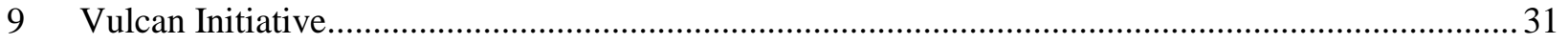

10 Outcomes, Ongoing Efforts and Recommended Future Research................................................... 33

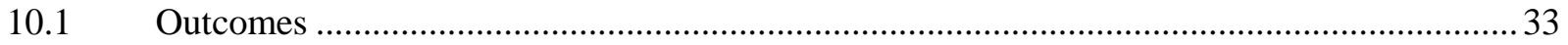

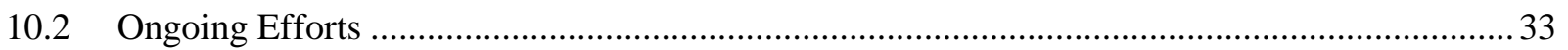

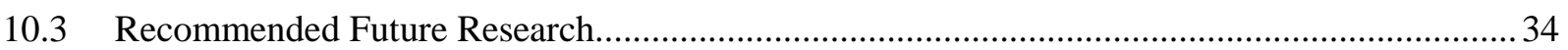

11 Summary and Conclusions..................................................................................................... 35

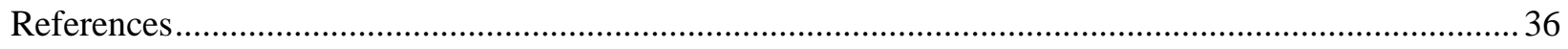

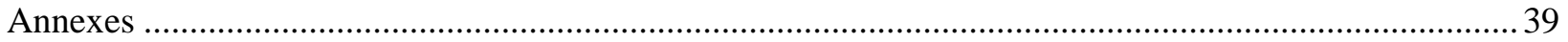




\section{Introduction}

Performance-based building codes have been implemented in numerous countries world-wide. In addition, performance-based approaches to fire safety analysis and design are widely used, both in countries with performance-based building codes as well as those with prescriptive-based codes. However, most building codes - prescriptive- or performance-based - lack quantitative risk, safety or performance criteria, and decisions regarding acceptance criteria often rests with the fire protection engineer and design team, often with no benchmarking against other buildings. As a result, there is a high degree of variability in fire engineered building design solutions and in the review and approval of these solutions, and therefore in the levels of fire safety provided in buildings that have been designed using performance methods. There have been few fire-related failures that can be attributed to "unacceptable" fire safety performance being delivered under the current performance-based fire safety design framework. However, performance failures under prescriptive codes and in other regulated areas, perceived quality concerns, and a desire to be more transparent have motivated several countries to try and better understand and quantify the level of fire safety and performance being provided in deemed-tosatisfy solutions (acceptable solutions, approved documents) and to establish quantitative measures for use in next generation performance-based building codes and performance-based fire safety design approaches.

In order to help address issues of risk and performance quantification, this effort began with the lofty goals of developing a methodology that could be used for identifying, quantifying and agreeing the level of building fire risk as reflected in building codes and in practice, and providing guidance for the development of quantified design fire loads and performance criteria which can be used in the next generation of performance-based building codes and fire safety design. The intent was to structure the methodology and guidance so as to achieve target levels of tolerable building fire safety and performance.

While significant progress was made in each of these areas, no 'magic bullet' was found which addresses all of the concerns in any particular area. There are several reasons for this, many which are obvious and generally understood in practice, while others which are more subtle, having been revealed during the course of this work. First, the problem is highly complex - combining social and political aspects of risk perception and tolerability with technological approaches to risk and performance assessment - in a data poor environment where a broadly agrees and comprehensive taxonomy is lacking. Second, fire risk assessment tools and methods exist, but targets or levels of 'tolerable' risk and methods to characterize them are not broadly agreed across social, technical, economic and political arenas. This starts with simple concepts such as who or what is at risk, from what, and what level of safety or protection is appropriate.

Similar challenges exist with respect to characterizing and defining performance expectations. While many engineering disciplines have defined 'performance' within their area, and assessment tools, methods and (some) data exist to support performance assessment, a common understanding across disciplines is lacking, and a structure for holistic performance characterization of a building is absent. This is particularly challenging with respect to development of a performance structure for regulation, which necessarily should consider all performance aspects in delivering a 'well-performing' building under the conditions expected and operation and use desired over the life of the building. This is not just an issue of different disciplines (e.g., structural versus fire), but manifests even when limited to a single 
discipline / performance area, such as fire. In the current paradigm, building fire performance related to life safety might be defined differently than building fire performance for property protection, which might be different from building fire performance for protection of mission. In the end, however, it is the performance of the building against fire - with respect to all performance objectives - which is important [1]. This can be illustrated by example.

On March 17, 2000, lighting struck the industrial plant of Philips NV, located in Albuquerque, New Mexico, USA [2]. As a consequence a small fire started within the facility but was extinguished by sprinklers and staff in less than 10 minutes. There were no injuries and the fire fighters arrived at the plant just to record a minor blaze. Considered solely from a fire performance perspective, this event and response could be considered a success. For example, following current performance-based design guidance, the objective may have been to limit the spread of fire, criteria may have been established for controlling a fire to a certain size, a sprinkler system was determined to be appropriate for fire mitigation, and in the end, the sprinkler system operated as intended and limiting the fire. However, this 10-minute fire ultimately resulted in some US $\$ 2 \mathrm{~b}$ in losses. How did this occur? It could be argued that the loss occurred as a result of focusing on code requirements, or even on a fire protection objective for the facility (e.g., limit fire size), and missing the impact of the facility fire performance on the company and those clients which this facility supplied. If the focus was on the broader performance of system in which the facility was only one part, things might have turned out very differently.

In this case, the Philips plant was engaged in manufacturing of semiconductor chips for some 30 clients, including the mobile phones companies Nokia and Ericsson, whose orders accounted for 40 percent of the Albuquerque plant's production. As one might expect, a semiconductor manufacturing facility such as this cannot tolerate any dirt or particulate in normal activities, in any of its clean rooms, much less soot in case of a fire. While the fire was small, therefore, the first order impacts could be anticipated to be high, particularly if soot or other products of combustion from the fire could affect the fabrication process or chip storage. This in fact occurred. However, that was not the sole contributor to the loss. Not only did the fire destroy the chip batches in the furnace (with an equivalent of thousands of mobile phone production) but also smoke, soot and the tramping of staff and fire fighters from the fire scene (in the mix of dirt and water) contaminated chips at every stage of the production, increasing that loss to millions of mobile phone chips. Unfortunately, the losses for Philips did not stop at the ones related to property damage. Phillips estimated that removing the dirt from the clean rooms would result in one week of down time. However, after two weeks, Philips staff realized that the disruption caused by the fire would take several weeks before production could restart. This had a significant impact relative to the responses to the fire from the facility's main clients, Nokia and Ericsson.

When Nokia and Ericsson were informed about the fire and Philip's initial estimate of downtime, they each dealt with the situation differently. The Nokia response was to work closely with Philips and other chip providers so to maintain its own production of mobile phones and satisfy its customers in a period of time when demand for this type of product was booming worldwide. Ericsson's reaction was different: they treated the fire incident at the Philips plant as a 'technical matter' which would result as a chip production disruption of one week only (Philip's original estimate), which is something that could easily be taken care of. Unfortunately for Ericsson, the disruption lasted longer and by the time it realized the size of the disruption, it was too late and Ericsson failed to deliver mobile phones to its customers. 
Having failed to deliver its new generation of mobile phones, Ericsson reported losses between US\$430 and US\$570 million in the first disruption-affected quarter. In addition to the fire disruption effects, incorrect product mix and marketing problems which followed contributed to what ultimately became a US $\$ 2.34$ billion loss for Ericsson's mobile phone division by the end of 2000. Results from this included loss of market share to Nokia, and to a merger of Ericsson with Sony for them to continue in the areas of design, production and marketing mobile of phones. By contrast, Philips's chip sale loss, estimated to a US\$40 million, was almost covered by a 39 million Euro settlement with its insurance company.

While one can argue that Philips ended up ok, at least as compared to Ericsson, the point is that a focus on fire protection system performance, as opposed to the overall system performance (manufacturer, insurer and client), led to intolerable outcomes. Examples such as this made it clear that 'performance' had to be recast in a more holistic way, such that the focus is not specifically on the fire and how people and systems respond to the fire, but on the impact that a fire (or other event) might have on the safety and operational performance of the 'system' within which the building resides. Likewise, at a building level, the focus needs to be on the broader 'building-occupant system' performance, and not just the fire protection systems performance. This is critical because the overall risk and vulnerability profile and operational and safety performance expectations of a building are ultimately a function of the 'buildingoccupant' system and how that system might be disrupted by a fire or other event, and less about the 'event-mitigation' approach commonly used today.

In reviewing the Philips fire and others [3], it also became clear that in order to better characterize the risk posed by fire within a 'building-occupant' system, specifically how likely it might be to have an event (fire) that results in an intolerable outcome (consequence), there is benefit to decoupling the frequency (probability, likelihood) of event occurrence from the analysis of potential consequences and the likelihood that they will occur [4]. It is also necessary to introduce the concept of targets and vulnerability in the assessment for both direct and in-direct consequences. The role of fire safety management over the life of the building is an important part of the assessment as well. It was also found that evaluation of the fire protection measures, in isolation and independent of how the building will be used throughout its life, might lead to a 'disconnect' between these measures and the context of the building in use. In numerous instances, investigation reports of fire events reflected how the interaction between the building, fire and occupants influence each other during events, and how normal use of the building could have a negative impact on fire system performance. This led to the understanding that the system within which fire protection is being designed needs to be considered in two states: chronic, or normal operation, and acute, or operation at the time an event such as fire occurs [1,4]. The fire disruptive event itself needs to be considered between two chronic states of the system, because of the importance of the recovery phase after fire extinguishment.

One sees this type of behavior happening over and over in the literature, often with respect to how people use buildings during a fire (acute state) in much the same manner as they have come to use the building during the normal (chronic) state (e.g., exiting the way they came in, failing to close doors behind them which might help control fire, ...). In a fire, evacuation becomes an acute response by building occupants for whom fire is a disruptive event, which occurs during the otherwise normal or chronic building use. Since means of egress are not completely independent from the other building components, such as rooms or other spaces delimited by doors, corridors, atria, both the chronic and acute environments need to be considered. If the chronic situation is to prop open the doors to facilitate normal use, for example, but 
there is an expectation that the doors will be closed during an acute condition (e.g., fire), then the expected building fire performance may not be achieved. This is a significant contributor to the risk assessment - reliability of expected system performance.

Analysis of the situation with current approaches to performance-based design also highlighted issues associated with lack of data for frequency and consequence analysis, and with wide variation in the application of tools and data for each. On the frequency (probability, reliability) data side, current guidance often points engineers to such resources as National Fire Protection Association (NFPA) statistics on fires in buildings of different occupancies. However, the data are often aggregated, and the classification NFPA uses is different than the building uses identified in the International Building Code (IBC) [5], which can be in turn have variations when one goes from a general classification (such as Institutional) to a specific type of institution (e.g., ambulatory care), to a specific building (hospital) design. The net result is that readily available data might not provide all that much guidance for a specific building design, and that more specific data and guidance as to how to use the data may be needed [6].

The same is true for the consequence analysis component. There is a wide range of tools available for fire effects, evacuation, structural analysis and more. Within each component, there is wide variation in the tools, the data required for the tools to be used, the certainty in predictive capability, user concerns and more $[7,8]$. More specific guidance is helpful, and is indeed needed. In addition, however, data in a format which can be consistently applied would also be helpful, especially in key areas such as design fire data. If one could collect data into a readily accessible place and present it in a readily useable format, provide guidance on how to use the data appropriately in the analysis tool, and provide users a platform for learning and applying the data and tools to common building configurations, the overall uncertainty in the performance-based design process and confidence in application of tools and data would go up. This research explored these issues in some detail, proposing a web-based environment (test-beds) within which data could be found, applied using tools to a variety of building configurations, to address a broad range of building fire performance issues, within the risk-informed performance-based framework [1, 79]. Of particular benefit to practicing engineers right away is the database of design fire curves and template for engineers and scientists to upload more for all to use [see Annex F and G]. In due course these and other data, tools and methods will be available via the Vulcan Initiative website, a portal established to facilitate information exchange, test-bed studies and more (http://www.vulcaninitiative.net/index.html, Beta version, last accessed 30 June 2014).

Ultimately, the above components and more have been integrated into a new framework for a riskinformed performance-based fire design [1, 4] and integrated into the Vulcan Initiative platform. While much more work is needed, the foundation has been laid by the effort to describe the necessary components needed to fully realize the new approach. Of particular need, in addition to data, is the development of detailed guidance documents, focused on specific occupancy types. A structure for how the guidelines can be prepared, and the type and level of detail of information required, is outlined in [1]. It is hoped that the Vulcan Initiative platform can serve as a mechanism for facilitating development of these guidelines in the future. 


\section{Report Structure}

As reflected in the introduction, a significant amount of research and development has resulted from this project, including publication of a Ph.D. dissertation and numerous journal and conference papers, compilation of design fire data for use in consequence analysis, and Beta-version launch of a web portal for facilitating collection, use, and advancement of data, tools and methods for use in a risk-informed performance-based environment. Given the availability of the publications in particular, this report has been structured to provide a brief overview of each research focus area and outcomes, with reference to the publication in which details can be found. In addition, where permitted, the publications are reprinted as annexes to this report. Several of the annexes have been provided as unique files as they are awaiting NIST CGR numbers.

The major sections of the report are as follows:

Section 3 - Need for New Performance-Based Design Approach: this portion of the report and associated reference papers discusses shortcomings in current codes, guidelines and practice, and where efforts should be focused to address these in next generation guidelines.

Section 4 - Need for Paradigm Shift to Accommodate New Approach: this portion of the report and associated reference papers discusses why a new way of thinking is needed in terms of considering the whole of building performance, and the role of the building and targets, as part of an integrated system.

Section 5 - Framework for Risk-Informed Performance-Based Design: this portion of the report and associated reference papers outlines the new framework, highlighting the major components.

Section 6 - Risk Characterization and Analysis Issues: this portion of the report and associated reference papers looks to the future in terms of thoughts for how risk characterization can be better accomplished, providing a potential approach.

Section 7 - Consequence Analysis Issues: this portion of the report and associated reference papers discusses issues with selecting the right tool for the job, addressing uncertainty and variability, and reminding engineers of the need to consider the dynamic integration of fire-people-building interaction as part of consequence assessment.

Section 8 - Data: this portion of the report overviews data collected as part of this effort, including data on HRR curves for use in modeling provided in associated spreadsheets.

Section 9 - Vulcan Initiative Website: this portion of the report and associated reference papers overviews the current Beta version of the website and the plans for future enhancement.

Section 10 - Outcomes, Ongoing Efforts and Recommended Future Research

Section 11 - Summary and Conclusions

Annex A - Alvarez Ph.D. Dissertation (NIST GCR pending)

Annex B - High-Level Comparison of IFEG, SFPE PBD Guide, BS 7974, and ISO 13387 (NIST GCR pending) 
Annex C - Alvarez unpublished manuscript for Building Research \& Information which discusses the paradigm shift and associated components.

Annex D - Albrecht life safety risk assessment of room-corridor arrangement

Annex E - Albrecht life safety risk assessment of atrium arrangement

Annex F - Guidelines for using "HRR Catalog”

Annex G - Interflam 2013 paper on Vulcan Initiative

Annex $\mathrm{H}$ - Structure and pages of Beta version of the Vulcan Initiative website 


\section{$3 \quad$ Need for New Performance-Based Design Approach}

To understand the context for why change is needed, a review was undertaken of worldwide experience using standards, codes and guidelines related to performance-based fire protection design for buildings over the past twenty or so years [1,3], building upon prior research of a similar nature [10-12] in order to obtain an up-to-date understanding of the situation. This benchmarking exercise identified examples of shortcomings in the interpretation, application and implementation of the performance-based design process, apparent inconsistency in the resulting levels of performance achieved and several opportunities to enhance the process, as summarized below [1, 3, 4].

- The application of generic guidance, as embodied in current performance-based design and fire safety engineering guidelines, to specific projects may result in important fire performance concerns being missed, especially but not exclusively by inexperienced engineers. Advising someone to 'develop fire scenarios' and 'consider occupant characteristics' is a good starting point, but does little to help identify how to actually construct a fire scenario, or what occupant characteristics to consider, or how occupant characteristics might change by building use or by country where it is located, etc. This need is also highlighted in [6], presented as Annex A.

- There are numerous shortcomings with the definition, use and quantification of performance / design / acceptance criteria by the fire protection engineer (FPE) on a one-off, project-specific basis, as opposed to applying them to all facilities of like type and characteristics. The first issue is that these criteria should be determined by policy makers, since they reflect minimum risk, safety and performance targets for public safety. This should not be an individual fire protection engineer decision. This is not to say that the fire protection engineering community cannot suggest criteria based on scientific and engineering knowledge, data and tools of evaluation, but that the policy makers should decide which criteria to implement and to achieve what targets.

- In current practice, the selection of design fire scenarios is focused on the evaluation of fire protection systems performance, often in isolation, rather than to test the holistic building fire safety performance and the performance of the building as part of a larger system. As discussed with the Philips example in the Introduction, failure to consider what ultimately determines acceptable or tolerable performance can result in fire protection designs which are ineffective when needed.

- Given the lack of data for undertaking quantitative risk assessments with a high degree of confidence, many engineers conduct comparative analysis between the levels of expected performance resulting from an engineered solution with the levels of expected performance based on prescriptive requirements that are devoted to protect building occupants. However, as reported in the literature these are often undertaken without an appropriate or comprehensive basis of comparison, especially considering that the prescriptive provisions most likely did not consider any specific fire scenarios or quantitative performance targets. There are risk-informed approaches, however, which can be effective comparative analyses (see Annex D).

- Current fire engineering guidelines contain insufficient guidance to determine the most influential factors affecting the efficacy of proposed fire protection design solutions. In part this comes from the lack of guidance identified above, but also the lack of requiring identification and treatment of uncertainty, and demonstration of robustness of the design through sensitivity analysis and other tests. 
- There is significant shortcoming in current practice associated with assuming 'idealized' performance of fire protection measures (i.e., they will always work and they will always be in the same condition as at the time of design, omitting deficiencies resulting from age, users, etc.) as compared with 'real life' performance of installed measures. In reality, the efficacy of fire protection systems can be lowered by human action (e.g., blocking sprinkler heads, closing valves, blocking doors open, increasing fuel load) and general component aging and reliability issues. While current practice might require certain testing, inspection and maintenance be undertaken, there is widespread evidence of inuse systems not being in appropriate condition to perform as expected at the design stage.

- There is generally too specific of a focus on consequence analysis of design fire scenarios around narrow aspects of building component or fire safety system performance, without having the entirety of the required or desired performance picture adequately defined. This again touches on the Philips type problem: the sprinkler system worked as designed, but the overall performance of the fire safety system (which should have included post-fire procedures) failed.

- There appears to be significant use of 'literature values' (i.e., input parameter values found in the literature) in analysis and modeling without demonstration that the values are appropriate to the specific problem at hand, or that the values are the appropriate ones to use (as selected from multiple options).

In a related effort, evaluation of a set of existing, English-language guides and standards on performancebased design for fire and fire safety engineering was undertaken to identify commonalities and areas of significant difference (see [13], included as Annex B). As with the review by Alvarez, it was found that while common structure exists, and some guides / standards go into more detail than others, as Alvarez also found the guidance is generic with respect to how one specifically identifies occupant and building characteristics of concern, fire scenarios of concern, design basis fires that are appropriate, and suitable criteria to apply, as well as the extent to which uncertainty and sensitivity should be addressed in the evaluation of proposed mitigation options.

In order to overcome the challenges identified during these reviews, it is suggested that the solution is to: (1) re-center the performance-based fire protection design process on the subject of its application, that is to say the system formed by the building and its occupants, as opposed to fire protection systems assessment; (2) create a risk-informed performance-based fire protection design process wherein the level of detail in guidance documents is increased and focused on specific occupancies and characteristics; and (3) provide a mechanism to help fire protection engineers select the most appropriate tools and data for the types of applications they are considering. How this can be achieved is addressed in subsequent sections. 


\section{Need for a Paradigm Shift to Accommodate New Approach}

While a wide range of definitions and criteria exist in the literature, it is suggested that main drivers for application of performance-based design (PBD) include demands from stakeholders for better building performance in use across a wide range of stakeholder expectations, in conjunction with a change in legislation allow a broader use of engineered options instead of simply fulfilling prescriptive requirements. Within a PBD framework, the demand of the 'end users' of the building (i.e. building occupants) become priorities so that PBD provides a more 'client' oriented process than the one used when following building code regulations. Conceptually, a PBD approach can be applied to all the components of a building project, including among others, acoustics, aesthetics, operability, sustainability, and safety. It involves numerous actors, including on one hand the building users who should define the level of performance of the building, and on the other hand, the building industry which should create optimal solutions in order to achieve this level of performance within a regulatory framework established by policy makers.

However, because of the complexity of the engineering thinking related to these building components, PBD guidance has been (a) segmented such that each engineering discipline has to consider separately how clients' objectives connected with each of the building components should be achieved, and (b) 'genericized' to accommodate multiple solutions. This applies not only to design of building components dedicated to the normal use of the building (e.g., mechanical components including heating, ventilation, and air conditioning (HVAC) and plumbing) but also to building components installed to address disruptive events, such as fires, earthquakes, or any type of emergencies susceptible to affect the safety of building occupants or damage the building contents and structure. As such, while PBD guidance has thus far been elaborated to treat discipline-specific 'normal' building performance (e.g., energy, HVAC) and specific safety objectives (e.g. fire and earthquakes) those conducting analyses must have specialized expertise, and there is little integration across or between disciplines. In practice, however, the building end users are not really interested in the performance of individual building components and systems, but rather, the performance of the building as a whole. To achieve this, the design team is expected to address the multitude of building components and systems and have them co-operate in order to achieve this seamless daily performance for both normal use and during and after disruptive events. This does not always occur as well as would be hoped.

Therefore, given the shortcomings in the existing approaches relative to needs of uses, a new paradigm for building performance was developed around the concept of 'building-occupant' systems, for which a new risk-informed, performance-based analysis and design approach was structured based on how 'disruptive events' perturb the system. In brief, the idea is that instead of focusing on the performance of a particular technical system to function as intended (e.g., defining acceptable performance of a sprinkler system as activating at a certain fire size), the performance assessment should be conducted in the context of how the technical system helps to achieve the user-defined performance of the building during and after the event (e.g., fire). For PBD for fire, this means moving away from performance defined in terms of performance of mitigation systems in isolation, to fire performance of the building-occupant system in achieving more global life safety, building performance, operational performance or related objectives. A summary of key elements of the new paradigm are provided below and detailed in Annex A [1] and C [14] and overviewed in [4]. 


\subsection{Building-Occupant System}

In many countries, buildings are classified in terms of the general class of use, such as places of assembly, business occupancies, residential, and so forth. However, these general descriptions lack the complexity to describe the interaction of the building users in the context of the building. To address this, it is recommended to identify more appropriate 'building-occupant' systems. An obvious way to categorize the different existing 'building-occupant' systems is to follow the classification established in building regulations. However, as pointed out in the Introduction and detailed in [1, 14], there is significant inconsistency in classification systems, and insufficient detail to adequately characterize building hazards and occupant risks. After reviewing several taxonomies and classification systems, a definition was developed: a 'building-occupant system' is a system defined by a structure (i.e., building) inside which occupants are engaged in a primary activity which can be quantified (e.g. activity number carried out by day or week) such that the performance of the system can be estimated by the level of the activity. In this paradigm, occupants are defined as persons who are physically inside the system, independently of the duration of their stay, and building components are defined as physical portions of the system, which can include spaces dedicated to a particular occupant activity (e.g., room for sleeping) of the system or in support of that activity (e.g. HVAC system).

If one looks at a hospital, for example, there are different building areas which can be identified according to the functions they provide, such as reception areas, emergency rooms, examination rooms, operating rooms, patient rooms and intensive care units. Any area which can be grouped by function is defined as a 'functional' zone, as they are created to fulfill the functions related to the daily objectives of the facility. In addition, there are utility areas which provide support functions, such as power, heating, ventilation and air-conditioning (HVAC), throughout the facility. These utility areas are to be identified as 'utility' zones, either as individual spaces (i.e., mechanical rooms, electrical rooms, cafeteria...) or throughout the building (such as the HVAC system). When designating zones, care should be taken to define them based on the 'building-occupant' system characteristics of importance. It is also important to identify direct and indirect relationships between the different areas of a system.

For example, Figure 1 illustrates the required level of detail for different functional zones of a hospital, describing the types of population in each of the zones. For instance, people located in the reception area are future in-patients, visitors and staff and almost all of them are mobile and conscious. This is important as they would require no or little assistance in case of a hazardous disruptive event such as a fire. Inpatients located in emergency rooms or in operating rooms are undergoing surgery and are connected to life-supporting machines. This is important as extracting them during a fire would require following procedures and requiring time that may not be compatible with a rapidly growing fire. In addition, while a utility zone supporting a reception area may be important to facilitate the comfort of the occupants, a utility zone supporting an operating room functional zone is essential. If a fire occurs in the utility zone supporting a reception area the impact in the reception area could be limited to an 'inconvenient' loss of power or lighting. If a fire occurs in the utility zone supporting the operating room, the impact could be life-threatening. 


\section{Hospital}

\begin{tabular}{|c|c|}
\hline Reception & Staff + in-patients (mostly mobile) + \\
\hline Examination & Staff + in-patients (not mobile and \\
\hline Emergency rooms & Staff + in-patients (not mobile) \\
\hline Operating rooms & Staff + in-patients (not mobile) \\
\hline Intensive care & In-patients (not mobile) \\
\hline Patient rooms & In-patients (not mobile and mobile) + \\
\hline
\end{tabular}

Figure 1. People description according different functional zones of a hospital

To summarize, characteristics of occupants within specific locations of a building, as well as the intended function of spaces in a building and contents in those spaces which are essential to achieving the required function need to be clearly understood, identified and categorized. This constitutes essential information required by the fire protection engineer (FPE) in order to address stakeholder objectives for 'buildingoccupant system' when elaborating a fire safety strategy. However, no current performance-based design process directs one to examine a building at such a level of detail, explains the reasons why such a level of detail is important, or provides guidance how to approach the assessment. In large part this is because current processes are focused too much on the fire event itself instead of being target-oriented, focusing on the objectives of concern within the specified functional zones or a well-defined 'building-occupant' system.

\subsection{Chronic and Acute Operation}

One can view buildings as having two states: chronic, or normal operation, and acute, which reflects some perturbation to the system (e.g., fire, power outage...). As long as things are generally fine in the chronic state, no thought is given to actions required during acute states. As noted above, this logic carries over to the performance of individual systems in a building. Generally speaking, building end users (e.g., owners, managers, occupants...) are not really interested in the performance of individual building components and systems, but rather, the performance of the building as a whole in maintaining acceptable conditions and operations in the chronic state. ${ }^{1}$ If the users can function well in the building, everything is fine. However, this can result in complacency with respect to maintaining systems which are infrequently used. This is especially true of systems which are only in place for emergencies, such as fire protection systems. As has been shown by reviewing the literature [1, 3], if the chronic state of the building is not considered during the design phase, assumptions about the efficacy of systems installed for use during acute states may be inappropriate (e.g., if it is assumed that fire doors will provide separation, yet it can be expected

\footnotetext{
${ }^{1}$ Building users clearly have some concern with systems which impact daily use (chronic operations), such as lighting, HVAC, elevators, etc. However, owners and managers are focused more on the fact that the building works to support their operations, without significant concern for small disruptions in individual support systems.
} 
that occupants will prop open the doors, the expected performance of the fire doors during an actual emergency may not be achieved. As such, as part of the paradigm shift, it is deemed imperative to consider how the building-occupant system is expected to operate in its chronic state, and from that assess the efficacy of mitigation measures during acute states (fire, other).

\subsection{Disruptive Events}

Primary stakeholders in a building project, including the building owner and the potential users, generally define building performance objectives in terms of the everyday uses of the building (chronic state). In a hospital, for example, this performance is related to the type of treatments offered, the number of patients who can be treated, the types of equipment and services needed to treat patients, and so forth. For a school, performance is related to delivering education to the target student population, the number of registered students, the numbers and qualification of teachers or faculty required to deliver education, etc. For a museum, it is related to the exhibits and holdings, number of exhibition attendees who can be accommodated, security of the holdings, etc. Unfortunately, the owners and operators of these buildings do not always think about events which can disrupt this daily use (acute states). This has an impact not only during use, but with respect to decisions made at the design stage. Disruptive events can be of different natures [2], such as: supplier business disruption leading to operational vulnerabilities; fires, earthquakes, severe weather, accidents or terrorism leading to hazard vulnerabilities; currency exchange fluctuations leading to financial vulnerabilities; or new foreign competitors leading to strategic vulnerabilities. Such disruptive events can significantly impact the operation of a building and the mission it supports. If the building owner and other key actors are unprepared, the disruptive event can have catastrophic effects on continued operations [15]. Thus, in the new paradigm, fire should be viewed as a disruptive event which causes a transition in the building-occupant system from a chronic state to an acute state, and assessment of the overall system performance should be made with consideration of both conditions, up to the establishment of a new chronic state.

\subsection{Summary of Key Concepts}

In summary, there are several key concepts in the 'building-occupant system' paradigm which need to be incorporated into the next generation risk-informed performance-based approach:

- Functional zones: spaces which are directly linked to the performance of the system (e.g. in hospitals, visiting areas where patients are checked in, patient rooms where patients are being prepared for surgery, operating rooms, intensive care units and patient rooms where patients recover before checking out);

- Utility zones: spaces which indirectly contribute to the performance of the system, often providing support to the "functional zones" (e.g. storage rooms, electrical rooms, mechanical rooms);

- Targets: key elements whose performance is of concern within systems (the actors or users of the functional zones). For example, targets can be building occupants (patients including their visiting families and friends and staff in hospitals, pupils and teachers in schools) or building contents (important piece of equipment required to contribute to the performance of the system such as a newly developed micro-chip in high tech industry or a priceless artifact in a museum); 
- Disruptive events: every possible event (technological events, natural events, socio-economical events) having an effect on the performance of the system. A disruptive event lasts between two chronic states of the system.

- Chronic states of the system: which represent the situations of the system while it is operating as designed or after each modification of its design (e.g. normal use of the system).

- Chronic objectives: objectives the system is designed or subsequently modified, to attain during its chronic states;

- Acute objectives: objectives the system is designed or subsequently modified, to attain during disruptive events;

- Event effects: damaging effects of a disruptive event on a target. These can be 'direct effects' or 'indirect effect.' With respect to fire as a disruptive event, 'direct effects' reflect fire-induced damage upon targets, such as heat, toxic, corrosive, irritant effects. 'Indirect effects' reflect loss of building components which are vital for the targets to perform in the system. For example, a fire can through 'direct fire effects' such as heat directly damage power cables to a life supporting equipment, which then has an indirect effect on the safety of people connected to this equipment.

Going forward, these concepts have a significant impact on how a risk-informed performance-based fire protection design should be structured. To understand and characterize the risk, one needs to understand the building-occupant system, how the users expect the system to work in its chronic state, and how a disruptive event can affect the overall system during acute states. Analysis cannot be 'genericized' to broad groups, such as 'occupants', but should be focused on targets (which may be occupants) in the context of the functional and utility zones of a building, as the criteria for acceptable performance may vary by location for the targets (e.g., a patient in an ICU will have different tolerances to fire effects than a nurse working in the same ICU). Analysis of the risk must then be considered for disruptive events which impact the chronic states of performance in each functional and utility zone in terms of both direct and in-direct impacts. This holds true for quantification of likelihood of disruptive event and estimation of the consequences. Risk and consequence analysis should consider the likely response of systems required only during acute states, and the likely response of occupants given their propensity to think in terms of chronic operations. Reliability and efficacy of the systems designs should be assessed in this context as well. 


\section{$5 \quad$ Framework for Risk-Informed Performance-Based Fire Design}

Given the challenges with existing performance-based fire protection design approaches, and the benefits to be gained from a paradigm shift which revolves around assessment of overall performance of a 'building-occupant' system during chronic states and as disrupted by unwanted events (acute states), considering target vulnerabilities across functional and utility zones, a new framework for risk-informed performance-based analysis and design was developed [1, 4, 13]. While developed with an eye toward fire as the disruptive event, the framework is robust enough to be used with any disruptive event (e.g., natural hazard, power outage), as the focus is on response of the system to perturbations rather than performance of individual system components with respect to their operation.

First, the new framework separates the political aspect from the technical one, concentrating the political aspect at the very start and the very end of the analysis and design process, leaving only the technical aspects to the fire protection engineer (FPE). In the context of this framework, the political process includes regulated issues as well as stakeholder decisions. The principle of this separation is illustrated in Figure 2. At the start of the process, the stakeholders define the project and present all of the characteristics of the 'building-occupant' system to be examined: building parameters, occupant parameters and functional/support zones used during 'chronic states' of the system. The stakeholders still have to agree on the main 'chronic' goals and objectives related to the considered 'building-occupant' system and indicate if specific building attributes are of concern (e.g., atrium, high rise configuration). These are considered political aspects of the problem, as decisions are required by others than the FPE alone. Once decided, all of this information is transmitted to the FPE who starts the technical aspect of the process by selecting fire risk acceptance metrics that corresponds to the considered project.

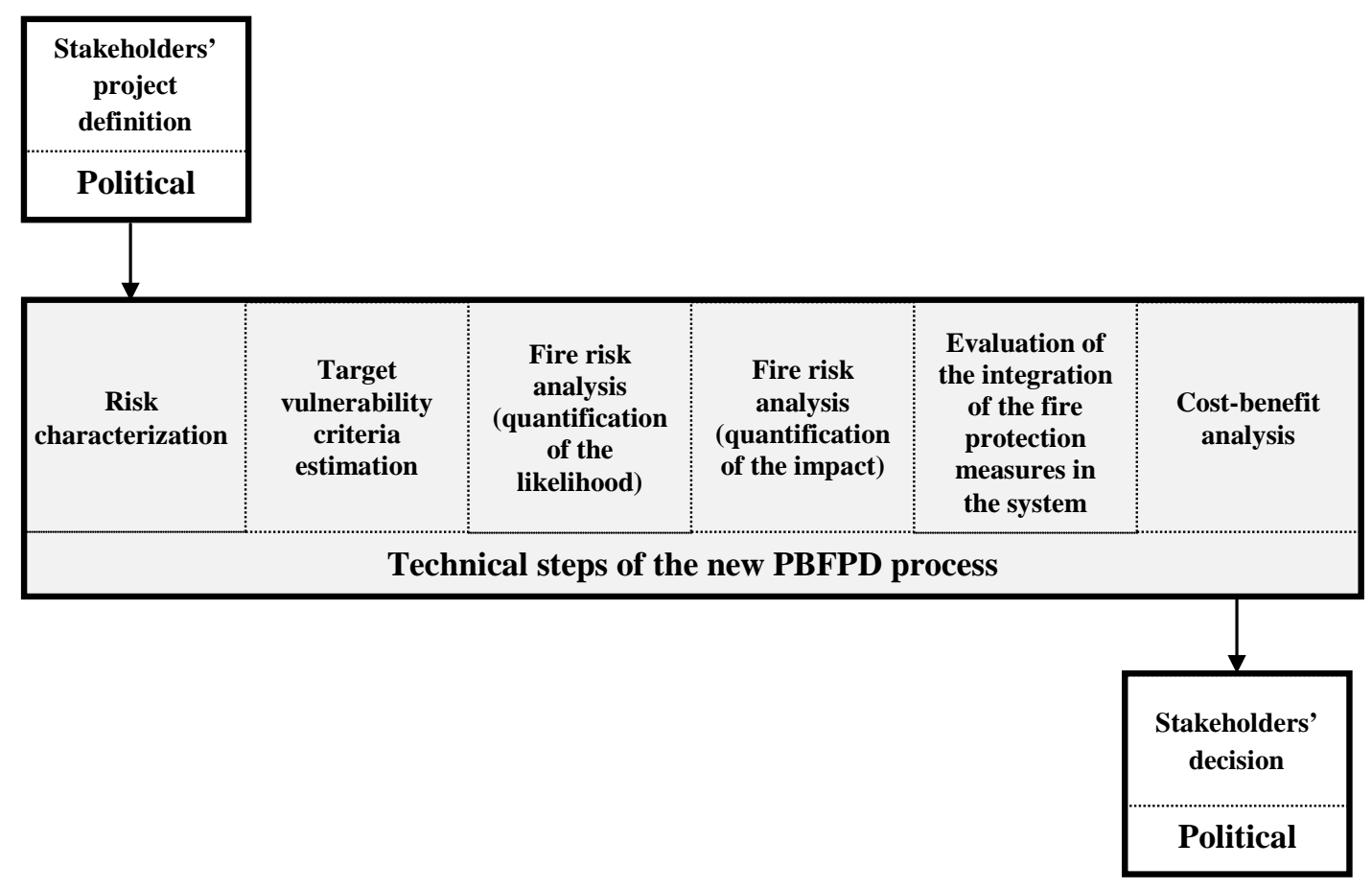

Figure 2. Risk-Informed PB Design Process [1, 4] 
The first technical step, risk characterization, is about translating the fire safety engineering problem from a stakeholders' perspective to a FPE perspective, where the FPE has must consider all the targets and define risk metrics relevant to the different targets of the studied system. During Step 1, fire risk curves or matrices are used to translate stakeholder risk and performance objectives into the process for assessing the performance of the system to withstand fire threats, according to how often and how damaging these threats are. This is schematically illustrated in Figure 3 [4].

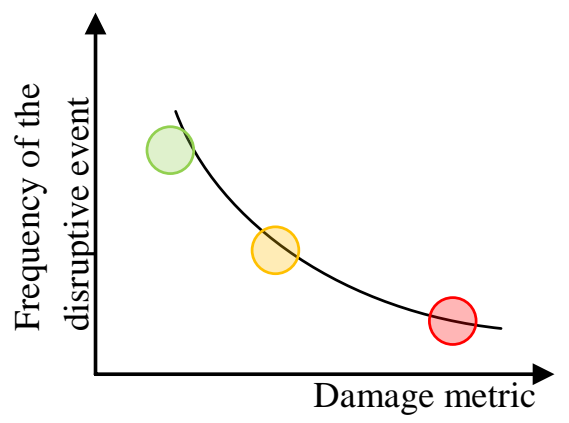

\begin{tabular}{|l|l|l|l|l|l|l|}
\cline { 2 - 7 } \multicolumn{1}{l|}{} & \multicolumn{5}{l|}{ Probability } \\
\hline & & Class 1 & Class 2 & Class 3 & Class 4 & Class 5 \\
\hline & Level 5 & & & & & \\
\cline { 2 - 7 } & Level 4 & & & & & \\
\cline { 2 - 7 } & Level 3 & & & & & \\
\cline { 2 - 7 } & Level 2 & & & & & \\
\cline { 2 - 7 } & Level 1 & & & & & \\
\hline
\end{tabular}

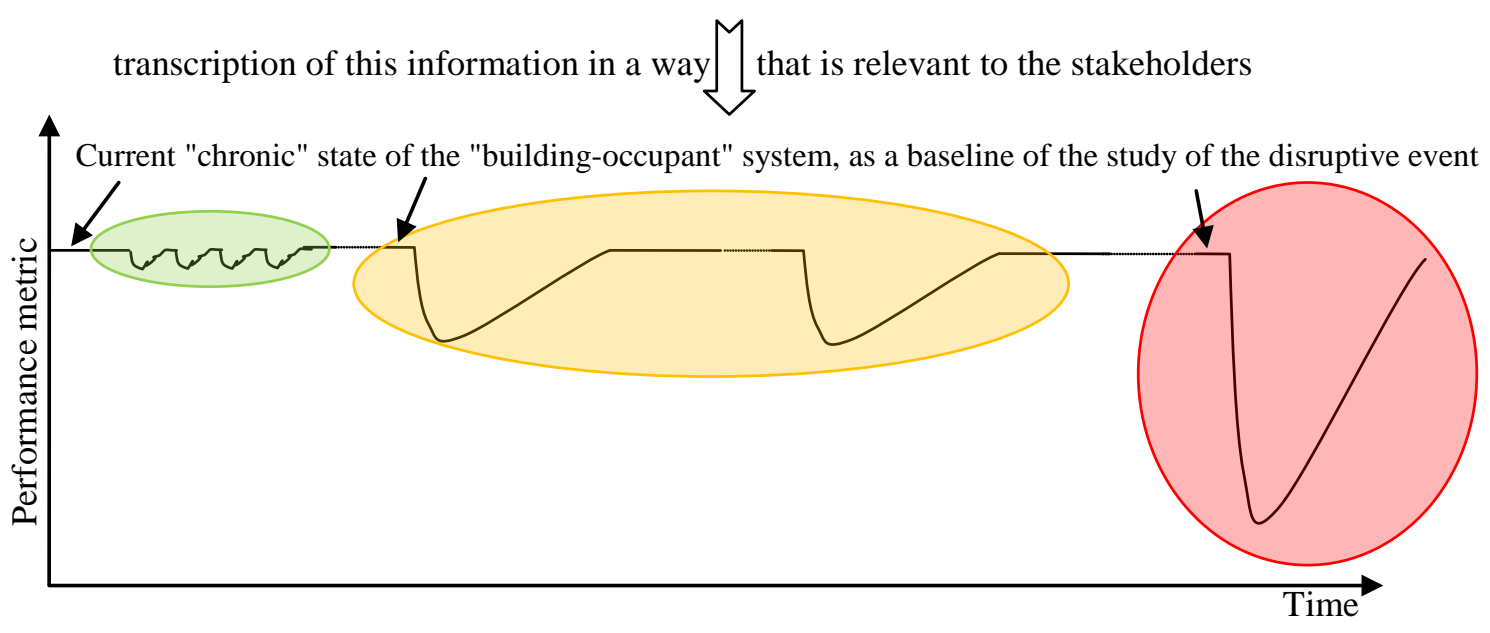

Figure 3. Risk Characterization [1, 4]

The stakeholders can then assess whether the performance of the building-occupant system meets their objectives, and if not, how they would modify the risk or performance objectives accordingly. This is illustrated in Figure 4. In this example, for a 'frequent' disruptive event, the stakeholders allow the performance of the system to be less than the one defined in the risk characterization: in other terms, they allow more property loss or a longer recovery time, depending on the damage metric. For a 'less frequent' disruptive event, the stakeholders allow the performance of the system to decrease as the one defined in the risk characterization. For a 'rare' disruptive event, the stakeholders do not allow the performance of the system to be less than the one defined in the risk characterization. Based on their performance requirements, a new fire risk curve can be constructed and fire disruptive events will then be assessed by their locations, in terms of (probability and consequences), relative to this new fire risk curve. 


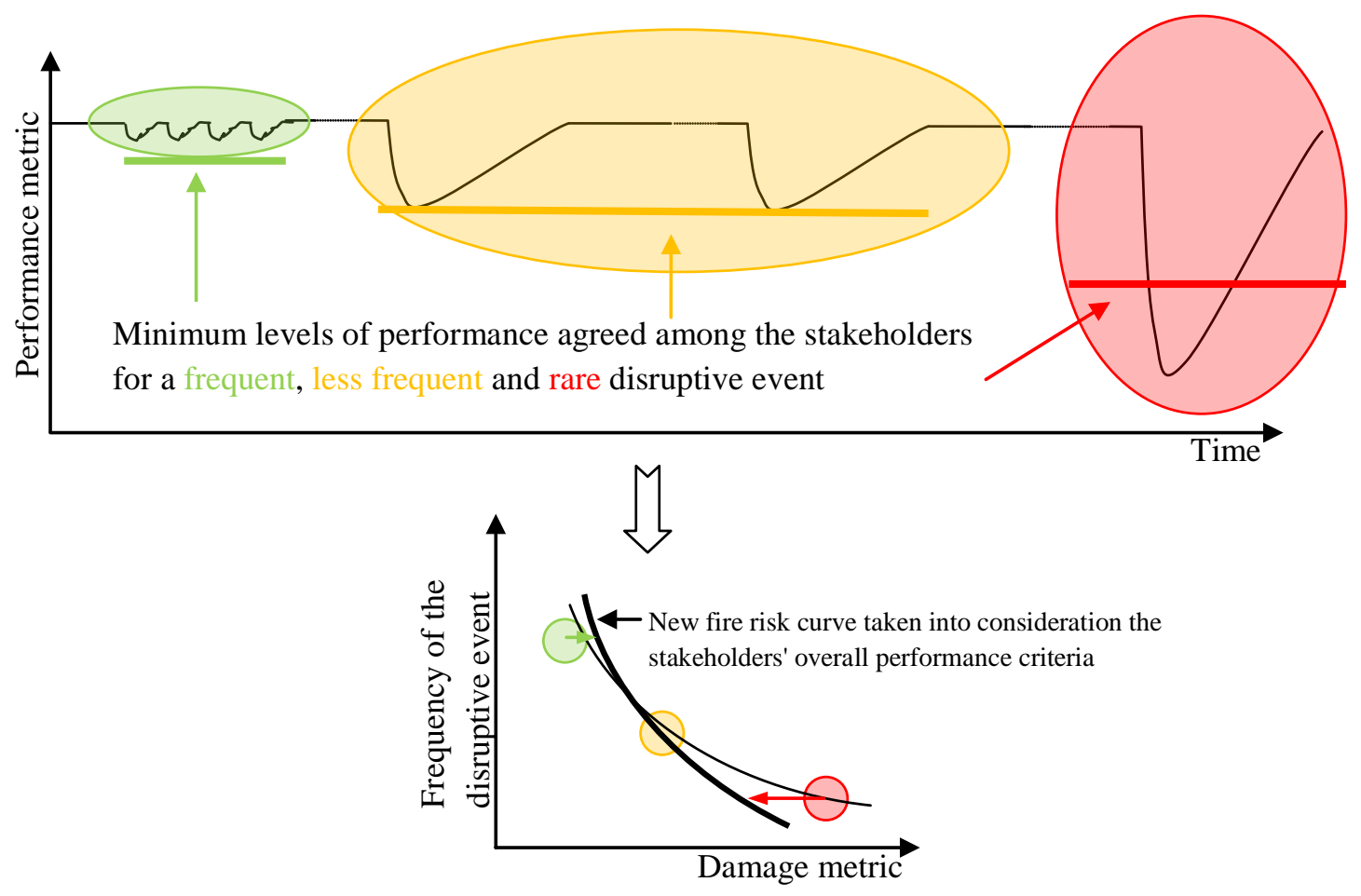

Figure 4. Risk Criteria Adjustment [1, 4]

In Step 2, the FPE gathers target vulnerability metrics according to the nature and characteristics of each target of concern (as provided by the stakeholders). The FPE must then quantify the vulnerability criteria for each target in case of the disruptive event (e.g. evaluating the mechanisms by which the disruptive event can have direct and indirect effects on each listed target while taking into consideration the capacity/incapacity of the target to absorb the damage from the disruptive event and still be functional/loses its functionality). These could be, for example, tenability criteria for occupants (which may vary by occupant characteristic or functional zone), thermal heat flux criteria for cabling or other critical equipment or utilities, whose loss might have an indirect effect on other targets as well (e.g., a patient on life support), and so forth.

The FPE then needs to gather information and functional descriptions of the building-occupant system, identifying critical components such as functional zones, utility zones, location, characteristics and vulnerabilities of targets... With this information the FPE can then undertake fire risk analysis, which is purposely disaggregated in the framework as frequency analysis (Step 3) and consequence analysis (Step 4). In Step 3 it is anticipated that the FPE will apply various fire hazard analysis (FHA) and fire risk analysis (FRA) tools, including failure mode and effects analysis (FMEA), fault tree analysis (FTA), event tree analysis (ETA), as appropriate. ETA can be used with zones containing targets to assess performance of mitigation measures, using most probable fire ignition locations from NFPA data or other statistics as initiation points of these trees. In conjunction, FTA can be used with 'affected targets' being the final/top point in order to capture the indirect threats to the considered targets. Overall, the aim of Step 
3 is for the FPE to assess and address fire events and associated responses that are relevant to the performance of the system in a quantified manner (i.e., assessment of fire events that could affect the stakeholders' targets and fire protection measures or safety barriers to prevent these events from occurring, with a frequency estimated on fire ignition frequencies and reliability of the considered fire protection measures).

Step 4 involves evaluation of event impact on the system targets. This involves analyses familiar to the FPE, including assessment of fire development and spread, response of people, structures other targets to fire, time for occupants to reach a place of safety, and so forth. However, the consequences should not be restricted to narrow areas of focus, such as occupant evacuation, but should be conducted within the context of the larger building-occupant system (again, consider the Philips case: the analysis may have demonstrated that the sprinkler could control the fire within 10 minutes of initiation, but likely missed the \$2B loss). Even when focused on a particular component (e.g., occupant safety), the issue of different target characteristics, different zones, and direct and in-direct impacts needed to be considered, as outlined in the hospital example above.

A key aspect of consequence analysis is quantification of design fires for use in assessing the potential for possible mitigation measures (trial design options) to deliver expected performance for the scenarios identified. A critical component of this analysis is selection of the design fire curve. Presently, little guidance exists on specifically how to construct a design fire curve, or from what data one should select suitable curves, and how to address associated uncertainty. In addition, a significant issue from the regulatory side is variability in the fire curves selected and used from one project to another and one fire to another. More on design fire curves and data can be found in Section 8 of this report.

When conducting consequence analysis, it is important to consider the dynamic conditions of fire development and target response in an integrated manner. Currently, for example, safety of building occupants is often estimated via the (RSET/ASET) concept. While this can be appropriate if applied correctly (that is, considering each occupant relative to the fire as the fire and evacuation progresses), the ASET/RSET concept is currently applied in too much of an independent manner: fire effects models are used to estimate the time to reach untenable conditions, while separately egress models are used to develop estimates the time required for the building occupants to reach a place of safety, and often there is no time-based integration of the separate models and the influences on each other. In addition, current guidelines do not contain enough guidance on how to treat uncertainty and variability: how changes in building, fuel or human factors affects fire growth, or how human factors impact time to reach a safe place, and overall how uncertainty impacts the results of the evaluation of fire scenario consequences.

With respect to the dynamic nature of the problem, the proposed framework focuses FPEs on the building-occupant system, which requires integrated analysis to be conducted of the building-occupantfire interactions. In addition, the framework includes a forum for collaborative projects, called 'test bed' environments [7-9], developed to facilitate the determination of the most appropriate tools, data and methods for FPEs to apply in order to quantify fire impacts for specific 'building-occupant' systems and for specific issues such as occupant evacuation, property protection or building structural response. With respect to uncertainty and variability, there are ways that this can be treated in a risk-informed manner. These include use of probability distributions on input variables for fire effects and evacuation models, and considering the cumulative probability function that is produced, such as described by Notarianni 
[16], Baker et al. [17], Lord et al. [18] and others. There are also reliability-based approaches which can be applied, such as described by Albrecht [19-21]. Examples of how Albrecht's are applied, and how fit into the new risk-informed performance-based framework, are presented in Annex D and E [21].

Ultimately, when the frequency and consequence analyses are complete, the FPE can propose sets of fire protection measures in order to minimize the occurrence of the damaging fires and mitigate the impact of these fire events on the system performance (i.e. the consequences of the fires events affecting the system targets). The benefits of various mitigation options, in terms of decreases of fire frequencies and impacts, can be synthesized in a risk curve as illustrated in Figure 5, with no protection measures, and with one or two sets of protection measures.

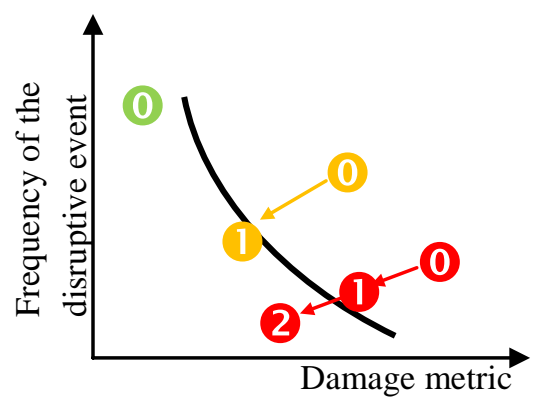

Figure 5. Impact of Mitigation Options on Risk [1, 4]

Step 5 of the new process is aimed to avoid critical situations where the fire protection measures installed in a 'building-occupant' system are ignored, or 'rejected' by this system, potentially leading to a catastrophe in case of a fire occurring. It does this by requiring the FPE to analyze how protection measures are used in the 'chronic' state of the building so as to try and prevent the measures from being counterproductive or 'rejected' by the system due to competing objectives or simple ignorance of the operation or benefit of the safety measure by building users. An example of a 'rejected' measure can be seen in the photograph in Figure 6, taken in a relatively new hotel (less than 10 years old).

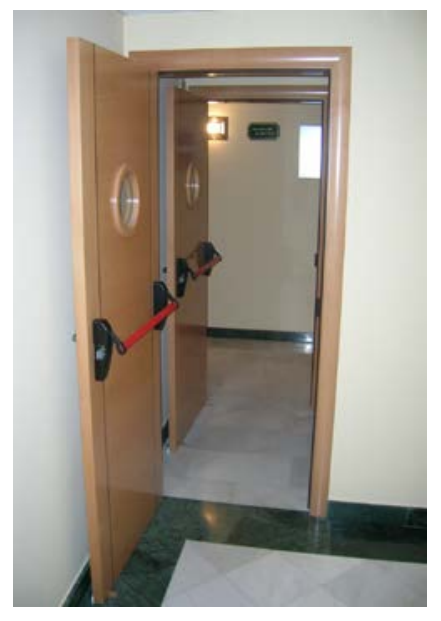

Figure 6. Hotel Stairway Lobby Vestibule [1, 4] 
The photograph shows a vestibule with two fire rated doors, designed to protect the single stairwell within the 5-story hotel, from being invaded by smoke in case of a fire [4]. The 'acute objective' is that the closed doors will prevent smoke spread. However, the 'chronic objective' is to the ease of passage of guests with luggage between the hotel rooms and elevator lobby, which is shared with the stairwell. In this case, the 'chronic objective' is achieved by blocking the doors open, which negates the protection designed for the 'acute' event.

Step 5 goes beyond the documentation of how the fire protection measures are designed, installed and maintained in the current PBD processes, which primarily focus on telling the building/owner manager what they should do to keep the protection systems operational, but do not take into account failure in the design process (e.g., see NFPA 101 Design Scenario 8), requiring the FPE to evaluate how the fire protection measures previously considered in the fire risk analysis would be integrated into the studied system, in other terms, if they are going to be compatible with the system components which are used on an everyday basis so they are not counter-productive and therefore ignored or worse rejected by the system.

Step 6 of the technical process is for the FPE to perform a cost-benefit analysis of the fire protection measures established during the fire risk analysis. Cost-benefit analysis is only suggested in current PBD guidance. However, a clear aim of stakeholders is to cost-effectively mitigation fire risks in the context of overall system performance, so this needs to be a required step. Returning to the Philips example, the fire safety system that was in place ultimately contributed to a \$2B loss: it is likely that had the expected value of the supply chain interruption was included in the overall assessment, it would have been possible to allocate more resource to preventing that situation.

At the end of the new risk-informed performance-based design process, a political decision is taken by the stakeholders based upon a technical analysis by the FPE, including results from a fire risk analysis describing how often and deep fire events would degrade the overall performance of the system, a document showing how the selected fire protection measures would be integrated into the system and a corresponding cost-benefit analysis of these measures.

While this framework might be unfamiliar to many FPEs, it actually mirrors quite well the risk-informed performance-based approaches which already exist in specific industries. In the nuclear power area, for example, the risk metric is based on core damage frequency (CDF) - not on fire in particular. The CDF is a political 'risk tolerance' criteria, in the USA set by the Nuclear Regulatory Commission (NRC), and reflects an unacceptable outcome from any 'acute event' (e.g., accidental failure, earthquake, attack, whatever - not just fire), and the fire risk assessment component focuses on potential for a fire in either a 'functional zone', such as turbine hall or control room, or a fire in a 'utility zone', such as a cable vault or switchgear room, to result in an unacceptable outcome. The 'targets' in the analysis are then any system or component that could lead to CDF, including cables, control equipment, operators, etc.

More detail on the framework and component parts can be found in the associated references and annexes to this report. In addition, a few critical issues and associated further research needs as outlined in Sections 6 and 7 that follow. Section 8 discusses data used and developed as part of the framework development, with Section 9 overviewing the web-based test-bed environment discussed above. 


\section{Risk Characterization and Analysis Issues}

Tools and techniques for fire risk analysis are fairly well developed (e.g., see [22]). However, guidance and techniques for fire risk characterization, while discussed in the literature and in guidance documents in broad terms [22-26], is lacking at a detailed level. A possible path forward has been identified as part of this research [1] but was not able to be advanced within the period of study. The proposed approach is briefly overviewed below.

Since risk characterization metrics are tied to the systems they represent, a possible formulation for these metrics is a fraction, where the numerator deals with the fire events in a defined period of time and the denominator describes a relevant parameter of the system. Different objectives may be considered by the different stakeholders. All stakeholders are concerned by life safety so the metric numerator should include parameters dealing, for example, with annual deaths and injuries caused by fires affecting the considered systems; the denominator would include some information relevant to the activity of the occupant in the considered building. For property protection, the numerator of the corresponding metric could include parameters describing, for example, the amount of damage due to fires, including direct and indirect fire damage. For business interruption, the metric numerator could include the number of days lost in production due to fire events in similar industrial systems. This approach was taken by Kobayashi and Nozaki [27]. Table 1 presents their findings related to commercial buildings, defined in terms of four different classes based on floor area and number of stories. Figure 7 presents the corresponding fire risk with an estimation of the damage area as a function of annual exceedance of probability.

Table 1. Calculations conditions for example risk curves [27]

\begin{tabular}{|c|c|c|}
\hline Classification & Median floor area $\left(\mathrm{m}^{2}\right)$ & Median Number of Stories \\
\hline Group "H" & 36,597 & 10 \\
\hline Group "LL" & 31,124 & 5 \\
\hline Group "LM" & 11,239 & 4 \\
\hline Group "LS" & 2,148 & 2 \\
\hline
\end{tabular}

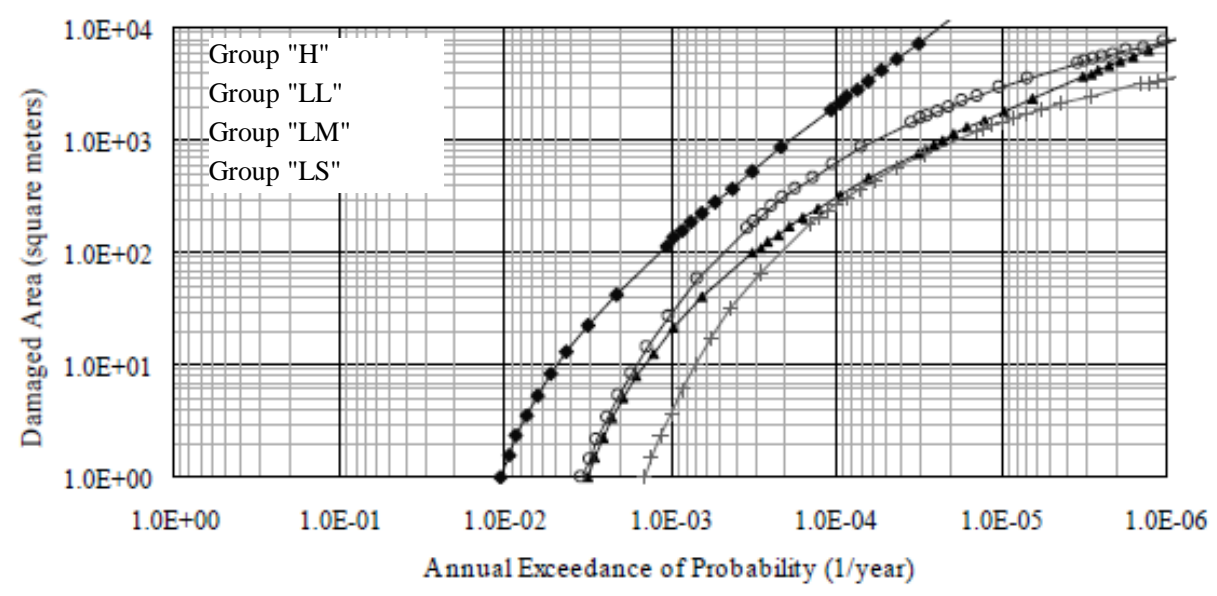

Figure 7. Example of fire risk curves for commercial buildings [27] 
Risk matrix or fire risk curves such as the one presented in Figure 7 can be established for 'buildingoccupant' systems, based on the corresponding fire statistics which describe the appropriate metric for each objective considered by the project stakeholders. For example, Tsujimoto [28] presented fire risks to Japanese occupants in residential buildings, hospitals and hotels from 1969 to 2000, as annual deaths per $10^{5}$ users' year stays in each kind of place with the corresponding metrics:

$$
\text { Residential buildings: } \frac{\text { annual deaths by residential fires }}{\text { population }}
$$

$$
\begin{gathered}
\text { Hospitals: } \frac{\text { annual deaths by hospital fires }}{\text { (total number of sickbeds in Japan) x (annual used rate) }} \\
\text { Hotels: } \frac{\text { annual deaths by hotel fires }}{\text { annual total number of hotel guests }}
\end{gathered}
$$

Based on these metrics, he presented the death risk a person takes at one night in each place:

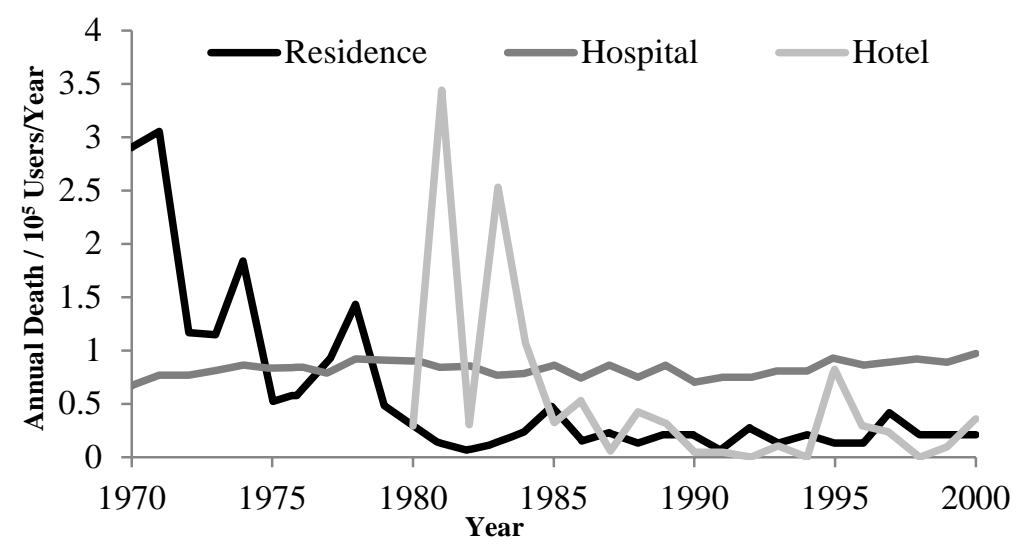

Figure 8. Death risk trends in selected Japanese buildings between 1969 and 2000 [28]

Particular care should be taken when aggregating buildings into a similar category. This situation is not only due to the evolution with time of building characteristics (e.g. open space office floors versus compartmented office floors) but also due to the evolution with time of building code prescriptive requirements regarding fire safety. For example, Tsujimoto [29] also looked at establishing a correlation

\begin{tabular}{|c|c|}
\hline 1961.4 & patients room over $4^{\text {th }}$ floor $\geqq 1500 \mathrm{~m}^{2}$ \\
\hline 1967.7 & $4^{\text {th }}$ floor to $10^{\text {th }}$ floor; floor area more than $100 \mathrm{~m}^{2}$ over $11^{\text {th }}$ floor \\
\hline 1973.6 & $\begin{array}{l}\text { total floor area is over } 6000 \mathrm{~m}^{2} \text { except one-story hospital; over } 11^{\text {th }} \text { floor; floor area more than } \\
1000 \mathrm{~m}^{2} \text { which floor is underground or without window }\end{array}$ \\
\hline 1974.6 & retroactive application to existing building \\
\hline 1988.4 & total floor area is over $3000 \mathrm{~m}^{2}$ except one-story hospital \\
\hline
\end{tabular}
between fatalities in hospitals and the number of beds with or without sprinklers.

Table 2. Transition of Requirement for Sprinkler Installation of Hospital (Fire Code in Japan) [28] 


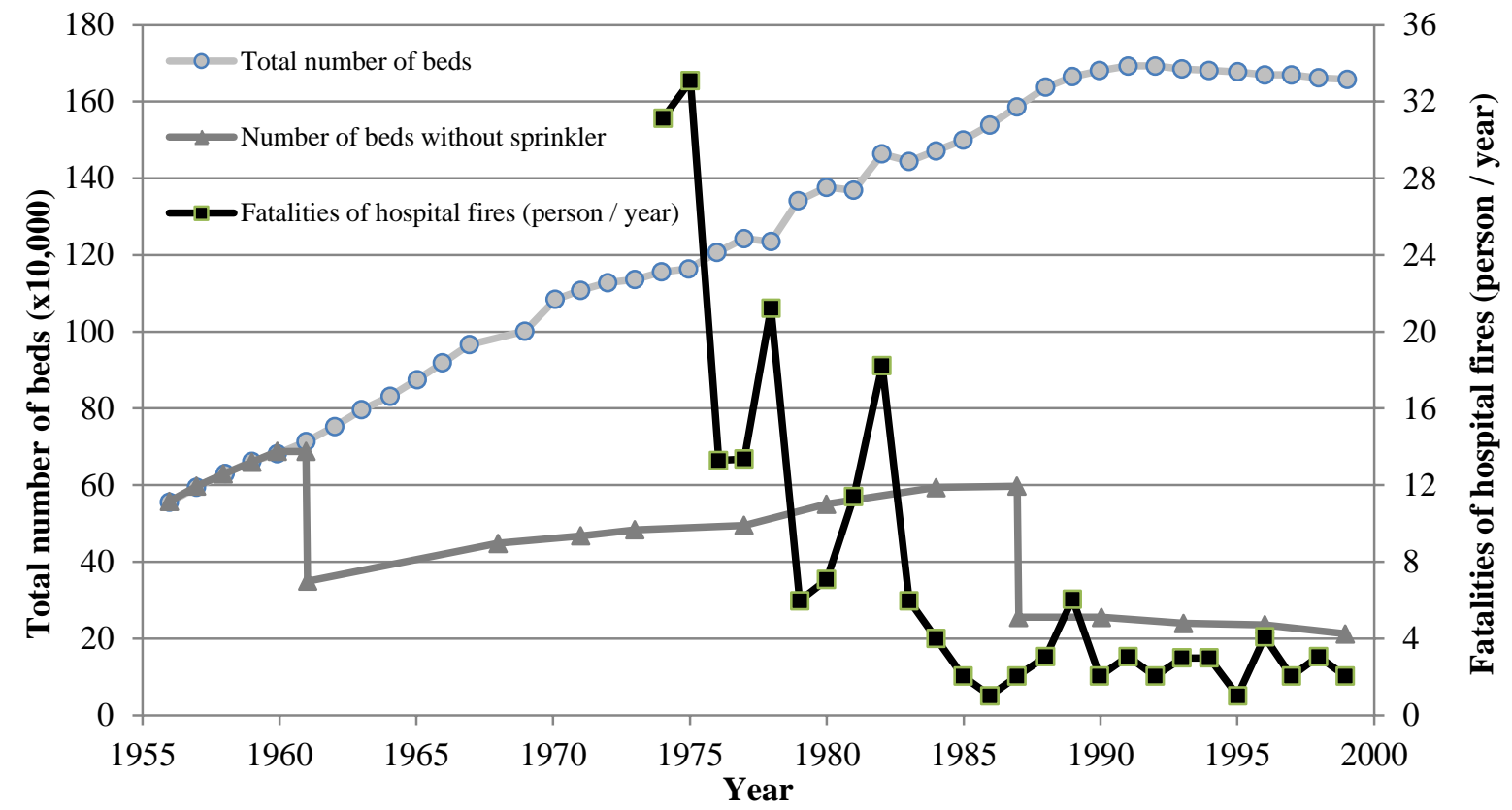

Figure 9. Correlation between Fatalities in Hospital and Number of Beds [28]

It should be noted that some information output collected while performing research for the risk characterization Step (e.g. information related to the characterization of fires and of the considered systems) can be used as input for the next steps related to fire risk analysis (fire likelihood and fire consequence evaluation). For example, while assessing information about fire statistics and past fire events, elements of information related to scenarios, fire ignition, fire propagation in terms of frequency and intensity of damage should also be collected. Also, within the 'building-occupant' system paradigm, characteristics of the different types of systems should also be collected so to have more information about the potential targets located inside the different parts of the systems. 


\section{$7 \quad$ Consequence Analysis Issues}

Most fire protection engineers (FPEs) are familiar with consequence analysis in terms of estimating outcomes of fire scenarios via fire effects modeling and evacuation modeling, and in some cases explosion analysis, structural response analysis and other specialized tools. However, as the use of computational tools for consequence analysis increases, there are associated concerns with predictive capability of the tools, both in terms of the tool itself and with respect to user decisions, including selection of the appropriate tool for the problem, selection of appropriate input data, proper characterization of the reliability of the prediction given uncertainty and variability of the input, and adequately linking dynamically-related issues, such as occupant influence on fire growth and spread during evacuation and how that is modeled $[1,8]$. In a risk-informed environment, various techniques can be applied to address variability in the overall risk prediction, as discussed in Section 5 (e.g., see [16-22]). However, at the consequence analysis stage, it is still important to develop reliable estimates.

As discussed in [7-9], the reliability of estimates can be increased with selection of the right tool for the problem, having reliable and consistent characterizations of the design fire, and taking care to integrate between fire-people-building interactions in the analysis. With respect to selecting the right tool, the decision should be made in the context of the level of accuracy needed in the prediction, predictive capability of the tool, and the availability of input data that is representative of the scenario being modeled. These issues are impacted by knowledge and time. As such, the 'right tool for the job' might change as a project develops. At the start of the project, in the feasibility and concept design phases, the level of detail in the analysis is quite low as the FPE can only provide an idea of the measures to install (based on the prescriptive requirements and the possible deviations to them) as data required to perform any analysis is still scarce. If fire effects tools are needed, algebraic models are mainly used, with a high calculation speed. During the scheme design, data related to the interior design of the building becomes available and more sophisticated tools can then be used, such as zone models. In the detailed design phase, the details of the project are known and 3-D simulations can be used - if needed and if time allows - as the time for analysis is shorter as we go along the project, running these complex simulations requires a considerable amount of time, compared to the use of previous tools, and since these tools generate a lot of useful information, data treatment of 3-D simulations is also time consuming.

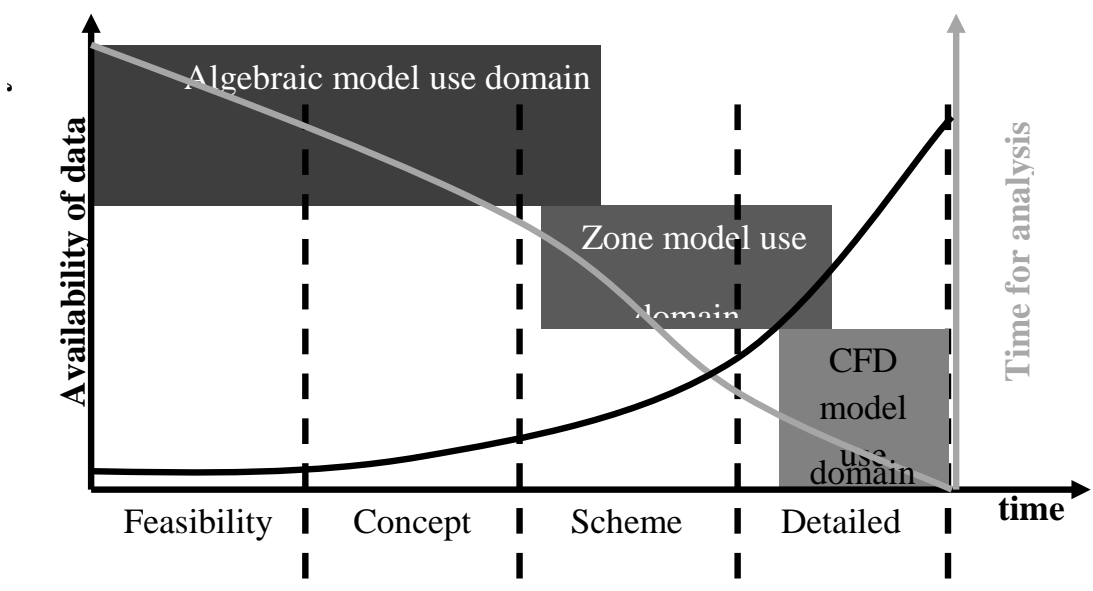

Figure 10. Fire effects tools domains as a function of a new building project phases [7] 
Figure 10 is applicable to the whole building project. If a specific safety point is known at the concept design phase, and if it is also known that the degree of details would require a more complex tool than an algebraic model or even a zone model, the FPE would have to somehow obtain, from the design team, the data needed in order to use such a more complex tool at the earlier stage. As stated previously, performing such calculations uses significant time and resources and the results are highly dependent on the input parameter values. Using input parameter values at the start, which in the end would be quite different from the ones that would be finally needed, could lead to dramatic changes in the design, not only of the fire protection features but also in the design of the building itself, and could mean expending considerable resource for limited value.

However, if a set of 'test bed' studies existed, which reflect similar projects, the information could place the FPE in a better position to ask the design team for needed input parameter values, or at least range of values, based on the experience of the test bed studies. This is one focus of the Vulcan Initiative (see Section 9), where on-line test-bed environments are envisioned to allow engineers to gain experience on determining what level of sophistication of tool is needed for what type of problem by conducting various exercises, and to obtain parameter values based on the exercises. An example of a parameter study which uses this concept is described in [29].

With respect to selecting design fires, there is a concern that while some sources of data exist, such in the SFPE Handbook of fire Protection Engineering, there can be inconsistency in which materials and associated heat release rate curves one selects (e.g., see [30], the format required for implementation of the HRR curve and related fire parameters into different tools, and the proper implementation by the user of the curve and associated data into a tool [6-9]). To help address these issues, data has been collected on fuel packages for use in fire effects modeling (see Section 8) and a test-bed environment is being created via the Vulcan Initiative (see Section 9).

Finally, it is important that while the future is integrated tools capable of managing fire and egress modeling, fire and structural effects, and until then, engineers need to develop guidelines on how to conduct the dynamic analysis which integrates fire-people-building interactions throughout the analysis process. 


\section{Data}

Risk-informed performance-based design is necessarily data driven. While some data sources exist, such as NFPA statistics on fires by occupancy types, or heat release rate curves in the SFPE Handbook of Fire Protection Engineering, the discipline still generally lacks qualified data for use in fire engineering analysis. In this project, the team looked at developing a mechanism to facilitate collection and use of data of all types - building configurations for analysis, fire frequency data, heat release rate curves, and more - in an environment that is readily accessible to practicing engineers, and which can be added to by practicing engineers, researchers and others. The mechanism is the Vulcan Initiative, as described in Section 9. Along the way, however, data of various types was gathered, in part to populate the initial generation of the Vulcan Initiative and well as to illustrate to others the type and level of data and information being sought to enhance the effort.

\subsection{Building Geometries}

This effort resulted in the collection of the following representative building configurations for use in performance-based analyses within the test-bed environment:

- A 5-story library, including shelves, individual booths, classrooms, storage areas, etc.

- A 3-story dormitory building including sleeping rooms, kitchen areas, etc.

- The reconstruction of the Station Nightclub, based on the simulations performed by NIST in the NCSTAR reports

- A two-story duplex based on the simulations performed by NIST in the Keokuk fire investigation

- A high rise hospital including patient floor, operating rooms, intensive care units, cafeteria, and an atrium

- A one-story hospital

- Several high-rise office buildings

Several of these building configurations have been formatted for fire effects analysis using FDS or other fire effects tools, as well as for evacuation analysis with two different evacuation tools (Pathfinder from Thunderhead Engineering Consultants and STEPS from Mott MacDonald Group). These building configurations will be available via the Vulcan Initiative website.

\subsection{Design Fire Data}

As part of this project, a "HRR catalog" in the form of an Excel spreadsheet has been established to be a free repository of information about one of the major components of risk-informed performance-based design: the Heat Release Rate (HRR) of a fuel item. One of the main sources of HRR data embodied in the HRR Catalog is the chapter by Vytenis Babrauskas in the SFPE Handbook of Fire Protection Engineering (Section 3, Chapter 1 for the $4^{\text {th }}$ edition). The objective for the HRR catalog is to collect heat release rates of "real products" or items that could be considered in an engineering analysis requiring fire modeling. Thus, the HRR catalog contains HRR evolution with time (called "HRR curves") of mattresses and wardrobes or of office worker cubicles that could be used to assess the consequences of a fire in a hotel guestroom or an office open space, respectively. 
The origin of the HRR catalog came after noticing that even if the SFPE Handbook chapter is unmatched in terms of extent of data it provides (as it includes real products alphabetically ranging from beddings to windows made of plastics), its printed format could be improved in the era of information technology. For instance, publication restrictions of the SFPE Handbook generate updates every few years ( $3^{\text {rd }}$ edition: 2002, $4^{\text {th }}$ edition: 2008) and it is not practicable to devote hundreds of pages on this particular but essential topic in a single book covering all the aspects of fire protection engineering. As a result, it was thought that providing information on the Internet would remove these restrictions in terms of space and content update. Attempts were made and webpages can be found but, unfortunately, instead of expanding the paper format, these webpages condensed even more the information presented in the SFPE Handbook under the form of tables.

Within the Vulcan Initiative, participants would have the opportunity to help implementing a database or catalog for heat release rates. A more pragmatic approach than a webpage configuration has been taken so that the information would not be contained (and therefore restricted) to the limits of webpage visualization but expended, as needed in separated and self-supported files. By its own nature, the heat release rate data is graphic and consists of the evolution of the HRR with time. Other information related to the test performed to obtain the HRR data can be associated with parameters such as the nature of the test, time to the maximum HRR or if additional measurements were made during the test (soot, CO...). As a consequence, it was decided to use a Microsoft Excel spreadsheet to gather all the information regarding heat release rates of real products. Excel presents the advantage to be relatively easy to use, widely known in Academia and work environment and with the latest version, it is possible to share the same document "on the Cloud" so that a single document is used and can be updated by multiple participants of the Vulcan Initiative.

The organization of the contents of the HRR catalog spreadsheet, and how a participant to the Vulcan Initiative can help implementing it for the benefits of the Fire Protection Engineering community, is provided in Annex F.

In addition, a 'Test_HHR_Catalog_raw_data” (raw data) spreadsheet has been developed. The Test HRR spreadsheet expands on work by a WPI student [31], who had collected approximately 50 heat release rate curves and associated information. Students in the Performance-Based Design course at WPI were asked to add HRR curves. However, many of the students deviated from the given format so a decision was made to compile all of the HRR curves into a single spreadsheet of 'raw data' to be formatted at a later time. This 'raw data' spreadsheet contains more than 200 potential items, which can be formatted to the now established templates included in the HRR_Catalog spreadsheet. The 'raw data' spreadsheet is submitted as to prove how potentially efficient collaboration can be between the engineering community who needs easy to use data and Academia who has the resources to deliver such data. Students joining the engineering community would also know that this data exists and how to use it.

The 'HRR catalog' and 'raw data' spreadsheets are provided separately. 


\section{$9 \quad$ Vulcan Initiative}

The Vulcan Initiative was created as a way to facilitate the establishment of guidelines for each technical step of the new risk-informed performance-based design process as elaborated in this report. In brief, it is a web-based portal where participants can access data, conduct analyses in test-bed environments, and upload data for use by others. The Beta web site contains the structure with which one can upload a 'project' for analysis and selected input sheets for data. A project contains the characteristics of a 'building occupant' system, such as the building layout, the list of stakeholder targets.

In the Vulcan Initiative, one participant willing to apply the new PBFPD process for a particular project will successively go through the following components: fire risk characterization will include databases on fire statistics and on the census of specific systems, fire damage criteria will include databases on how fire can affect people and building contents that are relevant to stakeholders for property protection or business continuity objectives. Fire risk analysis will include tools to assess the likelihood and the consequences of fires, as well as their corresponding databases relative to fire ignition frequencies, reliability of fire protection measures, production of heat and fire effluents from combustible packages, human behavior and structural response. Cost-benefit analysis will include tools to assess the cost of installing and maintaining fire protection measures in specific systems.

Participants to the Vulcan Initiative are welcome to upload the projects of their choice, at the present time even if there is still a lot of research to be undertaken to complete the guidelines. By doing so, they will provide needed input data which could be used for 'test bed' environment studies described above. By sharing the characteristics of their system and presenting the issues related to their project, these "project owners" could be joined, in the short term, by others in the Fire Protection Engineering community having the same issues. On the long term, they will ultimately benefit from the results of the studies as these results will be applied to their own project or similar projects (see Figure 11).

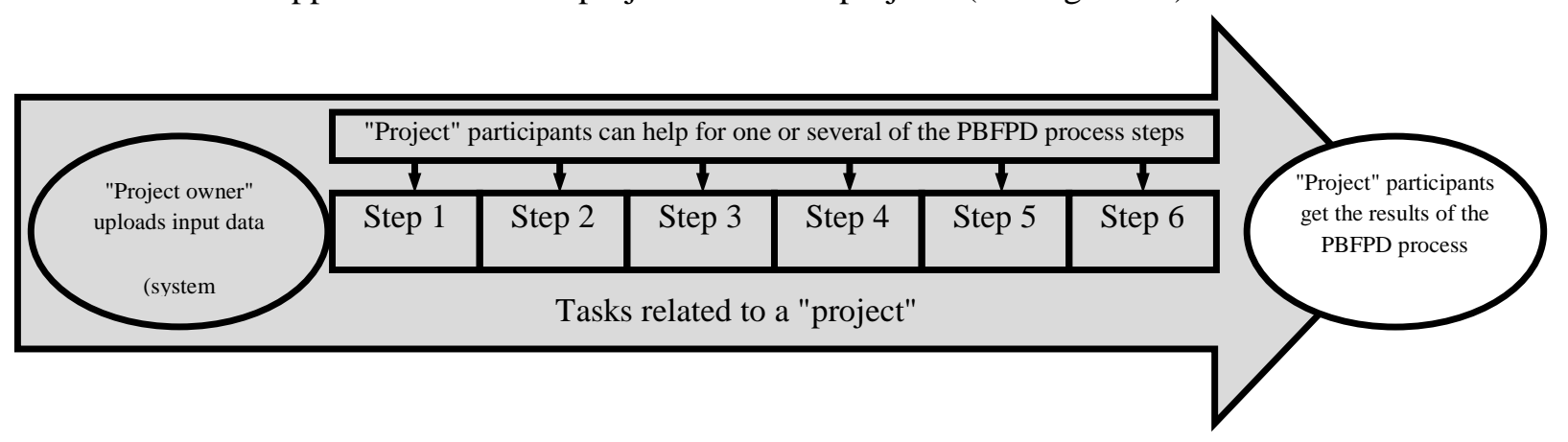

Figure 11. Organization of a "project" in the Vulcan Initiative [9]

Examples of projects included in the Vulcan Initiative site include a hospital, a high-rise hotel and a mall, created in academia, from the Worcester Polytechnic Institute (WPI), USA. The 5-story hospital was based on an actual building design, modified with specific features such as a 'function space,' so as to allow students experience in assessing different fire scenarios and evacuation, protect in place and relocation scenarios. The 30-story high-rise hotel with associated convention space was developed at WPI to provide an environment within which to have students assess such factors as fire scenarios, evacuation schemes and mitigation measures (such as smoke exhaust in atria and meeting spaces). The 3-story shopping mall was likewise developed at WPI to have students assess such factors as fire scenarios, 
evacuation schemes and mitigation measures (such as smoke exhaust and material control). These projects can serve as examples for future students, and new projects could be added to the Vulcan Initiative using these configurations and associated data. WPI hopes to be joined by other institutions around the world, as well as tool developers, architects, code officials and others, from whom advice could be requested and interaction in the virtual environment can help address 'real world' issues and facilitate development of new detailed guidelines as outlined above.

The structure of the Beta version of the Vulcan Initiative website (http://www.vulcaninitiative.net/index.html) can be found in Annex G and H. It is expected that the Vulcan Initiative website will be modified extensively in the coming years. 


\section{Outcomes, Ongoing Efforts and Recommended Future Research}

As with any research effort, what can be done within a particular period of effort does not reflect the totality of the impact and opportunities which follow the initial efforts. Such is the case with this project, where outcomes are just beginning to influence future direction, ongoing efforts are underway to further develop concepts, and pathways for future research in this area have been developed.

\subsection{Outcomes}

This report has summarized the major outcomes from this research effort. In brief, a new framework for a risk-informed performance-based approach to fire safety analysis and design has been proposed. It is structured around a paradigm in which the performance analysis is conducted relative to the performance of a building-occupant system within a broader context of the managing risk of an acute event (e.g., fire) on the chronic state of the system. It proposes development of specific guidance for building-occupant systems, nominally structured around real building occupancy and daily use issue, which:

- Provide detailed directions as to how to characterize the risk

- Adequately identify targets and vulnerabilities, both direct and in-direct,

- Better assess and mitigate the likelihood of disruptive events impacting the desired performance of the building-occupant system, and

- Develop mitigation strategies which are cost-effective within the context of the overall buildingoccupant system.

In addition, a test-bed environment has been proposed - the Vulcan Initiative - with a Beta version web portal developed, to facilitate a common location for data and information in support of risk-informed performance-based design. A key feature of the website when completed will be the ability for practitioners, students and others to interactively use building geometries, data and analysis tools to gain and share experiences in the application of the new process.

To support the use of the web-based test-bed environment, data have been collected and made available on heat release rate curves and associated information as part of a database on design fire curves, and a selection of building geometries for use fire effects, evacuation and other modeling and analysis have been compiled. Case studies related to test-bed environments are being assembled as well.

To date, more than ten publications have been developed as part of disseminating information about the development of the framework, the paradigm shift, the test-bed environment and the web portal.

\subsection{Ongoing Efforts}

Even though the funded part of this effort is now over, unfunded work by various team members continues to be undertaken due to their dedication to the advancement of the concepts and dissemination of information developed in this project. Work continues, for example, on guidance for risk characterization, development of HRR data, parametric studies [29], and collection of geometries and case study examples for use in the Vulcan Initiative test-bed environment. 
In addition, concepts related to risk characterization, focus on targets and vulnerability criteria for targets, better characterization of scenarios of concern based on risk characterization, and more robust data for design fire characterization have been introduced to the SFPE Standards Committee on Design Fire Scenarios for consideration in development of future standards. Similarly, discussions have been held with members of ISO TC92 SC4 with the aim of introducing outcomes of this research into the ISO standards on fire safety engineering.

\subsection{Recommended Future Research}

There are several areas which need additional research and development to facilitate adoption and use of the new framework for risk-informed performance-based design for fire.

The Vulcan Initiative and associated web portal need to be advanced and developed to facilitate its use as a repository and access point to guidance, data, tools and test-bed environments and outcomes in support of risk-informed performance-based design for fire. Ideally a sponsor, such as the Society of Fire Protection Engineers, NIST or other, who sees benefit to the portal, will be able to assist and perhaps take over management of the site in the future.

A better-defined approach to risk characterization is needed. While the foundations have been laid in terms of the building-occupant system and disruptive event paradigm, guidance for how stakeholders can appropriately characterize fire risk within this paradigm is needed.

Data on frequency of fire ignition, spread and impact are needed, as are data on system reliability and availability. While national data, such as from the NFIRS system on number of fires per year helps, it is often presented by occupancy groups that lump distinct "building-occupant" systems. Besides, more data, such as is available in the insurance industry, is needed to estimate performance indicators related to property protection and business continuity, as well as fire protection system reliability and efficiency. This is for the risk characterization as well as the risk analysis components

Guidance on development of scenarios and quantification of design fires for use in analysis is needed. While efforts such as those by the SFPE Standards Committee on Design Fire Scenarios are tackling this within the construct of the existing PBD paradigm, different guidance is needed for use within the building-occupant system and disruptive event paradigm. In fact, guidance (and data) relative to each step of the new framework - focused on specific building-occupant systems - is needed. (The Vulcan Initiative and associated web portal is hoped to be one mechanism for facilitating development of this guidance).

Ultimately, as data are collected, case studies undertaken, and experience is gained within the Vulcan Initiative, specific recommendations for code changes relative to building risk and performance levels, target vulnerability criteria, design fires and more can be developed. 


\section{Summary and Conclusions}

Performance-based building codes have been implemented in numerous countries world-wide. In addition, performance-based approaches to fire safety analysis and design are widely used, both in countries with performance-based building codes as well as those with prescriptive-based codes. However, most building codes - prescriptive- or performance-based - lack quantitative risk, safety or performance criteria, and decisions regarding acceptance criteria often rests with the fire protection engineer and design team, often with no benchmarking against other buildings. As a result, there is a high degree of variability in fire engineered building design solutions and in the review and approval of these solutions, and therefore in the levels of fire safety provided in buildings that have been designed using performance methods. There have been few fire-related failures that can be attributed to "unacceptable" fire safety performance being delivered under the current performance-based fire safety design framework. However, performance failures under prescriptive codes and in other regulated areas, perceived quality concerns, and a desire to be more transparent have motivated several countries to try and better understand and quantify the level of fire safety and performance being provided in deemed-tosatisfy solutions (acceptable solutions, approved documents) and to establish quantitative measures for use in next generation performance-based building codes and performance-based fire safety design approaches.

In order to help address issues of risk and performance quantification, this effort has advanced a new framework for a risk-informed performance-based approach to fire safety analysis and design. It is structured around a paradigm in which the performance analysis is conducted relative to the performance of a building-occupant system within a broader context of the managing risk of an acute event (e.g., fire) on the chronic state of the system. It proposes development of specific guidance for building-occupant systems, nominally structured around building use and occupancy issue, which provide detailed directions as to how to characterization the risk, adequately identify targets and vulnerabilities, both direct and indirect, better assess and mitigate the likelihood of disruptive events impacting the desired performance of the building-occupant system, and develop mitigation strategies which are cost-effective within the context of the overall building-occupant system.

In addition, a test-bed environment has been proposed - the Vulcan Initiative - with a Beta version web portal developed, to facilitate a common location for data and information in support of risk-informed performance-based design. A key feature of the website when completed will be the ability for practitioners, students and others to interactively use building geometries, data and analysis tools to gain and share experiences in the application of the new process.

To support the use of the web-based test-bed environment, data have been collected and made available on heat release rate curves and associated information as part of a database on design fire curves, and a selection of building geometries for use fire effects, evacuation and other modeling and analysis have been compiled. Case studies related to test-bed environments are being assembled as well. 


\section{References}

1. Alvarez Rodriquez, A., An Integrated Framework for the Next Generation of Risk-Informed Performance-Based Design Approach Used in Fire Safety Engineering, PhD Dissertation, Worcester Polytechnic Institute, December 2012 (to be published as NIST GCR, in press, NIST, Gaithersburg, MD, USA).

2. Sheffi, Y., The Resilient Enterprise, Massachusetts Institute of Technology Press, 2005.

3. Alvarez, A., Meacham, B.J., Dembsey, N.A. and Thomas, J.R., "20 Years of Performance-Based Fire Protection Design: Challenges Faced and a Look Ahead,” Journal of Fire Protection Engineering, DOI: 10.1177/1042391513484911, on-line 24 July 2013: print Vol. 23, No. 4., November 2013.

4. Alvarez, A., Meacham, B.J., Dembsey, N.A. and Thomas, J.R., “A Framework For Risk-Informed Performance-Based Fire Protection Design For The Built Environment,” Fire Technology, DOI: 10.1177/1042391513494923, Vol. 50, pp161-181, 2014.

5. International Building Code, International Code Council, Washington, DC, 2012.

6. Alvarez, A. and Meacham, B.J., "Towards and Integrated Performance-Based Design Approach for Life Safety across Different Building Use Groups,” proceedings, Interflam 2010, Interscience Communication, Ltd., London, July 2010.

7. Alvarez, A. and Meacham, B.J., “'Ready-to-Use’ Building Layouts and Combustible Packages for 3D Fire Simulations,” Proceedings - Fire and Evacuation Modeling Technical Conference, Baltimore, MD, 16 August 2011.

8. Alvarez, A. and Meacham, B.J., “'Test bed' Environment Process for Assessing the Appropriateness of Engineering Tools to be Used in Performance-Based Design Applications," Proceedings, $9^{\text {th }}$ SFPE International Conference on Performance-Based Codes and Fire Safety Design Methods, SFPE, Bethesda, MD, June 2012.

9. Alvarez, A., Ferreira, M.A. and Meacham, B.J., "The VULCAN INITIATIVE: a web platform for the next generation of performance-based fire protection design,” Proceedings, Interflam 2013, Interscience Communication, Ltd., London, June 2013.

10. Meacham, B.J., "International Experience in the Development and Use of Performance-Based Fire Safety Design Methods: Evolution, Current Situation, and Thoughts for the Future,” Invited Paper, Proceedings of the International Association for Fire Safety Science, $6^{\text {th }}$ International Symposium, Poitiers, France, July 1999, pp.59-76.

11. Meacham, B.J., “The Evolution of Performance-Based Codes and Fire Safety Design Methods,” GCR 98-763, NIST, Gaithersburg, MD, 1998.

12. Meacham, B.J., Moore, A., Bowen, R. and Traw, J., "Performance-Based Building Regulation: Current Situation and Future Needs,” Building Research \& Information, Vol. 33, No. 1, pp.91-106, 2005. 
13. Boutin, V. and Meacham, B.J., Comparison of the International Fire Engineering Guidelines, SFPE Engineering Guide on Performance-Based Fire Protection, BS7974 - Application of Fire Safety Engineering Principles to the Design of Buildings and ISO 13387 - Fire Safety Engineering - Part 1: Application of Fire Performance Concepts to Design Objectives, WPI, Worcester, MA, January 2013 (to be published as a NIST GCR - awaiting number).

14. Alvarez, A., Meacham, B.J., Dembsey, N.A. and Thomas, J.R., "Using A Systems Approach to Assess How Disruptive Events Affect Building Overall Performance,” unpublished manuscript, for submittal to Building Research \& Information.

15. Knight, R.F. and Pretty, D.J., The Impact of Catastrophes on Shareholder Value, The Oxford Executive Research Briefings. Templeton College, University of Oxford, England.

16. Notarianni, K.A and Parry, G., "Uncertainty," Section, 5, Chapter 4, SFPE Handbook of Fire Protection Engineering, NFPA, Quincy, MA, 2008

17. Baker, G., Wade, C., Spearpoint, M. and Fleischmann, C., "Developing Probabilistic Design Fires for Performance-based Fire Safety Engineering," $9^{\text {th }}$ Asia-Oceana Symposium on Fire Science and Technology, Procedia Engineering, Vol. 62, pp639-647, 2013.

18. Lord, J., Meacham, B.J., Moore, A., Fahy, R. and Proulx, G., Guide for Evaluating the Predictive Capability of Computer Egress Models, NIST GCR 06-886, National Institute of Standards and Technology, Building and Fire Research Laboratory, Gaithersburg, MD, December 2005.

19. Albrecht, C., “Quantifying life safety: Part I: Scenario-based quantification,” Fire Safety Journal, Vol. 64, pp87-94, 2014.

20. Albrecht, C., “Quantifying life safety: Part II: Quantification of fire protection systems,” Fire Safety Journal, Vol. 64, pp81-86, 2014.

21. Albrecht, C. and Meacham, B.J., "Risk-Informed and Performance-Based Life Safety Design in Atrium-Type Buildings,” Proceedings, $10^{\text {th }}$ International Conference on Performance-Based Codes and Fire Safety Design Methods, SFPE, Bethesda, MD, 2014.

22. Meacham, B.J., Johnson, P.J., Charters, D. and Salisbury, M., “Building Fire Risk Analysis,” Section 5, Chapter 12, SFPE Handbook of Fire Protection Engineering, 4th Ed., NFPA, Quincy, MA, USA, December 2008.

23. Meacham, B.J., “Understanding Risk: Quantification, Perception and Characterization,” Journal of Fire Protection Engineering, Vol. 14, No. 3, pp.199-228, 2004.

24. SFPE Engineering Guide - Fire Risk Assessment, Society of Fire Protection Engineers, Bethesda, MD, November 2006.

25. ISO 16732-1:2012, Fire Safety Engineering-Guidance on Fire Risk Assessment, International Organization for Standardization (ISO), Geneva, Switzerland. 
26. BS 7974-7, “Part 7-Probabilistic Risk Assessment," Code on the Application of Fire Safety Engineering Principles to the Design of Buildings, British Standards Institute, London, UK.

27. Y. Kobayashi and H. Nozaki, A Statistical Method to Evaluate Fire Risks in Non-Residential Buildings in Japan," in: Fire Safety Science: Proceedings of the Eight International Symposium, China, International Association for Fire Safety Science, 2005, pp. 341-352.

28. M. Tsujimoto, Death Risk by Building Fires in Japan and its Usage, Fire Science and Technology, vol. 23, no. 4, 2004, pp. 304-311.

29. Alvarez-Rodriquez, A., Meacham, B.J. and Almejmaj, M., "A Parametric Multi-Tool Study to Assess Smoke Management System Performance for an Atrium," to be published in Proceedings, SFPE $10^{\text {th }}$ International Conference on Performance-Based Codes and Fire Safety Design Methods, Surfers Paradise, Australia, 12-14 November 2014.

30. Fleischmann, C.M., “Is Prescription the Future of Performance Based Design?” Fire Safety Science 10: 77-94. 10.3801/IAFSS.FSS.10-77, 2011.

31. WPI Graduate Independent Study Project, Arthur Gager, 2011. 


\section{Annexes}




\section{Annex A}

An Integrated Framework for the Next Generation of Risk-Informed Performance-Based Design Approach Used in Fire Safety Engineering

Ph.D. Dissertation, Alberto Alvarez, (C2012 


\title{
AN INTEGRATED FRAMEWORK FOR THE NEXT GENERATION OF RISK-INFORMED PERFORMANCE-BASED DESIGN APPROACH USED IN FIRE SAFETY ENGINEERING
}

\author{
by \\ Alberto ALVAREZ RODRIGUEZ \\ A Dissertation Submitted to the Faculty of the \\ WORCESTER POLYTECHNIC INSTITUTE \\ in partial fulfillment of the requirements for the \\ Degree of Doctor of Philosophy \\ in \\ Fire Protection Engineering
}

December 2012

APPROVED:

Dr. Brian J. Meacham, Major Advisor

Department of Fire Protection Engineering

Dr. Nicholas A. Dembsey, Advisor

Department of Fire Protection Engineering

Dr. Russell Thomas, Advisor

National Research Council, Canada

Dr. Kathy A. Notarianni, Department Head

Department of Fire Protection Engineering

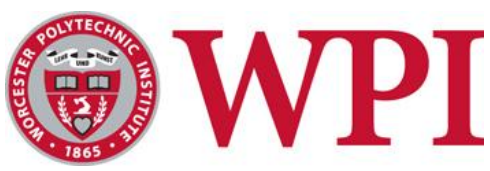





\begin{abstract}
Review of decades of worldwide experience using standards, codes and guidelines related to performance-based fire protection design for buildings has identified shortcomings in the interpretation, application and implementation of the performance-based design process, wide variation in the resulting levels of performance achieved by such designs, and several opportunities to enhance the process. While others have highlighted shortcomings in the past, as well as some ideas to enhance the process, it is proposed that a more fundamental change is needed.
\end{abstract}

First, the political and technical components of the process need to be clearly delineated to facilitate better analysis and decision-making within each component. Second, the process needs to be changed from one which focuses only on fire safety systems to one which views buildings, their occupants and their contents as integrated systems. In doing so, the activities associated with the normal operation of a building and how they might be impacted by the occurrence of a fire event become clearer, as do mitigation options which account for the behaviors and activities associated with normal use.

To support these changes, a new framework for a risk-informed performance-based process for fire protection design is proposed: one which is better integrated than current processes, that treats a fire event as a disruptive event of a larger and more complex "building-occupant" system, and that provides more specific guidance for engineering analysis with the aim to achieve more complete and consistent analysis.

This Ph.D. Dissertation outlines the challenges with the existing approaches, presents the "building-occupant" system paradigm, illustrates how viewing fire (or any other hazard) as a disruptive event within an holistic "building-occupant" system can benefit the overall performance of this system over its lifespan, and outlines a framework for a risk-informed performance-based process for fire protection design. Case studies are used to illustrate shortcomings in the existing processes and how the proposed process will address these. This Dissertation also includes a plan of action needed to establish guidelines to conduct each of the technical steps of the process and briefly introduces the future work about how this plan could be practically facilitated via a web-platform as a collaborative environment. 


\section{EXECUTIVE SUMMARY}

Performance-based design (PBD) approaches are being developed for numerous engineering disciplines, including mechanical, structural, and fire protection engineering. Allowed nowadays in the building regulatory framework of more and more nations, the application of these approaches has made possible real innovative and aesthetically pleasing as well as safe, efficient and cost-effective building designs.

However, PBD approaches are still not as widely applied as some predicted two decades ago. In part, this is because the political and technical aspects of PBD have been intertwined. This creates challenges as approaches and solutions to political and technical challenges can be quite different.

The decision to apply PBD approaches instead of following the prescriptive requirements of building codes is a political choice agreed among the different building stakeholders, who may have different (if not competing) objectives related to the buildings performance. In addition, final selection of a design option is also a political decision, in this case of the client, which should be informed by engineering analysis but not made by the engineer. In the political sense, then, the application of current PBD approaches for fire remains limited, as:

- The building design team can be reluctant to use a PBD approach, as when compared to the strict application of the prescriptive code requirements, it can be quite costly in terms of time and resources while its outcome may be rejected by enforcement officials, leading to more delays, more spending and alterations of the initial design.

- The regulators and enforcement officials express various concerns with PBD, including:

- Selection and use of performance criteria, which should be a policy decision, but is currently largely a technical decision made by the FPE, usually with agreement of project stakeholders, as they are not regulated.

- The comparison of a building safety level established through application of a PBD approach with the one established by the prescriptive requirements.

- The validation of the tools, data and methods used in the PBD approach.

On the technical aspect of fire protection engineering, it should be noted that while having a solid research base, this discipline has not yet reached a mature state. When academic programs started to be established in the 1970's, their main focus was to incorporate research results in the understanding of fire phenomena. Nowadays, they have added modules including risk concepts and human behavior. In spite of these abundant research results, the transfer of information from research into practice suffers from the inertia intrinsic to practitioners, policy makers and law enforcers when confronted with new engineering methods and concepts. 
In the 2000's, the publishing of performance-based fire protection design (PBFPD) documents including guides and guidelines from fire protection engineering societies (e.g. Society of Fire Protection Engineers) or international committees (e.g. International Organization for Standardization or Inter-jurisdiction Regulatory Collaboration Committee) as well as codes and standards embodied in some national regulations (e.g. Sweden, New Zealand and Japan) appeared as a benefit but turned out to be a drawback to the dissemination of PBD approaches. For instance, the PBFPD processes currently included in codes, standards, guides and guidelines were written at a time when it was a priority to introduce the global concepts of the PBFPD process, to model all the phenomena, and to determine and assess the influence of critical components of the PBFPD process. With this purpose in mind, they had to be generic in order to be used as widely as possible. This generic attribute of all the PBFPD documents, initially looking for uniformity in the application of their respective PBFPD process, led to a diversity of results from fire protection engineers who, used to follow prescriptive requirements, might not fully understand how the generic concepts were to be applied to specific and innovative projects.

As an engineering discipline, fire protection engineering relies on the utilization of tools and models in order to quantify relevant parameters describing the fire phenomena themselves, occupant evacuation and structural response. Since property protection, business continuity, heritage preservation and environmental protection are objectives of potential interest for a building project stakeholder, fire protection engineers, if not directly assessing relevant parameters unique for taking into consideration these objectives, still needs to communicate with the corresponding experts and to incorporate their assessment into their own assessment. In other terms, fire protection engineering has expanded to become a real inter-disciplinary field, which means that not only fire protection engineers have to keep up to date with fundamental research in their main disciplines (e.g. fire dynamics, fire modeling) but they are required to constantly expand their knowledge to other disciplines, as well as being aware of innovations occurring in the built environment with new materials and new construction practices.

Engineering calculation methods are presented in only a few regulations, usually as recommended practice, but are limited to particular and isolated part of the whole engineering problem (e.g. temperature and velocity in an unobstructed and axisymmetric fire plume). Fortunately, along with the development of computer science, tools were developed to assess temperature profiles and smoke transport for simulated user-input fires, with more or less definition of the complexity of the building geometries (e.g. atrium space, multiple rooms and multiple floors) and specificities (e.g. mechanical ventilation). Evacuation tools, dealing with human behavior and structural response tools were also developed on their own. Unfortunately, all these tools provided with a more or less easy-toimplement graphic user interface, remain research tools with relatively limited validation domains, and their use in PBD application requires fire protection engineers to have a good understanding of the uses and limits of the tools, especially when they need to combine the different results from each tool for their global engineering analysis. User effects as well as the need to apply these tools for configurations they were not tested or designed for, raise skepticism and concerns from the authorities having jurisdiction when judging the validity of the PBD application process which is still largely dependent on the calculations performed with these tools. 
Recognizing this wide range of expectations, concerns and challenges related to the use of current PBFPD processes, the research presented in this Ph.D. dissertation identifies a path forward for advancing performancebased fire protection design and the fire safety engineering profession, founded on three fundamental concepts:

1. Fire protection engineers need to make a paradigm shift from one in which fire is the center of the problem, to one in which building performance metrics are evaluated in the case of fire events. This paradigm shift is necessary because current PBFPD guidelines are so focused on design fire scenarios, to the extent that fire protection measures deemed appropriate at the time of design might not be the most appropriate when implemented in a building, that key aspects of resultant fire protection designs might be ignored or worse "rejected" by the occupants of the building when needed the most, since fire is not a daily concern of building occupants. Fires, as with earthquakes, floods or even terrorism, instead have to be seen as one of many potential 'acute' disruptive events that may occur during the 'chronic' lifespan of a building. In consequence, fire protection measures should be an integrated part of a "building-occupant" system formed by specific building types, the activities being undertaken in the buildings, and the building occupants in order to limit the effects of fire events on the overall performance of the system, which is the main concern of the system stakeholders.

2. To assess the effects of fire or any other disruptive event on the overall performance of the building-occupant system, and result in a mitigation strategy which considers the impact of the 'acute' event within the 'chronic' lifespan of a building, a system-specific, risk-informed performance-based process has been established. This process clearly separates the technical aspect related to the tasks engineers have to perform (acute impact analysis) from the political aspect which determines the normal (chronic) performance expectations of the system stakeholders, including the level of degradation in building performance that the stakeholders would accept in the case where disruptive events affect their system. As a consequence of this separation, the technical stage of the process becomes transparent, both for stakeholders who establish the performance targets (political decision) and for the engineers in charge of the evaluation of the disruptive effects on the system performance (technical analysis).

3. To facilitate the paradigm shift and successfully implement the new risk-informed, performance-based guidelines for use within the building-occupant systems framework, detailed guidelines are needed for a broad set of building-occupant systems. While development of such guidelines was outside of the scope of this $\mathrm{Ph}$. D. research, since it requires the participation of many different actors, time and resources that are not compatible with a single Ph.D. program, a plan of action is proposed to facilitate creation of the guidelines for each of the technical steps of the risk-informed, performance-based process for specific "building-occupant" systems. As future work, a web-platform dedicated to facilitating and speeding up the execution of the plan, is being developed and will follow the publication of this Ph. D. dissertation. 


\section{ACKNOWLEDGEMENTS}

I would like to thank all of those who have helped me in all aspects of this work.

First and foremost, I would like to thank Prof. Brian J. Meacham, my WPI advisor, for sharing his expertise in the numerous fields he masters (Fire Protection Engineering, Risk Assessment and Code Making), for encouraging me in the development of new ideas and concepts, for providing me with a constant and endless guidance in his too busy and demanding schedule, and for trusting me with being one of his Teaching Assistants, with giving some lectures in his courses and with helping him design some course contents. This research would have been impossible without his unselfish support and patience.

I would like to thank Prof. Nicholas A. Dembsey, my WPI co-advisor, for his feedback and comments that contributed to a more comprehensive presentation of a complex research. I would also like to acknowledge him as an outstanding instructor of fundamental fire research such as Fire Dynamics and Fire modeling.

I would like to thank Dr. Russ Thomas, my co-advisor from National Research Council - Canada, for his outside perspective of a policy maker, so my research would resonate to others than Fire Protection Engineers and researchers.

After more than a decade in the workplace, it was a great experience to be back in academia, especially in the Fire Protection Engineering Department directed by Prof. Kathy A. Notarianni. It was a life time opportunity to learn from dedicated and expert professors, as well as to be a Teaching Assistant (so to realize how deeply dedicated all the professors are). A special Thank to Sasha Strong, Catherine Fradette and Mary Racicot for their efficiency in taking care of all the official tasks.

I would like to thank Mrs. Lynne Riley, from the George C. Gordon Library for helping me with copyright issues, referencing and for showing me all the useful material available to Fire Protection Engineers, online and offline. Being able to look through these resources allowed a very good start in my Ph.D. (or any) research.

I would like to express hearty thanks to the other Ph.D. students in the "Thinker" team: Hae-Jun Park and Majed Almejmaj, for their highly valued help and bouncing ideas, as well as all the other students (Dr. Joel Sipe, Dr. Kulbhushan Arvind Joshi, Dr. Scott Rockwell, Mihyun (Ester) Kim, Jan Thomas, and Young-Geun You) who shared the cozy Ph.D. student office.

I would like to thank the US National Institute of Standards and Technology (NIST) for supporting the research on which this present $\mathrm{Ph} . \mathrm{D}$. dissertation is based, under grant 60NANB10D228. 


\section{TABLE OF CONTENTS}

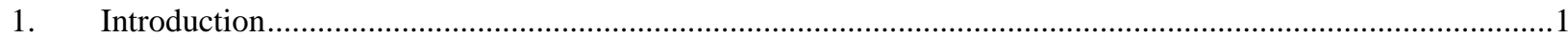

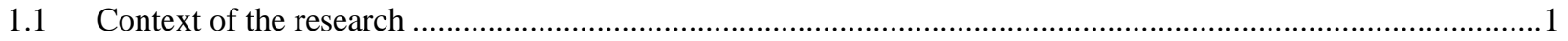

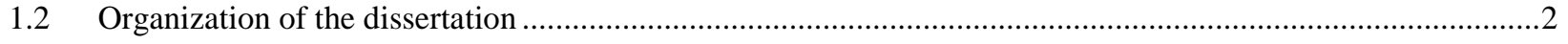

2. Twenty Years of Performance-Based Fire Protection Design: Challenges Faced and a Look Ahead .................5

2.1 Technical and political challenges related to the use of PBFPD processes...........................................................

2.1.1 Technical challenges related to the use of PBFPD processes ..................................................................

2.1.2 Political challenges related to the use of PBFPD processes........................................................................

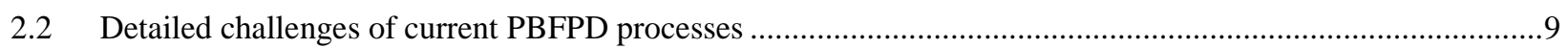

2.2.1 Challenges when applying generic guidance to specific projects .................................................................11

2.2.2 Challenges associated with the definition, use and quantification of the performance/acceptance criteria .......12

2.2.3 Challenges associated with the selection of fire design scenarios ................................................................16

2.2.4 Challenges when dealing with a priori lists of performance criteria and design fire scenarios .........................17

2.2.5 Challenges when comparing levels of performance between an engineering solution and the one based on

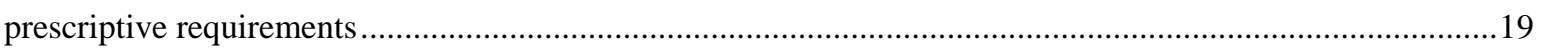

2.2.6 Challenges related to the determination of influential factors affecting the evaluation of trial designs ..........21

2.2.7 Challenges when dealing with "idealized" design features and "real life" installed and running features........21

2.2.8 Challenges when estimating the consequences of fire design scenarios .......................................................22

2.2.9 Challenges when adapting literature values, when available, to use in models .............................................23

2.3 Summary of the challenges related to the use of current PBFPD processes .................................................25

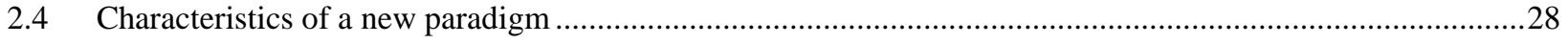

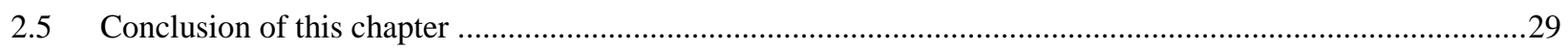

3. Using A Systems Approach To Assess How Disruptive Events Affect Building Overall Performance ...........33

3.1 Definition of the daily performance of a "building-occupant" system and its decrease during a disruptive

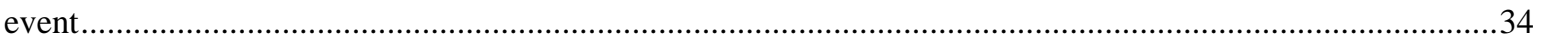

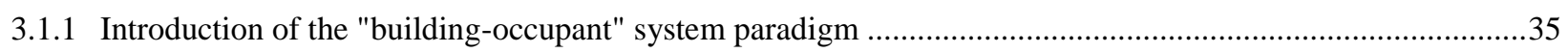

3.1.2 Characterization of the effects of a disruptive event on the performance of a "building-occupant" system.....39

3.1.3 Key-concepts of "building-occupant" systems ..........................................................................................42

3.2 Identifying and avoiding competing objectives within a "building-occupant" system ....................................43

3.2.1 Fire safety objective competing with "chronic" objectives established at a design stage ...............................43

3.2.2 Fire safety objectives competing with "chronic" objectives established after the design stage .......................44

3.2.3 Fire safety objectives competing with "chronic" objectives evolving over very long period of time ...............45

3.2.4 Fire safety objectives competing with "chronic" objectives evolving over short or long periods of time ........46

3.2.5 Impact of "chronic" objectives in performing the risk analysis related to disruptive events ...........................48

3.3 Theoretical treatment of disruptive events affecting the performance of "building-occupant" systems ............50

3.3.1 Fire is one disruptive event among others which may be "covered" by a contingency plan............................50 
3.3.2 PBFPD processes must examine the actions and events of the recovery phase following a fire

3.3.3 Specific interconnections may exist between different types of targets or between a target and a building component, so a fire can have a direct or an indirect impact on targets.

3.4 Practical treatment of disruptive events affecting the performance of "building-occupant" systems ...............52

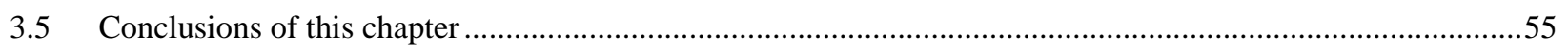

4. A Framework For Risk-Informed Performance-Based Fire Protection Design For The Built Environment....57

4.1 Challenges of the current PBFPD processes: the need to be more specific ..................................................58

4.2 Shifting the paradigm: studying how a global system formed by a building and its occupants reacts when a

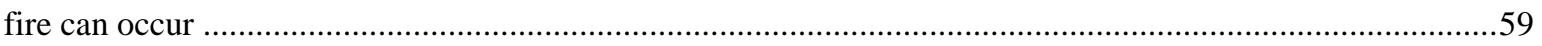

4.3 Application of the system performance-based process to fire disruptive events: Creating a new PBFPD

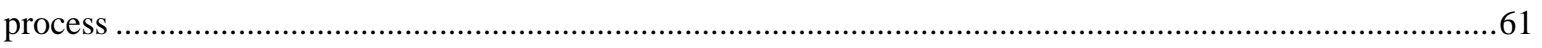

4.3.1 The new PBPFD process is a target oriented process within the "building-occupant" system paradigm ..........62

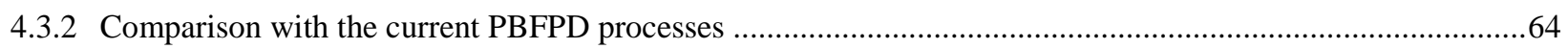

4.4 Proof of concept of the New PBFPD process: closing "Iteration Zero" (verification of the usability of the process).

4.5 Closing "Iteration Zero" (demonstration of the ability to overcome the challenges encountered by the use of

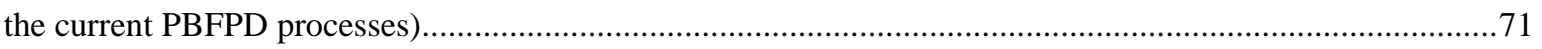

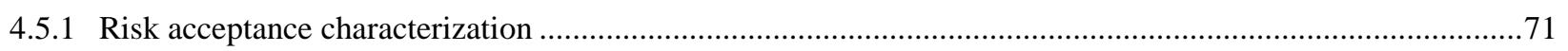

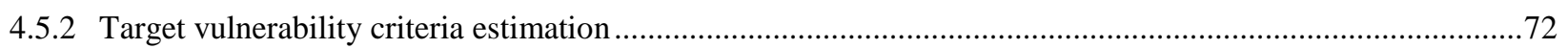

4.5.3 Fire risk analysis (quantification of the likelihood) ...............................................................................

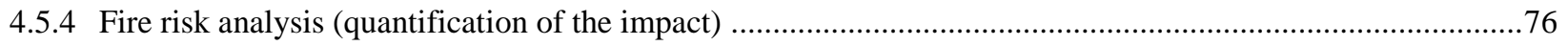

4.5.4.1 Quantification of impact vs. quantification of consequences ................................................................... 76

4.5.4.2 Tools and data needed for the quantification of the impact of fire events .................................................76

4.5.5 Integration of the fire protection measures into the "building-occupant" system .............................................77

4.5.6 Cost-Benefit analysis of the fire protection measures.............................................................................. 79

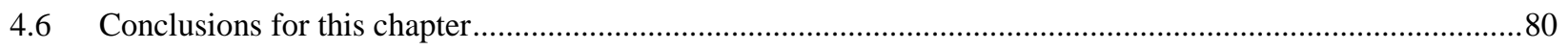

5. Establishing a plan of action for the development of guidelines in support of the framework for risk-informed performance-based fire protection design . .82

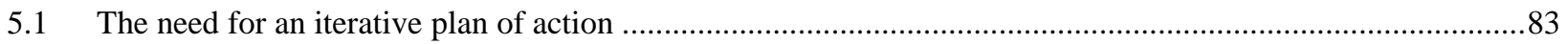

5.2 Importance of the involvement of the stakeholders for establishing validation domain of models needed at

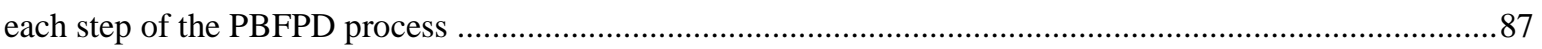

5.3 Application of the plan of action to obtain the necessary guidelines to perform each step of the new PBFPD

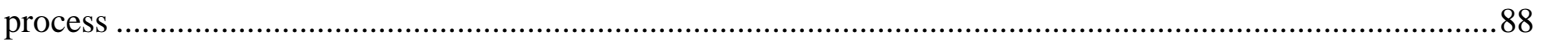

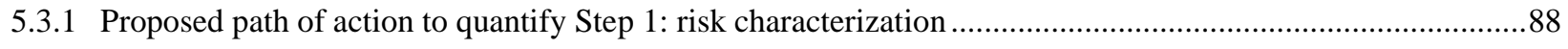

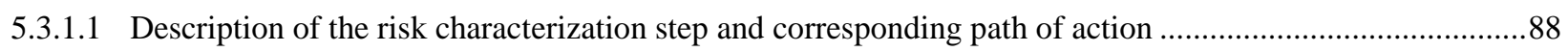

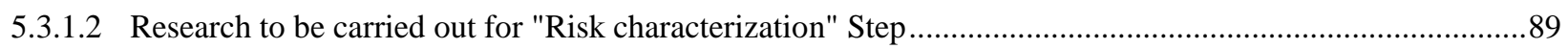

5.3.1.3 Establishing guidelines or standards for assessing risk characterization for "building-occupant" systems ..93 
5.3.1.4 Using the guidelines for performing Step 1 in a PBFPD process..............................................................94

5.3.2 Proposed path to quantify Step 2: Target vulnerability criteria estimation .......................................................94

5.3.2.1 Description of the target vulnerability criteria estimation step and corresponding path of action ................94

5.3.2.2 Research to be carried out for estimating vulnerability criteria...............................................................95

5.3.2.3 Establishing guidelines or standards for assessing vulnerability criteria of human/equipment/structures in

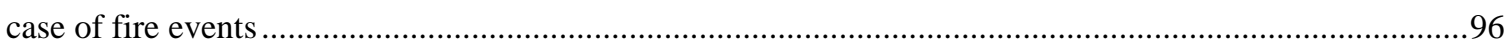

5.3.2.4 Using the guidelines for performing Step 2 in a PBFPD process ..........................................................96

5.3.3 Proposed path to quantify Step 3: Fire risk analysis (quantification of the likelihood) .................................96

5.3.3.1 Description of the fire risk analysis (quantification of the likelihood) step and corresponding path of action .

5.3.3.2 Research to be carried out for the process step related to the quantification of the likelihood of fire events 98

5.3.3.3 Establishing guidelines or standards for assessing the quantification of the likelihood of fire events ..........99

5.3.3.4 Using the guidelines for performing Step 3 in a PBFPD process ............................................................100

5.3.4 Proposed path to quantify Step 4: Fire risk analysis (quantification of the impacts) …..................................100

5.3.4.1 Description of the fire risk analysis (quantification of the impacts) step and corresponding path of action .....

5.3.4.2 Research to be carried out for the process step related to the quantification of fire events consequences ..101

5.3.4.3 Establishing guidelines or standards for assessing the quantification of fire event consequences ...............102

5.3.4.4 Using the guidelines for performing Step 4 in a PBFPD process .............................................................102

5.3.5 Proposed path to quantify Step 5: Evaluation of the integration of the fire protection measures in the system 102

5.3.5.1 Description of the step relative to the evaluation of the integration of the fire protection measures in the system and corresponding path of action

5.3.5.2 Research to be carried out for the process step related to the evaluation of the integration of the fire protection measures in the system

5.3.5.3 Establishing guidelines or standards for assessing the integration of fire protection measures in a considered

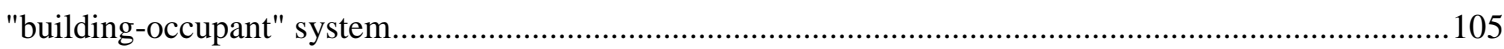

5.3.5.4 Using the guidelines for performing Step 5 in a PBFPD process ..........................................................105

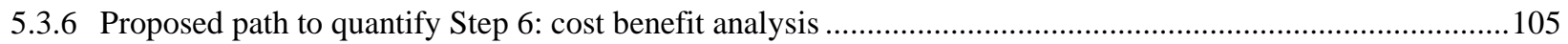

5.3.6.1 Description of the cost-benefit analysis step and corresponding path of action .........................................105

5.3.6.2 Research to be carried out for the process step related to fire protection measures cost benefit analysis ...106

5.3.6.3 Establishing guidelines or standards for fire protection measures cost benefit analysis ...........................106

5.3.6.4 Using the guidelines for performing Step 6 in a PBFPD process ...........................................................106

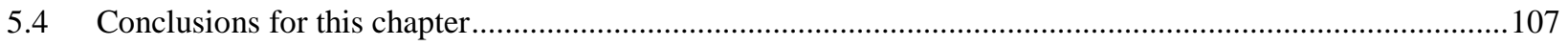

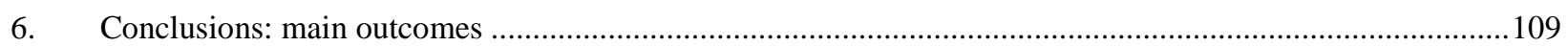

7. Future work 


\section{LIST OF FIGURES}

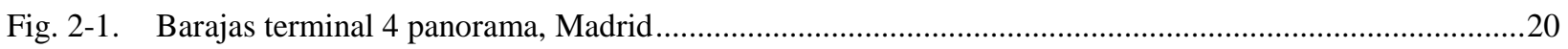

Fig. 2-2. Level of Fire Safety and the reduction due to the different processes [50]............................................22

Fig. 3-1. Examples of facilities under the ICC IBC Institutional class (I2) ..........................................................36

Fig. 3-2. People description according different functional zones of a hospital...................................................38

Fig. 3-3. "Disruptive event" profile of the Philips Plant fire (Albuquerque, New Mexico, USA), March 17, 2000,

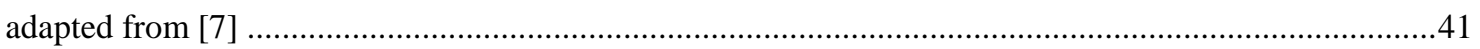

Fig. 3-4. Examples of airport architectural designs ........................................................................................

Fig. 3-5. Examples of impacts of the security "chronic" condition in airports ......................................................45

Fig. 3-6. Examples of a) well lit facility ("Nightingale" ward), b) private patient room in a hospital ....................46

Fig. 3-7. Christmas tree located close to exit routes and main entrance of a shopping mall ....................................47

Fig. 3-8. Example of commitment in a Japanese game center ..........................................................................49

Fig. 3-9. Example of a French department store display during sales ....................................................................49

Fig. 3-10. Political and technical steps of the system specific risk-informed performance-based process ................52

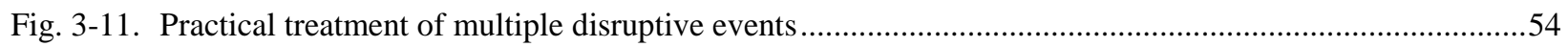

Fig. 4-1. Fire exit way finding problematic in a conference center ...................................................................60

Fig. 4-2. Application of the system performance-based process to a fire disruptive event ....................................62

Fig. 4-3. Steps to be performed in the technical aspect of the proposed PBFPD process ......................................64

Fig. 4-4. Relative influence of the stakeholders and the fire protection engineer in the different steps of the

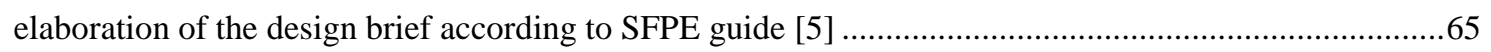

Fig. 4-5. Comparison between the new PBFPD process and the PBFPD process established by SFPE [5] ............66

Fig. 4-6. Translation of fire risk characterization in the "building-occupant" system paradigm .............................68

Fig. 4-7. Translation of the performance requirements of the "building-occupant" system as fire risk characterization .69

Fig. 4-8. Schematic representation of the risk reduction of scenarios of disruptive events .....................................70

Fig. 4-9. Concept differences between the FPE current paradigm and the "building-occupant" system paradigm..74

Fig. 4-10. Indirect effects of a fire upon the overall "building-occupant" system performance .................................74

Fig. 4-11. Blocked opened doors in a vestibule separating hotel room corridor from a stairwell in a hotel ..............79

Fig. 5-1. Plan of action: "climbing the research to application/regulatory ladder".................................................83

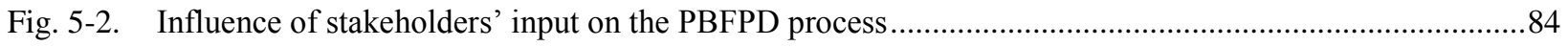

Fig. 5-3. Interconnections between the step researches of the proposed PBFPD process ......................................86

Fig. 5-4. Proposed path to risk acceptance characterization .................................................................................. 89

Fig. 5-5. Example of fire risk curves for commercial buildings [14] ...............................................................91

Fig. 5-6. Death risk trends in Japanese residential buildings, hospitals and hotels between 1969 and 2000 [15] ....91

Fig. 5-7. Correlation between Fatalities in Hospital and Number of Beds [15] ...................................................92

Fig. 5-8. Proposed path to target vulnerability criteria estimation ........................................................................95

Fig. 5-9. Proposed path to the quantification of the likelihood of fire events .......................................................98 
Fig. 5-10. Proposed path to the quantification of the impacts of fire events

Fig. 5-11. Levels of fire safety as a function of building phases and the introduction of redundant fire protection measures, adapted from [27] 103

Fig. 5-12. Proposed path to the Evaluation of the integration of the fire protection measures in the system..... 104

Fig. 5-13. Proposed path to the cost-benefit analysis of the trial designs 106

Fig. 7-1. Interconnections between tools, input data and 'test bed' environments 112

Fig. 7-2. Occupant populations as a function of buildings ..... .113

Fig. 7-3. Fire distributions as a function of buildings 114

Fig. 7-4. Effects of fire distributions on building occupant populations

Fig. 7-5. Validation domains for different "building-occupant" systems, in comparison with the physical domain of possibilities involving buildings, fires and occupants 115

\section{List OF TABLES}

Table 2-1. Performance criteria gathered in codes, standards and guides and guidelines [4] ..............................13

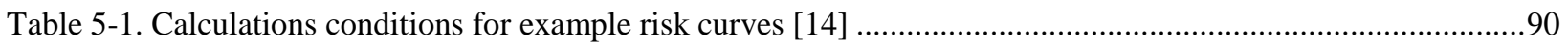

Table 5-2. Transition of Requirement for Sprinkler Installation of Hospital (Fire Code in Japan) [15] ..................92

Table 5-3. Structure Fires in Health Care Facilities, Excluding Nursing Homes by Extent of Flame Damage [8] .....99 


\section{INTRODUCTION}

\subsection{Context of the research}

Fire safety issues have to be considered for the built environment, as fire is one of the technological hazards of concern. Regulations regarding fire safety have been implemented for centuries, most often with new requirements developed mainly after disasters.

Fire safety regulations are typically implemented via "building codes" and "fire codes," which in turn rely on reference standards and guides for deeper technical aspects. For example, in the USA, a state might promulgate a building code based on the International Building Code [1], a model building code developed by the International Code Council. The IBC in turn requires the installation of sprinklers in particular types or classes of buildings. The technical specification of the sprinkler system design is referenced to a design and installation standard published by the National Fire Protection Association [2]. In the USA system, the requirements in the building code and reference standards are highly prescriptive.

The concept of performance-based design (PBD) for fire protection emerged in the 1970s in the USA in order to consider alternatives to the prescriptive design with the objective to obtain a built environment at least as safe as the one that would have been designed according to the regulation. This concept emerged in other countries, such as England and Australia in the 1980s and 1990s as fire safety engineering (FSE).

PBD has been used in cases where the involved stakeholders (mainly the building owner and the architects) wanted to design a building that was "outside of the box". Unique buildings such as skyscrapers, buildings with inner large open spaces (atria), complex built environments such as subway transit stations or airport terminals and even buildings inside buildings are the best candidates for the use of PBD, as prescriptive regulations have a difficult task to consider generic solutions to such particular buildings.

While national building codes are primarily concerned with the safety of the building occupants, with some variations to include the neighboring people and outside personnel operating during emergency situations, PDB solutions may also incorporate objectives that are not life-safety related such as business continuity, property protection, environment protection, and heritage preservation.

It should be noted that the engineering process of PBD is currently aimed at comparing the final engineering design with the one elaborated from the prescriptive regulation within a particular jurisdiction, as the final design would have an equivalent level of safety to that provided by the "prescriptive" solution. Because non life-safety objectives may not be fully addressed in local building codes, authorities having jurisdiction may accept the PBD solution that they judge acceptable while not adequate to fulfill objectives such as property 
protection. In other terms, as authorities having jurisdiction are used to judging prescriptive solutions aimed at life safety objectives, the PBD solutions they deem acceptable may not address non life safety objectives that could be of a major concern for other building stakeholders.

Several countries around the world have integrated performance-based elements into their regulations at two fundamental levels:

- at a technical level, as fire protection engineering still requires significant research in order to describe and model all the different phenomena;

- at a political level, as PBD is part of a decision-making process involving stakeholders' risk acceptance, determined at a national level with regulations and at a local level when the authorities having jurisdiction judge the PBD report acceptable or not, based on their own risk acceptance/aversion level.

A building project implies the participation of different groups of stakeholders, including contractors, building owners and users, architects, mechanical engineers, fire protection engineers and the authority having jurisdiction which approves the construction and the use of the project. These groups are involved at different stages of the project and undertake different tasks and mandates. So, each of these groups defines the performance of the project according to their mandates that run for a limited time or expand to the overall lifespan of the building. The overall performance of a building depends on the interrelations between the different components of the building such as the architectural system, the climate system, and components used for emergency situations, many of these components are separately managed by specific engineers.

\subsection{Organization of the dissertation}

The dissertation is organized into seven chapters as follows:

Chapter 1 (this Introduction) provides some background and context to the Ph.D. research.

Chapter 2 presents the results of a review of two decades of worldwide experience using standards, codes and guidelines related to performance-based fire protection design for buildings, in terms of challenges and shortcomings resulting from the application of these documents. Two key outcomes of this review are that (1) several of the challenges which have been identified are strongly linked to the application of generic guidance to specific problems, which results in critical details being missed, and that (2) some of the engineering issues are treated within a political context, while they should be addressed as purely technical issues. 
Chapter 2 served as the basis of a paper that was submitted to the Journal of Fire Protection Engineering (submitted 12 August 2012, with the manuscript number JFE-12-0035), which was under review when this dissertation was published.

Chapter 3 presents a new study paradigm organized around systems formed by specific building types, the activities being undertaken in the buildings, and the building occupants that I define as "building-occupant" systems. It focuses on how events such as fires or any other emergency situations can affect the overall performance of these systems. A system specific risk-informed performance-based process is established in order to assess the effect of a single or multiple disruptive effects of any type on the overall performance of the system.

Chapter 3 served as the basis of a paper that was submitted to the journal Building and Environment (submitted 29 November 2012, with the manuscript number BAE-D-12-01181) and was under review when this dissertation was published.

Chapter 4 presents the application of the aforementioned process to fires as they constitute one of the main disruptive events that can affect the overall performance of a "building-occupant" system. This chapter focuses on how a successful implementation of the corresponding new risk-informed PBFPD approach will require acceptance of the need for a paradigm shift from one in which fire is the center of the problem to one in which building performance metrics are evaluated in case of fire events. This chapter also details the different steps of the new PBFPD process and how this process differs from the current ones, notably in separating technical steps from political steps related to decision making and policy. Finally, this chapter presents how the process is practically applied to a project and it focuses on a proof of concept of the new PBFPD process.

Chapter 4 served as the basis of a paper that was submitted to Fire Safety Journal (submitted 3 December 2012, with the manuscript number FISJ-D-12-00256) and was under review when this dissertation was published.

Chapter 5 presents an iterative plan of action related to the establishment of the guidelines required to perform each of the technical steps of the process presented in the previous chapter for fire disruptive events. It provides elements of research currently available in the technical literature and how these elements could be incorporated into future guidelines. It also emphasizes on the importance of the involvement of the stakeholders for establishing the validation domain of models needed at each step of the PBFPD process.

Chapter 6 summarizes the main outcomes of this $\mathrm{PhD}$ research study.

Chapter 7 briefly introduces future work and how this plan could be practically facilitated via a web-platform as a collaborative environment. 
A total of three appendices (A1 to A3) are provided at the end of this document as supplementary material.

Appendix A1 is a paper titled "Towards an Integrated Performance-Based Design Approach for Life Safety Across Different Building Use Groups" which was presented at the international conference "Interflam 2010". This paper stated the advantages and drawbacks of using fire incident databases and fire investigation reports as information for selecting and quantifying fire scenarios. It also indicated the relevance of other sources such as building and fire codes, agency- or occupancy- specific guidance. This paper also showed the limitations of generic methods used to treat this information and that established in current Performance-Based Fire Protection Design (PBFPD) guidelines, based on the differences between configurations found in assemblies, offices, hospitals and so forth, which make it difficult, if not impossible to develop detailed guidelines without dealing with the elements that make a building occupancy specific. It also replaced fires as one of the "perturbations" occurring in buildings, which specific types had specific "chronic" or everyday demands.

Appendix A2 is a paper titled "Ready-to-Use" Building Layouts and Combustible Packages for 3-D Fire Simulations" which was presented at the Fire and Evacuation Modeling Technical Conference 2011. This paper first introduced the concept of 'test bed' studies related to the use of fire effects tools for given applications, with an emphasis on the fire Computational Fluid Dynamics model FDS (Fire Dynamics Simulator) developed by US National Institute of Standards and Technology. It also proposed to establish databases gathering together already constructed 3-D building layouts, fire and combustible packages containing information on heat release rates and fire effluent productions that fire protection engineers or researchers could easily use.

Appendix A3 is a paper titled "'Test bed' environment process for assessing the appropriateness of engineering tools to be used in performance-based design applications," published in the Proceedings of the $9^{\text {th }}$ International Conference on Performance-Based Codes and Fire Safety Design Methods. This paper extended the concept of 'test bed' studies to all the engineering tools as it developed a new holistic approach for selecting tools to be used in performance-based fire protection design applications, at a technical level due to the complexity of the tools involved (fire effects tools, evacuation tools, structural response tools) and at a user level due to the facts that tools are used in a specific context, where input data may not be available as needed, analytical methods from already existing standards may be preferred to more sophisticated engineering methods based on their better acceptance by the authority having jurisdiction.

\section{References}

1. International Code Council (2012), International Building Code, 2012 edition, International Code Council

2. NFPA (2010), NFPA 13 "Standard for the Installation of Sprinkler Systems" 


\section{TWENTY YEARS OF PERFORMANCE-BASED FIRE PROTECTION DESIGN: CHALLENGES FACED AND A LOOK AHEAD}

In recent decades, more and more building regulatory systems around the world have permitted or required a performance-based approach to fire protection design instead of requiring that code prescriptions be followed $[1,2]$. This option was interesting to the market because it enabled innovation, aesthetics and optimization of usable space, while maintaining an acceptable level of safety [3]. In addition, this option also added more emphasis on safety objectives other than ones related to life safety such as property protection, business continuity, environmental protection and historical preservation. From an engineering perspective, the performance-based fire protection design framework is valuable as it integrates scientific knowledge into the design process so that fire protection engineers (FPEs) can do more than rely on code prescriptions that are usually implemented as a political response, after major accidents, of code enforcers and Authorities Having Jurisdiction (AHJ). Besides, using a variety of tools as a support, the analysis should bring more engineering rigor and "furthermore, performance-based design should result in a comprehensive fire protection strategy in which all systems are integrated, rather than designed in isolation" [4].

Basically, the current approach to Performance-Based Fire Protection Design (PBFPD) can be divided into the following three major steps (as reflected in such guidance such as BSI [5], ISO [6],IFEG [7] and SFPE [8]):

1) Stakeholders establish goals and objectives, which are then translated by fire protection engineers into design objectives and performance criteria. Then, stakeholders agree on fire design scenarios upon which trial designs, elaborated by the FPEs, are evaluated. This part of the process is documented in the Fire Engineering Brief (FEB);

2) The FPE evaluates the consequences of the selected fire design scenarios and compares their outcomes with the selected performance criteria. In order to do so, he/she uses appropriate tools to evaluate the development of the fire (fire effects tools), the evacuation of the building occupants, and the response of the structure (and the building contents and systems) to the fire design scenarios;

3) The FPE elaborates trial designs that pass the performance criteria, the stakeholders decide which one to finally retain for the considered project and the FPE writes the related documentation in terms of specification, operation, and maintenance of the fire protection measures.

The current approach relies on guidelines and standards which are rather generic in nature, process-oriented documents, which do not specify critical components such as performance (design) criteria, fire scenarios, quantified design fires, and required means of design evaluation/verification. All of these decisions are left to the FPE working in concert with project-specific stakeholders. This has led to a wide variation in designs and levels of delivered performance. In 2007, examining the New-Zealand perspective, Wade et al. [11] identified that a "perceived deficiency in the [fire engineering practice was] the lack of clear guidance from the regulator for performance criteria and design fire characteristics and scenarios for use in performance-based design. This [meant it was] difficult to achieve a uniform approach and consistent safety level through the country". 
Nonetheless, based on the large number of performance-based design projects which have been showcased in the literature over the past 20 years, it seems clear that this process has been accepted by AHJs and the other stakeholders involved in the project, that is to say, building owners, designers, reviewers, enforcers, insurers, contractors and the Fire Services. Examples of these projects include a unique hotel and Casino complex [12], a complex rental car facility integrated in an international airport [13], extension of an existing airport [14], and numerous high-rise buildings $[15,16]$. However, I have not learned as much as I might have from these since the level of detail in published summaries is sometimes light, full PBFPD reports are often client confidential, not all jurisdictions may make all design documentation available, and few comparative reviews have been undertaken.

Reviews of performance-based codes (e.g., building codes in Australia, New Zealand, England and others), performance-based design processes (like the one elaborated in the SFPE PBD Guide or actual PB design solution), and codes that allow a performance-based design option (e.g., NFPA 5000 [17]) can be found in the technical literature $([18,19])$. Nevertheless, many deal only with the global comprehension of the PBD process and possible ways to cope with generic technical issues and better interconnection between FPEs, "lawmakers and people making standards" [20]. In applying the Fire Engineering Brief process, Schulz and Feeney [21] found shortcomings in the process, particularly when stakeholders are risk averse and unfamiliar with new design methods, which would lead to a higher (and more or less variable) amount of justifications needed for the "selection of input parameters and relevant design scenarios". It should be noted that they also plead for incorporating flexibility as "design and preferences for different solutions change over the course of the project [...] which will invoke the need for specific discussion with various stakeholders (especially those involved in the regulatory approval)".

In the USA, there is no centralized mechanism for consolidating feedback regarding how the PBFPD process is handled from a regulatory perspective, so comparative reviews are lacking. There are several reasons for this:

- The building regulatory system in the USA is managed by the states - there is no federal government mandate and therefore no centralized systems for building regulation at the federal level.

- There is no standardized mandatory system for review and acceptance of PBFPD at a state or local level. Acceptance of PBFPD projects therefore varies widely across cities, counties and US states.

- AHJs may have considered that each PBFPD project was unique in terms of key fire engineering components (e.g., quantification of performance criteria, selection of fire design scenarios, implementation of fire protection measures), so no reason was seen for collecting and compiling the specifics of each project. 
Also, while there is PBFPD in the USA, the USA has not embraced performance-based building codes. In 2008, Tubbs and Okawa [18] examined why the International Code Council (ICC) Performance Code (PC) has not been widely adopted since its first publication in 2001. They noted that one barrier to that adoption or to the general adoption of the PBFPD option in the USA in general, was related to the use of computational tools and to data availability: even though they recognized that advancements had been realized in computational fluid dynamics (CFD) based fire effects models as well as with egress models, they noted that challenges still existed: "all models of course have their limitations but if well documented and understood by the designer[, they] can be excellent design tools. The aspect that is most crucial to their use is the appropriate inputs. [...] This continues to be one of the largest barriers to wide spread implementation of performance based codes and design". This barrier is related to the technical aspect of the application of PBFPD, notably linked to the use of tools (model limitation and validity) and data availability. Tubbs and Okawa also found a barrier related to the approval process: the "uncertainty when applying the code in terms of qualifications and related process issues" made the AHJ "very wary of reviewing and approving PB designs especially those that are well beyond the basic code requirements". In other terms, when accepting a PBFPD instead of prescriptive requirements, the AHJ liability was extended further than when simply verifying that the code provisions have been followed, even if the AHJ could still rely on a peer reviewer.

Thus, 20 years of experience of using guidelines that are too generic in nature has resulted in considerable variability in the application and in the acceptance of the PBFPD option. Because of the generic nature of the guidelines, the selection of acceptance criteria and fire designs is more a 'collegial political' choice than an outcome of a real characterization and treatment of the fire risk in the building. Theoretically this means that within the same community, three different engineering firms can develop three different designs for the same building project, each of which results in different levels of risk in terms of occupants, property and mission. Furthermore, simply by moving the building location to another community, the same designs could be accepted or rejected based solely on the perspectives of the different stakeholders involved. To address these issues, FPEs need a more robust framework, with a clear and explicit process to help characterize the life safety risk, the property risk and the business risk, which will result in buildings with more equivalent levels of safety.

\subsection{Technical and political challenges related to the use of PBFPD processes}

Across the world, attempts have been made to address this need, within the regulated structure of national codes and standards and using different approaches, but they all seemed to have failed in one way or another, in part because of the challenges posed by the applicability of generic approaches. The challenge of being too generic applies to the technical aspect of the engineering method, as well as the decision making process embedded in the application of the approach itself, which is referred in this dissertation as the political aspect of the PBFPD process. As mentioned by Brannigan et al. [22] as early as 1996, "technological and policy issues raise fundamentally different kinds of questions: 
- Technical decisions are those which deal with scientific or technological phenomenon that are the subject of well-defined scientific or technical decision processes.

- [Political or] Policy decisions are those which involve weighing of competing social, legal, cultural, technical and other judgmental factors in the regulatory process".

The main technical and political challenges related to the use of PBFPD are presented as follows.

\subsubsection{Technical challenges related to the use of PBFPD processes}

Decades ago, when the PBFPD concept was introduced into national regulations, fire protection engineering was still in its "infancy stage" [2]. As a result, efforts were primarily undertaken to increase the global knowledge related to the consequences of a fire in a building. Some advances were also made in describing human behavior during the evacuation process $[23,24]$, and fire loads were added to the more well established formulas for the resistance of structures [25]. In addition, SFPE [26] indicated that research related to the use of PBFPD process had to be undertaken in order to address uncertainties in the following areas:

- Knowledge relating to the science and engineering being used, due to limitations on the amount of knowledge available for used in models,

- Human behavior, related to "unknowns with regard to the exact behavior of people",

- Risk perception, attitudes and values, as it is "difficult to capture all societal views when undertaking a project".

In order to address these uncertainties, research was undertaken regarding the technical aspect of the PBFPD process. However, it was not addressed in the definition of the PBFPD process itself, in particular in its political aspect, which links the engineering analysis results with the policy decision making process. For example, in 1997, Richardson et al. [27] already listed technologies required for PBFPD. Their list included extended examples of technologies to assess combustibility of construction materials, fire growth, smoke spread, fire resistance of compartmentation and structural assemblies, occupant evacuation and to lesser extent examples of technologies related to fire risk assessment and fire cost calculations. By looking at the technical literature, it can be seen as a plethora of elements that contribute to the reduction of uncertainties in the technical aspect of the PBD process, but there are a lot less regulatory details which interface the political aspect of PBD with the technical aspect.

\subsubsection{Political challenges related to the use of PBFPD processes}

Since different levels of performance are achieved at different costs, political decisions of the PBFPD process can supersede technical decisions. As used here, political decisions refer to those made by stakeholders, which 
can include government (at all levels), clients, and others. For example, in some situations the cost of installing and maintaining a sprinkler system could exceed its benefits in terms of the property remaining undamaged by a fire. For some stakeholders, this technical solution, which leads to a technically-acceptable fire safety design, may not be politically considered because of its cost. Charters and Ramachandran [28] illustrated this point with a PBFPD study that demonstrated business continuity and property protection benefits to an operator of bus garages in the UK if installing sprinkler systems in these facilities. "However, the cost-benefit analysis and the operator's contingency plans meant that there was no cost-benefit or consequence case for installing sprinkler [in] the bus garage. As a result of the risk assessment, the operator did implement other forms of safeguard and fire precaution".

In some cases, it is possible to compare the cost-benefit ratio of two different fire protection design options, particularly when they are both technically viable (sprinkler vs. fire rating barriers), but it can be quite difficult to assess the relative costs and benefits of a technical fire protection measure as compared with a managerial fire prevention measure (e.g. management of fire loads and ignition sources). In the case of nightclubs, managerial procedures such as allowing more people than the prescriptive limit in conjunction with the use of fireworks in an environment with flammable linings and ceiling have repeatedly led to fire disasters (Lame Horse Club, December 5, 2009 - Santika Pub, January 1, 2009 - Wuwang Club, September 21, 2008 República Cromañón, December 30, 2004 - Station nightclub, 2003). One might ask what the costs of having strict managerial procedures which would have prevented the over capacity of the nightclubs and elements that led to a very fast spreading fire would have been as compared to the costs and the benefits of sprinklers. The implementation of managerial procedures in preventing the start or mitigating the consequences of a fire also raises the issue of their enforcement and their real efficiency or contribution in a benefit-cost analysis.

More detailed discussion of the analysis of the current PBFPD processes is presented as follows, in terms of challenges that these current processes have to overcome in order to ultimately establish guidelines that would be more complete to follow through for the fire protection engineer and easier to verify for the authorities having jurisdiction.

\subsection{Detailed challenges of current PBFPD processes}

From the time PBFPD processes were elaborated to their current applications in at least 15 countries, practitioners, code enforcers and researchers have shared their experience, in technical publications and during conferences. They discussed on the advantages and drawbacks of applying and accepting PBFPD processes by identifying critical issues related, not only to the use of a particular process, but also to the definition of the steps of the process itself and to the interactions between the technical aspect and the political aspect of such processes. Before describing these issues in detail, consider the following examples of concerns, expressed across almost the last two decades. 
In 1992, Grubits [29] suggested that a "performance building code must:

- Set out the process to be adopted,

- Provide the factors to be considered in design,

- Specify the performance levels to be attained,

- Adopt explicit safety margins,

- Specify what relevant data sources are acceptable".

Ten years later, Johnson [19] indicated that "many of [the challenges related to the use of PBFPD were] more in the policy, regulatory, approval and accreditation area, rather than in the science and technology field, although clearly traditional fire research is still needed, especially in the area on safety factors and uncertainty". He discussed some of the challenges, which concerned the Australian PBFPD process or the generic application of PBFPD:

- What should the extent be to which property protection be regulated on behalf of the community (which is concerned by sustainability, job protection, environmental protection) or on behalf of the building owners and insurers?

- Fire fighters protection is addressed but application of performance criteria for building occupants does not seem to fit for these trained and better fit people. No guidance is given to get approved performance criteria for fire fighters.

- The concept of risk does not appear to be acknowledged by the regulators, which can lead the fire protection engineer to be legally exposed in case of a rare catastrophic event even though the building design seemed robust and appropriate to all the involved stakeholders. "It is essential that building codes and legislation recognize the balance of risk and cost. A key factor is the completion, validation and greater use of risk-cost models to 'measure' and agree levels of risk and acknowledge this in our regulatory frameworks".

- Certification, accreditation and fees of people involved in the performance-based fire protection design, as well as the independence of the peer reviewers and consistency of the approval process are still in discussion.

- Maintenance of the fire protection measures and change in the use of the building are linked to the issues of enforcement and approval of changes.

- Data "for input to [PBFPD] methods and models continues to be a limitation requiring conservative design".

- "The degree to which building codes are open and closed to internationally accepted standards, products and technologies is becoming a major challenge to international trade". 
He concluded that "these challenges need[ed] continuing research, debate and consultation across all sectors of this industry, and leadership both nationally and internationally. [...] In particular the need to improve administrative and regulatory processes [were] probably even more important than further development of the science and technology".

Also in 2002, Barber and Merkestein [30] also explored the "issue of inconsistency in the approvals process and the reasons behind the difficulties in achieving a transparent design resolution, for PB fire engineering". They referred to Meacham [1] who had "recognized the need for peer review and a high degree of education for both AHJ's and fire engineers". They also concluded that "a formal level of training, communication, forums and more education in performance based design and fire science for AHJ's and fire engineers is required.[...] The fire engineering community as a whole (fire engineers and AHJ's) should be working to achieve a globally recognized process of approvals".

More recently, in 2008, Johnson et al. [31] indicated that "in fire engineering for the built environment the process of hazard analysis, development of fire scenarios and choice of design fires for fire engineering calculations are the most problematic".

These examples show multiple challenges in the application of PBFPD processes, at a technical level and at a political level. The following paragraphs discuss the key challenges which have been identified in more detail.

\subsubsection{Challenges when applying generic guidance to specific projects}

To date, codes, standards, guides and guidelines related to PBFPD have been written in order to be used for any type of built environment and project. Paradoxically, this generic applicability has made the guidelines ineffective in helping engineers thoroughly apply the PBFPD process for a particular project. Parameters to be considered in the PBFPD process are presented, but even if their influences within the overall analysis may seem obvious to a trained FPE, they may not be for the stakeholders. In addition, the way parameters are introduced in the generic PBFPD processes can be confusing even for the FPE. For example, in the SFPE engineering guide to PBFPD [8], information related to the building and its occupants, needed for the analysis is only presented in its Chapter 8, as it should be considered for characterizing design fire scenarios. Numerous building items, including building services and processes, operational characteristics, environmental factors, as well as occupant items are cited in this chapter but their uses within the PBFPD process are not explicitly indicated in the rest of the engineering guide. Neither their metrics (for example, how is the "social affiliation" item supposed to be considered as a parameter of egress models?) nor influences on the overall analysis are indicated. It should be noted that this guide indicates in its Section 6.2.2 that "the process of developing quantifiable design objectives should focus on target(s)", but that focus is totally absent in the subsequent 
chapters dealing with the development of design fire scenarios. By this, SFPE [8] defines targets are as "building, compartment, process, or occupant that is protected in order to meet a specific stakeholder objective".

A similar observation can be made with respect to the International Fire Engineering Guidelines (IFEG) [7]. The principal building characteristics (1.2.3 of IFEG) are listed upfront because "in order to evaluate or design a building's fire safety system, it is important to understand the building's characteristics and its normal mode of functioning. The principal characteristics should be identified early in the FEB process in order to facilitate the decisions that need to be made and issues to be resolved". Dominant occupant characteristics are listed in the following section (1.2.4 of IFEG), as they "should be considered in identifying the design occupant groups for the building [...] explained in Section 1.2.12 of these Guidelines", which states that "if any occupant groups have characteristics which would influence the outcome of a fire scenario, they should be considered for identification as a design occupant group. In some cases, the design occupant group may consist of only one person". The IFEG provide an example of design occupant groups for hospitals: staff defines the detection time and the pre-movement time while movement times would be defined by the types of patients. In spite of this single detailed example, it is unfortunate that the Methodology Part of the IFEG does not go on while presenting methods to assess the evacuation process (chapter 2.8 of IFEG) and that the Data Part of the IFEG does not include any corresponding data on design occupant groups, or at least help the FPE by providing ways to access this data.

To summarize, PBFPD processes included in codes, standards, guides and guidelines were written at a time when it was a priority to introduce the global concepts of the PBFPD process, to model all the phenomena, and to determine and assess the influence of critical components of the PBFPD process. With this purpose in mind, they had to be generic in order to be used as widely as possible. After decades of application of these processes, it seems that this wide applicability turned to be a drawback leading to all the challenges presented as follows. For this reason, it appears that the next generation of guidelines will have to include more details and specificities of the considered types of projects, to which all the engineering process have to be refocused on.

\subsubsection{Challenges associated with the definition, use and quantification of the performance/acceptance criteria}

Custer and Meacham [4] defined performance criteria (also called acceptance criteria) as "metrics against which building materials, assemblies, systems, components, design factors and construction methods will be evaluated on their ability to meet specific performance requirements". As early as 1997, they gathered the following performance criteria, which are presented in Table 2-1 with their references. The nature of the reference indicates the level of regulation (code, standard, guide and guideline). No change occurred between the editions of the references examined in Table 2-1 and the current official editions, if still in use. It should be noted that some thermal exposure criteria can also be found in standards and regulations used to determine the hazard distance to people exposure from a LNG fire, outside a built environment [32]. 
Acceptance criteria are derived from fire protection goals (life safety, property protection, business continuity...): they are highly dependent on the characteristics of the building occupants, contents and structure. When looking at the values collected in Table 2-1, these characteristics can be implicit: for example, the criteria associated with "level of fire gases" mix the person height (1.6 m component) with the height of the room $(0.1 \mathrm{H})$. The criteria related to heat radiation effects on people seem derived from physiological studies and translate well the potential damage to building occupants while receiving radiative heat fluxes from a fire. What is more disturbing is that the last criterion in Table 2-1 can be found in Section 921.2 of the sixth edition of the Massachusetts State Building Code as the design criteria of a smoke control system. In consequence, since the performance criteria are a technical transcription of a political agreement, it seems interesting to find the rationale behind the selection and the quantification of the published performance criteria. Nevertheless, this task is out of the scope of the current dissertation.

Table 2-1. Performance criteria gathered in codes, standards and guides and guidelines [4]

\begin{tabular}{|l|l|l|}
\hline \multicolumn{1}{|c|}{ Performance Criterion } & \multicolumn{1}{|c|}{ Reference } & Date \\
\hline $\begin{array}{l}\text { The deflection of reinforced concrete structural } \\
\text { members shall not exceed that permitted by } \\
\text { ACI } 318\end{array}$ & $\begin{array}{l}\text { The BOCA National Building Code, } \\
\text { Building Officials and Code } \\
\text { Administrators, International, County } \\
\text { Club Hills, IL }\end{array}$ & 1993 \\
\hline $\begin{array}{l}\text { The level of fire gases shall not be lower than 1.6 } \\
+(0.1 \mathrm{H}) \mathrm{m}, \text { where } \mathrm{H} \text { is the height of the room }\end{array}$ & $\begin{array}{l}\text { Swedish Board of Building, Housing } \\
\text { and Planning, Building Regulations, } \\
\text { Sweden }\end{array}$ & 1994 \\
\hline $\begin{array}{l}\text { Limiting conditions for tenability caused by heat } \\
\text { radiation: less than } 2.5 \mathrm{~kW} / \mathrm{m}^{2} \text { can be tolerated for } \\
\text { over } 5 \mathrm{minutes} \text {; } 2.5 \mathrm{~kW} / \mathrm{m}^{2} \text { can be tolerated for } \\
30 \text { seconds; } 10 \mathrm{~kW} / \mathrm{m}^{2} \text { can be tolerated for } \\
4 \text { seconds }\end{array}$ & $\begin{array}{l}\text { Fire Engineering Guidelines, Fire Code } \\
\text { Reform Centre, Limited, Australia }\end{array}$ & 1996 \\
\hline $\begin{array}{l}\text { The smoke layer interface (shall be maintained) } \\
\text { above the highest of either: the highest unprotected } \\
\text { opening to an adjoining space, or } 6 \text { feet above the } \\
\text { floor level of exit access open to the atrium for a } \\
\text { period of } 20 \text { minutes }\end{array}$ & $\begin{array}{l}\text { The BOCA National Building Code, } \\
\text { Building Officials and Code } \\
\text { Administrators, International, County } \\
\text { Club Hills, IL }\end{array}$ & 1993 \\
\hline
\end{tabular}

Deterministic values of performance criteria have been published and some are embedded in regulations (such as Sweden, Japan and New Zealand). Even with these quantified performance criteria, there is a lack of guidance on how these generic values are to be applied. Custer and Meacham [4] indicated that many countries using or developing performance-based codes have not included values for the performance criteria because, even if some performance criteria may be applicable to any design situation, the selection of performance criteria remains situation-dependent. 
Furthermore, these performance criteria are not really being used to assess the performance of the building to withstand the fire threat; rather, they indicate a technical perception of the potential damage to building occupants, contents and main structure. It is proposed that "performance criteria" should be called "fire effect criteria", as there is a subsequent layer of analysis needed in order to quantify the actual performance of the building. The level of building performance should be quantified by answering questions such as: how many casualties or injuries would be caused by year of use of the building? How many days a fire would cause business interruption?

Regarding life safety objectives, the performance criteria seem to be implicitly associated with a "no injuries or casualties" performance of the building in case of a fire, at least for building occupants "not intimate with the initial fire development" [33]. Fire events produce effluents and heat that can cause these injuries and casualties, and FPEs are trained to assess these productions. Nevertheless, in case of a fire or emergency situation in a highly populated area (theater, stadium, nightclub...) people could result as casualties, not because of toxic or thermal threat but because they stampede and get crushed at some points on the evacuation process. As a recent example, a student was crushed to death, two others were in a critical condition and at least six (or eight) other people injured after a stampede at a nightclub in Northampton, UK. The club was overcrowded (1,300 capacity). It is not clear if a fire alarm went off when people were asked to leave the club to get into their buses [34]. This phenomenon should also be included when assessing life safety performance criteria associated with fires in buildings. When reviewing different PBFPD processes, a performance criterion associated with a crush effect in case of stampede for exits has not been found or mentioned: without such a quantified criterion, how would FPEs reconstruct the Brooklyn theater fire which killed 278 people on December 5, 1876, the Iroquois theater fire (Chicago), which killed 602 people on December 30, 1903 or more recently the Uphaar Cinema fire (Delhi, India) which killed 59 people and seriously injured 103 people on June 13, 1997 ?

With respect to fire performance across all types of building structures, the "Eurocodes" [25] provide an interesting example of how the fire threat is considered, specifically for structures made of concrete, steel or timber. The main idea of these documents is to evaluate the action of a "structural fire design" as one more action on the structure, such as actions imposed by natural hazards such as earthquake, wind, and snow. The definition and the evaluation of the consequences of the "structural fire design" only concern the structure of the building and not its occupants and contents. Nevertheless, Kruppa [35] indicated that the safety of people could be considered:

- During a fire evacuation by estimating if the time before collapse of the structure was less than the time to ensure the safety of people (which has to be estimated elsewhere) and

- After a fire, if the remaining deformation of the building components was less than the maximum allowed deformation assessed after the cooling phase. 
In 1997, using an analogous concept taken from the American Society of Civil Engineers, Lucht [36] proposed to introduce a simple state equation where the resistance or "strength" of the building was greater than the sums of the applied loads: a smoke load, heat load and carbon monoxide load were added with corresponding safety factors and then compared with the combined "resistance" of the fire protection systems and the exit system, pondered by their reliability factors. In 1999, Meacham [2] attempted to expand upon this concept, with a specific focus on evacuation analysis and associated uncertainties in the process. Concerning the definitions of the loads and resistances of the fire threat, Fitzgerald [37] had already established a list of technical differences between the building structural system and the "far more complex" building fire safety system, rendering unpractical the merging of the two concepts. In 2004, Bukowski [38] considered that "fire [was] an event like an earthquake or hurricane, but where these natural events [had] statistical distributions in time (magnitude and return frequency), fires [were] unique because nearly all fires start[ed] small and gr[e]w until they r[a]n out of fuel or air or [were] extinguished. Large fires [were] generally the results of many things going wrong simultaneously, and thus represent[ed] a string of conditional probabilities that [were] not well described in normal terms, One suggestion for how to develop design fire specifications specific to a building space to result in the same stress on the space ha[d] been proposed but this [did] not address the issue of return frequency".

After reviewing the pros and cons from the technical literature, I decided that this potential way to include fire as an additional load was not the most adequate to deal with building occupant evacuation or protection of building contents, in spite of its usefulness to assess structural component response in case of a fire. In conclusion, this example shows that it does not seem possible to mix methods of evaluations of performance criteria for different objectives. This implies that different objectives (life safety, property damage...) have to be assessed according to their corresponding level of performance.

In addition, for life safety objectives, I consider that the corresponding criteria values should be a consensus of engineers, not only dealing with fire protection engineering but also toxicology and psychology. For a deterministic point of view, a single value per fire effect criterion could be defined for target types. For a probabilistic approach, a distribution should be given.

To summarize, as it is quantified in the current PBFPD processes, the performance criteria should be called "fire effect criteria". The terminology "performance criteria" should describe the actual level of performance achieved by the considered project, for each of its safety objectives agreed among its stakeholders. Research to attain a consensus for fire effect criteria assessment between the different engineering disciplines should be done, not only for building occupants, but also building contents relevant to the stakeholders (i.e. important piece of equipment, electronic cabinet used for process safety, priceless artifact) as well as environmental ecosystems potentially affected by the fire itself and the chemicals used for its extinguishment. 


\subsubsection{Challenges associated with the selection of fire design scenarios}

SFPE [8] indicates that "in a deterministic analysis, one or more possible fire scenarios can be developed as design fire scenarios that are representative of potential worst credible fires in a particular building [...]. The central challenge in scenario selection is finding a manageable number of fire scenarios that are sufficiently diverse and representative". Unfortunately, this guide, or any other guide, guideline or regulation, does not provide the fire protection engineer and the involved stakeholders with detailed explanations on what the representativeness of potential worst credible fires in a particular building has to be:

- $\quad$ "Worst credible fires" seem to imply that fires having developed to quite a large extent while remaining credible are the ones to be considered. This denomination is too vague because the intensity of the fires necessary to have an effect on targets (building occupants, contents and structures) depends on the nature of the targets and on the relative position between the fire and the targets. The ICC Performance Code gives different levels of "fire maximal tolerable damage" as a function of the importance of the building [39] but it does not provide a method to define scenarios leading to these different damage levels. It should be noted that focusing on high intensity fires does not necessary means that less intense fires are "covered" even if SFPE also indicates that "finding a representative sample of scenarios ensures that if the design is safe for those scenarios, then it should be safe for all scenarios, except those specifically excluded as too unrealistically severe or too unlikely to be fair tests of the design". In the nuclear power production field, the OECD Committee on the Safety of Nuclear Installations (CSNI) indicates, in one of its own technical opinion papers, that "not all large nuclear power plant fires are significant from a public safety point of view, nor are all safety significant fires large" [40]. As early as 1999, Brannigan summarized concerns from himself and others regarding how design fire scenarios were selected and characterized; Dr Hall from NFPA was cited regarding the modeling of fire scenarios with: "If only a few scenarios are modeled explicitly, then each one is implicitly required to be representative of a much larger and more varied collection of other scenarios. There may be no good evidence to support this" [41]. This cited remark is so important that it still written, with no change, in the latest edition of the NFPA Fire Protection Handbook [42]. Brannigan also stated that the original meaning of a "scenario" used to "represent a technical description of the social expectation of safety" was redefined so "scenarios stopped including the entire hazard, and became instead just a specified design fire". Building and occupant characteristics which defined the problem boundaries were then relegated to the background as input parameters of fire scenarios which became the focus of all the PBFPD process.

- The context related to the term "manageable" is not defined but Hall and Watts [42] link that term to the "computational burden" of assessing the consequences of these scenarios, as well as the "shakiness of the available data and a desire to minimize the number of different terms supported by expert judgments". This context then implicitly states that in a time limited framework, such as the project consulting environment, scenarios would be excluded or "clustered" with other scenarios because of time and resources constraints. 
NFPA 101 Life Safety Code [33] presents a list of design fire scenarios associated with the life safety of building occupants (not related to the fire origin) and a list of scenarios (similar to the NFPA one) is proposed to be integrated in the building regulations of New Zealand. It should be noted that the scenarios of the NFPA list are qualified as "challenging" and are not necessary the "credible worst case scenarios". Hall [43] explains that "excluding reliability issues, the conditions that make a scenario challenging tend to fall into two types:

- Conditions that lead to a more rapid onset of unacceptable outcomes (such as death) or a more rapid onset of fire conditions that are taken as proxies of unacceptable outcomes (such as incapacitation, flashover, or structural collapse);

- Conditions that line up with system limitations, which primarily means uncovered or shielded fire locations".

Concerning the second type of conditions, fire protection systems have different modus operandi. I assume that when the PBFPD process is used to evaluate the benefits of changing one fire protection feature (usually a prescriptive requirement) by an alternative, scenarios challenging both options should have to be elaborated, and the overall analysis would not only have to be based on the damage ratio between the two options but also contain the evaluation of the likelihood of these scenarios and of the cost of installing and maintaining the different fire protection options. None of this is discussed in the current PBFPD processes I reviewed.

\subsubsection{Challenges when dealing with a priori lists of performance criteria and design fire scenarios}

In the current PBFPD processes, the fire design scenarios and the criteria are selected and agreed upon among the involved stakeholders prior to any development of trial designs, without any estimation of the likelihood of the selected fire scenarios. Babrauskas [44] argued that "the fire scenarios and what happen[ed] to the building upon encountering a given scenario, [were] items for the designer to propose to the building official. The building official [could] then reject the proposal, but he [or she would] have no objective grounds for doing so". Related to this preoccupation and in order to have a more cohesive sets of performance criteria and design fire scenarios across their jurisdictions, some national regulations decided to "prescribe" a priori lists of performance criteria and design fire scenarios. New Zealand building current regulation constitutes a typical example of that situation. I concede that in the short term, AHJs of New Zealand would be able to better judge applications based on a PBFPD process where scenarios are predefined but in the long term, I anticipate difficulties in applying these scenarios to very complex and unusual projects. Some difficulties are presented below.

As presented in the previous point, NFPA [45] introduced a list of 8 design fire scenarios as follows: "to provide a comprehensive design (i.e., to demonstrate how the fire safety system will respond to a variety of fires), more than one scenario should be considered. It is suggested that, at a minimum, the following three 
types of scenarios be considered: 1) High-frequency, low-consequences (typical) 2) Low-frequency, high consequence (high challenge) 3) Special problems scenario". The intent or the ideas behind some of the listed scenarios are presented in the NFPA 101 Handbook but not in the corresponding standard. I deplore the fact that this type of information is "lost" when editing the standard as it is more important to tell a FPE what problem he/she needs to solve than how he/she has to solve the problem.

Considering "severe" (or "high challenge") a priori lists of performance criteria and design fire scenarios may lead in some cases, to the failure of all trial designs, even considering as many or more fire protection features as the prescriptive requirements.

Regarding performance criteria of the New Zealand regulation, in 2008, Lloydd [46] indicated: "there are two sets of criteria: a simple set of criteria, if passed, no further analysis is required, and a more detailed set of criteria, for which a more detailed analysis is required. [...] The simple tenability criteria are based upon zero exposure of occupants to the negative effects of the fire. If occupants are kept away from all smoke and heat at all times, the building is considered to meet the requirements of the code [:]

1. The clear layer height must remain at a minimum height of $2.5 \mathrm{~m}$ from floor level, and

2. The maximum upper layer temperature reached shall not exceed $200^{\circ} \mathrm{C}$.

As can be quickly identified, rooms and spaces with ceilings lower than $2.5 \mathrm{~m}$ will not pass the simple criteria and more detailed analysis will always be required for these spaces. Also, the simple criteria may not be suitable for very large spaces where stratified layers may not form and a more detailed analysis of the conditions within the space may be required".

When dealing with a list of design fire scenarios, I have similar comments: what to do when selecting the "loss of one exit" scenario when the building has a single main exit stairs? Based only on the basic description of this scenario, it may imply to the AHJ that the building may require at least two exits, or the AHJ may agree with the other stakeholders to "ignore" that scenario as it is permitted in the PBFPD process. What is the meaning of this scenario when in the prescriptive regulation (e.g. US ICC International Building Code [47]), the second exit is only required for a specific numbers of occupants and stories in the building, along with its main function (assembly, institutional...)? Besides, the scenario label itself is subject to interpretation. For a loss of exit, one could put the fire (i.e. untenable conditions) in the stairwells, but also anywhere in the exit path. If the exits are designed according to requirements, does one still have to consider the scenario where one exit is loosed?

Regulators want more specificity regarding the scenarios characteristics (i.e. evolution of the heat release rate with time) because scenarios constitute the core of how the fire protection design is judged to be acceptable and the variability regarding their characteristics is too large. 
Even with a list of pre-defined scenarios, there are so many parameters to evaluate in order to characterize each of the scenarios of any pre-defined list: the definition of the fire threat, including the location of the $1^{\text {st }}$ burning item, the evolution with time of the heat release rate, the production of fire effluents and their spread within the built environment, the initial position of the building occupants (movable targets), the time required for these occupants to be aware of the fire condition, to realize the emergency situation and start to evacuate, the selection of the exit routes by the occupants and their travel speed are. This parametric characterization of fire design scenarios is not precise enough so the variability in interpretation of these scenarios increases not only among the different stakeholders but also FPEs. New Zealand regulators tried to implement these parameters, that is to say specify values for the different parameters of each scenario in a non-mandatory application guidance [46]. For example, the heat release rate evolution with time or "HRR curve" is specified as an "atsquare" curve. Nevertheless, no explanation is given on the selection by the regulators of the value of the $\alpha$ parameter: is it a mean value based on the potential fire hazard of the combustible building contents? How does that value correspond with the actual situation of the considered project? How much could the actual building content configuration vary before another value of the $\alpha$-parameter has to be considered by the regulators?

For tunnel ventilation design applications, in 2007, Miclea et al. [48] gathered values of the recommended minimum values of the heat release rate to consider, as follows: "the UN ECE recommendations suggested a minimum fire size of $30 \mathrm{MW}$. This is used in many countries such as Austria, Germany and Switzerland, whereas provisions of $50 \mathrm{MW}$ can be found in the design standards of Germany and Britain". The authors also compared these values with the one reached in the Runehamar tunnel tests where fire from ordinary heavy goods vehicles could reach as high as $200 \mathrm{MW}$. This example illustrates the fact that quantified parameter values embedded in the regulations certainly decrease variability in the application of the PBFPD process but they also need to be well documented with their applicability domain.

In conclusion, attempts made by standard associations, and even regulatory bodies to define more quantification of performance criteria and design fire scenarios seemed a positive action in order to increase coherence in the PBFPD process applications. Nevertheless, intents and ideas behind developing fire scenarios in such lists are lost in their transcription into the regulatory framework, while on the contrary they should be put forward in this context (to explain why the situations analyzed by the scenarios should matter), instead on having the regulations "prescribing" more and more details on the scenario specifications (on how the FPE has to calculate the scenario consequences). Applications already showed some limitations and drawbacks of this concept.

\subsubsection{Challenges when comparing levels of performance between an engineering solution and the one based on prescriptive requirements}

The acceptability of an engineering fire protection design can be made according to a comparative evaluation of this design with the ones elaborated using the corresponding regulatory requirements. In some projects where 
innovation is the main driver, like for example, the need to have beautiful, large, bright airports to accommodate the exponential increase of air traffic since the 1970's, as well as the connective use of airports with nearby hotels and car renting or parking sites. Fig. 2-1 shows the "check in" hall of Terminal 4 Barajas airport in Madrid. Such wonderful airport aesthetics are without comparison with the airport ancestors provided with compartmented long corridors. Comparing the fire safety options of these two types of airports would not make sense as their designs, which constitute their true nature, are too different.

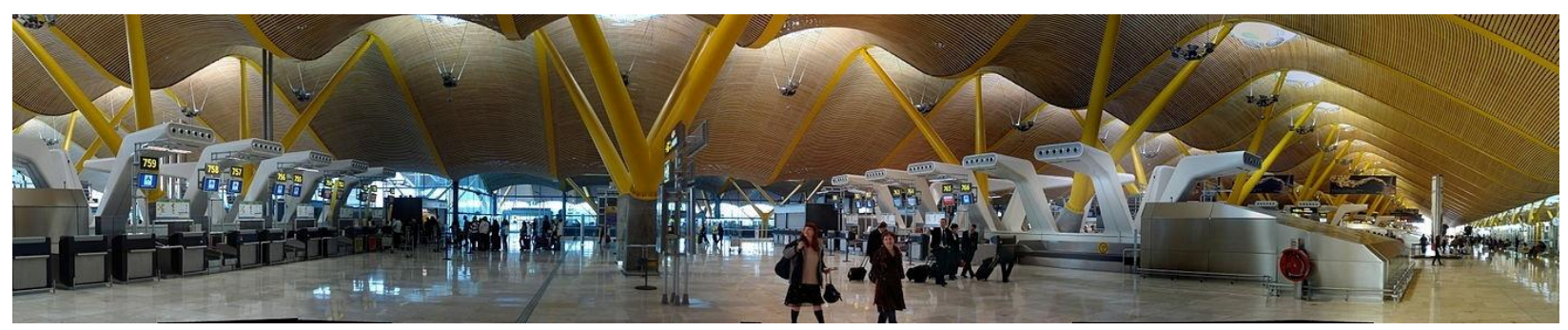

(source: http://en.wikipedia.org/wiki/File:Barajas_terminal_4_panorama,_Madrid.jpg, in the public domain)

Fig. 2-1. Barajas terminal 4 panorama, Madrid

What about new performance criteria such as sustainability? Performance of a building is not exclusively related to life safety, which is the primary objective of most building codes (including no harm to adjacent building and safety of fire emergency responders as in the New Zealand regulation). Fire protection requirements are then mainly established according to this safety objective. The other stakeholders' goals and objectives, such as property protection, heritage preservation, would require specific regulations. Standards exist but they are not at the regulatory highest levels [49], which "focuses on performance-based evaluation as an important alternative to prescriptive codes" [50]).

Building codes authorize trade-off between different fire protection requirements, usually when the considered building is fully equipped with sprinklers. For example, in offices, the ICC International Building Code states that the maximum common path of egress travel shall not be more than 75 feet $(22860 \mathrm{~mm})$ if the office building is not sprinklered and 100 feet $(30480 \mathrm{~mm}$ ) if the office building is fully sprinklered [47]. Scenarios to be used in estimating the engineering solutions would also be used for the deem-to-comply requirements. For the list of selected scenarios, there is no certainty that the quantified trade-offs inscribed in the regulation would pass the selected scenarios.

In conclusion, comparison of performance levels between an engineering design and a prescriptive one is not a trivial exercise. I assume that the rationale behind the quantification of the requirements embedded in building codes is based on previous "good practices", partial empirical evidence and not on system approach of the problem, especially when trade-offs are concerned. This rationale does not have a common background with the one used in the PBFPD processes, so I do not retain this form of comparison in the rest of this chapter. 


\subsubsection{Challenges related to the determination of influential factors affecting the evaluation of trial designs}

SFPE [8] lists factors affecting the evaluation of trial designs (cf. §10.2.1 of SFPE guide) but these factors are not clearly assessed nor always considered (sensitivity of subsystem output to design objectives, knowledge level [uncertainties], benefit versus cost [cost could be prohibitive and it may change the design objectives \{cf. $\S 10.1 .5 .4$ of SFPE guide\}], and absolute or comparative evaluation). IFEG [9] provide a list of input parameters and output parameters for each of the sub-systems these guidelines present: fire initiation and development and control, smoke development and spread and control, etc. Nevertheless, they do not provide a hierarchy on the relative influence of all these parameters. For these parameters needed for the quantification of the fire consequences, as well as other factors needed to perform a PBFPD process, no examined standards, guides and guidelines [7-10] established a hierarchy between the influences of these factors. Additional factor influences, such as the "user effect" on tools, also have to be assessed [26]. Besides, in the consulting environment, such assessments are difficult due to time and resources constraints. Evaluating trial designs is rendered complex because of multiple interconnected influences at a process level (influence in selecting scenarios, performing cost-benefit analysis), at a technical level (influence of the characteristics of the design fire scenarios) and at a political level (agreement on performance criteria).

\subsubsection{Challenges when dealing with "idealized" design features and "real life" installed and running features}

When applying the PBFPD "concept of optimization" in the design phase of a project, difficulties may arise for futures changes. In 2004, Ryber et al. [51] identified related minefields and proposed possible tools to overcome these difficulties. Besides, Stenstad and Bjørkmann [52] examined the interconnections between the different stakeholders involved in implementing PBFPD in the execution phase of a new project, which concern the "architect, the different engineering firms and contractors. Each company is responsible for a limited part of the building project related to their contract and will have no survey, nor responsibility for the project as a whole [...]. "Minor" changes may be done without anyone questioning the consequences. In this way, prerequisites defined in the [Fire Safety Strategy] FSS report may be overlooked and not taken care in a proper way". Looking at the problematic related to the use of safety margins, they indicated that the "uncertainties to fire safety resulting from the design, execution, administration and maintenance of a building [were] most likely to reduce the level of safety from that stated by the building code. We [were] fortunate that our traditional buildings include[d] both materials and individual elements of construction that often [left] us with considerable redundancies. It [was] important to recognize this when we [tried] to identify the inherited or as called the political level of safety", as shown in Fig. 2-2.

Even if most of the important decisions related to a new project fire safety have to be taken during the project conceptual design phase, documentation and maintenance protocols of the installed fire protection measures have to be transmitted to the actual users of the building as these users would be the ones who would have to deal with a real fire event. These aspects are not included in the evaluation of the trial design. A solution could 
be conceptually acceptable but not compatible with the actual use of the building, with or without considering significant changes in the building management or use.

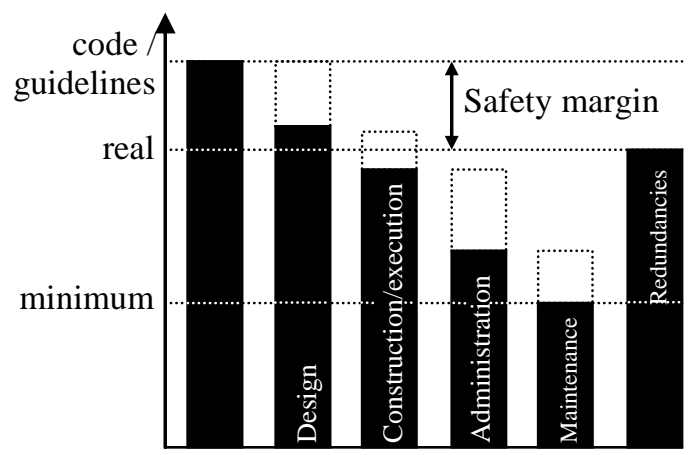

Fig. 2-2. Level of Fire Safety and the reduction due to the different processes [52]

\subsubsection{Challenges when estimating the consequences of fire design scenarios}

Tools related to the estimation of the effects of a fire (fire effects tools) have been developed separately from the tools related to the estimation of the evacuation process and from the tools related to the estimation of the structural response in case of fire. This situation arise from the fact that these three components of the fire protection engineering calculations were so complex and different from one another that they required these separate developments. Nevertheless, attempts to jointly calculate fire effects and egress are in development (such as FDS-EVAC co-developed by NIST and VTT).

Life safety objectives are often analyzed through two concepts: ASET (Available Safe Egress Time) and RSET (Required Safe Egress Time). In 2008, Averill et al. [53] assessed that priority had been given to the estimation of the ASET concept. I assume that their assessment relies on the fact that FPEs are more trained to deal with the estimation of fire effects than the estimation of the evacuation process; because egress modeling had been a concern for FPEs for decades, as soon as they tried to calculate the RSET. Indeed, in 1988, Kendik [54] stated that an early distinction was made between two egress model categories: movement models and behavior models and in 1999, Shields [55] presented a possible path to follow in order to develop human behavior knowledge as "hard science alone cannot solve the "fire problem"". This dichotomy in solving the "fire problem" can be seen, for examples, in the fact that there is still no or seldom feedback of the evacuation side to the fire side (i.e. building occupants closing doors while escaping) or evaluation of the counter flows of fire fighters and emergency responders and their actions on people and fire. Challenges are then related to the education of the FPE, who must not only be trained to estimate fire effects, but also evacuation of building occupants and structural response in case of a fire. 
Besides, it is necessary to verify the appropriateness of tools to be used for a given the application, as well as the user's ability to use such sophisticated research tools. Documents published by SFPE [26,56] ISO [57] or ASTM $[58,59,60,61]$ provide generic guidance on the use or on the validation of computer models. In addition to the generic status of these guidelines and standards, it should be noted that the application of such documents has to be reassessed with updated versions of the same models and with new models. One example of applied document concerns a fire detection computer model [62]. It should be noted that I was not able to find any document which provides guidance on the interactions of model uses to assess fire effects, occupant evacuation and response of structural building elements.

\subsubsection{Challenges when adapting literature values, when available, to use in models}

As previously presented in this chapter, consensus of the fire protection engineering profession and the regulators should be found for the values of the "fire effect criteria" so that reports can be published regarding these criteria. Governmental institutes NIST [63] or INERIS [64], international societies such as SFPE [65] or ISO [66] should provide such reports, so national regulators and AHJ could reference the recognized values and, if necessary, adapt them for their own purposes. Current works in ISO TC92/SC3 are dedicated to the revision of an International Standard providing guidelines for the estimation of time to compromised tenability limits [67].

In any engineering practice, injecting appropriate data in tools is as essential as using the appropriate tool in order to solve a given problem. Care should be taken when selecting and using data from any source as:

- Data obtained from experiments performed decades ago does not necessary represent current data as material properties and people characteristic distributions constantly evolve,

- Some data needed to use tools is still missing so FPEs have to use their "expert judgment" to adapt the available experimental data to use with a chosen tool, and

- Tools (models) also evolve with knowledge of the phenomena they represent. Experimental data is usually collected in order to supply validation points for a model. The data collection process is then elaborated in order to coincide with the model paradigm. In other words, the data may be model dependent; changing the model may disqualify a data validation set to be used in another model.

Current PBFPD processes emphasize on the importance of using appropriate data with appropriate tools. As an example, Part 3 of IFEG "provides a selection of data that may be used in applying [its] methodologies [gathered in its] Part 2 or other chosen methodologies. This does not preclude the use of other data that might be chosen by the fire engineer and that are acceptable to regulatory authorities or certifiers. Caution should be used in applying data because it may not be relevant as a result of: 
- New methodologies

- New technologies

- $\quad$ New materials

- $\quad$ Varying regulatory requirements

- Cultural differences

- Construction practices".

Nevertheless, the current PBFPD processes fail to provide the necessary level of detail with which the FPEs and the different stakeholders, including peer reviewers, have to scrutinize the datasets used while performing any PBFPD process.

Without validated repositories for input data, FPEs are forced to spend time and resources to look for appropriate data and demonstrate to the stakeholders that their chosen datasets can be used for the application they are analyzing. This statement is also valid for a researcher who usually starts his/her research by collecting data already found by prior researchers and relevant to his/her particular study.

Concerning the values of all the parameters needed in order to perform a calculation of the consequences of a fire, it should be noted that attempts were or are currently made to develop repositories of data collections usable by FPEs:

- Fire data was made available by the US National Institute of Standards and Technology (NIST), which created the Fire And Building Educational Resource Collection (FABERC) [68]. This database is no longer accessible via "faberc.org", but some experimental results from fires conducted by NIST still can be found at its own website.

- The need for egress data collections was advocated by Fahy and Proulx [69]; Gwynne [70] with NIST support started to develop a web portal to support such a database, its structure being elaborated and ready for beta-testing.

- Standardized methods are in progress (i.e. NFPA 557 in the USA [71]) in order to collect basic data such as fire load and reliability of systems in a coherent and harmonized manner, which really permit to collect, use and compare data from different studies.

As long as the FPE community is not ready to consolidate such databases and standardize procedures to collect and apply data in order to provide appropriate data to use in any PBFPD process, FPEs and stakeholders will be required to spend unnecessary time and resources to find data and validate its use for each and every project. Even with the most elaborate and sophisticated PBFPD process, using inappropriate data produces erroneous results which may lead to a building performance dramatically below its expected level of performance. 


\subsection{Summary of the challenges related to the use of current PBFPD processes}

A large number of articles in journals and conference proceedings that describe challenges and concerns regarding the use of PBFPD processes, published as early as the first drafts of these processes, and covering the last two decades, have been analyzed. It has been determined that significant challenges still exist in the application of these processes in practice and that major changes are needed to address them.

1. Applying generic guidance to specific projects

The PBFPD processes currently included in codes, standards, guides and guidelines were written at a time when it was a priority to introduce the global concepts of the PBFPD process, to model all the phenomena, and to determine and assess the influence of critical components of the PBFPD process. With this purpose in mind, they had to be generic in order to be used as widely as possible. After decades of application of these processes, it appears that this wide applicability has turned out to be a significant drawback, leading to a number of specific challenges as presented here and summarized below. For this reason, it is proposed that the next generation of guidelines will have to include more details and specificities of the considered types of projects, to which all the engineering process has to be refocused on.

2. Defining, using and quantifying the performance/acceptance criteria

As quantified in the current PBFPD processes, performance criteria should actually be called "fire effect criteria". The terminology "performance criteria" should describe the actual level of performance achieved by the considered project, for each of its objectives agreed among its stakeholders. Research to attain a consensus for criteria assessment between the different engineering disciplines should be done, not only for building occupants, but also building contents relevant to the stakeholders (i.e. important piece of equipment, electronic cabinet used for process safety, priceless artifact) as well as environmental ecosystems potentially affected by the fire itself and the chemicals used for its extinguishment.

\section{Selecting fire design scenarios}

Attempts made by standard associations and regulatory bodies to define more quantification of performance criteria and design fire scenarios seemed a positive action in order to increase coherence in the PBFPD process applications. However, the intents and ideas behind developing fire scenarios, as ultimately reflected in such lists, are generally lost in their transcription into the regulatory framework. This is unfortunate because these intents and argument should be provided in context with the scenarios to explain why the situations analyzed by the scenarios should matter, instead on having the regulations "prescribing" more and more details on the scenario specifications or how the FPE has to calculate the scenario consequences. 
4. Comparing the levels of performance between an engineering solution and the one based on prescriptive requirements

Comparison of performance levels between an engineering design and a prescriptive one is not a trivial exercise, yet that is a common approach taken. I assume that the rationale behind the quantification of the requirements embedded in building codes is based on previous "good practices", partial empirical evidence and not on system approach of the problem, especially when trade-offs are concerned. This rationale is not appropriate for a PBFPD process, and is not recommended without being made much more transparent (which is difficult, especially given (3) above).

5. Determining the most influential factors affecting the evaluation of trial designs

Current PBFPD processes list factors affecting the evaluation of trial designs, but these factors are not clearly assessed nor always adequately considered with respect to such attributes as sensitivity of subsystem output to design objectives, knowledge level (uncertainties), benefit versus cost (cost could be prohibitive and it may change the design objectives), or absolute versus comparative evaluation. There is no hierarchy between the influences of these factors. Additional factor influences, such as the "user effect" on tools, also have to be assessed. In the consulting environment, such assessments are difficult due to time and resources constraints, thereby making them less likely to be undertaken. Likewise, evaluating trial designs is rendered complex because of multiple interconnected influences at a process level (influence in selecting scenarios, performing cost-benefit analysis), at a technical level (influence of the characteristics of the design fire scenarios) and at a political level (agreement on performance criteria), and lack of data, time and resources means that the evaluation required does not always get done at a level that it should.

6. Dealing with "idealized" design fire protection measures and "real life" installed and running measures At present, most PBFPD processes consider "idealized" representations of future actual conditions, often times not accounting for how buildings are used and the state of systems over time. At the time of design, decisions may be made without all stakeholders being involved, and without the stakeholders understanding the implications for the future. Even if the fire protection "design" is the most important aspect of any building design project, things may change during construction that need to be documented and accounted for, and maintenance of systems and consideration of how the systems performance with respect to normal operation of the building becomes critical once the building is occupied. These aspects are not explicitly included in the evaluation of the trial design by current PBFPD processes. As a result, a "design" solution could be conceptually acceptable but incompatible with the actual use of the building, with or without considering significant changes in the building management or use. 
7. Estimating the consequences of fire design scenarios

While an integrated approach to building fire performance is the target of current PBFPD processes, estimation of consequences is not at all integrated. Life safety objectives are often analyzed through two concepts: ASET and RSET. Tools related to the estimation of the effects of a fire (fire effects tools) have been developed separately from the tools related to the estimation of the evacuation process and from the tools related to the estimation of the structural response in case of fire. Data are often lacking for all required analyses and shortcuts are taken. As a result, these analyses (fire effects, evacuation, structural fire performance) are typically undertaken in isolation. As a result, it is not always clear how factors such as fire and evacuation interactions are addressed (e.g., occupants opening and closing doors, which can change burning characteristics), or which parts of the process are most sensitive to changes from initial design assumptions, or where greatest sources of uncertainty and variability exist. Challenges also exist with engineers selecting appropriate tools to be used for given the applications, as well as the user's ability to use sophisticated research tools in design.

8. Adapting literature values, when available, to use in models

In any engineering practice, use of appropriate data in analytical or computational tools is as essential as using the appropriate tool in order to solve a given problem. Care should be taken when selecting and using data from any source as:

- Data obtained from experiments performed decades ago does not necessary represent current data as material properties and people characteristic distributions constantly evolve,

- Some data needed to use tools is still missing so FPEs have to use their "expert judgment" to adapt the available experimental data to use with a chosen tool, and

- Tools and models also evolve with knowledge of the phenomena they represent. Experimental data is usually collected in order to supply validation points for a model. The data collection process is then elaborated in order to coincide with the model paradigm. In other words, the data may be model dependant; changing the model may disqualify a data validation set to be used in another model.

However, current PBFPD processes fail to provide the necessary level of detail with which the FPEs and the different stakeholders, including peer reviewers, have to scrutinize the datasets used while performing any PBFPD process. Without validated repositories for input data, FPEs are forced to spend time and resources to look for appropriate data and demonstrate to the stakeholders that their chosen datasets can be used for the application they are analyzing. This statement is also valid for a researcher who usually starts his/her research by collecting data already found by prior researchers and relevant to his/her particular study. 


\subsection{Characteristics of a new paradigm}

As summarized above, several challenges with current PBFPD processes have been identified. Even where found in the literature, successful applications of PBFPD processes showed that addressing the challenges are currently costly in time and resources, in order to solve the engineering problem (technical level) and get an agreement among all the involved stakeholders (political level). Because the current PBFPD processes are generic, it seems difficult to incorporate any feedback of the successful applications into these processes in order to overcome the presented challenges and therefore reduce the uncertainties and concerns associated with them. In addition, the current PBFPD processes are centered on the study of the fire protection measures, which sometimes can lead to differences on the way these measures are designed and then used when the building is occupied. Furthermore, designers are not taking as full advantage of data and tools, for the types of applications being addressed, as they can or perhaps should.

In order to overcome these challenges, it is suggested that the solution is to: (1) re-center the PBFPD process on its application subject, that is to say the system formed by the building and its occupants, (2) create PBFPD processes that are specific to different types of occupancies, and (3) to provide a mechanism to help FPEs select the most appropriate tools and data for the types of applications they are addressing. To address (1), by integrating the study of the fire protection measures as a component of the overall study of a "buildingoccupant" system, challenges with taking fire systems out of context of building operations could be identified and then hopefully minimized. In addition, this shift in the paradigm, from the study of the fire protection measures to the whole "building-occupant" system not only allows to extract all the data required to perform the analysis but also to characterize the context for which the analysis is carried out and which determine the overall performance of the system vis-à-vis the fire threat. Explanations related to this paradigm shift as well as the main characteristics of the new paradigm based on a "building-occupant" system are detailed in the following chapter of this dissertation. To address (2), by developing system-specific guidance, a much greater level of guidance can be provided, thus minimizing challenges in application and interpretation of data, use of tools and methods of evaluation. A new risk-informed PBFPD process, based on the system paradigm, has been elaborated, which separates the technical decisions to be elaborated by the FPE and the political decisions to be taken by the involved stakeholders. The risk-informed PBFPD process that would be able to overcome the challenges listed in this chapter is presented in Chapter 4 of this dissertation. To address (3), by creating 'test bed' environments, displayed on an web-platform, FPEs and all other interested parties are expected to share their own knowledge on tool uses and therefore fill the need for guidelines to aid the selection of appropriate fire consequence analysis tools for specific types of fire protection engineering applications [72]. 


\subsection{Conclusion of this chapter}

Challenges in applying current PBFPD processes arise from technical and political levels. Challenges still exist concerning the definition/quantification of the strategic elements of any PBFPD process: the performance criteria (which current denomination should be changed to "fire effect criteria"), design fire scenarios, use of tools to quantify the trial designs. Efforts are made to consolidate databases gathering information related to buildings, fires and occupant behaviors but it is still necessary to make such databases available for the whole engineering community. Besides, validation and verification domains related to the tools still need to be defined according to the engineering problems these tools are used to solve. A new proposition has been elaborated in that matter [69]. Challenges related to the difference between the building design and its numerous alterations during its lifespan should be better considered in the examined PBFPD processes.

\section{References}

3. Meacham, B.J. (1998), The evolution of Performance Based Codes and Fire Safety Design Methods. Report no. NIST GCR 98-761. Gaithersburg, MD: National Institute of Standards and Technology

4. Meacham, B.J. (1999), International Experience in the Development and Use of Performance-Based Fire Safety Design Methods: Evolution, Current Situation and Thoughts for the Future. Fire Safety Science: proceedings of the Sixth International Symposium, University of Poitiers, France, 5-9 July 1999. London: International Association for Fire Safety Science, 1999; pp. 59-76

5. Hadjisophocleous, G.V., Bénichou, N. and Tamin, A.S. (1998), "Literature review of performance-based codes and design environment", Journal of Fire Protection Engineering, Vol. 9, No. 1, pp. 12-40

6. Custer, R. and Meacham, B.J. (1997) Introduction to performance-based Fire Safety, Society of Fire Protection Engineers

7. (BSI) British Standard Institute (2001), Application of fire safety engineering principles to the design of buildings. Code of practice - BSI 7971:2001

8. (ISO) International Organization for Standardization (1999), "Fire safety engineering -- Part 1: Application of fire performance concepts to design objectives," ISO/TR 13387-1:1999

9. IFEG (2005) International Fire Engineering Guidelines, Australian Building Codes Board, Department of Building and Housing (New Zealand), International Code Council (USA), and National Research Council (Canada),2005 edition

10. SFPE (2007), SFPE Engineering Guide to Performance-Based Fire Protection, Society of Fire Protection Engineers

11. Wade, C., Beever, P., Fleishmann, C., Lester, J., Lloydd, D., Moule, A., Saunders, N. and Thorby, P. (2007), "Developing Fire Performance Criteria for New Zealand's Performance Based Building Code", presented at the Fire Safety Engineering International Seminar, 26 and 27 April 2007 in Paris, France, available at: http://www.branz.co.nz/cms_show_download.php?id=f8f5f396ba47ccae10e62e5c335d917d4d9301c0 (checked 2012.06.06)

12. Evans, D.H. (1998), "Luxor Hotel and Casino: An Application of Performance-Based Fire Safety Design Methods," Proceedings of the Pacific Rim Conference and 2nd International Conference on Performance-Based Codes and Fire Safety Design Methods, International Code Council/SFPE, pp. 477-494

13. Suarez, A. (2007), "Performance Based Design for the Miami Inter-modal Center -Consolidated Rental Car Facility," APICI Conference: Performance-Based Design for Buildings, Industry and Transport, (presentation available at: http://www.alamys.org/documentos/apici_2007/download/Miercoles/5_grupo_m/Alfredo\%20Suarez/PBD\%20Suarez\% 20-\%20BM\%20FINAL.pdf, checked 2011, 12, 12) 
14. Morgan, H.P., Williams, C., Harrison, R., Shipp, M.P. and De Smedt, J.C. (1995), "Hot Smoke Ventilation Test at Brussels Airport," Proceedings of the International Conference on Fire Research and Engineering, Orlando, Florida, USA, September 1995, pp.495-551

15. Chow, W. K. (2005), "Building Fire Safety in the Far East," Architectural Science Review, vol. 48, issue 4, pp. 285294

16. Quiter, J. R. (1996), "Application of Performance Based Concepts at the Stratosphere Tower, Las Vegas, Nevada". Fire Risk and Hazard Assessment Symposium. Research and Practice: Bridging the Gap. Proceedings. National Fire Protection Research Foundation. June 26-28, 1996, San Francisco, CA, pp. 118-126

17. NFPA 5000 (2012), Building Construction and Safety Code, 2012 edition, National Fire Protection Association

18. Tubbs, B. and Okawa, R. (2008), "Performance Codes and Design in the US, an International Code Council (ICC) Perspective," Proceedings of the $7^{\text {th }}$ International Conference on Performance-Based Codes and Fire Safety Design Methods, Society of Fire Protection Engineers, pp. 59-65

19. Johnson, P. (2002), "Performance Based Fire Safety Regulation \& Building Design - The Challenges in the $21^{\text {st }}$ Century," Proceedings of the $4^{\text {th }}$ International Conference on Performance-Based Codes and Fire safety Design Methods, Society of Fire Protection Engineers, pp. 3-13

20. Takeichi, N., Matsumoto, K. and Wataru, G. (2008), "Review Japanese performance-based code- Recommendation by Research committee on Building legislation in AIJ," Proceedings of the $7^{\text {th }}$ International Conference on PerformanceBased Codes and Fire Safety Design Methods, Society of Fire Protection Engineers, pp. 25-33

21. Schulz, J. and Feeney, M. (2008), "The Fire Engineering Brief Process in Performance Based Fire Engineering - Is it Working?," Proceedings of the $7^{\text {th }}$ International Conference on Performance-Based Codes and Fire Safety Design Methods, Society of Fire Protection Engineers, pp. 35-46

22. Brannigan, V. Smidts, C and Kilpatrick, A. (1996), "Regulatory Requirements for Performance Based Codes Using Mathematical Risk Assessment," Proceedings of Interflam'96. Interscience Communications Ltd, London, pp.621-630

23. Bryan, J.L. (2002), "Behavioral Response to Fire and Smoke." in The $3^{\text {rd }}$ SFPE Handbook of Fire Protection Engineering, edited by P.J. DiNenno. Quincy, MA: National Fire Protection Association, pp. 3-315 - 3-341

24. SFPE (2003), Engineering guide: Human behavior in Fire, Society of Fire Protection Engineers, June 2003

25. (CEN) European Committee for Standardisation (1990), EN 1990: Basis of Structural design

26. SFPE (2004), SFPE Code Official's Guide to Performance-Based Design Review, Society of Fire Protection Engineers - International Code Council, June 2003

27. Richardson, J.K, Yung, D., Lougheed, G.D. and Hadjisophocleous, G.V. (1997) "The Technologies Required for Performance-Based Fire Safety Design," Proceedings of the 1996 International Conference on Performance-Based Codes and Fire Safety Design Methods, 24-26 September 1996, Ottawa, Ontario, Canada, Society of Fire Protection Engineers, pp. 191-201

28. Charters, D. and Ramachandran, G. (2011), Acceptance Criteria, Chapter 4 of Quantitative Risk Assessment in Fire Safety, Spon Press, p.193

29. Grubits, S. (1992), "Fire Safety Engineering Research in Australia," Proceedings of the International Fire Safety Engineering Conference, Commonwealth Scientific and Industrial Organisation, Sydney, Australia

30. Barber, D. and Van Merkestein, R. (2002), "Can the approval of Performance Based Solutions Be Improved?," Proceedings of the $4^{\text {th }}$ International Conference on Performance-Based Codes and Fire safety Design Methods, Society of Fire Protection Engineers, pp. 143-154

31. Johnson, P., Gildersleeve, C. and Williams, P. (2008), "Road Tunnel Fire Safety - Approach to Fire Scenarios," Proceedings of the $7^{\text {th }}$ International Conference on Performance-Based Codes and Fire safety Design Methods, Society of Fire Protection Engineers, pp. 251-262

32. Raj, P. K. (2008), "A Review of the Criteria for People Exposure to Radiant Heat Flux From Fires," Journal of Hazardous Materials 159, pp. 61-71

33. NFPA (2009a), NFPA 101 Life Safety $\operatorname{Code}^{\circledR} 2009$ edition, National Fire Protection Association

34. The Sun (2011), "Woman crushed to death in nightclub stampede - Eyewitness says there was rush to exits," available athttp://www.thesun.co.uk/sol/homepage/news/3881282/Woman-crushed-to-death-in-nightclub-stampede.html (checked 2011, 10, 23) 
35. Kruppa, J. (1997), "Performance-Based Code in Fire Resistance: a First Attempt by Eurocodes," Proceedings of the 1996 International Conference on Performance-Based Codes and Fire Safety Design Methods, 24-26 September 1996, Ottawa, Ontario, Canada, Society of Fire Protection Engineers, pp. 217-228

36. Lucht, D.A. (1997), "Public Policy and Performance-Based Engineering," Proceedings of the 1996 International Conference on Performance-Based Codes and Fire Safety Design Methods, 24-26 September 1996, Ottawa, Ontario, Canada, Society of Fire Protection Engineers, pp. 65-87

37. Fitzgerald, R.W. (1996), "Thoughts on Building Codes, Design Standards, and Performance Evaluations for Firesafety," Proceedings of the 1996 International Conference on Performance-Based Codes and Fire Safety Design Methods, 24-26 September 1996, Ottawa, Ontario, Canada, Society of Fire Protection Engineers, pp. 127-137

38. Bukowski, R.W. (2004), "Building Regulatory Systems in a Post-September 11 World," Proceedings of the $5^{\text {th }}$ International Conference on Performance-Based Codes and Fire Safety Design Methods, 6-8 October 2004, Society of Fire Protection Engineers, pp. 15-25

39. (ICC) International Code Council (2009), International Code Council Performance Code for Building and Facilities

40. (NEA) Nuclear Energy Agency (2002) CSNI Technical Opinion Papers (No. 1: Fire Probabilistic Safety Assessment for Nuclear Power Plants; No. 2: Seismic Probabilistic Safety Assessment for Nuclear Facilities), Nuclear Energy Agency - Organisation for Economic Co-operation and Development (available at: http://www.oecdnea.org/nsd/reports/nea3948-fire-seismic.pdf) (last checked; 2011-10-25)

41. Brannigan, V. (2000), "Fire Scenarios or Scenario Fires? Can Fire Safety Science Provide the Critical Inputs for Performance Based Fire Safety Analyses?," Fire Safety Science: Proceedings of the Sixth International Symposium, International Association for Fire Safety Science, pp. 207-218

42. Hall, J.R. Jr and Watts, J. Jr (2008), Fire Risk Analysis, Volume 1, Section 3, Chapter 8 of the 20th edition of the Fire Protection Handbook, NFPA

43. Hall, J.R. Jr (2011), "Defining the Challenge: Selecting Fire Scenarios for Fire Protection System Design and Evaluation," Proceedings of SUPDET 2011: Suppression, Detection and Signaling Research and Applications - a Technical Working Conference, March 22-25, 2011, available athttp://www.nfpa.org/assets/files//PDF/Proceedings/SUPDET11HallAbstract.pdf(checked 2011, 10, 25)

44. Babrauskas, V. (1998), "Ensuring the Public's Right to Adequate Fire Safety under Performance-Based Building Codes," Proceedings of the Pacific Rim Conference and $2^{\text {nd }}$ International Conference on Performance-Based Codes and Fire Safety Design Methods, International Code Council/SFPE, pp. 239-247

45. NFPA (2009), NFPA 101 Life Safety Code $^{\circledR}$ Handbook, eleventh edition, edited by R. Coté and G. E. Harrington, National Fire Protection Association, pp.667-669

46. Lloydd, D. (2008), Evaluation of the Conceptual Framework for Performance Based Fire Engineering Design in New Zealand, Fire Engineering Thesis, Department of Civil Engineering, University of Canterbury

47. International Code Council (2012), International Building Code, 2012 edition, International Code Council

48. Miclea, P.C., Chow, W.K., Shen-Wen, C., Junmei, L., Kashef, A.H and Kang, K. (2007), "International Tunnel FireSafety Design Practices," ASHRAE Journal, August 2007, pp. 50-60

49. NFPA (2010), NFPA 914 standard "Code for Fire Protection in Historic Structures"

50. Watts, J. M. (2001), "Fire Protection Performance Evaluation for Historic Buildings," Journal of Fire Protection Engineering, Vol. 11 - November 2001, Society of Fire Protection Engineers, pp. 197-208

51. Ryber, M., Kylefors, M., Nählinder, J. and Nystedt, F. (2004), "The Minefields of Performance-Based Fire Safety Design," Proceedings of the $5^{\text {th }}$ International Conference on Performance-Based Codes and Fire Safety Design Methods, 6-8 October 2004, Society of Fire Protection Engineers, pp. 36-41

52. Stenstad, V. and Bjørkmann, W.R. (2004), "A Systematic Approach to Fire Safety Design," Proceedings of the $5^{\text {th }}$ International Conference on Performance-Based Codes and Fire Safety Design Methods, 6-8 October 2004, Society of Fire Protection Engineers, pp. 67-78

53. Averill, J., Reneke, P. and Peacock, R.D. (2008), "Required Safe Egress Time: Data and Modeling," Proceedings of the $7^{\text {th }}$ International Conference on Performance-Based and Fire Safety Design Methods (April $16-18,2008$ ), Society of Fire Protection Engineers (available at http://fire.nist.gov/bfrlpubs/fire08/PDF/f08011.pdf) (checked 2011, 10, 25) 
54. Kendik, E. (1988), "Means of Escape - 1988 How Close Are we to Modelling Egress from Buildings in Fire?," Proceedings of Interflam' $88,4^{\text {th }}$ International Fire Conference, pp. 156-163

55. Shield, T.J. (1999), "The Science of Human Behaviour: Past Research Endeavours, Current Developments and Fashioning a Research Agenda," Fire Safety Science: Proceedings of the Sixth International Symposium, International Association for Fire Safety Science, pp. 95-114

56. SFPE (2011), SFPE Engineering Guide - Guidelines for Substantiating a Fire Model for a Given Application, SFPE G.06.2011, Society of Fire Protection Engineers

57. (ISO) International Organization for Standardization (2008), "Fire safety engineering -- Assessment, verification and validation of calculation methods," ISO 16730:2008

58. (ASTM) American Society for Testing and Materials (2007a) E1591-07: Standard Guide for Obtaining Data for Deterministic Fire Models, ASTM

59. (ASTM) American Society for Testing and Materials (2007b) E1895-07 Standard Guide for Determining Uses and Limitations of Deterministic Fire Models (Withdrawn in 2011, no replacement), ASTM

60. (ASTM) American Society for Testing and Materials (2007c) E1472-07 Standard Guide for Documenting Computer Software for Fire Models (Withdrawn in 2011, no replacement), ASTM

61. (ASTM) American Society for Testing and Materials (2011) E1355-11: Standard Guide for Evaluating the Predictive Capability of Deterministic Fire Models, ASTM

62. SFPE (2002), Engineering guide: Evaluation of the Computer Model DETACT-QS

63. Kuligowski, E. (2009), "Compilation of Data on the Sub lethal Effects of Fire Effluent," NIST Technical Note 1644, National Institute of Standards and Technology

64. (INERIS) Institut National de l'Environnement Industriel et des Risques (2011) Fiches de données toxicologiques et environnementales, available at: http://www.ineris.fr/substances/fr/page/21 (175 hazardous substances are listed at 2012/12/10)

65. SFPE (2000), Engineering guide: predicting $1^{\text {st }}$ and $2^{\text {nd }}$ degree skin burns from thermal radiation, Society of Fire Protection Engineers, March 2000

66. (ISO) International Organization for Standardization (2011), "Guidelines for assessing the fire threat to people," ISO 19706:2011

67. (ISO) International Organization for Standardization (2011), "Life-threatening components of fire — Guidelines for the estimation of time to compromised tenability in fires," ISO/DIS 13571, revision of first edition ISO 13571:2007

68. Woycheese, J.P., Raghavan, V., Kim, M. and Geller, F. (2006), Online Access to and Data analysis Tools for Experiments in Building and Fire Science. Final Report, National Institute of Standards and Technology (NIST GCR 06-894)

69. Fahy, R.F. and Proulx, G. (2001) Toward Creating a database on delay times to start evacuation and walking speeds for use in evacuation modeling, Report NRCC-44758, National Research Council Canada (available at:http://www.nrccnrc.gc.ca/obj/irc/doc/pubs/nrcc44758/nrcc44758.pdf, checked 2011/11/28)

70. Gwynne, S.M.V. (2011), "Improving the Collection and Use of Human Egress Data," Fire Technology - Online First

71. NFPA (2012), NFPA 557: Standard for Determination of Fire Loads for Use in Structural Fire Protection Design, Proposed Standard Next Edition: 2012, National Fire Protection Association

72. Alvarez, A. and Meacham, B.J. (2012), 'Test bed' environment process for assessing the appropriateness of engineering tools to be used in performance-based design applications, Proceedings of the $9^{\text {th }}$ International Conference on Performance-Based Codes and Fire Safety Design Methods, 20-22 June 2012, Hong Kong 


\section{USING A SYSTEMS APPROACH TO ASSESS HOW DISRUPTIVE EVENTS AFFECT BUILDING OVERALL PERFORMANCE}

The main drivers for performance-based design (PBD) are demands from users for better building use performance, in conjunction with a change in legislation allowing a broader use of the PBD option instead of prescriptive requirements. Within a PBD framework, the demand of the "end users" of the building become priorities [1] so that PBD provides a more "client" oriented process [2] than the one used when following building code regulations.

Performance-based design (PBD) applies to all the components of a building project related to, among others, acoustics, aesthetics, operability, sustainability, and safety. Then, it involves numerous actors including, on one hand, the building users who should define the level of performance of the building and on the other hand, the building industry which should create optimal solutions in order to achieve this level of performance within a regulatory framework established by policy makers.

Because of the complexity of the engineering thinking related to these building components, PBD guidance has been segmented such that each engineering discipline has to consider separately how clients' objectives connected with each of the building components should be achieved. This statement is not only valid for building components dedicated to the normal use of the building (e.g. mechanical components including heating, ventilation, and air conditioning (HVAC) and plumbing) but it also concerns building components installed to address disruptive events, such as fires or earthquakes. In other words, some PBD guidance has thus far been elaborated to treat fire safety objectives exclusively [3] while other guidance only addressed earthquakes [4] as these hazards are very specific and the engineers quantifying these hazardous situations have specialized expertise.

However, in practice, the building end users are not really interested in the performances of different building components as they wish to experience, on a daily basis, the performance of the building as a whole [5]. As such, the design team individual entities; rather members dealing with the multitude of building components have then to co-operate in order to achieve this seamless daily performance [6].

The research presented in this chapter originated from a review of decades of worldwide experience of the performance-based option for fire protection design, which identified shortcomings in the interpretation, application and implementation of performance-based fire protection design (PBFPD) processes. This review is presented in the previous chapter of this dissertation. I found that the application of these processes, which the aim of is centered on the design of fire protection measures, and not building performance, may lead to the possibility that these measures, deemed appropriate at the building design stage, might be ignored or worse 
"rejected" by the building end users when needed the most, since fire is not a daily concern of these users. I realize that this can be generalized to any disruptive event and mitigation strategies.

This chapter presents the outcomes of my research related to the treatment of disruptive events on the overall performance of a building project, using fire as an example:

- first, I define a system formed by specific building types and their associated occupants, so as to characterize the nature of disruptive events and theirs effects on the overall performance of that system;

- second, I establish a risk informed performance-based design process which would be applicable to any disruptive event and include a step evaluating the integration of the protection measures into the considered system.

\subsection{Definition of the daily performance of a "building-occupant" system and its decrease during a disruptive event}

Primary stakeholders in a building project, including the building owner and the potential users, generally define building performance objectives in terms of the everyday uses of the building. For a hospital, this performance is related to the type of treatments offered, the number of patients who can be treated, the types of equipment and services needed to treat patients, and so forth. For a school, performance is related to delivering education to the target student population, the number of registered students, the numbers and qualification of teachers or faculty required to deliver education, etc. For a museum, it is related to the exhibits and holdings, number of exhibition attendees who can be accommodated, security of the holdings, etc. Unfortunately, the owners and operators of these buildings do not always think about events which can disrupt this daily use. This has an impact not only during use, but with respect to decisions made at the design stage.

Disruptive events can be of different natures [7], such as:

- $\quad$ supplier business disruption leading to operational vulnerabilities,

- fires, earthquakes, severe weather, accidents or terrorism leading to hazard vulnerabilities,

- currency exchange fluctuations leading to financial vulnerabilities,

- new foreign competitors leading to strategic vulnerabilities.

Such disruptive events can significantly impact the operation of a building and the mission it supports. If the building owner and other key actors are unprepared, the disruptive event can have catastrophic effects on continued operations [8]. Because of my experience, I will be focusing, for this chapter, on fires as an example of a class of disruptive events, as well as an example on how my paradigm of study, centered around a "building occupant" system differs from the one considered in the current PBFPD processes, centered around the fire protection measures themselves. 


\subsubsection{Introduction of the "building-occupant" system paradigm}

In many countries, buildings are classified in terms of the general class of use, such as places of assembly, business occupancies, residential, and so forth. However, these general descriptions lack the complexity to describe the interaction of the building users in the context of the building. To address this, I looked to identify a more appropriate "building-occupant" system. In order to define the system formed by specific building types and their associated occupants, which I call "building-occupant" systems, I first looked at building code classifications. To frame this discussion, I focus on healthcare occupancies. I also focus on the situation in the USA.

An obvious way to categorize the different existing "building-occupant" systems is to follow the classification established in building regulations. For example, in the USA, Chapter 3 of the International Building Code (IBC) established by the International Code Council (ICC) provides 10 different groups [9]. The purpose of the building (or part of the building) determines the group of the building (or part of the building). "Sections 303 through 312 of the ICC IBC identify the occupancy characteristics of each of the 10 groups. In some of these sections, specific group classifications having requirements in common are collectively organized such that one term applies to all". For example, Groups I-1, I-2, I3, and I-4 are individual groups for Institutional-type buildings. The general term "Group I", however, includes each of these individual groups. Prescriptive requirements are defined for each of these groups, with specific requirements when applicable: for example, Section 403 adds requirements if the building qualifies as a "high-rise" building; Section 404 adds requirements related to the presence of an atrium in the building; Section 407 adds provisions for occupancies in Group I-2.

By reviewing the occupancy group classification of the ICC IBC, I determined that this classification is too coarse to take into consideration all the specificities of different "building-occupant" systems. For Institutional Group I-2 defined according to the ICC IBC classification, detoxification facilities, nursing homes, hospitals, and mental hospitals do need the same requirements. In all these facilities, populations are vulnerable, unable to evacuate without assistance but they are very different and the building systems are also very different, as shown in Fig. 3-1. A classification, such as the one established in ICC IBC, is a "good" start but still necessitates going in a deeper taxonomy level to clearly define a proper "building-occupant" system.

Related to this point, Lataille [10] indicated that "prescriptive codes apply to facilities with widely varying characteristics. For example, the same prescriptive codes apply to an office building whether it has one or several stories, small or large building footprint, or low or high combustible loading. Different provisions in these codes might apply to different buildings, so the prescriptive protective scheme can vary from building to building". This statement issued for prescriptive requirements can be extended to the PBFPD processes. 


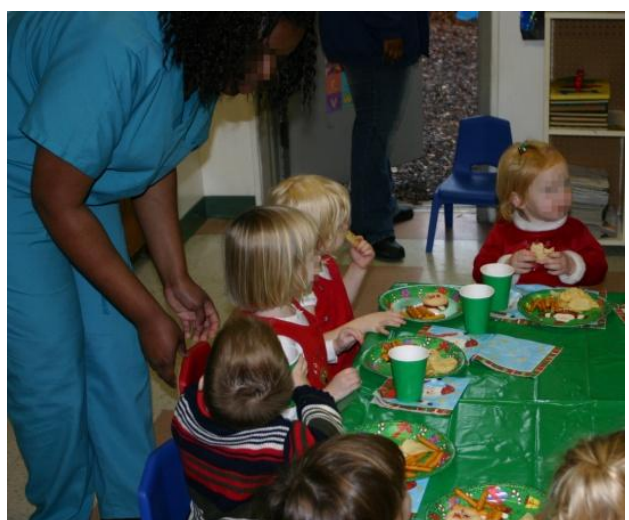

a) Child care facility, source: http://www.flickr.com/photos/shaggypaul/351385178/, free to share and remix with the attribution of the work to "Shaggy Paul"

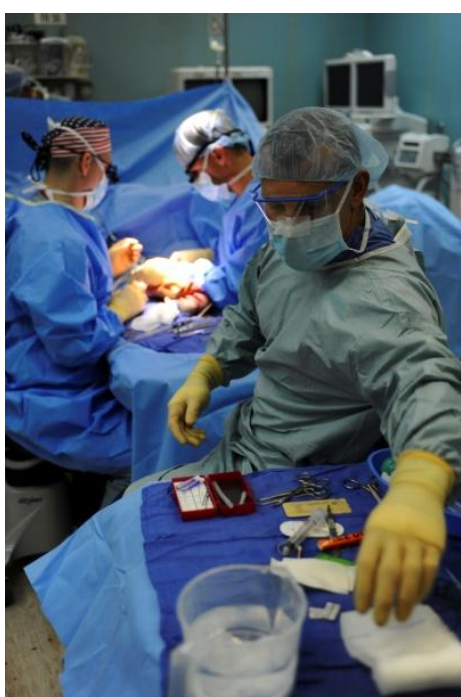

b) Hospital, source:

http://www.flickr.com/photos/usnavy/ 5913202904/sizes/o/in/photostream/, free to share and remix with the attribution of the work to Official U.S. Navy Imagery

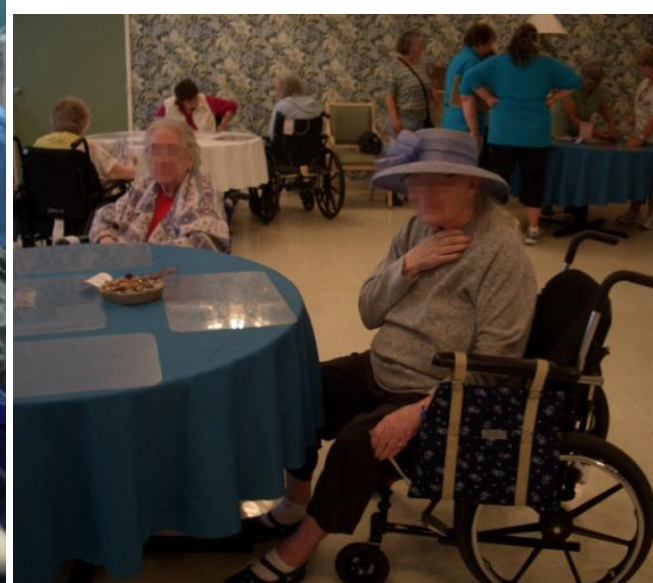

a) Nursing home, source: http://www.flickr.com/photos/13384589@N00/2780553 $606 /$, free to share and remix with the attribution of the work to by "Robinsan"

Fig. 3-1. Examples of facilities under the ICC IBC Institutional class (I2)

Performance-based building codes present an opportunity to go beyond 'simple' classifications and consider more specific "building-occupant" system features. However, this requires the stakeholders and design team to focus more effort on describing the system as part of the PBFPD process. The structure of some PB building codes helps facilitate this. For example, one distinction of the ICC Performance Code (ICC PC) approach [11] from the IBC and from many other performance building codes is its classification of the building in terms of performance groups (Section 302.1 of ICC PC): "the objective of the assignment of use and occupancy classification is to identify the primary uses of buildings and facilities, and portions of buildings and facilities, and to identify risk factors associated with these uses, in order to facilitate design and construction in accordance with other provisions of this code". This classification is useful to demonstrate that the PBFPD process has to take into consideration the importance of the building for societal expectations in respect of the level of safety.

As the ICC PC is one of the building codes developed by ICC, the building uses are to be taken from the prescriptive "Uses and Occupancy Classification" chapter of the ICC IBC. Nevertheless, the ICC PC performance group classification goes beyond the IBC classification in considering the building "importance" to the community, which allows for making a distinction between different buildings inside a same IBC occupancy classification. For example, a hospital that is intended to remain functional after an earthquake or other hazard event, to care for those who may be injured in the event, can be designated as having a higher level of performance than other healthcare facilities in the same geographical area. As such, a higher level of performance and resiliency during and after a hazard event is warranted. 
Looking at other systems, I found the classification by the US Bureau of Census [12] more useful than the ones defined in building codes in defining more precisely the "building-occupant" systems . In this taxonomy a distinction is made between child day care (with the code 624410), general hospitals (with the code 622110), Psychiatric and Substance Abuse Hospitals (with the code 62221) and nursing care facilities (with the code 62311). In addition to providing a better "building-occupant" system descriptor, a benefit of using this taxonomy is that the Bureau of Census periodically collects information concerning each of its categorical areas, which can be helpful in the performance assessment.

Based on this taxonomy, I defined a "building-occupant" system as a system defined by a structure (i.e. building) inside which occupants are primarily engaged in a specific activity. This activity is quantified (e.g. activity number carried out by day or week) and then the performance of the system is estimated by the level of this activity.

Occupants are defined as persons who are physically inside the system, independently of the duration of their stay. Building components are defined in my paradigm as physical portions of the system which can include, for example, spaces dedicated to a particular occupant activity of the system or in support of that activity (e.g. HVAC system).

If I examine a hospital, I can see that there are different building areas which can be identified according to the functions they provide, such as reception areas, emergency rooms, examination rooms, operating rooms, patient rooms and intensive care units. I call any such area which can be grouped by function as a "functional" zone, as they are created to fulfill the functions related to the daily objectives of the facility. In addition, there are utility systems and areas which provide support functions, such as power, heating, ventilation and air-conditioning (HVAC), throughout the facility. These utility systems can be located in "utility" zones (mechanical rooms, electrical rooms, cafeteria...) or throughout the building (such as the HVAC system). When designating zones, care should be taken to define them based on the "building-occupant" system characteristics of importance. It is also important to identify direct and indirect relationships. 


\section{Hospital}

\begin{tabular}{|c|c|}
\hline Reception & Staff + in-patients $($ mostly mobile $)+$ visitors \\
\hline Examination rooms & Staff + in-patients (not mobile and mobile) \\
\hline Emergency rooms & Staff + in-patients (not mobile) \\
\hline Operating rooms & Staff + in-patients (not mobile) \\
\hline Intensive care units & In-patients (not mobile) \\
\hline Patient rooms & In-patients (not mobile and mobile) + visitors \\
\hline
\end{tabular}

Fig. 3-2. People description according different functional zones of a hospital

For example, Fig. 3-2. illustrates the required level of detail for different functional zones of a hospital, describing the types of population in each of the zones. For example, people located in the reception area are future in-patients, visitors and staff and almost all of them are mobile and conscious. This is important as they would require no or little assistance in case of a hazardous disruptive event such as a fire. In-patients located in emergency rooms or in operating rooms are undergoing surgery and are connected to life-supporting machines. This is important as extracting them during a fire would require following procedures and requiring time that may not be compatible with a rapidly growing fire [13]. In addition, while a utility zone supporting a reception area may be important to facilitate the comfort of the occupants, a utility zone supporting an operating room functional zone is essential. If a fire occurs in the utility zone supporting a reception area the impact in the reception area could be limited to an 'inconvenient' loss of power or lighting. If a fire occurs in the utility zone supporting the operating room, the impact could be life-threatening.

To summarize, characteristics of occupants within specific locations of a building, as well as the intended function of spaces in a building and contents in those spaces which are essential to achieving the required function needs to be clearly understood, identified and categorized. This constitutes essential information required by the Fire Protection Engineer (FPE) in order to address stakeholder objectives for "buildingoccupant" systems when elaborating a fire safety strategy. However, no current PBFPD process directs an FPE to examine a building at such a level of detail, explains the reasons why such a level of detail is important, or provides guidance how to approach the assessment. In large part this is because current PBFPD processes are focused too much on the fire event itself instead of being target-oriented, focusing on the objectives of concern within the specified functional zones or a well-defined "building-occupant" system. 
3.1.2 Characterization of the effects of a disruptive event on the performance of a "building-occupant" system

To show the importance of considering the building to be analyzed as being part of a system network, let us describe the events that started with a small fire in a manufacturing plant in USA and ended up with a US $\$ 2.34$ billion loss for one of the plant clients. This example is taken from Sheffi's book "The Resilient Enterprise" [7].

On March 17, 2000, lighting struck the industrial plant of Philips NV, located in Albuquerque, New Mexico, USA. As a consequence a small fire started within the facility but was extinguished by sprinklers and staff in less than 10 minutes. There were no injuries and the fire fighters arrived at the plant just to record a minor blaze. From a fire protection engineering design perspective this could be considered a success, with systems operating as intended. However, due to ensuing activities, the damage to the plant contents and disruption to the plant activity was tremendous.

So why was the disruption so significant? First, the plant was engaged in manufacturing of semiconductor chips for some 30 clients, including the mobile phones companies Nokia and Ericsson, whose orders accounted for 40 percent of the Albuquerque plant's production. Indeed, a semiconductor manufacturing facility such as this cannot tolerate any dirt or particulate in normal activities, in any of its clean rooms, much less soot in case of a fire. Not only did the fire destroy the chip batches in the furnace (with an equivalent of thousands of mobile phone production) but also smoke, soot and the tramping of staff and fire fighters from the fire scene (in the mix of dirt and water) contaminated chips at every stage of the production, increasing that loss to millions of mobile phone chips. The losses for Philips did not stop at the ones related to property damage. Removing the dirt from the clean rooms implied that the production would be back up after one week. This was the Philips estimation right after the fire, but two weeks later, Philips staff realized that the disruption caused by the fire would take weeks before production could restart. When two of the main clients of Philips, Nokia and Ericsson received the call from Philips on March 20, 2000, they each dealt differently with this situation, which ended up with two very different business outcomes.

As soon as it received the call, Nokia started to work closely with Philips and other of its providers so to maintain its own production of mobile phones and satisfy its customers in a period of time when demand for this type of product was booming worldwide. Ericsson's reaction was different: they treated the fire incident at the Philips plant as a "technical matter" which would result as a chip production disruption of one week only, which is something that could easily be taken care of. Unfortunately for Ericsson, the disruption lasted longer and by the time it realized the size of the disruption, it was too late and Ericsson failed to deliver mobile phones to its customers. 
As a result of the small fire that occurred in 2000 at the Philips Albuquerque plant, Philips's chip sale loss, estimated to a US\$40 million, was almost covered by a 39 million Euro settlement with its insurance company; this loss only accounted for 0.6 percent of the US\$ 6.8 billion semiconductor global benefits of Philips for 2000 .

Having failed to deliver its new generation of mobile phones, Ericsson reported losses between US $\$ 430$ and US\$570 million in the first disruption-affected quarter, due to a lack of parts, that is to say more than ten times Philips' losses. In addition to the fire disruption effects, incorrect product mix and marketing problems are to be blamed for Ericsson's US\$2.34 billion losses in the mobile phone division by the end of 2000. This situation led to a Sony-Ericsson merging for designing, producing and marketing mobile phones, in April 2001. In addition to its competitor economic situation, Nokia's fire disruption treatment helped to increase its percentage of the mobile phone market.

Fig. 3-3. illustrates the profile of a disruption of the system, adapted from [7] for a fire disruption, based on the aforementioned Philips fire. Prior to the fire, the plant is performing at a certain level, i.e. it is manufacturing (x) chips for its clients. The disruptive event occurs (fire on March 17, 2000) and the performance of the plant decreases, leading to a full impact of a completely stopped production. In this case, the performance of the plant went down to zero for weeks. The full impact was the sum of the direct consequence of the fire (damage to the furnace and smoke spread) and of the indirect consequence of the fire fighting operations (staff and fire fighters walking all around the plant and contaminating all the remaining furnaces). The recovery time was not the expected one week but several weeks. A long term impact was observed, as Nokia engineers sent to the Philips plant in the recovery phase ended up with increasing the pre-event production rate.

For the authority having jurisdiction (AHJ) approving the use of the plant, the life safety objective was not compromised. Related to fire safety, the plant could have been "code compliant" or designed to perform as well as a building provided with regulatory requirements. With regard to property protection objectives, the fire did not lead to severe damage of the production line in itself, but it contaminated all the production (with the involuntary help of the staff and fire fighters). It should be noted that Philips adopted a risk transfer towards insurance companies and hardly "suffered" from the disruptive event. On the long term, even if its premium may be more expensive, the subsequent boost of production may have compensated for the monetary loss. However, not all entities that suffer such as disruption are so lucky [8]. 


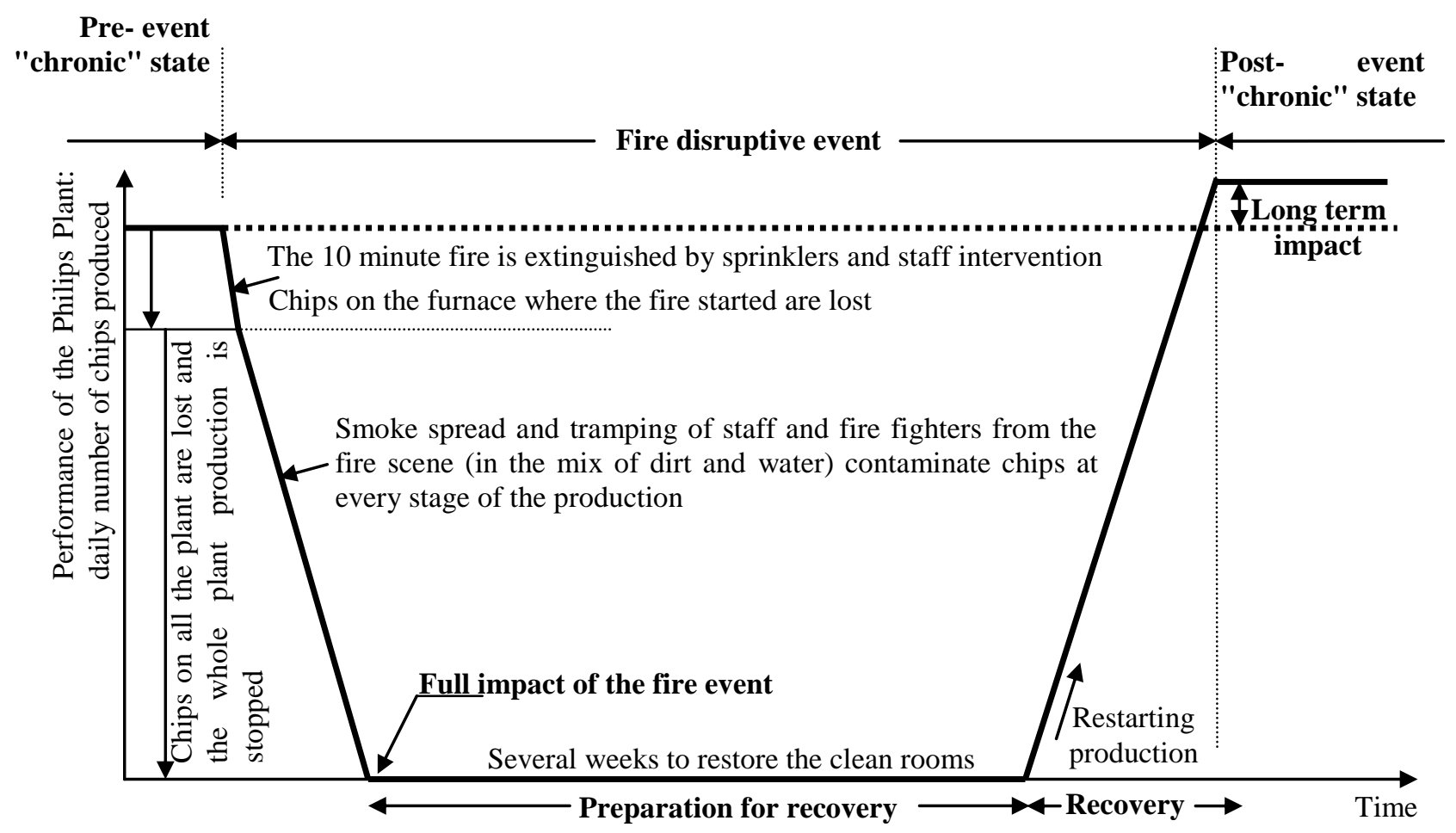

Fig. 3-3. "Disruptive event" profile of the Philips Plant fire (Albuquerque, New Mexico, USA), March 17, 2000, adapted from [7]

In the "building-occupant" system paradigm, fire is one of many disruptive events that may (or may not) occur during the lifespan of a building. In current performance-based fire protection design (PBFPD) guidelines, the design for fire is focused on the fire scenario only: from the fire ignition to the fire extinguishment. This runs the risk of ignoring how the normal operations of the building will influence human actions and systems when a disruptive event occurs.

So, I consider the system formed by the building and its occupants, and analyze the fire as a "disruptive event" or perturbation of the "building-occupant" system. Independently of providing safety to its occupants in case of emergencies, a building is designed, operated and maintained to perform objectives that correspond to the everyday uses of a building, objectives that I qualify as "chronic". Objectives associated with emergency situations related to disaster events, including natural hazards, technological hazards and terrorism, that may occur or not during the life span of the building are then qualified as "acute". 


\subsubsection{Key-concepts of "building-occupant" systems}

In order to summarize my "building-occupant" system paradigm, I have several key concepts:

- Functional zones: spaces which are directly linked to the performance of the system (e.g. in hospitals, visiting areas where patients are checked in, patient rooms where patients are being prepared for surgery, operating rooms, intensive care units and patient rooms where patients recover before checking out);

- Utility zones: spaces which indirectly contribute to the performance of the system, often providing support to the "functional zones" (e.g. storage rooms, electrical rooms, mechanical rooms);

- Targets: key elements who's performance is of concern within systems (the actors or users of the functional zones). For example, targets can be building occupants (patients including their visiting families and friends and staff in hospitals, pupils and teachers in schools) or building contents (important piece of equipment required to contribute to the performance of the system such as a newly developed micro-chip in high tech industry or a priceless artifact in a museum);

- Chronic states of the system: which represent the situations of the system while it is operating as designed or after each modification of its design (e.g. normal use of the system).

- Chronic objectives: objectives the system is designed or subsequently modified, to attain during its chronic states;

- Disruptive events: every possible event (technological events, natural events, socio-economical events) having an effect on the performance of the system. A disruptive event lasts between two chronic states of the systems.

- Acute objectives: objectives the system is designed or subsequently modified, to attain during disruptive events;

- Event effects: damaging effects of a disruptive event on a target. These can be 'direct effects' or 'indirect effect.' With respect to fire as a disruptive event, "direct effects" reflect fire-induced damage upon targets, such as heat, toxic, corrosive, irritant effects. "Indirect effects" reflect loss of building components which are vital for the targets to perform in the system. For example, a fire can through 'direct fire effects' such as heat directly damage power cables to a life supporting equipment, which then has an indirect effect on the safety of people connected to this equipment. 


\subsection{Identifying and avoiding competing objectives within a "building-occupant" system}

Generally speaking, a "building-occupant" system is designed by architects to perform according to "chronic" objectives. From a societal point of view, a "chronic" objective for hospitals is to cure sick or injured patients, and for schools to educate people. However, there are also have societal goals to safeguard the most vulnerable populations. Because society does not want patients or pupils to suffer from a potential fire that can occur in the respective buildings they use, a life safety objective is added to the performance of these buildings, and any other type of building or built environment for that matter. While life safety from fire is the focus of most fire protection engineering analyses, fire protection measures are only one component of the "building-occupant" system, and in some cases competing objectives may exist.

\subsubsection{Fire safety objective competing with "chronic" objectives established at a design stage}

When looking for the goals and objectives that are relevant for the different stakeholders involved in a project, a FPE also has to verify that the safety objectives related to the fire risk in the system are not competing with all the other stakeholders' objectives. Let's see how this point is already considered in the current PBFPD processes.

For example, the International Fire Engineering Guidelines (IFEG) [14] indicate that "in addition [to general regulatory objectives], the client may have various non-fire related objectives for the building design that impact on the fire safety of the building. For example, the client may require:

- Increased security

- Extensive natural lighting

- An open plan layout

- The use of new materials

- Measure to improve energy efficiency and sustainability

- Flexibility for future uses

- Low life-cycle cost".

Unfortunately, the IFEG do not provide any guidance on how to consider these additional objectives, which can be competing with the ones related to fire safety. As a result, there is currently no guidance for managing competing objectives in current PBFPD processes during the design stage. If the FPE happens to identify and address such issues through discussion with stakeholders, it is more by experience or chance than by direction. 


\subsubsection{Fire safety objectives competing with "chronic" objectives established after the design stage}

Building stakeholders may decide to establish additional "chronic" objectives, a long time after the design phase, when the building is actually operating. For example, as a result of the 11 September 2001 events, increased security at airports multiplied check points that may impede safe egress capabilities in the case of an emergency. It should be noted that increased security has now become a "chronic" condition, not only for that type of transportation but also in major crowd gathering configurations and events. It should be noted that adding more security check points concentrate people in certain areas, people that are managed to follow predefined and controlled paths. This configuration induces a competition between the security crowd management and the needs for efficient and safe accessible escape routes in the case of an emergency, fire or other disrupting event. Not only does this security driven "chronic" condition compete with the conditions employed for dealing with emergency situations, but it also competes with a previous "chronic" objective of the architectural design to have uncongested pedestrian movement in the airport, as well as the aesthetic goal to have passengers walking in a quiet, spacious environment (compare Fig. 3-4. which visually translates the ideal vision of the designer with Fig. 3-5. which illustrated the real situations of airports).

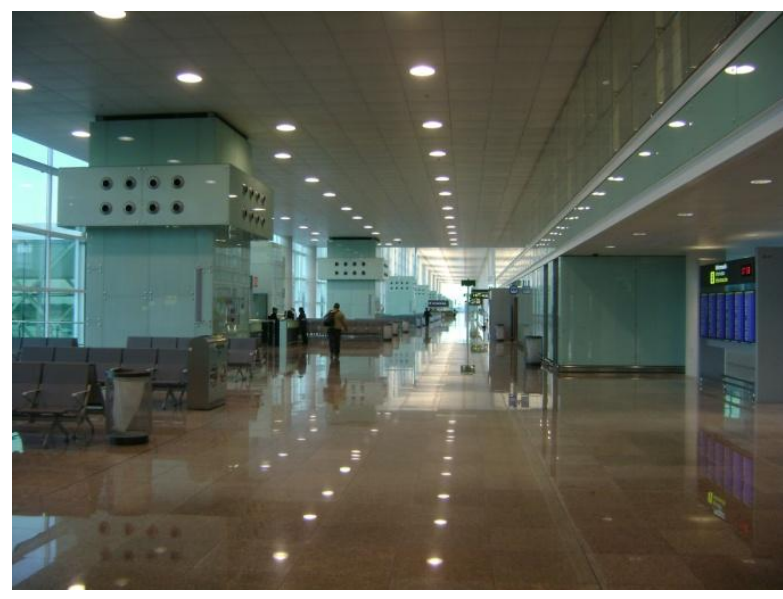

a) Barcelona Airport Terminal 1

source: http://www.flickr.com/photos/francesc 2000/4583309008/, free to share and remix with the attribution of the work to Francesc_2000

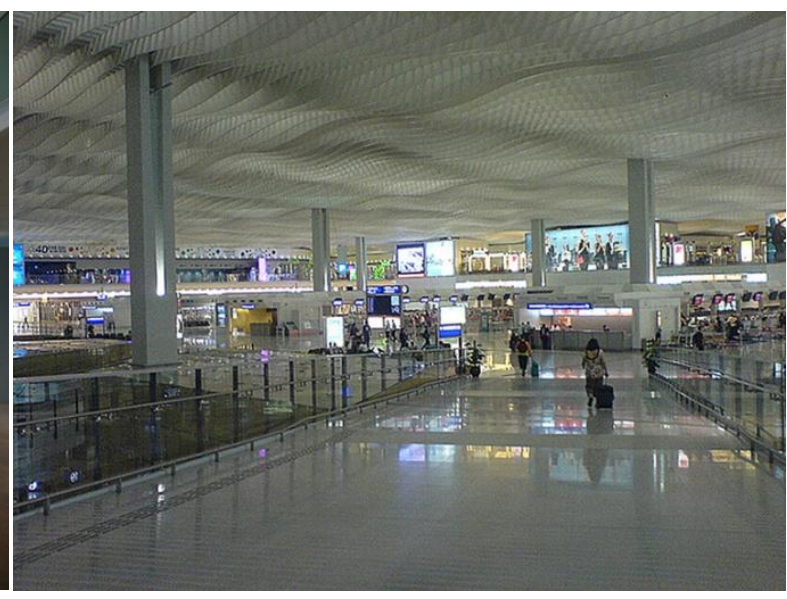

b) Hong Kong Airport Terminal 2 source: http://www.flickr.com/photos/gkpics/953052759/, free to share and remix with the attribution of the work to jgmarcelino

Fig. 3-4. Examples of airport architectural designs 


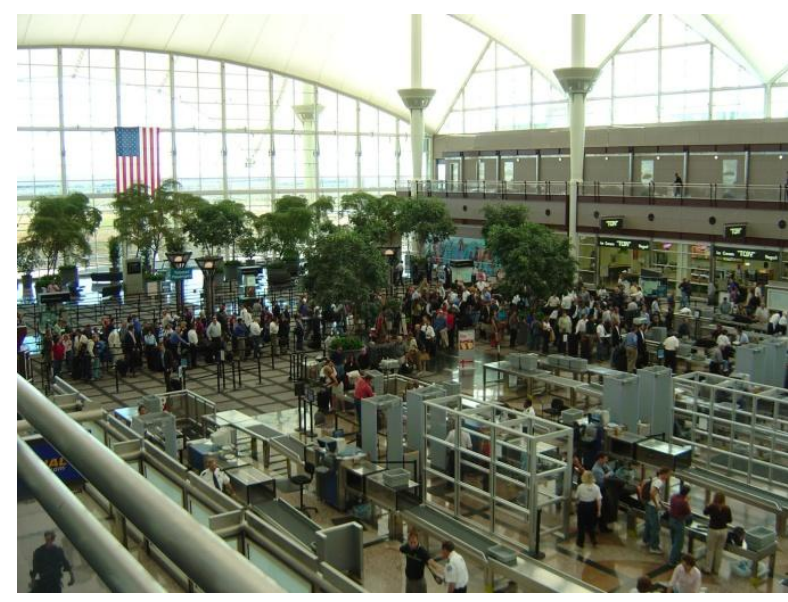

a) source: http://www.public-domain-image.com/full-image/peoplepublic-domain-images-pictures/crowd-public-domain-imagespictures/airport-security-lines.jpg-copyright-friendly-image.html, in the public domain, Author: Kitt Hodsden

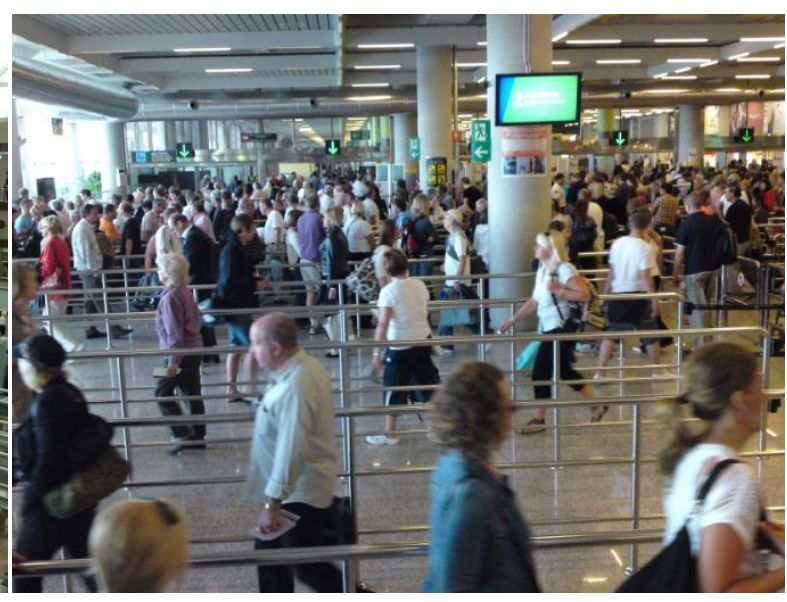

b) Palma de Mallorca Airport source: http://www.flickr.com/photos/kalleboo/3536493996/, free to share and remix with the attribution of the work to Karl Baron

Fig. 3-5. Examples of impacts of the security "chronic" condition in airports

The only way to address such concerns is to build into the PBFPD process a mechanism for not only looking at expected normal operations (chronic use) but for triggering reassessment if certain operational schemes are modified by the building in use. While PBFPD processes like that from SFPE tries to address this by having the FPE identify bounding conditions and to develop an Operations Manual, it is not clear from my review that these mechanisms are being utilized as intended (cf. previous chapter of this dissertation).

\subsubsection{Fire safety objectives competing with "chronic" objectives evolving over very long period of time}

As another example, consider how the design of hospitals 30 years ago assumed one set of chronic objectives, for which specific measures were designed to address fire events, and how internal changes to the hospitals may negate the benefit of those fire protection measures. Starting in the 1850's, based on Florence Nightingales' "Notes on Hospital", hospital wards were designed as large, open, well-lit facilities so that nurses could supervise a lot of patients [15]. As illustrated in Fig. 3-6(a), the "chronic" objective at that time was nurse and staff efficiency. Later, patient privacy and comfort became the primary concerns and the "Nightingale" ward design was replaced by a series of patient rooms (Fig. 3-6(b)) [16].

Looking at these two configurations from a fire safety point of view, the following comments can be made: in an open patient ward, staff is present and can detect a fire (or any agitated patient) as soon as possible and may extinguish the fire before it spreads away from the $1^{\text {st }}$ burning item. In case the fire is not detected and controlled that quickly, smoke and fire may spread fast and evacuation of all ward patients becomes vital. In the private patient room configuration, fire detection would rely on automatic detection rather than detection by staff who are only briefly present in each patient room. An automatic suppression system could also prevent the patients in the room from being injured and a door closing upon fire detection could limit smoke and fire spread outside of the room of fire origin. This example clearly illustrates that the design of the system is highly 
dependent of its "chronic" objectives, which design has a strong impact on how the fire protection measures should be designed, installed and maintained as a whole as these measures both include managerial and technical measures, prevention and protection measures. More detailed "chronic" objectives related to hospitals can be found in [17].

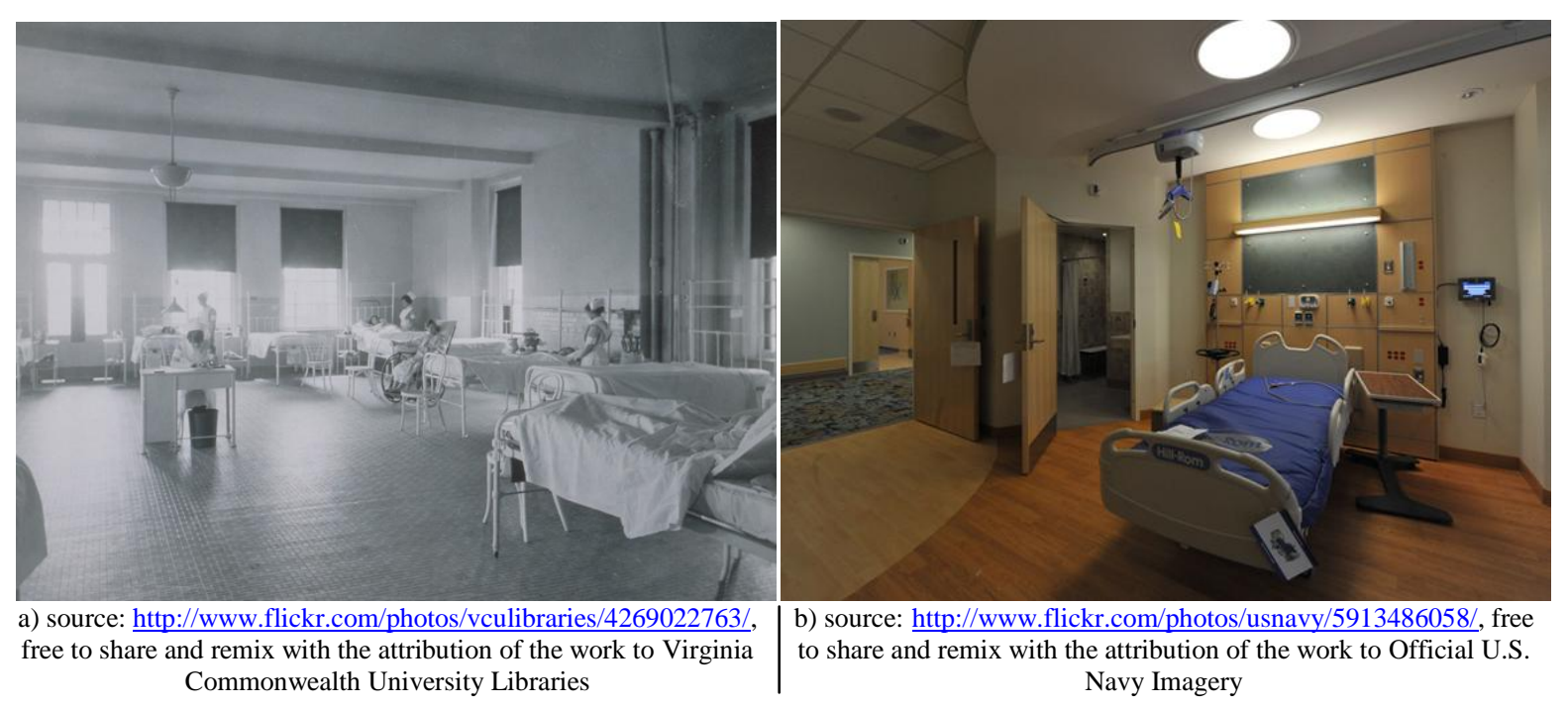

Fig. 3-6. Examples of a) well lit facility ("Nightingale" ward), b) private patient room in a hospital

\subsubsection{Fire safety objectives competing with "chronic" objectives evolving over short or long periods of time}

A "building-occupant" system is dynamically defined with time. A convention center is a typical example of such a system characteristic: the structure of the building remains the same in the lifespan of the building but the interior configuration constantly changes as a function of the exhibitions proposed by the convention center. From a FPE perspective, nature, amount and location of fire loads are very different for a comic convention, boat show, sport event, etc. Distributions of attendee characteristics (e.g. age, gender) are also relevant and should therefore be gathered and their consequences considered in the fire risk evaluation analyzed by the FPE.

Looking at turnover rates of building materials and their impact on the environment, Wærp and Holthe [18] notably conducted surveys and interviews of property managers and architects in Norway. The following paragraph is extracted from their paper:

"The architects were asked which materials that are often replaced in buildings. This is dependent on type of building and year of construction of the building. In office building interior materials is often changed e.g. flooring materials, ceilings, interior walls and lightening are all changed within 5-15 years. Buildings that are refurbished today are from 1970-80. Solutions and materials are in general poor. There are necessary to change ventilation. After 25 years you are left with façade (when quality is good), stairway and load bearing structure. In building from about 1900 more components are kept: e.g. doors, windows, ceilings, facades and often original interior materials. New buildings from today will probably 
have better quality than in the $1970-80$, but there will probably be frequently change in surface materials".

This information illustrates the fact that even if a building remains an office building during its whole lifespan, the nature and the amount of material (including combustible materials) as well as the exit pathways (interior separation may change or completely disappear with "open space" configurations) have to be reassessed periodically to verify that the performance of the system regarding fire safety has not decrease.

It should be noted that building occupant demographics also evolve over long period of times, which may have a significant impact on emergency situations. For example, fire evacuation parameters such as walking speed and crowd density, established from experiments in the late 1980's, should take into consideration population obesity increase. Global ageing population should also be considered [19].

The "building-occupant" system can be stable over its life (i.e. a shopping mall would remain a shopping mall) but the nature of the individual shops inside may vary in time. Fluctuations can also be seen in the characteristics of this system concerning the population number and repartitions during the day (food court being more populated around meal times) and days of the week. Transitory combustibles can be located in the common areas (outside the mall shops) for more or less extensive periods of time (e.g. Christmas decorations in Fig. 3-7). It is necessary to consider of all these fluctuations when assessing fire protection system performance (e.g., sprinkler efficiency and combustible control, for this shopping mall example).

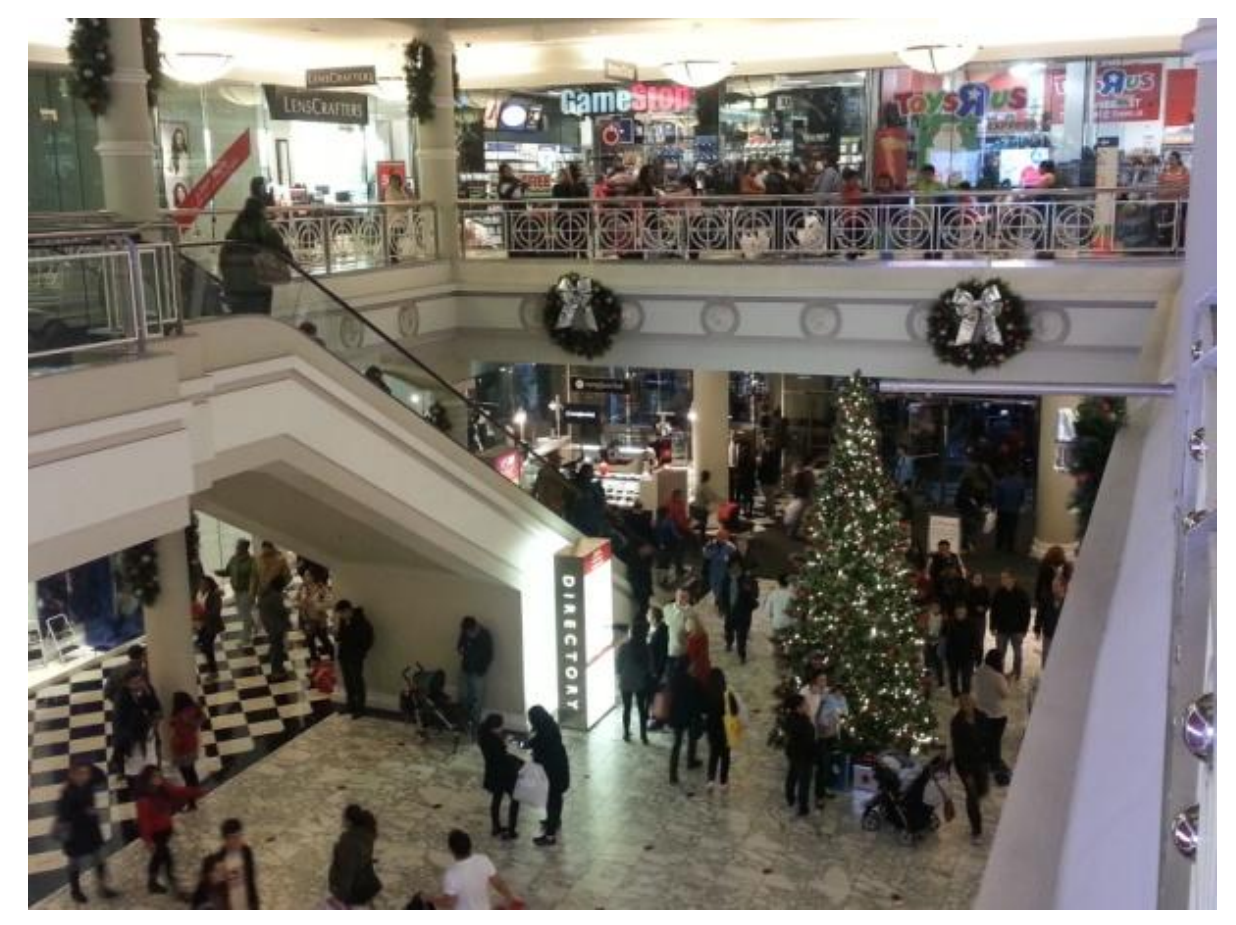

Fig. 3-7. Christmas tree located close to exit routes and main entrance of a shopping mall 
The "building-occupant" system also "reacts" when new components are introduced inside. Introduction of new components, used for "chronic" objectives, may have an influence on the fire risk, because of their own hazardous properties. This situation is reviewed by the FPEs when analyzing fire hazards, and it is even quickly integrated into standards and good practices when the introduction of the hazardous components is anticipated. Following are two examples:

- In health care facilities, alcohol-based hand-rub solutions have been found to be more effective for standard hand washing or hand antisepsis by health care workers than soap or antimicrobial soaps. Placing dispensers of alcohol-based solutions in corridors and suites of rooms is expected to decrease the estimated more than 88,000 patient deaths attributed to US hospital-acquired infections [20]. It should be noted that there is an estimated single annual death in hospital or hospice facility [21]. In other terms, numerous combustible liquid sources were added to reach a new "chronic" state, in order to decrease the risk for hospital patients to suffer from nosocomial diseases. This change in the "chronic" state of the system has been already analyzed by the National Fire Protection Association (NFPA) which integrated it into their Life Safety Code, NFPA 101 [22]. The point is that if analysis of a new hazardous material introduced in the system is carried out by the FPE, analysis of a new fire protection measure into the "building-occupant" system also needs to be carried out, especially if this measure is a managerial one. This is illustrated by the second example below.

- Also in the health care facilities, O'Connor [23] indicated that for these facilities which established smokefree environment / no smoking policies, it was observed that visitors were giving smoking materials to patients and residents without the health care staff's knowledge and that this system adaptation was found to explain why this type of ignition source was not decreasing in the corresponding fire statistics.

\subsubsection{Impact of "chronic" objectives in performing the risk analysis related to disruptive events}

Knowledge of the "chronic" objectives is also important when estimating how long building occupants delay their evacuation after an alarm starts. In case of a fire, the estimation of this "pre-movement" time is related to several factors, and particularly to two called "commitment" and "focus". In Fig. 3-8, people seem quite focus on playing slot machines, inside a Japanese game center. The row of slot machines is itself designed to maximize occupancy time by a single person whom is provided with a chair, has repetitive actions to perform in a very focused vision range, with people in the near proximity, which make it very easy to lose track of time and difficult to be aware of anything happening in the surroundings. People are committed to go on playing as

long as they have still money to feed the machines. The "chronic" objective of these games centers (as well as of western casinos), related to a high degree of focus and commitment, leads to an increase of the "premovement" time, and therefore competes with the life safety objectives to have all these people evacuate as soon as possible in case of emergency. 


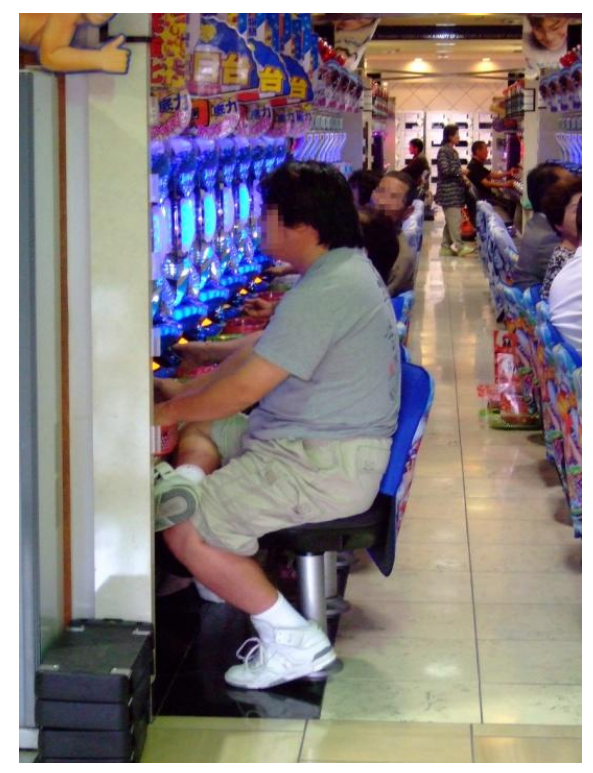

(source: http://www.flickr.com/photos/davidooms/2964039286/, free to share and remix with the attribution of the work to David Ooms)

Fig. 3-8. Example of commitment in a Japanese game center

It should be noted that in case of an emergency many building users have a strong tendency to try to leave via the route that they entered by rather than using the nearest exit [24]. Displays in department stores and shopping malls are designed to make the potential buyer go from one stand or shop to another: the position of the displays, always changing, can also have some influence on the movement time as people need to find their way out. Estimation of egress paths would be much different when considering design floor layout empty of the movable booths and the real layouts during Sales periods (Fig. 3-9). Besides, lots of additional "Sale" signs may also make it more difficult to locate Exit signs. In consequence, during Sales periods, the use of exits other than the one people used to enter the department store might be lower than in regular store usage.

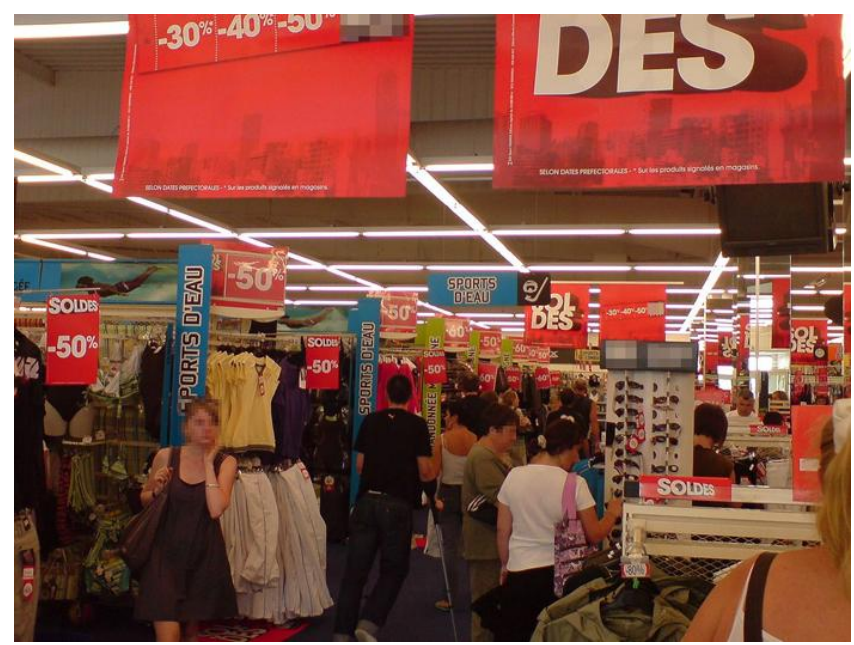

(source: http://fr.wikipedia.org/wiki/Fichier:Ambience_de_solde.jpg, put into public domain by Wikimedia Commons User Medjaï)

Fig. 3-9. Example of a French department store display during sales 


\subsection{Theoretical treatment of disruptive events affecting the performance of "building- occupant" systems}

\subsubsection{Fire is one disruptive event among others which may be "covered" by a contingency plan}

For some types of building occupancies, a contingency plan is elaborated to ensure the safety of the building occupants and minimize the recovery period in the event of an emergency (fire, power or communications blackout, tornado, hurricane, flood, earthquake, civil disturbance, etc.). These plans mainly concerns installations of Performance Group IV, according to the ICC PC classification [11]: such as hospitals or designated earthquake, hurricane and other emergency shelters. They describe the actions of the building personnel to be performed for different scenarios. For example, the contingency plan of a hospital may contain information related to a fire or the loss of HVAC system by a fire. Examination of these contingency plans is needed to verify that the emergency actions are coherent with the ones elaborated by a PBFPD process.

\subsubsection{PBFPD processes must examine the actions and events of the recovery phase following a fire}

The actions required in the recovery phase need specific documentation to insure that the system components related not only to fire safety but all other components used by the system, are back in full operational mode. This specific need is illustrated by the fires that successively occurred in a New Orleans warehouse (Louisiana, USA), on March 21, 1996. Based on the information collected in the NFPA investigation report [25], the uncompartmented warehouse contained a combination of high racks (equipped with in-rack sprinklers) and low racks (not all with in-rack sprinklers). A first arson type fire successively started in a low rack section unprotected by in-rack sprinklers, was detected by staff who unsuccessfully tried to extinguish it, activated one over-head sprinkler which action did not extinguish nor control the fire, and eventually was declared out by the fire fighters, about 5 hours after they arrived on site. At that point, "once fire control had been achieved, all of the sprinkler systems in the facility were manually shut down by closing the individual OS\&Y valves on the risers", as a result of the opening of numerous sprinkler heads throughout the warehouse, causing extensive water damage. Without evaluating the damage to the electrical system caused by water, the electric service of the building was restored, starting the second fire, in a high rack storage area, by ignition of combustible materials with arcing of damage wiring in this area. "As soon as the second fire was discovered, facility personnel began opening the OS\&Y valves on the ceiling and in-rack sprinkler systems. However, because these systems were impaired during the initial stages of the second fire, they were overwhelmed". This time, the fire destroyed all the contents of the warehouse and collapsed the structure. The second fire was declared out several days after the fire fighters arrived a second time on site.

This fire event illustrates the importance of the actions to be performed and the needed documentation (as procedures or check-lists) in the recovery period, after the fire is extinguished. These actions not only concerned the impaired fire protection system but also one utility system to the warehouse, i.e. electricity. The authors of 
the investigation report [25] advocated for a utility restoration in a "planned and coordinated manner, and only after a complete survey of the damage has been taken" so "that everyone involved with the overhaul and restoration operations be aware of what actions are being taken by the different agencies and services involved". Nevertheless, they "were unable to identify any reference in an NFPA standard, code, or recommended practice that addressed the issue of restoration of utilities and how it should be handled following an emergency".

After reviewing current PBFPD processes, I found them quite focused on the fire development itself, from ignition to extinguishment so that they ignore the recovery phase, which is essential to consider for the system as demonstrated by the New Orleans warehouse consecutive fires.

\subsubsection{Specific interconnections may exist between different types of targets or between a target and a} building component, so a fire can have a direct or an indirect impact on targets

In some systems, building occupants and building systems may have strong interconnections: in a hospital, people can be connected to life supporting machines, so fires impacting these machines (directly or indirectly) can affect the life safety of the people connected to them. Indirect effects of a fire on such patients could result from a fire damaging the distribution of electricity in the building, as well as the backup of this utility.

Also in a hospital, a HVAC/filtration system provides air quality and control of microbe and odor migration between the different functional zones of the hospital. Scott [13] studied a smoldering fire that happened in a storage room in a hospital in New Zealand, in 2008. Smoke generated by this fire traveled via a HVAC duct from the storage room to an operating room. This situation can be qualified as a direct impact of the fire, because the fire effluents directly affect the safety of the patient and of the medical staff (even if the room where the fire was located was not the same room where the targets were located). Keeping the same configuration, the HVAC/filtration system provides microbe migration control by maintaining a pressure differential between different functional zones: this $\Delta \mathrm{P}$ assures that microbes are not going from the examination room towards the operating rooms where people are more vulnerable to this threat. A fire damaging the HVAC system ability to maintain this $\triangle \mathrm{P}$ would compromise the safety of the patients most vulnerable to infections. Thus, this last example also illustrates the indirect effects of a fire on targets.

In healthcare facilities, the main safety targets are the patients. Losing a building component from a fire may affect patients. In other terms, the safety of the patient may depend on the safety of a building component. The opposite configuration also exists in some building occupancies. The most emblematic example of this configuration is the nuclear power plant, where staff may be in relative danger in case of a fire but have to remain within the plant in order to maintain the nuclear core within a safety range. 


\subsection{Practical treatment of disruptive events affecting the performance of "building- occupant" systems}

Within my "building-occupant" system paradigm, I established a risk-informed performance-based process which could be applied to quantify the effects of any type of disruptive events affecting the overall performance of a specific system.

At the initial step of the process illustrated in Fig. 3-10, the stakeholders of a considered "building-occupant" system clearly indicate the nature and the characteristics of the system in terms of "chronic" objectives. This step is essential as it specify the parameters of the "building-occupant" system to be examined in terms of building components, occupants and functional/support zones used by the system in order to achieve the "chronic" objectives.

This initial step is also a "political" step of the risk-informed performance-based process as the system stakeholders need to come to an agreement on the system main goals and decide whether the system will possess specific building attributes such as an atrium or a high rise configuration.

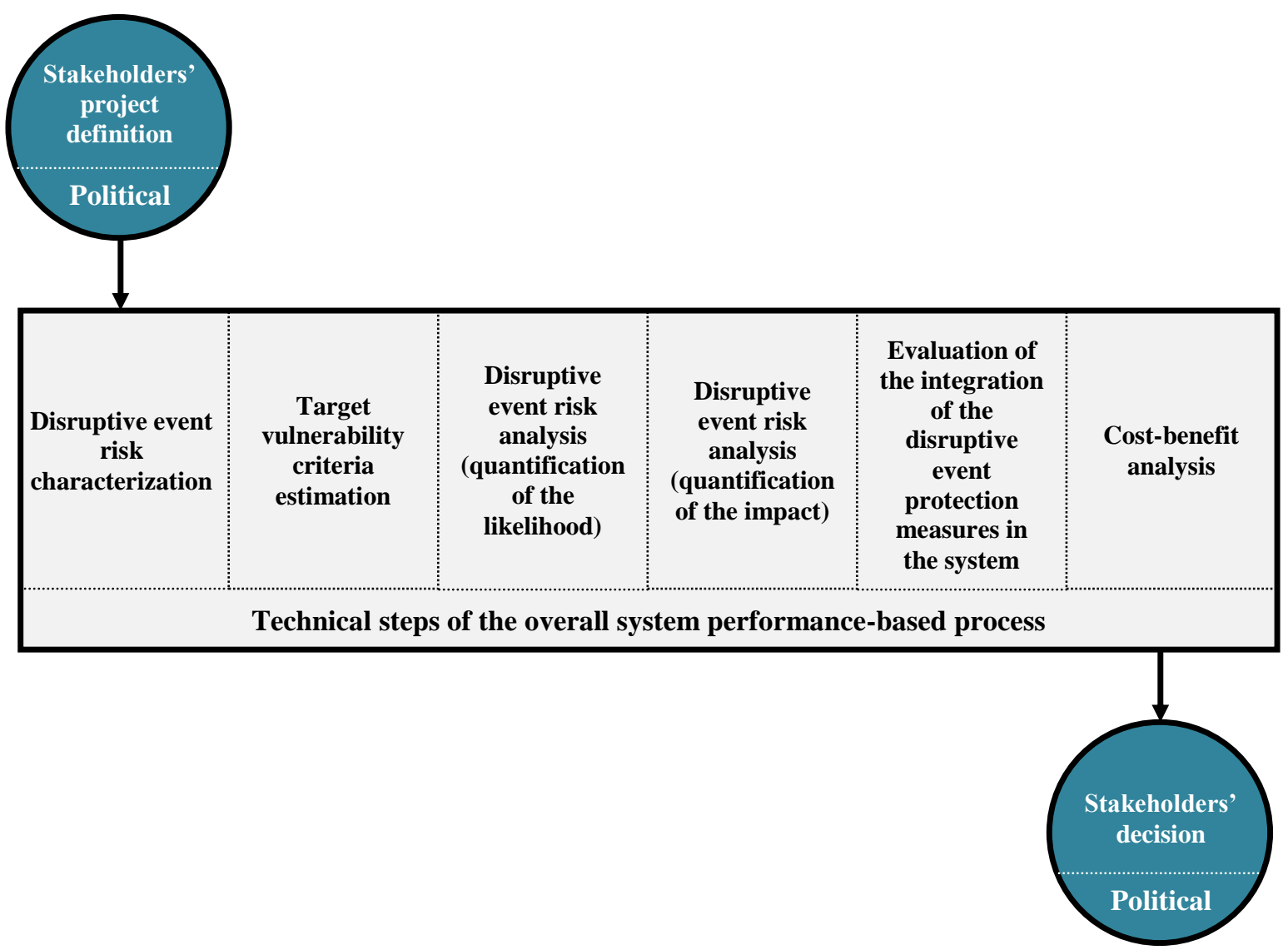

Fig. 3-10. Political and technical steps of the system specific risk-informed performance-based process 
All the information gathered by the stakeholders is then transmitted to the engineer in charge of evaluating the impact of a certain type of disruptive event on the overall performance of the system: FPEs to deal with fires, structural engineers for earthquakes, etc. Since the system targets are the components which contribute to the overall performance of the "building-occupant" system, it is imperative that the stakeholders list in this step of the process all the system targets so that the engineer take them into consideration while performing the technical steps of the process.

At this point, the corresponding engineer carries out the "technical" part of the process, which mainly consists of a target oriented risk analysis, by performing the steps as follows:

- selecting risk acceptance metrics that are representative of the considered system in relation to the stakeholders' listed targets during the chronic use of the building. The aim of the "risk characterization" step is to correlate the likelihood of the disruptive events which occur during chronic operation with vulnerability criteria for each of the listed target (e.g. assessing how often the disruptive event causes injuries or casualties when the target is the building occupant, based on statistics and past events) - Step 1;

- quantifying the vulnerability criteria for each target in case of the disruptive event (e.g. evaluating the mechanisms by which the disruptive event can have direct and indirect effects on each listed target while taking into consideration the capacity/incapacity of the target to absorb the damage from the disruptive event and still be functional/loses its functionality) - Step 2;

- carrying out a risk analysis of the effects of the disruptive event on the overall performance of the system, via the characterization of both the likelihood - Step 3 and the impact - Step 4 of the disruptive event on each of the listed targets;

- evaluating the integration of the protection measures against the disruptive event, analyzed in the risk analysis, so to verify that these measures, once installed, would not be ignored or misused by the system end users - Step 5;

- performing a cost-benefit analysis of the protection measures against the disruptive event, analyzed in the risk analysis - Step 6.

At the end of the technical steps of the performance-based process, the engineer dealing with a certain type of disruptive event will transmit three important documents (or three components of a consolidated document) back to the system stakeholders:

- $\quad$ one document containing the results of the disruptive event risk analysis (from technical Step 3 and Step 4) including a risk matrix or risk curves and explaining how the engineer's proposed protection measures reduce the risk of the disruptive event affecting the performance of the studied system, 
- one document describing the possible interactions of the protection measures designed by the engineer against the disruptive event and the other components of the studied system,

- one document estimating the costs and the benefits to install and maintain the proposed protection measures.

Based on the results of the technical steps of the system performance-based process, the stakeholders finally decide on the set of protection measures they want to be installed in the system, knowing how well these protections would help the system to mitigate the impact of the disruptive events on the performance of the "building-occupant" system in its chronic state, how well these protections would be integrated in the system and how much they would cost to install and maintain.

In case the performance-based process is simultaneously conducted on several disruptive events, the different engineers involved in proposing protection measures against their respective disruptive events have to generate a common additional document since it is important to verify that all their additional protection measures are not counterproductive (Fig. 3-11). It should be noted that the initial political step is identical for the stakeholders as they only need to provide once, in their own terms, the specifics of their "building-occupant" system. The "translation", in terms of solving the right problem for each disruptive event, is made by the corresponding engineer in the technical step related to risk characterization.

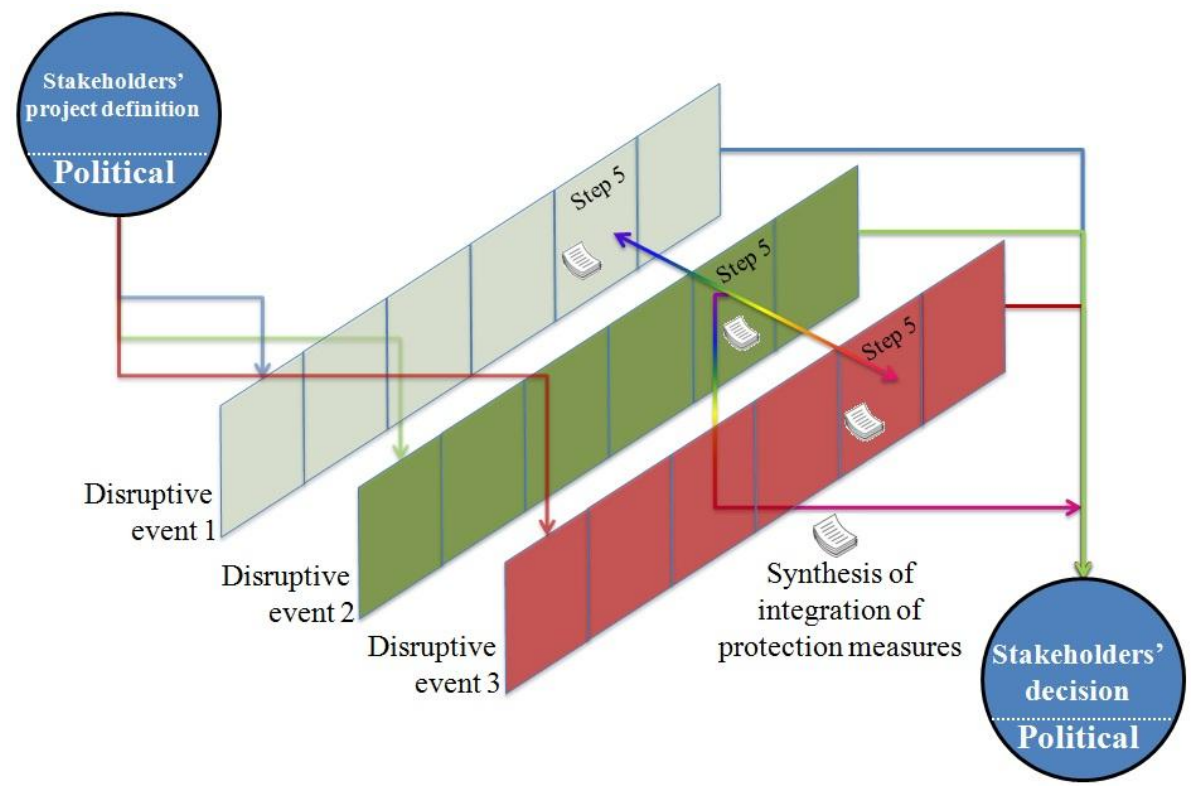

Fig. 3-11. Practical treatment of multiple disruptive events 


\subsection{Conclusions of this chapter}

Designing a building project is a complex enterprise involving project stakeholders who are the main drivers of the project concept and professional groups who are the main drivers of the actual realization of the project. In addition to this complexity, differences arise between the building project at its design phase and when the building is actually exploited by its end users.

The performance of a building depends on the interrelations between the different components of the building which are separately designed by specific engineers, having their own objectives to fulfill, so the final integration of all the building components may not be optimal. When these components concern disruptive events, i.e. events affecting the daily performance of the building such as fires, it was found that the end users might misuse or ignore the protection measures against the disruptive events, because these measures were not integrated well enough by the end users.

This chapter presented the outcomes of research carried out in order to:

- define a paradigm of study organized around systems formed by specific building types and their associated occupants so to clearly determine how hazardous disruptive events such as fires affect these system daily performance,

- introduce a corresponding system specific risk-informed performance-based design process, which could take into consideration the complexity of such systems and their evolution during disruptive events.

\section{References}

1. Zalejska-Jonsson A. Evaluation of low-energy and conventional residential buildings from occupants' perspective. Building and Environment 58 (2012) 135-144

2. International Council for Research and Innovation in Buildings and Construction. Performance Criteria of Buildings for Heath and Comfort. Report CIB number 292, prepared by ISIAZ-CIB Task Group TG 42. 2004

3. SFPE Engineering guide to Performance-Based Fire Protection - Second Edition, 2007

4. SEAOC, Performance-Based Seismic Engineering of Buildings, Volume I, Structural Engineers Association of California, April 3, 1995

5. Ornstein SW et al. Performance evaluation of a psychiatric facility in Sao Paulo. Facilities 27, 3/4 (2008) 152-167

6. Spekkink D. Performance Based Design of Buildings - PeBBu Domain 3 - Final Domain Report - Performance Based Buidling Network (PeBBu) October 2005 (availabe http://www.pebbu.nl/resources/allreports/downloads/07_D3_FinalReport.pdf, checked 10/31/2012)

7. Sheffi Y. The Resilient Enterprise, Massachusetts Institute of Technology Press. 2005 
8. Knight RF and Pretty DJ. The Impact of Catastrophes on Shareholder Value, The Oxford Executive Research Briefings. Templeton College, University of Oxford, England

9. International Code Council (ICC) International Building Code, 2012

10. Lataille JI. Factors in Performance-Based Design of Facility Fire Protection. Fire Protection Engineering, 2nd quarter 2008, Society of Fire Protection Engineers, 2008 (available at: http://magazine.sfpe.org/fire-protection-design/factorsperformance-based-design-facility-fire-protection, checked 10/31/2012)

11. International Code Council (ICC) Performance Code, 2012

12. US Department of Commerce, Bureau of Census, North American Industry Classification System (NAICS) Definitions. 2007 (available at: http://www.census.gov/eos/www/naics/2007NAICS/2007_Definition_File.pdf, checked $10 / 31 / 2012)$

13. Scott D. Fire in an operating Theatre - What really Happened? - A Case Study of a Fire in a Private Hospital in Hamilton, New Zealand. Proceedings of the 4th International Symposium on Human Behaviour in Fire 2009, pp. 313322

14. (ABCB) Australian Building Codes Board. International Fire Engineering Guidelines, 2005 edition

15. Richardson R. Florence Nightingale and hospital design. King's College, London. 2010 (available at: http://www.kingscollections.org/exhibitions/specialcollections/nightingale-and-hospital-design/florence-nightingaleand-hospital-design, checked 10/31/2012)

16. Tolley M. Institutional Buildings, the Built Environment - Public Spaces. 2011 (available at: http://martintolley.com/environment/BuiltEnv2EnvPsy6.html, checked 10/31/2012)

17. Alvarez A. and Meacham B.J., Towards an Integrated Performance-Based Design Approach for Life Safety Across Different Building Use Groups, in: Proceedings of the 12th International Interflam Conference, Nottingham, UK, 2010

18. Wærp S. and Holthe K. Turnover Rate and Environmental Load for Building Materials - Checkpoints in Design Process. $\quad$ CIB14251, SINTEF. 2009 (available at: http://www.sintef.info/upload/Byggforsk/Bibliotek/Publikasjonsdatabasen/CIB14251.pdf, checked 10/31/2012)

19. Spearpoint M and MacLennan HA. The effect of an ageing and less fit population on the ability of people to egress buildings. Safety Science, vol. 50, issue 8,1675-1684, October 2012

20. (NFPA) National Fire Protection Association. NFPA 101 Life Safety Code ${ }^{\circledR}$ Handbook, eleventh edition, edited by R. Coté and G. E. Harrington, NFPA, pp.667-669. 2009

21. Flynn J.D. Structure Fires in Medical, Mental Health, and Substance Abuse Facilities, February 2009, National Fire Protection Association. 2009

22. (NFPA) National Fire Protection Association. NFPA 101 Life Safety Code ${ }^{\circledR} 2009$ edition, NFPA. 2009

23. O'Connor D.J. Health care occupancies, chapter 15, section 20 of the 20th edition of the Fire Protection Handbook, National Fire Protection Association, 2008

24. Kobes M. et al. Way finding during fire evacuation; an analysis of unannounced fire drills in a hotel at night. Building and Environment 45 (2010) 537-548

25. Comeau E. and Puchovsky M. NFPA Fire investigation report, Warehouse fire, New Orleans, Louisiana, March 21, 1996, National Fire Protection Association. 1996 


\section{A FRAMEWORK FOR RISK-INFORMED PERFORMANCE-BASED FIRE PROTECTION DESIGN FOR THE BUILT ENVIRONMENT}

Twenty years of experience with performance-based fire protection design (PBFPD) was reviewed and I determined that shortcomings and challenges still need to be addressed in order to expand the application of PBFPD processes as an option to the prescriptive requirements imposed by building regulations (cf. Chapter 2 of this dissertation). Existing guidance related to these processes has been found to be too generic, meaning that fire protection engineers (FPEs) are required to significantly expand upon the information provided by this guidance when applying it to their specific projects resulting in wide variation in practice. Furthermore, the application of these processes requires the agreement by all of the involved stakeholders regarding key elements of these processes, such as the definition of the performance criteria and the selection of the fire design scenarios against which the trial designs would be evaluated: issues upon which stakeholders have to expertise.

Given these findings, I conducted research aimed to ultimately lead to the establishment of more specific guidance for PBFPD, which provides more specific technical guidance and which incorporates a new process separating the 'political' decisions taken by the stakeholders from the 'technical' analysis to be performed by the FPEs.

One important initial finding of my research was that the generic characteristics of the current PBFPD processes could be attenuated when establishing guidance for specific building use groups and for specific objectives (e.g. life safety, business continuity, heritage preservation) [1].

In addition, my research indicated that current PBFPD processes are, on one hand too fire focused, and on the other hand too centered on the design of fire protection measures, leading to the possibility that fire protection measures deemed appropriate at the time of design might not be the most appropriate when implemented in a building, as key aspects of the fire protection design might be ignored or worse "rejected" by the occupants of the building when needed the most, since fire is not a daily concern [1].

A risk informed performance-based design process was then established in order to assess the overall performance of systems formed by specific building types and their associated occupants in case of disruptive events, such as fire, natural hazards, and economic crisis, affecting these systems (cf. Chapter 3 of this dissertation).

This chapter presents the application of this system specific risk-informed performance-based design process for the treatment of fire events, and how it differs from the current PBPFD processes, notably by providing a level of detail that is lacking in current PBFPD processes and by clearly separating the political steps from the technical ones, leaving the FPEs with a straightforward independent technical part. 
I estimate that a successful implementation of the new system performance-based design process for the treatment of fire events will require acceptance, by the FPE community and the involved stakeholders, of the need for a paradigm shift from one in which fire is the center of the problem to one in which building performance metrics are evaluated in the case of fire events.

\subsection{Challenges of the current PBFPD processes: the need to be more specific}

It was found that there are complications with respect to application of the current PBFPD approaches from a regulatory perspective. While existing PBFPD approaches focus on fire and fire systems, they are very generic in how they do so, not specifying what scenarios to consider, how to characterize design fire, for which occupant attributes, and so forth. To a certain extent, such flexibility was targeted due to (a) the wide range of building considerations for which the PBFPD approach might be used, and (b) because specifics of design fires and acceptance criteria can be considered public policy decisions, not engineering decisions, as they help define tolerable levels of performance or risk. While such flexibility works well for engineers, it did not sit well with regulatory officials, since there was no clear way to determine 'good' designs. As a result, wide variation

existed in developed designs, and in order to lessen the variation, some countries have now moved to 'prescribe' certain performance factors, such as scenarios, fires and criteria. While this is in some ways helpful, it also misses aspects of importance that need to be addressed. However, it helps highlight the need to separate 'political' decisions from 'technical' ones.

There are many more challenges for fire protection engineers created by the current PBFPD processes being too generic, which have been identified and detailed in Chapter 2 of this dissertation. For the purpose of this chapter, they can be characterized as:

1. Applying generic guidance to specific projects, often times lacking the detail necessary for comprehensive analyses, which may result in important fire performance concerns being missed.

2. Defining, using and quantifying the performance/acceptance criteria, which should be determined by policy makers and decision makers (AHJs), not by the FPEs.

3. Selecting fire design scenarios to test fire protection systems rather than to test building fire safety performance.

4. Comparing the levels of performance between an engineering solution and the one based on prescriptive requirements without have a good basis of comparison.

5. Having insufficient guidance to determine the most influential factors affecting the evaluation of trial designs.

6. Assuming "idealized" performance of fire protection measures (i.e., condition at time of design, omitting users) as compared with "real life" performance of installed measures over time, as impacted by occupant, and as otherwise impacted, 
7. Estimating the consequences of fire design scenarios on building performance without having the whole performance picture adequately defined.

8. Resorting to adapting literature values, when available, to use in models, rather than being forced to demonstrate the values are appropriate and/or utilize appropriate values.

As intimated in (2) above, there has to be a clear understanding of both technical and political issues, as several decisions in the PBFPD process are dependent on policy makers and decision makers (e.g., performance criteria and design fire scenarios have to be agreed upon by the considered stakeholders before the fire protection engineer can really start the technical part of the process). As such, it would be extremely beneficial for the PBFPD process to clearly delineate 'political' (joint) decisions from 'technical' ones, making the engineering tasks more straightforward to address.

\subsection{Shifting the paradigm: studying how a global system formed by a building and its occupants reacts when a fire can occur}

While the "fire protection systems" approach makes sense in retrospect, given the somewhat uncoordinated development of the PBFPD idea, process, tools for analysis, data and so forth, it meant that fire in the context of overall building performance has not necessarily been analyzed sufficiently. When I investigated building fire protection designs that were developed using this approach, I found that FPEs only consider the characteristics of a building and of its occupants only into the PBFPD process as parameters of the fire design scenarios and in the development and evaluation of fire protection measures. This consideration taking place during the design phase of a building project led to a "disconnect" between the fire protection components and the context of the building in use: FPEs expected that the fire protection measures would be correctly designed and maintained so they would operate as intended, as an independent component of the system formed by the building and its occupants. Unfortunately, this was found not to be the case. In numerous instances, investigation reports of fire events reflected how the interaction between the building, fire and occupants influence each other during events. For example, a warehouse which suffered small damage after a first fire controlled by an automatic sprinkler system was completely destroyed by a second fire some hours later as the sprinkler system was shut off due to some water damage caused by the opening of numerous sprinkler heads throughout the warehouse [2].

The photographs below (Fig. 4-1) were taken in a conference center. One fire exit sign is practically hidden behind the black signage. Even if delegates find the fire exit sign, they would probably use the double door to a conference room (that they probably use to go during the conference), instead of getting through the fire exit door located at the right end of the corridor, almost hidden by the blue panel. 


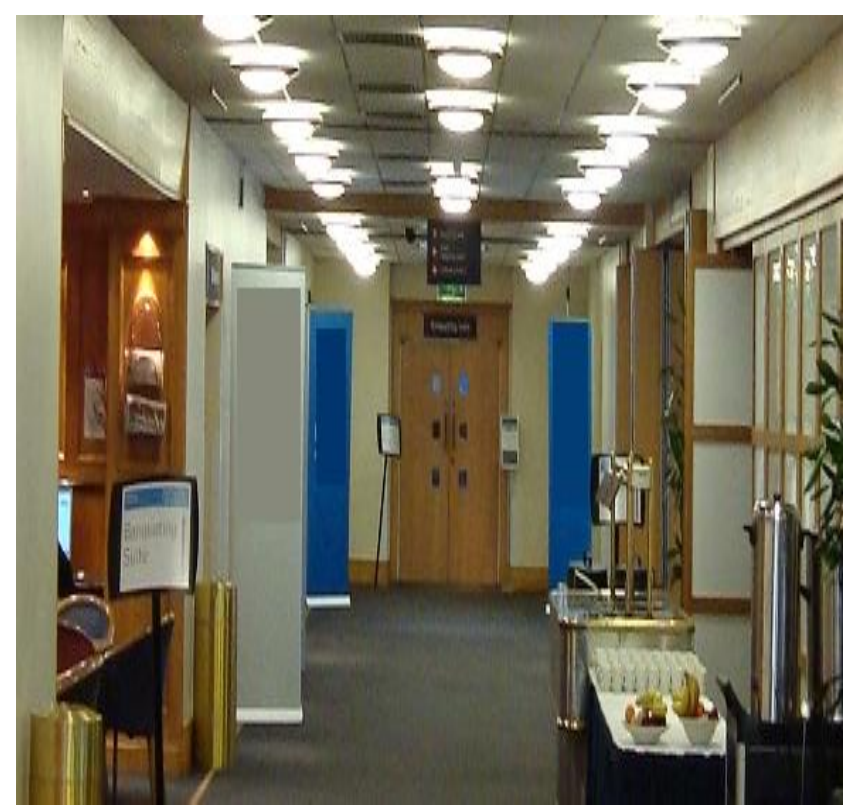

a) view from a corridor of a conference center

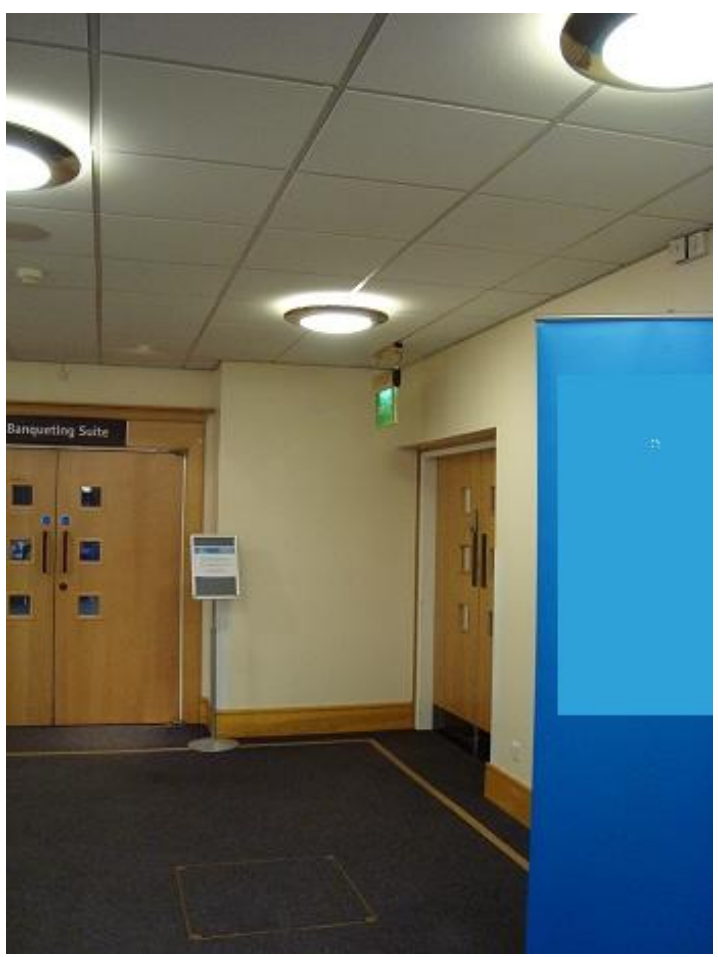

b) Fire exit door in the corridor side, mostly hidden by the blue panel and "competing" with the usual delegate path to go through the double door to a conference room

Fig. 4-1. Fire exit way finding problematic in a conference center

These illustrative examples made us consider that the study of the fire protection measures (technical systems and managerial procedures) could not be done without considering the system they are installed in. Indeed, on one hand, these measures involve the building occupants (during the evacuation process) for whom fire is a "disruptive" event during the otherwise normal building use. On the other hand, they are not completely independent from the other building parts as they deal with a lot of common space (e.g., rooms delimited by doors, corridors, atrium).

As a result, I needed to define a global system in which fire protection measures would be one component, among may, and then verify how shifting the paradigm of study to this system would prevent the fire protection component from being ignored (conference center example) or even worse rejected (warehouse example) by the occupants of the building when a fire occurs.

In addition, it should be noted that researchers have only recently started to incorporate building interior design in their models due to the complexity of simulating these details, as well as the needed time and resources to run the corresponding simulations. For example, Stern-Gottfried and Rein [3] looked at how building interior design influences fire spread in large, open-plan compartments while Oven and Cakici [4] examined how this building 
interior design influences the evacuation process during emergencies, as obstacles increase travel distances and create bottlenecks. Thus, fire researchers also realize the effects of the building use on the fire and the fire evacuation process and are developing tools to assess these effects. Back on the engineering side, by shifting the paradigm, I estimate that FPEs will incorporate the results of the fundamental fire research more easily and more quickly into their safety analyses.

\subsection{Application of the system performance-based process to fire disruptive events: Creating a new PBFPD process}

One challenge previously identified in this dissertation concerns the relationship between the technical aspect and the political aspect of the current PBFPD processes. By shifting the current fire centered paradigm associated with these processes to a paradigm centered on the study of a "building-occupant" system, the performance of the system can be assessed when this system is affected by any kind of disruptive events (technological hazard, natural hazard, economical hazard...) as presented in Chapter 3 of this dissertation.

In my "building-occupant" system paradigm, I defined several key concepts in the previous chapter. These concepts are summarized as follows:

"Targets" are the system agents responsible for the system daily performance (building occupants and components). During normal every day conditions or "chronic states of the system", they are located in "functional zones" where they carry out their activities associated with "chronic objectives", established in accordance with the system scope and performance. "Utility zones" include system support components such as electricity, HVAC and plumbing. "Disruptive events", such as fires, have to be considered between two consecutive "chronic states". In order to mitigate the "event effects" on the system performance, "acute objectives" have to be set up so to take into consideration "direct effects" and "indirect effects" with which the disruptive events can possibly damage the targets.

Detailed information about the "building-occupant" system paradigm and the system performance-based process are presented in the previous chapter of this dissertation. The application of this process to a fire disruptive event is presented in Fig. 4-2. Each step of the process will be explained in the subsequent parts of this chapter. 


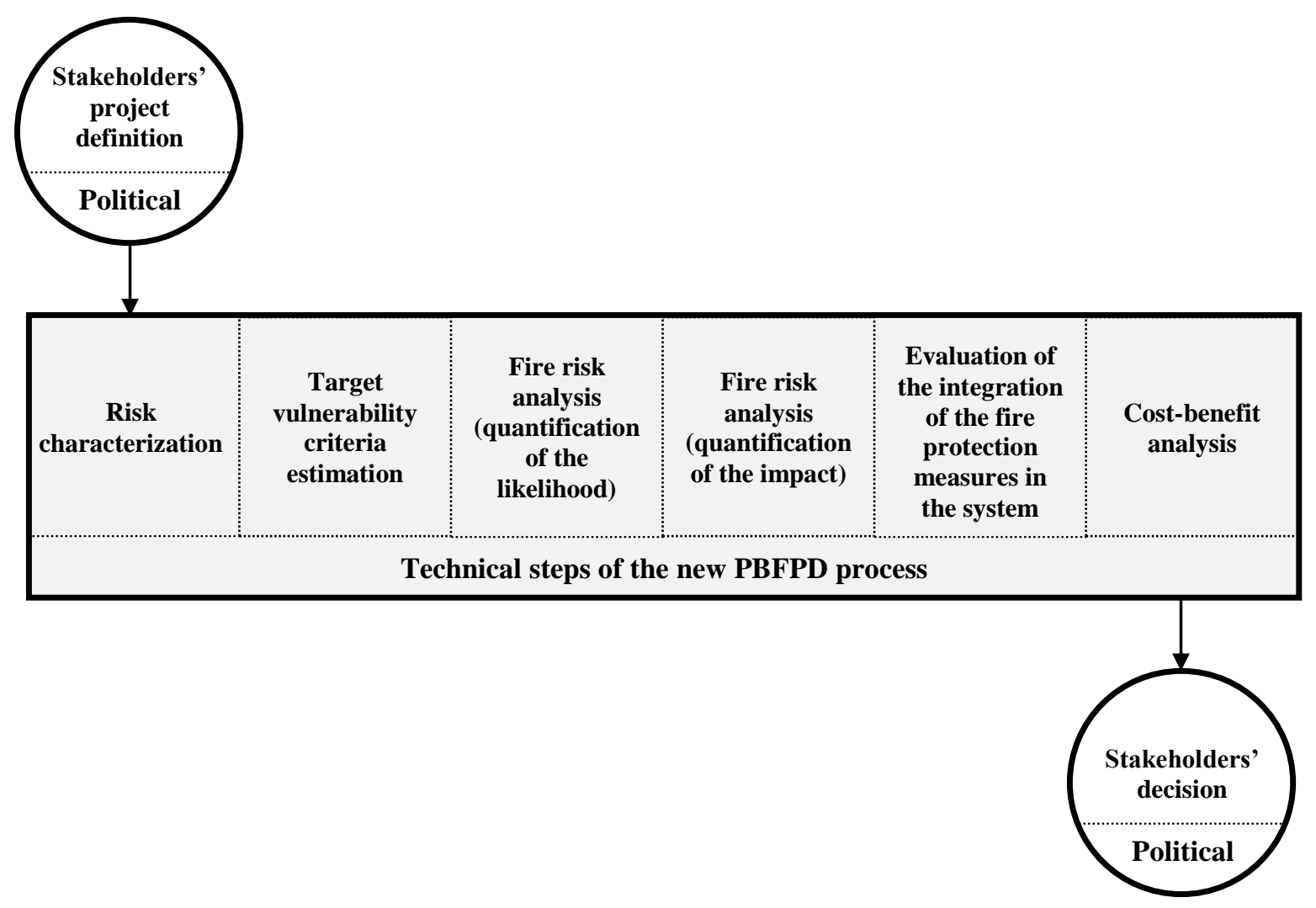

Fig. 4-2. Application of the system performance-based process to a fire disruptive event

The following section shows how the system performance-based process is applied in the case of the disruptive events being fires and how different this new PBFPD process is from the current ones.

\subsubsection{The new PBPFD process is a target oriented process within the "building-occupant" system paradigm}

The new process separates the political aspect from the technical one, concentrating the political aspect at the very start and the very end of the PBFPD process, leaving the technical aspect clearly within the realm of the FPE. Again, the political process includes regulated issues as well as stakeholder decisions. The principle of this separation is illustrated in Fig. 4-2.

- At the start of the PBFPD process, the stakeholders define the project and present all of the characteristics of the "building-occupant" system to be examined: building parameters, occupant parameters and functional/support zones used every day by the system. The stakeholders still have to agree on the main goals and objectives related to the considered "building-occupant" system and precisely what specific building attributes are of concern (e.g., atrium, high rise configuration...). These are considered political aspects of the problem, as decisions are required by others than the FPE alone. Once decided, all of this 
information is transmitted to the FPE who starts the technical aspect of the PBFPD process by selecting risk acceptance metrics that corresponds to the considered project;

- After performing the technical steps of the PBFPD process, the fire protection engineer will give three important documents back to the stakeholders:

- $\quad$ one document containing the results of the fire risk analysis (from Step 3 and Step 4) including a risk matrix or fire risk curves and how the selected fire protection measures reduce the fire risk for the studied system,

- one document describing the possible interactions of the fire protection measures and the other components of the considered "building-occupant" system,

- one document estimating the costs and the benefits of installing and maintain the proposed fire protection measures.

- based on the three documents provided by the FPEs, the stakeholders have all the information they need to take their decision regarding the fire protection measures they want in the studied "building-occupant" system, knowing how the overall performance of the system would be affected by fire events. This again is a "political" issue, as I consider that it is only the responsibility of the stakeholders to select the fire protection measures they will have installed in their systems in association with the loss of system performance that they ultimately accept for their system in the case of fire events.

It should be noted that some feedback is possible between the first technical task of the PBFPD process (risk characterization) and the stakeholders' description of the system, as at the beginning of a completely new project all the design features may not be available or finally set up, so changes that would influence the PBFPD may occur at that stage, implying some information feedback between the stakeholders and the FPE. Feedback is also considered concerning the risk characterization in the case the stakeholders have an idea of the level of risk they agree to accept. If it is so, this information is also gathered by the FPE as it will help him/her to design acceptable trial designs. More concerning this feedback process is presented in section 4.4 of this chapter.

It should be understood that the new PBFPD process is applied to specific "building-occupant" systems and not in a generic way which could be applied to every kind of project. In consequence, the guidelines that the FPEs use for a specific project are established for the type of "building-occupant" system the considered project is categorized into. This means that in order to apply the technical steps of the new PBFPD process (Fig. 4-3), specific guidelines for each of its six steps have to be written for specific and well defined "building-occupant" systems. 


\begin{tabular}{|c|c|c|c|c|c|}
\hline $\begin{array}{c}\text { Risk } \\
\text { characterization }\end{array}$ & $\begin{array}{c}\text { Target } \\
\text { vulnerability } \\
\text { criteria } \\
\text { estimation }\end{array}$ & $\begin{array}{c}\text { Fire risk } \\
\text { analysis } \\
\text { (quantification } \\
\text { of the } \\
\text { likelihood) }\end{array}$ & $\begin{array}{c}\text { Fire risk } \\
\text { analysis } \\
\text { (quantification } \\
\text { of the impact) }\end{array}$ & $\begin{array}{l}\text { Evaluation of } \\
\text { the integration } \\
\text { of the fire } \\
\text { protection } \\
\text { measures in } \\
\text { the system }\end{array}$ & $\begin{array}{c}\text { Cost-benefit } \\
\text { analysis }\end{array}$ \\
\hline
\end{tabular}

Fig. 4-3. Steps to be performed in the technical aspect of the proposed PBFPD process

Risk characterization is about translating the fire safety engineering problem from a stakeholders' perspective to a FPE perspective and to verify that the FPE has considered all the targets and define risk metrics relevant to the different targets of the studied system. In the "building-occupant" system paradigm, the problems FPEs have to solve are related to the characterization of the impact (in terms of occurrence and intensity) the targets are affected with, in case of fire events.

Then, for each considered targets, the FPE has to quantify how these targets are affected by direct and indirect effects of fire events, events involving a fire and defined between two "chronic" states of the system.

Fire risk analysis has then to be conducted in order to characterize the likelihood and the consequences of fire events on the targets. The FPE work is then to propose fire protection measures in order to minimize the occurrence of the damaging fires and mitigate the impact of these fire events on the system performance (i.e. the consequences of the fires events affecting system targets).

The next step of the technical process is then to evaluate how the fire protection measures analyzed in the fire risk analysis would be integrated into the studied system, in other terms, if they are going to be compatible with the components which are used on an everyday basis so they are not counter-productive and therefore ignored or worse rejected by the system. This step goes beyond the documentation on how the fire protection measures are designed, installed and maintained in the current PBFPD processes.

The last step of the technical process is for the FPE to perform a cost benefit analysis of the fire protection measures established during the fire risk analysis.

\subsubsection{Comparison with the current PBFPD processes}

When examining the portion of the PBFPD process established for example by the Society of Fire Protection Engineers [5] presented in Fig. 4-4, one can realize that the influence of the stakeholders remains important all along the process, while establishing the design brief, that is to say even before the fire protection engineer looks for solution with defining and evaluating trial designs. 

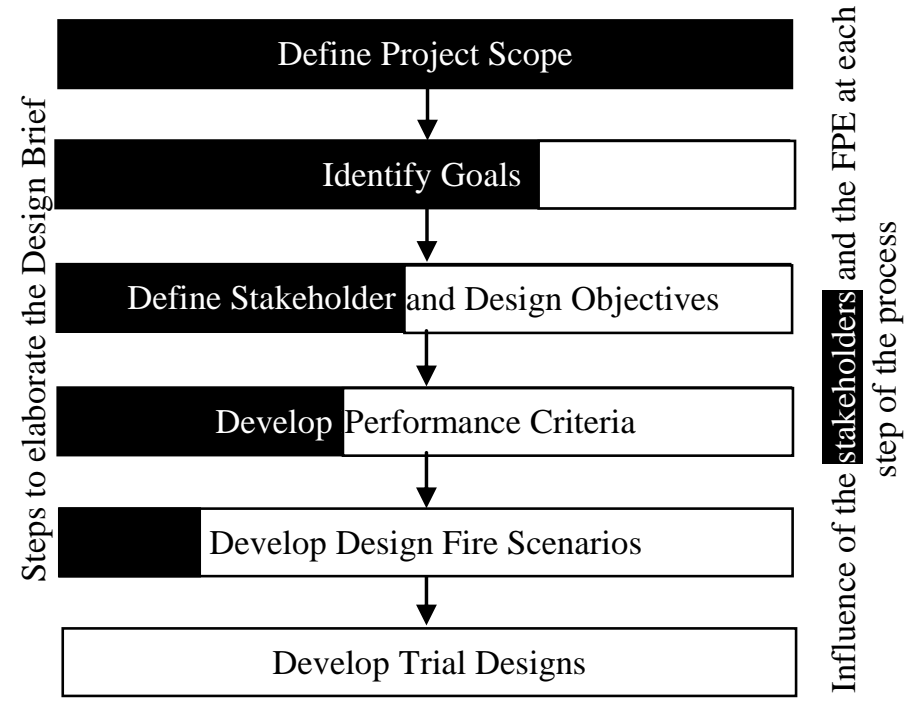

Fig. 4-4. Relative influence of the stakeholders and the fire protection engineer in the different steps of the elaboration of the design brief according to SFPE guide [5]

In conclusion, I estimate that the new PBFPD process allows a clear separation between the political aspect and the technical aspect of the process, which will bring the benefits for:

- the stakeholders who will only define the context of their considered system, in terms of their expected performance for the system to withstand fire events, and who will consider at the end of the process the different options proposed by the FPE based on a fire risk analysis, the evaluation of the integration of the fire protection measures into the system and their associated costs and benefits,

- the fire protection engineer who, after getting all the characteristics of the problem to solve, will conduct and independent straightforward engineering analysis and propose his solutions for the stakeholders to finally decide.

At the end of the new PBFPD process, a political decision is taken by the stakeholders based upon a technical analysis by the FPE, including results from a fire risk analysis describing how often and deep fire events would degrade the overall performance of the system, a document showing how the selected fire protection measures would be integrated into the system and a corresponding cost-benefit analysis of these measures. 


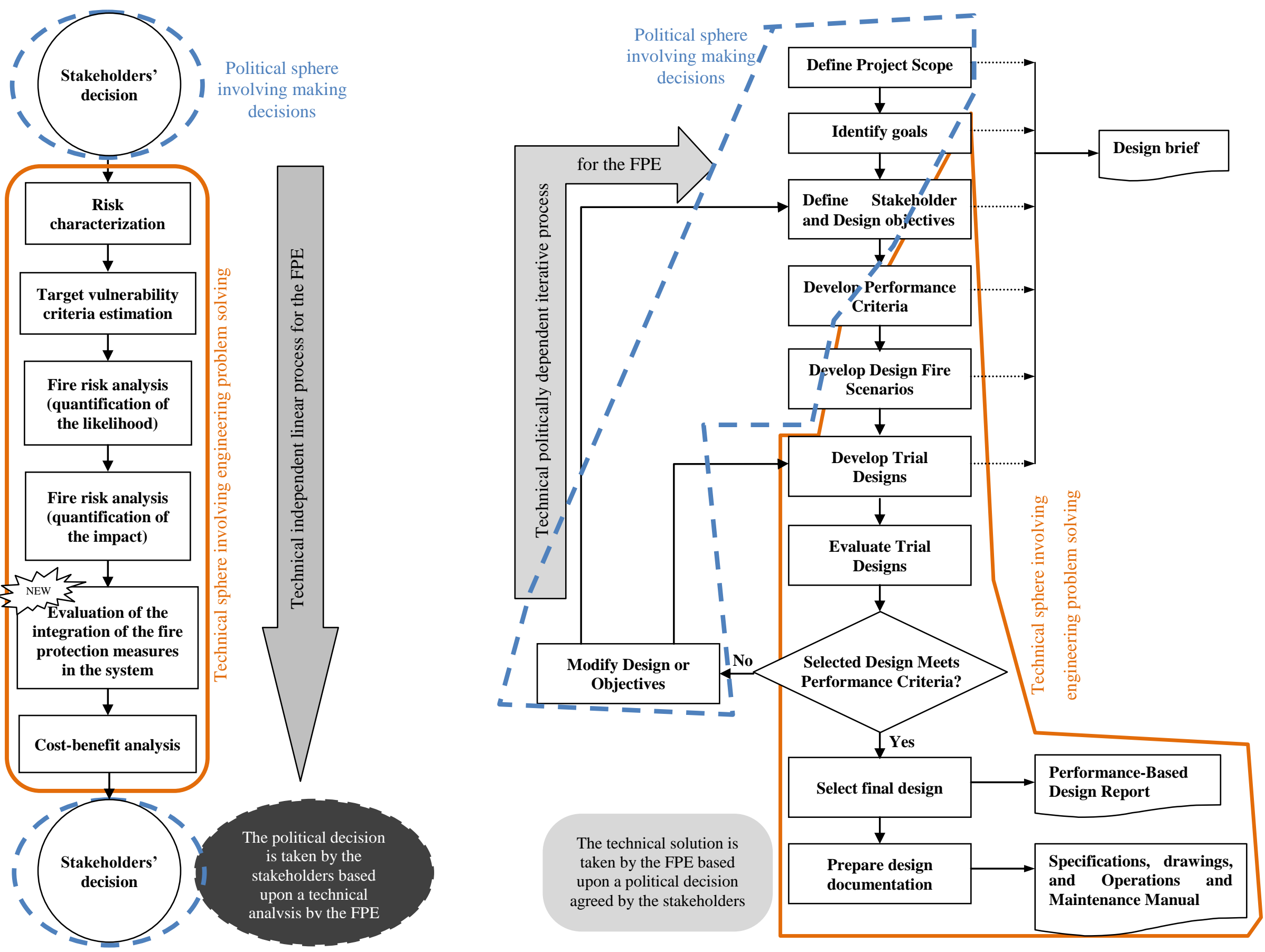

Fig. 4-5. Comparison between the new PBFPD process and the PBFPD process established by SFPE [5] 
As a consequence of shifting the paradigm from one which is centered on the fire and the fire protection measures to one which describes in details the "building-occupant" system and evaluates its performance, a new PBFPD process has been developed and the main differences between this new process and the current ones are illustrated in Fig. 4-5. The main difference can be summarized by the end products of these two different processes:

\subsection{Proof of concept of the New PBFPD process: closing "Iteration Zero" (verification of the usability of the process)}

Now that I have shifted the paradigm from the study of the fire event itself (as in the current PBFPD process) to the study of the effects of fire as a disrupting event of a "building-occupant" system and developed a new PBFPD process to accommodate this new paradigm, this section presents the proof of concept for this process. This proof of concept constitutes "Iteration Zero" of a longer-term goal for the profession: establishment of detailed guidelines for each step of the process for all types of systems declared relevant to stakeholders.

Based on Fig. 4-2, the new PBFPD process is used as follows:

The different stakeholders define the characteristics of the project under consideration or review. Context about the use of the "building-occupant" system is detailed in order to assess the importance of this system inside a system network. Targets are defined by the stakeholders, as well as functional zones and other relevant information on how the system performs on a daily basis (interconnections between functional zones, utility systems, relations between building occupants and building systems...). Eventual contingency plans are given to the FPE. Metrics related to the goals and objectives agreed among the involved stakeholders are then defined in order to assess the proper parameters or targets of the system's performance.

At this stage of the PBFPD process, stakeholders may or may not have a preconceived estimation of their required levels of performance for the considered system. If not, the performance metrics characterizing each of their goals and objectives are used by the FPE to conduct the technical part of the PBFPD process. Fire risk curves or matrices are used to translate into the PBFPD process, the performance of the system to withstand fire threats, according to how often and how damaging these threats are. This is schematically illustrated in Fig. 4-6. 


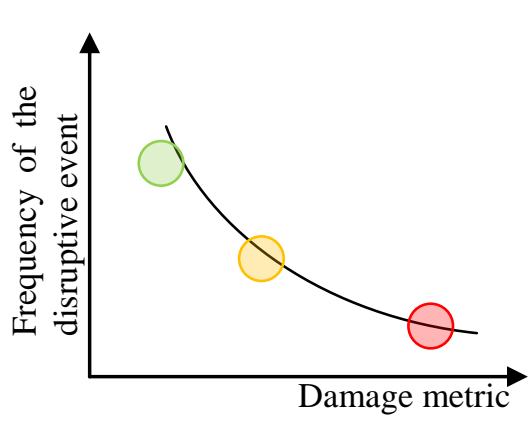

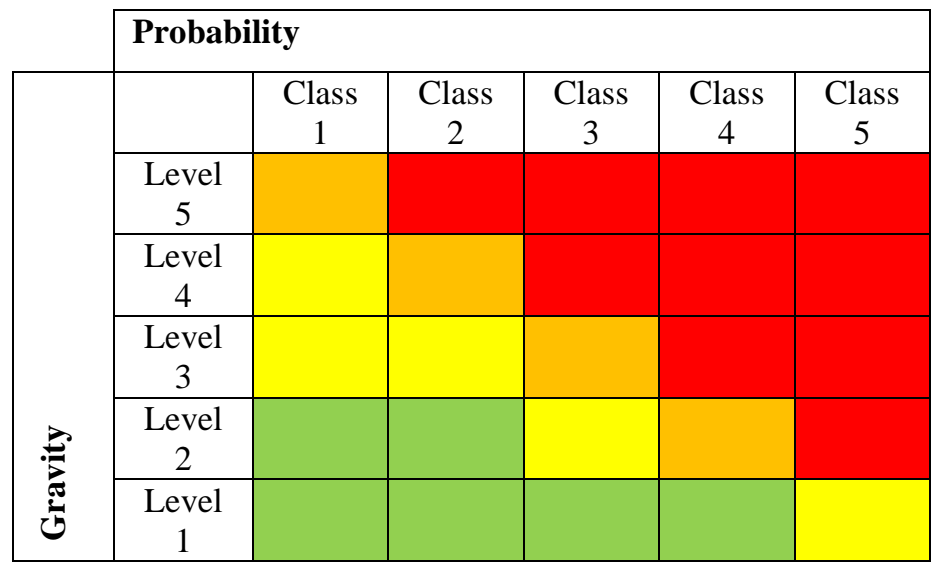

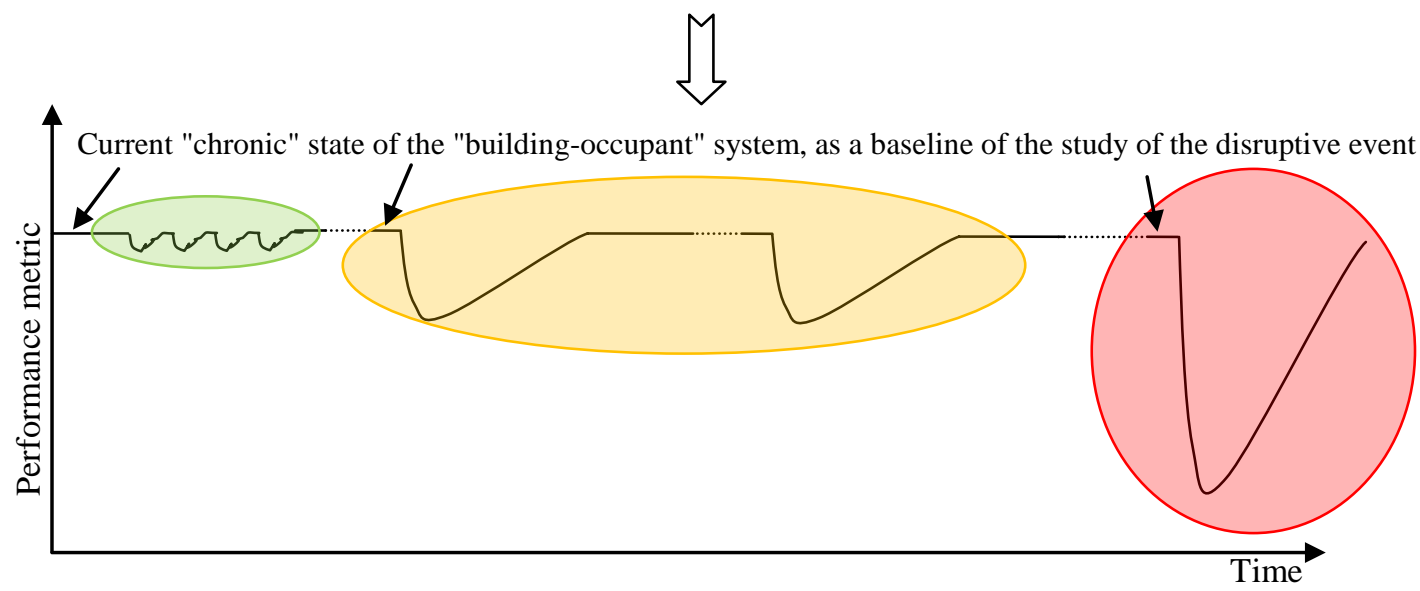

Fig. 4-6. Translation of fire risk characterization in the "building-occupant" system paradigm

Since the information related to the fire risk characterization is directly presented as fluctuations of the performance of the system, this information can be given back to the stakeholders who can then decide to clearly state their performance criteria, as illustrated, as an example, in Fig. 4-7. In this example, for a "frequent" disruptive event, the stakeholders allow the performance of the system to be less than the one defined in the risk characterization: in other terms, they allow more property loss or a longer recovery time, depending on the vulnerability metric. For a "less frequent" disruptive event, the stakeholders allow the performance of the system to decrease as the one defined in the risk characterization. For a "rare" disruptive event, the stakeholders do not allow the performance of the system to be less than the one defined in the risk characterization. Based on their performance requirements, a new fire risk curve can be constructed and fire disruptive events will then be assessed by their locations, in terms of (probability-consequences), relative to this new fire risk curve. 


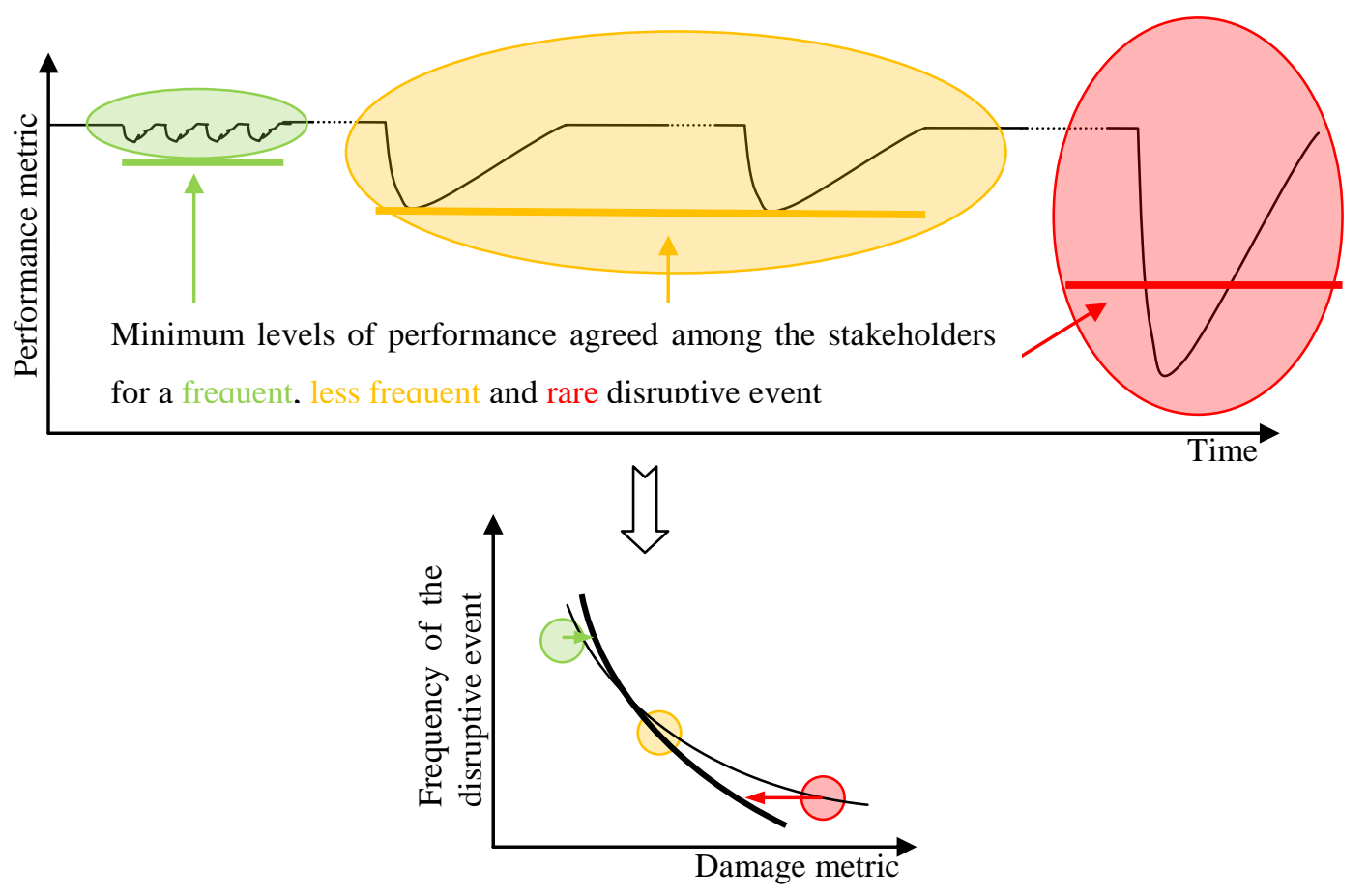

Fig. 4-7. Translation of the performance requirements of the "building-occupant" system as fire risk characterization

Targets vulnerability metrics are then gathered by the FPE, based on the targets' natures and characteristics.

Based on the description/information gathered about the system (functional zones, location and characteristics of targets...), the FPE performs the fire risk analysis. Event trees are used with zones containing targets and most probable fire ignition locations as initiation points of these trees. In conjunction, fault trees are used with "affected target" as final/top point, in order to capture the indirect threats to the considered targets. The aim of this PBFPD process step is for the FPE to cover fire events that are relevant to the performance of the system, that is to say the fire events that could affect the stakeholders' targets and to define fire protection measures or safety barriers to prevent these scenarios from occurring, with a frequency estimated on fire ignition frequencies and reliability of the considered fire protection measures. At the end of this process step, the benefits of the safety barriers, in terms of decreases of fire frequencies and consequences can be gathered in a synthetic form, as illustrated in Fig. 4-8. 


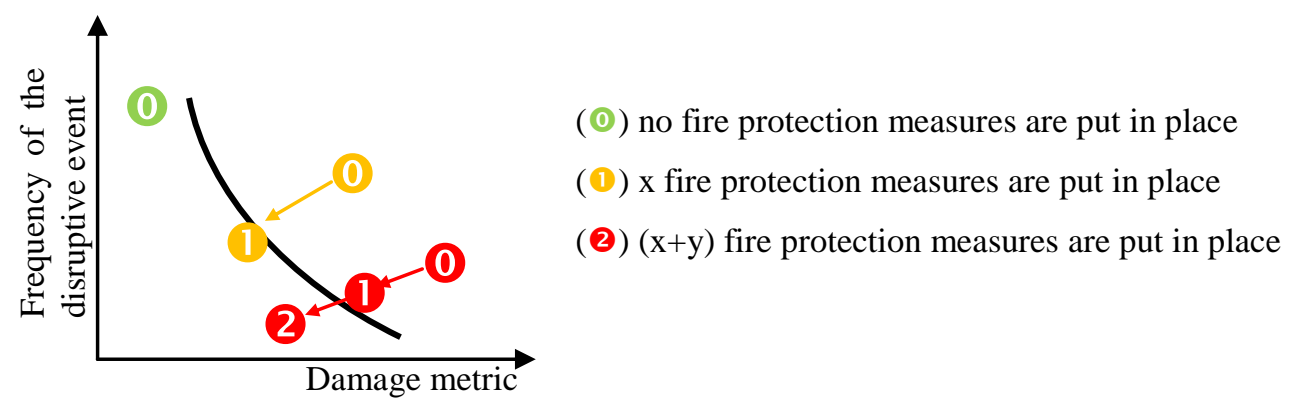

Fig. 4-8. Schematic representation of the risk reduction of scenarios of disruptive events

The next step of the proposed PBFPD process is performed to be sure that the inclusion of fire protection measures does not affect the performance of the other system components dedicated to achieve "chronic" objectives or other safety objectives. Not only is it verified that inclusion is not counterproductive for the daily performance of the system, in short term and in long term, but also that the safety barriers are maintained properly.

The final step of the technical part of the proposed PBFPD process is related to the cost-benefits of the fire protection measures.

At that point, the FPE delivers three important pieces of information to the stakeholders:

- The schematic representation of the risk reduction of scenarios with the different sets of fire safety barriers, as illustrated in Fig. 4-8, with a description of barriers and more details on the most "valuable" barriers, that is to say the ones which lower the fire risk the most,

- The means of verification that the fire safety barriers are not counterproductive for the level of performance of the analyzed system,

- The costs of the installation and maintenance of the different sets of fire safety barriers.

Based on that information, the stakeholders finally decide what fire protection measures to add as components of their system. 


\subsection{Closing "Iteration Zero" (demonstration of the ability to overcome the challenges encountered by the use of the current PBFPD processes)}

Challenges that FPEs, code regulators and authorities having jurisdictions are facing when applying the current PBFPD processes are briefly listed in section 4.1 of this chapter and presented in detail in Chapter 2 of this dissertation. The following paragraphs are dedicated to demonstrate how the proposed PBFPD process overcomes these challenges.

The main challenge related to the application of generic guidelines has been addressed with the proposed elaboration of detailed guidelines designed for specific "building-occupant" systems and with the organization of "target oriented" risk analyses. Also, the challenge related to the intricacy of the technical and political aspects of the current PBFPD processes is overcome as presented in Fig. 4-2, and detailed in Section 4.3.2 of this chapter.

The following demonstration aims to illustrate, with real fire events or constructed ones, that the proposed PBFPD process is more suitable to deal with the specificities of a "building-occupant" system than the current ones and therefore it points out where the FPE really needs to focus his/her analysis, what information is needed, for what step of the process and why this information matters. This demonstration is organized according the different steps of the proposed process. Each example is presented in three parts: the concern, how existing approaches fall short, and how my approach addresses the concern.

\subsection{1 $\quad$ Risk acceptance characterization}

Business continuity is often a FP goal but business recovery is not only dependant on the building that is analyzed but also on the network of buildings and industry it belongs to (cf. Chapter 3 of this dissertation), so establishing parameters of the performance of the analyzed building requires the FPE to look at not only how it operates by itself but also at how a disruptive event such a fire can decrease the performance level of the network. A "building-occupant" system is a dynamic one as its owner and users can constantly change during its life span, affecting how the system is used for, how it is managed and what level of performance is associated with it.

A generic PBFPD process is not as adaptable as a process which has been designed to take these changes into consideration as the analysis of the system is at the core of such an oriented process. The information related to the system is gathered at the start of the process, because the level of performance is a function of all these information, and the quantification of this level of performance is the "only" real engineering problem the FPE has to solve. Besides, the same information is needed across all the steps of the proposed process. In the current PBFPD processes, information and data are gathered more for the sake of running models than for 
characterizing what the engineering problem is about. In other terms, the current PBFPD processes were elaborated by FPEs for FPEs, incorporating thought processes they were trained to have, which explained why the systems analysis they borrowed in the 1970's quickly focused only on fire protection components. This independent state of mind still results nowadays in frictions mainly between the FPE and the architect / building owner.

Since the proposed process is integrated into a global system analysis, I assume that its application would tend to attenuate these frictions, not only in the design phase but each time the building users modify the characteristics of the analyzed system. Thus, the proposed process will also manage the dynamic changes of the system as fire disruptive events are characterized with taking into consideration the current "chronic" state of the system, as illustrated in Fig. 4-6.

\subsubsection{Target vulnerability criteria estimation}

As discussed in Chapter 2 of this dissertation, the terminology "performance criteria" defined in the current PBFPD processes does not apply to the quantification of the overall performance of a "building-occupant" system, but it rather corresponds to target conditions when affected by the direct effects of a fire. For example, SFPE [5] indicates that "performance criteria generally take the form of damage indicators. It is not necessary that the means of preventing at this stage [i.e. when defining them], but a complete understanding of the acceptable limits of damage and injury must be well understood. If the engineer develops the performance criteria, the damage indicators utilized should come from technical documents and their selection should be thoroughly explained and documented for stakeholders". SFPE also indicates that "performance criteria might include temperature of materials, gas temperatures, smoke concentration or obscuration levels, carboxyhemoglobin (COHb) levels, and radiant flux levels".

In my "building-occupant" system paradigm described in details in Chapter 3 of this dissertation, these "performance criteria" are indeed related to the effects of a fire on a target but they only integrate the fire negative input on the targets. In other terms, they do not quantify how the target itself will respond to these fire effects (e.g. submitted to the same smoke environment, a bedridden patient after surgery would be endangered before a hospital staff member and before a fire fighter). My "target vulnerability criteria" integrate this response, as my process is dedicated to the variations of performance of the targets in the case of a fire event, not only during the fire itself until these targets recover and reach again a "chronic" state.

Let us consider people as targets. I found out that life safety criteria currently focus on direct fire effects. However, there are other issues. For life safety, the following criteria are not considered in current PBFPD processes: criteria related to stampede (e.g. Brooklyn theater fire on December 5, 1876, Iroquois theater (Chicago) fire on December 30, 1903, and the much more recent Uphaar Cinema fire, in India on June 13, 1997) or indirect damage (when people are connected to life supporting machines). Several criteria are absolute 
values, with no notion of duration attached to it. When assessing the evacuation process, transitory states are not taken into consideration in the current approaches, as they do not detail the steps to perform a dynamic analysis of both the Available Safe Egress Time (ASET) and the Required Safe Egress Time (RSET). Loss of visibility may be transitory, in space (near the fire origin) or in time (until an eventual smoke management unit starts).

Because the proposed PBFPD process is target oriented, this specific step will include the most exhaustive and appropriate list of target vulnerability criteria required to perform the subsequent risk analysis. This is why the initial political step of my process is crucial as the stakeholders establish the list of targets (people, building content, etc) and describe how the activities of these targets contribute to the overall performance of the system.

\subsubsection{Fire risk analysis (quantification of the likelihood)}

It is intended that shifting the paradigm will also allow a more comprehensive and coherent definition of the performance of the "building-occupant" system among the stakeholders and the fire protection engineers. As a result, FPEs have to consider the fire problem inside this paradigm where the actors contributing to the performance of a system (building occupants and building components) have then to be the subject of a fire risk analysis as defined "targets" since fires affecting directly or indirectly these targets would diminish the overall performance of the system, which is the main concern of the stakeholders. It should be noted that "functional zones" and "utility zones" are concepts that are more accessible and understandable to the stakeholders than "fire zones" and "smoke compartments" that are centered about fire scenarios which are not a daily preoccupation of the building occupants. In order to fully grasp the impact of fire events and the benefits of implementing the system with fire protection measures, the FPEs need to communicate to the stakeholders with concepts that they are familiar with and verify that the FPE concepts integrate well with the stakeholders' ones.

As an example, Fig. 4-9. illustrates the differences of concepts between the "functional zones" in the "buildingoccupant" paradigm and the smoke compartments used by FPEs. In a), three functional zones have been established according to the system characteristics. Each functional zone contributes to the daily performance of the system. Without knowing this information, a FPE could design two different smoke compartments (in b)) according to the current PBFPD processes, resulting in affecting two or three functional zones in case of a fire spreading in Smoke Compartment 1 (SC1) or Smoke Compartment 2 (SC2) respectively (in c)). In terms of fire damage area, the consequences could concern up to the half of the system (in b). Nevertheless, in terms of performance for the system, up to three functional zones may be affected, potentially bringing the daily performance of the system to a zero. Shifting to the "building-occupant" system paradigm will allow the FPEs to better understand how the system operates in a daily basis and therefore establish fire protection measures to mitigate the effects of fire events on this daily performance, which is what the stakeholders are concerned about. 


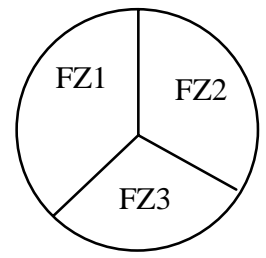

a) System division according to the "building-occupant" system paradigm - FZ: Functional zones

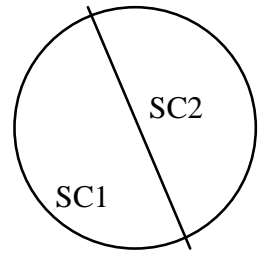

b) System division according to the current PBFPD processes SC: Smoke compartment

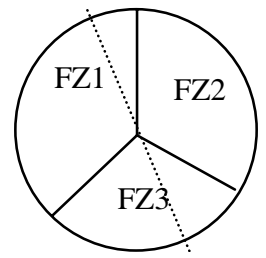

c) Impact on the system Functional Zones based on the Smoke Compartment division

Fig. 4-9. Concept differences between the FPE current paradigm and the "building-occupant" system paradigm

As indicated above, targets are components of the system that contribute to the performance of the system. These targets can be affected by direct and indirect effects of a fire event. As an example, Fig. 4-10. illustrates the impact of the indirect effects of a fire on the overall system performance, focusing on how this indirect effect is not taken into consideration in the current PBFPD processes. Because shifting to the "buildingoccupant" system paradigm clearly shows the FPEs connections between utility zones and functional zones, the FPEs would be able to evaluate the indirect impact of a fire in an utility zone upon the overall performance of the system.

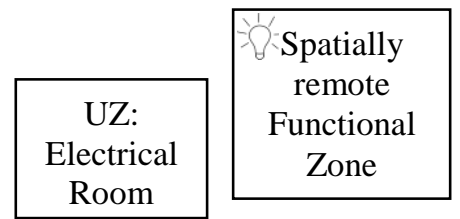

a) System division according to the "building-occupant" system paradigm - UZ: Utility zone

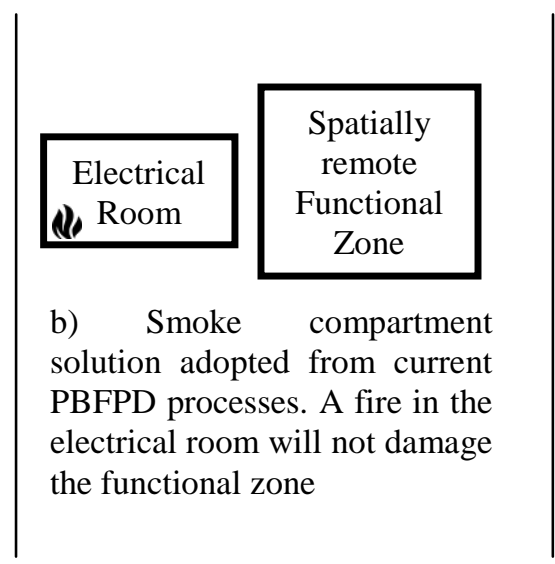

c) Impact on the system overall performance: Loss of Electricity in the Functional Zone: the Functional Zone is unable to perform

\section{Fig. 4-10. Indirect effects of a fire upon the overall "building-occupant" system performance}

The current PBFPD processes, being focused on the fire scenario, generally address fire "direct effects"; but are not describing how the "fire indirect effects" have to be analyzed and minimized. The new PBFPD process, being target-oriented, utilizes a fire risk analysis centered around the study of how often and how badly fire events can affect directly and indirectly the targets which contribute to the performance of the system. 
Since the performance of a system is affected by potential damaging effects to the system targets, FPEs need to take these specifics into consideration when elaborating their fire strategy. The stakeholders are the ones who define the system targets when they elaborate the overall objective of their systems. Thus, it is essential that the stakeholders transfer the information related to the system targets as soon as possible to the FPEs, who can then design specific fire protection measures in order to minimizes the fire impact on these targets, so ultimately the performance of the system is the least affected by fire events. No current PBFPD process indicates to a FPE the need to examine such a level of details or explains the reasons why this level is important because such processes are still too focused on the fire scenario itself instead of being target-oriented.

Fire protection measure reliability is not considered in the current PBFPD approaches based on a deterministic treatment of fire scenarios so that all the safety barriers are considered to be performing as designed. Exit signage is a typical example on how the efficiency of a fire protection feature varies from the design conceptual phase to the reality of the use in the system (Fig. 4-1).

In the proposed PBFPD process, target oriented scenarios are established with event trees and fault trees in order to determine all of the possible paths that can led to a target being affected in the case of a fire disrupting the system. In the current PBFPD processes using a probabilistic approach, only event trees are considered as a technique to assess the likelihood of scenarios because these scenarios focus on the possible direct consequences of the fires themselves and how the fire protection measures would mitigate these consequences (e.g. appendix E titled "Risk Analysis" of the SFPE engineering 2.3 guide [5] or Section.2 of IFEG [6]). In some PBFPD processes, fault trees are also used but mainly to assess the conditions of fire ignition or the causes of failures of a fire protection measures. Still, they fail to assess indirect threat paths on targets.

Technical fire protection measures are always indicated in examples of event trees. Human actions are indicated as additional sources of fire detection (e.g. nurse detecting a fire in a patient ward) or fire suppression (e.g. staff using portable fire extinguishers and of course fire fighters controlling and extinguishing a fire). Besides, I assume that some of the human actions are also considered in fault trees related to fire ignition frequency (arson, poor maintenance of electric equipment, uncontrolled hot spot...). Nevertheless, I have not seen in event trees the impact of actions of humans leading to an aggravation of the consequences of fire scenarios. Maybe some of them are embedded in the fire parameters themselves, like an unauthorized use of fireworks, which is an important fire ignition source and which can potentially lead to a rapid fire spread. But what about "over capacitating of the system" as it was repeatedly observed in the aforementioned night club disasters? Indeed, this "human action" item is "controlled" by the regulation and needs enforcement but within the "buildingoccupant" system framework, it is clear that item has to be considered in the PBFPD process as it is a flagrant example on how a "chronic" objective of a night club owner related to profitability competes with fire safety objective. Less flagrant but worth noticing are similar incidences in department stores during sales or airports during holiday seasons or right after strikes. 
Contrary to fire scenarios developed in the current PBFPD processes, the proposed process extend scenarios to take into consideration the period from fire extinguishment to the establishment of a new "chronic" state of the system, as explained in Chapter 3 of this dissertation.

\subsubsection{Fire risk analysis (quantification of the impact)}

\subsubsection{Quantification of impact vs. quantification of consequences}

As already indicated, fire scenario consequences are not limited to the extent of safe evacuation or direct fire damage, but they should include the effects of fighting the fire, including in term of monetary loss. Assessment of all impacts should be considered. For example, in open spaces, even if sprinkler heads locally activate, water tends to spread over a larger area than the area directly affected by the fire. As an example, at the Myrtle Beach Convention Center (USA), on October 12, 2011, a fire that started on a cherry picker lift in an exhibit hall activated sprinkler heads, which controlled the extent of fire spread. However, given the volume of smoke produced, a 2-hour effort by firefighters to remove the heavy smoke out of the exhibit hall was needed. Extensive damage to the machinery and water damage in the convention center were reported [7]. This example illustrates the concern that originates from the difference of perspective between the FPE who follows generic guidance to determine direct damages of the fire (e.g. sprinkler automatic system is adequate as the directly damaged area was small) and the building owner who is mainly interested in renting his convention center (e.g. water from sprinklers and smoke from the fire rendered useless a larger part of the convention center, which required cleaning before the overall damaged space was usable again). A more comprehensive and detailed example is presented in Chapter 3 of this dissertation, which clearly shows the dramatic aftermath of a cell phone company after a 10 minute fire.

The current PBFPD processes only deal with the direct consequences of a fire whereas the proposed process advocates for the quantification of fire impact of targets which contribute to the overall performance of a "building-occupant" system, evaluating direct and indirect fire effects as indicated in Section 4.5.2 and Section 4.5.3 of this chapter. Once again, the current PBFPD processes which are focused on fire scenarios, estimate direct fire effects between ignition and extinguishment, so they do not take into consideration the response of the different targets as well as the "recovery period" of the fire event.

As the proposed process is "target oriented", the FPE looks for this information which is essential for the study of the effects of fire events on the overall performance of a "building-occupant" system.

\subsubsection{Tools and data needed for the quantification of the impact of fire events}

Consequences on building occupants are often estimated via the (RSET / ASET) concept where RSET is the Required Safe Egress Time (i.e. time for building occupants to safely evacuate) and ASET is the Available Safe 
Egress Time (i.e. time before untenable conditions appear). This concept is currently applied in too much of an independent manner: on the one hand, using fire effects models, the FPE estimates the time to reach untenable conditions. On the other hand, as a completely independent calculation, using egress models, the FPE estimates the time required for the building occupants to reach a place of safety. Emphasis is given on the "fire" estimation as FPEs are trained to do such estimations but uncertainties related to human behavior in fires are still nowadays quite significant to drive the validity of all the (RSET / ASET) estimation.

Not enough guidance on how human behavior affects the results of the evaluation of fire scenario consequences is contained in the current PBFPD guidelines and the current process framework advocates for more guidance, as well as a more dynamic integration of the two calculations (fire and evacuation) [8].

For this step, the proposed PBFPD process focuses FPEs on the "building-occupant" system, which requires integrated analysis to be conducted of the building-occupant-fire situation. In addition, the proposed process defines a framework for collaborative projects, called 'test bed' environments [9], developed to facilitate the determination of the most appropriate tools, data and methods for FPEs to apply in order to quantify fire impacts for specific "building-occupant" systems and for specific issues such as occupant evacuation, property protection or building structural response. In the future, guidance established during these projects in cooperation with stakeholders (including AHJs) would speed up the validation of the use of tools for their corresponding systems and issues, while decreasing the uncertainties due to the tool models, input data and tool user.

\subsubsection{Integration of the fire protection measures into the "building-occupant" system}

Since the current PBFPD processes consider the installation and the maintenance of fire protection measures after the stakeholders agree on them, the responsibility shifts from the designer (FPE) to the user (building owner and occupants) to maintain with time the operability and the efficiency of the fire protection measures.

The current process analyses the effects of integrating fire protection measures into the system in order to prevent these measures from being counterproductive or even "rejected" by the system. During the Pattaya Royal Resort hotel fire, June 11, 1997, emergency doors were locked by hotel operators to prevent customers from leaving without paying. This Code violation in conjunction with a lack of sprinkler system and no fire alarm heard by the survivors were the main causes of at least 78 casualties and at least 64 injured people. Also in Thailand, in 1993, a fire in a toy factory killed 188 people and police reported that factory supervisors had locked the exits to prevent workers from taking breaks [10]. Exits doors "locked in an effort to monitor employees and prevent theft" was also observed, among many other deficiencies in the Triangle Shirtwaist Fire that happened in a factory in New York, on March 25, 1911, (one century ago) killing 147 of the more than 500 employees [11]. 
Lack of code enforcement is also to blame partially in the fire that occurred in a chicken processing plant in Hamlet (North Carolina, USA) September 3, 1991, leading to 25 fatalities and 54 injured people. The plant had not been inspected during the 11-year operation of the plant, several doors leading to the outside were locked, and survivors indicated that there was no real organization in the plant's evacuation [12].

As an example of how some fire protection measures can be "rejected" by the system, Fig. 4-11. illustrates that competition between "chronic" objectives and fire safety ones does not go in favor of the latter one. The picture in Fig. 4-11. has been taken in an actual hotel, where a vestibule with two fire rating doors has been design to protect the single stairwell of the hotel from being invaded by smoke in case of a fire spreading in the corridor where the hotel rooms were located. The "chronic" objective is related to the ease of passage between the hotel rooms to the lobby via the stairwell. The objective clearly supersedes the objective to maintain an eventual smoke separation with the vestibule.

As mentioned in Section 4.2 of this chapter, current PBFPD processes consider fire protection measures as independent of the system in which they are installed. While these measures are required to be maintained according to design specifications, the current processes do not include a mechanism to verify how these measures would be perceived by the building occupant before and more dramatically when a fire occurs. In that perspective, FPEs design "independent" fire protection measures and they estimate that the system, in which these measures are installed and maintained according to their design, will conform to all these specifications (i.e. that the system will adapt by itself to these specifications).

This specific step of the proposed PBFPD process is aimed to avoid critical situations where the fire protection measures installed in a "building-occupant" system are ignored, or "rejected" by this system, potentially leading to a catastrophe in case of a fire occurring. The "chronic" use of the system needs to be addressed and as for the previous process steps, it relies on the stakeholders' input during the initial step of the process in terms of "competing objectives". For the example illustrated by Fig. 4-11, a FPE might suggest the use of a smoke vestibule as a smoke control feature, yet not thinking about how that system could be defeated by the daily use of the hotel patrons whose objective is to have an unobstructed path while carrying their luggage from their room to the lobby via the stairwell. In my approach, in the document related to this process step, the FPE would have to communicate to the hotel stakeholders how fire safety management would address this, and if not deemed reliable by the stakeholders according to their "chronic" objectives, propose another option. 


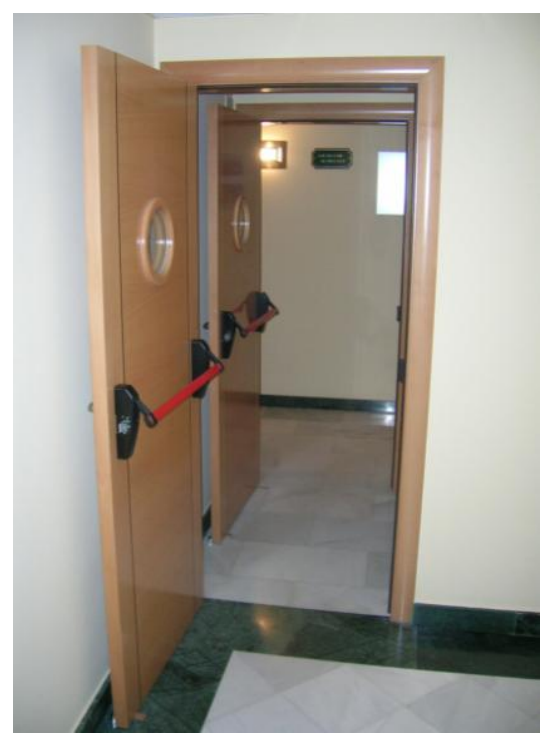

Fig. 4-11. Blocked opened doors in a vestibule separating hotel room corridor from a stairwell in a hotel

\subsubsection{Cost-Benefit analysis of the fire protection measures}

Building owners usually want to spend an optimum of resources correlating the cost associated with fire protection measures and their benefits, according to the level of fire risk they are ready to accept (level evaluation that I consider as a political decision in this research).

In the current PBFPD processes, SFPE [5] indicates that "if several successful trial designs are available, cost could be one of the factors used to select which successful alternative is used". Effectiveness of the fire protection measures defined by their availability (capability of the measure to perform its fire safety function at a given time) and their reliability, is also one of these factors. Nevertheless, SFPE does not indicate how these different factors should be evaluated and presented to the different stakeholders for their judgment (i.e. how a more effective but more costly measure should be finally installed instead of a less effective but less expensive one).

The "Cost-Benefit analysis" Step is the last technical step of the proposed PBFPD process. This would not be suggested but required. Guidance would need to be developed, based on approaches outlined by Ramachandran [13], Watts and Chapman [14] or others. The Cost-Benefit analysis, in conjunction with Step 3, which assesses the reliability of fire protection measures, and Step 5, which evaluates how these measures are designed and maintained in order to be well integrated in the system, represents the package of information that the FPE needs to provide so that in the final step of the process, stakeholders are able to make an informed decision of the fire protection measures based on system options, reliability and cost factors and finally select the ones for their system. 


\subsection{Conclusions for this chapter}

Research was undertaken as a response to the shortcomings and challenges related to the application of current performance-based fire protection design (PBFPD) processes. These difficulties were interpreted as a consequence of having generic guidelines for these processes which strongly rely on a political agreement between project stakeholders and the fire protection engineers. Besides, these generic guidelines seem too focused on fire scenarios so that fire protection measures deemed appropriate at the time of design might not be the most appropriate when implemented in a building, as key aspects of the fire protection design might be ignored or worse "rejected" by the occupants of the building when needed the most, since fire is not a daily concern.

As a consequence, it was estimated that a paradigm shift from one in which fire is the center of the problem to one in which building performance metrics are evaluated in the case of fire events, was necessary before implementing a new PBFPD process able to overcome all the current difficulties. A "building-occupant" system paradigm was then established along with a new risk-informed performance-based process focused on assessing the overall performance of the system in case of any type of event affecting its performance.

This chapter presented how this system performance-based process can be used for the treatment of fire events and how this new PBFPD process differs from the current ones. The new PBFPD process is system specific, so its associated guidelines cannot be generic as they are established by system categories.

Being focused on the system, a fire risk analysis is performed centered on the study of the actors of the system everyday performance and how fire protection measures can mitigate the effects of fire events on this everyday performance. Besides, the new PBFPD process contains a technical step dedicated on the evaluation of the integration into the system of the fire protection measures, selected after the fire risk analysis. A cost-benefit analysis finalizes the technical part of the process which has been performed independently and in a straightforward manner by fire protection engineers (FPEs). At the end of this technical part, FPEs have elaborated three documents detailing the results of the fire risk analysis, of the evaluation of the integration of the fire protection measures into the system and of the cost-benefit analysis. Based upon these documents, the stakeholders decide which fire protection measures they would have installed in their system. This process is then showing a complete separation between the "political" decision-making process and the "technical" resolution of the engineering fire problem,

As a proof of concept, it has been shown through text and examples how the new framework addressed the challenges with the existing approaches, operated within a more holistic "building-occupant" system paradigm, illustrated how viewing fire as a perturbation within the larger "building-occupant" system would increase fire safety performance over the life of a building, and deliver a higher level of building fire safety performance. 
For the time being, no detailed guidance has been established for the new PBFPD process. Nevertheless, the following chapter of this dissertation will describe how the new PBFPD process is implemented. In other terms, Chapter 5 contains a possible plan of action needed to set up the basis for models and databases that would ultimately be part of system specific guidelines related to each of the technical steps of the process. Due to the facts that the technical steps of the process are connected in terms of input-output and that they will require the competencies of FPEs, stakeholders, policy makers, experts in fire science, human behavior, structural engineering, toxicology and economics, it is already anticipated that this plan of action to be iterative.

\section{References}

1. A. Alvarez, B.J. Meacham, Towards an Integrated Performance-Based Design Approach for Life Safety Across Different Building Use Groups, in: Proceedings of the 12th International Interflam Conference, Nottingham, UK, 2010

2. E. Comeau, M. Puchovsky, NFPA Fire investigation report, Warehouse fire, New Orleans, Louisiana, March 21, 1996, National Fire Protection Association, 1996

3. J. Stern-Gottfried, G. Rein, Travelling Fires for Structural Design-Part I: Literature Review, Fire Saf. J. 54 (2012) $74-$ 85

4. V.A. Oven and N. Cakici, Modelling the evacuation of a high-rise office building in Istanbul, Fire Saf. J. 44 (2009) 115

5. SFPE, SFPE Engineering Guide to Performance-Based Fire Protection, 2nd edition, Society of Fire Protection Engineers, 2007

6. IFEG International Fire Engineering Guidelines, Australian Building Codes Board, Department of Building and Housing (New Zealand), International Code Council (USA), and National Research Council (Canada), 2005 edition

7. Firefighting News, Firefighters battle blaze at Myrtle Beach Convention Center, (available at: http://www.firefightingnews.com/article-us.cfm?articleID=102260, last checked 2012-09-20) 2011

8. V. Babrauskas, J.M. Fleming and B.D. Russel, RSET/ASET, a flawed concept for fire safety assessment, Fire and Materials 2010; 34:341-355

9. A. Alvarez and B.J. Meacham, 'Test bed' environment process for assessing the appropriateness of engineering tools to be used in performance-based design applications, Proceedings of the $9^{\text {th }}$ International Conference on PerformanceBased Codes and Fire Safety Design Methods, 20-22 June 2012, Hong Kong, 2012

10. The Independent, Hotel blamed as fire kills 78 at Thai beach resort, (available at: http://www.independent.co.uk/news/world/hotel-blamed-as-fire-kills-78-at-thai-beach-resort-1250217.html, checked 2012-09-20), 1997

11. J.S. Tubbs and B.J. Meacham, "Historic Events", chapter 2 of Egress Design Solutions - A Guide to Evacuation and Crowd Management Planning, John Wiley and sons, 2007

12. J. Yatts, Chicken Processing Plant Fires - Hamlet, North Carolina, and North Little Rock, Arkansas, Technical Report Series, United States Fire Administration, 1991

13. G. Ramachandran, Economics of Fire Protection, Routledge, New York, 1998

14. J.M. Watts Jr. and R.E. Chapman, in: P.J. DiNenno (Ed.), Engineering Economics, The SFPE Handbook of Fire Protection Engineering, fourth ed., National Fire Protection Association, Quincy, MA 02269, 2008 pp. 5/129-145. 


\section{ESTABLISHING A PLAN OF ACTION FOR THE DEVELOPMENT OF GUIDELINES IN SUPPORT OF THE FRAMEWORK FOR RISK-INFORMED PERFORMANCE-BASED FIRE PROTECTION DESIGN}

In order to apply the new PBFPD process to a specific system, FPEs would base their work upon guidelines written for each of the technical steps of the process and established for specific types of systems, since it has been demonstrated, in the previous chapters of this dissertation, that generic guidelines are at the origin of challenges when applying them to specific projects.

These guidelines for the specific systems are not as yet written as the required research still has to be carried out. Nevertheless, a plan of action (Fig. 5-1) applicable to any disruptive event type, including fire, is proposed in order to:

- collect and compile information from research associated with each step of the process. This information primarily comes from technical literature where general advances in all of the corresponding fields (fire research, human behavior, material engineering...) are applied to specific systems. At this stage, input from stakeholders is essential as they have the best knowledge of the characteristics of their systems (in terms of target definitions and attributes, descriptions of functional zones and utility zones and how the system performs in a daily basis). Some important results found for a particular step can be used as input for research associated with a subsequent step of the PBFPD process.

- establish guidelines or standards associated with each step of the process. The aim of the performed research gathering together stakeholders, fire protection engineering and experts in different fields, is to produce specific guidelines for each step and specific "building-occupant" systems. It is intended that if generic standards, guides and guidelines are already published or in progress in relation to a process step, they would be integrated within the "building-occupant" paradigm. It is also conceived that specific system guidelines may have a common aspects or comparison between different systems may be looked at. For example, in order to avoid the multiplicity of databases, a global database regrouping common attributes defined across multiple "building-occupant" systems may be created and consolidated with specific data. Methods, models and tools developed in a generalized and consistent manner to quantify fire events will also be considered in the guidelines and standards, as the most appropriate of them would be used to describe fire events occurring in such and such systems and would be detailed in the corresponding guidelines.

- thus, by "climbing the research to application/regulatory ladder", the FPE at the top the "ladder" will use guidelines and standards established for specific "building-occupant" systems, along with databases containing information and data relevant to the matter being considered. 


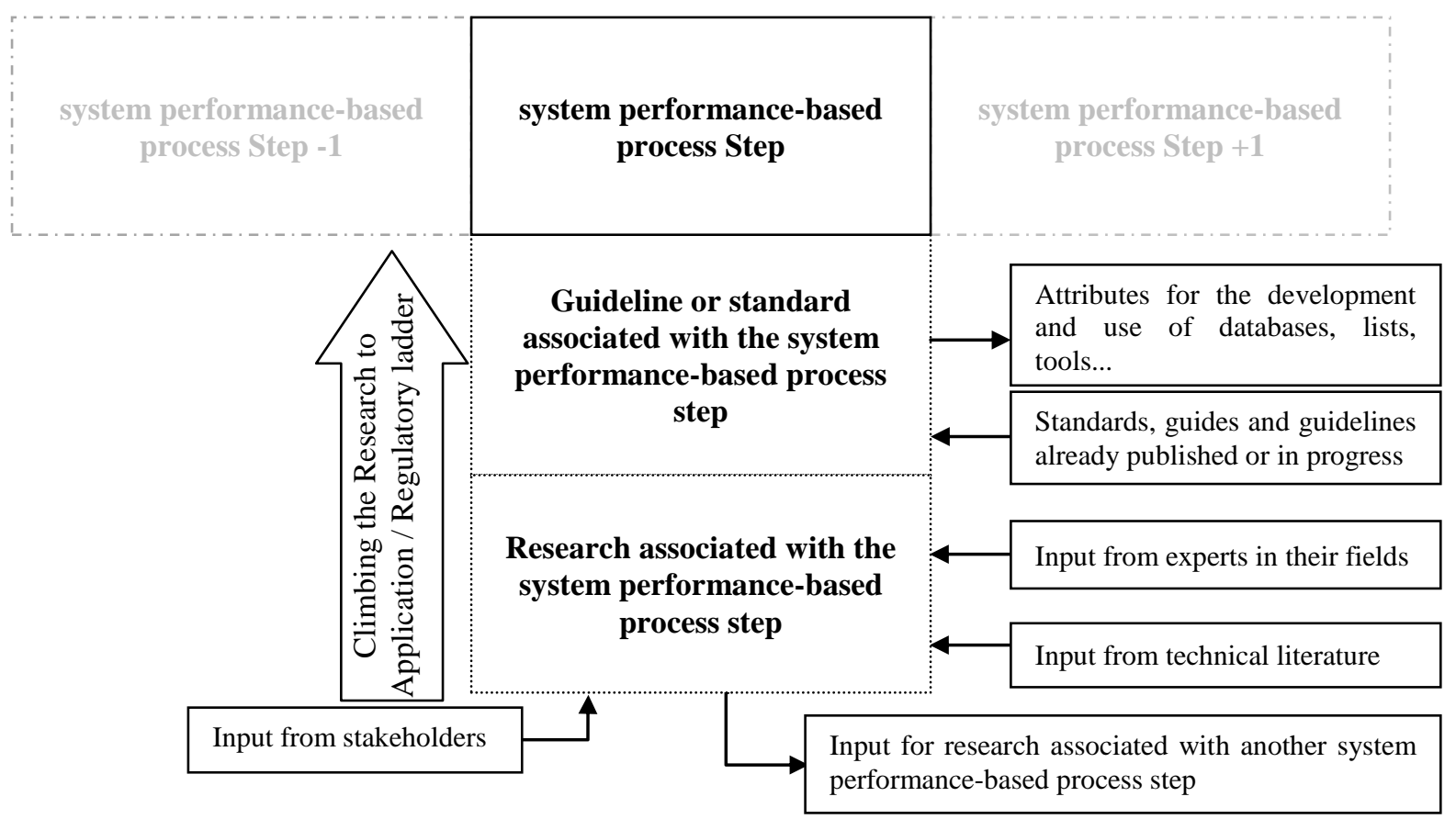

Fig. 5-1. Plan of action: "climbing the research to application/regulatory ladder"

This chapter proposes, for each technical step of the process, a plan of action including information that can already be extracted from past and current research. As well it outlines how I anticipate the future guidelines and standards related to the application of the new PBFPD process will be composed and structured. This plan of action, illustrated with Fig. 5-1, is planned to serve as the template of a decision-making process for the creation of the corresponding guidelines and standards for each step of the system performance-based process.

\subsection{The need for an iterative plan of action}

To perform, the PBFPD process presented in the previous section for a particular "building-occupant" system, FPEs need all the information related to the problem definition, that is to say the characteristics of the "buildingoccupant" system, including the nature of the different targets which determine the overall performance of the system. In order to perform the six different steps of the risk-informed PBFPD process, important information from the stakeholder has also to be collected, for each step of the process, as shown in Fig. 5-2. 


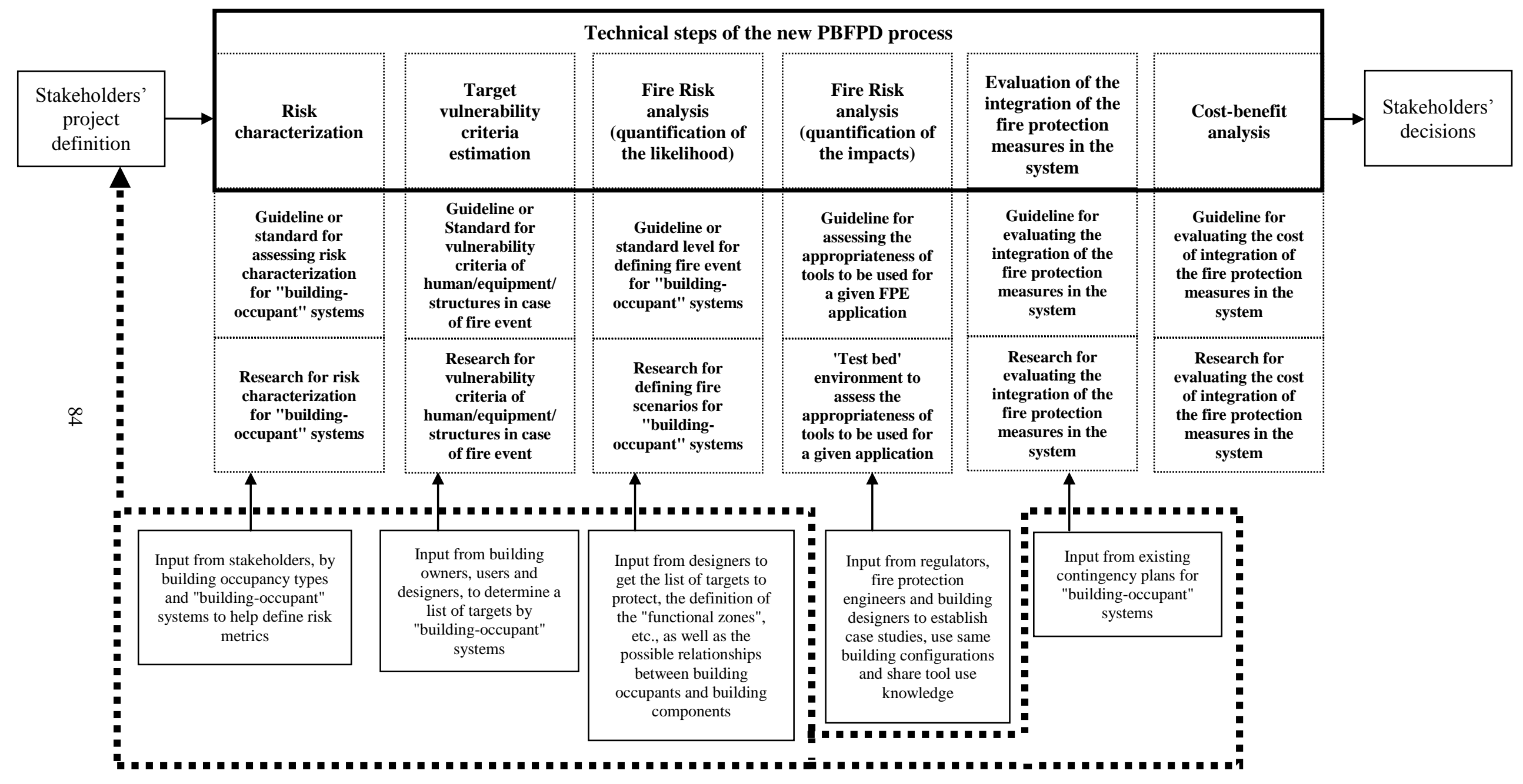

Fig. 5-2. Influence of stakeholders' input on the PBFPD process 
Input from the stakeholders is necessary to apply the research to "building-occupant" systems of interest, to canalize this research to obtain the corresponding guidelines in the shortest times possible. For example, the application of decision-making processes similar to that presented in Fig. 5-1 demonstrate that it has been successful in overcoming technical and political obstacles in risk-informed performance-based design processes concerning hazardous facilities. These applications namely concern industrial plants in France [1] and nuclear power plants in the USA [2,3]. Bringing all the aforementioned participants together allowed in the French example the shift of the regulation from a prescriptive method related to the prevention of the worst case scenarios and land management to a probabilistic risk assessment of all the possible scenarios (fires, explosions and toxic releases) having consequences outside of a considered industrial plant. Dedicated groups were organized according to the type of activity and hazardous products (e.g. chlorine fabrication, LPG (Liquefied Petroleum Gas) storage facilities, oil refineries). The US example was dedicated to the effects of potential fires on the safety of the pieces of equipment which maintain the nuclear core in a safe state.

The French example concerned the safety of the population located outside the plant and the environmental impact of the industrial plant. The evaluation of the consequences of a fire in a populated building requires the evaluation of both the fire effects (temperature increase, production and spread of smoke and toxic effluents) and the evacuation process (when people need to evacuate the building to a safe place). This latter, complex but essential evaluation has not been considered in the two aforementioned studies so it is not possible to directly transfer their results to the built environment. It should be noted that communication between research groups dedicated to each step of the process would be necessary because of the interconnections between the research on a specific step as illustrated in Fig. 5-3. Thus, the process needs to be iterative since output from some research on specific steps is necessary input for research on other steps in the process.

Besides, the needed research is both generic and applied:

- it is generic regarding research concerning the tools used in any step which is currently producing more elaborated tools that can be used in the PBFPD process. Advances in fire protection engineering tools is, of course, my main concern when looking at tools which are used to quantify the effects of a fire, but I will also be looking at tools which can help and speed up the process when dealing with statistics, risk analysis, and cost benefit analysis.

- it is applied regarding research concerning the data which would serve as input data for the models and tools. 


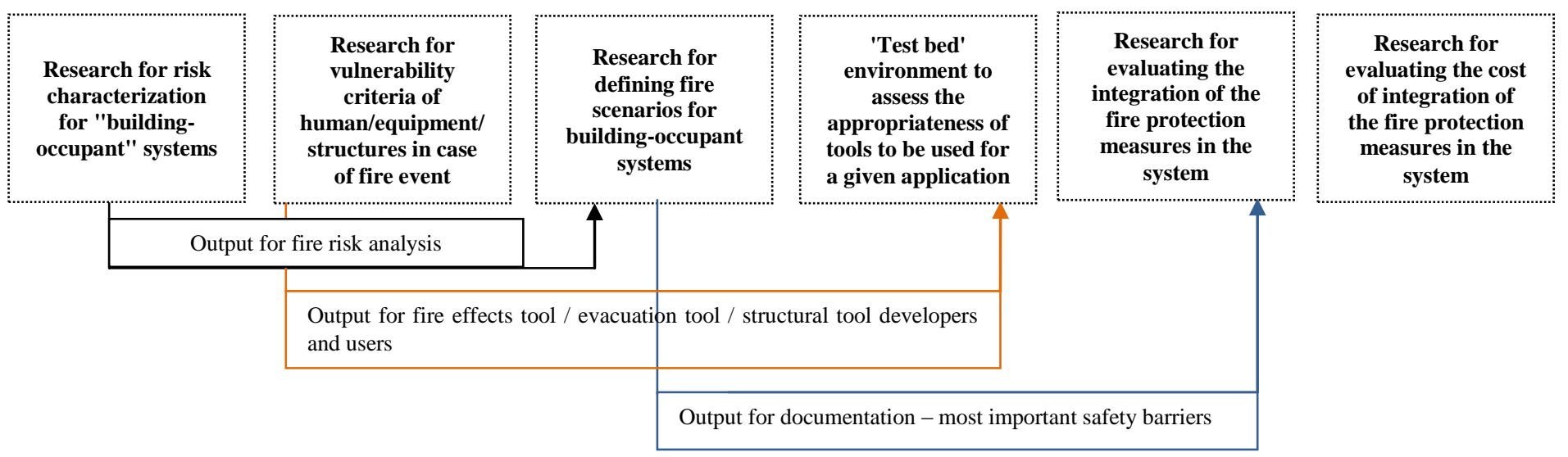

Fig. 5-3. Interconnections between the step researches of the proposed PBFPD process

Regarding the validation of tools, since each of the "building-occupant" system of interest constitutes a microdomain of analysis and study, it will not be necessary to have the tools validated on a macro-scale (i.e. all their possible domains of application) but around each established micro-domain, and this is the case for all of the tools used in the different steps of the process. The same concept can be applied for data research: small groups of experts dedicated to the study of particular "building-occupant" systems can work a lot more efficiently than researchers looking to embrace all the possible data distribution for the whole building environment.

In consequence, because the generic problem is broken into manageable and well defined pieces, i.e. the "buildingoccupant" systems, the iterations needed to conduct the research and establish the guidelines would be much quicker than trying to solve the engineering problem in a generic way. Besides, since every system has its own characteristics, not only the aforementioned technical challenges would be solved more quickly, but also the risk characterization components of this process would be better accepted as risk mechanisms (risk control, risk aversion, etc.) are not perceived the same way by stakeholders dealing, for example, with hospitals, schools or high-rise office buildings.

At last, in the USA, the National Fire Protection Association organizes committees in order to establish standards related to requirements and recommendations related to fire protection of specific building types. For example, the technical correlating committee on health care facilities was created to write the NFPA 99 Standard for Health Care Facilities [4] and it gathered members from health care systems, academics, US departments, fire protection consulting companies and fire protection equipment manufacturers. Organizing similar groups or taking advantages of these committees would also benefit the development of the different guidelines of the risk-informed PBFPD process. 


\subsection{Importance of the involvement of the stakeholders for establishing validation domain of models needed at each step of the PBFPD process}

In the past decades, models has been developed in a generic form because there was a tremendous need for fundamental research to describe and quantify all the different phenomena involved in a fire engineering evaluation, from the effects of the fire itself, to the building occupant process and the response of the building structure. Validation of these "research" models, as opposed to "engineering" models inscribed in codes and standards, has been and still remains a central question in the acceptance, by the authorities having jurisdiction, of engineering reports using the performance-based option of building codes [5]. Due to the complexity of the different types of aforementioned phenomena, scientists developed semi-empirical models based on a theoretical approach of the phenomenon completed by a "tuning" of these theoretical models with empiric correlations or factors. Thus, the contours of the validation domains of these semi-empirical models mainly correspond to the boundaries of the experimental tests that served to "tune" the models. It should be noted that setting up experiments for determining validation domains and thereafter increase them is a costly enterprise in terms of time and resources. Besides, as some empirical parameters are model dependant, experiments especially set up for assessing parameter values for one particular model may not be valuable or simply usable for increasing the validation domains of other models dealing with the same phenomenon as the other models may also have their own model dependant parameters which would have required different or additional specific experimental setting up.

Involvement of the project stakeholders is also crucial, not only for the execution of the political steps of the PBFPD process when this process will be applied to a particular project but also during all the process required to establish the corresponding step guidelines of the PBFPD process. This involvement is indeed essential because the stakeholders are the ones who know best the system they have designed and that they will ultimately use on a daily basis. The stakeholders know how the system behaves in a daily basis so they are able to describe, in details, the corresponding characteristic of the building components as well as the characteristics of the building occupants of the their system.

Benefits of having stakeholders participating at the research stage of each path include a better use of research as their data identifier input (i.e. targets' characteristics, risk metrics, functional zones, contingency plans...) would drive the need to obtain research data pertinent and if possible directly applicable all along the proposed PBFPD process. As a result of this participation at the research stage, the guidelines would contain if not all data values, processes that could lead to collect data while minimizing uncertainties and the use of engineering judgment. 


\subsection{Application of the plan of action to obtain the necessary guidelines to perform each step of the new PBFPD process}

As illustrated in Fig. 5-2, six different technical steps are required to be performed by the fire protection engineer.

This section briefly presents a possible way to elaborate these guidelines from research, past, present and future. Each guideline elaboration process is derived from the one presented for a risk-informed approach (Fig. 5-1), as each step requires the participation not only of FPEs and scientists, but also public officials and interested stakeholders.

\subsubsection{Proposed path of action to quantify Step 1: risk characterization}

\subsubsection{Description of the risk characterization step and corresponding path of action}

Risk characterization is the most important step of the process, as it defines and frames the engineering problem to be solved by the FPEs.

Within my "building-occupant" system paradigm described in detail in Chapter 3 of this dissertation, the system stakeholders define the main characteristics of their existing system or project, in the political initial step of the PBFPD process. They are concerned about the overall performance of their system, which is dependant of the "chronic objectives" associated with the system and they would like to know how this performance is affected in the case of fire events. The performance of the system is a function of the activity of the system "targets".

Since targets are defined as the actors of this performance, it is essential that the FPEs collect the list of these targets from the system stakeholders. The stakeholders' view of the fire problem is on the long term; in other terms fire events are disruptive events among many susceptible to occur during the lifespan of the system. The FPEs' view of the fire problem is focused on the fire disruptive events, how often they can occur and with which effects they have on the system targets.

The risk characterization step can be seen as the transfer of this problem, from the stakeholders' perspective to the fire protection engineer's perspective. Based on the stakeholders' list of system targets, FPEs have to define risk metrics which associate the frequency of the fire events with their effects on the system targets, as well as a quantification of these risk metrics.

I estimate that guidance related to current PBPFD processes focuses too early on the fire events for which safety goals and objectives are established upfront, leading to a potential disconnection between the stakeholders' overall concerns and the FPE specific fire-oriented analysis. The Risk characterization step is not only aimed at avoiding this disconnection at the start of the new PBFPD process (i.e. solving the wrong problem), but it is also useful at the 
end of the process when the FPEs communicate their results to the stakeholders as they can easily "transfer back" these results into the stakeholders' perspective.

The corresponding path to quantify the risk characterization step of the PBFPD process is illustrated in Fig. 5-4, and detailed in the following paragraphs.

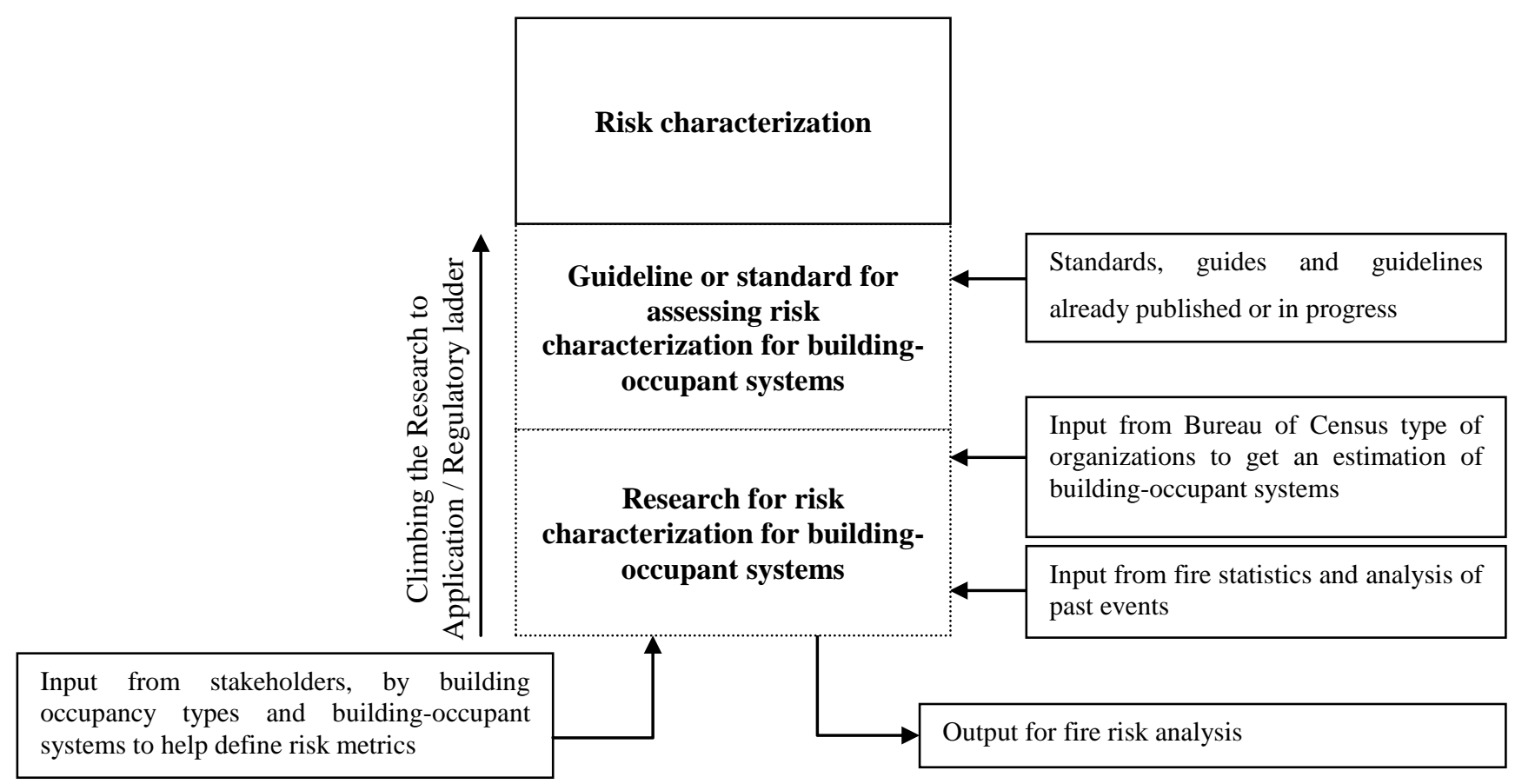

Fig. 5-4. Proposed path to risk acceptance characterization

\subsubsection{Research to be carried out for "Risk characterization" Step}

At a research level, stakeholders involved in similar "building-occupant" systems would help the fire protection engineer define the metrics that corresponds the closest to their own view on the performance of the systems.

Since these metrics are tied to the systems they represent, a possible formulation for these metrics is a fraction where the numerator deals with the fire events in a defined period of time and the denominator describes a relevant parameter of the system. Different objectives may be considered by the different stakeholders. All stakeholders are concerned by life safety so the metric numerator should include parameters dealing, for example, with annual deaths and injuries caused by fires affecting the considered systems; the denominator would include some information relevant to the activity of the occupant in the considered building. For property protection, the numerator of the corresponding metric could include parameters describing, for example, the amount of damage due to fires, including direct and indirect fire damage. For business interruption, the metric numerator could include the number of days lost in production due to fire events in similar industrial systems. 
Within the presented process, I consider that risk characterization may be assessed on two different set of data:

- fire statistics, which provide fire frequencies and damage estimation,

- census data related to defined "building-occupant" systems, which provides information of the number of systems within the same category.

In the USA, the National Fire Protection Association [6] and the Fire Administration [7] periodically publish fire statistics. Special reports are also published by building occupancy types [8]. Alvarez and Meacham [9] give examples of US census database consultation, for different system categories.

Within the "building-occupant" system paradigm, stakeholders identify targets and risk identification is carried out to figure out how fires can affect the targets and lead to a change of the system performance. It should be noted that several authors already applied this way of looking at fire statistics and tried to determine which metrics were the most appropriate to represent fire risk and communicate concerning the policy levels of this risk for different systems.

Examples from the technical literature showed that data, even if not "complete and perfect" [8,10-13], can be associated and treated by system category. Thus, Kobayashi and Nozaki [14] looked at different Japanese sources, which classified non residential buildings in several categories. Table 5-1 presents their findings related to commercial buildings, as they defined four different classes based on floor area and number of stories. Fig. 5-5 presents the corresponding fire risk with an estimation of the damage area as a function of annual exceedance of probability.

Table 5-1. Calculations conditions for example risk curves [14]

\begin{tabular}{|c|c|c|}
\hline Classification & Median floor area $\left(\mathrm{m}^{2}\right)$ & Median Number of Stories \\
\hline Group "H" & 36,597 & 10 \\
\hline Group "LL" & 31,124 & 5 \\
\hline Group "LM" & 11,239 & 4 \\
\hline Group "LS" & 2,148 & 2 \\
\hline
\end{tabular}




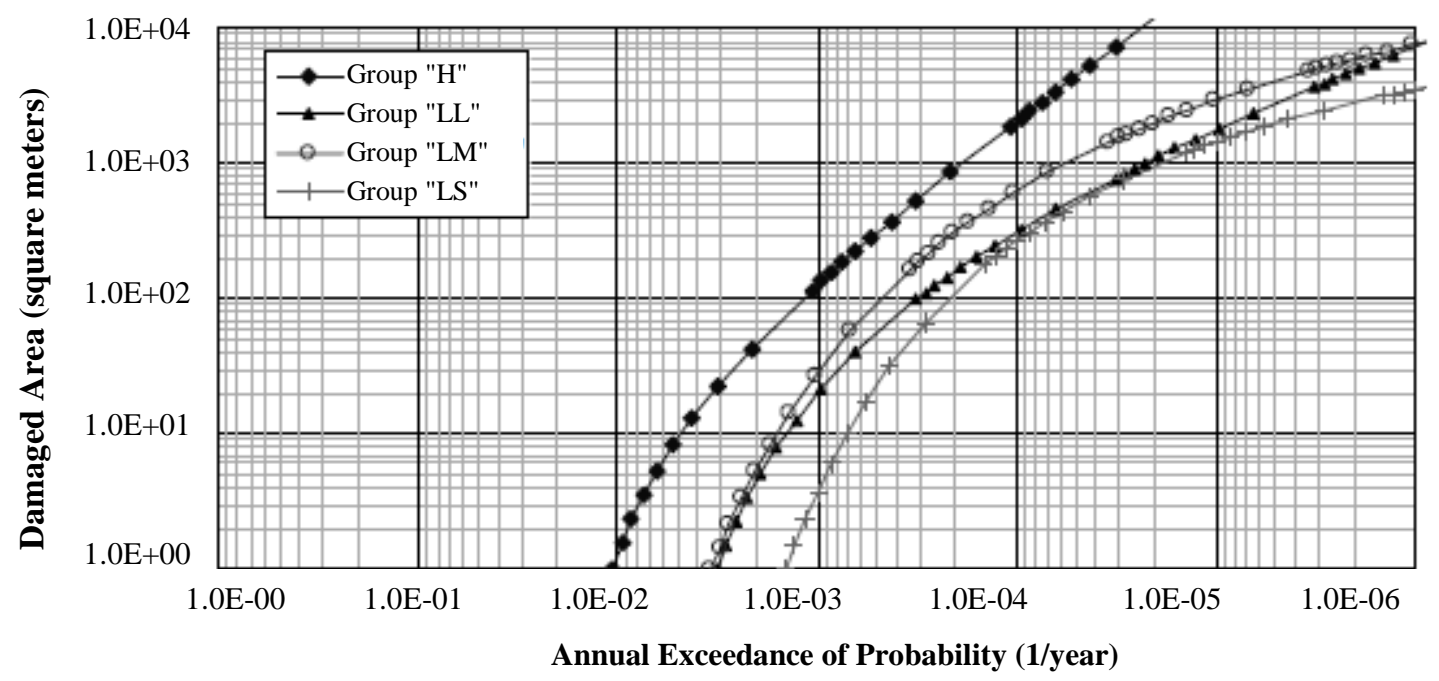

Fig. 5-5. Example of fire risk curves for commercial buildings [14]

Risk matrix or fire risk curves such as the one presented in Fig. 5-5. can be established for "building-occupant" systems, based on the corresponding fire statistics which describe the appropriate metric for each objective considered by the project stakeholders. For example, Tsujimoto [15] presented fire risks to Japanese occupants in residential buildings, hospitals and hotels from 1969 to 2000, as annual deaths per $10^{5}$ users' year stays in each kind of place with the corresponding metrics:

- for residential buildings: $\frac{\text { annua deaths by residentia ires }}{\text { population }}$

- for hospitals: $\frac{\text { annua deaths by hospita ires }}{\text { tota number of sickbeds in apan) } \mathrm{x} \text { annua used rate) }}$

- for hotels: $\frac{\text { annua deaths by hote ires }}{\text { annua tota number of hote guests }}$

Based on these metrics, he presented the death risk a person takes at one night in each place (Fig. 5-6).

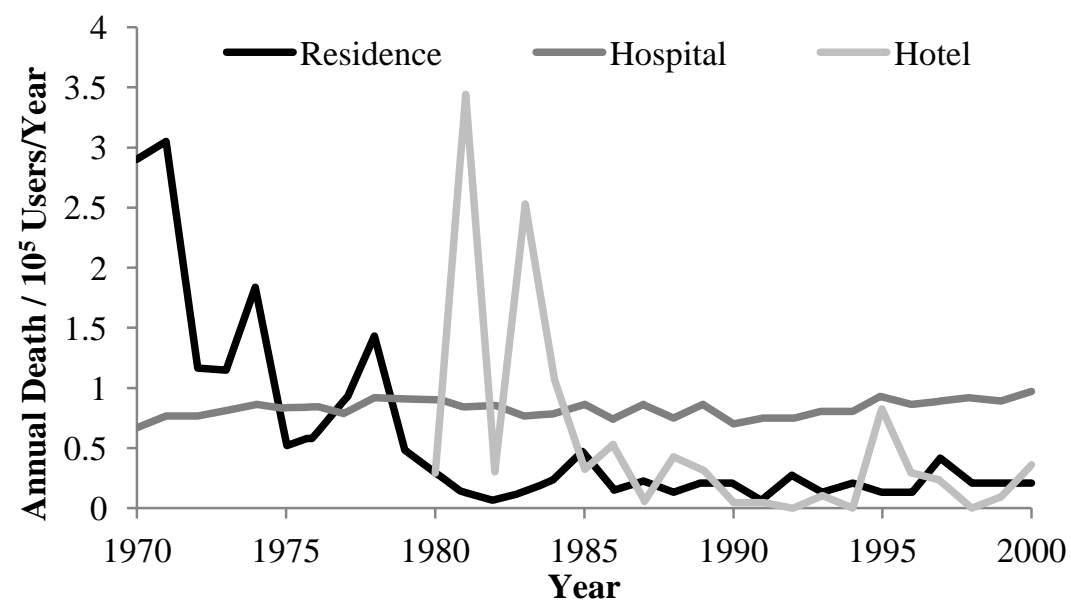

Fig. 5-6. Death risk trends in Japanese residential buildings, hospitals and hotels between 1969 and 2000 [15] 
Particular care should be taken when aggregating buildings into a similar category. This situation is not only due to the evolution with time of building characteristics (e.g. open space office floors versus compartmented office floors) but also due to the evolution with time of building code prescriptive requirements regarding fire safety. For example, Tsujimoto [15] also looked at establishing a correlation between fatalities in hospitals and the number of beds with or without sprinklers (Fig. 5-7), mainly between 1960 and 2000. He listed the regulatory changes concerning the installation of sprinkler systems in Japanese hospitals during the same period (Table 5-2) and established a relation between fire death and the number of beds with and without sprinkler estimated by the change of fire code summarized in Table 5-2 and statistics about hospitals.

Table 5-2. Transition of Requirement for Sprinkler Installation of Hospital (Fire Code in Japan) [15]

\begin{tabular}{|l|l|}
\hline 1961.4 & patients room over $4^{\text {th }}$ floor $\geqq 1500 \mathrm{~m}^{2}$ \\
\hline 1967.7 & $\begin{array}{l}4^{\text {th }} \text { floor to } 10^{\text {th }} \text { floor } \\
\text { floor area more than } 100 \mathrm{~m}^{2} \text { over } 11^{\text {th }} \text { floor }\end{array}$ \\
\hline 1973.6 & $\begin{array}{l}\text { total floor area is over } 6000 \mathrm{~m}^{2} \text { except one-story hospital } \\
\text { over } 11^{\text {th }} \text { floor } \\
\text { floor area more than } 1000 \mathrm{~m}^{2} \text { which floor is underground or without window }\end{array}$ \\
\hline 1974.6 & retroactive application to existing building \\
\hline 1988.4 & total floor area is over $3000 \mathrm{~m}^{2}$ except one-story hospital \\
\hline
\end{tabular}

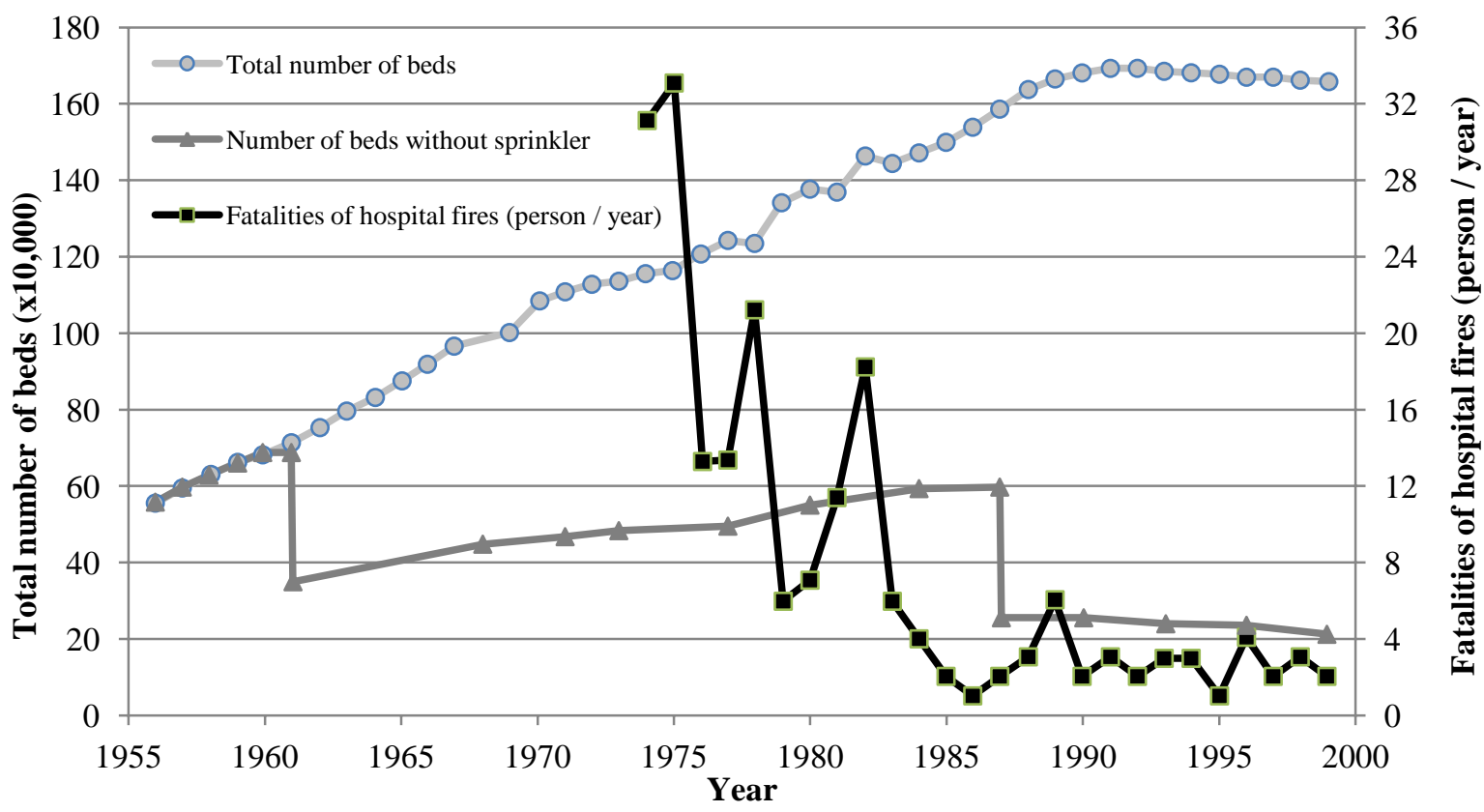

Fig. 5-7. Correlation between Fatalities in Hospital and Number of Beds [15] 
It should be noted that some information output collected while performing research for the risk characterization Step (e.g. information related to the characterization of fires and of the considered systems) can be used as input for the next steps related to fire risk analysis (fire likelihood and fire consequence evaluation). For example, while assessing information about fire statistics and past fire events, elements of information related to scenarios, fire ignition, fire propagation in terms of frequency and intensity of damage should also be collected. Also, within the "building-occupant" system paradigm, characteristics of the different types of systems should also be collected so to have more information about the potential targets located inside the different parts of the systems.

The aforementioned examples collected in the technical literature appear to be almost applicable within the risk characterization step of the new PBFPD process. The methods followed by the different authors would also serve as a basis for the risk characterization guidelines and standards.

\subsubsection{Establishing guidelines or standards for assessing risk characterization for "building-occupant" systems}

Standards, guides and guidelines dedicated to fire risk assessment or containing elements dealing with risk assessment are already published or in progress $[16,17]$. Guidance provided by these documents is still generic but contains some useful elements to be adapted in the new "building-occupant" system paradigm.

A major concern regarding the use of data for assessing risk characterization for "building-occupant" systems comes from the different origins of the needed data. For example, in the USA, the classification of buildings is not the same when established by:

- the National Fire Protection Association, which deals with fire statistics and proposes fire protection standards,

- the International Code Council, which elaborates building codes,

- the architects, who design buildings according specific functions,

- the Bureau of Census, which codifies business buildings according their activities.

Due to the fact that each of the corresponding building classifications were elaborated according to specific objectives, it would be quite difficult to look for a homogenous taxonomy across so many fields. Nevertheless, within the "building-occupant" system paradigm, guidance is provided by system category. In consequence, it is imperative that the system be well defined for each PBFPD step guidance and especially for the first step, which is the one defining the engineering problem to be solved.

Guidelines or standards for assessing risk characterization for "building-occupant" systems shall clearly state the definition of the system concerned by these guidelines or standards.

Once the system is well defined, the guidelines or standards related to the new PBFPD process Step 1 would contain information related to well defined "building-occupant" systems, including the definition of the system targets and 
their associated risk metrics for relevant objectives (life safety, property protection, business continuity...) as well as the quantification of these risk metrics, or at least a way to obtain this quantification, as again countries, regions and even cities may have been developing their own databases regarding fire safety and building/person census.

\subsubsection{Using the guidelines for performing Step 1 in a PBFPD process}

Once the guidelines related to Step 1 have been published for well defined "building-occupant" systems, the FPE can use its guidance for a project covered by the corresponding guideline as a means:

- To determine the targets which define the performance of the system according to the stakeholders, and

- To document how the fire risk associated with these targets is taken under consideration through the definition and possible quantification of appropriate risk metrics.

\subsubsection{Proposed path to quantify Step 2: Target vulnerability criteria estimation}

\subsubsection{Description of the target vulnerability criteria estimation step and corresponding path of action}

In Step 1 of the new PBFPD process, FPEs collected the targets which contribute to the system overall performance. Then, in Step 2, for each considered targets, FPEs have to quantify how these targets are affected by both direct and indirect effects of fire events, events involving a fire and defined between two "chronic" states of the system.

As the new engineering process is target oriented, it is essential to get the metrics allowing the estimation of the potential vulnerability of the targets. Vulnerability criteria metrics would have to include:

- Typical criteria related to fire impacts to humans (due to thermal threat, toxic threat and loss of visibility which impedes evacuation),

- Vulnerability criteria related to evacuation behaviors,

- Vulnerability criteria related to indirect fire threat to people,

- Vulnerability criteria related to safety equipment, building contents (e.g. for heritage preservation) and

- Vulnerability criteria related to the use of fire protection measures (sprinkler, fire fighting) on building contents and systems.

These vulnerability criteria have to be collected and the process by which the damage is assessed has to be a result of an agreement within the scientific community not only involving fire protection engineers but also:

- Toxicologists, psychologists, etc. when the targets are related to the life safety objective, 
- Operators, electronics engineers, etc. when the targets are related to the business continuity objective,

- Structural engineers, etc. when the targets are related to the property protection objective.

The corresponding path to quantify the target vulnerability criteria estimation step of the PBFPD process is illustrated in Fig. 5-8, and detailed in the following paragraphs.

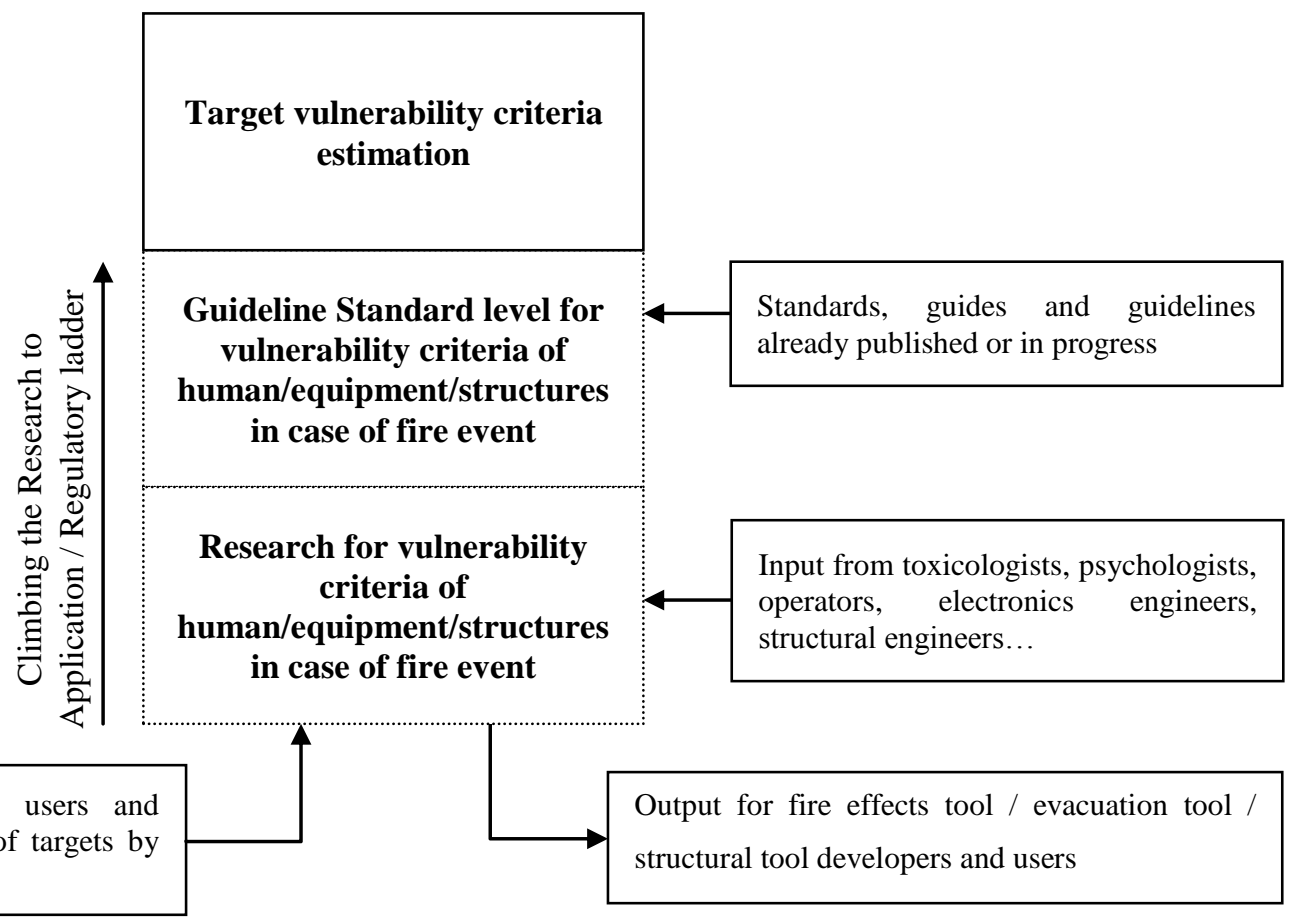

Fig. 5-8. Proposed path to target vulnerability criteria estimation

\subsubsection{Research to be carried out for estimating vulnerability criteria}

Methods of determining vulnerability criteria metrics as well as collecting and assessing collegially validated "technical" values to these criteria differ from the "performance criteria" presented in current PBFPD processes where they are prescribed by regulations or established via a political agreement among the project stakeholders. These prescribed values do not present the rationale behind them so it is quite difficult to validate their application to specific "building-occupant" systems (Cf. Chapter 2 of this dissertation).

Concerning the role of the stakeholders in that matter in the proposed PBFPD process, it should be noted that building owners and users are still actively consulted in this Step research as they are the most involved parties to determine the nature of the targets present in their "building-occupant" systems. Standards such as the one from ISO TC92 / SC3 [18] would contribute both the needed data and the worldwide consensus for human targets under fire 
threat. The input from building designers is also required, from the research stage to the guideline/standard final stage, in order to define the users' domain of application. It should be noted that some output from this task research could be sent to fire effects tool / evacuation tool / structural tool developers and users in order for them to get the target vulnerability criteria metrics considered in the tools.

\subsubsection{Establishing guidelines or standards for assessing vulnerability criteria of human/equipment/structures in case of fire events}

As mentioned above, vulnerability criteria are engineering values, collected from experiments and models. Fires in structures generate heat, toxic and irritant products, lower visibility, damage the structure which can lead to falling objects over escaping building occupants and emergency responders. Building occupants are very different populations across the building occupancy spectrum [9] and they are also different from the emergency responders in terms of how they can withstand a fire event. Due to the complexity of these phenomena to take into consideration, it seems that the first tasks to perform to create guidelines or standards are:

- To look at defined "building-occupant" systems and collect the targets which are considered by the corresponding interested parties or stakeholders, in terms of nature (i.e. occupants, piece of equipments, contents, etc.) and distribution (e.g. percentage of population easily affected by fire effects due to heath status);

- To analyze the possible ways of damaging these targets, during the fire event and in both short term and long term periods;

- To quantify these damages and the reaction of the different targets in terms of activity loss affecting the overall performance of the system.

\subsubsection{Using the guidelines for performing Step 2 in a PBFPD process}

While assessing the performance of a "building-occupant" system, the fire protection engineer will use the guidelines designed for Step 2 "target vulnerability criteria estimation" in order to determine the nature of the criteria (metrics determination) and to use validated values of these criteria that are relevant to the examined system (metrics evaluation).

\subsubsection{Proposed path to quantify Step 3: Fire risk analysis (quantification of the likelihood)}

\subsubsection{Description of the fire risk analysis (quantification of the likelihood) step and corresponding path of action}

In a deterministic approach, the current PBFPD processes do not specify detailed procedures on how to select fire design scenarios or they provide a list from where the FPE and the stakeholders can "pick up" and finally agree on the ones to use. Thus, the resulting fire design scenarios fell to consider the chronic use of a building, are focused on 
the fire event instead of being target oriented and miss the importance of the recovery phase. In this step of the proposed PBFPD process, event trees are elaborated in order to describe quantitatively the different fire scenarios, not only characterizing the events between ignition and extinguishment, but also including the procedures to go back to a new "chronic" state of the "building-occupant" system. Fault trees are also established in order to characterize all the different scenarios leading to target damage, so as to capture the indirect threats to the targets. Fire risk models are used in this process step to help calculate the scenario likelihoods.

Because the fire safety analysis is target oriented, input from designers is required to define the targets to protect from fire threat, the definition of the "functional zones", support systems, etc., as well as the possible relationships between the building occupants and the systems (i.e. life supporting systems for patients in Intensive Care Units in hospitals). Quantification of the trees notably requires ignition frequencies defined by functional zones of interest as well as the reliability records of the fire prevention and protection measures, also called "safety barriers" in this process. Analysis of past events, including investigations of major events would be collected and made available in a database. Life safety being a common objective among all stakeholders, this analysis is aimed at providing in fine detail guidance so that when using the proposed PBFPD process, a FPE would use this guidance to demonstrate that a considered project would have the adequate barriers to prevent such life-threatening events from occurring with the lowest probability practically achievable. Once this database is detailed enough and this analysis is done for lifethreatening events, regulators could set up this value (or class) of probability, which could become an upfront performance criteria at the start of the PBFPD process.

Besides, it is also expected that an output of this task research would be dedicated to implement building safety documentation, with at least the effects and the maintenance of the most important fire protection measures called "safety barriers".

The corresponding path relative to the PBFPD process step quantifying the impacts of fire events is illustrated in Fig. 5-9, and detailed in the following paragraphs. 


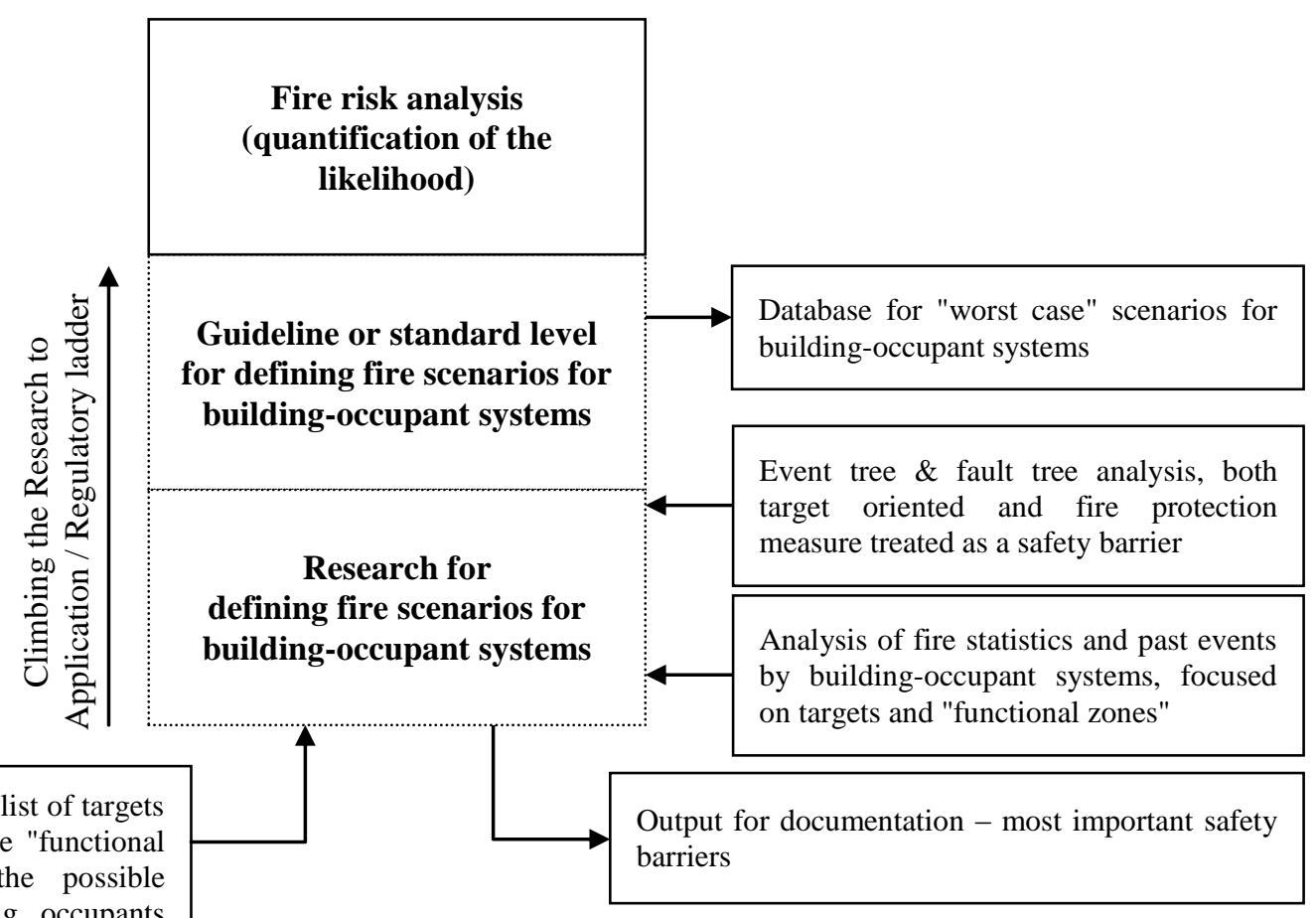

Input from designers to get the list of targets to protect, the definition of the "functional zones", etc., as well as the possible relationships between building occupants and building components

Fig. 5-9. Proposed path to the quantification of the likelihood of fire events

\subsubsection{Research to be carried out for the process step related to the quantification of the likelihood of fire events}

Table 5-3 below is an example of data presented in the NFPA reports of US fires in selected occupancies [8]. This data categorizes the number of casualties and injuries as well as the direct property damage for different extents of flame damage. A discrepancy appears between the fires that are related to the life safety objective as their maximum extent is the room of fire origin and the fires that are related to the property damage objective as the more the fire extents, the more damage it causes, which could indicate that the design fire scenarios for the life safety objective may not be the same for other business or property oriented objectives [9].This information reinforces the fact that the fire risk analysis needs to be target oriented in order to determine the appropriate scenarios for each of the considered targets relevant to the different stakeholders. 
Table 5-3. Structure Fires in Health Care Facilities, Excluding Nursing Homes by Extent of Flame Damage [8]

\begin{tabular}{|l|c|c|c|c|c|c|c|c|}
\hline \multicolumn{2}{|c|}{ Extent of Flame Damage } & \multicolumn{2}{|c|}{ Fires } & \multicolumn{2}{c|}{$\begin{array}{c}\text { Civilian } \\
\text { Deaths }\end{array}$} & \multicolumn{2}{c|}{$\begin{array}{c}\text { Civilian } \\
\text { Injuries }\end{array}$} & \multicolumn{2}{c|}{$\begin{array}{c}\text { Direct Property } \\
\text { Damage (in } \\
\text { Millions) }\end{array}$} \\
\hline Confined or contained fire & 560 & $18 \%$ & 0 & $0 \%$ & 8 & $9 \%$ & $\$ 0.1$ & $0 \%$ \\
\hline Confined to object of origin & 1,930 & $61 \%$ & 0 & $0 \%$ & 29 & $33 \%$ & $\$ 3.8$ & $18 \%$ \\
\hline Confined to room of origin & 510 & $16 \%$ & 1 & $100 \%$ & 44 & $51 \%$ & $\$ 4.2$ & $20 \%$ \\
\hline Confined to floor of origin & 60 & $2 \%$ & 0 & $0 \%$ & 1 & $1 \%$ & $\$ 2.1$ & $10 \%$ \\
\hline Confined to building of origin & 90 & $3 \%$ & 0 & $0 \%$ & 5 & $6 \%$ & $\$ 10.3$ & $49 \%$ \\
\hline Extended beyond building of origin & 10 & $0 \%$ & 0 & $0 \%$ & 0 & $0 \%$ & $\$ 0.7$ & $3 \%$ \\
\hline Total & $\mathbf{3 , 1 5 0}$ & $\mathbf{1 0 0 \%}$ & $\mathbf{1}$ & $\mathbf{1 0 0 \%}$ & $\mathbf{8 7}$ & $\mathbf{1 0 0 \%}$ & $\mathbf{\$ 2 1 . 3}$ & $\mathbf{1 0 0 \%}$ \\
\hline
\end{tabular}

\subsubsection{Establishing guidelines or standards for assessing the quantification of the likelihood of fire events}

Step 3 guidelines will be established for specific "building-occupant" systems, and more precisely for the different targets considered by the stakeholders when defining the performance of the systems, as the risk analysis is targetoriented in this study paradigm. They will contain results from fault tree analysis, where the outcomes would be presented, not only with the evaluation of the fire scenario likelihoods, but also with the degree with which the different targets are affected by the fire scenarios. Scenario grouping or scenario clustering have been considered in the current PBFPD processes in order to have a manageable set of scenarios which could represent most of the possible fire scenarios which could occur in a considered project. Nevertheless, this grouping is still achieved project by project and it still requires the agreement of the different stakeholders.

Concerning industrial facilities, Barry [19] proposes different ways to group or cluster scenarios. The categories listed below have been adapted from industrial facilities to common buildings:

- by exposure category, considering categories such as localized exposure, moderate exposure (limited to a defined area) and major exposure (large effect zone). It should be noted that NFPA also provides fire statistics by exposure categories, as presented in Table 5-3 of this chapter,

- by contributing factor breakdown to the fire events, considering "failures" or "potential weak links such as human error", failures of fire protection technical measures (automatic detector, automatic fire suppression system...) or failures of fire protection managerial measures (locked egress doors...). This categorization could be valuable when assessing the most important fire protection measures for a considered "building-occupant" system, 
- by hazard. In industrial plants, there are more issues than just the fire hazard to consider (explosion, release of toxic material). In common buildings, and in the present research, fire is the only hazard to be considered. This categorization could be used when different types of technological hazards are examined for "buildingoccupant" systems.

As within this "building-occupant" system paradigm, the risk analysis is target oriented, fault trees would also be considered in order to determinate not only the direct effects of fire events on targets but also the indirect effects of fire events (e.g., fires affecting life support system of a patient in an intensive care unit but not spreading in the vicinity of the patient).

A possible outcome for the guidelines to be established for assessing the quantification of the likelihood of fire scenarios would be the creation of databases for "worst case" scenarios for specific "building-occupant" systems, based on relevant investigation reports.

\subsubsection{Using the guidelines for performing Step 3 in a PBFPD process}

These guidelines are linked to a database of investigation reports on catastrophic fire events that happened in systems similar to the one examined by the fire protection engineer so the FPE can verify the examined system is provided with safety barriers which would prevent such catastrophic events from occurring in it. The fire protection engineer also uses the guidelines to select fire protection measure sets which are able to maintain the overall performance of the studied "building-occupant" system, as high as possible during fire events.

\subsubsection{Proposed path to quantify Step 4: Fire risk analysis (quantification of the impacts)}

\subsubsection{Description of the fire risk analysis (quantification of the impacts) step and corresponding path of action}

Current PBFPD processes include or reference calculation methods or tools that can be used to assess the consequences of the fire, with an emphasis on the estimation of the fire effects. Challenges related to the use of tools notably arise from the lack of validation of these tools, the "user effect" and the availability and estimation of the input data for all these tools. In this step of the proposed PBFPD process, fire effects tools, evacuation tools, structural response tools are used to estimate the consequences of fire scenarios for the considered targets. In spite of the tremendous amount of research and development related to the tools, they remain research tools and the results applied to fire engineering still nowadays require some engineering judgment. Use of engineering judgment will never go away. However, it is proposed that better guidance can be developed to help provide better uniformity in application and engineering analysis. To address this, it has been decided to create a 'test bed' environment in order to assess the appropriateness of engineering tools to be used for a given application. This environment, which implies the participation, not only of researchers who develop the tools, practitioners who apply them in an engineering environment, but also academia who can perform long term studies and stakeholders who are concerned by the validity of the tools to solve the engineering problems. 
The corresponding path relative to the PBFPD process step quantifying the impacts of fire events is illustrated in Fig. 5-10, and detailed in the following paragraphs.

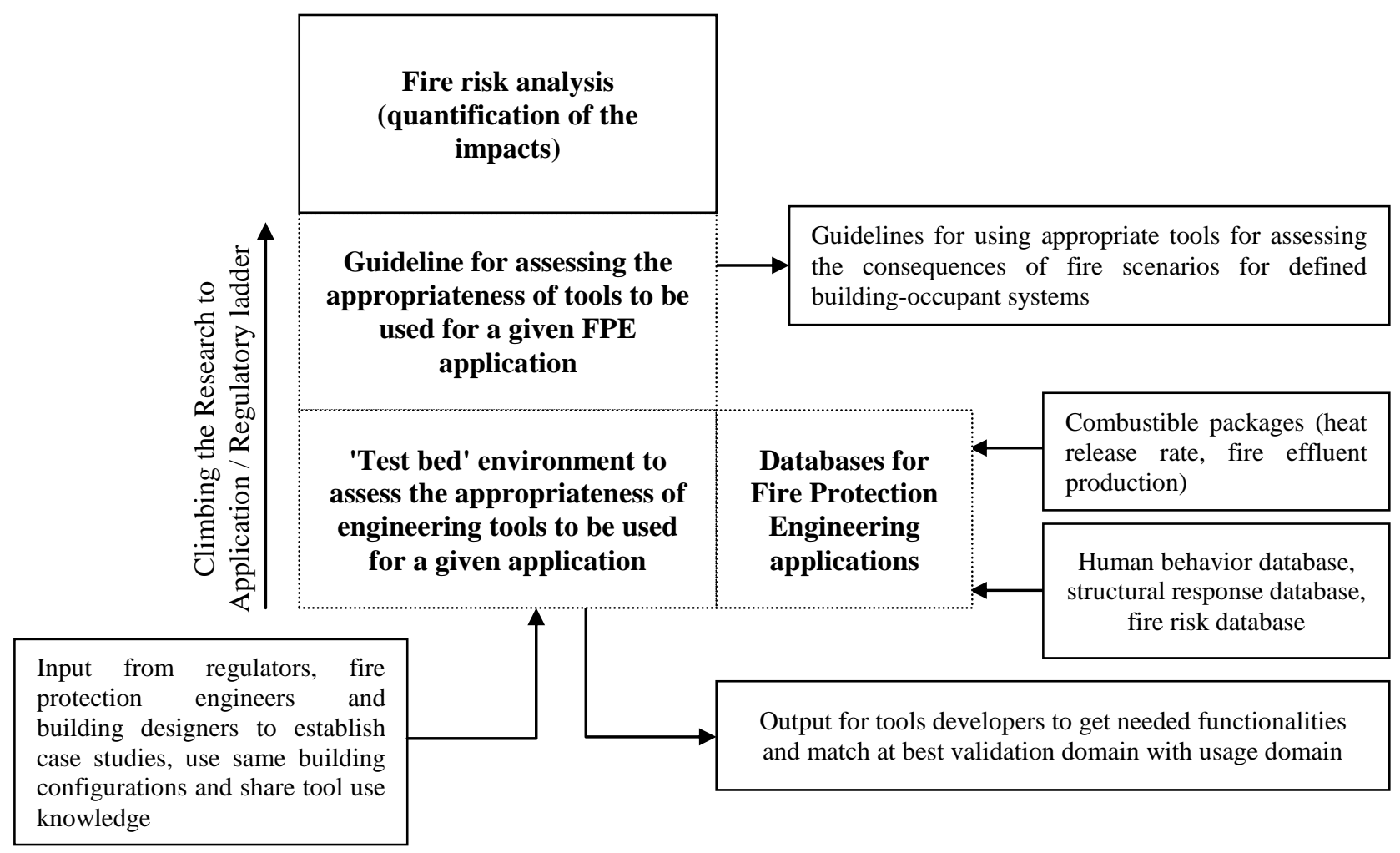

Fig. 5-10. Proposed path to the quantification of the impacts of fire events

\subsubsection{Research to be carried out for the process step related to the quantification of fire events consequences}

In the last two decades, fire research has made tremendous advances in elaborating models and providing tools which have helped the FPEs estimate the consequences of fires. At the same time, more tools became available for the FPEs to assess the evacuation process of building occupants.

Within Step 4 of the proposed PBFPD process, a coordinated action is proposed for assessing the appropriateness of engineering tools to be used for given applications, i.e. FPEs quantify the impacts of fire scenarios for specific "building-occupant" systems with tools validated for the domain characterized by these systems. This action involves the creation of 'test bed' environments where regulators, fire protection engineers and building designers establish case studies, use same building configurations and share tool use knowledge. More detailed explanations regarding the "test bed" environments are presented in [20,21]. 
It should be noted, that since not all of the necessary validated models and tools are ready for use, a possible output for tools developers from Step 4 research would be to get the functionalities needed by the users so as to match at best the tool validation domains with the tool usage domains.

Data required for the use of these tools is also a major concern. Database structures for fire effect tools and human behaviors exist and they could be used and populated for the common good of all the fire protection engineering community, not looking for all possible data but specific data designed system by system.

\subsubsection{Establishing guidelines or standards for assessing the quantification of fire event consequences}

Guidelines such as the ones published by SFPE [22], ASTM [23] and ISO [24] are important documents which help the fire protection engineer to demonstrate the appropriateness of a fire tool to be used for engineering purposes, describing how the tool validation process should be conducted. Nevertheless, these guidelines detail generic characteristics of the fire tools, such as particular fire phenomena: fire plume, fire spread or smoke transport while leaving the application side completely at the hands of the user of these guides. These documents have to be considered as a first step towards a more comprehensive and more coherent use of fire tools in the engineering community. Nevertheless, they still need to be completed with other guidelines which are application oriented that is to say guidelines which are not generic but are really applied to specific "building-occupant" systems.

These guidelines for the new PBFPD process will be centered around the application and they will concern all the tools which can potentially be used to solve the engineering problem, not only the ones dedicated to fire effects quantifications, but also evacuation process and response of the structures.

\subsubsection{Using the guidelines for performing Step 4 in a PBFPD process}

Once established for considered "building-occupant" systems, the guidelines for assessing the quantification of fire scenarios consequences are used by FPEs to help in the selection of the most appropriate tools to use, in conjunction with databases containing relevant values of input data for the tools. FPEs also use the guidelines to assess the effect of trial fire protection measure sets on the overall performance of the studied "building-occupant" system.

\subsubsection{Proposed path to quantify Step 5: Evaluation of the integration of the fire protection measures in the system}

\subsubsection{Description of the step relative to the evaluation of the integration of the fire protection measures in the system and corresponding path of action}

In the current SFPE conceptual design procedure for fire protection design [25], the evaluation of the integration of the fire protection measures in the system comes after the final trial design has been selected by the stakeholders and in a form of a testing plan including commissioning and acceptance testing and an Operation and Maintenance 
manual. SFPE indicates that "during the design development and construction document phases, the conceptual designs evolve into detailed designs of systems and the plans and specifications that will be used for bidding and constructing the building. The design development and construction documentation are not described in [its] guide. However, guidance for the coordination of design documentation is given in chapter 12 [of its guide]". SFPE also indicates that "coordination between disciplines is critical during these phases in order to ensure proper interaction between systems".

The 2005 edition of the International Fire Engineering guidelines (IFEG) [26] includes paragraph 1.2.13 which states that "real-life safety over ensuing decades will be highly dependent on elements other than the approved design", such as construction, commissioning, management and use, and maintenance. IFEG differ from the SFPE guide [25] as they include these elements into the design brief (which they call the Fire Engineering Brief, FEB). In paragraph 1.2.13 of IFEG, it is mentioned that "the FEB should access any tangible measures addressing the question of how high, or how low, one can prudently expect standards for the above elements to be maintained over the life of the building". Nevertheless, it should be noted that IFEG do not provide more insight on how these elements should be determined, quantified and included in the overall process. Besides, when looking at Figure 1.3.2 of IFEG describing the analysis of trial designs, the incorporation of the elements established in its paragraph 1.2.13 only affect the final report, as is the case with the SFPE guidelines.

A challenge related to the application of current PBFPD processes concerns the difference in the fire safety provided by fire protection measures between the conceptual design phase and the reality of the building use has been partially taken into consideration by adding redundancies in the fire protection measures as illustrated in Fig. 5-11. Nevertheless, this challenge is amplified by the aforementioned "disconnection" between the fire protection measures and the rest of the "building-occupant" system, not only in terms of technical measures but also in terms of managerial measures.

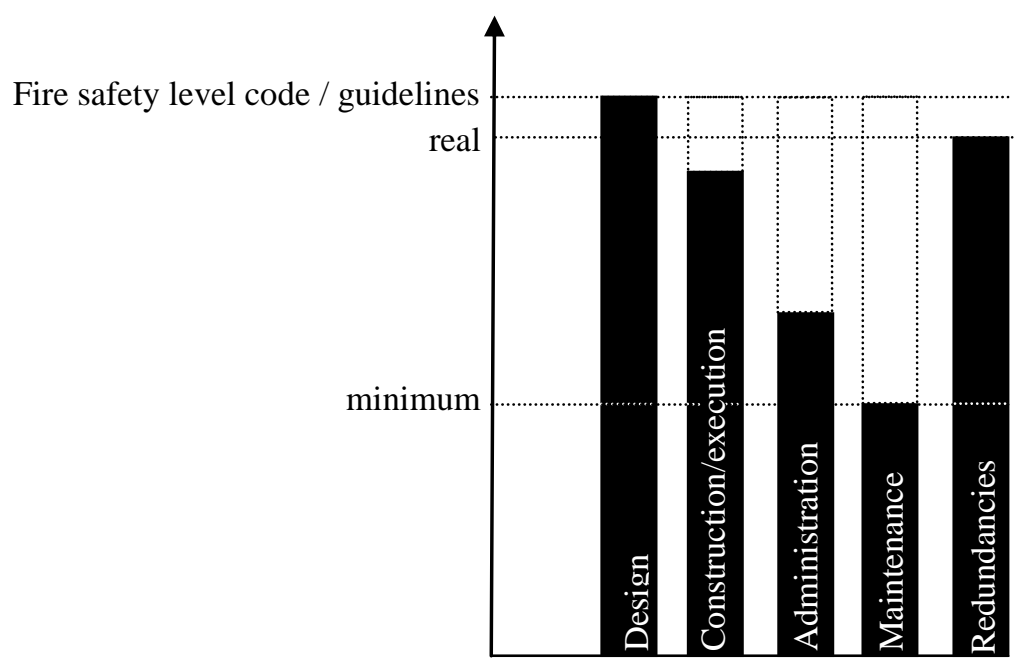

Fig. 5-11. Levels of fire safety as a function of building phases and the introduction of redundant fire protection measures, adapted from [27] 
In the new PBFPD process, Step 5 relative to the evaluation of the integration of the fire protection measures in the system has to be done in order to be sure that the installation of these fire protection measures which are used for emergency situations are not counter-productive in the everyday use of the building. A feedback loop will be instituted for each fire protection measures or for sets of fire protection measures. This $5^{\text {th }}$ important technical step is performed because of the challenges related to the maintenance and the possible changes of the building use once the design phase and the construction phase are completed (Cf. Chapter 2 of this dissertation).

The corresponding path relative to the PBFPD process step evaluating the integration of the fire protection measures into the system is illustrated in Fig. 5-12, and detailed in the following paragraphs.

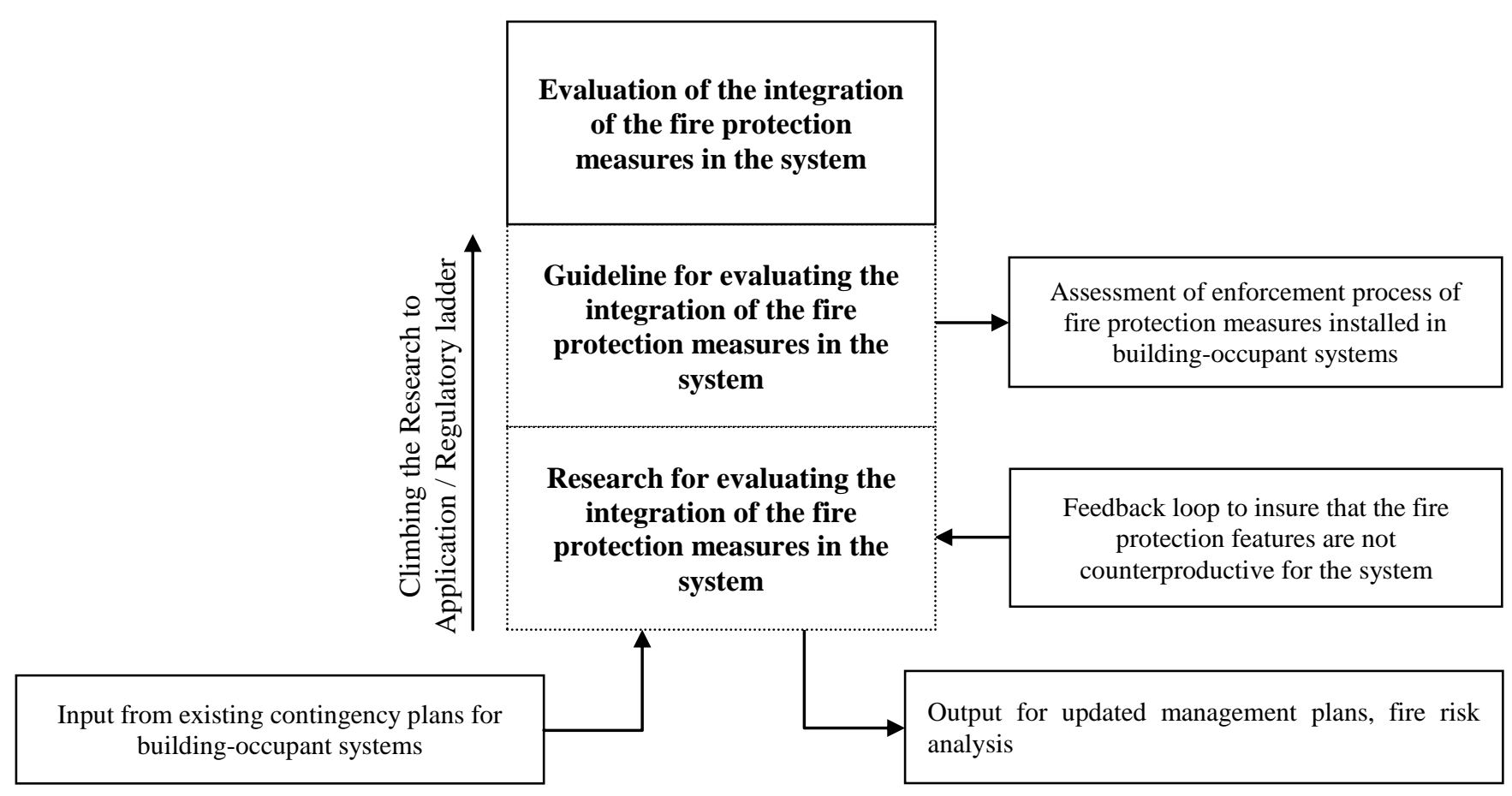

Fig. 5-12. Proposed path to the Evaluation of the integration of the fire protection measures in the system

\subsubsection{Research to be carried out for the process step related to the evaluation of the integration of the fire} protection measures in the system

Because the paradigm of study shifted from the fire event to the study of the effects of fire as a disruptive event of a "building-occupant" system, input from existing contingency plans are examined in order to verify that their own safety measures are not in contradiction with the proposed fire protection measures to be installed. Maximization of potential uses of the same measures dealing with different types of disruptive events or even "chronic" uses of the building can also be assessed in this process step. 
Care will be taken in the associated documentation for the stakeholders so as to point them to the parameters of the fire scenarios that should remain under a certain range under pain of leading to a "worst case" scenario event. This integration or lack of, fire protection measures will then help the FPE focus on these particular parameters so the building owner, manager and occupants are required to keep them within a certain range. Interconnection is also made with the quantification of fire risk analysis: a sensitivity analysis should be performed for the most important parameters or sets of parameters in order to notably avoid the "worst case" scenarios from happening with a higher frequency.

\subsubsection{Establishing guidelines or standards for assessing the integration of fire protection measures in a} considered "building-occupant" system

One important foreseen output of the guidelines or standards related to the assessment of the integration of fire protection measures in a considered "building-occupant" system concerns the assessment of the enforcement process of these fire protection measures. The prescriptive requirements will also have their enforcement assessed this way, in a similar way Tsujimoto [15] looked at the effects of the installation of sprinklers in patient room in Japanese hospitals (cf. § 5.3.1.2 of this chapter) on fire casualties.

\subsubsection{Using the guidelines for performing Step 5 in a PBFPD process}

The output of this step is also an essential document for the different stakeholders concerning the possible interactions of the fire protection measures and the other components of the considered "building-occupant" system.

\subsubsection{Proposed path to quantify Step 6: cost benefit analysis}

\subsubsection{Description of the cost-benefit analysis step and corresponding path of action}

This step is carried out in order to assess the cost associated with implementing fire protection measures in the "building-occupant" system. Once again, the separation of the different "building-occupant" systems would make it easier to integrate the results of this cost-benefit analysis, considering these impacts would be different when looking at the same fire protection measure for a small new building, a small extension of a large building or a large new building (as illustrated by Charters and Ramachandran [28] about sprinklers in schools).

The corresponding path relative to the PBFPD process step performing the cost-benefit analysis of the fire protection measures into the system is illustrated in Fig. 5-13, and detailed in the following paragraphs. 


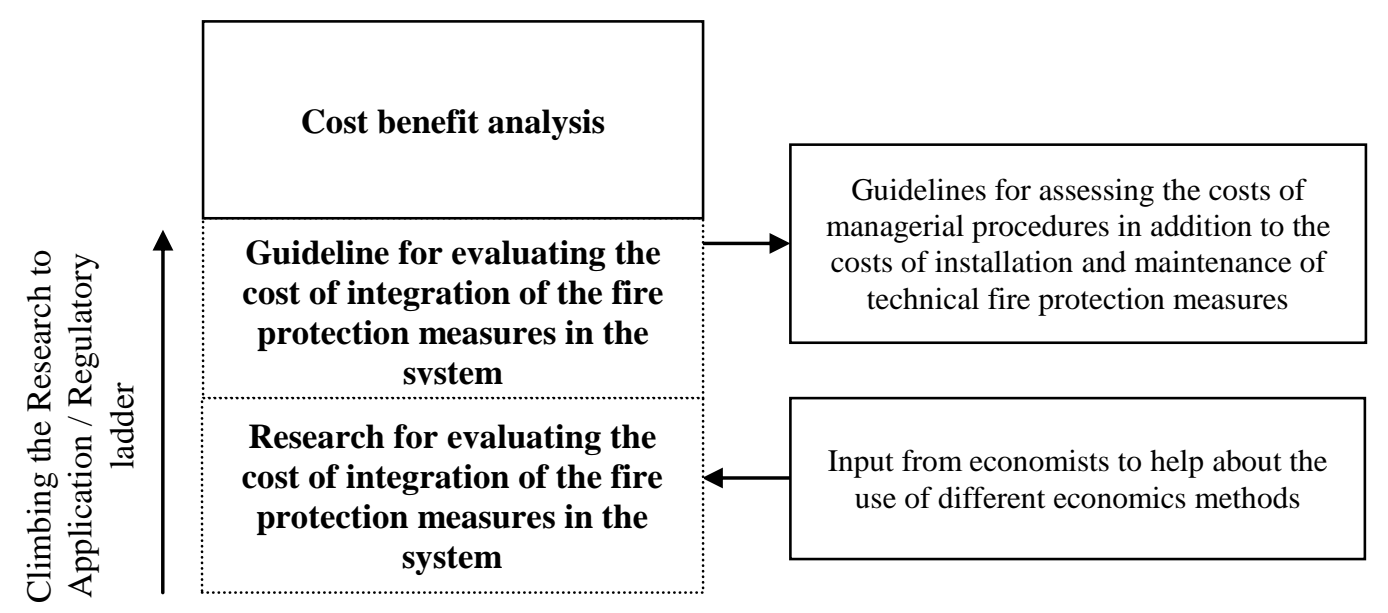

Fig. 5-13. Proposed path to the cost-benefit analysis of the trial designs

\subsubsection{Research to be carried out for the process step related to fire protection measures cost benefit analysis}

As research concerning the determination of the target vulnerability criteria (Step 2) requires the help from experts in toxicology, psychology, electronic engineers or structural engineers, this process step also requires a consequent input from experts outside of the fire protection engineering field: economists.

\subsubsection{Establishing guidelines or standards for fire protection measures cost benefit analysis}

For the process step related to the evaluation of the costs and benefits of fire protection measures proposed to be installed and maintained in well defined "building-occupant" systems, guidelines will be established to include the assessment of managerial procedure costs in addition to the costs associated with technical fire protection measures.

\subsubsection{Using the guidelines for performing Step 6 in a PBFPD process}

The output of this step is also an essential document for the different stakeholders concerning the costs and the benefits of installing and maintaining the fire protection measures proposed as a results of the fire risk analysis steps (Step 3 and Step 4) along with the document related to the integration of these fire protection measures into the "building-occupant" system, in the study paradigm. 


\subsection{Conclusions for this chapter}

In order to overcome the shortcomings and challenges related to the application of current performance-based fire protection design (PBFPD) processes, a new PBFPD process has been developed within a "building-occupant" system paradigm.

Although the technical steps of the new process have been defined, guidance relative to the application of these steps still require research as well as the establishment of guidance specific to "building-occupant" systems.

This chapter detailed the actions fire protection engineers would be required to perform for each of the six technical steps of the new risk-informed PBFPD process and how these actions are similar to or different from the ones performed in the current PBFPD processes. For each step of the process, a plan of action has been proposed in order to describe the nature of the information that would be inscribed in the future guidance, and how this information would become a part of future guidelines and standards. Useful elements of information extracted from past and current research involving experts from a large spectrum of competencies and the systems stakeholders, as well as information from standardization efforts were presented for each step.

\section{References}

1. J. Taveau, Risk assessment and land-use planning regulations in France following the AZF disaster, Journal of Loss Prevention in the Process Industries, Volume 23, issue 6, (2010) 813-823

2. U.S. Nuclear Regulatory Commission (2007), Verification and Validation of Selected Fire Models for Nuclear Power Plant Applications - (NUREG-1824, EPRI 1011999) Volume 1: Main Report, U.S. Nuclear Regulatory Commission and Electric Power Research Institute, 2007

3. NFPA 805, Performance-Based Standard for Fire Protection for Light Water Reactor Electric Generating Plants, 2010

4. NFPA 99, Health Care Facilities Code, 2012

5. SFPE, SFPE Code Official's Guide to Performance-Based Design Review, Society of Fire Protection Engineers - International Code Council, June 2003

6. M.J. Karter, Jr., Fire Loss in the United States during 2011, National Fire Protection Association, September 2012 (available at: http://www.nfpa.org/assets/files/PDF/OS.fireloss.pdf)

7. U.S. Fire Administration/National Fire Data Center, Fire in the United States2003-2007, Fifteenth Edition, October2009

8. M.Ahrens, Selections from the U.S. Fires in Selected Occupancies - Health Care Facilities, excluding Nursing Homes, National Fire Protection Association, Quincy, MA (USA), March 2006

9. A. Alvarez, B.J. Meacham, Towards an Integrated Performance-Based Design Approach for Life Safety Across Different Building Use Groups, in: Proceedings of the 12th International Interflam Conference, Nottingham, UK, 2010

10. J.R. Thomas, "The use of fire statistics in guiding research and code development", Interflam 2007, proceedings of the eleventh conference, volume 2, pp. 1139-1147, Interscience Communications, London (UK), 2007, also 
available as: J.R. Thomas, "The use of fire statistics in guiding research and code development", NRCC-49243, National Research Council Canada, 2007

11. M Salisbury, P Johnson, E. Yii and M.C. Hui, "QRA and fire safety - a beneficial experience...", Interflam 2007, proceedings of the eleventh conference, volume 2, pp. 1253-1263, Interscience Communications, London (UK), 2007

12. R. Fahy, Available Data and Input Into Models, chapter 4.3 of the "Workshop on Building Occupant Movement During Fire Emergencies, June 10-11, 2004, National Institute of Standards and Technology", NIST Special Publication 1032, NIST, March 2005

13. K. Tillander, "Utilisation of statistics to assess fire risks in buildings", VTT publication 537, VTT Technical Research Centre of Finland, 2004 (available at: www.vtt.fi/inf/pdf/publications/2004/P537.pdf)

14. Y. Kobayashi and H. Nozaki, A Statistical Method to Evaluate Fire Risks in Non-Residential Buildings in Japan," in: Fire Safety Science: Proceedings of the Eight International Symposium, China, International Association for Fire Safety Science, 2005, pp. 341-352

15. M. Tsujimoto, Death Risk by Building Fires in Japan and its Usage, Fire Science and Technology, vol. 23, no. 4, 2004, pp. 304-311

16. ISO/TR 16732-1:2012, Fire Risk Assessment

17. NFPA 557, Standard for the determination of fire loads for use in structural fire protection design, 2012

18. ISO/DIS 13571, Life-threatening components of fire - Guidelines for the estimation of time to compromised tenability in fires, revision of first edition ISO 13571:2007, 2011

19. T. F. Barry, Risk-Informed, Performance-Based Industrial Fire Protection, TFBarry Publications, Tennessee Valley Publishing, 2002

20. A. Alvarez and B.J. Meacham, "Ready-to-use" Building Layouts and Combustible Packages for 3-D simulations, proceedings of the Fire and Evacuation Modeling Technical Conference, 2011

21. A. Alvarez and B.J. Meacham, 'Test bed' environment process for assessing the appropriateness of engineering tools to be used in performance-based design applications, in: Proceedings of the 9th International Conference on Performance-Based Codes and Fire Safety Design Methods, Hong Kong. 20-22 June 2012

22. SFPE, SFPE Engineering Guide - Guidelines for Substantiating a Fire Model for a Given Application, SFPE G.06.2011, Society of Fire Protection Engineers, 2011

23. ASTM E1591-07, Standard Guide for Obtaining Data for Deterministic Fire Models, American Society for Testing and Materials, 2007

24. ISO16730:2008, Fire safety engineering -- Assessment, verification and validation of calculation methods

25. SFPE, SFPE Engineering Guide to Performance-Based Fire Protection, 2nd edition, Society of Fire Protection Engineers, 2007

26. IFEG, International Fire Engineering Guidelines, Australian Building Codes Board, Department of Building and Housing (New Zealand), International Code Council (USA), and National Research Council (Canada), 2005 edition

27. V. Stenstad and W.R. Bjørkmann, A Systematic Approach to Fire Safety Design, in: Proceedings of the $5^{\text {th }}$ International Conference on Performance-Based Codes and Fire Safety Design Methods, 6-8 October 2004, Society of Fire Protection Engineers, 2004, pp. 67-78

28. D. A. Charters and G. Ramachandran. Quantitative Risk Assessment in Fire Safety. Spon Press, 2011 


\section{CONCLUSIONS: MAIN OUTCOMES}

The research presented in this dissertation is aimed at establishing the next generation of performance-based fire protection design (PBFPD). It originated from the fact that despite being in use for more than 20 years, the application of PBFPD remains limited, several shortcomings exist, and an increasing number of countries are moving toward 'prescribed performance' to address the gaps. There are many contributing factors. Research has been carried out in two principal areas: the relationship between occupants and fire safety measures in the contexts of holistic building performance expectations and the everyday use of the building, and into the lack of specifics within current PBFPD approaches.

This conceptual research, carried out in a paradigm centered around systems defined by building types and their associated occupants, led to the establishment of a functional new PBFPD process which would require all the actors involved in its application to shift to this system based paradigm from the current one related to the design of fire protection measures. Guidelines required to use the new process, for each of its steps and for relevant systems, were not established during this Ph.D. as they would require many years of research and development. Nevertheless, a plan of action dedicated to their establishment has been presented in this dissertation.

The main outcomes of the research are presented below:

- A review of two decades of application of PBFPD processes highlights challenges in applying these current processes both at technical and political levels. Challenges still exist concerning the definition/quantification of the strategic elements of any PBFPD process: the performance criteria (which current denomination should be changed to "fire effect criteria"), design fire scenarios, and the use of tools to quantify the trial designs.

- Despite efforts made to consolidate databases gathering information related to buildings, fires and occupant behaviors, it is still necessary to make such databases available to the whole engineering community. Besides, validation and verification domains related to the tools still need to be defined according to the engineering problems these tools are used to solve.

- A "building-occupant" system has been defined, along with its main characteristics: "Targets" are the system agents responsible for the system daily performance (building occupants and components). During normal every day conditions or "chronic states of the system", they are located in "functional zones" where they carry out their activities associated with "chronic objectives", established in accordance with the system scope and performance. "Utility zones" include system support components such as electricity, HVAC and plumbing. "Disruptive events", such as fires, have to be considered between two consecutive "chronic states". In order to mitigate the "event effects" on the system performance, "acute objectives" have to be set up so to take into consideration "direct effects" and "indirect effects" with which the disruptive events can possibly damage the targets. 
- The performance of a building is related to objectives set up for the normal use of the building and it is important to quantify how disruptive events can affect this performance.

- A building design agreed among different stakeholders covers many and sometimes competing objectives, not only dealing with normal building uses, but also during disruptive events.

- There is a need for a system approach to assess the overall building performance in order to prevent some installed building components being ignored or misused by the building occupants, especially during emergency situations.

- Within the "building-occupant" system paradigm, a risk-informed system specific performance-based approach has been established in order to quantify the effects of disruptive events on the overall building performance and to help verify that the protection measures installed in the system formed by precise building types and their associated occupants are well integrated in this system.

- The aforementioned system specific process was applied to deal with fire disruptive events, that is to say to quantify the effects of fire events on the overall performance of the system. The main difference between the current PBFPD processes and the new one is related to their respective problem definition: the current processes are focused on the design of fire protection measures that would mitigate the effects of fire scenarios defined between ignition and extinguishment while the new process is aimed to assess how fire protection measures, as an integrated component of the system, would help mitigate the effects of fire events, including the recovery period of the system.

- Being focused on the system, a fire risk analysis is performed centered on the study of the actors of the system in their everyday performance and how fire protection measures can mitigate the effects of fire events on this everyday performance. Besides, the new PBFPD process contains a technical stage dedicated to the evaluation of the integration into the system of the fire protection measures, selected after the fire risk analysis. A costbenefit analysis finalizes the technical part of the process which has been performed independently and in a straightforward manner by fire protection engineers (FPEs). At the end of this technical part, FPEs have elaborated three documents detailing the results of the fire risk analysis, of the evaluation of the integration of the fire protection measures into the system and of the cost-benefit analysis. Based upon these documents, the stakeholders decide which fire protection measures they would have installed in their system. This process is then demonstrating a complete separation between the "political" decision-making process and the "technical" resolution of the engineering fire problem. As a consequence of this separation, the technical stage of the process becomes transparent, both for stakeholders who establish the performance targets (political decision) and for the engineers in charge of the evaluation of the disruptive effects on the system performance (technical analysis);

- As a proof of concept, it has been shown through text and examples how the new framework addressed the challenges with the existing approaches, operated within a more holistic "building-occupant" system paradigm, 
illustrated how viewing fire as a perturbation within the larger "building-occupant" system would increase fire safety performance over the life of a building, and deliver a higher level of building fire safety performance.

- It is important to include the "building-occupant" system stakeholders not only in the making of the guidelines for each technical step of the proposed process, but also in the research process itself, as these stakeholders know the particularities of their systems;

- Multiple iterations would be required in order to establish the guidelines as the process steps are dependant in terms of input-output;

- Research for the different steps would require more or less time and resources, as well as the participation of engineers from disciplines other than fire protection engineers;

- Technical literature contents (including engineering tools and input data), as well as standards and codes relative to the different technical steps of the process would have to be examined and applied to specific "building-occupant" systems. Collections and examination of the past studies are still relevant even if the data might require to be updated (e.g. walking speed values were established in the last 1980's and pieces of furniture in the NIST furniture calorimeter experiments may be outdated as materials have evolved since then). 


\section{FUTURE WORK}

The future work is aimed at the establishment of guidelines, specific to "building-occupant" systems and in elaborating each technical step of the proposed PBFPD process. One can imagine the difficulty in managing the development of guidelines for all the steps, for all the possible "building-occupant" systems:

- interactions between these steps have to be examined and assessed,

- $\quad$ the research needed for each step guideline is currently at different level.

In consequence, there is a need for coordination of all the efforts as well as a repository of the information gathered for each step, from the initial research gathering, to its analysis and to the establishment of the corresponding guidelines.

Such an environment which facilitates this coordination and stores the guideline development has been created in the form of a web-platform. The original idea of a web-platform was associated with the 'test bed' environments for fire effects tools as presented in Appendix A2. Along with the objective of performing studies to assess the appropriateness of tools to be used for performance-based applications, this first version of the web-platform was also intended to contain databases for "fuel packages" ready to use in 3-D simulations.

The development of this original web-platform was put on hold as the research presented in this Ph.D. dissertation was carried out. As the new PBFPD process was elaborated with its six different technical steps, it was found that the structure of the original web-platform could be used to facilitate the establishment of the process step guidelines and serve as a repository for input data.

Indeed, each step can be perceived as an engineer step aimed at the quantification of important parameters required to solve the engineering problem: how to quantify and mitigate the effects of fire events on the overall performance of a considered "building-occupant" system? In other terms, each step would require the use of corresponding tools, supplied with the input data needed to use these tools, in order to solve a specific step issue for a considered "building-occupant" system (Fig. 7-1). The latter part, solving a specific step issue for a considered "buildingoccupant" system, is precisely why the 'test bed' environments were created in the first place.

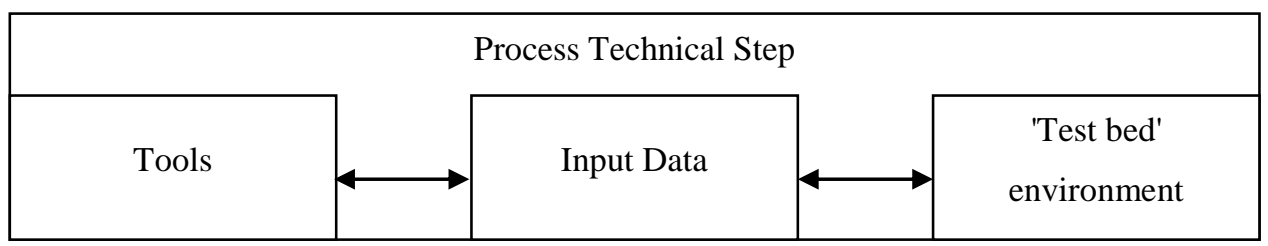

Fig. 7-1. Interconnections between tools, input data and 'test bed' environments 
It should be noted that tools related to the "Target Vulnerability Criteria Estimation" Step are not primarily about using engineering tools but mostly using data established by specialists such as:

- toxicologists, clinicians and psychologists for assessing threshold damaging fire effects on people,

- material engineers and electronic engineers for assessing threshold damaging fire effects on valuable artifacts and pieces of equipment important for the system performance,

- $\quad$ structural engineers for assessing threshold damaging fire effects on building structures.

The importance of the use of 'test bed' environments is illustrated in a schematic way with the four following figures: Fig. 7-2. shows that different populations can be defined according to the buildings in which they are located. Due to the building configurations and contents, particular fire distributions can be determined for different types of buildings, as illustrated by Fig. 7-3. According to their characteristics, building occupants are more or less sensitive to the effects of a fire. Fig. 7-4. shows how the different populations could be more or less affected by the fire distributions established by building types. At last, Fig. 7-5. integrates the different domains linking buildings, their occupants and the types of fires that could occur in these buildings and it shows the importance of establishing 'test bed' environments, in order to concentrate the efforts of tool developers to validate their tools in priority for the domains defined by the "building-occupant" systems.

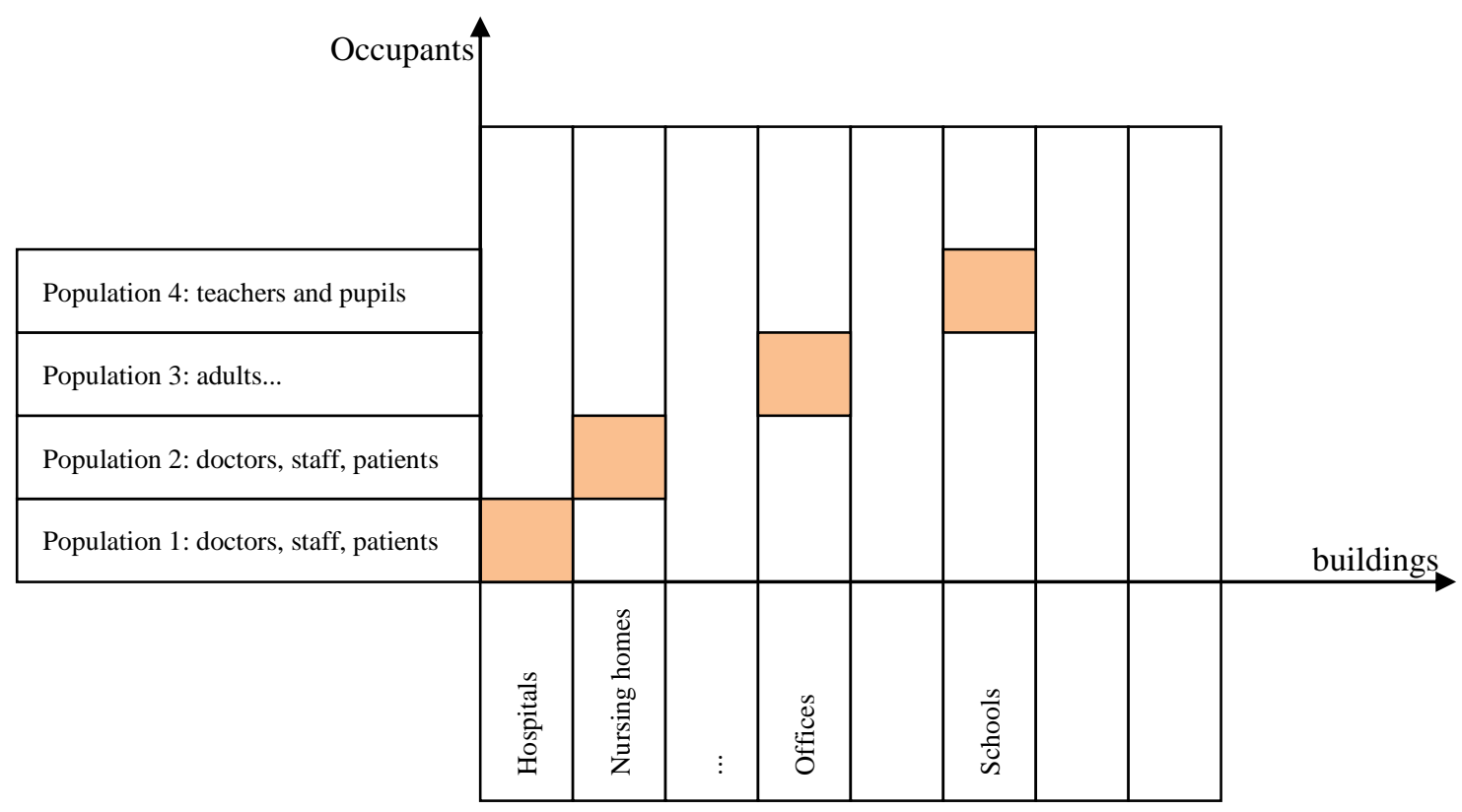

Fig. 7-2. Occupant populations as a function of buildings 


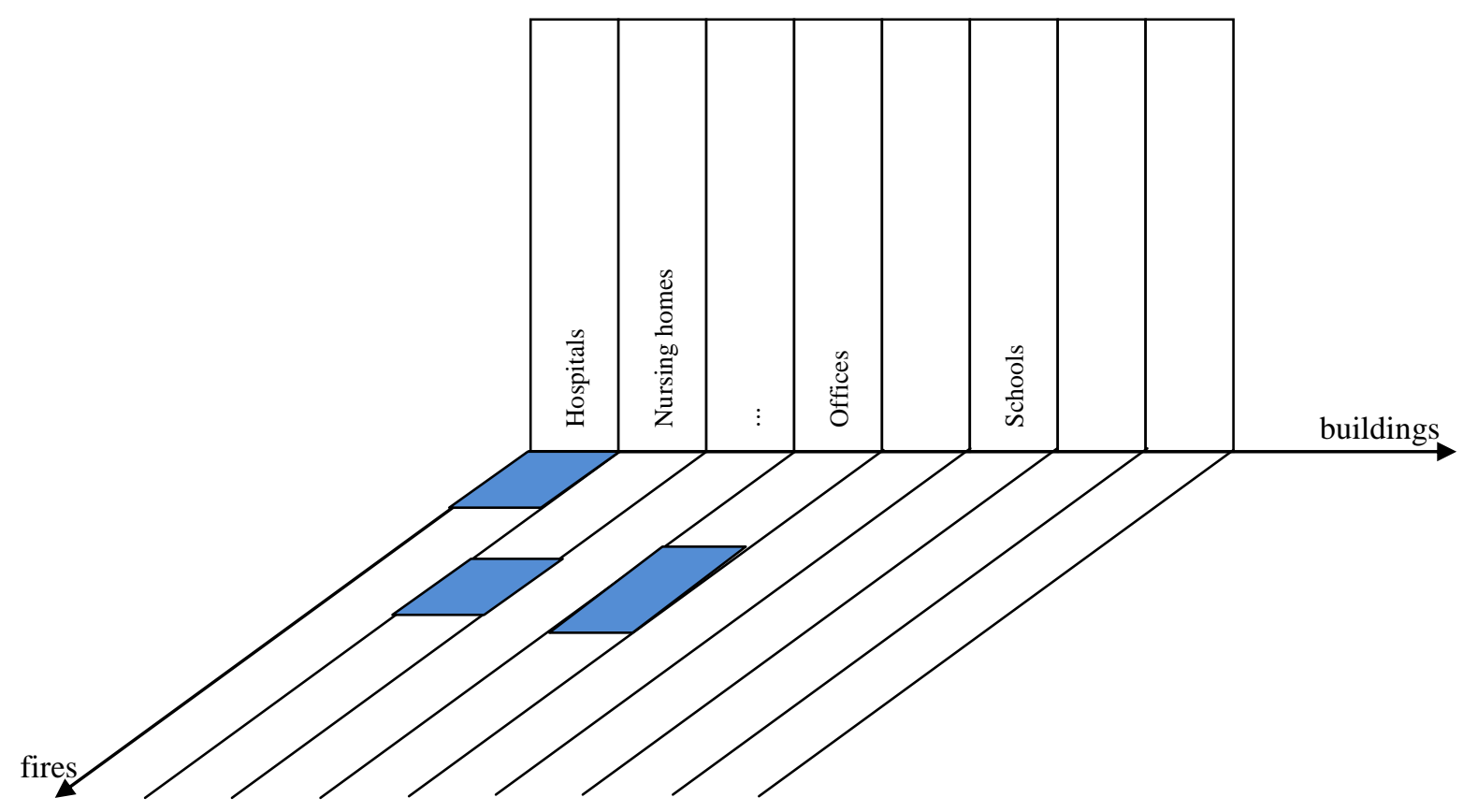

Fig. 7-3. Fire distributions as a function of buildings

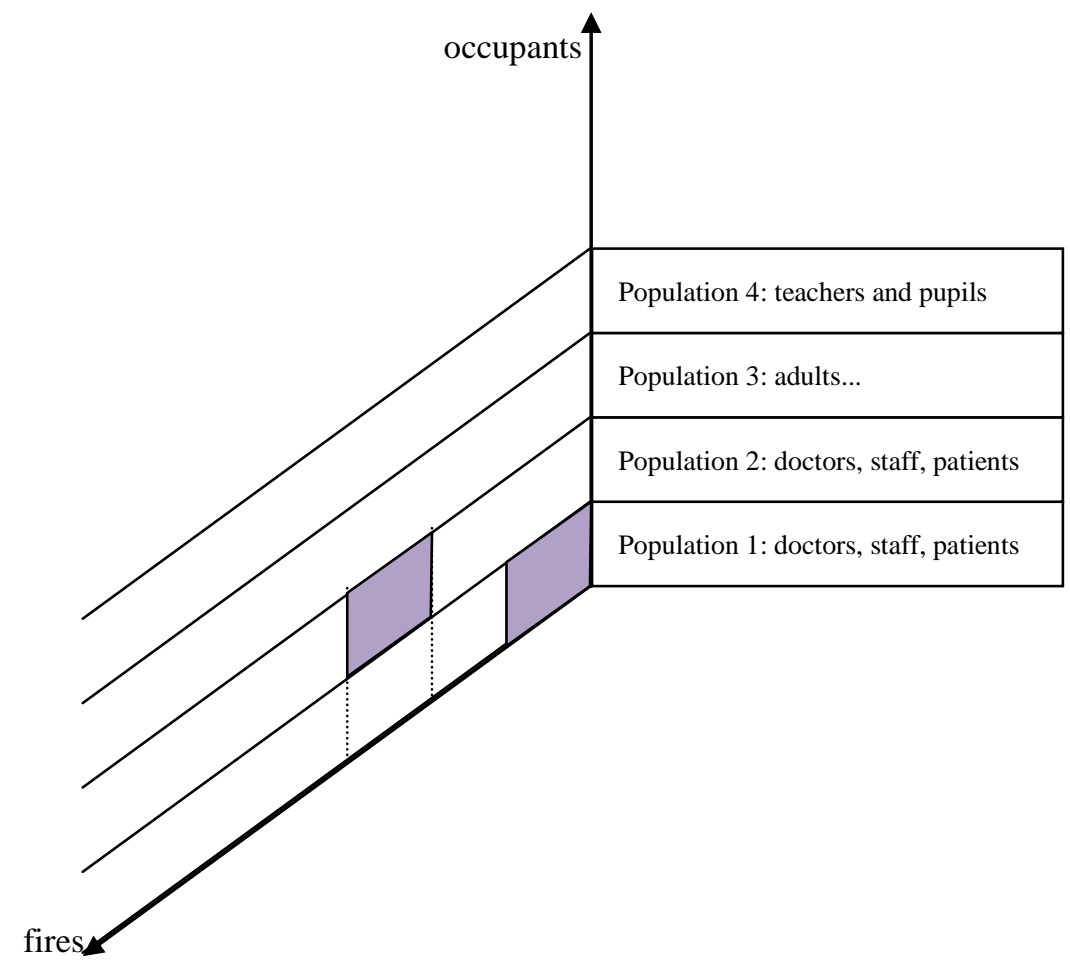

Fig. 7-4. Effects of fire distributions on building occupant populations 


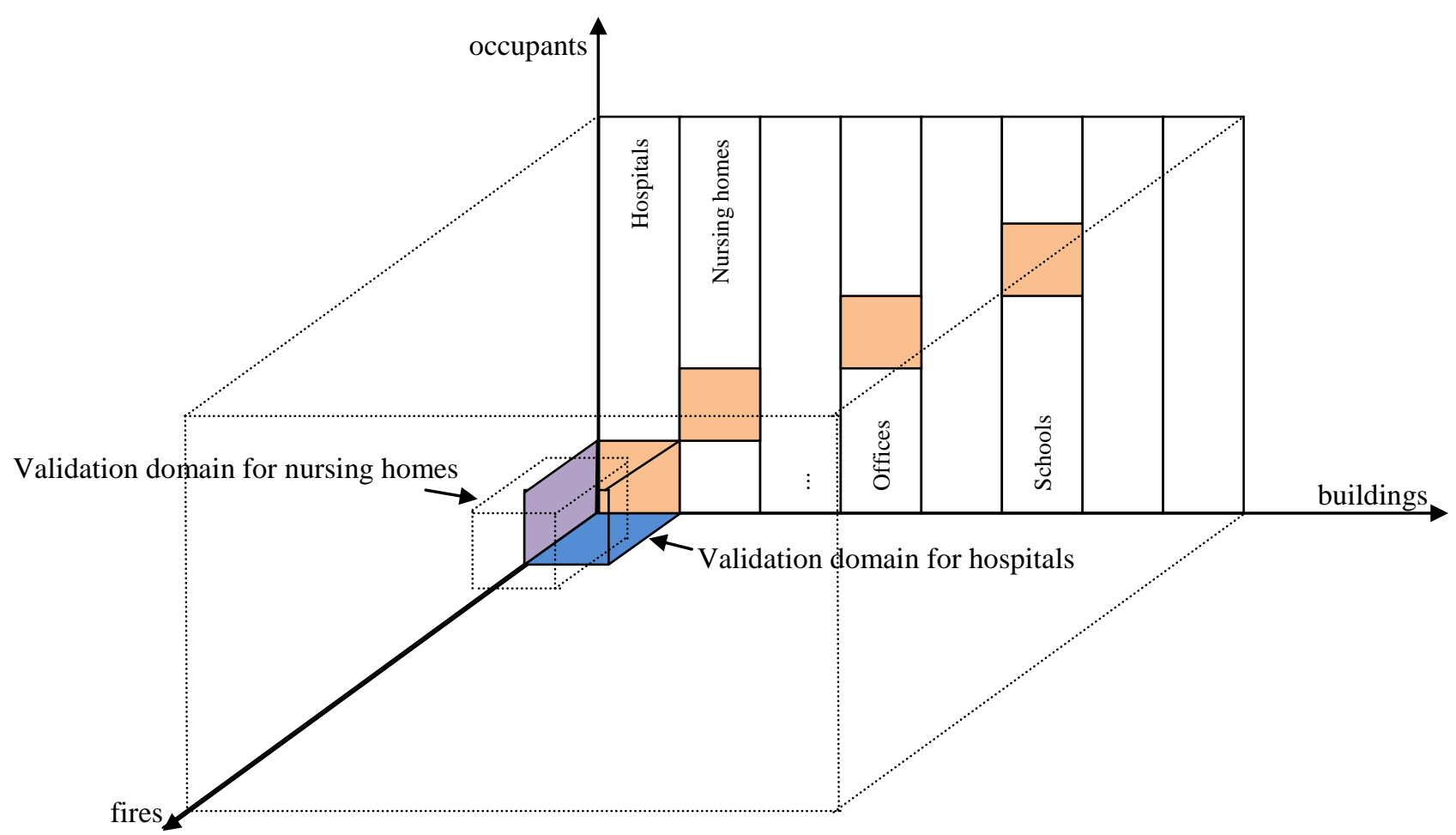

Fig. 7-5. Validation domains for different "building-occupant" systems, in comparison with the physical domain of possibilities involving buildings, fires and occupants

Future work will then consist in establishing relevant "building-occupant" systems and in communicating all their descriptive information to tool developers, as well as the important engineering issues related to each of these systems.

It should be noted that some informative structure has been developed in recent years in order to aggregate in one place all the information related to a building. Indeed, some future work will be related to incorporating into the web-platform, information collected via the use of Building Information Modeling (BIM). The National Building Information Model Standard Project Committee defines BIM as:

"Building Information Modeling (BIM) is a digital representation of physical and functional characteristics of a facility. A BIM is a shared knowledge resource for information about a facility forming a reliable basis for decisions during its life-cycle; defined as existing from earliest conception to demolition.

A basic premise of BIM is collaboration by different stakeholders at different phases of the life cycle of a facility to insert, extract, update or modify information in the BIM to support and reflect the roles of that stakeholder." 



\author{
Appendix A1 \\ "Towards an Integrated Performance-Based Design Approach \\ for Life Safety Across Different Building Use Groups" \\ presented at the international conference "Interflam 2010"
}

Reprinted with permission of Interscience Communications Ltd, UK

Original source:

Alvarez, A. and Meacham, B.J., "Towards an Integrated Performance-Based Design Approach for Life Safety Across Different Building Use Groups" in: Interflam2010: proceedings of the $12^{\text {th }}$ international Fire Science \& Engineering Conference, East Midlands Conference Centre, University of Nottingham, UK, 5-7th July 2010, Interscience Communications Ltd, UK, volume 2, pp. 1259-1270 - ISBN: 978-0-9556548-7-9 (set of 2 volumes) 


\title{
TOWARDS AN INTEGRATED PERFORMANCE- BASED DESIGN APPROACH FOR LIFE SAFETY ACROSS DIFFERENT BUILDING USE GROUPS
}

\author{
Alberto ALVAREZ \& Brian J. MEACHAM, Ph.D., P.E. \\ Worcester Polytechnic Institute, 100 Institute Road, MA 01609 (USA) \\ (al_alvarez@wpi.edu)
}

\section{INTRODUCTION}

A main advantage of Performance-based Design (PBD) approaches for fire safety is to allow for the engineering of design solutions that provide at least an equivalent means of protection to prescriptive building and fire code requirements, but without imposing undesired constraints on aspects of building design, such as design flexibility, innovation, or maximization of cost/benefit ratio. Another advantage of PBD approach is to consider multiple stakeholders' objectives: not only the life safety objective which is the primary objective of building codes, but also architectural and user objectives, as well as business interruption and property protection. Performance criteria established for each objective are the parameters used to evaluate the suitability of a PBD solution. Nevertheless, these parameters are not explicit and they need an agreement of the involved stakeholders. For life safety, performance criteria are associated with the assessment of fire effects on people, often in terms of threshold values of temperature, thermal radiation, toxicity, or visibility. This assessment is also based on design fire scenarios, which are developed upon representative design fire scenarios. These design fire scenarios also need the agreement of the different stakeholders.

A range of guides, guidelines and standards have been developed in order to help the engineer elaborate PBD solutions and the Authority Having Jurisdiction (AHJ) approve the final design ${ }^{(1-5)}$. Even though these guidelines emphasize the importance of various parameters upon the acceptability of design solutions, they fail to provide a detailed framework for evaluating a specific building project, mainly because their scope of application is too broad. Known difficulties in achieving a homogeneous working framework for the engineer and the AHJ are related to, among others ${ }^{(6)}$ :

- the definition of quantified acceptance criteria,

- the selection of design fire scenarios,

- the tools used to perform the fire consequence analysis,

- the quantification of the most important parameters of the overall fire risk estimation.

In considering the many challenges with PBD as currently carried out, a simple idea emerged based on the fact that fire safety requirements are defined in regulation according to the building occupancy use: PBD solutions should address the intent of the issues embodied in the prescriptive regulations. Since existing PBD guidelines have already introduced the importance of building and occupant characteristics to PBD solutions, albeit without quantifying that importance, a next logical step is to develop more specific PBD guidance around these characteristics, drawing upon supplemental data for the PBD analysis from operational and loss experience. This paper outlines the concept of an integrated approach to PBD that is based around building use groups and focused on life safety.

\section{BREAKING DOWN A COMPLEX TRIPARTITE HETEROGENEOUS FRAMEWORK}

Developing a good building fire safety design requires appropriate consideration of the interaction between the building, the people who occupy it, and the fire and its effects (Fig. 1). At present, this concept is embodied in existing guidance documents in a rather generic manner, asking engineers to consider building characteristics, occupant characteristics and fire characteristics. 


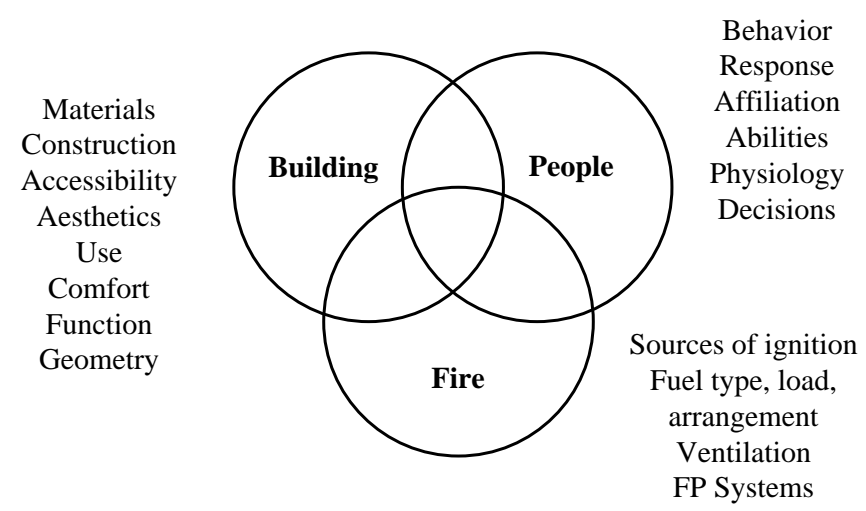

Figure 1. Building life safety design framework related to fire event

Since most of the current guidelines are rather generic, a gap exists in that critical differences between configurations found in assemblies, offices, hospitals and so forth are not necessarily addressed. More detailed guidance would be helpful, but it is difficult, if not impossible, to develop detailed guidelines without dealing with the elements that make a building occupancy specific. This is where a connection to building use / occupancy / type can be helpful. Where used in building regulations, "building occupancy" is associated with characteristics of occupants that are going to use it on a regular basis: patrons in places of assembly, students in schools, elderly people in nursing homes, detainees in prisons, travelers in airports and subway stations, etc. In considering how this concept can be applied more specifically to the PBD process, the relationship can be viewed through the prism of the "building occupancy spectrum" (Fig. 2).

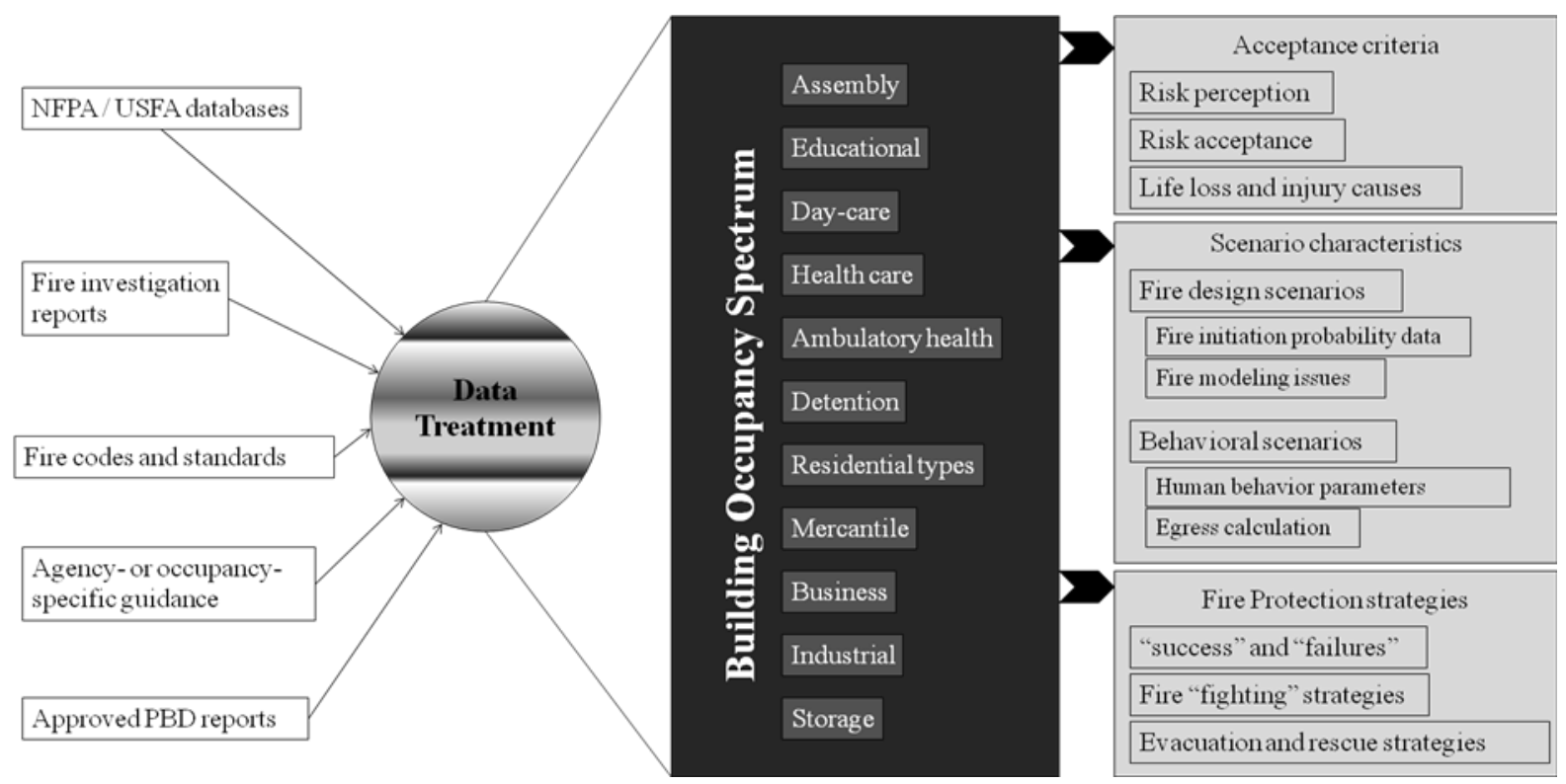

Figure 2. Data treatment schema of various sources, through the building occupancy spectrum, in order to get qualitative and quantitative parameters used in PDB approach

In order to develop detailed occupancy-specific guidelines, several steps are needed:

- First, the proposed framework is used to examine different sources in order to collect pertinent data for each building occupancy, and to try to solve issues related to the perception of risk, the level of risk acceptance the AHJ is prepared to accept (or has accepted in the past), and the nature of the causes that led to fire injuries and life loss (so to extract quantified performance criteria).

- Next, scenario characteristics will be elaborated considering the parameters of the fire development itself (fire design scenarios) and considering the human behavior parameters needed to perform egress calculations (behavioral scenarios). 
- Finally, examination of different fire protection strategies would be conducted, including data from fire events where these strategies were either efficient or inadequate to ensure the fire safety function. As staff, rescuers and fire fighters are also components of the fire protection system, data will also be collected for each building occupancy type, since the nature, actions and number of this people vary with occupancy types.

At present, the development of the framework is based primarily on data available in the USA, with input to the proposed framework mainly composed of data gathered from:

- Fire statistics collected by the National Fire Protection Association (NFPA) and the US Fire Administration (USFA) - in their databases as well as fire investigation reports. This is seen as primary main sources for fire data. Indeed, information from fire statistics and fire investigations reports is important to collect and analyze as these past events are the most realistic ones. These sources are particularly valuable for estimating human behavior parameters as people were actually put into situation. Similar investigation reports may include coroner reports as they can appear very useful to determine the toxic doses absorbed by the fire victims and the circumstances of fire fatalities ${ }^{(7)}$;

- Building and fire codes and standards (International Code Council (ICC), NFPA, local). These are important to consider not only because they are the documents where prescriptive requirements are presented so they represent the point of comparison with Performance-based Design alternatives, but also because some valuable information can be extracted when examining the factors that contributed to regulation changes;

- Agency- or occupancy-specific guidance (e.g., General Services Administration (GSA), Department of Veterans Affairs (DVA), Joint Commission on Accreditation of Healthcare Organizations (JCAHO), etc). These are important to obtain occupancy-specific requirements that may go over and above minimum building and fire regulation, including operational guidelines for staff, employees and other who have an impact on fire safety;

- AHJ-approved Performance-based Design reports. These are important because they reflect approved parameters for acceptance criteria, scenarios and fire protection strategies. It should be noted that these collected parameters only give an indication of accepted values as it is intended that they are highly dependent on the decision making process that allowed the engineer and the AHJ (and the other relevant stakeholders) to approve these parameters on a particular project.

\section{CHARACTERIZING THE BUILDING OCCUPANCY SPECTRUM}

Although life safety is a key objective of the proposed PBD framework, the building occupancy spectrum has to be constructed from a much broader perspective than fire safety alone. This is because buildings are the creation of architects - designed for clients and occupants primarily for "normal" use. This is where many of the other guides fall short - they assume the emergency condition to be a primary driver in building and occupant response, when in fact this in not the case. As reflected in Figure 1, the integration of fire safety features, although vital to the building global safety, is not a primary, or at least not the sole concern of the building users/designers/owners. This is where building occupancy classification can help. However, classification of buildings by several agencies dealing with fire safety (i.e. ICC and NFPA for regulatory purposes or NFPA and FEMA for fire statistics) is not homogeneous.

A primary classification of the building uses is given in Figure 2, but this classification may not be detailed enough to capture all the specificities of all the possible uses of a building. For health care facilities, for example, $\operatorname{ICC}^{(8)}$ gathers the following buildings in its institutional group I2: child care facilities, detoxification facilities, hospitals and mental hospitals and nursing homes. The problem with all the different subdivisions in the building occupancies is that the sampling decreases in size as one selects one particular type of building. Table 1 provides the different sub-categories of US hospitals inventoried by the American Hospital Association (AHA) for 2008. 


\begin{tabular}{|l|c|}
\hline Number of U.S. Community Hospitals & 5,010 \\
\hline Number of Federal Government Hospitals & 213 \\
\hline Number of Nonfederal Psychiatric Hospitals & 447 \\
\hline Number of Nonfederal Long Term Care Hospitals & 129 \\
\hline Number of Hospital Units of Institutions (Prison Hospitals, College Infirmaries, etc.) & 16 \\
\hline Total Number of All U.S. Registered* Hospitals & 5,815 \\
\hline
\end{tabular}

*An institution may be registered by the American Hospital Association as a hospital if it is accredited as a hospital by the Joint Commission on Accreditation of Healthcare Organizations (JCAHO) or is certified as a provider of acute services under Title 18 of the Social Security Act and has provided the Association with documents verifying the accreditation or certification.

\section{Table 1. Classification of US registered hospitals by $\mathrm{AHA}^{(9)}$ in 2008}

As presented in Figure 3, health care facilities ("inpatient" facilities) represent a "small" number in comparison with office buildings that were estimated ${ }^{(10)}$ to 824,000 in the USA in 2003 . Figure 4 shows that the current stock of offices still contains a significant portion of buildings that were constructed prior to 1970 (an estimated 346,000 - about 42\% of the existing office buildings in 2003).

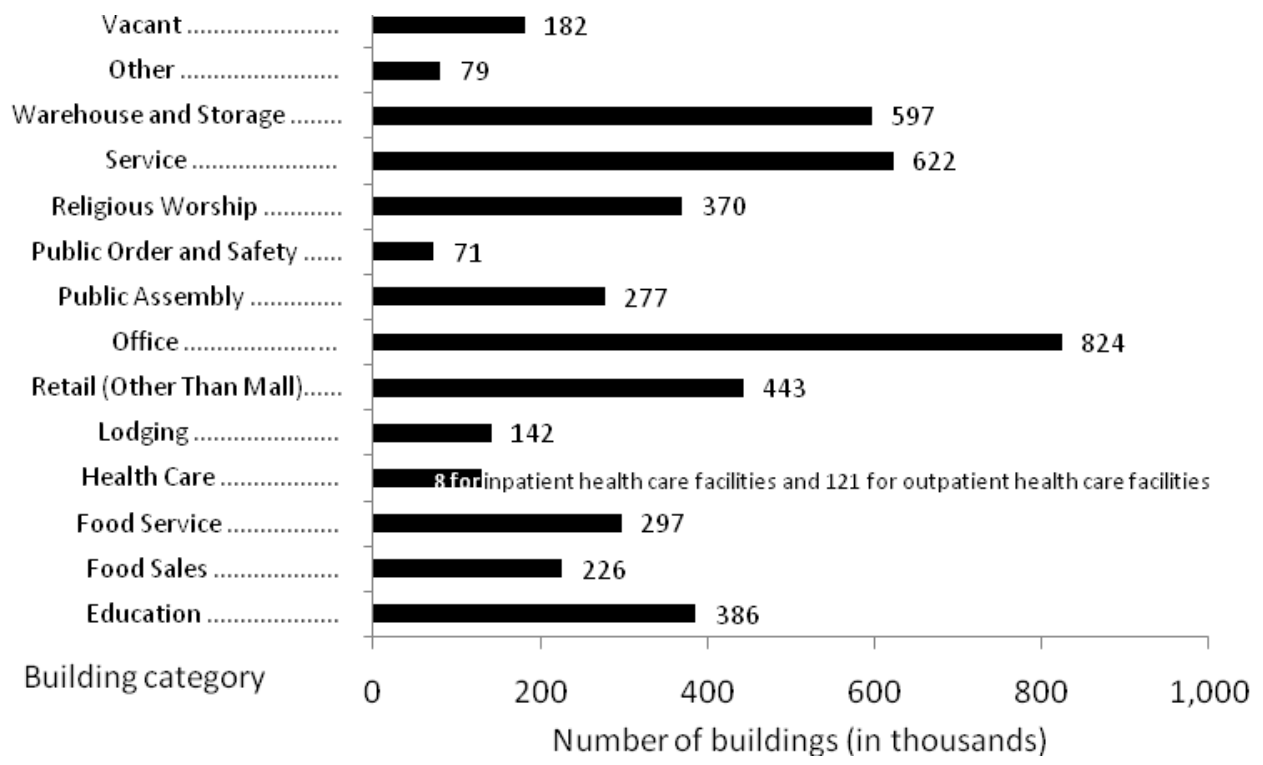

Figure 3. Commercial building distribution according to their occupancy type in the USA in $2003^{(10)}$

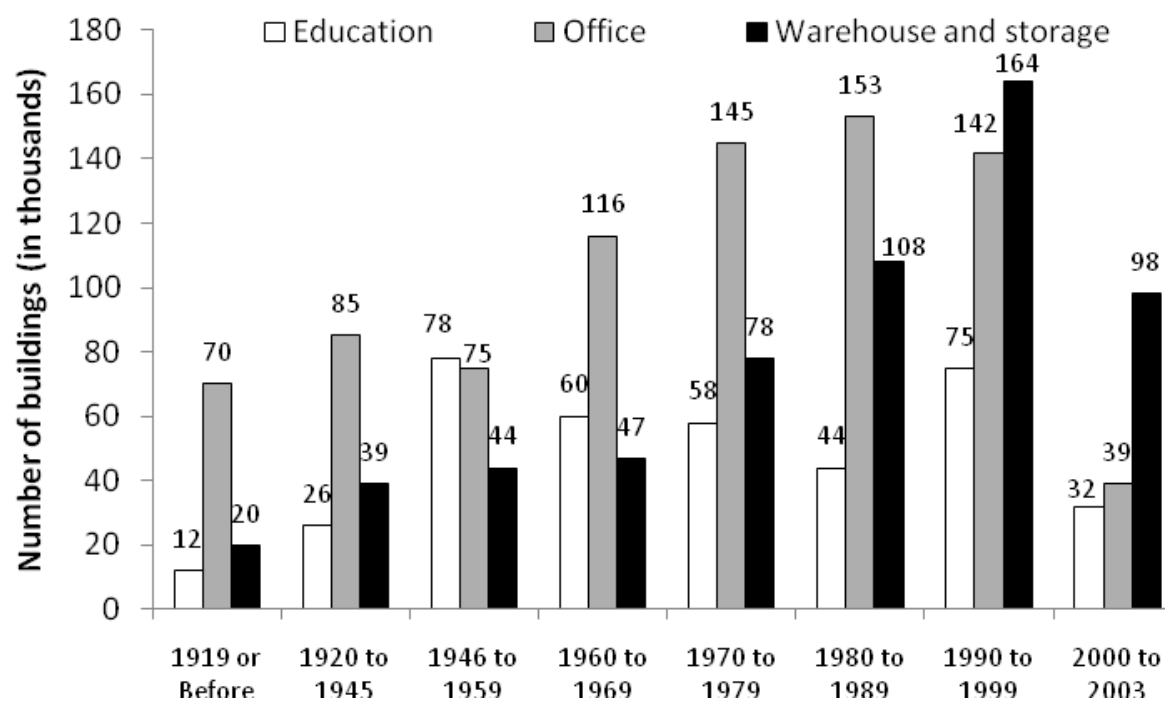

Figure 4. Construction year distribution of three building occupancy uses ${ }^{(10)}$ 


\section{ASSESSING ACCEPTANCE CRITERIA FOR FIRE SAFETY OBJECTIVES}

With respect to acceptance criteria related to the life safety objective(s) for different building groups, the aforementioned PBD guidance documents agree that data should be collected in regard to the targeted population (adult workers in offices are more "resistant" to the effects of a fire than children in schools, elderly people in retirement homes or patients in hospitals). Ideally, this means that the quantified criteria should take the different types and levels of vulnerability into consideration. However, specifics regarding the targeted populations and possible systematic methods to assess them are not provided. In addition, if the guides also consider the estimation of individual risk or societal risk, they do not provide a detailed method regarding the estimation of these risks for

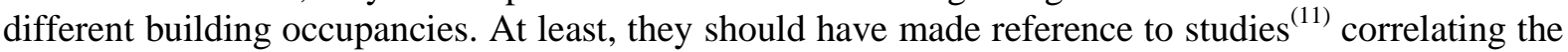
levels of "acceptable" risk with the population vulnerability and the level of risk control which are both functions of the building occupancies: societies and individuals are more concerned about the possible loss of multiple "vulnerable" persons who do not control their own risk than about the loss of the same amount of persons who seem to willingly take some risks (patients in hospitals and children in schools are highly dependent on other people to evacuate during emergency situations, whereas workers in industrial plants accept to be at the vicinity of hazardous materials, in exchange of a monetary compensation).

The use and occupancy classification for specific buildings or facilities, as described by $\operatorname{ICC}^{(4)}$ already takes into consideration the fact that some buildings can represent a "substantial hazard to human life in the event of failure" (jails and detention facilities are then classified in Performance Group III) or they can be "designated as essential" (hospitals are then classified in Performance Group IV). In a sense, this classification shows that buildings classified in higher performance groups, the magnitude of the design hazardous event or "perturbation" has to be moderate, if not mild.

This notion of "perturbation" - in the context of other stakeholders' objectives, such as business interruption - has been examined in some detail, with key observations summarized in the following paragraphs.

\section{Specific building types have specific "chronic" demands}

The concept of "competing objectives" is not new, and it has been noted that competing objectives should be addressed in PBD ${ }^{(12)}$. However, there has been little or no discussion with respect to how one prioritizes competing objectives. In a move toward understanding how users might prioritize objectives, the terms 'chronic' and 'acute' are introduced. As used here, the association between the building and its occupants during normal use is described through "chronic" objectives - those objectives which are based on the regular use of the building. In this taxonomy, hazard events (fire, flood, earthquake...) may be seen as "perturbations" of the "building-occupant" system. Objectives (or situations) associated with such events are then defined as "acute". Buildings are complex structures by essence; in addition to the building parts devoted to its chronic functions (e.g., auditorium in theater, classroom in school), buildings contain systems intended to support the chronic operation of the building (electricity, plumbing, heating, ventilating and air conditioning, etc). These support systems are used in an everyday basis, where as the fire protection systems (as part of all emergency systems) are meant to be used in the specific event of a fire (and unwanted false alarms). Because of this objective dichotomy, competing priorities may appear between the "chronic" objectives and the "acute" ones related to fire safety. This is important when trying to understand how people might respond in acute situations as compared with chronic conditions.

Tubbs and Meacham ${ }^{(13)}$ summarize some of these competing priorities related to hospitals:

- patients' comfort is offered by large, well-lit facilities that challenge the fire safety concept of compartmentation,

- design flexibility due to ever-changing programmatic needs may appear as a cost-benefit challenge for the fire safety design,

- $\quad$ security needs challenge safe egress capabilities. 
Other examples related to the above include:

- open spaces in 'spec' office buildings, which are outfitted at the request of the entity renting the space, may conflict with compartmentation desires;

- during the lifespan of a building, contents and occupants may vary in characteristics and number, especially in the numerous buildings of multi-occupancy type;

- following the events of September 11, 2001, an increase of security points inside public places creates situations that challenge the chronic objective of providing uncongested pedestrian access and movement and the acute fire safety objective of easy egress (e.g., many spaces where airport security screening has been set up where probably not designed for large numbers of densely packed people queuing up and the exit system may not be designed to readily accommodate this).

Looking at hospitals in particular, other "chronic" objectives exist due to their very specific design: patients in Intensive Care Units (ICU) are often connected to machines that keep them alive, operating rooms are designed to be sterile and outfitted with life-sustaining equipment that cannot be quickly removed, etc. In addition to the criteria associated with the fire threat, performance criteria related to the safeguarding of the life supporting pieces of equipment should be established, not only as a result of the fire threatening conditions but also as a result of a potential application of a fire suppression system. For hospital wards, the main nurse station could be positioned in an open corridor so nurses have a constant view of the ICU (hospital stakeholder's objective), which is in not in accordance with the fire safety objective of limiting the smoke and fire spread by adding compartmentation features.

"Chronic" objectives may also appear in clear contradiction with the safety objective of evacuation in case of a fire in buildings such as correctional facilities where people have to be kept behind locked doors. Less obvious types of buildings such as casinos are primarily designed to have the patrons focused on staying at the same spot for long periods of time.

With respect to chronic objectives, perturbations, and acute objectives, a crucial concept to analyze and quantify is the duration of the shift between the "chronic" (normal) condition to the "acute" (fire emergency) condition - this can have a significant impact on establishment of required safe egress time (RSET). Another critical concept to analyze and quantify is the period required to restore the facility to "chronic" (normal) operations.

It is also important to note that in particular areas, safety objectives can also compete, especially when hazardous materials are involved. For example, in plants manufacturing nuclear fuel, PMMA based "glove boxes" that are specially treated with lead to absorb the effects of radioactive materials that operators manipulate are a very important source of combustible. Nevertheless, they may appear to be more effective for this safety purpose than the glass based "glove boxes" because the "chronic" objective supersedes the "acute" objective. Fire can also disrupt a safety procedure of a hazardous system; in that case, restoration of that safety procedure may also supersede fire safety protocols. In order to deal with this potential competition of objectives, a feedback loop between the different stakeholders should always been applied.

Chronic objectives and fire safety objectives also have to adapt in time. In day-care occupancies and health care occupancies, one of the biggest challenges is reducing the chances that a patient may acquire a health care-associated (nosocomial) infection. Related to this objective, the introduction of alcohol-based hand rubs was considered as a potential source of fire, especially when positioned above an electrical source. In consequence, NFPA had to study this fire hazard issue, introduced specific paragraphs in the 2006 version of the Life Safety Code and revised them in its 2009 version $^{(3)}$ (paragraphs 18.3.2.6 and 19.3.2.6 for health care facilities).

To address the above issues, the proposed integrated approach requires describing the building's "chronic" uses and related demands, which comes before the integration of the stakeholders' objectives with respect to acute objectives associated with system perturbations. It also requires consideration of the transition between the chronic (normal) use of the building and the fire emergency period, which is a key issue in the evacuation. 


\section{Risk tolerance criteria and building uses}

Some building occupancy uses are more regulated than others because the associated societal risk tolerance varies according not only to the likelihood and the consequence of fire events, but also to the number of simultaneous casualties, vulnerable populations and the level of safety control that the public concedes to third parties. A characteristic example of low fire risk tolerance applies to health care facilities, where vulnerable populations are present and where the public literally puts their lives into the hands of the healthcare facility staff.

As an aftermath of the Wincrest Nursing Home fire (arson) that caused 24 deaths on January 30, 1976, the City of Chicago and its Board of Health made several safety improvements including ${ }^{(14)}$ :

- installing a sprinkler system in all new and existing nursing homes and that the new sprinkler systems must be connected with the fire alarm system,

- requiring emergency training for all nursing home staff which includes transporting patients during an emergency,

- abolishing dead end corridors in nursing home,

- organizing disaster plan and regular emergency drills made by the Board of Health,

- enforcing smoking rules so residents / visitors must smoke in designated areas supervised by staff.

In 2003, two fires occurred in two different unsprinklered nursing homes in the US: one fire in Hartford, Connecticut, causing 16 casualties and one fire in Nashville, Tennessee, causing 15 deaths. As a consequence, Centers for Medicare and Medicaid Services (CMS) of the US Department of Health and Human Services issued on August 13, 2008 a final rule regarding fire safety requirements for Long Term Care facilities and more particularly, the installation and the maintenance of automatic sprinkler systems in the whole building: "This final rule requires all Long Term Care facilities to be equipped with sprinkler systems by August 13, 2013. Additionally, this final rule requires affected facilities to maintain their automatic sprinkler systems once they are installed ${ }^{(15) "}$.

Several lessons can be drawn from these two sets of events:

- because of the US regulatory system, cities, states and the whole nation can decide of their own requirements regarding fire safety. A tragic event occurring in one state (Illinois in 1976) was not enough to "trigger" the same level of requirements in other states;

- nevertheless, health care management has entered under a federal scope as the federal financial participation rate ranges from 50 to 83 percent of each dollar spent by a state which is then required to describe the nature and scope of its program in comprehensive written plans submitted to $\mathrm{CMS}^{(16)}$. If the regulation is enforced at a federal level, more facilities will be affected by the regulation and the corresponding sampling in fire statistics may get larger (even if the sprinkler requirement is adopted nationwide, states still have the possibility to increase the level of safety by requiring additional fire safety measures);

- the population is getting older so the public is going to be more and more concerned about multiple deaths fires occurring in nursing homes and other health care facilities (it should be noted that an average of about 2,300 of the nation's approximately 16,300 US nursing homes reported a structural fire each year from 1994 through 1999 and that annually, the average number of fire related nursing home deaths nationwide was about five $\left.{ }^{(17)}\right)$.

These two examples are relevant of the very low risk tolerance of the AHJ (local and federal) is prepared to accept in case of fires in nursing homes. As a consequence, the minimum requirements are associated with the installation and the maintenance of a sprinkler system, which efficiency to prevent the extension of a fire is quite high. For this particular case, it seems that any PBD approach would have to consider a sprinkler system in this type of facilities as a fire safety measure, as an imperative demand from the AHJ.

Going forward, the situation for nursing homes and requirements for sprinklers will serve as a basis for assessing other occupancies, as it is expected that similarities may exist for other highly regulated building uses, and capturing such experience is important to benchmarking "tolerable" safety. 


\section{SELECTING AND EVALUATING DESIGN FIRE SCENARIOS}

Considering the elaboration and the selection of design fire scenarios upon which the PBD solutions are to be based, Chapter 8.3 of the SFPE Engineering Guide to Performance-Based Fire Protection Design ${ }^{(1)}$ (SFPE Guide) presents various techniques that can be used in identifying possible fire scenarios, such as Failure Modes and Effects Analysis (FMEA), failure analysis, "what if?" analysis. It also states that "the scarcity of the [historical] data needed to assigning probabilities [to fires] can limit this approach for conducting Performance-based Design for a specific [new] project". Concerning past fire histories, it is indicated that they "can provide some very useful input by identifying potential failures of various items, as well as frequencies and severities of fires". It should be noted that the SFPE Guide presents various tools useful to describe the scenarios as possible chains of events; quantified data is still to be gathered in order to quantify the probabilities of these events. Unfortunately, like the SFPE Guide, most guides provide fewer sources about how to quantify the possible events than tools used to identify possible scenarios. Nevertheless, the guides suggest that data should be collected using fire incident databases as they provide some information regarding how fire started, spread and ultimately led to fatalities and injuries (or building damage for a property loss objective). Studies on the reliability of fire protection systems including smoke detectors and automatic suppression systems are also sparingly available, as often only single values are given in quantitative risk assessment studies. Here again, guidance documents on Performancebased Design are very generic, as they were not designed to provide detailed methods of conducting a PBD approach for a particular building project. They also propose different methods to achieve the fire safety goals of the PBD approach, using risk matrix or a quantified fire risk assessment, and they emphasize different aspects on the selection of design fire scenarios. Nevertheless, they all agree to obtain data for fire statistics and fire investigations reports of "historical fires".

As pointed out previously, it seems important to intensively examine fire incident databases and fire investigation reports in order to extract the most accurate parameters of "real" fires and therefore to constitute a validated, if not exhaustive, base for the parameters needed to imagine and ultimately select the design fire scenarios (with eventually their estimated incidence on the overall fire risk). Table 2 below is an example of data presented in the NFPA reports of US fires in selected occupancies ${ }^{(18)}$. This data shows a correlation between the extent of flame damage and the number of casualties and injuries as well as the direct property damage. A discrepancy appears between the fires that are related to the life safety objective as their maximum extent is the room of fire origin and the fires that are related to the property damage objective as the more the fire extents, the more damage it causes, which could indicate that the design fire scenarios for the life safety objective may not be the same for other business or property oriented objectives. This table, as well as the global results that are usually presented in the NFPA reports, is too general to be used in a Quantitative Risk Analysis. For example, 510 fires confined to room of fire origin led to 44 civilian injuries. What is the number of fires that led to multiple $(5,10$, even 44$)$ injuries? Did these fires occur in the same type of health care facilities, in the same state, with the same fire ignition conditions?

\begin{tabular}{|l|c|c|c|c|c|c|c|c|}
\hline \multirow{2}{*}{ Extent of Flame Damage } & \multicolumn{2}{|c|}{ Fires } & \multicolumn{2}{c|}{$\begin{array}{c}\text { Civilian } \\
\text { Deaths }\end{array}$} & \multicolumn{2}{c|}{$\begin{array}{c}\text { Civilian } \\
\text { Injuries }\end{array}$} & $\begin{array}{c}\text { Direct Property } \\
\text { Damage (in } \\
\text { Millions) }\end{array}$ \\
\hline Confined or contained fire & 560 & $18 \%$ & 0 & $0 \%$ & 8 & $9 \%$ & $\$ 0.1$ & $0 \%$ \\
\hline Confined to object of origin & 1,930 & $61 \%$ & 0 & $0 \%$ & 29 & $33 \%$ & $\$ 3.8$ & $18 \%$ \\
\hline Confined to room of origin & 510 & $16 \%$ & 1 & $100 \%$ & 44 & $51 \%$ & $\$ 4.2$ & $20 \%$ \\
\hline Confined to floor of origin & 60 & $2 \%$ & 0 & $0 \%$ & 1 & $1 \%$ & $\$ 2.1$ & $10 \%$ \\
\hline Confined to building of origin & 90 & $3 \%$ & 0 & $0 \%$ & 5 & $6 \%$ & $\$ 10.3$ & $49 \%$ \\
\hline Extended beyond building of origin & 10 & $0 \%$ & 0 & $0 \%$ & 0 & $0 \%$ & $\$ 0.7$ & $3 \%$ \\
\hline Total & $\mathbf{3 , 1 5 0}$ & $\mathbf{1 0 0 \%}$ & $\mathbf{1}$ & $\mathbf{1 0 0 \%}$ & $\mathbf{8 7}$ & $\mathbf{1 0 0 \%}$ & $\mathbf{\$ 2 1 . 3}$ & $\mathbf{1 0 0 \%}$ \\
\hline
\end{tabular}

Table 2. Structure Fires in Health Care Facilities ${ }^{(18)}$, Excluding Nursing Homes by Extent of Flame Damage (1999-2002 Annual Averages) 
NFPA reports, as well as USFA reports, are a good starting point in order to collect generic information about fires in selected occupancies. Nevertheless, results shown in these reports do not seem to be directly usable for populating event trees, as important parameters of the event trees were blended in making the data too generic. A possible way to overcome this situation is to analyze directly the data in the NFPA or USFA databases, by segmenting once again the problem and considering each type of health care facilities considered in Table 2. Investigation reports also are an alternative to the generic data found in the aforementioned NFPA reports. Some of them have been published as a consequence of multiple death fires.

The extensive work by Bryan ${ }^{(19)}$, DiNenno and Milke on 65 fires in heath care facilities between 1977 and 1980, is to be analyzed thoroughly as it contains a lot of information about behavioral response patterns of staff and patients, as well as the efficiency of the different technical fire safety measures in these facilities.

According to Tillander ${ }^{(20)}$, the best source of information regarding the necessary input for fire quantitative risk assessments is fire statistics, even she also stated that "the statistical approach can be used only existing buildings on which the data is not too sparse. When suitable statistics are available, the point estimates or the probability distributions can be derived". Nevertheless, Tillander as well as Salisbury ${ }^{(21)}$ et al. indicate that the predictive use of statistical data should be made with care, as the conditions which have made up the data may be different in the future. This remark is also valid when looking at statistics from the past, prior to a major change in fire safety requirements implementation or in building contents, such the one that occurred with the advent of plastic materials. Considering the case of nursing homes, fire trends over the years would have to be assessed in conjunction with the decrease of the number of nursing homes (sampling), changes in the fire safety tasks of the staff, as well as the ratio staff / patient, the patient pathologies and age distributions.

Another advantage of fire investigations is connected with the improvement of fire modeling when this technique is used, for forensic purposes, to analyze the development of a fire event. Data for fire models are sometimes estimated from specific experiments conducted with actual materials collected on the fire scene ${ }^{(22)}$, which is a way to narrow the uncertainties associated with the variability of the parameters of fire modeling and human behavior for the incident being investigated.

\section{PROPOSING AND EVALUATING FIRE SAFETY STRATEGIES}

Building codes or fire safety standards are organized in the USA or around the world, in relation to the type of facilities or particular types of hazards that could be located in facilities. Comparisons between a prescriptive fire safety solution and an engineering solution are then based on the type of building occupancy.

Data from fire incident statistics and investigation reports can also be used in order to determine if the building where a fire occurred was defined according to the prescriptive regulations. This kind of data should be exploited in order to set up the level of safety of the prescriptive regulation at the time the building was constructed or renovated. By examining fire statistics for several years, it should be possible to quantify the benefits or eventually the drawbacks of the last implemented fire safety requirements. For heath care facilities, regulated by the Joint Commission on Accreditation of Healthcare Organizations (JCAHO) and for all these facilities which established smoke-free environment / no smoking policies, it was observed that visitors were giving smoking materials to patients and residents without the health care staff's knowledge ${ }^{(23)}$. This phenomenon was found as to explain why this type of ignition source was not decreasing in the corresponding fire statistics.

At last, a feedback loop, as designed in models used in system dynamics to investigate the knock-on effects of changes on a system, should always been applied to verify that the implementation of a fire safety management measure does not end up with creating an unsafe counterproductive measure. 


\section{Fire drills in health care facilities}

Because of the lack of mobility of vulnerable patients, importance is given to the health care staff as components of fire detection, fire alarm, evacuation / defense in place strategy and even fire extinguishment. Fire drills appear to be an adequate means to quantify the level of skill maintenance by the staff in this matter. The American Health Care Association ${ }^{(24)}$ (AHCA) presents the following review of the Life Safety Code by the Center for Medicare \& Medicaid Services (CMS).

"Life safety surveyors have recently been citing facilities in which all staff members did not participate in at least 4 quarterly fire drills per year. Although this may sound like a simple and reasonable requirement, not all staff members are present when their shift has a drill. Staff members may be on vacation, sick, in training outside the facility, etc. Nowhere in the Life Safety Code does it require that all staff members must participate in a minimum of 4 fire drills per year".

The NFPA requirements in the Life Safety Code $^{(3)}$, concerning staff training and fire drills, in heath care facilities are mentioned in:

- paragraph 18.7.1.2: all employees shall be periodically instructed and kept informed with respect to their duties under the required [plan for the protection of all persons in the event of fire];

- paragraph 18.7.1.6: drills shall be conducted quarterly on each shift to familiarize facility personnel (nurses, interns, maintenance engineers, and administrative staff) with the signals and emergency action required under varied conditions;

- paragraph 18.7.1.8: employees of health care occupancies shall be instructed in life safety procedures and devices.

The Life Safety Code does require that a minimum of 4 fire drills per shift per year for a total of 12 fire drills be held by a facility. Sections A18 \& 19.7.1.2 states that "the purpose of a fire drill is to test and evaluate the efficiency, knowledge, and response of institutional personnel in implementing the facility fire emergency plan". The purpose of the drill is to test the capabilities of the staff present during the drill. Nevertheless, it is very likely that during actual fires in facilities, all staff on the shift will not be present. An excellent opportunity to test this situation is to conduct a drill when all staff is not present.

For its part, NFPA ${ }^{(25)}$ is aware that the purpose of fire drills is "not to disturb or excite patients" as paragraph 18.7.1.5 (and 19.7.1.5) states that "infirm and bedridden patients shall not be required to be moved during drills to safe areas or to the exterior of the building". NFPA also indicates that "many health care facilities conduct fire drills without disturbing patients by choosing the location of the simulated emergency in advance and by closing the doors to patients' rooms or wards in the vicinity prior to initiation of the drill".

It should be noted that inspections and surveys are also a good means to collect data, not only about installed and maintained technical fire safety measures but also for estimating the actual level of implication of staff and other operators in fire or other emergency situations.

\section{CONCLUSIONS}

Existing Performance-based guidance documents describe possible ways to create alternate solutions to prescribed requirements. However, even though they emphasize the importance of parameters such as the definition of the acceptance criteria or the selection of the design scenarios, they are too general in defining and quantifying these parameters for a particular project. In order to help identify and evaluate the relative importance of the most influential parameters of a PBD approach for a project, an integrated approach to PBD for life safety across different building use groups is proposed. 
In creating the integrated PBD approach, a first task consisted of breaking down the analysis and design problem into manageable pieces categorized by building occupancy uses, defined in part by their own everyday or "chronic" objectives. The analysis of "chronic" objectives for occupancies such as healthcare facilities, casinos, airports, and offices has already illustrated a competition between their respective chronic objectives and the "acute" ones defined in emergency situations such as fires, which are perceived as a perturbation of the "building-occupant" system. Because of this competition, a tremendous effect exists of having building occupants "shift" from their usual activities to the emergency evacuation process, which is very important since this effect has to be quantified in egress calculations as it determines the "pre-movement" time of the RSET. It has also be found that, for objectives related to business interruption of buildings defined as "essential to the community", the period following the "perturbation" is also important. Thus, the examination of the "chronic" objectives, for every building occupancy uses, appears to be a necessary task to perform prior to any fire safety analysis. Techniques, derived from the field of system dynamics, appeared to be useful in order to analyze the effects of implementing the categorized "building-occupant" systems with fire safety measures and their use will tend to be generalized within the proposed PBD approach.

The benefit of looking more closely at regulatory, operational and loss history though the study of US certified nursing homes showed that the low fire risk tolerance of this specific building occupancy use had a tremendous impact on the minimal level of fire safety demanded by the Authority Having Jurisdiction, as the installation and maintenance of sprinklers are required for new and existing nursing homes. This situation and resulting requirements for sprinklers will serve as a basis for assessing other occupancies, as something similar could also appear for other highly regulated building uses.

When analyzed through the spectrum of the building occupancy uses, data sources, including but not limited to fire statistics and fire investigation reports, tend to provide more pertinent and applicable data for similar projects, therefore reducing uncertainties related to the use of generic data. Inspections and surveys related to very precise situations will also be included in order to gather specific data on fire management procedures, as it was shown that staff constitutes a showpiece of the fire safety strategy in nursing homes.

\section{REFERENCES}

${ }^{1}$ Society of Fire Protection Engineers, SFPE Engineering Guide to Performance-Based Fire Protection, Second Edition, SFPE, Bethesda, MD (USA) 2007

${ }^{2}$ Society of Fire Protection Engineers, SFPE Code Official's Guide to Performance-Based Design Review, SFPE, Bethesda, MD (USA) 2004

${ }^{3}$ National Fire Protection Association, NFPA 101 "Life Safety Code ${ }^{\circledR} "$, NFPA, Quincy, MA (USA) 2009

${ }^{4}$ International Code Council, ICC Performance Code for building and facilities, International Code Council, INC., Whittier, CA (USA), 2009 edition

${ }^{5}$ International Fire Engineering Guidelines (IFEG), Australian Government, State and Territories of Australia, 2005

${ }^{6}$ Meacham, B.J., "International Experience in the Development and Use of PerformanceBased Fire Safety Design Methods: Evolution, Current Situation, and Thoughts for the Future," Invited Paper, Proceedings of the International Association for Fire Safety Science, $6^{\text {th }}$ International Symposium, Poitiers, France, July 1999, pp.59-76

${ }^{7}$ Ian Thomas, Dorothy Bruck and Michelle Barnett, "Is Consideration Of Evacuation Relevant to Most Fire Fatalities? Using the CESARE Coronial Database to Investigate the Utility of ASET/RSET Calculations", Proceeding of the $4^{\text {th }}$ International Symposium on Human Behaviour in Fire, pp.411-420, Interscience Communications, London (UK), 2009

${ }^{8}$ International Code Council, International Building Code, section 308, (USA) 2009 
${ }^{9}$ American Hospital Association, Fast Facts on US Hospitals, http://www.aha.org/aha/resource-center/Statistics-and-Studies/fast-facts.html

${ }^{10}$ US Energy Information Administration (EIA) - 2003 Commercial Buildings Energy Consumption Survey (CBECS) Detailed Tables - most recent available, released: September 2008 (http://www.eia.doe.gov/emeu/cbecs/cbecs2003/detailed_tables_2003/detailed_tables_2003.htmll\#enduse03)

${ }^{11}$ Wolski, A., Dembsey, N. and Meacham, B., "Accommodating Perceptions of Risk in Performance-Based Building Fire Safety Code Development," Fire Safety Journal, Elsevier, London, Vol. 34, No. 3., pp.297-310

${ }^{12}$ Meacham, B.J., Editor, and Johann, M., Associate Editor, Extreme Event Mitigation in Buildings: Analysis and Design, National Fire Protection Association, Quincy, MA, April 2006

${ }^{13}$ Jeffrey S. Tubbs and Brian J. Meacham, "Design solutions", chapter 9 of Egress Design Solutions - A Guide to Evacuation and Crowd Management Planning, John Wiley and sons, 2007

${ }^{14}$ Emergency Management Higher Education Program Report - Federal Emergency Management Agency (FEMA) (training.fema.gov/EMIWeb/edu/ARRPT/January\%2030,\%202009.doc)

${ }^{15}$ Department of Health and Human Services - Centers for Medicare \& Medicaid Services 42 CFR Part 483 - [CMS-3191-F] RIN 0938-AN79 "Medicare and Medicaid Programs; Fire Safety Requirements for Long Term Care Facilities, Automatic Sprinkler Systems", Federal Register, vol. 73, No. 157, Wednesday, August 13, 2008, pages 47075-47092, 2008

${ }^{16}$ United States General Accounting Office, "Medicaid Financial Management - Better Oversight of State Claims for Federal Reimbursement Needed" - GAO-02-300, February 2002 (http://www.gao.gov/new.items/d02300.pdf)

${ }^{17}$ United States Government Accountability Office, "Nursing Home Fire Safety - recent fires highlight weaknesses in federal standards and oversight" — GAO-04-660, July 2004 (http://www.gao.gov/new.items/d04660.pdf)

${ }^{18}$ Marty Ahrens (NFPA), Selections from the U.S. Fires in Selected Occupancies - Health Care Facilities, excluding Nursing Homes, NFPA, Quincy, MA (USA), March 2006

${ }^{19}$ J.L. Bryan, P.J. DiNenno, and J.A. Milke "The Determination of Behavior Response Patterns in Fire Situations, Project People II. Final Report - Incident Reports, August 1977 to June 1980", NBS-GCR-80-297, Washington DC (USA), December 1980

${ }^{20}$ Kati Tillander, "Utilisation of statistics to assess fire risks in buildings", VTT publication 537, VTT Technical Research Centre of Finland, 2004

${ }^{21} \mathrm{M}$ Salisbury, P Johnson, E Yii and MC Hui, "QRA and fire safety - a beneficial experience...", Interflam 2007, proceedings of the eleventh conference, volume 2, pp. 1253-1263, Interscience Communications, London (UK), 2007

${ }^{22}$ William Grosshandler, Nelson Bryner, Daniel Madrzykowski, and Kenneth Kuntz, Report of the Technical Investigation of The Station Nightclub Fire, report NIST NCSTAR 2: Vol. I and Vol. 2, National Institute of Standards and Technology, June 2005

${ }^{23}$ Daniel J. O'Connor, "Health care occupancies", chapter 15, section 20 of the $20^{\text {th }}$ edition of the Fire Protection Handbook, NFPA, 2008

${ }^{24}$ American Health Care Association (AHCA) "Life Safety Update: Staff Participation in Fire drills" http://www.ahcancal.org/facility_operations/fire_life_safety/Pages/StaffParticipationinFireDrills.aspx

${ }^{25} \mathrm{NFPA}$, Info on health care occupancies, http://www.nfpa.org/itemDetail.asp?categoryID=792\&itemID=20722\&URL=Safety Information/For consumers/Occupancies/Nursing homes/Info on health care occupancies 


\section{Appendix A2}

"Ready-to-Use" Building Layouts and Combustible Packages for 3-D Fire Simulations" presented at the Fire and Evacuation Modeling Technical Conference 2011 


\title{
"READY-TO-USE" BUILDING LAYOUTS AND COMBUSTIBLE PACKAGES FOR 3-D FIRE SIMULATIONS ${ }^{(\mathbf{a})}$
}

\author{
Alberto ALVAREZ and Brian J. MEACHAM \\ Worcester Polytechnic Institute \\ 100 Institute Road, Higgins Laboratories \\ Worcester, MA, 01609, USA \\ e-mail: al_alvarez@wpi.edu
}

\begin{abstract}
In recent years, complex 3-D computational fire effects models have been widely used by fire protection engineers to simulate the consequences of fire and to assess effectiveness of fire mitigation options. This has happened in part because these tools have become increasingly user friendly. However, it may not always be appropriate to use a complex model just because it is available. In addition, the use of these complex tools requires considerable time, both for users to create input data files and analyze the results, and for computers to produce the simulations. With respect to input files, independent of the description of the initial designbasis fire itself, information and data are lacking about the way the building itself should be described as input data, the degree of detail that is necessary in order to capture the elements that affect the validation of the simulation, and how to optimize mesh size so that critical elements can be properly incorporated without resulting in a prohibitively lengthy calculation time. In order to begin addressing these issues, this project aims to provide guidance on how to select the right type of tool to fit the engineering application, to collect and make available to the entire fire community, representative building layouts for common occupancy groups, such as schools, offices in high-rise buildings, and hospitals, which can form a common basis for estimating, assessing and verifying building-related model parameters, and to collect and make available a set of 'combustible packages' representing 3-D objects such as chairs, couches, and beds, which contain heat release rate, chemical reaction, and toxicity properties needed for the simulations. Together, the tool selection guidance, building configurations and combustible packages will help fire protection engineers become both more efficient and effective in applying the best tools for the application at hand.
\end{abstract}

\section{INTRODUCTION}

Within the performance-based fire protection design framework, tools are used in order to estimate the consequences of fire design scenarios, upon which different fire protection trial designs are evaluated.
A fire scenario describes the evolution with time of the fire, from its ignition to its extinguishment. Not only fire is a threat to the building occupants, but also to the building itself, to its contents and to its own structure. Life safety is a common objective for any built environment and concerning fire hazard, it is essential to evaluate the consequences of the fire in terms of heat effects (temperature and thermal dose) as well as in terms of toxicity and visibility loss which can prevent occupants from finding their way to a safe place so they subsequently succumb to untenable heat and toxic conditions. In order to conduct this analysis, a fire design scenario shall contain information necessary to evaluate the heat released during the fire and also fire effluent productions. This information is then added to the information related to the description of the built environment and incorporated, as user input, to fire effects tools. When selecting appropriate tools for analysis, several factors need to be considered.

\section{Different levels of complexity}

The Society of Fire Protection Engineers (SFPE, 2011) defines the three following types of fire effects tools, based upon their levels of complexity:

- algebraic models, which include empirical or analytical equations to describe localized phenomena such as the plume region (temperature and velocity), the ceiling jet, and smoke filling in an enclosed space;

- zone or lumped parameter models, which divide spaces into control volumes where the quantities are spatially homogeneous (and which often include add-on sub-models dealing with particular aspects of the fire description);

- Computational Fluid Dynamics (CFD) models, which can calculate flows through complex geometries by dividing the considered space in relatively small elements where a set of governing equations is numerically solved.

Hybrid tools combining a zone model with a CFD model, a fire effects models with a HVAC network model may also be considered when assessing fire consequences. 
Understanding and recognizing the differences in level of complexity and outcomes delivered is the first step in matching tools to applications.

\section{Different uses have different constraints}

The next step in selecting a tool is to understand issues associated with objectives and constraints on the project, such as time, resources, and level of analysis required. At the start of a complex project in the consulting environment, for example, fire protection engineers (FPEs) are often asked to provide ideas of the possible fire protection measures, even when the project itself is not well defined. At this stage, the level of analysis required will be driven by the level of complexity needed given the scarcity of input data describing the project (i.e., building layout and combustible contents which provide potential fire sources) and the potential impact of the analysis on the project direction. As a project passes through the steps of feasibility, concept design and schematic design, FPEs are able to refine their initial ideas using more complex tools as appropriate.

Ultimately, many projects which require performance-based analysis involve complex building geometries, which present challenges for the use of algebraic and zone models. As such, given the availability of CFD fire effects tools, and the fact that they can handle more complex geometries, they can appear to be the 'best' candidates for assessing the fire protection design of such projects. However, due to computational constraints (in terms of processors which manage the computational time and in terms of usable memory which sets up the limits of the refined computational grid), it may not practical or costeffective to perform one, let alone a series of detailed CFD simulations. In such cases, a decision often needs to be made regarding the trade-off between complexity and time. In the end, it may be that the FPE has to rely on less complex fire effects tools from a time perspective, while demonstrating that the less complex tools are validated for handling the complex geometry (i.e., the FPE needs to demonstrate how the uncertainties related to adapting the complex geometry for less sophisticated tools is not significantly or inappropriately changing the outcome of the engineering solution).

While time constraints may be an issue for practicing engineers, and time and complexity trade-offs may be required, this is not the case in other environments, such as academia, research and high risk or hazard industries. In the academic or research environments, for example, it is not uncommon for multi-year studies to be conducted. Such studies may involve developing new tools, expanding existing tool capabilities, and assessing better ways to apply existing tools to solve complex engineering problems.

An example of a long-term study dealing with better ways to use tools to solve an engineering problem can be illustrated by Francesco Colella's PhD thesis titled "Multiscale Modeling of Tunnel Ventilation Flow and Fires" (Colella, 2010), conducted at the Politecnico di Torino. His research objective is related to the design of smoke extraction in tunnels of several kilometers in length. In this case, a dichotomy exists between the needed accuracy to simulate the flows around the smoke extractors and the fire, which requires describing the local environment with cells of a few centimeters, and the smoke flow along the whole tunnel, which requires millions of cells and a manageable computational time to perform a series of scenarios to test the smoke control system. In the referenced work, this dichotomy led to the formulation of a method allowing the coupling of a CFD fire effects tool with a 1-D ventilation network tool. The outcome is a hybrid tool where information is transferred between the tools and a formula describing the minimum extent of the CFD computational domain where results are similar to the ones estimated with the full CFD representation of the tunnel.

For an example of a very particular and highly regulated sector which is high-risk / high hazard, one can consider efforts within the nuclear power industry, where multi-year projects involving nuclear power plant operators, researchers, governmental agencies and regulators, have been undertaken (Barrachin et al., 2000; Siu et al., 2008). In this environment, not only have there been sustained research projects aimed at tool development and assessment (e.g., NIST/NRC efforts), but also development of a process for applying different level of complexity tools at different stages in the assessment and design process within a general quantitative (or probabilistic) risk assessment (QRA or PRA) framework. For example, within a QRA process, different types of fire effects tools can be selected as follows:

- In the first instance, simple tools which can be quickly applied are utilized in order to screen out fire scenarios which would have no impact on the QRA. This first level of analysis primarily consists of applying algebraic models that can be edited in a spreadsheet for handing thousand of calculations. Since this application is aimed at the elimination of the fire scenarios which are not relevant for the QRA, it only requires coarse description of the domain and conservative assumptions of the fire development. 
- A second more detailed level of analysis can then be conducted by applying more complex fire effects tools to the remaining scenarios. The specific application here is to determine quantities that would actually be input for the QRA related to fire risk. The events to be considered may be framed in time periods of several minutes (e.g., time to the first correcting action) to several hours (in cases where the fire has been spreading and more and more correcting actions have to be taken in order to maintain core safety). Because thousands of simulations may be required to understand the risk, and if the compartments can be characterized with simple geometries (e.g., "shoe box" shaped rooms), application of a zone model appears to be the optimum solution in order to get the corresponding fire QRA input data.

- Once specific areas of concern are identified, CFD tools can then be used to handle specific scenarios involving geometries, such as cable trays supporting the transmission of power or control information regarding core management or safety. In such cases, detailed local information is needed to describe the combustion and flame spread in cables trays, which constitute at the same time extended fire areas and targets important for the core safety in the global QRA.

\section{Data availability and fire phenomena}

Two additional critical criteria in the selection of a candidate tool for a given application are the availability of the input data required to effectively apply the tool, and the making sure that the fire phenomena that the tool simulates matches the assessment needs.

Assuming for this discussion that the three types of fire effect tools are available and have been validated to correctly represent the physics for a given application, the next criterion regarding appropriateness of a tool for an application could then be determined by the amount and goodness of information that can be collected for the data input needed by the different tools. The recently published SFPE Guidelines for Substantiating a Fire Model for a Given Application (SFPE, 2011) provides a good starting point, noting for example the need to identify:

- details of the spatial domain representing the built environment,

- fire design scenario timeframes (from several minutes for a single room flashover application to several hours for assessing the collapse of a structure due to a generalized fire),
- material properties not only describing the combustible contents but also the other building elements which "absorb" heat and fire effluents as well as the load-bearing elements,

- initial and boundary conditions, including initial temperature in and outside the built environment and the ventilation conditions (initial conditions including the window and doors status (opened or closed) as well the boundary conditions (how the doors are leaking or how the mechanical ventilation network is set up).

The final attribute which can be used to assess the appropriateness of a tool for a given application is related to the application itself; what is being assessed, and what features of a tool are required to support that assessment. For example, an application could be related to assessing fire propagation inside the room of fire origin with respect to the safety of the occupants in the room. In that case, tools would be needed to assess the fire spread from the $1^{\text {st }}$ burning item to the subsequent ones until the flashover is reached. Fire effects tools including models assessing flame characteristics, ignition by radiation fluxes, etc. would then be considered. Using a tool which is too coarse for the application may not yield the level of information required to make a good assessment. By contrast, the application purpose may be to consider the safety of occupants remote from the compartment of fire origin, without a need to focus on how the fire initially develops. In this case, the application is more concerned with species production and spread outside of the room of origin than with the fire development. In these cases, the same tool may be appropriate to solve different parts of each problem, but in different ways and at different levels of complexity. In the first instance, a CFD model may be needed to obtain the degree of analysis needed in the room of origin, and a zonemodel may not yield sufficient detail. In the second case, however, a zone model may be appropriate for simulating initial conditions in the room of origin, with a CFD model need to assess smoke and hot gas spread outside the room of origin.

\begin{tabular}{llcccc} 
EXAMPLES & OF & \multicolumn{2}{c}{ STUDIES } & TO & BE \\
\hline CONDUCTED & RELATED & TO & THE & USE & OF \\
\hline FIRE EFFECTS & TOOLS & FOR & GIVEN \\
\hline APPLICATIONS & & & &
\end{tabular}

It is suggested that the above issues form the basis for development of 'best practice' guidelines for selecting fire effects tools based on their appropriateness to the application at hand. These guidelines would be used in collaboration with related guidance, such as the SFPE Guidelines for 
Substantiating a Fire Model for a Given Application ${ }^{1}$ and SFPE Guide to Predicting Room of Origin Fire Hazards (SFPE, 2007a) and other such guidance, and would support a wide range of industry stakeholders, including:

- FPEs, to select the appropriate tool to solve their engineering problems,

- $\quad$ researchers to develop more tool functionalities and to increase tool validation, and

- the regulators and authorities to have more confidence in the engineering solutions when these tools are used.

However, in order to ultimately produce comprehensive 'best practice' guidelines to assess the appropriateness of a fire effects tool for a given application, it is suggested that a series of both generic and specific studies need to be conducted. The intent of these studies is to utilize multiple participants to develop data and case history to illustrate a wide range of issues, such as level of detail needed in building configurations for different types of problems or occupancies (e.g., life safety in hospitals versus apartments), or detail required in characterizing 'fuel packages' for use in models to meet assessment objectives. Below is the outline of the selection process and examples of generic studies that can be conducted for supporting the tool selection process. As described in the previous section, these studies ultimately have to be based on cases representing a given application, as results of such studies are highly dependent of the given application definition and context.

\section{Process outline and generic 'test bed' environment for guiding selection of the right tool for a given application}

In this effort we aim to demonstrate that by applying a specific process for a set of 'test bed' building configurations of a particular use (categorized by building occupancy groups), for a particular range of configurations (determined by design fires scenarios) targeting a particular outcome (safety objectives including life safety, property protection, business continuity, etc.), the results of each 'test bed' study, defined in that context, will yield data which will lead to a guideline of the selection of appropriate tools for that type of situation.

\footnotetext{
${ }^{1}$ The difference between the existing SFPE Guide and the proposed approach is that the existing guide helps to justify use of a tool, once selected, and the proposed approach helps guide selection of an appropriate tool.
}

The reason for collecting ranges of buildings by building occupancy groups is to obtain an extensive database of information related to layouts of representative buildings, rather than individual building layouts, which can then serve as the basis of guidelines that are occupancy group based (e.g., guide to application of fire effects tools in healthcare occupancies). Also, in a broader context, determining the building occupancy group is the first step in assessing its fire protection requirements whether one follows prescriptive building regulations or the performance-based design process (a first step being to define the scope of the project, notably by identifying the intended use and occupancy of the building (SFPE, 2007b)).

The process that is envisaged to conduct a 'test bed' study case is composed of the following steps:

1. Identify occupancy group for study focus

2. Collect building configurations for study

3. Identify study parameters (e.g., selection of tool for assessing safety objectives)

4. Set up building layouts for fire effects (zone models, CFD models) and their evacuation counterpart

5. Identify objectives and criteria (life safety, property protection, mission continuity)

6. Select fire scenarios for study (additional guidance in other work)

7. Perform the fire (and evacuation) simulations with the different sets of tools (and for different mitigation strategies, as appropriate)

8. Analyze the results in terms of the safety objectives

9. Assess ability of tool to address defined performance issue

10. Conclude by establishing guidelines related to the tool comparison process and its outcome.

With respect to the 'test bed' studies, it is important to note that each individual case does not need to be validated; that is, the objective of performing the case studies using different tools is not to increase the validation domain of the tools, but to obtain information about the application of the different tools for attaining different objectives. Likewise, the case studies themselves do not result in de facto design fire scenarios for the considered building occupancy group. These two objectives (increasing the validation domain of tools, selecting fire design scenarios for performance-based applications), while important to the overall process, are out of the scope of the studies presented in this paper. Cf. (Alvarez and Meacham, 2011) for more information. 
Also, it is important to have participants undertaking the case studies from across the whole spectrum of the fire engineering community - from consulting engineers to regulators, and by engineers and regulators from around the world. Such diversity and breadth of participation would provide the potential to add more tools, more fire scenarios, and more variants in the building configurations, and the resulting 'test bed' study guidelines would be more directly included in the larger performance-based fire protection design framework. (Having 20 engineers from 10 countries apply tools and fire scenarios that they select for a common set of objectives for a set of 5 healthcare configurations would yield much more robust data than 2-3 engineers applying the same tool to a single building configuration.)

While processes similar to the above exist at a generic level (e.g., SFPE Guide to PerformanceBased Fire Protection) they lack the detail and the data to help users make informed judgments. This approach aims to both provide added detail to the process and data to support the justification of the tool selection.

\section{Specific case studies: issues related to the use of} CFD fire effects tools

The use of CFD fire effects tools is quite complex and necessitates that the user also deals with uncertainties related to the use of these tools. Here are some examples of issues related to the "user effects" related to CFD fire effects tools - issues that would have to be addressed when using this kind of tools in Step 7 of the 'test bed' study process.

\section{Grid selection for a better optimization of} computational meshes of a CFD fire effects tool

Spatial domain can be categorized as one source of "user effects" uncertainty (SFPE, 2011). For a CFD fire effects tools, grid sensitivity should be performed in order to determine at what grid refinement the desired outcomes become grid independent. However, care should be taken to assure other design objectives are met as well.

For example, Sztarbala (2011) indicates that "when LES model is used, the number of grid elements must be increased. A maximum edge length of $0.15 \mathrm{~m}$ is recommended for grid elements in flow-relevant areas. For other areas the maximum edge length should not exceed $0.50 \mathrm{~m} "$. However, these grid cell sizes may not be compatible with the time and computing resources of FPEs in the consulting environment, as they would require extensive parallel processing power and memory. In addition, these grid sizes may not be needed for the resolution of analysis required. In addition, some CFD tools allow the definition of multiple meshes with different grids, which allows some flexibility. However, communication between the different grids may affect the results. Looking at this issue in a more comprehensive manner can lead to developing user guidance when designing for all computational grids.

\section{Influence of detailed geometry on the results of the simulations}

It is known that the computational mesh, which simulates the spatial domain of the project of interest, has an influence on the results provided by CFD fire effects tools. However, there is no real guidance on how to deal with this issue. For specific outcomes of fire scenarios, it may be necessary to perform a simulation with a high level of details. Because of calculation time it would require, such simulations which include details of building contents and structural elements are rarely performed in practice because they are not compatible with the time constraints of engineering studies. To address this issue, it would be beneficial to establish guidance on the degree of detail needed for particular design aspects (e.g., contents, structural features) that are "just" needed with respect to the degree of details required in the description of the building geometry.

Looking at this issue would help to:

- indicate whether the simulation of all a building in 3-D is necessary,

- determine the minimum degree of details needed to get access to the information, describing temperature profiles, smoke and toxic fire effluent propagation required to perform an analysis of the evacuation of building occupants.

In addition, by looking at different safety objectives for the same building configuration, one could verify if the building description established for an occupant evacuation could be used for design fire scenarios related to property protection or business interruption.

\section{Detailed geometry description v. computational time and result accuracy}

CFD fire effects tools allow a refined description of the building structural elements and contents, which represent heat sinks and obstacles that can modify the buoyant smoke and hot gases trajectory. Whereas these structural elements and contents can be described in detail in 3-D simulations, and these details may influence the results of the simulations, but at a cost of an increased computational time, a series of simulations should be performed in order to estimate how the detailed geometry description affect the result accuracy to the detriment of computational time. 


\section{Verification of the consistency of results}

As indicated in Chapter 5 of the SFPE Guidelines for Susbtantiating a Fire Model for a Given Application (verification and validation), using multiple tools for the same configuration may demonstrate that the "results make sense. Especially for more complex models, performing an analysis with another tool could result on a non-sensical result" (SFPE, 2011). While this kind of analysis is not a primary objective of the 'test bed' studies presented in this paper, results from the 'test bed' studies of fire effects tools for a given application can serve as a basis for a verification of the consistency of results between different types of tools.

\section{Inclusion of Hybrid modeling in the 'test bed' studies}

As presented previously, attempts have been made to create hybrid tools which can combine the accuracy of the CFD model with the computational speed of zone models. Other recent examples of such hybrid tools for estimating fire effects concern:

- the simulation of large geometries such as large buildings or large passenger ships, with a CFD model / zone model hybrid developed by the University of Edinburgh (Burton et al, 2011),

- the estimation of HVAC flows in case of fire in a building based on a coupling of a HVAC network model with the Fire Dynamics Simulator (FDS) developed by Floyd (2011).

Hybrid tools appear to be promising new tools, which can also be included in the 'test bed' studies presented above. It will also be important to analyze the process the hybrid models underwent so to collect information not only about the computational time gain with minimum accuracy loss, but also the assumptions related to the fabrication of the hybrid tools as these assumptions may be highly dependent on the applications of the tools, that is to say the set of configurations the tools were designed for.

\section{ORGANIZATION OF THE 'TEST BED' STUDIES}

As presented above, the first steps in the process are obtaining layouts for occupancy groups and defining analysis objectives. Once this has been done, the analysis starts with setting up the building layouts.

\section{Setting up building layout (Step 4)}

The following process for generating building layouts for FDS from different building configuration sources has already been established and is presented below.

\section{Process to generate "ready-to-use" building layouts} for Fire Protection design purposes

Architects design the overall building layout using 3-D software that is able to render the geometry of the rooms, spaces and exit pathways. Furniture and building contents, as well as nature of the structural elements would be described in this software files. Architect engineers dealing with the description of the building systems, such as the HVAC system, also describe their data using 3-D software. To facilitate the 'test bed' studies of real building geometries for a range of occupancy groups, it would be helpful to have a set of 'ready-to-use' building layouts. The process in order to get these layouts for FDS simulations, from architect design files, is described in Figure 2 below.

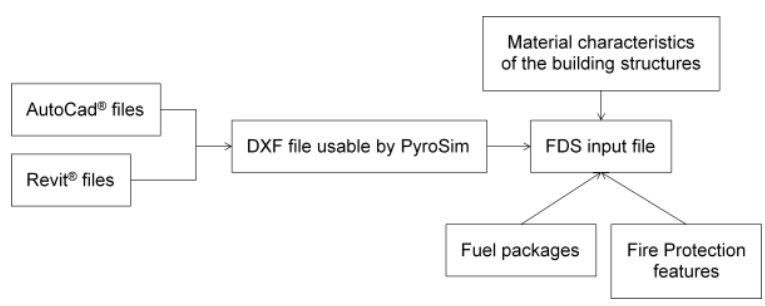

Figure 2: Process currently followed to create FDS building layouts.

In the $8^{\text {th }}$ International Conference on Performancebased Codes and Safety Design Methods (SFPE, 2010) the case study was related to a 6 story office building where 4 stories had to be converted into a night club. Table 1 presents the different fire effects and evacuation tools used by the participating countries. Compiling the building layouts presented in Table 1, as well as the fire scenarios selected by the different countries would constitute a fast way to carry the $1^{\text {st }}$ tasks of a 'test bed' study case related to that configuration.

Table 1: Fire effects tools and evacuation tools used by different countries (SFPE, 2010)

\begin{tabular}{|l|l|l|}
\hline Country & \multicolumn{1}{|c|}{ Fire effects } & \multicolumn{1}{c|}{ Evacuation } \\
\hline $\begin{array}{l}\text { New } \\
\text { Zealand }\end{array}$ & $\begin{array}{l}\text { Zone model } \\
\text { (BRANZFIRE) }\end{array}$ & Algebraic models \\
\hline USA & CFD model (FDS) & Algebraic models \\
\hline Australia & Zone model (CFAST) & PATHFINDER \\
\hline France & $\begin{array}{l}\text { Zone model } \\
\text { (CIFI2009) and CFD } \\
\text { model (FDS) }\end{array}$ & Algebraic models \\
\hline $\begin{array}{l}\text { Hong } \\
\text { Kong }\end{array}$ & CFD model (FDS) & MODELMAKER \\
\hline Japan & $\begin{array}{l}\text { Algebraic models and } \\
\text { zone model (BRI2002) }\end{array}$ & SimTread \\
\hline Sweden & CFD model (FDS) & STEPS \\
\hline
\end{tabular}


In addition, other potential sources of building layouts are NIST investigation reports (Station nightclub, office building of the Cook County hospital or part of the World Trade Center) or published articles including building layouts for estimating fire consequences or even crowd evacuation.

Going forward, however, it would be helpful to obtain building layouts, from architects, which represent a wide range of building configurations over a spectrum of building occupancy groups. Table 2 presents a list of building configuration layouts to be implemented in the near future, with a focus on getting the description of the spatial domain in FDS.

Table 2: List of building configuration layouts to be implemented in the near future

\begin{tabular}{|l|l|}
\hline Building occupancy type & \multicolumn{1}{|c|}{ Example } \\
\hline Assembly & Library \\
\hline Heath care & Hospital \\
\hline Educational & High school \\
\hline Residential & Dormitory \\
\hline
\end{tabular}

Examples of building layouts are included in the conference presentation slides.

To facilitate use by a broad range of stakeholders, the building layouts will ultimately be distributed to a Google user group to be tested across the world (as materials and fire protection features vary with countries) and versions of these layouts usable for other fire effects tools as well as for evacuation modeling will also be developed. Before the end of the year, the layouts will be distributed to a small group of fire protection engineers across the world for some feedback. It should be noted that these configurations will not include any fire components or fire protection features. The information gathered in the Google user group on the building configurations is aimed to be as exhaustive as possible in describing the building contents and occupants so to remain accessible and usable even for upgraded versions of the currents tools or future tools.

\section{Selecting fire scenarios (Step 6)}

Whatever the fire effects tool, be it based on algebraic models, zone models or CFD models (when not using a pyrolysis model), the description of the fire remains a user input data of crucial importance. A primary component of the fire design scenario is the fire design curve which represents the evolution with time of the heat release rate (HRR) of the corresponding fire. This "HRR curve" will allow the calculation of the heat hazard component of the fire.
In parallel to the evolution with time of the HRR, the evolution of the fire effluents (smoke, toxic and irritant products) is also essential to estimate the toxic hazard component of the fire.

When using fire effects tools, two options for establishing the HRR curve are possible:

- $\quad$ the HRR curve can be predefined, from ignition to extinguishment, and used as an input for all the different types of fire effects tools, or;

- the HRR curve can be left to the different fire effects tools estimate as follows: the location and nature of the $1^{\text {st }}$ burning item are given and the tool has to assess fire propagation to the other fuel items which nature and position are known.

Whatever option is selected, and because no pyrolysis model is intended to be used in the present scope of the 'test bed' studies, the user has to provide HRR curves for single fuel packages, describing the evolution of the HRR they can individually produce once ignited.

\section{HRR curve database}

When looking for heat release rates for building contents, from furniture to curtains, from appliances to even cars, a primary source of information is the SFPE Handbook chapter dedicated to heat release rates, written by Babrauskas (2008). This chapter contains numerous references that can lead to a significant amount of data from furniture calorimeters, including heat release rates evolution with time, soot and toxic component yields. In addition, by reviewing NIST publications alone, some fifty different experiments have already been included in a database, along with the available snapshots and videos. This number will be expanded by looking at more NIST studies, as well as tapping into test data from around the world. Before the end of the year, it is planned to distribute the database to a small group of fire protection engineers across the world for feedback and contribution to the database.

\section{Smoke and fire effluents}

Smoke and fire effluent production and movement quantification are an important part of the engineering problem, related not only to life safety objectives, but also to property damage, and environment protection. Products of combustion can have an impact on people safe evacuation (affecting their safe escape), on building contents (damaging costly pieces of equipment or historical artifacts), on business continuity (causing the malfunction or the destruction of manufacturing goods, processing chains, or equipment assuring the safety of the process), or on the environment (when toxic or hazardous materials are released in quantities that can impact the environment). Thus, it is essential to 
estimate the nature and the kinetics of the fire effluents.

In solving engineering problems related to fire effluent impact on building occupants and contents, it is necessary to assess the production, transport and deposition/absorption of these effluents inside the building and also outside for environmental safety objective. Transport and deposition of airborne particles constitute very complex subjects by themselves and these phenomena are greatly influenced by the building layout, which adds another study to the ones already presented in the previous sections dedicated to the building layouts. Production of fire effluents are related to the fire spread on the burning combustibles, which include the also complex pyrolysis processes of usually heterogeneous materials, as well as the ventilation conditions around the fire scene (i.e. the fire is underventilated or not).

When reviewing NIST furniture calorimeter tests, it was noted that the information related to the production of fire effluents was rarely provided. Additional information may be collected when material properties are collected, i.e. at laboratory scale, such as soot yields, $\mathrm{CO}$ yields, $\mathrm{CO} / \mathrm{CO}_{2}$ ratios, etc., if possible for pre-flashover and post-flashover conditions, as these values are dependent of the ventilation conditions around the burning fuel item.

\section{'Combustible packages' for 3-D simulations}

The objective of providing 'combustible packages' ready for 3-D simulations came from the FDS user point of view and the availability of third party software developed in order to facilitate the creation of FDS input data files. Indeed, if such software is able to create and duplicate building elements as presented in the previous section, why not trying to do the same for combustible elements.

For FDS, the heat release rate is defined by a surface area, that is to say, that the specification of the burning areas is required. Because of this requirement, the evolution with time of the burning areas has to be included as an input data. In some cases, the burning area is set up as a constant and at the maximum of the combustible object area(s). Nevertheless, for complex setups of combustible building contents, which have been burnt in furniture calorimeter, videos clearly show the flame propagation from the ignition localized point to the complete flame engulfment of the set up, which can occur several minutes later as a peak of HRR.

The description of the flame spread over the combustible building content is necessary when assessing the fire spread inside the compartment or space where the content is located, as the estimation of the ignition of the second burning item is dependent on the radiation received by this target from the $1^{\text {st }}$ burning building content. This heat transfer mechanism can be estimated using a CFD fire effects tool so it requires the flame characteristics which are dependent on the evolution with time of the HRR and of the burning areas. It should be noted that such a detailed characterization is not required in the far field, that is to say when the given application is related to the phenomena that occur outside the room of fire origin, i.e. for example when assessing the smoke spread in exit pathways outside the room of fire origin. The degree of details for the 'combustible packages' is also dependent of the given application, as well as the other input parameters presented in the previous sections.

Even for relatively simple building content geometry, such as a wood dresser, the question of the burning areas remains: if all the HRR is distributed at the top area of the wood dresser, activation of a heat detector would be quicker than if the HRR is distributed on the lateral areas of the wood dresser. In the latter distribution, ignition of a second burning item located in front of the wood dresser would be quicker.

Since some snapshots and videos are available from the NIST for different building contents including a wood dresser, it was then decided to study the influence of the burning areas evolution with time on the ignition of a second burning item and on heat detection at the ceiling level.

NIST/BFRL experiments related to the combustion of a loveseat, a mattress (with center ignition and corner ignition) and a wood dresser were selected. Burning areas were defined according to the flame spread pattern on the burning item. Fractions of the HRR were then distributed among the defined areas so the resulting modeled flames would have the same length as the ones in the snapshots or video. In the corresponding FDS simulations, devices were located in front and at the periphery of the burning item and temperatures were recorded under the ceiling to estimate the activation time of thermal elements located there.

Detailed analysis of the results will be available in the near future. Even so, thus far the particular study shows the feasibility of such a detailed description of combustible burning items. By the end of the year, a primary series of 'combustible packages' will be set up and distributed to a small group of fire protection engineers across the world for some feedback.

Examples of 'combustible packages' for FDS are given in the conference presentation slides. 
Creation of a fire protection engineering 'test bed' study pool (Step 7 to Step 10)

Performing Step 7 and Step 8 of the 'test bed' study process requires significant time and resources to collect the targeted data. It is not feasible for a single entity from within the fire protection engineering community to conduct all the needed studies - not only from a resource perspective, but because each sector within the FPE community has its own goals and objectives, prerogatives and time and resources constraints. In addition, Steps 5-10 require participation of people from all sectors in any case.

Conducting such studies with all these different people would benefit all of them in different manners:

- The consulting companies would acquire better understanding of the use of tools for a given engineering application, optimizing their resources and time;

- The students and professors in Academia could use the case studies as practical examples of engineering problems;

- The governmental agencies could set up research programs focusing on the problems and needs of the engineering community;

- Engineering societies could elaborate guides and guidelines improving the use of engineering tools for given applications, where appendices would be added with the results of specific cases;

- Regulators and Authorities having jurisdictions would consider the improvements in the use of tools in projects based on performance based design fire protection options.

The aim, then, is to encourage the establishment of a sector-wide and world-wide group of users to participate in the 'test bed' studies outlined above, with the objective of developing data which will lead to a guideline for the selection of appropriate tools for specific building occupancy types and configurations.

\section{REFERENCES}

Alvarez, A. and Meacham, B. J. (2011), "Towards the next generation of performance-based fire protection design for the built environment", manuscript to be submitted for publication in September 2011
Babrauskas, V. (2008), "Heat Release Rates," SFPE Handbook for Fire Protection Engineering, $4^{\text {th }}$ edition, section 3 , chapter 1, (3)1-(3)59

Barrachin, G., Chaussard, M., Bertrand, R., Bonneval, F and Mattei, J.M. (2000), "Insights from the Blayais 1 NPP Fire PSA," Proceedings of the $5^{\text {th }}$ International Conference on Probabilistic Safety Assessment and Management, volume 3/4, 2093-2098

Burton D., Grandison A., Patel M., Galea E., Ewer J. (2011), "Development of a Hybrid Field/Zone Fire Model," Proceedings of the Tenth International Symposium of IAFSS

Collela, F. (2010), "Multiscale Modelling of Tunnel Ventilation Flows and Fires," British Research Establishment $\mathrm{PhD}$ thesis collection

Floyd, J. (2011), "Coupling a Network HVAC Model to a Computational Fluid Dynamics Model Using Large Eddy Simulation," Proceedings of the Tenth International Symposium of IAFSS

Society of Fire Protection Engineers (SFPE) (2007a), Guide to Predicting Room of Origin Fire Hazards

SFPE (2007b), SFPE Engineering Guide to Performance-Based Fire Protection

SFPE (2010), Proceedings \& Case Studies of the $8^{\text {th }}$ International Conference on Performance-based Codes and Safety Design Methods

SFPE (2011), Guidelines for Substantiating a Fire Model for a Given Application

Siu, N. O., Hyslop, J. S. and Nowlen, S. P. (2008), "Fire Risk Analysis for Nuclear Power Plants," SFPE Handbook for Fire Protection Engineering, $4^{\text {th }}$ edition, section 5 , chapter $14,(5) 258-(5) 273$

Sztarbala, G. (2011), "Computational Fluid Dynamics as a tool of fire engineers - good practice," Presentation at Eurofire 2011

\section{INFORMATION}

This work is supported by grant 60NANB10D228 from the US National Institute of Standards and Technology. 


\section{Appendix A3}

'Test bed' environment process for assessing the appropriateness of engineering tools

to be used in performance-based design applications

presented at the 9th International Conference on Performance-Based Codes and Fire Safety Design Methods, in Hong Kong, 20-22 June 2012.

Reprinted with permission of the Society of Fire Protection Engineers

Original source:

Alvarez, A. and Meacham, B.J., "'Test bed' environment process for assessing the appropriateness of engineering tools to be used in performance-based design applications" in: Proceedings of the $9^{\text {th }}$ International Conference on Performance-Based Codes and Fire Safety Design Methods, 20-22 June 2012, Hong Kong, 2012, Society of Fire Protection Engineers 


\title{
'Test bed' environment process for assessing the appropriateness of engineering tools to be used in performance-based design applications
}

\author{
Alberto Alvarez and Brian J. Meacham, Ph.D., P.E., FSFPE \\ Department of Fire Protection Engineering, Worcester Polytechnic Institute, \\ 100 Institute Road, Worcester, MA, 01609, USA
}

\section{TOPIC}

There is a need for guidelines to aid the selection of appropriate fire consequence analysis tools for specific types of fire protection engineering applications. This is not to be confused with the recent SFPE Guide [1], which aims to help engineers justify (substantiate) why they selected a particular tool, but rather, to help engineers choose wisely before analysis begins. Within the fire community, the primary beneficiary of such guidelines is the fire protection engineer who applies the tools (dedicated to assess fire effects, evacuation processes and response of structures) and analyses the results in terms of safety objectives. However, other stakeholders involved in evaluating and accepting the performance of a building or structure to withstand the fire risk, such as building owners or managers, other members of the design team, insurers and authorities having jurisdiction would also benefit, since part of the evaluation/acceptance process is based on the analyses performed using the aforementioned tools. Researchers from academia, the government or the private sector who are involved in developing such tools would also benefit from the guidelines as they would re-enforce the link between the scientific research domain and the engineering application field. The need for such guidelines, and a structure for a 'test bed' environment for assessing the appropriateness of tools for different engineering applications, is discussed.

\section{PROBLEM CONTEXT}

In general, performance-based design approaches for fire protection design require:

1. The definition of goals, objectives, performance criteria,

2. The selection of fire design scenarios upon which trial designs are evaluated,

3. The assessment of the consequences of the fire design scenarios using fire effects tools (and evacuation tools...) that are selected according to the needed degree of analysis.

In order to assess consequences (third point), input data that describes the considered built environment and the fire scenarios is required. Tools that are currently used for fire consequence analysis address a range of phenomena: for example, fire effects (temperature increase, production and movement of smoke and toxic effluents, loss of visibility), occupant response and movement (occupant behavior and travel speed), and material, equipment and structural response to fire. In addition to the range of tools available, the tools have different levels of sophistication in being able to incorporate more or less detail, e.g., more or less physical phenomena for the fire effects tools, more or less psychological phenomena for the evacuation tools, and more or less details of the considered built environment components and systems for the structural response tools. 
Guidelines have recently appeared to help the fire protection engineer "substantiate a fire model for a given application" [1].This is in addition to guidelines that help the engineer understand the performance-based design process [2] and one which assists code officials in the review of performance-based designs [3]. In addition, websites are emerging which bring together users and developers of various fire engineering tools. This includes a site focused on Fire Dynamics Simulator (FDS) from the US National Institute of Standards and Technology (http://groups.google.com/group/fds-smv) and a site focused on users of evacuation models (http://www.evacmod.net/). Such sites and the people who use them collect considerable information related to the use of these tools. The International Conferences on PerformanceBased Codes and Fire Safety Design Methods, managed by SFPE, have been presenting case studies where fire protection engineering national teams provide their analysis.

However, linkages between the guidelines and websites on processes, applications, data, and tools are lacking. In addition, there is significant diversity in the scenarios and buildings being used for developing and testing tools and methods. If better linkages are made, and a set of comprehensive 'test beds' can be developed - which can be used for testing all types of fire engineering tools - for a variety of applications - there are significant benefits to be realized by those who develop, use and review the tool applications.

This paper introduces a new holistic approach related to the selection of engineering tools to be used in performance-based fire protection design applications. When completed, this approach will differ significantly from current practice, taking into consideration not only tools for modeling fire phenomena, but also tools for modeling building occupant evacuation, structural response and even risk analysis. In addition, the context for use of the tools will be integrated in the method for selecting appropriate tools.

\section{DEVELOPING A NEW HOLISTIC APPROACH FOR SELECTING TOOLS TO BE USED IN PERFORMANCE-BASED FIRE PROTECTION DESIGN APPLICATIONS}

For performance-based fire protection design (PBFPD) applications, engineering tools are used to assess the outcomes of the design fire scenarios. In the past decade, fire protection engineering appeared to have left its infancy stage, as it started to incorporate scientific elements from outside its core fundamentals (i.e. fire science), from toxicology, human behavior, computing, statistics, etc. The result is that the fire protection engineer has a wide range of tools available for PBFPD applications, as outlined above. Since arguably more work has been carried out concerning development of fire effects tools than the other types of tools, the initial focus of this work is on fire effects tools.

\section{Assessing appropriate applications of fire effects tools}

In the USA, significant efforts have been undertaken in recent decades regarding uses, applications and limitations of fire effects tools, mainly originating from a collaborative project initiated by the US Nuclear Regulatory Commission (NRC), which led to an extensive series of reports [4], freely available spreadsheets and more. The SFPE Guidelines for Substantiating a Fire Model for a Given Application [1] was based on this body of work. The SFPE Guidelines, 
recently published, not only includes an extensive appendix related to the fire-related phenomena which are relevant to PBFPD (such as gas layer temperature and depth, heat flux or gas concentrations) but it also notes the need to identify elements that of concern to the considered design fire scenarios for PBFPD applications [5], for example:

- Details of the spatial domain representing the built environment,

- Fire design scenario timeframes (from several minutes for a single room flashover application to several hours for assessing the collapse of a structure due to a generalized fire),

- Material properties not only describing the combustible contents but also the other building elements which "absorb" heat and fire effluents as well as the load-bearing elements,

- Initial and boundary conditions, including initial temperature in and outside the built environment and the ventilation conditions (initial conditions including the window and doors status (opened or closed) as well the boundary conditions (how the doors are leaking or how the mechanical ventilation network is set up).

Chapters related to verification and validation of fire effects tools, as well as the user effects and documentation, nicely complement the key aspects that a Code's Official is looking for when assessing a PBFPD report [3].

While these recent works are all helpful, it is worth noting that concerns related to appropriateness of tools used in PBFPD appeared as early as the developments of these tools and the PBFPD methods themselves. For instance, in 1992, Friedman [6] dealt with how well a model could predict quantities, what procedures would have to be followed to assess the accuracy of a model. He proposed two options to perform such a task:

1. The first one is to express the accuracy of a model as a percentage deviation of prediction for measurement. Using that option would arise problems related the cost of performing necessary full-scale tests, assessing the errors of the experimental devices as well as the poor reproducibility of such tests due to the stochastic nature of the fire phenomenon;

2. The second option is to focus on the capability of a model to answer the following questions: will the second combustible item ignite? Will a relatively small fire be able to actuate a nearby sprinkler? Will toxic conditions in a corridor near the fire compartment be such as to prevent escape through the corridor? Will an exposed beam fail, causing collapse?

As Fire Protection Engineers, we are more concerned about the second option and how confident we would be in answering the aforementioned questions, in a holistic context regarding the fire safety of a building. The first option is related to the verification process and it is undeniable that FPEs would prefer to support their analysis with using a model which describes fire phenomena as closely as possible. Nevertheless, the second option is still FPE prime concern as recognized by Friedman: even if a "perfect" model able to describe the reality of the fire phenomena existed, uncertainties in the input parameters, which the users had to select, would introduce a decrease in the reliability of the model to answer the questions in point 2 above with an a clear "yes or no". Examples of uncertainties in the user input parameters are: the composition of the combustible items, which would influence the evolution with time of the heat release rate and the production of smoke and toxic effluents, the percentage of absorbed moisture, which would influence the thermal inertia of a gypsum board. 
Friedman stated that the decrease in the tool reliability could be as low as 50\% (random guess) as illustrated in Figure 1a, when considering a single input parameter. For an actual tool, which itself bears uncertainties in terms of the simplification of the physical world and use of numerical techniques, Figure $1 \mathrm{~b}$ shows that the uncertainty range due to a single input parameters gets bigger.

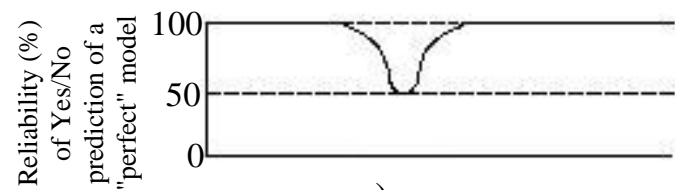

a)

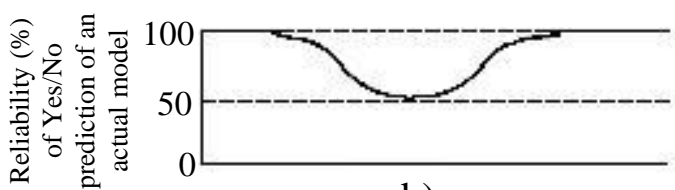

b)

Figure 1: Reliability of the predictive capability of a model to clearly state "yes or no" to an engineering question, as a function of single input parameter values, a) for a "perfect" model and b) for an actual model [6]

In 2002, Mowrer [7] used a similar concept to describe the capability of a tool to clearly state if a performance criterion used in the PBFPD option has been achieved or not. This time, the range of uncertainties is associated with the power of the analytical tools (i.e. the capability of the tools to simulate the fire phenomenon). His concept is presented in Figure 2, where he stated that the perfect analytical tool would be the one that eliminated the uncertain middle area. His point of view differed from Friedman's one for addressing the concept in Figure 2, but he joined Friedman in stating that "perhaps the worst mistake a fire modeler can make is to run a model only once and then rely on those results as conclusive without considering how variations in input parameters might affect the results".

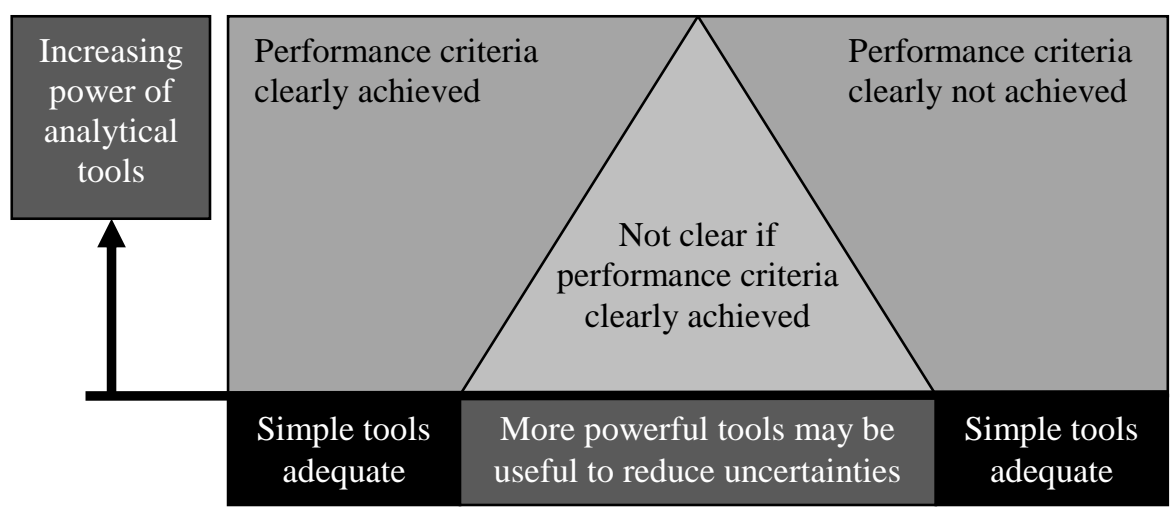

Figure 2: Ideal representation of calculation results as a function of the increasing power of the analytical tool employed [7]

Nevertheless, by mixing Figure 1 and Figure 2, the following concept emerges: (a) there are ranges of input parameters to be used in conjunction with simple tools that allow the fire protection engineer to clearly state if a performance criterion is achieved or not, so that (b), for the cases delimited by the ranges of all input parameters, it would be possible to use even the simplest tool to perform an engineering analysis, without sacrificing any certainty concerning the achievement, or not, of the performance criteria, and (c) for the other cases, the use of more "powerful" or more complex tools would reduce the uncertainties when dealing with 
configurations not covered by the simple tools. Furthermore, (d) the transition between the two cases (from the case where the performance criteria are clearly achieved, or not to the case where they are not clearly achieved) is where a switchover analysis, related to the use of the tools (Mowrer's concept) in addition to the one related to the values of the input parameters of a tool (Friedman's concept), should take place. ${ }^{1}$

\section{Tools are only as accurate as their weakest link: developing the design fire curve}

It is not surprising that the most influential parameter of fire effects tools is the design fire curve, which "usually establish[es] a relationship between heat release rate and time"[2], as it is the generating driver for temperature increase, smoke and toxic effluent production that ultimately impact targets such as building occupants, contents and structure.

SFPE [2], for example, indicates that "several methods can be used to define a design fire curve: using published data, fire testing, or calculating a theoretical fire size. In a fire protection engineering design, it can be useful to consider more than one of these methods". It should be noted that some of these methods are based on a series of standardized tests because there was always a need to connect test data serving to characterize materials with scientific data used for engineering calculations. Indeed, fire rating elements (door, floors...) cannot be tested according to every possible design fire curve.

Let's consider, for example, how fire propagation from a burning item to a combustible: there are some empirical correlations and procedures which allow quick estimations of the possible ignition of a second fuel source from the radiation emitted by a first fuel source. The International Fire Engineering Guidelines (IFEG) [8] identifies the following methods:

- Mikkola and Wichman (1989) consider both thermally thin and thermally thick materials,

- Tewarson (2002) requires data related to the TRP, or ignition temperature and some material characteristics, in order to calculate delay before ignition

- Quintiere and Harkleroad (1985) used LIFT data in a simplified thermally thick solution,

- Toal et al. (1989) used cone calorimeter and ISO Ignitability Apparatus,

- Babrauskas (1981) performed series of tests burning combustibles and established three different curves relating the ignition distance of the second burning item to the peak mass loss rate of the first one and according to the second item ignitability.

Based on the review of these elements, it seems that the most sophisticated fire effects tools (existing so far) are still dependent on the user evaluating, on his/her own, the most influential parameter of fire effects tools: elaboration of the design fire curve prior to its introduction into the tool as an input file.

\footnotetext{
1 Switchover analysis is one of the many types of evaluation techniques accounting for known variations and unknown effects [2], so not only this concept established above is useful for tool selection but also could serve as a basis for establishing sets of tool input parameters which lead to a switchover of the analysis conclusion.
} 


\section{Assessing appropriate applications of tools for solving PBFPD problems: the technical}

layer

Another layer of complexity appears when considering that not only are fire effects tools used to estimate the outcome of a design fire scenario, but also:

- evacuation tools are needed when assessing whether life safety performance criteria are achieved, and

- structural response tools are needed when assessing whether a built structure would withstand the design fire scenarios.

Comparison between the required safe egress time (RSET) and the available safe egress time (ASET) is widely accepted as an approach when dealing with time-based egress calculations. In the ASET/RSET approach, calculations regarding the "fire" side (ASET) and the "people" side (RSET) are usually performed separately. Fire Protection Engineers have to estimate the time before untenable conditions are reached versus the time required for the building occupants to safely evacuate and manually assess interactions. Using different tools to assess both times, and relying on the engineer to integrate the outcomes, results in concerns and constraints as well. It should be noted that research tools such as FDS+EVAC allows simultaneous calculations of fire propagation and evacuation process, Building_EXODUS allows input from the fire effects tools SMARTFIRE and the evacuation software STEPS allows input from the fire zone model CFAST and FDS. Nevertheless, even with these most elaborate tools, not only the influence of the fire on the people ability to evacuate still needs more integration, mostly about decision making, but also the effect of people actions on the fire needs to be modeled within these tools.

Looking at the pre-movement time, for example, there is a "large" range associated with the time occupants take before starting their evacuation, as illustrated in Figure 3. The time when people receive the first clue that a fire event is occurring is also based on a distribution rather than a single value, as people can be notified by various means other than a smoke alarm, or centralized fire notification system connected to the automatic fire detection system.

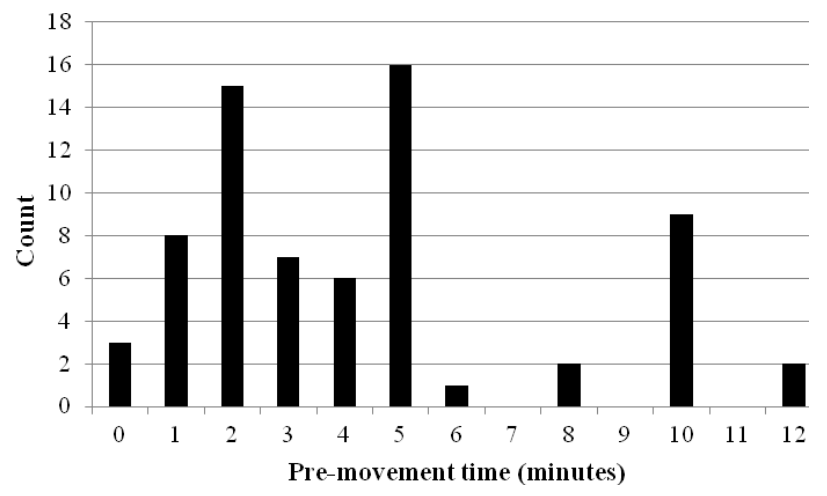

Figure 3: Pre-movement time reported after the fire in the Cook County Administration fire, October 17, 2003 Chicago, IL [9]

Mixing the estimation of the RSET and the ASET in a probabilistic risk assessment, authors have come out with the schematic representation of Figure $4: f_{\varepsilon}(t)$ the probability density distribution function of individual evacuation time. $\mathrm{f}_{\mathrm{A}}(\mathrm{t})$ is the probability density distribution function of ASET. This figure has been established considering uncertainties of the design fire curve and 
characterizing occupant pre-movement time as a normal distribution, as an analogy with the result presented in Figure 3. Chu et al. [10] stated that "two curves are overlapping which indicates there is a probability that untenable conditions may occur before all occupants evacuate to a safe place".

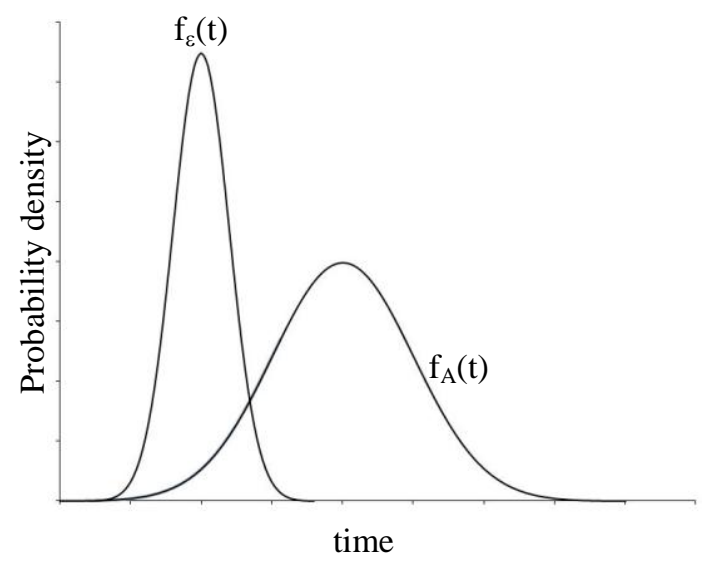

\section{Figure 4: Hypothetical probability density distributions of individual evacuation time $\left\{\mathbf{f}_{\varepsilon}(t)\right\}$ and ASET $\left\{\mathbf{f}_{\mathrm{A}}(\mathbf{t})\right\}[10]$}

Looking at risk assessment would lead to different results when considering different tools, as the overlapping portions of the two probability functions may be different. The advantage of this type of result is that uncertainties are taken into consideration in the result shown to the AHJ, so we are now introducing the concept of probability of failure/success and not giving "absolute numbers" (this current situation then tends to increase the liability of the fire protection engineer as the AHJ is asking for some certainty of analysis outcomes, when in fact fire protection engineer is dealing with events that can potentially occur within a wide realm of possibilities).

\section{Assessing appropriate applications of tools for solving PBFPD problems: the usability layer}

Figure 5 illustrates the 'usability' concept (right tool at the right time) for a fire protection engineer (FPE) dealing with a new building design project. In this concept, the use of tools needed to conduct analysis varies along the timeline of the project:

- At the start of the project, in the feasibility and concept design phases, the level of detail in the analysis is quite low as the FPE can only provide an idea of the measures to install (based on the prescriptive requirements and the possible deviations to them) as data required to perform any analysis is still scarce. If fire effects tools are needed, algebraic models are mainly used, with a high calculation speed;

- During the scheme design, data related to the interior design of the building becomes available and more sophisticated tools can then be used, such as zone models;

- In the detailed design phase, the details of the project are known and 3-D simulations can be used - if needed and if time allows - as the time for analysis is shorter as we go along the project, running these complex simulations requires a considerable amount of time, compared to the use of previous tools, and since these tools generate a lot of useful information, data treatment of 3-D simulations is also time consuming. 


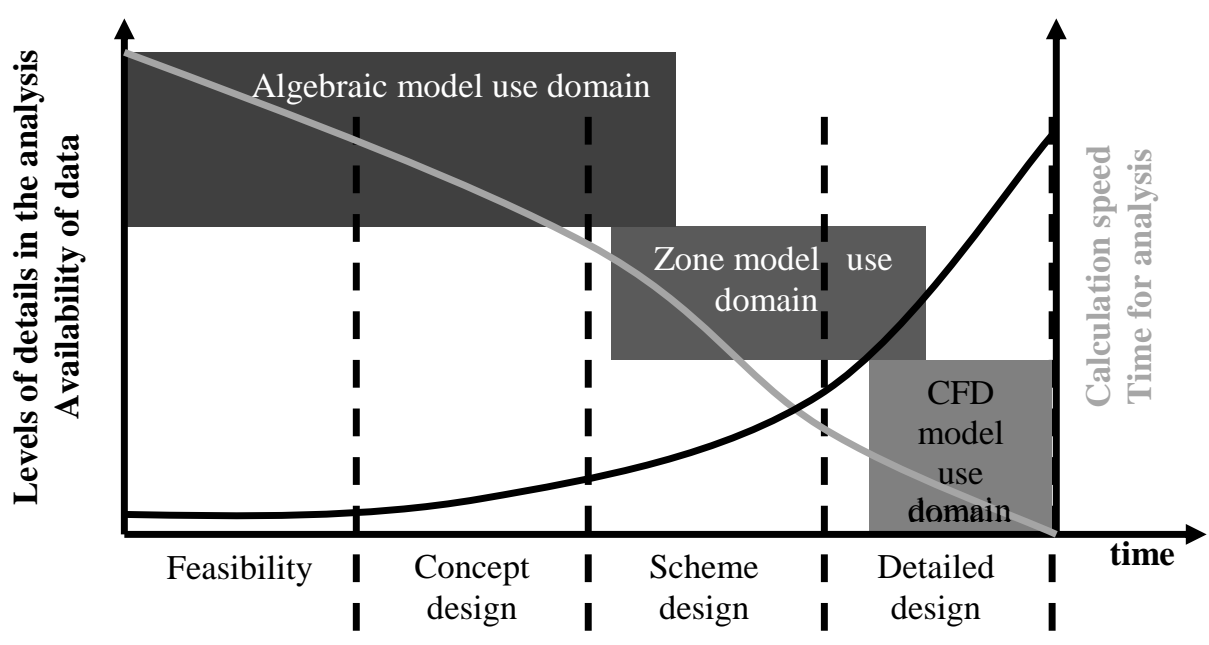

Figure 5: Fire effects tools domains as a function of a new building project phases

Figure 5 is applicable to the whole considered building project. If a specific safety point is known at the concept design phase, and if it is also known that the degree of details would require a more complex tool than an algebraic model or even a zone model, the FPE would have to somehow obtain, from the design team, the data needed in order to use such a more complex tool at the earlier stage. As stated previously, performing such calculations uses significant time and resources and the results are highly dependent on the input parameter values. Using input parameter values at the start, which in the end would be quite different from the ones that would be finally needed, could lead to dramatic changes in the design, not only of the fire protection features but also in the design of the building itself, and could mean expending considerable resource for limited value. However, if a set of 'test bed' studies existed, which reflect similar projects, the information could place the FPE in a better position to ask the design team for needed input parameter values, or at least range of values, based on the experience of the test bed studies.

For PBFPD applications, another constraint that has to be considered appears in the regulatory environment. National standards, such as NFPA 204 for smoke and heat venting [11], NFPA 92 for smoke control systems [12], and so forth may be used in conjunction with building code regulations, to help a project to be accepted by the Authority Having Jurisdiction (AHJ) because these standards are recognized by these AHJs. An engineering analysis incorporating the analytical methods of such standards would not require so extensive justification as the ones purely based on more sophisticated engineering methods.

In conclusion, within a PBFPD framework, the selection of appropriate tools for a given application depends on many layers:

- a technical layer where tools differ on how well they describe physical phenomena that are relevant to a given application, on how well the user has to consider the input parameters (mainly the design fire curve), how well the specialized tools communicate with each other (fire effects tools with evacuation models and so forth),

- a usability layer where tools are used in a specific context, where input data may not be available as needed, analytical methods from already existing standards may be preferred to more sophisticated engineering methods based on their better acceptance by the AHJ. 


\section{ORGANIZATION OF A 'TEST BED' ENVIRONMENT TO SUPPORT THE NEW APPROACH}

To address the challenges outlined above, a new approach is suggested in order to advance our ability to more appropriately apply the diversity of engineering tools that are available for the range of building fire challenges that FPEs face and the stage of the project at which the tools are needed. This approach involves two primary components:

- Development of new guidelines for the selection of appropriate tools for a given fire protection engineering type of application, and

- Development of a web-based 'test bed' within which to apply, assess, evaluate and expand upon the capabilities of the tools and of the profession.

Appropriate selection of a tool depends not only on its capabilities to "correctly" simulate the aimed physical phenomena, but also on the context in which the tool is used. At the same time, there is not always 'unlimited time' to undertake analyses, and having prior knowledge about the appropriate applications for the tools can help increase the efficiency and effectiveness of performance-based analyses. In order to help the fire protection engineering community to be better able to address such resource and time constraints related to the use of fire consequence analysis tools, a process for tool selection and a 'test bed' environment are proposed. The 'test bed' environment allows a wide variety of tools to be applied to common building configurations and fire protection challenges in order to build up knowledge and experience on selection and use of tools for various levels of fire protection analysis. The 'test bed' environment process is mainly composed of three following phases:

1. A "pre-processing phase" where study topics are selected and organized according the common interest of different participants (including not only the usual stakeholders involved in PBFPD projects but also researchers and people in academia) and availability of input data and building layouts,

2. A "performing and analyzing phase" where participants identify common safety objectives, safety functions and criteria, select together fire design scenarios to study with the tools and methods of their choice, upload the results to the website,

3. A "post-processing phase" where results of the tool applications are discussed in terms of their ability to address the defined performance issue, which discussion would eventually lead to the establishment of guidelines related to the tool comparison process, their usability and their relative outcome.

A more detailed process is presented in [5]. Each considered study topic will be associated with a portion of a website available to the 'test bed' participants, allowing free exchange of information and analysis. This organization is intended to maximize the number of participants and thus to contribute to a more extensive and validated study (with participants using differently the same tool so user influence would be addressed or with participants using different tools).

In the pre-processing phase, building layouts are collected from existing architectural projects or fictional ones, as long as they provide enough information to be used from correlations to CFD tools. Additional information for evacuation or structural response calculations may be also 
collected for use in upcoming hybrid tools such as the ones between a fire effects tool and a HVAC network model, as developed by Floyd [13]. During this phase, relevant information on a particular building or built environment is collected, including plans in AutoCAD ${ }^{\circledR}$ or REVIT $^{\circledR}$, interior layouts, and in some cases contents. Whatever tools are used by a fire protection engineer for his/her own purposes, these types of information are usually the basic information for the design team. Of course, as explained in the previous sections of this paper, not all the design information is available at the start of a project. Nevertheless, one of the primary aims of the 'test bed' environment studies is to assess the differences in the tool answers in relation to an engineering problem. This pre-processing phase would then be used as a feedback for the design team so they would know what information/data to provide the FPE as soon as possible so the FPE could use it in his/her analysis, especially for tools that would require lots and precise input data.

An initial 'test-bed' environment has been set up already, and several building configurations have been obtained. Examples of already collected building configurations are: hospital, library, high-rise office building, high school and dormitory. To supplement this set of configurations, examples of case studies could also be collected from the International conferences on performance-based codes and fire safety design methods [14].

In recent years, extensive work has been done in order to facilitate the transfer from architect's files to files usable for CFD fire effects tools (FDS via the software PyroSim or SMARTFIRE), evacuation models (Building_EXODUS or STEPS). Besides this project and all the work carried out by the aforementioned tool developers, Pin and Wu also [15] considered the use of the imported CAD file (ge1 extension file) in order to visualize the results in the SMOKEVIEW tool. This paper led us to consider how this representation might be misleading for the stakeholders, while judging the results provided by FDS, which performs the CFD calculations and the SMOKEVIEW layer which helps presenting the FDS results in the 3D geometry: if the geometry of the building is shown as very refined, the AHJ could think that the FDS calculations are refined at that level, which is usually not the case. The import of the geometry has to be considered as only making the process easier and faster for the FPE to build the geometry for calculations.

In the "performing and analyzing phase", which is really the core of the studies, safety objectives, safety functions and fire design scenario types are defined for each 'test bed' study. Given this information, participants are asked to perform simulations with the tools of their choices and upload the results in the website, providing details not only on the results but also on the use of the tools. Specific studies related to the use of CFD fire effects tools are presented in [5], including issues related to grid selection for a better optimization of CFD computational meshes, influence of detailed geometry on the results of the simulations, detailed geometry description versus computational time and result accuracy. Some specific studies related to evacuation models may also be defined and conducted among the participants.

In addition to studies related to the use of fire effects tools, studies related to the use of evacuation models, structural response models and fire risk models would also be included in the 'test bed' environments. The website would also be dedicated to facilitate information exchange about all types of engineering tool applications examples. Comparison studies such as the one 
performed by Lord et al. [16] on evacuation models would be welcome, rather based on study topics selected in the first phase of the 'test bed' studies than on a generic parametric analysis. This idea is linked to how the validation domain of the tools from research laboratory experiments could be extended in order to include all the diverse real life complex multi-story facilities which are the subject of PBFPD applications. The current process tends to involve a simultaneous and quite independent increase of the experimental input data ranges to correspond to real engineering projects. It is thought that (a) establishing a list of non-dimensional parameters which characterize related phenomena [17] and (b) describing the engineering projects with these parameters, would may cluster the application domain and this way lead to specific research to ultimately include these application clusters in the validation domain of the tools. McGrattan [17] stated that "the burden of [verification and validation] V\&V must be shared by the model developer and the user". In this matter, the 'test bed' environment is then designed to increase the collaboration between tool developers and users.

In parallel to collecting building layouts, a set of 'combustible packages' representing 3-D objects such as chairs, couches, and beds, which contain heat release rate, chemical reaction, and toxicity properties needed for the simulations, has been developed. The benefits of such data are that scenarios describe burning elements in the same way so that the focus of the 'test bed' studies remains the use of the tools for fire consequence analysis. A separate study, using different 'combustible packages' in FDS, shows that the same fuel item can be described differently whether the fire consequence analysis concerns the near field of the spreading fire or the far field. This study purpose is then to help the users of fire effects tools when characterizing the degree of details necessary to describe the design fire curves for a particular design fire scenario [18].

The third phase is dedicated to the analysis of the provided results by all participants of the previous phase and by the stakeholders who helped defined the safety objectives. This phase is aimed to provide the guidelines for selection of tools for a given application.

Benefits of conducting such 'test bed' studies are as diverse as the different participants to the studies [5]. Such guidelines related to the use of tools for PBFPD applications would be beneficial not only to consulting companies, engineering societies, regulators and AHJ, but also students and professors in Academia and governmental agencies which could set up research programs focusing on the problems and needs of the fire engineering community.

\section{ACKNOWLEDGEMENT}

This research is supported by NIST award 60NANB10D228.

\section{REFERENCES}

1. SFPE, Guidelines for Substantiating a Fire Model for a Given Application, 2011

2. SFPE, SFPE Engineering Guide to Performance-Based Fire Protection, 2007

3. SFPE/ICC, Code Official's Guide to Performance-Based Design Review (chapter 11), Society of Fire Protection Engineers and International Code Council, 2004 
4. NRC-EPRI, Verification and Validation of Selected Fire Models for Nuclear Power Plant Applications, vol. 1-7 (NUREG-1824 and EPRI 1011999, 2007)

5. Alvarez, A. and Meacham, B. J., ""Ready-to-use" Building Layouts and Combustible Packages for 3-D simulations", proceedings of the Fire and Evacuation Modeling Technical Conference, 2011

6. Friedman, R., "An International Survey of Computer Models for Fire and Smoke," Journal of Fire Protection Engineer, 4 (3), 1992, pp 81-92

7. Mowrer, F.W. (2002),"The Right Tool for the Job," Fire Protection Engineering Magazine (SFPE), Vol. 13, Winter, 2002, pp. 39-45

8. (ABCB) Australian Building Codes Board (2005), International Fire Engineering Guidelines, 2005

9. Proulx, G., Reid, I. and Cavan, N.R., Human Behavior Study, Cook County Administration Building Fire, October 17, 2003 Chicago, IL, Research Report No. 181, April 2004

10. Chu, G.Q., Chen, T., Sun, Z.H. and Sun, J.H., "Probabilistic risk assessment for evacuees in building fires," Building and Environment 42, 2007, pp. 1283-1290

11. NFPA 204: standard for Smoke and Heat Venting, National Fire Protection Association, 2012

12. NFPA 92: standard for Smoke Control Systems, National Fire Protection Association, 2012

13. Floyd, J., "Coupling a Network HVAC Model to a Computational Fluid Dynamics Model Using Large Eddy Simulation," Proceedings of the Tenth International Symposium of IAFSS, International Association for Fire Safety Science, 2011

14. SFPE, proceedings of the 8th International conferences on performance-based codes and fire safety design methods, Society of Fire Protection Engineers (2010)

15. Pin, Yat Fat and Wu, Kwun Hing, "Fire Modeling with CAD/GE1 Techniques," proceedings of the Fire and Evacuation Modeling Technical Conference, 2011

16. Lord, J., Meacham, B., Moore, A., Fahy, R. and Proulx, G, "Guide for Evaluating the Predictive Capabilities of Computer Egress Models", National Institute of Standards and Technology, NIST GCR 06-886, 2005

17. McGrattan, K. and Myers, T., "A Way to Characterize the Range of Validity of a Fire Model, proceedings of the Fire and Evacuation Modeling Technical Conference, 2011

18. Alvarez, A., Dembsey, N. A. and Meacham, B. J., "Combustible packages for 3D simulations using FDS - Simulating experiments in the FDS Chamber", manuscript to be submitted for publication in June 2012 


\section{Annex B}

Comparison of the International Fire Engineering Guidelines, SFPE Engineering Guide on Performance-Based Fire Protection, BS7974 Application of Fire Safety Engineering Principles to the Design of Buildings and ISO 13387 - Fire Safety Engineering - Part 1: Application of Fire Performance Concepts to Design Objectives 


\begin{abstract}
A High-Level Comparison of the International Fire Engineering Guidelines, BS 7974 - Application of Fire Safety Engineering Principles to the Design of Buildings, SFPE Engineering Guide to Performance-Based Fire Protection, ISO 13387 - Application of Fire Performance Concepts to Design Objectives
\end{abstract}

Prepared by

Valerie Boutin

Brian Meacham

Date

February 2013

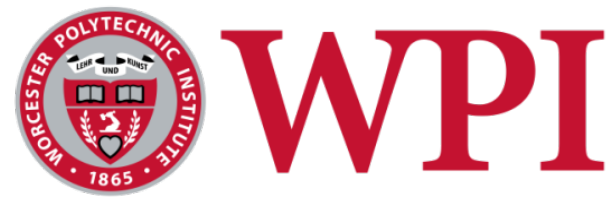

Department of Fire Protection Engineering Worcester Polytechnic Institute Worcester, MA 01609 USA http://www.wpi.edu/academics/fpe.html 


\section{NOTICE}

This report was prepared by Valerie Boutin and Brian Meacham as part of a research effort supported by the National Institute of Standards and Technology (NIST) Award 60NANB10D228 into characterization of risk, design fires, design fire scenarios and criteria as embodied in current fire safety engineering design guidance. Information presented in this report was obtained through a high-level review of the International Fire Engineering Guidelines, BS 7974, Application of Fire Safety Engineering principles to the Design of Buildings, the SFPE Engineering Guide to Performance-Based Fire Protection, ISO 13387, Application of Fire Performance Concepts to Design Objectives, and the comparison of BS7974 and the International Fire Engineering Guidelines conducted by Ove Arup \& Partners for the Scottish government in 2006. Reasonable attempts were made to verify the accuracy of the information provided, referenced and summarized in this report. However, neither the authors, nor Worcester Polytechnic Institute, nor any person acting on their behalf:

a. Makes any warranty, express or implied, with respect to the use of any information, apparatus, method or process disclosed in this report, or that such use may not infringe upon privately owned rights; or

b. Assumes any liabilities of whatsoever kind with respect to the use of, or damage resulting from use of, any information, apparatus, method or process disclosed in this report.

Any summaries, opinions, findings, conclusions or recommendations expressed in this report are those of the authors and do not necessarily reflect project sponsors, institutions, agencies or organizations. 


\section{EXECUTIVE SUMMARY}

This report provides a 'high-level' comparison of the International Fire Engineering Guidelines (IFEG) with BS 7974, Application of Fire Safety Engineering Principles to the Design of Buildings, the SFPE Engineering Guide to Performance-Based Fire Protection, and ISO 13387, Application of Fire Performance Concepts to Design Objectives. This comparison was supported by the National Institute of Standards and Technology (NIST) under Award 60NANB10D228 to WPI for research into various aspects of performance-based fire engineering design guidance and regulatory needs. The presentation of material in this report was formatted specifically to assist the IFEG Editorial Committee benchmark the relevancy of the IFEG relative to current fire safety engineering practice and informing possible updates or changes to the IFEG following the format a 2006 report which compared the IFEG to BS7974 for the Scottish government.

The comparison is provided in two parts: (1) a comparative summary of the structures of the four engineering guidance documents, and (2) a more detailed comparison of the specific information, data and methodologies provided in each document. While each of the documents reviewed includes references to other sources of information, these references were not reviewed as part of this effort. Likewise, no commentary is provided relative to the appropriateness or efficacy of the data and methods provided in the documents.

Based on this comparison, it is concluded that the International Fire Engineering Guidelines (IFEG) is contemporary in scope, process, and general methodologies used with BS 7974, Application of Fire Safety Engineering Principles to the Design of Buildings, the SFPE Engineering Guide to Performance-Based Fire Protection, and ISO 13387, Application of Fire Performance Concepts to Design Objectives. The general framework of all four approaches is effectively the same - a result of a high degree of overlap amongst developers of each. In addition, the methodologies used and evaluation methods recommended are largely the same. This is a function of the state of the art when the guides were developed (all prior to 2005) and the commonality of reference sources across the fire engineering community. Likewise, documentation requirements are largely the same.

In general, BS 7974 includes more detailed methods of evaluation than IFEG, ISO 13387 and the SFPE Guide, as these documents refer to other sources (IFEG has more than the other two). Each refers often to the SFPE Handbook of Fire Protection Engineering as well as to relevant standards. It is also worth noting that ISO has numerous 'sub-standards' - which link directly to ISO 13387 - that include much more detailed methodologies across all areas (fire, smoke, detection, etc.). While this makes the ISO 'suite' the most comprehensive, it may be considered by some cost-prohibitive from a practitioner perspective. (The ISO 'sub-standards' were not reviewed.)

One area lacking in the IFEG, ISO and SFPE Guide, as compared with BS 7974, is risk assessment and probabilistic methods. While IFEG, ISO and SFPE Guide all include some guidance, they largely refer out to other documents. SFPE has a guide on fire risk assessment, and ISO has a standard on fire risk assessment, for example, while BS 7974 includes probabilistic risk assessment as Part 7 of the package. While it was decided not to include guidelines currently under development (e.g., Nordic, European and others), the probabilistic approach is one area which these new documents are including. 


\section{EXECUTIVE SUMMARY}

This report provides a 'high-level' comparison of the International Fire Engineering Guidelines (IFEG) with BS 7974, Application of Fire Safety Engineering principles to the Design of Buildings, the SFPE Engineering Guide to Performance-Based Fire Protection, and ISO 13387, Application of Fire Performance Concepts to Design Objectives, for the purpose of helping the IFEG Editorial Committee benchmark the relevancy of the IFEG relative to current fire safety engineering practice and informing possible updates or changes to the IFEG.

The review is provided in two parts: a comparative summary of the structures of the four engineering guidance documents, and a more detailed comparison of the information, data and methodologies provided in each document. While each of the documents reviewed includes references to other sources of information, these references were not reviewed as part of this effort. Likewise, no commentary is provided relative to the appropriateness or efficacy of the data and methods provided in the documents.

Based on this review, it is concluded that the International Fire Engineering Guidelines (IFEG) is contemporary in scope, process, and general methodologies used with BS 7974, Application of Fire Safety Engineering principles to the Design of Buildings, the SFPE Engineering Guide to Performance-Based Fire Protection, and ISO 13387, Application of Fire Performance Concepts to Design Objectives. The general framework of all four approaches is effectively the same - a result of a high degree of overlap amongst developers of each. In addition, the methodologies used and evaluation methods recommended are largely the same. This is a function of the state of the art when the guides were developed (all prior to 2005) and the commonality of reference sources across the fire engineering community. Likewise, documentation requirements are largely the same.

In general, BS 7974 includes more detailed methods of evaluation than IFEG, ISO 13387 and the SFPE Guide, as these documents refer to other sources (IFEG has more than the other two). Each refers often to the SFPE Handbook of Fire Protection Engineering as well as to relevant standards. It is also worth noting that ISO has numerous 'sub-standards' - by which I mean standards that link to ISO 13387 - which include much more detailed methodologies across all areas (fire, smoke, detection, etc.). While this makes the ISO 'suite' the most comprehensive, it may be considered by some cost-prohibitive.

One area lacking in the IFEG, ISO and SFPE Guide, as compared with BS 7974, is risk assessment and probabilistic methods. While IFEG, ISO and SFPE Guide all include some guidance, they largely refer out to other documents. SFPE has a guide on fire risk assessment, and ISO has a standard on fire risk assessment, for example, while BS 7974 includes probabilistic risk assessment as Part 7 of the package. While it was decided not to include guidelines currently under development (e.g., Nordic, European and others), the probabilistic approach is one area which these new documents are including. 


\section{CONTENTS}

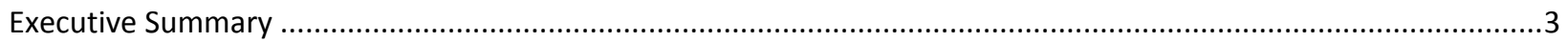

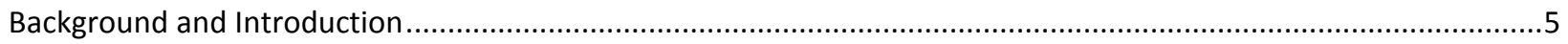

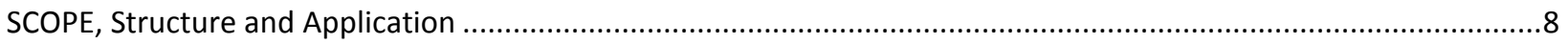

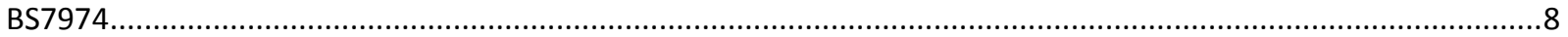

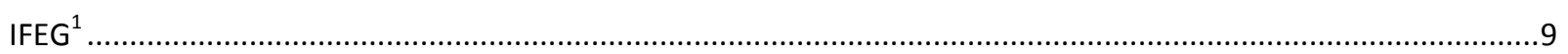

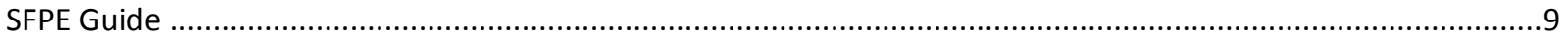

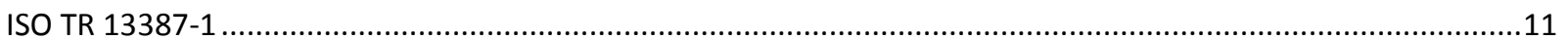

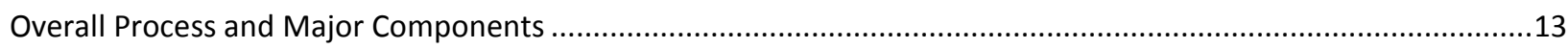

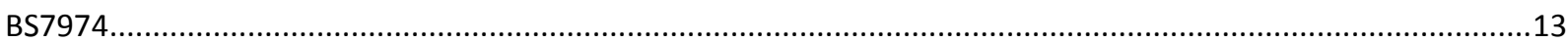

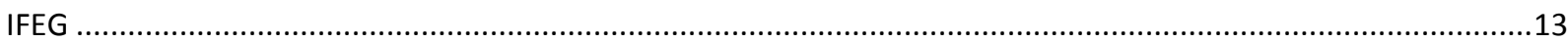

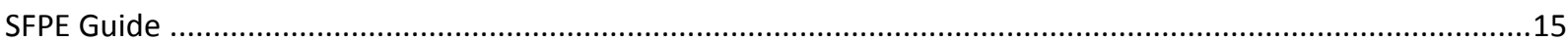

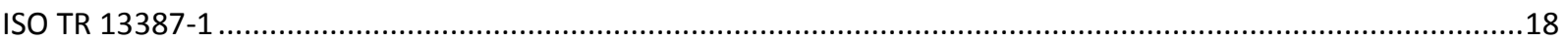

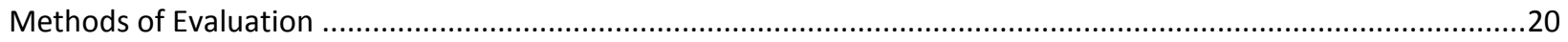

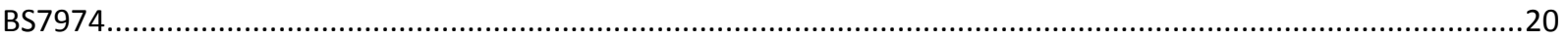

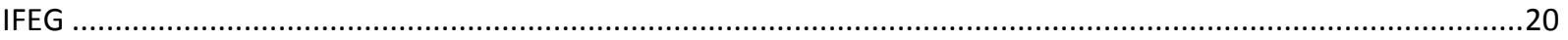

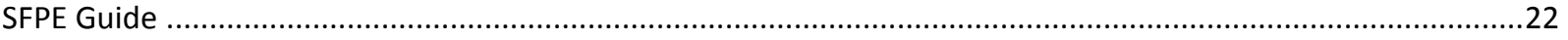

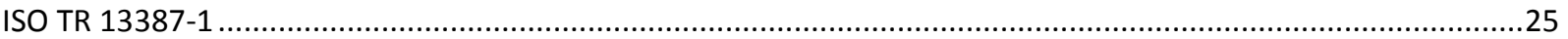

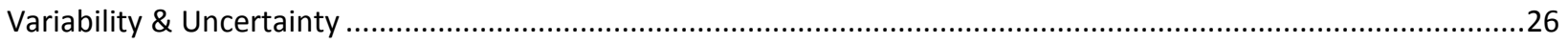

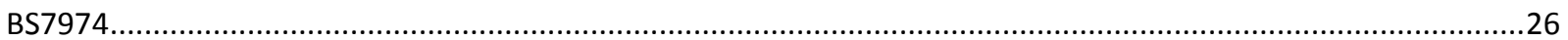

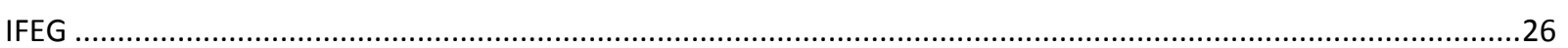

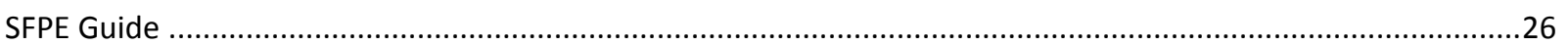

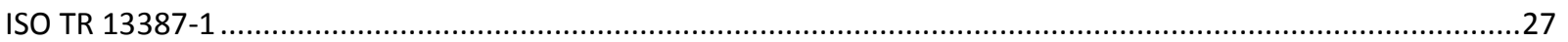

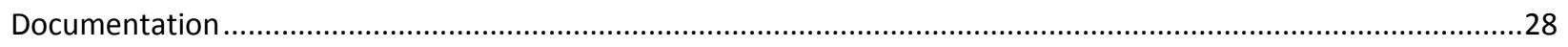

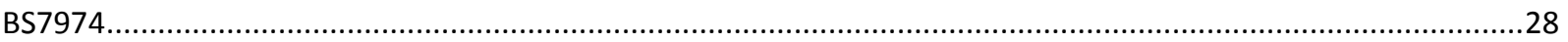

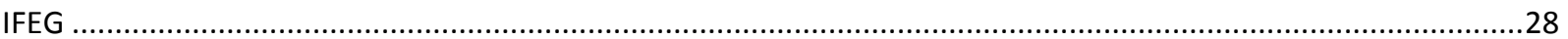

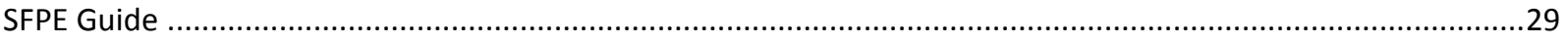

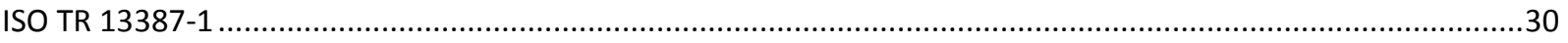

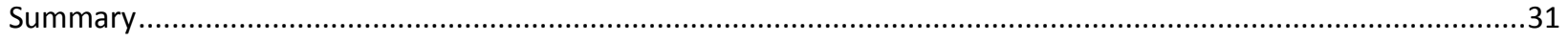

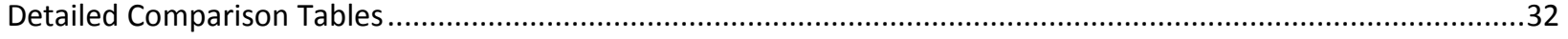




\section{BACKGROUND AND INTRODUCTION}

In 2010, the Editorial Committee (EC) for the International Fire Engineering Guidelines (IFEG) began its required 5year review of the IFEG to determine if it remained a contemporary document, fit for the purpose of providing guidance to fire safety engineers. This involved various surveys of fire engineers in EC member countries and of IRCC members. After the initial set of surveys, an EC meeting was held in Worcester, Massachusetts, USA, in October 2010.

At the October 2010 meeting, the EC agreed that the IFEG was a contemporary document and fit for purpose. However, the EC agreed that the IFEG should be compared with other contemporary fire engineering process documents in order to identify a potential scope for ongoing development. Brian Meacham, associate professor of fire protection engineering at Worcester Polytechnic Institute (WPI), offered to undertake a review of the IFEG in comparison to the SFPE Guide on Performance-Based Fire Protection and ISO 13387, Application of Fire Performance Concepts to Design Objectives, following the format of the comparison of the IFEG to BS 7974, Application of Fire Safety Engineering principles to the Design of Buildings, undertaken by Ove Arup \& Partners for the Scottish government in 2006. The target for the completion of the review was December 2012.

A subsequent meeting was held in March 2011 between Brian Meacham, Brian Ashe and Ray Loveridge to further discuss the outcomes of the Boston meeting and the scope of the comparative analysis. Key issues on the scope related to whether regulatory documents, such as the New Zealand Verification Method for Fire, which was significantly modified to include details on scenarios, design fire quantification, verification methods and criteria, and the new Swedish building regulations, which include similar components as well as a risk-based approach, should be considered. If was furthermore suggested that additional feedback from IRCC members and practitioners would be helpful. With respect to the IRCC, key questions included what value the IFEG is to them and what changes they might desire if they were to use them. This was asked in the light of whether the $A B C B$ would like to have responsibility, in the future, for the IFEG. This was discussed at the May 2011 IRCC meeting in Bergen, Norway, where IRCC members offered the following comments:

- Norway: fire engineering is part of most building designs. In most cases where the design is deviating from the Approved Document, a comparative analysis that may include deterministic and/or probabilistic analyzing methods is performed. British Standard AS7974:2001 'Application of fire safety engineering principles to the design of buildings. Code of Practice' is used when required. Standards Norway is intending to publish a revised version of the Norwegian standard NS 3901 Requirements to risk assessment for fire in construction works.

- Scotland: fire engineering of building designs is not common practice and British Standard AS7974:2001 is used when required.

- Austria: fire engineering of building designs is supported. However; German guidelines are adopted. Most practitioners would not speak English; therefore adoption of the IFEG would be impractical.

- $\quad$ Singapore: has no 'preferred' guidelines for use by practitioners and is keen to participate in the further development of the IFEG. Singapore sought more information on New Zealand's proposed reforms and questioned the expected scope of their contribution to development of the IFEG.

- New Zealand: supported further development of the IFEG.

- Canada: considered that Singapore's contribution could initially comprise development of a Singaporean 'Part 0 ' for inclusion in the IFEG and proposed that Singapore should collaborate with the Editorial Committee on future development of the IFEG.

- $\quad$ Australia: advised members that the ABCB did not intend to independently review the IFEG. 
Following the Bergen IRCC meeting, a decision was taken to obtain additional feedback from industry. In September 2011, at the ABCB Conference on Building Australia's Future, the EC received input from the Australian Society of Fire Safety (SFS), a 'practitioner' Society within the Institute of Engineers Australia, and the Australasian Fire and Emergency Services Authorities Council, a jurisdictional Fire Brigade group. Feedback from these groups indicated that while some significant changes would be welcome, these groups did not step up to help. The EC then questioned whether they should be responsible for promoting change, or whether change should be driven by industry. This question was posed to the IRCC. Response from IRCC members is as follows:

- Industry practitioners should become a champion of future reform of the IFEG.

- Restructuring the IFEG would not in itself be sufficient reform to augment current international application.

- International perspectives suggest the IFEG should remain a process document. An Australian perspective (SFS) suggests that the content should be updated and expanded to incorporate a relevant database.

- There would be benefit in exploring the merits of facilitating a consistent approach between the IFEG and the revised New Zealand approach.

In light of IRCC member response to the survey, it was evident there is limited international interest in reviewing the IFEG. Therefore the decision was taken that $A B C B$ should retain responsibility for the document and the existing EC should retain its editorial role. It was also decided that the EC should delay further review of the IFEG pending receipt of outcomes of the international comparative analysis, and that further review activities should be undertaken in collaboration with relevant stakeholders.

This document reflects the international comparison referred to above. The scope, as ultimately decided, is limited to a comparison of process and methodology embodied within the IFEG with those embodied within BS 7974, Application of Fire Safety Engineering principles to the Design of Buildings, the SFPE Engineering Guide to Performance-Based Fire Protection, and ISO 13387, Application of Fire Performance Concepts to Design Objectives.

The review is provided in two parts: a comparative summary of the structures of the four engineering guidance documents, and a more detailed comparison of the information, data and methodologies provided in each document. While each of the documents reviewed includes references to other sources of information, these references were not reviewed as part of this effort. Likewise, no commentary is provided relative to the appropriateness or efficacy of the data and methods provided in the documents.

Unless otherwise noted, discussion regarding comparison between BS7974 and the International Fire Engineering Guidelines (IFEG) comes from the review conducted by Over Arup and Partners for the Scottish government (report can be found at http://www.scotland.gov.uk/Resource/Doc/217736/0090824.pdf). Discussion on the SFPE Engineering Guide to Performance-Based Fire Protection and ISO 13387, Application of Fire Performance Concepts to Design Objectives, has been developed by the authors, drawing from the source documents as appropriate.

Based on decisions as outlined above, no consideration is given to current regulatory approaches, or to new guidance under development, such as the Nordic Fire Engineering Guidelines, the new SFPE standards committee on design fire scenarios and fires, or continued development of ISO documents in support of TR 13387 . To the latter point, both SFPE and ISO have a range of reference documents, to which their 'process' guidelines point, which were not then included in this comparison. For this reason, it should not be concluded that ISO and SFPE do not address several issues, but only that their process documents do not. 
This section of the report, then, provides a narrative summary of the scope, structure, process, and methodologies identified within the considered documents, including recommended processes developing, evaluating and documenting designs. The second part of the review provides, in tabular form, a comparison of how each of the considered documents addresses components of the overall fire safety engineering process, including specific methodologies and data that may be incorporated or referenced. While reasonable attempts have been made to include all aspects, it is possible that some errors or omissions exist, and this comparison should be considered appropriately. 


\section{SCOPE, STRUCTURE AND APPLICATION}

This section overviews the general scope, structure and application of the reviewed documents. In general, all four documents provide a framework for engineering analysis, which has flexibility to fit individual project needs, apply to new or existing construction, and require evaluation of design alternatives against criteria established by the engineering team. Each document identifies a set of fire safety 'systems' for which design solutions may be engineered.

\section{BS7974}

BS7974 is in effect a 'framework' code of practice under which sits a set of Published Documents [PD's]. This study embraces the PD's along with the BS 7974. The BS code of practice "provides a framework for developing a rational methodology for design of buildings using a fire safety engineering approach based on the application of scientific and engineering principles to the protection of people, property and the environment from fire".

It may be applied to new or existing buildings, to show that regulatory requirements can be met. It is intended to be applied to three main stages:

1. Qualitative Design Review [QDR]: in which the scope and objectives of the fire safety design are defined, performance criteria established and one or more potential design solutions proposed.

2. Quantitative Analysis: engineering methods are used to evaluate the potential solutions identified in the QDR.

3. Assessment Against Criteria: the output of the quantitative analysis is compared to the acceptance criteria identified in the QDR.

The BS7974 provides guidance on these procedures. The sub-systems in the PD's provide data and analytical methods for tackling the relevant quantitative analysis, and advice on acceptance criteria and suitable design approaches. The document structure with the sub-systems is illustrated in Figure 1.

BS7974 Code of Practice-

Application of fire safety engineering principles to the design of buildings

\begin{tabular}{|c|c|c|c|c|c|c|c|}
\hline $\begin{array}{l}\text { BSPD7974- } \\
0\end{array}$ & $\begin{array}{l}\text { BSPD7974- } \\
1\end{array}$ & $\begin{array}{l}\text { BSPD7974- } \\
2\end{array}$ & $\begin{array}{l}\text { BSPD7974- } \\
3\end{array}$ & $\begin{array}{l}\text { BSPD7974 } \\
-4\end{array}$ & $\begin{array}{l}\text { BSPD7974- } \\
5\end{array}$ & $\begin{array}{l}\text { BSPD7974- } \\
6\end{array}$ & $\begin{array}{l}\text { BSPD7974- } \\
7\end{array}$ \\
\hline $\begin{array}{l}\text { Guide to } \\
\text { design } \\
\text { framework } \\
\text { and fire } \\
\text { safety } \\
\text { engineering } \\
\text { procedures }\end{array}$ & $\begin{array}{l}\text { Initiation and } \\
\text { development } \\
\text { of fire within } \\
\text { enclosure of } \\
\text { origin }\end{array}$ & $\begin{array}{l}\text { Spread of } \\
\text { smoke and } \\
\text { toxic gases } \\
\text { within and } \\
\text { beyond the } \\
\text { enclosure of } \\
\text { origin }\end{array}$ & $\begin{array}{l}\text { Structural } \\
\text { response } \\
\text { and fire } \\
\text { spread } \\
\text { beyond the } \\
\text { enclosure } \\
\text { of origin }\end{array}$ & $\begin{array}{l}\text { Detection } \\
\text { of fire and } \\
\text { activation } \\
\text { of fire } \\
\text { protection } \\
\text { systems }\end{array}$ & $\begin{array}{l}\text { Fire service } \\
\text { intervention }\end{array}$ & Evacuation & $\begin{array}{l}\text { Probabilistic } \\
\text { risk } \\
\text { assessment }\end{array}$ \\
\hline
\end{tabular}

Figure 1: Structure of sub-systems in BS7974

Note that 0 and 7 are not sub-systems as such, i.e., they do not address characteristics of fire or safety systems. PDO provides guidance on procedure and PD7 provides guidance on risk assessment techniques, both being applicable to any of the other subsystem. 


\section{IFEG $^{1}$}

The guidelines document and approach uses a very similar sub-systems break-down of the subject to that used in BS7974. The guidelines are derived from an earlier Australian document (the draft National Building Fire Safety Systems code). In the early 1990's the original consultant team commissioned to draft the document that eventually became BS7974 in the UK, were in contact with members of the team who were working on the first edition of the Australian Fire Engineering Safety Systems code at the same time. There was cross-fertilization between these groups.

The UK group picked up the Australian sub-system concept and the Australian group adopted the UK QDR concept (though some of the terminology was altered). The structure of the IFEG after the 'national' introductory sections is in three parts:
1. Process
2. Methodologies
3. Data

The sub-system approach is introduced in section 1.3.1 of the IFEG document. As noted the IFEG sub-systems bear a very close resemblance to those used in BS7974. They are set out in Figure 2 below. The following quote from IFEG 1.3.2 is important in that it qualifies the importance of the whole sub-system principle:

"Typically, each building project is unique and similarly, each fire engineering evaluation is unique. It is not sensible, therefore, to set down detailed guidance on how the fire safety analysis should be undertaken. Instead, it is the responsibility of the fire engineer to plan the analysis for the particular project, based on the decisions taken during the preparation of the FEB as discussed in Chapter 1.2."

\begin{tabular}{|c|c|c|c|c|c|}
\hline Subsystem A & Subsystem B & Subsystem C & Subsystem D & Subsystem E & Subsystem F \\
\hline $\begin{array}{l}\text { Fire initiation } \\
\text { and } \\
\text { development } \\
\text { and control of } \\
\text { fire within } \\
\text { enclosure of } \\
\text { origin as well as } \\
\text { enclosures to } \\
\text { which fire } \\
\text { subsequently } \\
\text { spreads }\end{array}$ & $\begin{array}{l}\text { Development } \\
\text { and spread of } \\
\text { smoke within } \\
\text { the building, and } \\
\text { its control }\end{array}$ & $\begin{array}{l}\text { Spread of fire } \\
\text { beyond the } \\
\text { enclosure of } \\
\text { origin, impact on } \\
\text { structure and } \\
\text { how spread and } \\
\text { impact may be } \\
\text { controlled }\end{array}$ & $\begin{array}{l}\text { Fire detection } \\
\text { warning and } \\
\text { suppression. } \\
\text { Enables } \\
\text { suppression } \\
\text { effectiveness to } \\
\text { be estimated }\end{array}$ & $\begin{array}{l}\text { Occupant } \\
\text { evacuation and } \\
\text { control. Enables } \\
\text { estimate of time } \\
\text { to reach place of } \\
\text { safety }\end{array}$ & $\begin{array}{l}\text { Fire services } \\
\text { intervention. } \\
\text { Effectiveness of } \\
\text { intervention } \\
\text { including } \\
\text { suppression. }\end{array}$ \\
\hline
\end{tabular}

Figure 2: The IFEG sub-systems

\section{SFPE GUIDE}

The SFPE Guide is also a 'framework' document. It identifies a number of steps which should be undertaken in identifying relevant fire safety goals for a project, developing quantified design criteria against which to evaluate fire safety performance, developing fire scenarios and quantified design fires for use in the evaluation, and selection and evaluation of fire protection options. 
This SFPE Guide is applicable to new or existing projects. It overviews the basic building design process (Figure 3), indicating that the fire analysis and design approach can fit into the overall design process at any stage, and identifies what type of information or analysis may be needed at each step.

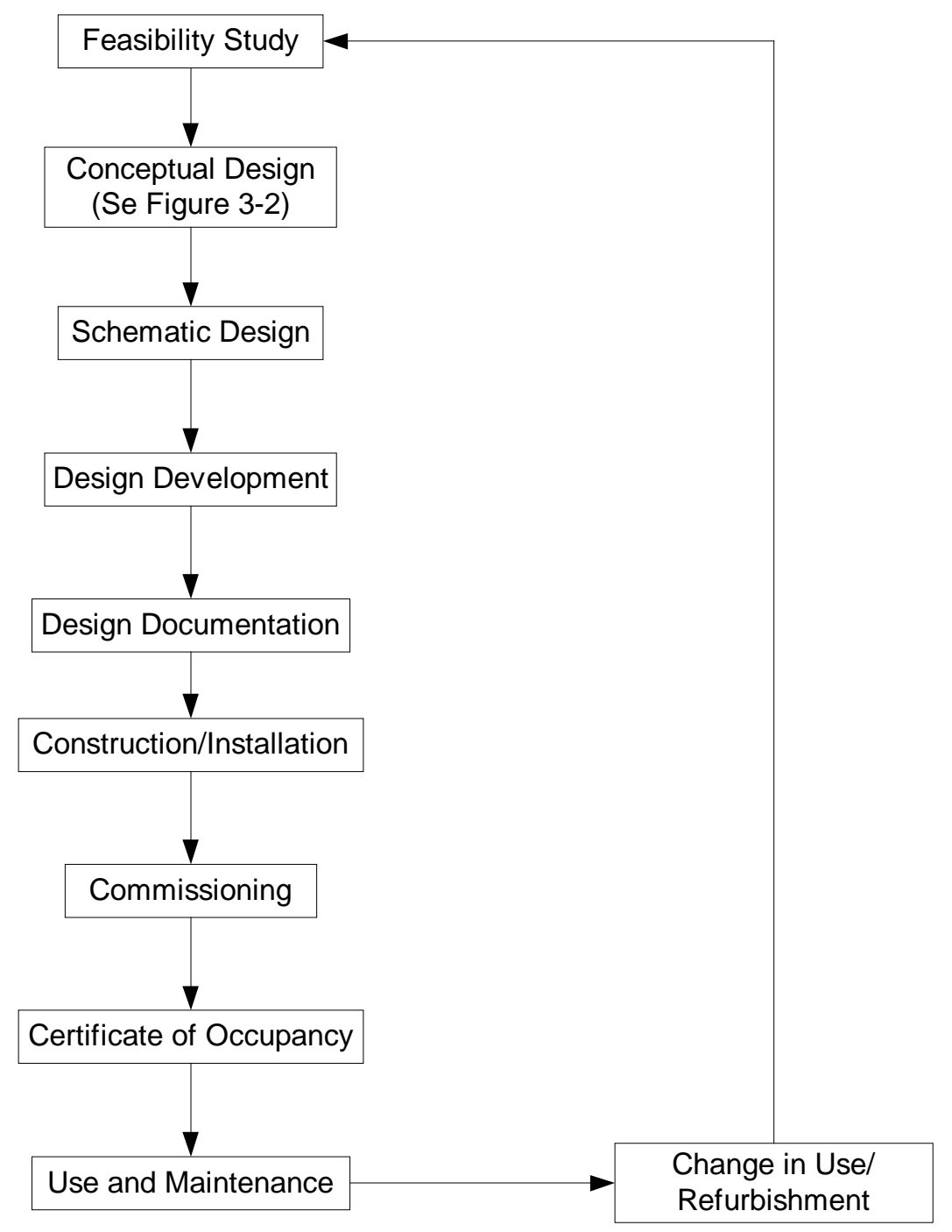

Figure 3: Basic Building Process

The SFPE Guide defines four levels of application which can be undertaken:

1) The performance-based design process can be used to evaluate and recommend fire protection options at the subsystem performance level, at the system performance level, or at the building performance level. At any level, the results could be evaluated on a comparative or absolute basis.

2) A subsystem performance evaluation typically consists of a simple comparative analysis in which it is required to demonstrate that a selected subsystem provides "equivalent" performance to that specified by a prescriptive based code. At this level, one subsystem is evaluated in isolation.

3) A system performance evaluation could consist of a comparative or absolute analysis. A system performance evaluation is used when more than one fire protection system or feature is involved. A system performance evaluation is more complex than a subsystem evaluation, as the analysis needs to take account of the interaction between various subsystems. 
4) In a building performance analysis, all subsystems used in the protection strategy and their interactions are considered. A performance-based design that takes into account total building fire safety can provide more comprehensive solutions than subsystem or subsystem performance analyses, because the entire building-fire-target interaction is evaluated.

Much like BS7974 and the IFEG, the SFPE Guide identifies six subsystems for which fire protection strategies can be developed:

1) Fire Initiation and Development (Section 9.2)

2) Spread, Control, and Management of Smoke (Section 9.3)

3) Fire Detection and Notification (Section 9.4)

4) Fire Suppression (Section 9.5)

5) Egress Provisions Including Occupant Behavior (Section 9.6)

6) Passive Fire Protection (Section 9.7)

The SFPE Guide outlines a series of steps for project documentation: the Fire Protection Engineering Design Brief, the Fire Protection Design Report, and an Operations and Maintenance Manual. The SFPE Guide informs users to carefully identify and document assumptions, limitations and bounding conditions relevant to any recommended design. Just as there was cross fertilization between the IFEG and BS7974 developers, the developers of the SFPE Guide were familiar with the concepts and approaches underpinning the IFEG, BS7974 and ISO TR 13387.

\section{ISO TR 13387-1}

ISO TR 13387-1 is similar to BS7974 in that it is a document which describes a framework for the provision of an engineered approach to the achievement of fire safety in buildings, based on the quantification of the behavior of fire and people. ISO TR 13387-1, coupled with the other ISO documents which provide more detailed aspects of fire safety design, can be applied to any type of new or existing building.

Much like BS7974, ISO TR 13387-1 is intended to be applied to three main stages:

1. Qualitative Design Review [QDR]: The review is qualitative because not all the values of the design parameters will be known and engineering judgment will need to be applied to obtain them. It is also qualitative because judgment will need to be used to decide on a limited number of important fire scenarios for later quantified analysis;

2. Quantitative Analysis: engineering methods are used to carry out a time-based quantified analysis using the appropriate subsystems - or use another appropriate method of analysis as indicated in the QDR, making sure that, wherever possible, mathematical models are verified;

3. Assessment against Criteria: the output of the quantitative analysis is compared to the acceptance criteria identified in the QDR.

4. Reporting Results: Documentation of the analyses.

Similar to the BS7974 and the IFEG, the ISO is divided into sub-systems. There are five sub-systems in total:

1) Initiation and development of fire and generation of fire effluents (ISO 13387-4)

2) Movement of fire effluents (ISO 13387-5)

3) Structural response and fire spread beyond the enclosure of origin (ISO 13387-6)

4) Detection, activation and suppression (ISO 13387-7)

5) Life safety: occupant behavior, location and condition (ISO 13387-8) 
The subsystems interact as in the illustration below (Figure 4):

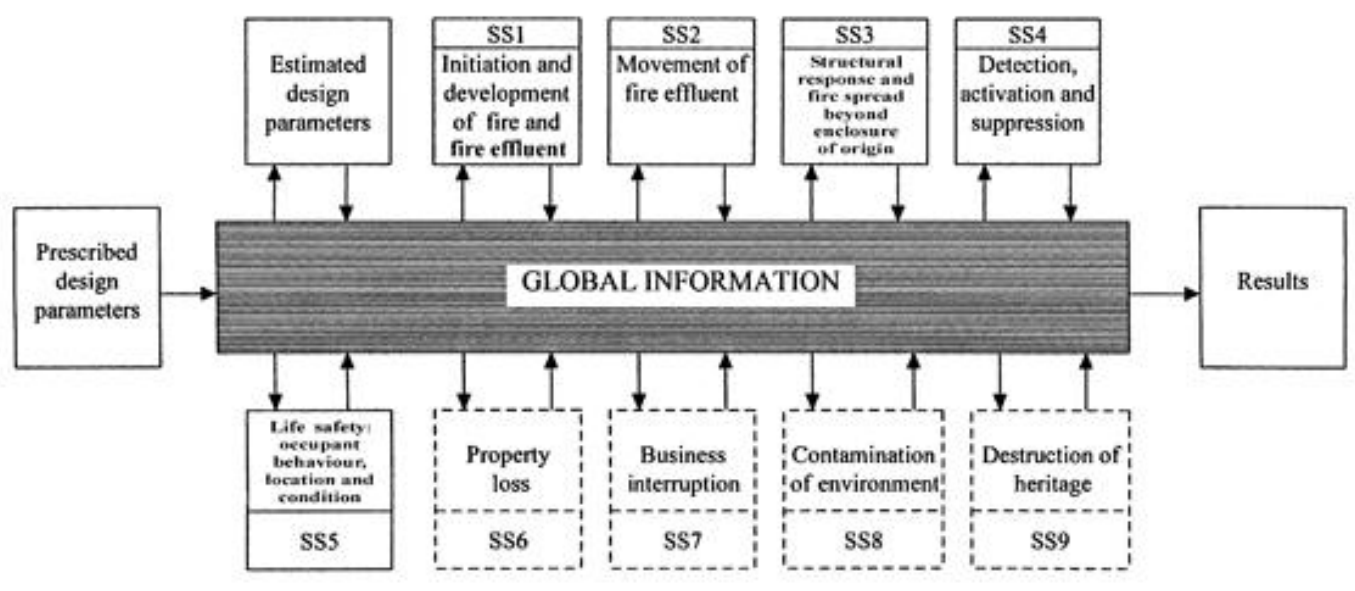

Figure 4: The global information framework as described in ISO TR 13387-1 


\section{OVERALL PROCESS AND MAJOR COMPONENTS}

This section provides an overview of the fire engineering process and the major components which are considered.

\section{BS7974}

As noted above, BS7974 is intended to be applied to three main stages, Qualitative Design Review, Quantitative Analysis and Assessment against Criteria, as outlined in Figure 5.

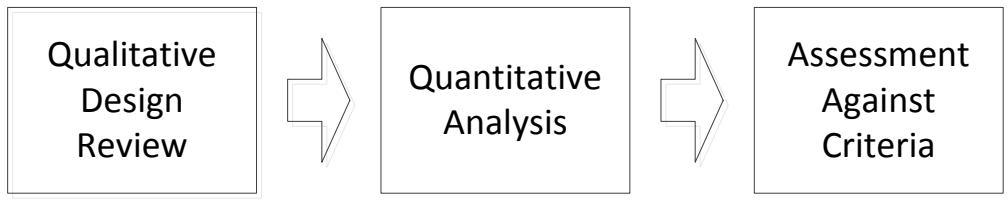

Figure 5: The engineering approach described in BS7974

In the Qualitative Design Review (QDR), the scope and objectives of the fire safety design are defined, performance criteria are established and one or more potential design solutions proposed. Engineering methods are then used to evaluate the potential solutions during the quantitative review. The output of the quantitative analysis is compared to the acceptance criteria identified in the QDR. The QDR is roughly equivalent to the Fire Engineering Brief (FEB) in the IFEG and Fire Protection Engineering Design Brief (FPEDB) in the SFPE Guide.

\section{IFEG}

The "Process" section of the IFEG offers guidance on what issues should be addressed in the Fire Engineering Brief [FEB]. The FEB is a process as well as a document. It defines the scope of the fire engineering analysis, and the basis on which that analysis will be undertaken. All interested parties including the Authority Having Jurisdiction $[\mathrm{AHJ}]$, have to be involved, since key components of the FEB include acceptance criteria. These criteria are likely to be more detailed than the Functional Standards of building regulations.

The process outlined in the IFEG is as follows:

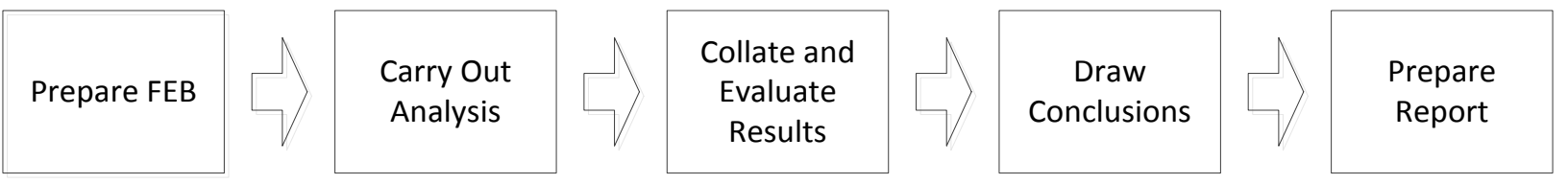

Figure 6: Sequence of the fire engineering process in the IFEG

The IFEG gives an illustration [Figure 7 see below] of a process for developing a FEB. The IFEG notes that the FEB may vary based on the requirements of a project. The steps shown in Figure 7 may be re-ordered, omitted or an iterative process introduced. The first stage in the Guidelines is the preparation a Fire Engineering Brief (FEB). A practical criticism of the FEB principle identified in the Arup report is that it is generally impossible to follow in a real project since there are many unknowns in the early stages. The IFEG acknowledges this, noting that there are many unknowns in the early stages, and noting that there may well be iterative loops in its development and in accepting that there may be preliminary "test" calculations/analyses to establish the likelihood of success before trial designs are defined ready for fuller analysis. Typically there may be some exploratory 'hand calculations' before the fire engineer advises the design team to take a particular approach, after which a more time-consuming analysis may be carried out to test the approach, once the design has been further developed. The FEB is not 
necessarily fixed [1.2.14]: "Sometimes, as the analysis of a design proceeds or as a project develops, it may be appropriate to revise the FEB, adopting the same consultative approach as with the original. The 'final' FEB will be incorporated into the overall report"

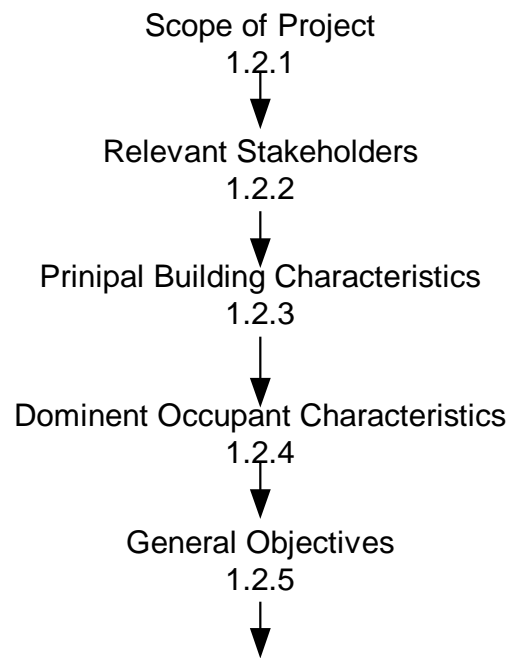

Hazards and Preventative and

Protective Measures Available

Trial Designs for Assessment

1.2.7

$\downarrow$

Non-complience issues and

Specific Objective or Performance Requirements

1.2 .8

$\downarrow$

Approaches and Methods of Analysis

1.2 .9

$\downarrow$

Acceptance Criteria and Factors

of Safety for the Analysis

1.2.10

1

Fire Scenarios \& Parameters for Design Fires 1.2.11

Parameter for Design Occupant Groups 1.2.12

Standards of Construction, Commissioning,

Management, Use and Maintenance

The FEB Report

1.2.14

Figure 7: Process for developing a FEB 


\section{SFPE GUIDE}

The SFPE Engineering Guide describes the process for performance based design and analysis process as illustrated in Figure 8 below.

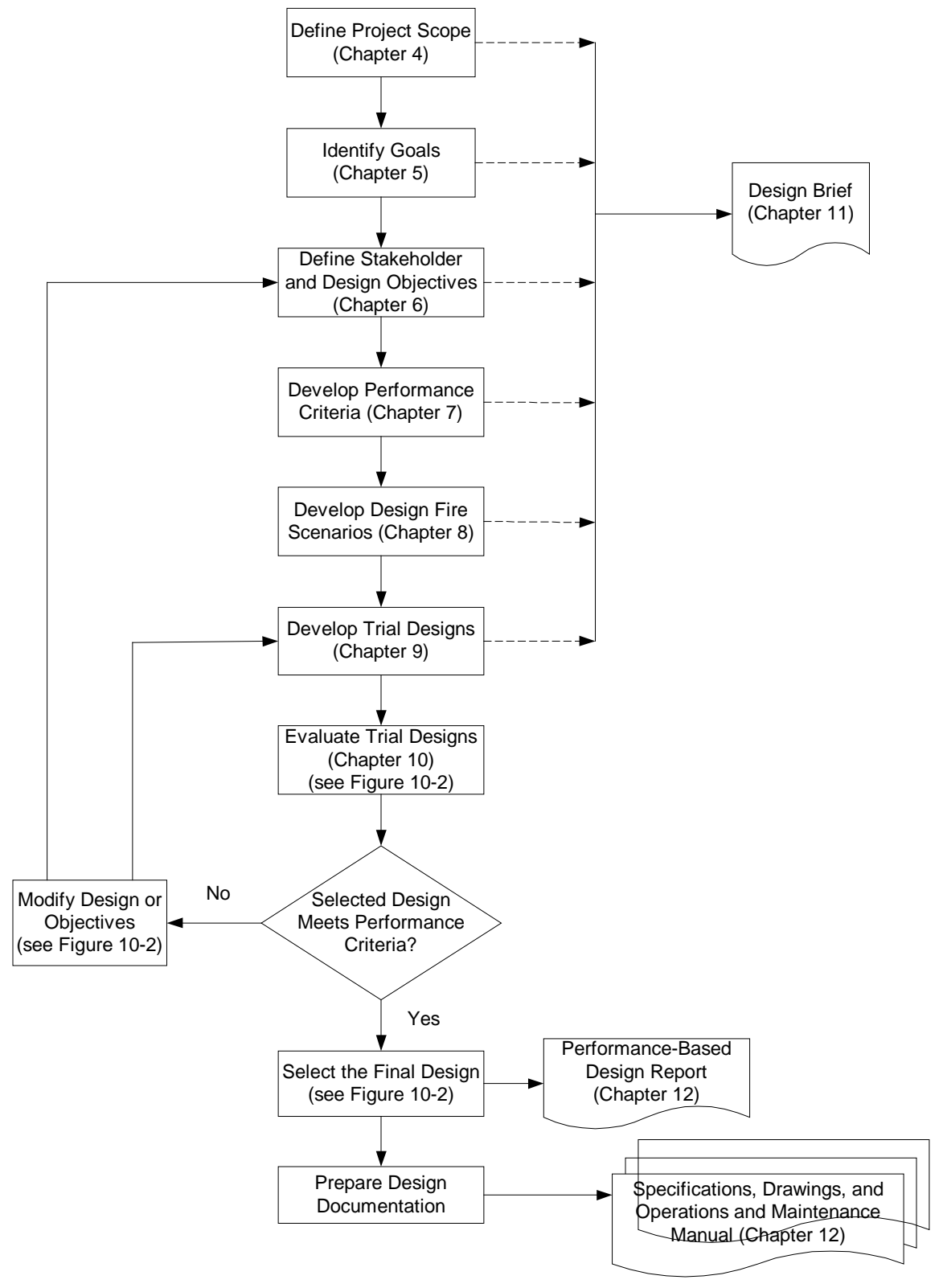

Figure 8: Performance based design and analysis procedure

The first step in the SFPE process is to develop the Fire Protection Engineering Design Brief which consists of 6 major components:

1. Define Project Scope

2. Identify Goals

3. Define Stake holder and Design Objectives 


\section{Develop Performance Criteria \\ 5. Develop Design Fire Scenarios \\ 6. Develop Trial Designs}

Each of these subsections is discussed in its own chapter. The component is defined and all the necessary parts are highlighted. The majority of the time, examples are provided.

For setting goals and objectives, discussion is provided in the main body of the Guide, with examples provided in the appendices. Unlike BS7974, specific criteria are not suggested, with references provided to engineers to seek criteria and values as appropriate to their project and approach (e.g., deterministic or probabilistic).

Several illustrations are provided to aid in the development of fire scenarios (Figure 9) and trial designs (Figure 10 and Figure 11).

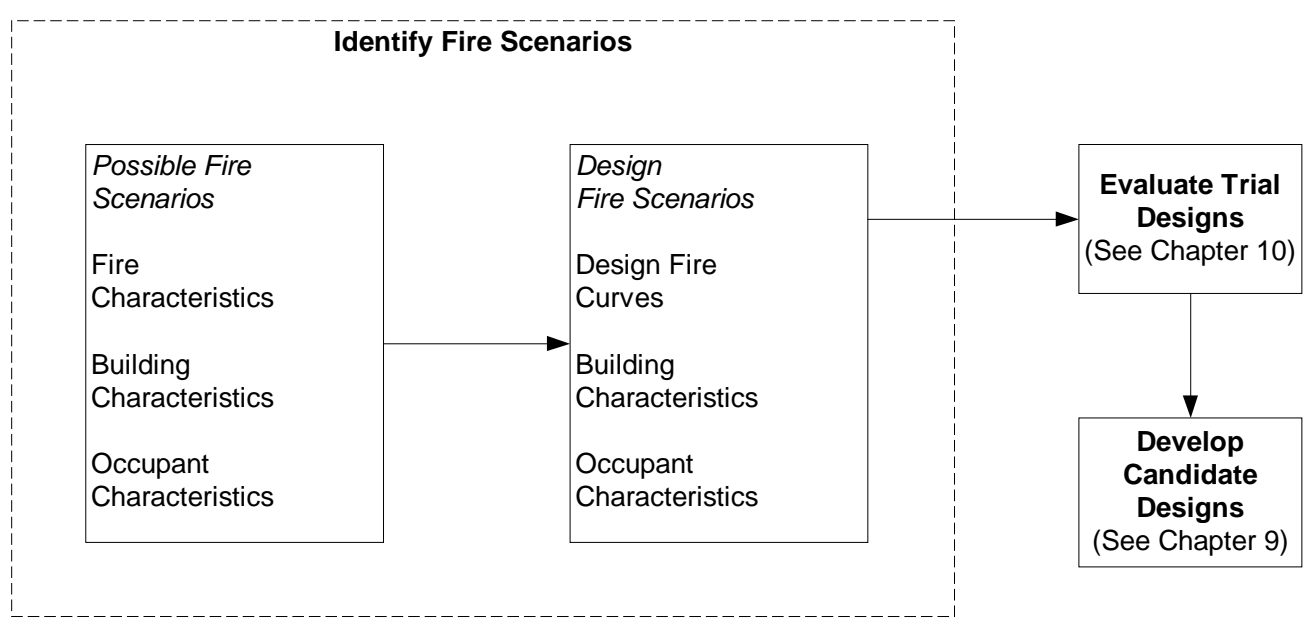

Figure 9: Development of fire scenarios

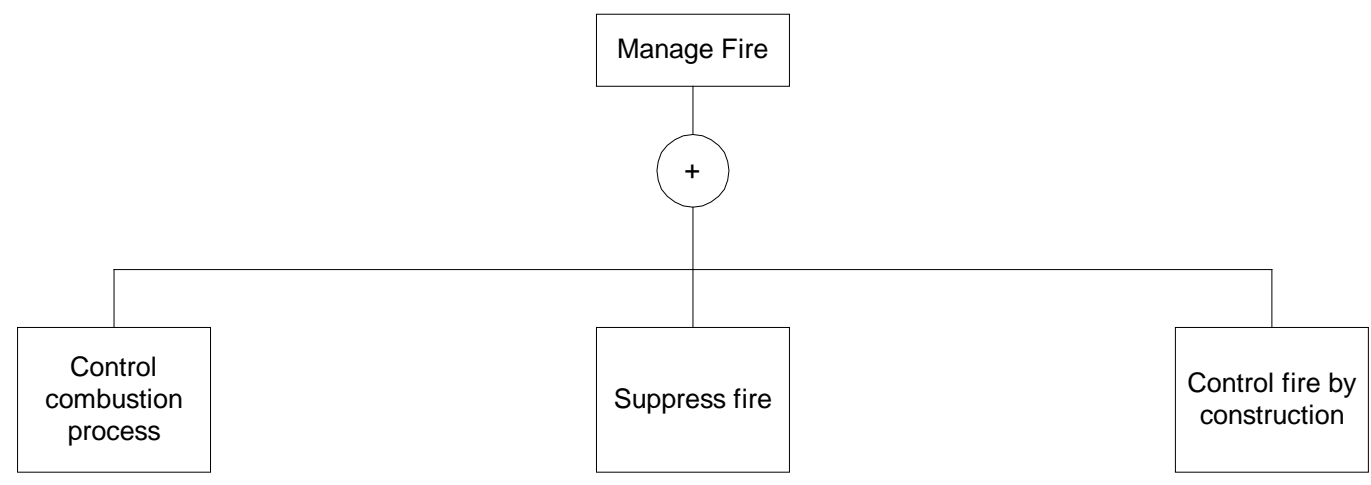

Figure 3: Top Level of the Firesafety Concepts Tree 


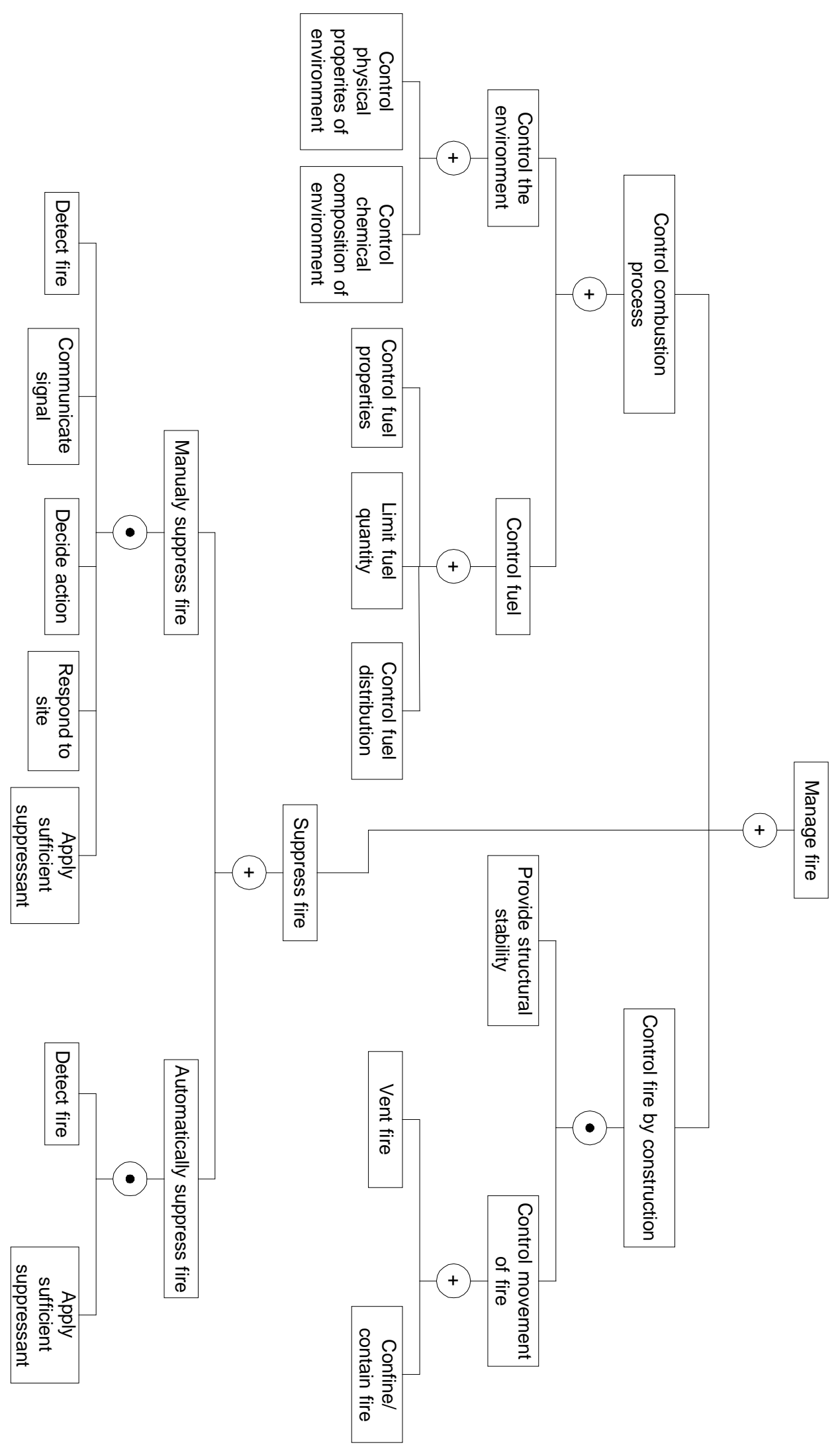

Figure 4: Limiting the spread of fire 


\section{ISO TR 13387-1}

As noted above, the ISO standard defines four main steps in the overall process:

1. Qualitative design review (QDR)

2. Quantitative analysis of design

3. Assess the outcome of the analysis against the safety criteria

4. Report and present the results

The steps are discussed in greater detail in the ISO 13387-1 document. The figure below gives a visual representation of the steps.

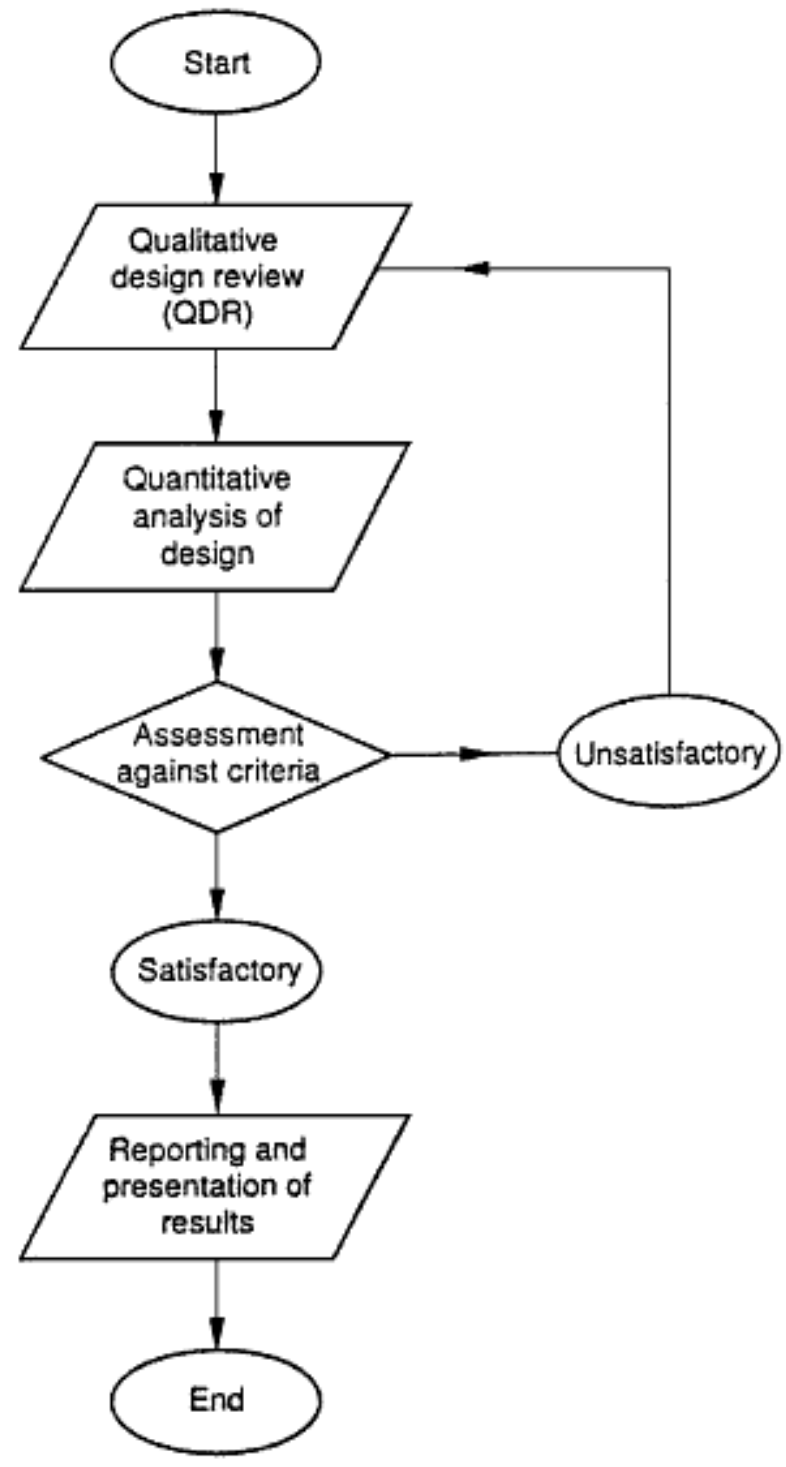

Figure 5: ISO basic fire safety design process 
A major step in the QDR is the identification of design fire scenarios. The components of a design fire scenario are:

- Type of fire

- Internal ventilation conditions

- External environmental conditions

- Performance of each of the fire safety measures

- Type, size, and location of ignition source

- Distribution and type of fuel

- Fire load density

- Fire suppression

- State of doors

- Breakage of windows

- Building air-handling system

Examples of typical design fire scenarios are provided. There are a total of 10 steps in creating a design fire scenario:
1) Type of fire
2) Location of fire
3) Potential fire hazards
4) Systems impacting on fire
5) Occupant response
6) Event tree
7) Consideration of probability
8) Consideration of consequences
9) Risk ranking
10) Final selection and documentation

The steps to the design fire scenario are explained in more detail in ISO 13387-2. 


\section{METHODS OF EVALUATION}

This section overviews how the various documents address methods of evaluation which may be used.

\section{BS7974}

The evaluation approached are discussed in the various subsystem (PD) documents (e.g., BSPD7974 1 through 7), which describe different areas of fire safety engineering and methods of evaluation in some in detail. The PD documents were not reviewed as part of this effort.

\section{IFEG}

Within the IFEG there are various diagrams which illustrate levels of evaluation, starting with a 'top-level' view that identifies components to consider (Figure 13), and including several detailed flow charts and process for component evaluation (e.g., smoke filling, occupant pre-movement time, etc.).

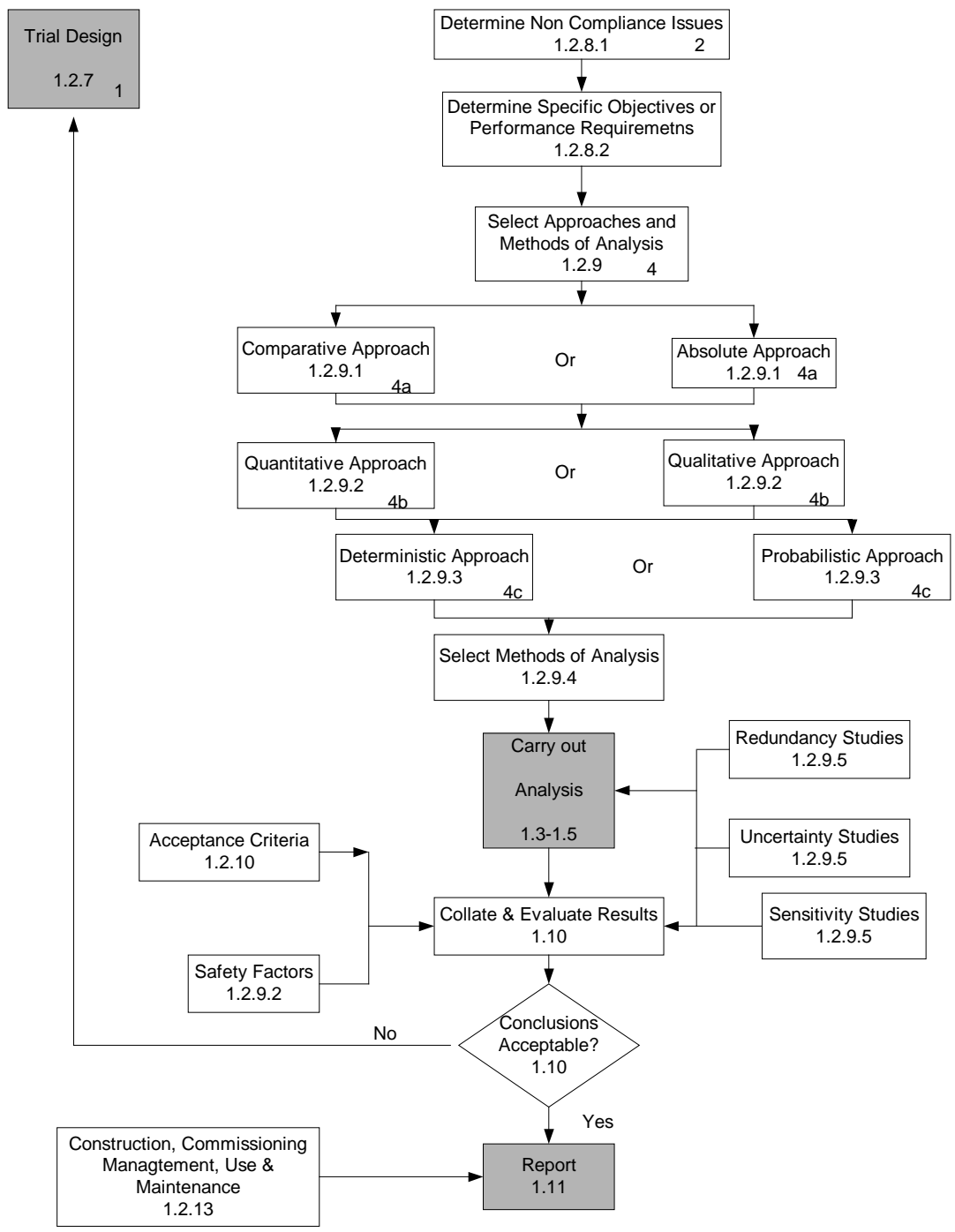

Figure 63 
For each sub-system, a description is provide and flow charts are included which indicate how analysis may be undertaken. IFEG Section 1.4.1 notes that these charts are only for guidance, and do not necessarily cover all the factors which may be relevant to a particular case. An example from sub system 1 'fire initiation and development' is shown as an illustration in Figure 14 below.
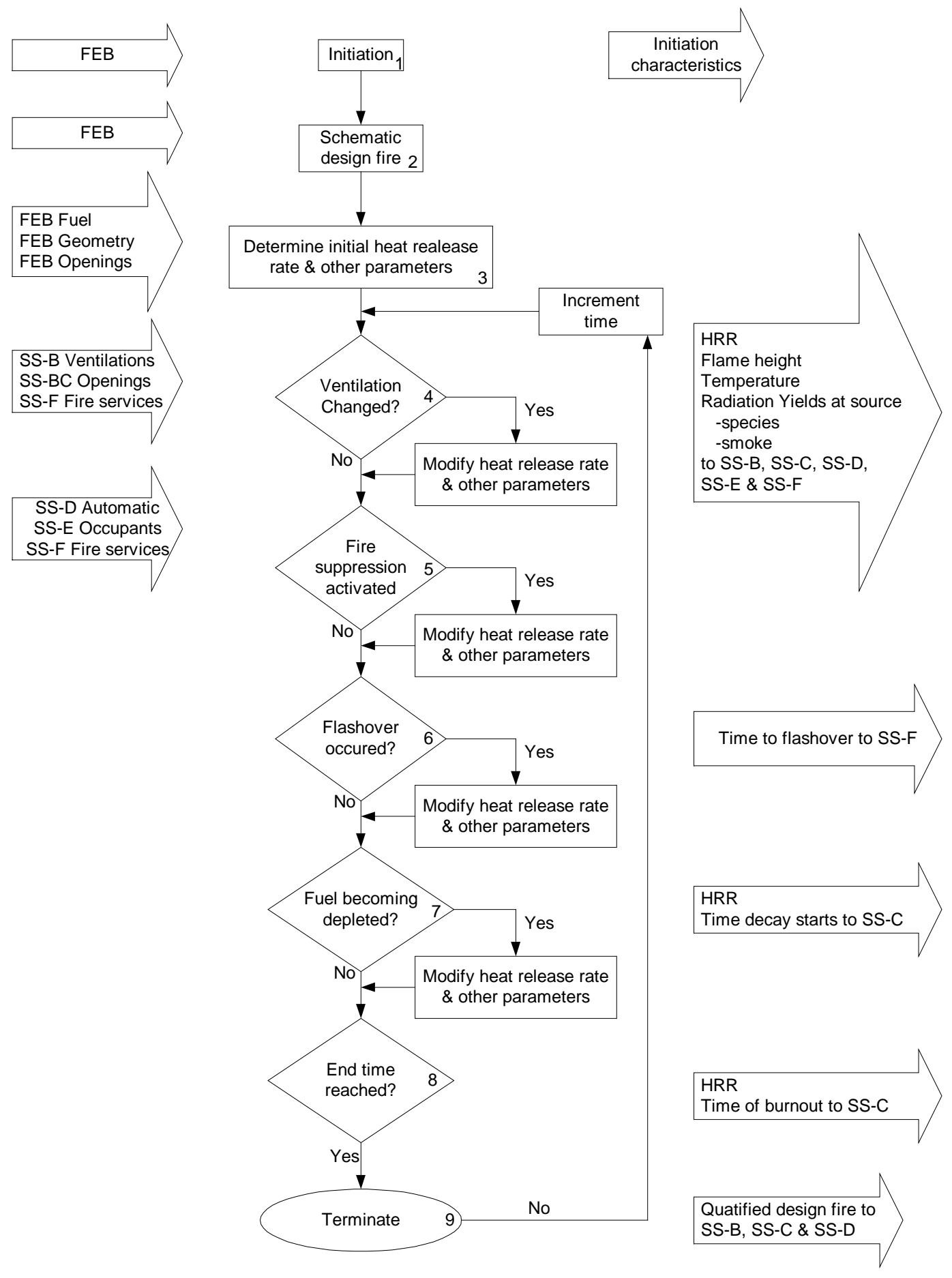

Figure 7: Flow chart from IFEG for sub-system on fire initiation and development 


\section{SFPE GUIDE}

Much like the IFEG, the SFPE Guide provides some general flowcharts for guiding evaluation, but notes that specifics are left to the designer and the 'subsystem' of focus. An overview of the approach is shown in Figure 15 below.

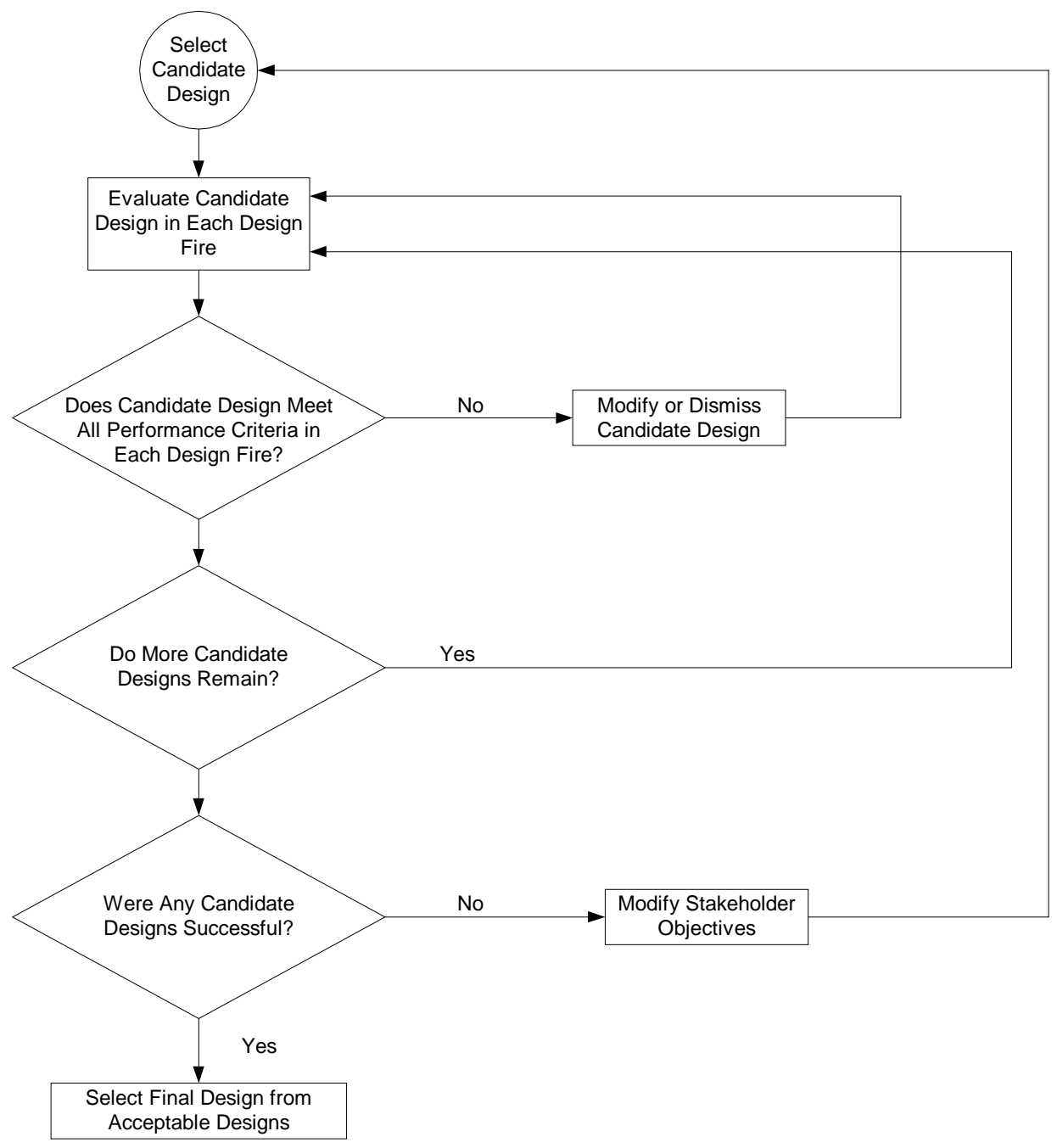

Figure 8: Flow chart for evaluating trial designs

While not illustrated in the above figure, the SFPE Guide allows for deterministic or probabilistic analysis. Guidance is provided in various chapters of the Guide as well as in appendices. It is noted that the level of evaluation should match the need of the project and the problem, and can range from application of simple analytical relationships and hand calculations to complex computers simulation for deterministic analyses, and qualitative to quantitative risk and probabilistic analyses.

There are also flowcharts provided to aid evaluation of the selected designs based on their focus (e.g., fire spread, smoke spread, ...). This is illustrated in Figures 16-19 below. 


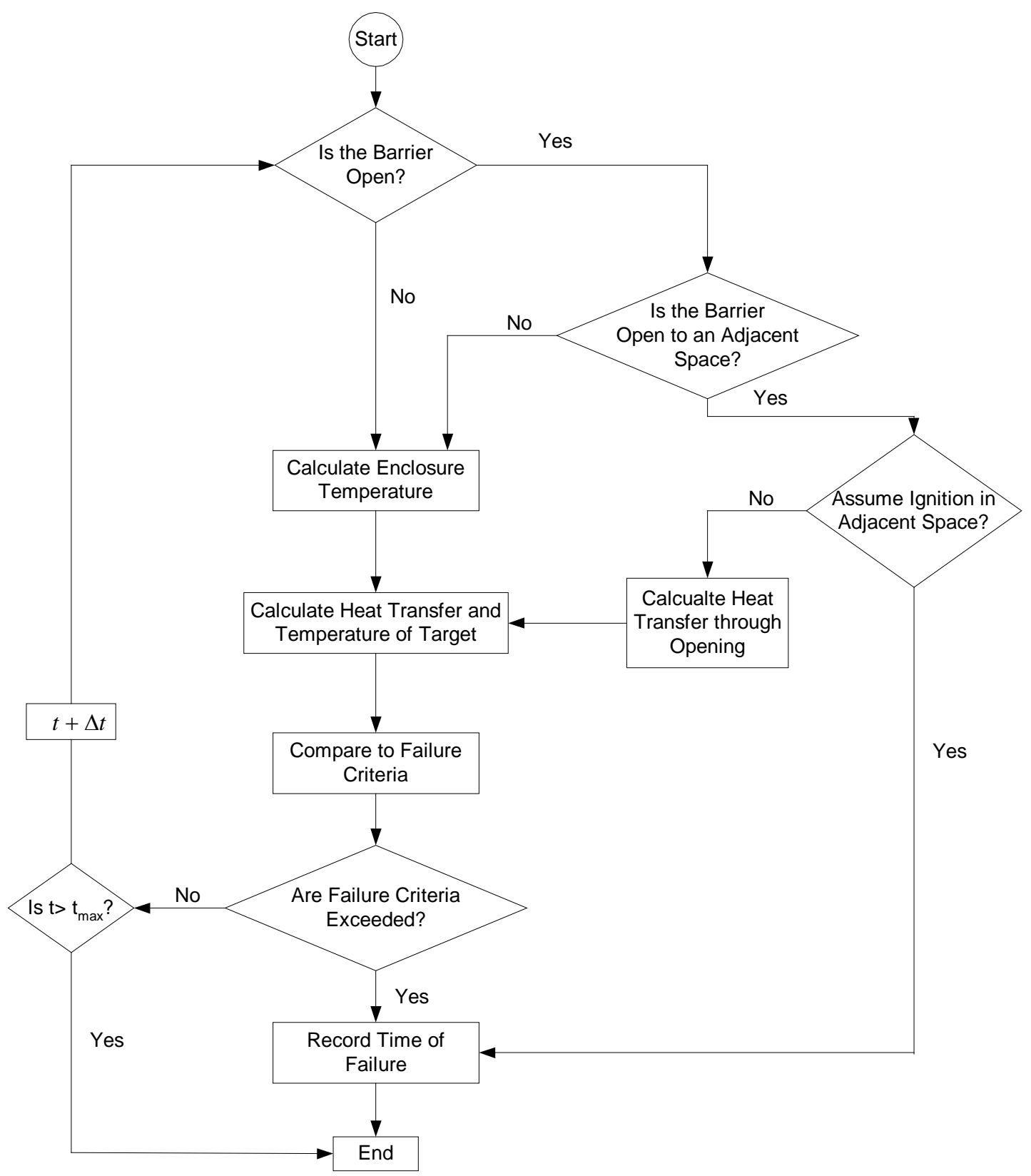

Figure 9: Flow chart for evaluating fire spread from enclosure 


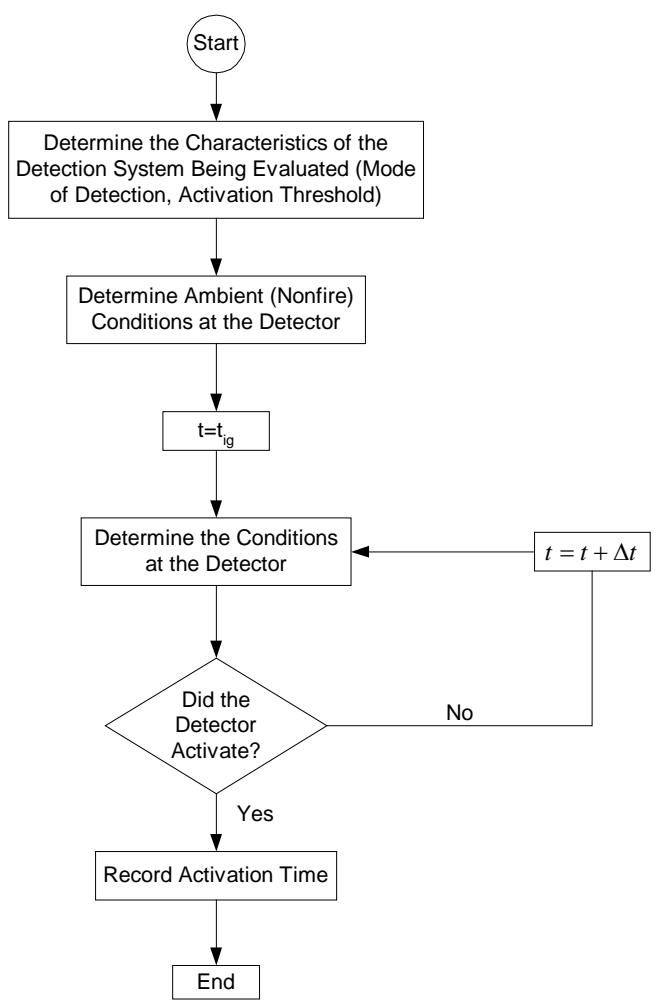

Figure 10: Flow chart for estimating detector activation

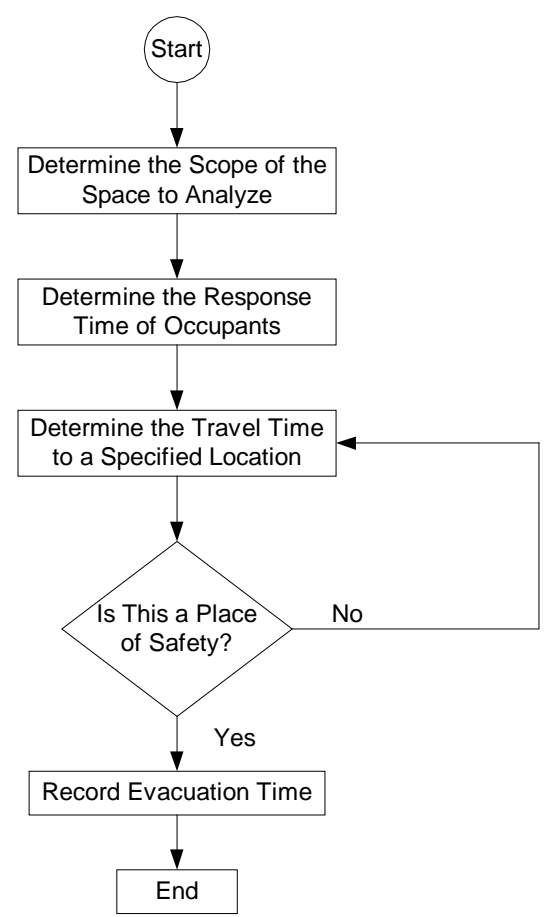

Figure 18: Flow chart for determining occupant escape time

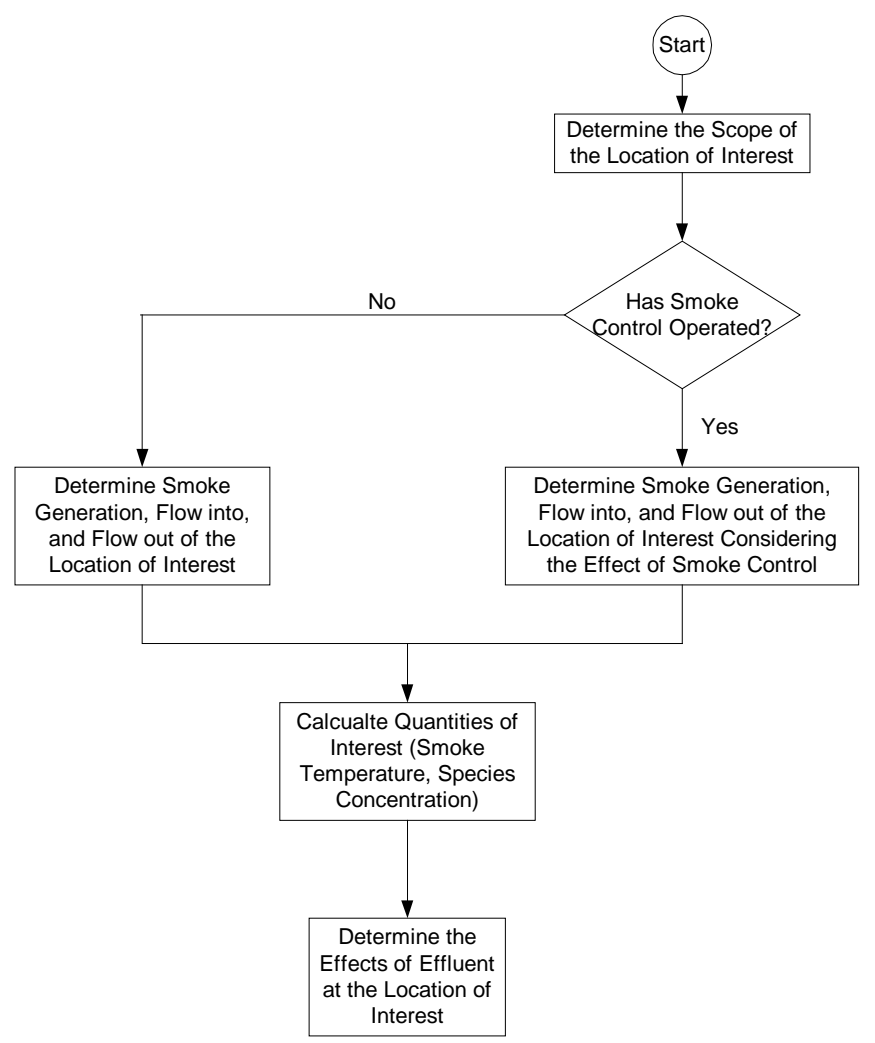

Figure 19: Flow chart for evaluating smoke development 


\section{ISO TR 13387-1}

Much like BS7974, ISO 13387-1 provides general guidance, with detailed methodologies being provided in reference standards (e.g., deterministic methods are given in the documents dealing with the subsystems, ISO/TR 13387-4, ISO/TR 13387-5, ISO/TR 13387-6, ISO/TR 13387-7.)

Like the IFEG, SFPE and BS7974, ISO 13387-1 states that the type of analysis to be provided needs to be carefully considered, with it being imperative that the type of analysis fits the needs of the situation. For example, if the time of egress for a uniform crowd needs to be determined, then a hand calculation may be sufficient. However, if the effect of smoke movement is going to be involved then a more detailed model may be needed. The types of methods recommended include:

- Simple calculation

- Computer-based deterministic analysis

- Probabilistic studies

- Experimental methods 


\section{VARIABILITY \& UNCERTAINTY}

This section overviews how the considered documents address issues of uncertainty and variability in analysis and design. For the most part, all documents handle this in a general way, identifying that uncertainty is a concern, but in few instances provided details as to how to undertake uncertainty and sensitivity analyses (which are referenced to other sources).

\section{BS7974}

Analysis of variability and uncertainty within the BS 7974 approach is addressed in BSPD7974-7, which can be applied to any of the other subsystems. This document was not reviewed in detail as part of the comparison.

\section{IFEG}

Part 1 Section 2 describes the process of analysis. In this section safety factors, sensitivity studies, redundancy studies, and uncertainty studies are discussed. The factors of safety are listed as:

- The extent of redundancy in the trial design

- The reliability of the various components of the fire safety system

- The analysis methods used

- The assumptions made for the analysis

- The results of an uncertainty analysis

- The acceptance criteria used

- The consequences of a fire

\section{SFPE GUIDE}

Section 10.5 of the SFPE discusses the variability and uncertainty in performance based design. There are 6 main principles that must be followed:

1) The engineering design process must provide a level of assurance that the designed system or component achieves its performance criteria for the design fire scenarios. The analysis must account for expected variations in materials, components, demands, performance, and occupant characteristics. In prescriptive-based code designs, an unstated excess capacity is used to address variations. (The required design might actually perform better than necessary.) Prescriptive-based code designs with an engineering basis could prescribe a minimum safety factor in an attempt to compensate for unknown variables. This safety factor is derived from either practical experience or estimates of appropriate conservatism. The safety factor commonly applied in a structural stress analysis is an example.

2) For performance-based designs, an allowance must be included to account for unknowns and variations and to provide a level of confidence in the final design. This allowance could be based on historically derived safety factors, an uncertainty analysis, or analysis margins. Each of these techniques is described in future sections

3) Assumptions, limitations in calculation procedures, and variability in actual versus evaluated scenarios result in uncertainty. Therefore, including explicit uncertainty or safety factors in deterministic-based system-performance evaluations might be appropriate. However, unnecessary or excessive use of safety factors should be avoided if the basic assumptions and calculation procedures are known or have been demonstrated to be highly conservative. 
4) Detains on available computer models might not allow explicit evaluation of uncertainty. Conservative approaches to design fire scenarios and performance criteria could be utilized to address uncertainty and safety factors.

5) The engineer, in consultation with other stakeholders, should determine whether it is appropriate to include explicit safety factors within the evaluation, or whether the assumptions and calculation procedures are intrinsically and sufficiently conservative.

6) When safety factors are not used, the engineer should understand not only the theory behind uncertainty or margin analysis but also its application to a complex fire protection engineering design

Other sections in 10.5 address Uncertainty in the Engineering Design Process, Safety Factors, Classical Uncertainty Analysis, Input Uncertainties, Construction and Use Variations, Analysis Margin, Importance Analysis, and Sensitivity Analysis.

Uncertainty in the Engineering Design Process includes:

- Uncertainties about the science and engineering being used

o Theory and Model Uncertainties

o Data and Model Inputs

- Calculation Limitations

o Design Fire Scenario Selection

- Uncertainties about human behaviors during a fire

- Uncertainties about risk perceptions, attitudes, and values

\section{ISO TR $13387-1$}

The ISO standard acknowledges 4 main areas of uncertainty:

1. The choice and definition of the scenario(s)

2. The formulation of an appropriate conceptual model for a chosen scenario

3. The formulation of the associated computational model

4. The input data and other chosen parameters

ISO 13387-1 states that the uncertainties from each stage should be combined to get an overall level of uncertainty. It is acknowledged that the level of uncertainty for all steps may not be determined and that there is not a "generally accepted methodology for combining them". Annex E describes these problems in more detail. Until a generally accepted methodology can be identified, safety factors used in the proposed solution will need to have a "degree of professional judgment". 


\section{DOCUMENTATION}

This section overviews key elements of the analysis and design which should be documented.

\section{BS7974}

The BS 7974 requires a Qualitative design review (QDR), which includes the following components. A report with the evaluation methods used, and analysis against the criteria, is to be provided at the project completion.

- Scope of the Project

- Relevant Stakeholders

- Principal Building Characteristics

- Dominant Occupant Characteristics

- General Objectives

- Hazards and Preventive and Protective Measures Available

- Trial Designs for Assessment

- Non-compliance Issues and Specific Objectives or Performance Requirements

- Approaches and Methods of Analysis

- Acceptance Criteria and Factors of Safety for the Analysis

- Fire Scenarios and Parameters for Design Fires

- Parameters for Design Occupant Groups

- Standards of Constructions, Commissioning, Management, Use and Maintenance

\section{IFEG}

The IFEG process documents the initial agreements and analysis in the Fire Engineering Brief (FEB). The FEB contains the following:

- Scope of the project

- Relevant stakeholders

- Principal building characteristics

- Dominant occupant characteristics

- General objectives

- Hazards and preventive and protective measures available

- Trial designs for evaluation

- Anon-compliance issues and specific objectives or performance requirements

- Approaches and methods of analysis

- Acceptance criteria and factors of safety for analysis

- $\quad$ Fire scenarios and parameters for design fires

- Parameters for design occupant groups

- Standards of construction, commissioning, management, use and maintenance

Designs are then evaluated and a final report is made. The following format is recommended:

- Executive Summary

- Introduction 
- $\quad$ Fire Engineering Brief

- Analysis

- Collating and Evaluating the Results

- Conclusions

- References

- Appendices

\section{SFPE GUIDE}

The SFPE Guide outlines three major documentation components: Fire Protection Engineering Design Brief (Chapter 11), Performance-Based Design Report (Chapter 12) and Supporting Documentation (Chapter 12).

The following content is recommended for the FPEDB:

- Project scope and definition

- Documentation of project participants

- Participants' qualifications

- General project information

- Description of building and occupant characteristics

- Project goals

- Project objectives

- Performance criteria

- Design fire scenarios

- One or more trial designs

- Critical design assumptions

- Critical design features

- Levels and methods of evaluation

- References

- Record of agreement of the above

The following content is recommended for the FP Design Report:

- Project scope

- Project participants

- Goals and objectives

- Performance criteria

- Fire scenarios and design fire scenarios

- Final design

- Evaluation

- Critical design features and assumptions

- References

Associated with, but separate from, the Design report are the following:

- Drawings and specifications (may be separate document)

- Test plan and documentation

- Field change reporting and documentation 
- Verification of compliance

- Operating and maintenance manual

\section{ISO TR 13387-1}

As with the other processed, application of the ISO process culminates in a report. The report format can vary depending on the needs of the particular situation, however it is recommended that the text summarize the study and the detailed portions (calculations, computer outputs, etc.) be in the appendix. Typically the following components are included:

- Objectives and scope of the assessment

- Description of the building and its fire safety installations

- Description and characteristics of the occupants

- Fire safety objectives

- Results of the qualitative design review

- Basis for selecting fire scenarios for analysis

- Acceptance criteria

- Trial designs

- Any influences of fire safety management

- Analysis of results, detailing:

o Assumptions

o Description of models used and their limitations

o Input and output data for each subsystem

o Engineering judgments

o Calculation procedures

o Validation of methodologies

o Sensitivity analyses

- Comparison of results of analysis with acceptance criteria

- Fire protection installations

- Management requirements, including a fire safety manual

- Conclusions, giving explicitly

o Requirements for fire protection

o Any limitations on use

- References

0 Drawings

o Design documentation

o Technical literature 


\section{SUMMARY}

Based on this review, it is concluded that the International Fire Engineering Guidelines (IFEG) is contemporary in scope, process, and general methodologies used with BS 7974, Application of Fire Safety Engineering principles to the Design of Buildings, the SFPE Engineering Guide to Performance-Based Fire Protection, and ISO 13387, Application of Fire Performance Concepts to Design Objectives. The general framework of all four approaches is effectively the same - a result of a high degree of overlap amongst developers of each. In addition, the methodologies used and evaluation methods recommended are largely the same. This is a function of the state of the art when the guides were developed (all prior to 2005) and the commonality of reference sources across the fire engineering community. Likewise, documentation requirements are largely the same.

In general, BS 7974 includes more detailed methods of evaluation than IFEG, ISO 13387 and the SFPE Guide, as these documents refer to other sources (IFEG has more than the other two). Each refers often to the SFPE Handbook of Fire Protection Engineering as well as to relevant standards. It is also worth noting that ISO has numerous 'sub-standards' - by which I mean standards that link to ISO 13387 - which include much more detailed methodologies across all areas (fire, smoke, detection, etc.). While this makes the ISO 'suite' the most comprehensive, it may be considered by some cost-prohibitive.

One area lacking in the IFEG, ISO and SFPE Guide, as compared with BS 7974, is risk assessment and probabilistic methods. While IFEG, ISO and SFPE Guide all include some guidance, they largely refer out to other documents. SFPE has a guide on fire risk assessment, and ISO has a standard on fire risk assessment, for example, while BS 7974 includes probabilistic risk assessment as Part 7 of the package. While it was decided not to include guidelines currently under development (e.g., Nordic, European and others), the probabilistic approach is one area which these new documents are including. 
DETAILED COMPARISON TABLES 
Subsystem 1 - Initiation and development of fire within enclosure of origin - pre-flashover

\begin{tabular}{|c|c|c|c|c|c|}
\hline & IFEG & BS 7974 & SFPE & ISO 13387 & Comments \\
\hline Ignition & $\begin{array}{l}\text { It is appreciated that in most } \\
\text { cases a deterministic approach } \\
\text { is utilized and a fire initiation is } \\
\text { a presumption for the fire } \\
\text { engineered analysis. The use of } \\
\text { event trees to determine fire } \\
\text { ignition and spread is } \\
\text { recognized. Some information } \\
\text { is provided on ignition } \\
\text { characteristics. Time to ignition } \\
\text { of second object is discussed. } \\
\text { The time to flame contact is } \\
\text { given as a conservative value. } \\
\text { For fire spread through } \\
\text { radiation Babrauskas } \\
\text { relationship between mass loss } \\
\text { rate and ignition distance is } \\
\text { shown. Data is provided on } \\
\text { ignitability limits for common } \\
\text { fuels for both piloted ignition. } \\
\text { Extensive references to } \\
\text { Babrauskas "Ignition } \\
\text { Handbook". }\end{array}$ & $\begin{array}{l}\text { A list of common ignition } \\
\text { sources is provided. }\end{array}$ & 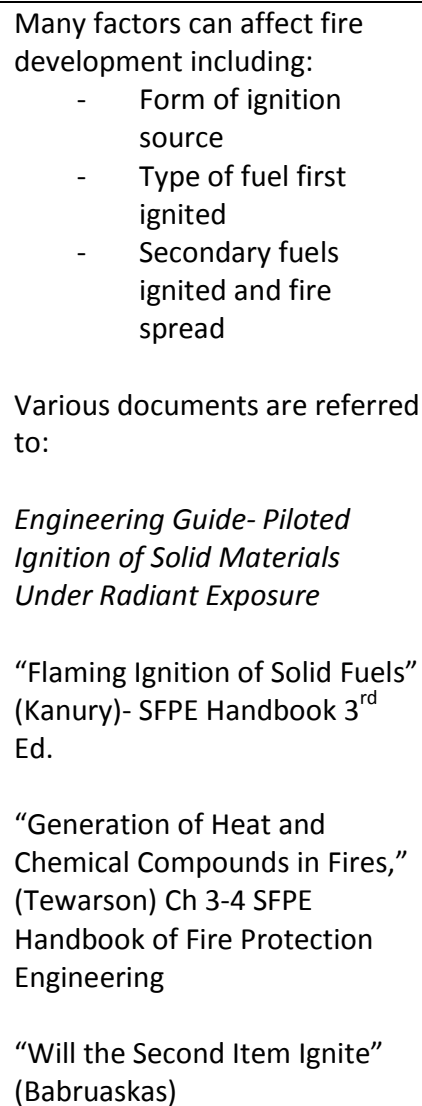 & $\begin{array}{l}\text { In deterministic fire safety ignition is } \\
\text { often assumed to occur and no } \\
\text { calculations on the ignition process } \\
\text { are needed. Evaluation of ignition is } \\
\text { needed to evaluate if one product can } \\
\text { be replaced by another. It is also } \\
\text { often necessary to determine if a } \\
\text { potential ignition source is likely to } \\
\text { cause ignition of adjacent items. A } \\
\text { design tree is provided with factors to } \\
\text { consider when assessing ignition } \\
\text { potential. Heat-conduction theory } \\
\text { equation is given for ignition delay of } \\
\text { thermally thick materials and } \\
\text { thermally thin materials. The ignition } \\
\text { of solids is discussed in: } \\
\text { "Will the Second Item Ignite?" } \\
\text { (Babrauskas) } \\
\text { "The Growth of Fire- Ignition to Full } \\
\text { Involvement, in Combustion } \\
\text { Fundamentals in Fire" (Thomas) }\end{array}$ & $\begin{array}{l}\text { NA. The IFEG is more detailed } \\
\text { and also provides more } \\
\text { references for additional } \\
\text { information. SFPE also } \\
\text { provides addition references } \\
\text { for more information. }\end{array}$ \\
\hline $\begin{array}{l}\text { Fire Load } \\
\text { Densities }\end{array}$ & $\begin{array}{l}\text { Allowed to be assessed by } \\
\text { surveys. }\end{array}$ & $\begin{array}{l}\text { Allowed to be assessed by } \\
\text { surveys. }\end{array}$ & $\begin{array}{l}\text { Fuel load of the building should } \\
\text { be estimated. } \\
\text { Fuel loads should be assessed } \\
\text { based on: } \\
\begin{array}{cl}\text { - } & \text { State (Solid, liquid, } \\
& \text { gas) } \\
\text { - } & \text { Type and quantity of } \\
\text { - } & \text { fuel } \\
\text { - } & \text { Fuel configuration } \\
\text { - } & \text { Rate of heat release } \\
- & \text { Rate of fire growth } \\
\text { - } & \text { Production rate of } \\
& \text { combustion product }\end{array}\end{array}$ & $\begin{array}{l}\text { Factors that need to be considered } \\
-\quad \text { Nature of combustibles } \\
-\quad \text { Geometric arrangement of } \\
\text { - } \quad \text { Ge fuel } \\
-\quad \text { Ignitability of the fuel } \\
-\quad \text { Rate of heat release } \\
\text { - characteristics } \\
\text { - } \quad \text { Eentilation } \\
\text { - } \quad \text { Expornal heat flux } \\
\text { Experimental data is also available. } \\
\text { Refers to "Ignition of liquid fuels" } \\
\text { (Kanury). }\end{array}$ & $\begin{array}{l}\text { Identical. Both use the same } \\
\text { equation for fire load density. } \\
\text { SFPE is similar. }\end{array}$ \\
\hline
\end{tabular}


Subsystem 1 - Initiation and development of fire within enclosure of origin - pre-flashover

\begin{tabular}{|c|c|c|c|c|c|}
\hline & IFEG & BS 7974 & SFPE & ISO 13387 & Comments \\
\hline & $\begin{array}{l}\text { Generic data- Swiss data } \\
\text { collected 1967-1969, it is also } \\
\text { reproduced in Warrington- } \\
\text { BCjC's "Fire resistant barriers } \\
\text { and structures (2000)" The CIB } \\
\text { W14 workshop report is also } \\
\text { referred to. }\end{array}$ & $\begin{array}{l}\text { Generic data- The CIB W14 } \\
\text { workshop report is referred to. }\end{array}$ & $\begin{array}{l}\text { The CIB W14 report is referred } \\
\text { to for fuel loads for various } \\
\text { occupancy types. } \\
\text { Refers to: Fuel Properties and } \\
\text { Combustion Data SFPE } \\
\text { Tables and Charts (Babruaskas) } \\
\text { FPH }\end{array}$ & & $\begin{array}{l}\text { Similar. IFEG provides more } \\
\text { information. SFPE refers to } \\
\text { other documents for } \\
\text { additional information }\end{array}$ \\
\hline & $\begin{array}{l}\text { Where the CIB W14 workshop } \\
\text { figures are utilized, it is } \\
\text { recommended the } 95 \% \text { fractile } \\
\text { value should be taken as the } \\
\text { fire load. }\end{array}$ & $\begin{array}{l}\text { Where the CIB W14 workshop } \\
\text { figures are utilized, it is } \\
\text { recommended that in the UK } \\
\text { the } 80 \% \text { fractile value should } \\
\text { be taken as the fire load. }\end{array}$ & $\begin{array}{l}\text { "Where there is expected to be } \\
\text { limited control over the fuel } \\
\text { load a conservative estimate } \\
\text { should be developed" }\end{array}$ & & Contradicting \\
\hline \multirow[t]{2}{*}{$\begin{array}{l}\text { Heat release } \\
\text { rates }\end{array}$} & $\begin{array}{l}\text { Convective fraction is } \\
\text { approximated to } 70 \% \text { of total } \\
\text { heat release. }\end{array}$ & $\begin{array}{l}\text { Data for convective heat } \\
\text { release fractions rates refers } \\
\text { to SFPE handbook. }\end{array}$ & $\begin{array}{l}\text { Multiple sources are provided: } \\
\text { ASTM E1591, Standard Guide } \\
\text { for Obtaining Data for } \\
\text { Deterministic Fire Models } \\
\text { The SFPE Handbook- "Heat } \\
\text { Release Rates" (Babrauskas) } \\
\text { "Upholstered Furniture HRR } \\
\text { measured with a Furniture } \\
\text { Calorimerter" (Babrauskas, } \\
\text { Lawson, Walton, Twilley) } \\
\text { Heat Release in Fires } \\
\text { (Babrauskas \& Grayson) } \\
\text { CIBSE Guide E Fire Engineering } \\
2003 \\
2005 \text { Ed. of International Fire } \\
\text { Engineering Guidelines } \\
\text { NFPA } 130 \text { Standard for Fixed } \\
\text { Guideway Transit Systems }\end{array}$ & $\begin{array}{l}\text { Burning rates of materials and } \\
\text { products are referenced to: } \\
\text { "Calorimetry" SFPE Handbook of Fire } \\
\text { Protection Engineering (Janssens) } \\
\text { "Generation of Heat and Chemical } \\
\text { Compounds in Fires" SFPE Handbook } \\
\text { of Fire Protection of Engineering } \\
\text { (Tewarson) } \\
\text { "Burning Rates" SFPE Handbook of } \\
\text { Fire Protection of Engineering } \\
\text { (Babrauskas) } \\
\text { "Fire Safety of Upholstered } \\
\text { Furninture" (Sundstrom) }\end{array}$ & \multirow[t]{2}{*}{$\begin{array}{l}\text { NA. SFPE refers to various } \\
\text { documents for additional } \\
\text { information }\end{array}$} \\
\hline & $\begin{array}{l}\text { No recommendation on an } \\
\text { appropriate heat release } \\
\text { model. }\end{array}$ & $\begin{array}{l}\text { Q*-Dimensionless heat release } \\
\text { rate as described by Zukoski, } \\
\text { referred to Drysdale-An } \\
\text { introduction to fire dynamics. }\end{array}$ & $\begin{array}{l}\text { "Several methods can be used } \\
\text { to define a design fire curve: } \\
\text { using published data, fire } \\
\text { testing, or calculating a } \\
\text { theoretical fire size." }\end{array}$ & & \\
\hline
\end{tabular}


Subsystem 1 - Initiation and development of fire within enclosure of origin - pre-flashover

\begin{tabular}{|c|c|c|c|c|c|}
\hline & IFEG & BS 7974 & SFPE & ISO 13387 & Comments \\
\hline \multirow[t]{2}{*}{$\begin{array}{l}\text { Characteristic } \\
\text { fire growth } \\
\text { curves- } \mathrm{t}^{2}\end{array}$} & $\begin{array}{l}\text { "Growth times" referenced to } \\
\text { NFPA } 204 .\end{array}$ & $\begin{array}{l}\text { Fire growth parameters as } \\
\text { described in NFPA 92B. }\end{array}$ & $\begin{array}{l}\text { The following documents were } \\
\text { referred to: } \\
\text { NFPA 92B } 2005 \text { Ed. and PD } \\
7974 \text { parts 0-8 } 2002 \text { Ed. are } \\
\text { referred to }\end{array}$ & $\begin{array}{l}\text { The rate of fire growth in stored } \\
\text { goods may be obtained from NFPA } \\
204 \text { and SFPE Handbook }\end{array}$ & Similar/Identical \\
\hline & $\begin{array}{l}\text { Occupancy related fire growth } \\
\text { times referenced to NFPA } 204 .\end{array}$ & $\begin{array}{l}\text { Picture gallery-slow } \\
\text { Dwelling-medium } \\
\text { Office-medium } \\
\text { Hotel reception-medium } \\
\text { Hotel bedroom-medium } \\
\text { Shop-fast } \\
\text { Industrial storage or plant } \\
\text { room-Ultra-fast }\end{array}$ & & & Similar/Identical \\
\hline $\begin{array}{l}\text { Heat release } \\
\text { rates per unit } \\
\text { area }\end{array}$ & $\begin{array}{l}\text { No recommendations on peak } \\
\text { heat release rates. }\end{array}$ & $\begin{array}{l}\text { Shops- } 550 \mathrm{kw} / \mathrm{m}^{2} \\
\text { Offices- } 290 \mathrm{kw} / \mathrm{m}^{2} \\
\text { Hotel rooms- } 250 \mathrm{kw} / \mathrm{m}^{2} \\
\text { Industrial (excl storage)- } 90 \text { - } \\
620 \mathrm{kw} / \mathrm{m}^{2}\end{array}$ & & & NA- More info in 7974 \\
\hline $\begin{array}{l}\text { Smoldering } \\
\text { fires }\end{array}$ & $\begin{array}{l}\text { Equation developed by } \\
\text { Quintere et al. (1982). }\end{array}$ & $\begin{array}{l}\text { Equation developed by } \\
\text { Quintere et al. (1982). }\end{array}$ & $\begin{array}{l}\text { Little data available. Need to } \\
\text { choose carefully in developing } \\
\text { any specific relationship for the } \\
\text { design fire curve heat release } \\
\text { rate. Smoldering fire can cause } \\
\text { fatalities or damage to critical } \\
\text { targets before established } \\
\text { burning }\end{array}$ & $\begin{array}{l}\text { Currently no quantitative methods. } \\
\text { Need to consider: } \\
\text {-presence of materials prone to } \\
\text { smoldering } \\
\text {-presence of potential ignition } \\
\text { sources }\end{array}$ & $\begin{array}{l}\text { IFEG and } 7974 \text { are identical } \\
\text { and provide more information } \\
\text { than SFPE }\end{array}$ \\
\hline $\begin{array}{l}\text { Heat release } \\
\text { within } \\
\text { enclosure for } \\
\text { flashover }\end{array}$ & $\begin{array}{l}\text { Walton \& Thomas (2002) } \\
\text { equation for heat release rates } \\
\text { needed to induce flash-over. }\end{array}$ & $\begin{array}{l}\text { Walton \& Thomas (2002) } \\
\text { equation for heat release rates } \\
\text { needed to induce flash-over. }\end{array}$ & $\begin{array}{l}\text { Following document was } \\
\text { referred to: } \\
\text { Fundamentals of Enclosure Fire } \\
\text { Zone Models (Quintiere) }\end{array}$ & \multirow{2}{*}{$\begin{array}{l}\text { The upper part of the enclosure will } \\
\text { have a hot gas layer. As the } \\
\text { temperature of the upper layer } \\
\text { approaches } 500 \text { oC the heat flux } \\
\text { becomes so high that flashover may } \\
\text { occur }\end{array}$} & $\begin{array}{l}\text { IFEG and } 7974 \text { are identical. } \\
\text { Noted misprint in IFEG on } \\
\text { definition of terms. SFPE } \\
\text { refers to a different document }\end{array}$ \\
\hline $\begin{array}{l}\text { Temperature } \\
\text { within } \\
\text { enclosure prior } \\
\text { to flashover }\end{array}$ & No recommendations. & $\begin{array}{l}\text { Equation presented by } \\
\text { McCaffrey et al. } 1981 \\
\text { recommended. }\end{array}$ & & & NA \\
\hline $\begin{array}{l}\text { Flame length } \\
\text { for axi- } \\
\text { symmetric fire } \\
\text { source }\end{array}$ & $\begin{array}{l}\text { Flame length is estimated with } \\
\text { the McAffrey and } \\
\text { Heskestadequations. }\end{array}$ & $\begin{array}{l}\text { Flame length according to Cox } \\
\text { and Chitty, } 1980 \text {. } \\
\left(0.2^{*} Q^{\wedge}(2 / 5)\right)\end{array}$ & & \multirow{2}{*}{$\begin{array}{l}\text { Flame size is directly proportional to } \\
\text { the rate of heat release in the fire. } \\
\text { Refers to Flame Heights and Fire } \\
\text { Hazard Calculations for Large Open } \\
\text { Hydrocarbon Fires both in SFPE } \\
\text { Handbook }\end{array}$} & $\begin{array}{l}\text { Dissimilar, but not } \\
\text { contradicting }\end{array}$ \\
\hline $\begin{array}{l}\text { Flame length } \\
\text { for line sources }\end{array}$ & No recommendations. & $\begin{array}{l}\text { The equation shown is } \\
\text { referenced to DD240-1. }\end{array}$ & & & $\begin{array}{l}\text { NA-7974 provides more } \\
\text { information. }\end{array}$ \\
\hline
\end{tabular}


Subsystem 1 - Initiation and development of fire within enclosure of origin - pre-flashover

\begin{tabular}{|c|c|c|c|c|c|}
\hline & IFEG & BS 7974 & SFPE & ISO 13387 & Comments \\
\hline $\begin{array}{l}\text { Flame lengths } \\
\text { for corner room } \\
\text { and wall fires. }\end{array}$ & No recommendations. & $\begin{array}{l}\text { "Corner room fires are likely to } \\
\text { increase flame heights by } 75 \% \\
\text { and wall fires by } 32 \% \text { " this is } \\
\text { referenced to Zukoski. }\end{array}$ & & & $\begin{array}{l}\text { NA- } 7974 \text { provides more } \\
\text { information. }\end{array}$ \\
\hline $\begin{array}{l}\text { Flame } \\
\text { temperature }\end{array}$ & Heskestad (2002) equations. & No recommendations. & $\begin{array}{l}\text { Refers to Chemistry and Physics } \\
\text { of Fire (Drysdale) FPH }\end{array}$ & & $\begin{array}{l}\text { NA- IFEG provides greater } \\
\text { detail. SFPE refers to a } \\
\text { different document }\end{array}$ \\
\hline $\begin{array}{l}\text { Flame radiation } \\
\text { \& flame } \\
\text { emissivity }\end{array}$ & $\begin{array}{l}\text { Standard radiation } \\
\text { calculations. The emissivity } \\
\text { can be conservatively set to } 1 \text {. }\end{array}$ & $\begin{array}{l}\text { If the flame length is over } 1 \mathrm{~m} \\
\text { and the flame is luminous it is } \\
\text { common to assume black body } \\
\text { behavior. Emissivity = } 1 \text {. } \\
\text { Standard radiation calculation } \\
\text { with view factor. It is } \\
\text { suggested that the influence of } \\
\text { air flow should be taken into } \\
\text { account. }\end{array}$ & $\begin{array}{l}\text { Refers to } \\
\text { Engineering Guide to Assessing } \\
\text { Flame Radiation to External } \\
\text { Targets from Liquid Pool Fires }\end{array}$ & & $\begin{array}{l}\text { IFEG and } 7974 \text { are identical. } \\
\text { SFPE refers to a separate } \\
\text { document }\end{array}$ \\
\hline Smoke yield & $\begin{array}{l}\text { No relationships are given for } \\
\text { mass conversion factors. A } \\
\text { basic equation is shown }\end{array}$ & $\begin{array}{l}\text { Smoke mass conversion } \\
\text { factors for flaming and non- } \\
\text { flaming combustion. The } \\
\text { smoke mass conversion factors } \\
\text { are referenced to the SFPE } \\
\text { handbook. }\end{array}$ & $\begin{array}{l}\text { The following document was } \\
\text { referred to: } \\
\text { "Generation of Heat and } \\
\text { Chemical Compounds in Fires" } \\
\text { SFPE }\end{array}$ & $\begin{array}{l}\text { If it is a smoldering fire or if the area } \\
\text { of interest is far from the point of fire } \\
\text { origin: } \\
\text { Assuming no gases leak out from the } \\
\text { room: } C(t)=\frac{1}{V_{\text {encl }}} \int_{0}^{t} \dot{m}_{i}(t) d t \\
\text { If the volume flow rate into and out of } \\
\text { the enclosure are known: } \\
C(t)=\frac{1}{V_{\text {encl }}} \int_{0}^{t}\left[C_{\text {in }}(t)-C_{i}(t)\right] V(t) d t\end{array}$ & $\begin{array}{l}\text { NA-7974 provides more } \\
\text { information. SFPE refers to a } \\
\text { separate document }\end{array}$ \\
\hline \multirow[t]{2}{*}{ Optical density } & $\begin{array}{l}\text { The light depletion equations } \\
\text { is Bouguer's law. It is however } \\
\text { shown in the fire detection } \\
\text { section. }\end{array}$ & $\begin{array}{l}\text { The light depletion equations } \\
\text { is Bouguer's law. }\end{array}$ & & $\begin{array}{l}\text { Different systems of units are used to } \\
\text { describe smoke density. Annex A of } \\
\text { ISO 13387-4. It is recommended to } \\
\text { use the natural-logarithm-based } \\
\text { system of units: } \\
\qquad K=\frac{1}{l} \ln \frac{I_{0}}{I}\end{array}$ & \multirow[t]{2}{*}{ IFEG and 7974 are identical } \\
\hline & $\begin{array}{l}\text { Optical density data required } \\
\text { for smoke detector activation } \\
\text { is expressed in } \mathrm{dB} / \mathrm{m} \text {. }\end{array}$ & Optical density given in $\mathrm{dB} / \mathrm{m}$. & & $\begin{array}{l}\text { Refers to: } \\
\text { SFPE Handbook } \\
\text { Introduction to Fire Dynamics } \\
\text { (Drysdale) } \\
\text { Combustion Fundamentals in Fire } \\
\text { (Cox) }\end{array}$ & \\
\hline $\begin{array}{l}\text { Mass optical } \\
\text { density }\end{array}$ & $\begin{array}{l}\text { No discussion on mass optical } \\
\text { density. }\end{array}$ & $\begin{array}{l}\text { Relations for mass optical } \\
\text { density for different fuels is } \\
\text { shown. Referenced to SFPE } \\
\text { handbook. }\end{array}$ & & & $\begin{array}{l}\text { NA- } 7974 \text { provides more } \\
\text { information }\end{array}$ \\
\hline
\end{tabular}


Subsystem 1 - Initiation and development of fire within enclosure of origin - pre-flashover

\begin{tabular}{|c|c|c|c|c|c|}
\hline & IFEG & BS 7974 & SFPE & ISO 13387 & Comments \\
\hline Visibility & $\begin{array}{l}\text { No discussion on visibility of } \\
\text { signage etc. }\end{array}$ & $\begin{array}{l}\mathrm{S}=(10 / \mathrm{D}), \mathrm{S}=\text { visibility distance, } \\
\mathrm{D}=\text { optical density } \mathrm{db} / \mathrm{m} \text {. If a } \\
\text { sign is back illuminated its } \\
\text { visibility distance can be } \\
\text { increased by a factor of } 2.5 \text {. }\end{array}$ & $\begin{array}{l}\text { The following documents were } \\
\text { referred to: } \\
\text { "Behavioral Response to Fire } \\
\text { and Smoke" (Bryan) SFPE } \\
\text { "An Introduction to Fire } \\
\text { Dynamics" (Drysdale) } \\
\text { "Smoke Production and } \\
\text { Properties" (Mulholland) } \\
\text { "Toxicity Assessment of } \\
\text { Combustion Products" (Purser) } \\
\text { SFPE }\end{array}$ & & $\begin{array}{l}\text { NA- } 7974 \text { provides more } \\
\text { information. SFPE provides } \\
\text { multiple sources }\end{array}$ \\
\hline $\begin{array}{l}\text { Mass } \\
\text { production of } \\
\text { CO and other } \\
\text { species }\end{array}$ & $\begin{array}{l}\text { CO yield factors referenced to } \\
\text { "part three of these } \\
\text { guidelines" no data is however } \\
\text { found in the appendices. The } \\
\text { equations shown are basic } \\
\text { concentration equations. }\end{array}$ & $\begin{array}{l}\text { The mass conversion factor for } \\
\text { CO is given as } 0.013 \mathrm{~m}_{\mathrm{f}} \text {. This } \\
\text { value, and other conversion } \\
\text { factors, is referenced to the } \\
\text { SFPE handbook. }\end{array}$ & $\begin{array}{l}\text { Refers to Generation of Heat } \\
\text { and Chemical Compounds in } \\
\text { Fires (Tewarson) }\end{array}$ & 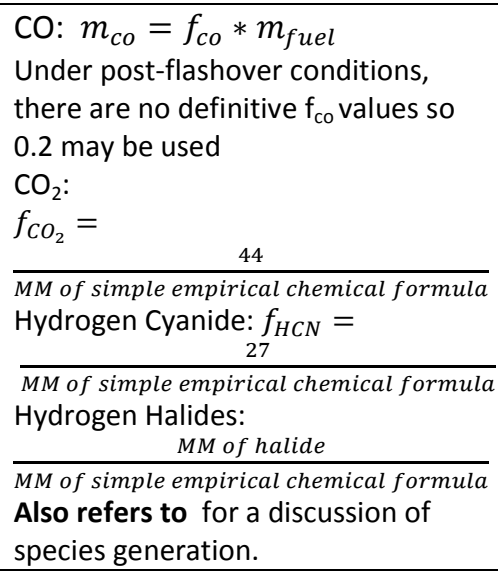 & $\begin{array}{l}\text { NA- } 7974 \text { provides more } \\
\text { information. SFPE refers to } \\
\text { outside source }\end{array}$ \\
\hline
\end{tabular}


Subsystem 1 - Initiation and development of fire within enclosure of origin - flashover

\begin{tabular}{|c|c|c|c|c|c|}
\hline & IFEG & BS 7974 & SFPE & ISO 13387 & Comments \\
\hline \multirow[t]{2}{*}{$\begin{array}{l}\text { Time to } \\
\text { flashover }\end{array}$} & $\begin{array}{l}\text { Flashover occurs when the hot } \\
\text { layer temperature reaches } \\
\text { approximately } 600^{\circ} \mathrm{C} \text { or when } \\
\text { radiation at floor level from } \\
\text { the hot smoke layer reaches } \\
20 \mathrm{~kW} / \mathrm{m}^{2}\end{array}$ & $\begin{array}{l}\text { "Flashover can be assumed to } \\
\text { occur when sustained flaming } \\
\text { from combustibles reaches } \\
\text { that ceiling and the } \\
\text { temperature of the hot gas } \\
\text { layer is between } 550^{\circ} \mathrm{C} \text { and } \\
600^{\circ} \mathrm{C} \text {. If flames from the } \\
\text { combustibles do not reach the } \\
\text { ceiling, or the temperature } \\
\text { remains below } 550^{\circ} \mathrm{C} \text { flashover } \\
\text { can be assumed to be } \\
\text { unlikely." }\end{array}$ & $\begin{array}{l}\text { The following factors will affect } \\
\text { the time to flashover: } \\
\text { - } \quad \text { Surface area of the } \\
\text { enclosure } \\
\text { - } \quad \text { The area of enclosure } \\
\text { openings } \\
\text { - } \quad \text { Te effective height of } \\
\text { - } \quad \text { enclosure openings } \\
\text { - } \quad \text { Veat release rate } \\
\text { - } \quad \text { Thermal properties of } \\
\text { compartment } \\
\text { boundaries }\end{array}$ & \multirow[t]{3}{*}{$\begin{array}{l}\text { The heat release rate and other } \\
\text { characteristics following flashover } \\
\text { should be based upon those } \\
\text { applicable to a fuel-bed-controlled or } \\
\text { ventilation-controlled fire. }\end{array}$} & $\begin{array}{l}\text { IFEG and } 7974 \text { are similar. } \\
\text { SFPE lists factors affecting } \\
\text { flashover }\end{array}$ \\
\hline & $\begin{array}{l}\text { When } 80 \% \text { of the fuel has been } \\
\text { consumed the fire can be } \\
\text { assumed to decay either: } \\
\text {-linearly } \\
\text {-at rate determined } \\
\text { experimentally } \\
\text {-at any rate that can be } \\
\text { justified }\end{array}$ & $\begin{array}{l}\text { For design purposes it may be } \\
\text { assumed that heat release } \\
\text { rates remain constant until } \\
80 \% \text { of the fuel has been } \\
\text { consumed and the decay } \\
\text { phase starts. Kawagoe and } \\
\text { Sekine equation for linear } \\
\text { decline }\end{array}$ & & & IFEG and 7974 are similar \\
\hline $\begin{array}{l}\text { Heat release } \\
\text { rate at } \\
\text { flashover }\end{array}$ & $\begin{array}{l}\text { Thomas (1981) for no } \\
\text { consideration of wall thermal } \\
\text { properties. No } \\
\text { recommendations for thermal } \\
\text { effects of enclosures. }\end{array}$ & $\begin{array}{l}\text { Walton \& Thomas (2002) for } \\
\text { no consideration to wall } \\
\text { thermal properties. McCaffrey } \\
\text { for when thermal effects of } \\
\text { enclosures is considered. }\end{array}$ & & & $\begin{array}{l}\text { IFEG and } 7974 \text { are identical for } \\
\text { cases where no consideration } \\
\text { is taken for thermal effects of } \\
\text { enclosures. } 7974 \text { provides } \\
\text { further information. }\end{array}$ \\
\hline
\end{tabular}




\begin{tabular}{|c|c|c|c|c|c|}
\hline & IFEG & BS 7974 & SFPE & ISO 13387 & Comments \\
\hline $\begin{array}{l}\text { Mass burning } \\
\text { rate in } \\
\text { ventilation } \\
\text { controlled } \\
\text { conditions }\end{array}$ & $\begin{array}{l}\text { Uses Drysdales' equation for } \\
\text { mass flow, with a reasonable } \\
\text { and referenced assumption } \\
\text { regarding underventilated } \\
\text { fires. }\end{array}$ & $\begin{array}{l}\text { Uses Thomas, 1973, equation for the } \\
\text { mass flow in an underventilated fire or } \\
\text { an unreferenced equation for fuel mass } \\
\text { flow (it is identical to the one in Drysdale } \\
\text { 1999). }\end{array}$ & $\begin{array}{l}\text { Not } \\
\text { addressed }\end{array}$ & $\begin{array}{l}\text { Rate of burning can be determined from } \\
\text { consideration of air flowing into the } \\
\text { compartment. Refers to Estimating } \\
\text { Temperatures in Compartments (SFPE- } \\
\text { William, Walton, Thomas). } \\
\text { The energy release rate can be determined } \\
\text { from consideration of the effective heat of } \\
\text { combustion of the fuel. Refers to An } \\
\text { Introduction to Fire Dynamics (Drysdale). }\end{array}$ & $\begin{array}{l}\text { IFEG, BS7974 and ISO are } \\
\text { similar }\end{array}$ \\
\hline $\begin{array}{l}\text { Mass burning } \\
\text { rate in fuel bed } \\
\text { controlled } \\
\text { conditions }\end{array}$ & $\begin{array}{l}\text { No equations are suggested. } \\
\text { References are made to } \\
\text { Babrauskas section in the SFPE } \\
\text { handbook and Sardqvists } \\
\text { "Initial fires". It is } \\
\text { recommended that } \\
\text { "appropriate engineering } \\
\text { judgement" should be applied } \\
\text { when setting fire rates. }\end{array}$ & $\begin{array}{l}\text { An effective fire duration of } 20 \text { minutes } \\
\text { can be assumed in houses, offices, and } \\
\text { shops. Burning rate is based on } \\
\text { assessment that the total initial fire load } \\
\text { burns in } 1200 \text { seconds. Another equation } \\
\text { for fuel bed controlled fires is presented } \\
\text { with no reference to its origins. Time to } \\
\text { reach burnout after flashover is shown as } \\
\text { two times the mass of fuel left at } \\
\text { flashover divided by peak rate mass } \\
\text { burning rate. }\end{array}$ & $\begin{array}{l}\text { Not } \\
\text { addressed }\end{array}$ & $\begin{array}{l}\text { The burning rate of fuel-bed-controlled fires is } \\
\text { dependent upon the nature and geometric } \\
\text { arrangement of the fuel. The rate of burning } \\
\text { is dependent upon the surface area of the } \\
\text { fuel. Refers to Burning Rates (SFPE Handbook- } \\
\text { Babrauskas). }\end{array}$ & Different in all \\
\hline $\begin{array}{l}\text { Standard } \\
\text { temperature- } \\
\text { time curve }\end{array}$ & \multirow{6}{*}{$\begin{array}{l}\text { Short discussion on the } \\
\text { existence of empirical time- } \\
\text { temperature curves. Reference } \\
\text { given to Lie (1994). }\end{array}$} & $\begin{array}{l}\text { Recognizes the ISO and BS } 476 \\
\text { temperature-time curve. }\end{array}$ & $\begin{array}{l}\text { Not } \\
\text { addressed }\end{array}$ & $\begin{array}{l}\text { Under the furnace fire section: } \\
\text { Standard temperature-time curve equation: } \\
\qquad T_{g}=T_{a} 345 \log _{10}(8 t+1)\end{array}$ & \multirow{6}{*}{$\begin{array}{l}\text { BS7974 and ISO } 13387 \text { provide } \\
\text { many equations and data } \\
\text { while the information found in } \\
\text { IFEG is very limited. }\end{array}$} \\
\hline \multirow[t]{2}{*}{$\begin{array}{l}\text { Hydrocarbon } \\
\text { temperature- } \\
\text { time curve }\end{array}$} & & $\begin{array}{l}\text { Large pool fire, in accordance with BS } \\
476-20 .\end{array}$ & $\begin{array}{l}\text { Not } \\
\text { addressed }\end{array}$ & $\begin{array}{l}\text { Under the furnace fire section: } \\
\text { Hydrocarbon temperature-time curve } \\
\text { equation: } \\
\begin{array}{c}T_{g}=1080\left(1-0.325 e^{0.167 t}-0.675 e^{-2.5 t}\right) \\
+T_{a}\end{array}\end{array}$ & \\
\hline & & $\begin{array}{l}\text { Temperature curve in accordance with } \\
\text { BS EN 1991-1-2:2002. }\end{array}$ & $\begin{array}{l}\text { Not } \\
\text { addressed }\end{array}$ & \multirow{4}{*}{$\begin{array}{l}\text { Other temperature-time curves are specified } \\
\text { in national and ISO test methods for testing a } \\
\text { range of products or specific applications. } \\
\text { Their application in fire safety engineering is } \\
\text { therefore limited. They may be useful when } \\
\text { comparison needs to be made to performance } \\
\text { determined during the test }\end{array}$} & \\
\hline $\begin{array}{l}\text { Slow heating } \\
\text { curve }\end{array}$ & & $\begin{array}{l}\text { Two heating curves for slow heating fires. } \\
\text { Reference to BS 1363-2:1999. }\end{array}$ & $\begin{array}{l}\text { Not } \\
\text { addressed }\end{array}$ & & \\
\hline $\begin{array}{l}\text { Maximum } \\
\text { temperature } \\
\text { curve }\end{array}$ & & Equation referenced to M.law 1978. & $\begin{array}{l}\text { Not } \\
\text { addressed }\end{array}$ & & \\
\hline $\begin{array}{l}\text { Ventilation } \\
\text { controlled } \\
\text { temperature- } \\
\text { time curve }\end{array}$ & & $\begin{array}{l}\text { Kawagoe and Sekine equation dependent } \\
\text { on opening factor. }\end{array}$ & $\begin{array}{l}\text { Not } \\
\text { addressed }\end{array}$ & & \\
\hline
\end{tabular}


Subsystem 2 - smoke control - design objectives and strategies

\begin{tabular}{|c|c|c|c|c|c|}
\hline & IFEG & BS 7974 & SFPE & ISO 13387 & Comments \\
\hline \multirow[t]{4}{*}{$\begin{array}{l}\text { Design } \\
\text { Objectives }\end{array}$} & $\begin{array}{l}\text { Evaluate effect on Means of } \\
\text { Escape [MoE]. }\end{array}$ & $\begin{array}{l}\text { Protection of MoE- clear layer } \\
\text { solutions. }\end{array}$ & $\begin{array}{l}\text { The following document was } \\
\text { referred to: } \\
\text { NFPA 204, Guide for Smoke and } \\
\text { Heating Venting. }\end{array}$ & & $\begin{array}{l}\text { IFEG and } 7974 \text { are identical. } \\
\text { SFPE refers to another } \\
\text { document }\end{array}$ \\
\hline & $\begin{array}{l}\text { Temperature control } \\
\text { mentioned with regards to fire } \\
\text { spread. }\end{array}$ & $\begin{array}{l}\text { Temperature Control- protects } \\
\text { materials within the smoke } \\
\text { zone. }\end{array}$ & & & $\begin{array}{l}\text { IFEG and } 7974 \text { are similar- } \\
\text { both outline advantages of } \\
\text { controlling temperatures }\end{array}$ \\
\hline & $\begin{array}{l}\text { Evaluate effect on FF } \\
\text { operations }\end{array}$ & $\begin{array}{l}\text { Assist fire fighting operations- } \\
\text { prevent hot smoky layers } \\
\text { occurring in certain situations. }\end{array}$ & & & IFEG and 7974 are identical \\
\hline & & $\begin{array}{l}\text { Property Protection- limiting } \\
\text { heat flux on structure through } \\
\text { exhaust. }\end{array}$ & & & $\begin{array}{l}\text { N/A- No mention in IFEG of } \\
\text { limiting heat fluxes }\end{array}$ \\
\hline \multirow[t]{6}{*}{ Techniques } & Containment mentioned. & $\begin{array}{l}\text { Smoke containment- physical } \\
\text { measures to prevent the } \\
\text { spread of hot and smoky } \\
\text { products- smoke curtains, } \\
\text { walls etc. }\end{array}$ & & & IFEG and 7974 are similar \\
\hline & Extraction mentioned. & $\begin{array}{l}\text { Smoke clearance- removal of } \\
\text { smoke after smoke has } \\
\text { finished being produced. }\end{array}$ & & & IFEG and 7974 are similar \\
\hline & Dilution mentioned. & $\begin{array}{l}\text { Smoke dilution- mixing smoke } \\
\text { with clean air to reduce the } \\
\text { concentration of toxic } \\
\text { products and increase } \\
\text { visibility. }\end{array}$ & & & IFEG and 7974 are similar \\
\hline & Natural ventilation mentioned. & $\begin{array}{l}\text { Smoke exaust ventilation- } \\
\text { natural or mechanical means } \\
\text { of removing smoke from top } \\
\text { of layer. }\end{array}$ & & & IFEG and 7974 are similar \\
\hline & $\begin{array}{l}\text { Zone pressurization } \\
\text { mentioned. }\end{array}$ & $\begin{array}{l}\text { Pressurization- effectively } \\
\text { contains smoke. Uses pressure } \\
\text { differences over openings. }\end{array}$ & & & IFEG and 7974 are similar \\
\hline & & $\begin{array}{l}\text { Depressurization- limiting } \\
\text { smoke movement by pressure } \\
\text { differentials. Fans pull air out } \\
\text { of designated spaces rather } \\
\text { than supplying it. }\end{array}$ & & & $\begin{array}{l}\mathrm{N} / \mathrm{A} \text { - depressurization not } \\
\text { mentioned in IFEG }\end{array}$ \\
\hline
\end{tabular}


Subsystem 2 - smoke control - design procedure and analysis

\begin{tabular}{|c|c|c|c|c|c|}
\hline & IFEG & BS 7974 & SFPE & ISO 13387 & Comments \\
\hline Inputs & $\begin{array}{l}\text { Building characteristics, heat } \\
\text { release rate profile, smoke } \\
\text { yield, characteristics, of smoke } \\
\text { management equipment, time } \\
\text { to smoke detection, } \\
\text { environmental effects }\end{array}$ & $\begin{array}{l}\text { Building characteristics } \\
\text { Occupant characteristics } \\
\text { Design fire- sub system } 1 \\
\text { Environmental influences- wind, internal air } \\
\text { movement, stack effect. } \\
\text { Active systems activation time. }\end{array}$ & $\begin{array}{l}\text { Refers to } \\
\text { - International Fire } \\
\text { Engineering Guidelines } \\
\text { - ISO TR } 13887 \\
\text { - PD } 7974 \text { Parts 0-8, } \\
\text { Application of Fire Safety } \\
\text { Engineering Principles to } \\
\text { the design of buildings } \\
\text { - Global Performance-Based } \\
\text { Design: Is it the Solution? } \\
\text { (Reiss) } \\
\text { - Evaluation of } \\
\text { Unsprinklered Fire Hazards } \\
\text { (Alpert and Ward) } \\
\text { - Introduction to the Use of } \\
\text { Fire Dynamics in } \\
\text { Performance Based Design } \\
\text { (Custer) } \\
\text { - Introduction to } \\
\text { Performance Based Fire } \\
\text { Safety (Custer and } \\
\text { Meacham) } \\
\text {-Performance-Based Fire } \\
\text { Scenarios" Primer \#3 } \\
\text { - "Goals, Objectives \& } \\
\text { Performance Criteria" } \\
\text { Primer \#1 }\end{array}$ & & $\begin{array}{l}\text { IFEG and } 7974 \text { are } \\
\text { identical. SFPE refers to } \\
\text { multiple documents }\end{array}$ \\
\hline $\begin{array}{l}\text { Heat Content of } \\
\text { Plume }\end{array}$ & $Q_{c}=0.7 Q$ & $\begin{array}{l}Q_{p}=X Q \text { where } X \text { is the fraction of heat as } \\
\text { convection }(0.4-0.9) \text {. Table provided for } \\
\text { different fuels. }\end{array}$ & \multirow{3}{*}{$\begin{array}{l}\text { The following document was } \\
\text { referred to: } \\
\text { "Compartment Fire- } \\
\text { Generated Environment and } \\
\text { Smoke Filling" (Cooper) SFPE } \\
\text { Handbook }\end{array}$} & \multirow{3}{*}{$\begin{array}{l}\text { Smoke Control in Fire Safety } \\
\text { Design (Properties of Fire } \\
\text { Plumes- Zukoski) } \\
\text { Smoke Controle in Fire } \\
\text { Safety Design (Fire Plumes- } \\
\text { Heskestad) } \\
\text { Smoke Control in Fire Safety } \\
\text { Design (Air entrainment into } \\
\text { buoyant jet flames and pool } \\
\text { fires- Delichatsios) } \\
\text { Usually, the heat release } \\
\text { rate in the plume equals the } \\
\text { convective fraction of heat } \\
\text { release rate. The convective } \\
\text { heat release rate is typically }\end{array}$} & $\begin{array}{l}\text { IFEG and } 7974 \text { are } \\
\text { dissimilar, but not } \\
\text { contradicting. More } \\
\text { information in } 7974 \\
\end{array}$ \\
\hline \multirow[t]{2}{*}{$\begin{array}{l}\text { Smoke Plumes } \\
\text { Above Fire } \\
\text { Source }\end{array}$} & $\begin{array}{l}\text { Mean flame height and virtual } \\
\text { origin mentioned. }\end{array}$ & $\begin{array}{l}\text { Luminous flame height- Cox and Chitty or } \\
\text { Heskestad- whichever is more onerous. } \\
\text { Calculations outlined for flame height and mass } \\
\text { flow rate of smoke and entrained air. }\end{array}$ & & & $\begin{array}{l}\text { IFEG and } 7974 \text { are } \\
\text { dissimilar, but not } \\
\text { contradicting. More } \\
\text { detail in BS } 7974 . \text { SFPE } \\
\text { refers to another } \\
\text { document } \\
\end{array}$ \\
\hline & $\begin{array}{l}\text { McCaffrey Model- equations } \\
\text { given for mass entrainment } \\
\text { rate for flame region, } \\
\text { intermittent flame region and } \\
\text { buoyant plume. }\end{array}$ & $\begin{array}{l}\text { Axi-symmetric plumes: Discussion about the } \\
\text { movement of smoke and air entrainment. }\end{array}$ & & & $\begin{array}{l}\text { IFEG and } 7974 \text { are } \\
\text { dissimilar, but not } \\
\text { contradicting. BS } 7974 \\
\text { has greater detail and } \\
\text { commentary. }\end{array}$ \\
\hline
\end{tabular}




\begin{tabular}{|c|c|c|c|c|c|}
\hline & IFEG & BS 7974 & SFPE & ISO 13387 & Comments \\
\hline \multirow[t]{4}{*}{$\begin{array}{l}\text { Smoke Plumes } \\
\text { Above Fire } \\
\text { Source }\end{array}$} & Not mentioned. & $\begin{array}{l}\text { Line Plume: Where } L=5 W \text { of fire base. Flame } \\
\text { height, mass flow of smoke. Dependant on } \\
\text { length of side and HRR. }\end{array}$ & & \multirow{4}{*}{$\begin{array}{l}\text { assumed to be } 70 \% \text { of the } \\
\text { total heat release rate. } \\
\text { McCaffrey plume expression } \\
\text { is also referred to Purely } \\
\text { Buoyant Diffusion Flames: } \\
\text { Some Experimental Results } \\
\text { (McCaffrey). This would use } \\
\text { the total heat release rate. }\end{array}$} & $\begin{array}{l}\text { N/A- not mentioned in } \\
\text { IFEG }\end{array}$ \\
\hline & $\begin{array}{l}\text { References the use of } \\
\text { reflection (Mowrer and } \\
\text { Williamson 1987). No } \\
\text { calculation given. }\end{array}$ & $\begin{array}{l}\text { Effect o fAdjacent Walls: the reduction of } \\
\text { entrained air from the perimeter causes the } \\
\text { flame height to lengthen. Flame height and } \\
\text { mass floor of smoke given for fire against wall } \\
\text { and in corner. }\end{array}$ & & & $\begin{array}{l}\text { IFEG and } 7974 \text { are } \\
\text { dissimilar, but not } \\
\text { contradicting. More } \\
\text { detail in BS } 7974\end{array}$ \\
\hline & Not mentioned. & $\begin{array}{l}\text { Fire induced winds: inlet air velocity causes the } \\
\text { flame jet to move away from opening. Mass } \\
\text { flow of smoke can be calculated. }\end{array}$ & & & $\begin{array}{l}\text { N/A- BS } 7974 \text { has more } \\
\text { information }\end{array}$ \\
\hline & $\begin{array}{l}\text { Stack effect makes reference } \\
\text { to Klote and Milke (2002). } \\
\text { Equation given for vertical } \\
\text { smoke flow rate }(\mathrm{kg} / \mathrm{s})\end{array}$ & $\begin{array}{l}\text { Stratification of Smoke: two equations for } \\
\text { stratification of smoke rise }(\mathrm{m}) \text {. Dependant on } \\
\text { temperature and height of rise. }\end{array}$ & & & $\begin{array}{l}\text { IFEG and } 7974 \text { are } \\
\text { dissimilar, but not } \\
\text { contradicting. }\end{array}$ \\
\hline \multirow[t]{3}{*}{ Ceiling Jets } & $\begin{array}{l}\text { Ceiling jet mentioned in } \\
\text { detection sub system. Short } \\
\text { explanation. }\end{array}$ & $\begin{array}{l}\text { Plume impingement on ceiling. Ceiling jets are } \\
\text { typically } 5-12 \% \text { of fire source to ceiling height } \\
\text { in depth. Maximum velocities and } \\
\text { temperatures occur in first } 1 \% \text { of fire source to } \\
\text { ceiling height. }\end{array}$ & \multirow[t]{3}{*}{$\begin{array}{l}\text { The following document was } \\
\text { referred to: } \\
\text { "Compartment Fire- } \\
\text { Generated Environment and } \\
\text { Smoke Filling" (Cooper) SFPE } \\
\text { Handbook }\end{array}$} & \multirow{3}{*}{$\begin{array}{l}\text { Defines a ceiling jet. For } \\
\text { commonly used expressions } \\
\text { refers to: } \\
\text { Calculation of Response } \\
\text { Time of Ceiling Mounted Fire } \\
\text { Detectors (Alpert) } \\
\text { Smoke Control in Fire Safety } \\
\text { Design (Evans) }\end{array}$} & $\begin{array}{l}\text { Dissimilar, but not } \\
\text { contradicting- BS } 7974 \\
\text { goes into more detail. } \\
\text { SFPE refers to another } \\
\text { document }\end{array}$ \\
\hline & $\begin{array}{l}\text { Axi-symmetric ceiling jet: } \\
\text { temperatures and velocities in } \\
\text { unconfined spaces discussed. } \\
\text { Equations outline the } \\
\text { maximum temperature rise } \\
\text { and maximum gas velocities } \\
\text { and is dependent on the radial } \\
\text { distances and height of ceiling } \\
\text { above the fire source (Alpert } \\
\text { 1972). }\end{array}$ & $\begin{array}{l}\text { Axi-symmetric ceiling jet: temperatures and } \\
\text { velocities in unconfined spaces discussed. } \\
\text { Equations outline the maximum temperature } \\
\text { rise and maximum gas velocities and is } \\
\text { dependent on the radial distance and height of } \\
\text { ceiling above the fire source (Alpert 1972). }\end{array}$ & & & $\begin{array}{l}\text { IFEG and } 7974 \text { are } \\
\text { identical }\end{array}$ \\
\hline & References Delichatsios (1981). & $\begin{array}{l}\text { Two-dimensions ceiling jet: Where beams or } \\
\text { corridors inhibit plume spread, the velocity and } \\
\text { temperature rises will be different to } \\
\text { unenclosed spaces. The velocity and } \\
\text { temperature rises are dependent on the width } \\
\text { of the corridor and the distance to a point } \\
\text { which wants to be found (Delichatsios 1981) }\end{array}$ & & & $\begin{array}{l}\text { IFEG and } 7974 \text { have } \\
\text { identical references-BS } \\
7974 \text { goes into more } \\
\text { detail }\end{array}$ \\
\hline $\begin{array}{l}\text { Flow from } \\
\text { enclosure } \\
\text { openings }\end{array}$ & $\begin{array}{l}\text { Rockett (1976) and Edmonds } \\
\text { (2002) equation given for mass } \\
\text { flow out of an opening. } \\
\text { Dependent on density of } \\
\text { smoke and opening. }\end{array}$ & $\begin{array}{l}\text { Calculation of mass flow of smoke from a } \\
\text { vertical opening before the onset of flashover is } \\
\text { considered (Thomas 1992). This is based on the } \\
\text { temperature rise, air density, depth of smoke } \\
\text { layer and the profile correction factor. Depth of } \\
\text { smoke layer is presented based on a constant } \\
\text { of proportionality. }\end{array}$ & & & $\begin{array}{l}\text { Dissimilar, but not } \\
\text { contradicting. }\end{array}$ \\
\hline
\end{tabular}




\begin{tabular}{|c|c|c|c|c|c|}
\hline & IFEG & BS 7974 & SFPE & ISO 13387 & Comments \\
\hline \multirow[t]{2}{*}{$\begin{array}{l}\text { Flow from } \\
\text { enclosure } \\
\text { openings }\end{array}$} & $\begin{array}{l}\text { Smoke spread from other than } \\
\text { the enclosure of fire origin is } \\
\text { stated as being difficult using } \\
\text { hand calculations are rarely } \\
\text { used although SFPE handbook } \\
\text { has some calculations. }\end{array}$ & $\begin{array}{l}\text { Spill Plumes: discusses the effect of large spill } \\
\text { areas. Large uncertainties can be involved. The } \\
\text { mass flow rates include the effect of the width } \\
\text { of the opening. Calculations for mass flow of } \\
\text { smoke presented. }\end{array}$ & & & $\begin{array}{l}\text { Dissimilar, but not } \\
\text { contradicting. BS } 7974 \\
\text { provides greater } \\
\text { discussion and provides } \\
\text { hand calculations. }\end{array}$ \\
\hline & $\begin{array}{l}\text { Flow through a horizontal vent } \\
\text { references Klote and Milke } \\
\text { (2002). Equation given for } \\
\text { vertical smoke flow. }\end{array}$ & $\begin{array}{l}\text { Flow of hot gases through natural horizontal } \\
\text { vents: calculation given to determine the mass } \\
\text { flow rate through a horizontal vent (Thomas et } \\
\text { al 1963). }\end{array}$ & & & $\begin{array}{l}\text { IFEG and } 7974 \text { are } \\
\text { similar- Different } \\
\text { equations with same } \\
\text { basis used. }\end{array}$ \\
\hline $\begin{array}{l}\text { Replacement } \\
\text { Air }\end{array}$ & Briefly mentioned. & $\begin{array}{l}\text { Essential for inlet to be provided, maximum } \\
\text { speed } 5 \mathrm{~m} / \mathrm{s} \text {. }\end{array}$ & & & $\begin{array}{l}\text { BS } 7974 \text { provides more } \\
\text { detail }\end{array}$ \\
\hline \multirow[t]{6}{*}{$\begin{array}{l}\text { Properties of } \\
\text { Smoke }\end{array}$} & $\begin{array}{l}\text { Upper temperature of layer } \\
\text { from McCaffrey. Dependent on } \\
\text { openings, materials in room } \\
\text { and fire size. }\end{array}$ & $\begin{array}{l}\text { Temperature of the hot gases: represented by } \\
\text { the relationship between fire size and mass } \\
\text { flow of smoke. }\end{array}$ & \multirow[t]{6}{*}{$\begin{array}{l}\text { Referred to Effect of } \\
\text { Combustion Conditions on } \\
\text { Species Production (Gottuk \& } \\
\text { Lattimer) SFPE }\end{array}$} & $\begin{array}{l}\text { If it is a smoldering fire or if } \\
\text { the area of interest is far } \\
\text { from the point of fire origin, } \\
\text { the temperature of the fire } \\
\text { effluent may not be high } \\
\text { enough for stratification to } \\
\text { occur. }\end{array}$ & $\begin{array}{l}\text { Dissimilar, but not } \\
\text { contradicting. }\end{array}$ \\
\hline & Not mentioned. & $\begin{array}{l}\text { Smoke volume flow rate: well mixed smoke } \\
\text { layer volume flow rate represented by } \\
\text { temperature and mass flow of the smoke. }\end{array}$ & & & $\begin{array}{l}\text { N/A- BS } 7974 \text { goes into } \\
\text { more detail }\end{array}$ \\
\hline & $\begin{array}{l}\text { Optical density of smoke: } \\
\text { expression given on the way } \\
\text { light is attenuated in respect to } \\
\text { source intensity and the } \\
\text { optical density of smoke. }\end{array}$ & $\begin{array}{l}\text { Optical density of smoke: expression given on } \\
\text { the way light is attenuated in respect to source } \\
\text { intensity and the optical density of smoke. The } \\
\text { optical density of smoke is a function of the } \\
\text { total volume of smoke and the mass optical } \\
\text { density of the fuel. }\end{array}$ & & $\begin{array}{l}\text { Smoke density can be } \\
\text { estimated by assuming the } \\
\text { space to be well-stirred }\end{array}$ & $\begin{array}{l}\text { N/A- BS } 7974 \text { goes into } \\
\text { more detail }\end{array}$ \\
\hline & $\begin{array}{l}\text { Visibility through smoke is not } \\
\text { given. Optical density per unit } \\
\text { length can be found. }\end{array}$ & $\begin{array}{l}\text { Visibility through smoke: visibility through the } \\
\text { smoke is one over the optical density per unit } \\
\text { length (Tewarson 1995). }\end{array}$ & & & $\begin{array}{l}\text { IFEG and } 7974 \text { are } \\
\text { similar- BS } 7974 \text { goes } \\
\text { into more detail }\end{array}$ \\
\hline & $\begin{array}{l}\text { Short discussion on the use of } \\
\text { gas species concentrations. } \\
\text { Consideration required for } \\
\text { certain toxins when related to } \\
\text { life safety. }\end{array}$ & $\begin{array}{l}\text { Gas species mass concentrations: discussion } \\
\text { about the means by which the mass } \\
\text { concentration of a particular species can be } \\
\text { found. }\end{array}$ & & & $\begin{array}{l}\text { Dissimilar, but not } \\
\text { contradicting. Greater } \\
\text { detail in BS } 7974\end{array}$ \\
\hline & Not mentioned. & $\begin{array}{l}\text { Gas volume concentrations: dependant on the } \\
\text { density of species. }\end{array}$ & & & $\begin{array}{l}\text { N/A- BS } 7974 \text { goes into } \\
\text { more detail. }\end{array}$ \\
\hline $\begin{array}{l}\text { Smoke } \\
\text { Reservoir Size }\end{array}$ & $\begin{array}{l}\text { No information given, } \\
\text { references made to; Drysdale } \\
\text { (1999), SFPE Handbook } \\
\text { (DiNenno 2002), Evans and } \\
\text { Klote (2003). Refers to NFPA } \\
\text { 92B and NFPA 204. }\end{array}$ & $\begin{array}{l}\text { Limits for smoke reservoir sizes in the absence } \\
\text { of computer modeling to } 2000 \mathrm{~m}^{2} \text { for MoE, } \\
2600 \mathrm{~m}^{2} \text { for powered and } 3000 \mathrm{~m}^{2} \text { for property. }\end{array}$ & & & $\begin{array}{l}\text { Dissimilar, but not } \\
\text { contradicting. Greater } \\
\text { detail in BS } 7974\end{array}$ \\
\hline
\end{tabular}


Subsystem 2 - smoke control - design procedure and analysis

\begin{tabular}{|c|c|c|c|c|c|}
\hline & IFEG & BS 7974 & SFPE & ISO 13387 & Comments \\
\hline $\begin{array}{l}\text { Minimum } \\
\text { Number of } \\
\text { Exhaust } \\
\text { Ventilators }\end{array}$ & $\begin{array}{l}\text { Refers to NFPA 92B and NFPA } \\
204\end{array}$ & $\begin{array}{l}\text { The phenomenon of plug holing is discussed } \\
\text { and the calculation for critical exhaust rate of } \\
\text { ventilators away from a wall is given from BRE } \\
368 \text {. The number of vents can be found from } \\
\text { the } m_{\text {crit }} \text { and the mass flow entering the layer. }\end{array}$ & & & $\begin{array}{l}\text { N/A- BS } 7974 \text { goes into } \\
\text { more detail. }\end{array}$ \\
\hline $\begin{array}{l}\text { Interactions of } \\
\text { Sprinklers and } \\
\text { Smoke } \\
\text { Ventilation }\end{array}$ & Not mentioned. & $\begin{array}{l}\text { Referenced to BRE } 368 \text { to determine whether } \\
\text { sprinklers will affect the designed smoke } \\
\text { control system and the effect the temperature } \\
\text { control will have on the sprinkler system. }\end{array}$ & & & $\begin{array}{l}\text { N/A- BS } 7974 \text { goes into } \\
\text { more detail. }\end{array}$ \\
\hline \multirow[t]{3}{*}{$\begin{array}{l}\text { Free hanging } \\
\text { Smoke Curtains } \\
\text { Of Plume }\end{array}$} & Not mentioned. & $\begin{array}{l}\text { Discussion on the problems associated with } \\
\text { free hanging smoke curtains and horizontal } \\
\text { deflections. }\end{array}$ & & & $\begin{array}{l}\text { N/A- BS } 7974 \text { goes into } \\
\text { more detail. }\end{array}$ \\
\hline & Not mentioned. & $\begin{array}{l}\text { Curtains containing a smoke layer: the } \\
\text { deflection of the smoke curtain can be } \\
\text { calculated from the parameters of the curtain } \\
\text { and projected smoke layer. Length of curtain } \\
\text { required is iterative. }\end{array}$ & & & $\begin{array}{l}\text { N/A- BS } 7974 \text { goes into } \\
\text { more detail. }\end{array}$ \\
\hline & Not mentioned. & $\begin{array}{l}\text { Curtains closing and opening: deflection of } \\
\text { curtain and length can be found. }\end{array}$ & & & $\begin{array}{l}\text { N/A- BS } 7974 \text { goes into } \\
\text { more detail. }\end{array}$ \\
\hline
\end{tabular}


Subsystem 2 - smoke control - smoke hazards

\begin{tabular}{|c|c|c|c|c|c|}
\hline & IFEG & BS 7974 & SFPE & ISO 13387 & Comments \\
\hline \multirow[t]{2}{*}{$\begin{array}{l}\text { Hazards of } \\
\text { smoke }\end{array}$} & $\begin{array}{l}\text { Visible and non visible product } \\
\text { of combustion or pyrolysis and } \\
\text { entrained air }\end{array}$ & $\begin{array}{l}\text { "airborne" products of } \\
\text { combustions, solid or liquid } \\
\text { particulates within a gaseous } \\
\text { mass. }\end{array}$ & & & $\begin{array}{l}\text { IFEG and } 7974 \text { are } \\
\text { similar/Identical }\end{array}$ \\
\hline & $\begin{array}{l}\text { "CO, } \mathrm{CO}_{2} \text {, and } \mathrm{HCN} \text { are often } \\
\text { considered for life safety } \\
\text { criteria." }\end{array}$ & $\begin{array}{l}\text { Most fire deaths from smoke } \\
\text { inhalation. } \\
\mathrm{CO}_{2}, \mathrm{H}_{2} \mathrm{O}, \mathrm{CO}, \mathrm{HCN} \text {. Further } \\
\text { preamble of smoke dangers. }\end{array}$ & & & IFEG and 7974 are similar \\
\hline $\begin{array}{l}\text { Smoke } \\
\text { Dynamics }\end{array}$ & $\begin{array}{l}\text { Influence of buoyancy and } \\
\text { combustion generated } \\
\text { products. Amount of air } \\
\text { entrained greatly exceeds } \\
\text { mass flow of fuel burned. }\end{array}$ & $\begin{array}{l}\text { Initial flow influenced by air } \\
\text { currents; fuel controlled fire } \\
\text { creats a plume, smoke rises to } \\
\text { ceiling, then radially spreads. } \\
\text { Air entrainment increases } \\
\text { colume and decreases } \\
\text { temperature. } \\
\text { Fire growth may be limited by } \\
\text { limited ventilation. }\end{array}$ & & & $\begin{array}{l}\text { IFEG and } 7974 \text { are dissimilar, } \\
\text { but not contradicting. }\end{array}$ \\
\hline
\end{tabular}


Subsystem 2 - smoke control - management, data and summary

\begin{tabular}{|c|c|c|c|c|c|}
\hline & IFEG & BS 7974 & SFPE & ISO 13387 & Comments \\
\hline $\begin{array}{l}\text { Fire Safety } \\
\text { Management }\end{array}$ & $\begin{array}{l}\text { Suggest management } \\
\text { procedures for active systems } \\
\text { particularly and consideration } \\
\text { required for passive systems. }\end{array}$ & $\begin{array}{l}\text { Defines the use of BS 9999:4 } \\
\text { to determine frequency of } \\
\text { maintenance. }\end{array}$ & & & IFEG goes into more detail. \\
\hline \multirow[t]{2}{*}{ Data } & $\begin{array}{l}0.7 \text { referred to as standard for } \\
\text { Convected fractions }\end{array}$ & $\begin{array}{l}\text { Convected fractions for } \\
\text { various materials. }\end{array}$ & & & $\begin{array}{l}\text { N/A- BS } 7974 \text { goes into more } \\
\text { detail. }\end{array}$ \\
\hline & $\begin{array}{l}\text { Means of determining Mass } \\
\text { Optical Density via use of } \\
\text { extinction coefficient. }\end{array}$ & $\begin{array}{l}\text { Mass optical densities and CO } \\
\text { yield of various materials. }\end{array}$ & & & $\begin{array}{l}\text { N/A- BS } 7974 \text { goes into more } \\
\text { detail. }\end{array}$ \\
\hline $\begin{array}{l}\text { Computer } \\
\text { Modeling }\end{array}$ & $\begin{array}{l}\text { Mentioned as a means of } \\
\text { analysis, no advice given. }\end{array}$ & $\begin{array}{l}\text { Discussion of model types, } \\
\text { zone models, CFD, thermal } \\
\text { radiation etc. }\end{array}$ & $\begin{array}{l}\text { The following documents were } \\
\text { referred to: } \\
\text { Introduction to Performance } \\
\text { Based Fire Safety (Custer and } \\
\text { Meacham) } \\
\text { Engineering Guide- Evaluation } \\
\text { of the Computer Fire Model } \\
\text { DETACT-QS } \\
\text { "An Updated International } \\
\text { Survey of Computer Models for } \\
\text { Fire and Smoke" (Carpenter } \\
\text { and Olenick) } \\
\text { "Deterministic Computer Fire } \\
\text { Models," (Walton, Carpenter, } \\
\text { Budnick) }\end{array}$ & $\begin{array}{l}\text { Potential computer models are } \\
\text { named in each subsection (Under part } \\
\text { 7). }\end{array}$ & $\begin{array}{l}\text { N/A- BS } 7974 \text { goes into more } \\
\text { detail. SFPE provides many } \\
\text { references to documents for } \\
\text { additional information }\end{array}$ \\
\hline Summary & $\begin{array}{l}\text { Where calculations and } \\
\text { concepts are not given, } \\
\text { reference one of a number of } \\
\text { books/papers. Good flow chart } \\
\text { of procedures. Some details } \\
\text { are brief. Some information in } \\
\text { other sub-systems. }\end{array}$ & $\begin{array}{l}\text { Provides defined areas to } \\
\text { provide smoke ventilation and } \\
\text { smoke control in enclosures } \\
\text { and large spaces. }\end{array}$ & $\begin{array}{l}\text { Mostly refers out to other } \\
\text { documents }\end{array}$ & $\begin{array}{l}\text { Mostly addressed in sub-system } \\
\text { details }\end{array}$ & $\begin{array}{l}\text { IFEG and } 7974 \text { provide the } \\
\text { answers, although only BS } \\
7974 \text { provides them within the } \\
\text { document. IFEG references } \\
\text { other document heavily, some } \\
\text { widely-used calculations are } \\
\text { not present. }\end{array}$ \\
\hline
\end{tabular}




\begin{tabular}{|c|c|c|c|c|c|}
\hline & IFEG & BS 7974 & SFPE & ISO 13387 & Comments \\
\hline General & $\begin{array}{l}\text { The recommended approach } \\
\text { to determining the appropriate } \\
\text { fire resistance of barriers is to } \\
\text { utilize the time equivalence } \\
\text { model and then use a barrier } \\
\text { that can achieve the resulting } \\
\text { fire period. }\end{array}$ & $\begin{array}{l}\text { Design guidance on openings into fire } \\
\text { enclosure: } \\
\text {-Doors should be assumed open if } \\
\text { enclosure has no other openings } \\
\text {-Doors should be assumed closed if } \\
\text { the enclosure has other openings } \\
\text {-All enclosure surfaces (including } \\
\text { glazed openings) may be assumed to } \\
\text { be imperforate for the duration of } \\
\text { fire provided analysis hasn't proved } \\
\text { otherwise. } \\
\text {-Monte Carlo analysis is } \\
\text { recommended to evaluate } \\
\text { combinations of openings. }\end{array}$ & $\begin{array}{l}\text { The following documents } \\
\text { were referred to: } \\
\text { An Introduction to Fire } \\
\text { Dynamics (Drysdale) } \\
\text { Surface Flame Spread } \\
\text { (Quintiere) }\end{array}$ & & $\mathrm{N} / \mathrm{A}$ \\
\hline $\begin{array}{l}\text { Heat Flow by } \\
\text { Conduction }\end{array}$ & No information given. & $\begin{array}{l}\text { Designer should take "great care" if } \\
\text { deciding to use a criterion of a } \\
\text { surface temperature on the } \\
\text { unexposed side in excess of } 200^{\circ} \mathrm{C} \text {. }\end{array}$ & $\begin{array}{l}\text { Refers to Chemistry and } \\
\text { Physics of Fire (Drysdale) }\end{array}$ & \multirow{3}{*}{$\begin{array}{l}\text { Classical textbooks on heat } \\
\text { transfer provide innumerable } \\
\text { hand calculation expressions for } \\
\text { calculating heat fluxes to and } \\
\text { from solids, liquids, and gases as } \\
\text { well as expressions for estimating } \\
\text { the resulting temperature profiles } \\
\text { in a target. These analytical } \\
\text { expressions are usually arrived at } \\
\text { by setting up the energy balance. }\end{array}$} & $\begin{array}{l}\text { N/A- } 7974 \text { provides quantified } \\
\text { guidance. SFPE references } \\
\text { another source }\end{array}$ \\
\hline $\begin{array}{l}\text { Heat Flow by } \\
\text { Convection }\end{array}$ & No information given. & $\begin{array}{l}\text { Criteria of } 500^{\circ} \mathrm{C} \text { can be used when } \\
\text { establishing likelihood of } \\
\text { spontaneous ignition due to } \\
\text { convection only. Piloted ignition is } \\
\text { assumed to be probable in the region } \\
400-450^{\circ} \mathrm{C} \text {. Some criteria given for } \\
\text { human tolerability levels, } 60^{\circ} \mathrm{C} \\
\text { saturated air is mentioned as } \\
\text { intolerable. }\end{array}$ & $\begin{array}{l}\text { Refers to Chemistry and } \\
\text { Physics of Fire (Drysdale) }\end{array}$ & & $\begin{array}{l}\text { N/A- } 7974 \text { provides quantified } \\
\text { guidance. SFPE references } \\
\text { another source }\end{array}$ \\
\hline $\begin{array}{l}\text { Heat Flow by } \\
\text { Radiation }\end{array}$ & $\begin{array}{l}\text { Various references to } \\
\text { publications regarding external } \\
\text { fire spread. Some data on } \\
\text { ignitability limits under radiant } \\
\text { heat flux. The spontaneous } \\
\text { ignition criterion for wood is } \\
\text { set to } 250-400^{\circ} \mathrm{C} \text {. }\end{array}$ & $\begin{array}{l}\text { Standard radiation relationships } \\
\text { shown. } 12.6 \mathrm{~kW} / \mathrm{m}^{2} \text { is mentioned as a } \\
\text { criterion, giving "some factor fo } \\
\text { safety". Possible to base analysis on } \\
\text { the increase of surface temperature } \\
\text { of the object exposed. For organic } \\
\text { solids a surface temp. criterion of } \\
600^{\circ} \mathrm{C} \text { is suggested for spontaneous } \\
\text { ignition, and } 300-410^{\circ} \mathrm{C} \text { for ignition } \\
\text { by flying brands under a radiative } \\
\text { heat flux. }\end{array}$ & $\begin{array}{l}\text { Refers to Chemistry and } \\
\text { Physics of Fire (Drysdale) }\end{array}$ & & $\begin{array}{l}\text { N/A- } 7974 \text { provides quantified } \\
\text { guidance. IFEG provides a } \\
\text { short commentary and } \\
\text { references to other guidance } \\
\text { documents. Only very brief } \\
\text { quantified guidance on } \\
\text { ignitability. } \\
\text { Some dissimilarity in criteria } \\
\text { for ignition of solids. } \\
\text { SFPE references another } \\
\text { source }\end{array}$ \\
\hline \multirow[t]{2}{*}{$\begin{array}{l}\text { Heat Flow by } \\
\text { Mass Transfer }\end{array}$} & \multirow[t]{2}{*}{$\begin{array}{l}\text { BS } 476-3 \text { is recommended for a } \\
\text { methodology assessing the } \\
\text { ignitability of roof coverings } \\
\text { subject to radiative heat fluxes } \\
\text { and flying brands. }\end{array}$} & $\begin{array}{l}\text { Presence of flying brands hard to } \\
\text { determine with any certainty. Should } \\
\text { be considered as piloted ignition } \\
\text { leads to lower necessary surface } \\
\text { temperatures. }\end{array}$ & & & \multirow[t]{2}{*}{$\begin{array}{l}\text { N/A- IFEG provides a very } \\
\text { short commentary, but does } \\
\text { reference a test method for } \\
\text { assessing ignitability of } \\
\text { surfaces exposed to flying } \\
\text { brands. } 7974 \text { does not provide }\end{array}$} \\
\hline & & Design care should be taken to mass & & & \\
\hline
\end{tabular}


Subsystem 3 - structural and passive fire protection - fire spread analysis

\begin{tabular}{|c|c|c|c|c|c|}
\hline & IFEG & BS 7974 & SFPE & ISO 13387 & Comments \\
\hline & & flow of burning liquids. & & & any quantified guidance. \\
\hline $\begin{array}{l}\text { Heat Flow by } \\
\text { Direct Pyrolysis } \\
\text { and Reaction to } \\
\text { Fire }\end{array}$ & No information given. & $\begin{array}{l}\text { A reasonable design approach is to } \\
\text { assume that all combustibles within } \\
\text { enclosure will at some point become } \\
\text { involved in the fire. Any part of } \\
\text { continuous combustible construction } \\
\text { that extends outside the enclosure } \\
\text { the enclosure should be viewed as } \\
\text { permitting fire spread beyond that } \\
\text { enclosure. }\end{array}$ & & & $\begin{array}{l}\text { N/A- Some practical guidance } \\
\text { from } 7974 . \text { No guidance in } \\
\text { IFEG. }\end{array}$ \\
\hline $\begin{array}{l}\text { Fire Spread in } \\
\text { Large } \\
\text { Enclosures }\end{array}$ & $\begin{array}{l}\text { It is recognized that assuming } \\
\text { simultaneous combustion in } \\
\text { enclosures over } 150 \mathrm{~m}^{2} \text { leads to } \\
\text { unrealistically high } \\
\text { temperatures in the enclosure. } \\
\text { It is recommended that the } \\
\text { floor area should be sub- } \\
\text { divided into smaller grids (10- } \\
50 \mathrm{~m}^{2} \text { ) and that fire spreads } \\
\text { from one grid to another. }\end{array}$ & $\begin{array}{l}\text { It is recognized that the size of the } \\
\text { enclosure influences the potential } \\
\text { fire severity and tat a fire in a large } \\
\text { compartment is more likely to be fuel } \\
\text { bed controlled than fires in smaller } \\
\text { compartments. }\end{array}$ & $\begin{array}{l}\text { Design Tree Figure 10-4 (Pg } \\
\text { 116) }\end{array}$ & $\begin{array}{l}\text { Refers to: } \\
\text { Toxic Potency Measurement for } \\
\text { Fire Hazard Analysis (Babrauskas, } \\
\text { Levin, Gann, Paabo, Harris, } \\
\text { Peacock, Yusa) } \\
\text { Combustion Products and their } \\
\text { Effects on Life Safety (Fire } \\
\text { Protection Handbook- Yamada } \\
\text { and Tanaka) }\end{array}$ & $\begin{array}{l}\text { Similar- The IFEG suggests a } \\
\text { quantified value, whilst } 7974 \\
\text { only provides a qualitative } \\
\text { comment. SFPE provides a } \\
\text { design tree for evaluation }\end{array}$ \\
\hline $\begin{array}{l}\text { Computer } \\
\text { Models }\end{array}$ & $\begin{array}{l}\text { Provides information on the } \\
\text { use of computer models in the } \\
\text { design process, and what one } \\
\text { should keep in mind when } \\
\text { utilizing computational } \\
\text { modeling. The models } \\
\text { discussed are zone and field } \\
\text { models used to establish fire } \\
\text { severity. The use of FEM } \\
\text { models is also discussed. }\end{array}$ & No information. & $\begin{array}{l}\text { Refers to Applying Models of } \\
\text { Fire Protection Engineering } \\
\text { Problems (Custer) FPH }\end{array}$ & Refers to ISO $13387-5$ & $\begin{array}{l}\text { N/A- IFEG provides more } \\
\text { information. SFPE refers to } \\
\text { another document }\end{array}$ \\
\hline
\end{tabular}


Subsystem 3 - structural and passive fire protection - general issues

\begin{tabular}{|c|c|c|c|c|c|}
\hline & IFEG & BS 7974 & SFPE & ISO 13387 & Comments \\
\hline $\begin{array}{l}\text { Recognition of } \\
\text { Fire Tests }\end{array}$ & $\begin{array}{l}\text { It is appreciated that the } \\
\text { standard fire test curves do } \\
\text { not represent a real fire time- } \\
\text { temperature curve. }\end{array}$ & $\begin{array}{l}\text { Information from standard } \\
\text { tests is reasonably well } \\
\text { understood. In most cases this } \\
\text { allows a rapid appraisal of an } \\
\text { element's ability to resist fire } \\
\text { spread and maintain structural } \\
\text { function. }\end{array}$ & $\begin{array}{l}\text { Acknowledged that fire testinc } \\
\text { can be used to collect heat } \\
\text { release data that may be used } \\
\text { for a design fire curve Refers to } \\
\text { small scale tests(ASTM E } 1321 \\
\text { and ASTM E 1354) furniture } \\
\text { (ASTM E } 1537 \text { and ASTM E } \\
\text { 1590) and room configurations } \\
\text { (ASTM E 603) } \\
\text { Refers to following documents: } \\
\text { The Cone Calorimeter } \\
\text { (Babrauskas) SFPE } \\
\text { Heat Release in Fires } \\
\text { (Babrauskas and Grayson) } \\
\text { ISO 9705: Full Scale Room Test } \\
\text { Calorimetry (janssens) SFPE }\end{array}$ & $\begin{array}{l}\text { Refers to BS } 476-32 \text { Fire Tests on } \\
\text { Building Materials and Structures. }\end{array}$ & $\begin{array}{l}\text { Dissimilar, but not } \\
\text { contradictory. SFPE provides } \\
\text { additional references for more } \\
\text { information }\end{array}$ \\
\hline $\begin{array}{l}\text { Time } \\
\text { Equivalence }\end{array}$ & $\begin{array}{l}\text { Recognizes and shows the } \\
\text { Eurocode } 1 \text { approach. The } \\
\text { recommended } k_{b} \text { value } 90.08- \\
0.045) \text { is however higher than } \\
\text { the recommendations given in } \\
\text { EC1. This is referenced to Kirby } \\
\text { (1999). }\end{array}$ & $\begin{array}{l}\text { Recognizes and shows the } \\
\text { Eurocode } 1 \text { approach. } k_{b} \text { is set } \\
\text { in a range of } 0.09-0.05 \text { with a } \\
\text { recommendation for UK for } \\
0.07 \text {. This is higher than the } \\
\text { values found in EC1. }\end{array}$ & & & $\begin{array}{l}\text { The recommendations given } \\
\text { are similar between the IFEG } \\
\text { and } 7974 \text { publications. They } \\
\text { do however differ from the } \\
\text { EC1. The EC1 suggests a } k_{b} \\
\text { ranging between } 0.04 \text { and } 0.07\end{array}$ \\
\hline \multirow{2}{*}{$\begin{array}{l}\text { Determination } \\
\text { of Fire } \\
\text { Conditions } \\
\text { Through } \\
\text { Engineering } \\
\text { Calculations }\end{array}$} & \multirow[t]{2}{*}{$\begin{array}{l}\text { Basic heat balance and } \\
\text { references to simple } \\
\text { relationships. }\end{array}$} & $\begin{array}{l}\text { Maximum temperature } \\
\text { equation shown, as well as a } \\
\text { similar equation for through } \\
\text { draught conditions. }\end{array}$ & $\begin{array}{l}\text { Refers to NFPA } 921 \text { Guide for } \\
\text { Fire and Explosion } \\
\text { Investigations }\end{array}$ & & \multirow[t]{2}{*}{$\begin{array}{l}\text { N/A- BS } 7974 \text { goes into more } \\
\text { detail. }\end{array}$} \\
\hline & & $\begin{array}{l}\text { Transient fire conditions } \\
\text { equations shown from DD ENV } \\
\text { 1991-2-2. }\end{array}$ & & & \\
\hline
\end{tabular}


Subsystem 3 - structural and passive fire protection - material performance

\begin{tabular}{|c|c|c|c|c|c|}
\hline & IFEG & BS 7974 & SFPE & ISO 13387 & Comments \\
\hline General & $\begin{array}{l}\text { Much of the information given } \\
\text { on this subject seems to be } \\
\text { taken from a standards } \\
\text { presented by the American } \\
\text { Society of Civil Engineers. } \\
\text { ASCE/SFPE 29, } 1999 .\end{array}$ & $\begin{array}{l}\text { Very detailed on the structural } \\
\text { performance of different } \\
\text { construction units in fire conditions. }\end{array}$ & $\begin{array}{l}\text { Refers to Engineering Guide- } \\
\text { Fire Exposures to Structural } \\
\text { Elements }\end{array}$ & $\begin{array}{l}\text { Refers to numerous documents } \\
\text { including: } \\
\text { Fire Safety Engineering Design of } \\
\text { Structures (Purkiss) } \\
\text { ASTM } 685 \text { Design of Buidling for } \\
\text { Fire Safety (Harmathy) } \\
\text { Structural Mechanics (SFPE } \\
\text { Handbook- Fitzgerald) }\end{array}$ & $\begin{array}{l}\text { N/A- BS } 7974 \text { goes into more } \\
\text { detail. SFPE provides a } \\
\text { reference for more } \\
\text { information }\end{array}$ \\
\hline \multirow[t]{2}{*}{ Concrete } & \multirow[t]{2}{*}{$\begin{array}{l}\text { Simplified design processes for } \\
\text { reinforced concrete members } \\
\text { are referenced to a number of } \\
\text { national standards from } \\
\text { Australia, New Zeeland, } \\
\text { Eurocode. }\end{array}$} & $\begin{array}{l}\text { Empirical equations based on the } \\
\text { standard time temperature curve to } \\
\text { predict temperature profiles within } \\
\text { concrete members. }\end{array}$ & \multirow[t]{2}{*}{$\begin{array}{l}\text { The following document was } \\
\text { referred to: } \\
\text { "Analytical Methods for } \\
\text { Determining Fire Resistance } \\
\text { of Concrete Members } \\
\text { (Fleishmann and Buchanan) }\end{array}$} & \multirow[t]{2}{*}{$\begin{array}{l}\text { Refers to ISO } 834-1 \text { test, the } \\
\text { optimum fire resistance of flexural } \\
\text { concrete members have been } \\
\text { observed when tested under } \\
\text { imposed end restraints of } \\
\text { between } 20-80 \%\end{array}$} & $\begin{array}{l}\text { NA- } 7974 \text { contains a lot of } \\
\text { practical guidance. IFEG } \\
\text { references to other sources } \\
\text { and only provides a rough } \\
\text { commentary. SFPE references } \\
\text { another source }\end{array}$ \\
\hline & & $\begin{array}{l}\text { Information given on thermal } \\
\text { elongation and shrinkage, specific } \\
\text { heat capacitiy, thermal conductivity, } \\
\text { density, and emissivity. }\end{array}$ & & & \\
\hline \multirow[t]{4}{*}{ Steel } & \multirow{2}{*}{$\begin{array}{l}\text { Eurocode 3- Design of Steel } \\
\text { structures is recommended as } \\
\text { a suitable guide for steel } \\
\text { design. Guidance is given on } \\
\text { when FEM methodology } \\
\text { should be used over simpler } \\
\text { methodologies. }\end{array}$} & $\begin{array}{l}\text { Section factors from BS } 5950-8 \text { and } \\
\text { temperature rise within a steel } \\
\text { member is calculated from DD ENV } \\
19931-2 .\end{array}$ & \multirow{4}{*}{$\begin{array}{l}\text { The following document was } \\
\text { referred to: } \\
\text { "Analytical Methods for } \\
\text { Determining Fire Resistance } \\
\text { of Steel Members" ( Milke) }\end{array}$} & \multirow[t]{4}{*}{$\begin{array}{l}\text { Refers to: } \\
\text { Fire Safety of Bare External } \\
\text { Structural Steel (Law and O'Brien) }\end{array}$} & \multirow{2}{*}{$\begin{array}{l}\text { N/A- IFEG provides a fair bit of } \\
\text { information on existing } \\
\text { standards. No practical } \\
\text { guidance is found in the } \\
\text { document. } \\
\text { BS } 7974 \text { provides more data } \\
\text { and guidance in the document } \\
\text { but other sources will still } \\
\text { need to be studied to perform } \\
\text { an analysis. } \\
\text { SFPE references another } \\
\text { source }\end{array}$} \\
\hline & & $\begin{array}{l}\text { Information given on thermal } \\
\text { elongation, specific heat capacity, } \\
\text { thermal conductivity, density, and } \\
\text { emissivity. }\end{array}$ & & & \\
\hline & $\begin{array}{l}\text { Protection to external steel } \\
\text { member is referenced to Law } \\
\text { and O'Brien (1981) and EC1 } \\
\text { and EC3. }\end{array}$ & $\begin{array}{l}\text { Protection to external steel member } \\
\text { is referenced to Law and O'Brien } \\
\text { (1981). }\end{array}$ & & & IFEG and 7974 are identical \\
\hline & $\begin{array}{l}\text { Short discussion on the } \\
\text { possible fire protection } \\
\text { measures available for steel } \\
\text { structures. }\end{array}$ & $\begin{array}{l}\text { Detailed recommendations of } \\
\text { calculation methodologies for } \\
\text { protected steel. }\end{array}$ & & & $\begin{array}{l}\text { N/A- } 7974 \text { provides more } \\
\text { practical guidance }\end{array}$ \\
\hline
\end{tabular}


Subsystem 3 - structural and passive fire protection - material performance

\begin{tabular}{|c|c|c|c|c|c|}
\hline & IFEG & BS 7974 & SFPE & ISO 13387 & Comments \\
\hline \multirow[t]{2}{*}{ Timber } & \multirow[t]{2}{*}{$\begin{array}{l}\text { Confirms a charring line equal } \\
\text { to the } 300^{\circ} \mathrm{C} \text { line of heating. } \\
\text { Refers to White (2002) and an } \\
\text { Australian Standard. EC } 5 \text { is } \\
\text { mentioned as a source of } \\
\text { charring rate equations. }\end{array}$} & $\begin{array}{l}\text { The charring rate is estimated using } \\
\text { Hadvigs (1981) equations. Equations } \\
\text { for time to maximum charring rate } \\
\text { and time dependent charring rates } \\
\text { shown. Charring rates from BS } 5268 \text { - } \\
4.1 \text { and DD ENV } 1995-1-2 \text { is shown. It } \\
\text { is suggested, in accordance with BS } \\
5268-4.1 \text {, that charring rates to } \\
\text { columns should be increased by } 25 \% \\
\text { compared to a beam. }\end{array}$ & $\begin{array}{l}\text { The following document was } \\
\text { referred to: } \\
\text { "Analytical Methods for } \\
\text { Determining Fire Resistance } \\
\text { of Timber Member" (White) }\end{array}$ & $\begin{array}{l}\text { Refers to: } \\
\text { "Analytical Methods for } \\
\text { Determining Fire Resistance of } \\
\text { Timber Member" (White) }\end{array}$ & \multirow{2}{*}{$\begin{array}{l}\text { Dissimilar, but not } \\
\text { contradictory. IFEG only } \\
\text { provides a very short } \\
\text { commentary of timber } \\
\text { behavior in fire, with } \\
\text { references to external sources } \\
\text { BS } 7974 \text { provides more data } \\
\text { and practical guidance, but } \\
\text { studies of external sources is } \\
\text { still necessary for a complete } \\
\text { analysis. } \\
\text { SFPE references another } \\
\text { source }\end{array}$} \\
\hline & & $\begin{array}{l}\text { Information given on thermal } \\
\text { elongation and shrinkage, specific } \\
\text { heat capacity, thermal conductivity, } \\
\text { density and emissivity. }\end{array}$ & & & \\
\hline Masonry & $\begin{array}{l}\text { Reference for methodologies } \\
\text { given to Australian Standard } \\
\text { AS } 3700 .\end{array}$ & $\begin{array}{l}\text { Information given on thermal } \\
\text { elongation and shrinkage, specific } \\
\text { heat capacity, thermal conductivity, } \\
\text { density, and emissivity. }\end{array}$ & & No specific reference & $\begin{array}{l}\text { N/A- } 7974 \text { provides } \\
\text { information that is more } \\
\text { related to thermal properties } \\
\text { rather than structural design. } \\
\text { IFEG appreciates that there is } \\
\text { not much guidance available } \\
\text { but still references a national } \\
\text { standard for some guidance. }\end{array}$ \\
\hline $\begin{array}{l}\text { Lightweight } \\
\text { Timber/ Steel } \\
\text { Frame } \\
\text { Assemblies }\end{array}$ & $\begin{array}{l}\text { References given to thermal } \\
\text { calculations on lightweight } \\
\text { timber walls performed by } \\
\text { Clancy (1999), Collier (1996) } \\
\text { and other. Lightweight steel } \\
\text { frame guidance is referenced } \\
\text { to Gerlich et al. }\end{array}$ & $\begin{array}{l}\text { General description on the fire } \\
\text { performance of these constructions. } \\
\text { The structural performance is } \\
\text { referenced to BS } 5268 \text {. }\end{array}$ & & No specific reference & $\begin{array}{l}\text { N/A- IFEG does not provide } \\
\text { any data or practical guidance } \\
\text { but refers to a number of } \\
\text { sources. }\end{array}$ \\
\hline Plastics & No information given. & $\begin{array}{l}\text { Information given on thermal } \\
\text { elongation and shrinkage, specific } \\
\text { heat capacity, thermal conductivity, } \\
\text { density, and emissivity. }\end{array}$ & & No specific reference & $\begin{array}{l}\text { N/A- } 7974 \text { provides more } \\
\text { information, mostly on the } \\
\text { thermal properties but some } \\
\text { also on structural } \\
\text { performance. }\end{array}$ \\
\hline Aluminum & No information given. & $\begin{array}{l}\text { Information given on thermal } \\
\text { elongation and shrinkage, specific } \\
\text { heat capacity, thermal conductivity, } \\
\text { density, and emissivity. Some } \\
\text { guidance on structural stress } \\
\text { behavior in raised temperatures. }\end{array}$ & & No specific reference & $\begin{array}{l}\text { N/A- } 7974 \text { provides more } \\
\text { information }\end{array}$ \\
\hline
\end{tabular}


Subsystem 4 - fire detection - components

\begin{tabular}{|c|c|c|c|c|c|}
\hline & IFEG & BS 7974 & SFPE & ISO 13387 & Comments \\
\hline General & & $\begin{array}{l}\text { Extensive references to BS } 5839 \text { and } \\
\text { BS EN } 54\end{array}$ & NFPA 72 is referred to & $\begin{array}{l}\text { The correct type of detection system } \\
\text { is essential because large numbers of } \\
\text { false alarms can lead to situation } \\
\text { where the alarm is ignored by many } \\
\text { or all. Refers to: } \\
\text { - Fire Suppression and Detection } \\
\text { Systems (Bryan) } \\
\text { - Detector Environment and } \\
\text { Detector Response: } \text { A Survey } \\
\text { (Holmstedt) } \\
\text { - Design of Detection Systems (SFPE } \\
\text { Handbook) }\end{array}$ & Different \\
\hline \multirow[t]{4}{*}{$\begin{array}{l}\text { Smoke } \\
\text { Detectors }\end{array}$} & $\begin{array}{l}\text { Two models mentioned: Optical } \\
\text { density and Heat detector } \\
\text { equivalence }\end{array}$ & $\begin{array}{l}\text { Mentions the research performed } \\
\text { regarding the temperature rise } \\
\text { needed to activate a smoke detector. }\end{array}$ & $\begin{array}{l}\text { Methodology for } \\
\text { Evaluation of the } \\
\text { Achievement of Smoke } \\
\text { Development } \\
\text { Performance Criteria. } \\
\text { Figure } 10-7\end{array}$ & $\begin{array}{l}\text { Refers to: } \\
\text { - Design of Detection Systems (SFPE } \\
\text { Handbook) } \\
\text { - Fire Detection Modeling. State of } \\
\text { the Art } \\
\text { - Smoke Production and Properties } \\
\text { (SFPE Handbook) } \\
\text { - Modified Theory for the } \\
\text { Characterization of Ionization } \\
\text { Smoke Detectors (Newman) }\end{array}$ & $\begin{array}{l}\text { IFEG and } 7974 \text { are identical. } \\
\text { SFPE provides a design tree }\end{array}$ \\
\hline & $\begin{array}{l}\text { Smoke detectors are assumed to } \\
\text { activate when the temperature is } \\
\text { raised } 13^{\circ} \mathrm{C} \text { above ambient } \\
\text { (Heskestad 1981). }\end{array}$ & $13^{\circ} \mathrm{C}$ above ambient is mentioned & $\begin{array}{l}\text { A method for } \\
\text { estimating the detector } \\
\text { activation time is given } \\
\text { in Figure 10-5 }\end{array}$ & & \\
\hline & \multirow[t]{2}{*}{$\begin{array}{l}\text { For the optical density detection } \\
\text { model only brief information is } \\
\text { provided, and a simple } \\
\text { correlation between light } \\
\text { depletion and detector threshold. } \\
\text { It is stated that calculations of the } \\
\text { optical density should be } \\
\text { performed for the plume or } \\
\text { preferably the ceiling jet. }\end{array}$} & $\begin{array}{l}\text { For flaming fires, DD } 240-1 \text { is } \\
\text { referenced for the equation showed } \\
\text { for smoke detector activation time. It } \\
\text { does also require the detectors } \\
\text { specific sensing threshold. Point-type } \\
\text { smoke detectors need a surrounding } \\
\text { air velocity of at least } 0.15 \mathrm{~m} / \mathrm{s} \text { to be } \\
\text { able to detect fire. }\end{array}$ & & $\begin{array}{l}\text { Photoelectric detectors depend on: } \\
\text { - The time to reach a given smoke } \\
\text { density at the location of the } \\
\text { detector } \\
\text { - The possible time lag due to the } \\
\text { delay in smoke entering into the } \\
\text { detector } \\
\text { - The possible time lag due to the } \\
\text { response of the sensor to smoke } \\
\text { inside the detector } \\
\text { Refers to: } \\
\text { - NFPA } 72 \text { : National Fire Alarm Code } \\
\text { - Design of Detection Systems (SFPE } \\
\text { Handbook) } \\
\text { - Fire Detection Modeling. State of } \\
\text { the Art }\end{array}$ & \multirow[t]{2}{*}{$\begin{array}{l}\text { Dissimilar, but not } \\
\text { contradicting. IFEG does not } \\
\text { really provide any calculations } \\
\text { on the activation of smoke } \\
\text { detectors. } 7974 \text { provides } \\
\text { more practical information, } \\
\text { especially on the heat } \\
\text { detector equivalence. }\end{array}$} \\
\hline & & $\begin{array}{l}\text { For non-flaming fires alternative } \\
\text { method will have to be sought. }\end{array}$ & & & \\
\hline
\end{tabular}


Subsystem 4 - fire detection - components

\begin{tabular}{|c|c|c|c|c|c|}
\hline & IFEG & BS 7974 & SFPE & ISO 13387 & Comments \\
\hline \multirow[t]{3}{*}{ Heat Detectors } & The concept of RTI is described. & The concept of RTI is described. & $\begin{array}{l}\text { Refers to } \\
\text { - "Design of Detection } \\
\text { Systems" (Schifiliti, } \\
\text { Meacham, and } \\
\text { Custer) in SFPE } \\
\text { Handbook }\end{array}$ & $\begin{array}{l}\text { Describes RTI and the conductivity } \\
\text { factor (c). Refers to Annex B and } \\
\text { Quantification of Thermal } \\
\text { Responsiveness of Automatic } \\
\text { Sprinklers Including Conduction } \\
\text { Effects (Heskestad). }\end{array}$ & $\begin{array}{l}\text { IFEG and } 7974 \text { are identical. } \\
\text { SFPE refers to another } \\
\text { document }\end{array}$ \\
\hline & \multirow{2}{*}{$\begin{array}{l}\text { Alpert (1972) ceiling jet model for } \\
\text { gas temperature and gas velocity } \\
\text { predictions. Additional equations } \\
\text { shown for special applications } \\
\text { such as high ceiling or partially } \\
\text { confined ceilings. These are } \\
\text { referenced to NFPA 92B. }\end{array}$} & $\begin{array}{l}\text { BS EN 54-5 is referenced for tables } \\
\text { showing detector response times. }\end{array}$ & & & \multirow{2}{*}{$\begin{array}{l}\text { Dissimilar, but not } \\
\text { contradicting. It should be } \\
\text { noted that the equations } \\
\text { shown for heat detector } \\
\text { activation are quite dissimilar, } \\
\text { it is however hard to } \\
\text { determine how much of an } \\
\text { impact this has on the } \\
\text { estimation of activation time. }\end{array}$} \\
\hline & & $\begin{array}{l}\text { Quinter et al. (1982) model for temp. } \\
\text { rise in the hot layer. This is suggested } \\
\text { as a worst case scenario for } \\
\text { combined fixed-temperature/heat- } \\
\text { rise detectors. Qualitative } \\
\text { commentary on cases where smoke } \\
\text { spread is confined by beams and } \\
\text { narrow corridors etc. }\end{array}$ & & & \\
\hline Beam Detectors & $\begin{array}{l}\text { An unreferenced equation is } \\
\text { shown for the optical density } \\
\text { required to cause activation of a } \\
\text { beam detector. }\end{array}$ & $\begin{array}{l}\text { A relationship for the obscuration is } \\
\text { shown. This is referenced to an EN } \\
\text { standard in draft. EN 54-12. }\end{array}$ & & $\begin{array}{l}\text { Operates on a light obscuration } \\
\text { principle. For information on } \\
\text { engineering evaluation of the } \\
\text { performance and response time of } \\
\text { light obscuration detector systems } \\
\text { refers to: } \\
\text { - Design of Detection Systems (SFPE } \\
\text { Handbook) } \\
\text { - Quantification of Thermal } \\
\text { Responsiveness of Automatic } \\
\text { Sprinklers Including Conduction } \\
\text { Effects (Heskestad). }\end{array}$ & $\begin{array}{l}\text { IFEG and } 7974 \text { are similar- The } \\
\text { equations shown are almost } \\
\text { the same, but they differ by a } \\
\text { factor } 10 \text {. One would think } \\
\text { that } 7974 \text { would therefore be } \\
\text { expressed in bel rather than } \\
\text { decibel, but this does not } \\
\text { seem to be the case. It is } \\
\text { therefore unclear if the } \\
\text { references used in the two } \\
\text { guides are interchangeable. }\end{array}$ \\
\hline \multirow[t]{2}{*}{$\begin{array}{l}\text { Aspirating } \\
\text { Detectors }\end{array}$} & $\begin{array}{l}\text { Manufacturers specifications and } \\
\text { SS-B "smoke development and } \\
\text { control" parameters. }\end{array}$ & $\begin{array}{l}\text { British Fire Protection Systems } \\
\text { Association "COP for Category } 1 \\
\text { Aspirating Detection Systems" (1996) } \\
\text { is referenced for information. }\end{array}$ & & & $\mathrm{N} / \mathrm{A}$ \\
\hline & $\begin{array}{l}\text { Each sampling point can be } \\
\text { modeled as an individual point } \\
\text { detector. Lon detection time } \\
\text { delays in large systems. }\end{array}$ & $\begin{array}{l}\text { When considering location of smoke } \\
\text { sampling points, the best analogy is } \\
\text { to consider them as individual point } \\
\text { detectors. Long detection time } \\
\text { delays in large systems. }\end{array}$ & & & IFEG and 7974 are identical \\
\hline
\end{tabular}


Subsystem 4 - fire detection - components

\begin{tabular}{|c|c|c|c|c|c|}
\hline & IFEG & BS 7974 & SFPE & ISO 13387 & Comments \\
\hline $\begin{array}{l}\text { Linear Heat } \\
\text { Detectors }\end{array}$ & No information. & $\begin{array}{l}\text { A brief discussion of the applicability } \\
\text { of linear detectors. The most } \\
\text { practical way of assessing their } \\
\text { performance is recommended to be } \\
\text { by regarding them as a continuous } \\
\text { line of heat detectors. }\end{array}$ & & $\begin{array}{l}\text { Thermal point or line detectors are } \\
\text { best suited to situation where cost } \\
\text { and reliability are overriding factors. } \\
\text { Response can be modeled by } \\
\text { calculating the heat transfer taking } \\
\text { place by convection between the gas, } \\
\text { and the detector, by conduction } \\
\text { through the detector body to the } \\
\text { mounting structure and by radiation } \\
\text { to/from the surroundings. }\end{array}$ & $\begin{array}{l}\text { N/A- } 7974 \text { provides more } \\
\text { information. }\end{array}$ \\
\hline $\begin{array}{l}\text { Flame } \\
\text { Detectors }\end{array}$ & $\begin{array}{l}\text { It is recommended that normal } \\
\text { radiation and view factor } \\
\text { equations should be utilized to } \\
\text { calculate the radiation impinged } \\
\text { on the detector. }\end{array}$ & $\begin{array}{l}\text { SFPE handbook relationship for the } \\
\text { level of radiation impinged on the } \\
\text { detector. The SFPE refers to standard } \\
\text { curves for fire size and distance. The } \\
\text { BS EN 54-10 standard is mentioned. }\end{array}$ & & & $\begin{array}{l}\text { Dissimilar, but not } \\
\text { contradicting. } 7974 \text { provides } \\
\text { quantitative guidance. }\end{array}$ \\
\hline Gas Detectors & $\begin{array}{l}\text { No acceptable methodology } \\
\text { available for detection times. }\end{array}$ & $\begin{array}{l}\text { Carbon monoxide detectors } \\
\text { mentioned, with a relationship for } \\
\text { the mass flow of } \mathrm{CO} \text { as a function of } \\
\text { total mass flow. A threshold value of } \\
40 \mathrm{ppm} \text { is mentioned. }\end{array}$ & & & $\begin{array}{l}\text { N/A- } 7974 \text { provides more } \\
\text { information. }\end{array}$ \\
\hline $\begin{array}{l}\text { Manual } \\
\text { Detection }\end{array}$ & No information. & $\begin{array}{l}\text { It is recognized that citing and } \\
\text { spacing of detectors to a standard } \\
\text { template (BS } 5839-1 \text { mentioned). Is } \\
\text { not likely to provide the optimum } \\
\text { performance and that engineered } \\
\text { layouts can provide a more effective } \\
\text { system. }\end{array}$ & $\begin{array}{l}\text { The following } \\
\text { document was referred } \\
\text { to: } \\
\text { NFPA 72, National Fire } \\
\text { Alarm Code. Appendix B }\end{array}$ & & $\begin{array}{l}\text { N/A- } 7974 \text { provides more } \\
\text { information. }\end{array}$ \\
\hline $\begin{array}{l}\text { Spacing of } \\
\text { Detectors }\end{array}$ & No information given. & $\begin{array}{l}\text { Evans (1993) NIST relationship } \\
\text { between heat release and spray } \\
\text { density. This is presented as a } \\
\text { conservative estimate. BS } 5306-2 \text { is } \\
\text { referred to for engineering guidance. }\end{array}$ & & $\begin{array}{l}\text { Refers to: } \\
\text { - NFPA 72: National Fire Alarm Code } \\
\text { - Fire Suppression and Detection } \\
\text { Systems (Bryan) } \\
\text { - Environment and Detector } \\
\text { Response: A Survey (Holmstedt, } \\
\text { Magnusson, Thomas) } \\
\text { - Quantification of Thermal } \\
\text { Responsiveness of Automatic } \\
\text { Sprinklers Including Conduction } \\
\text { Effects (Heskestad). } \\
\text { - Calculate the Response Time of } \\
\text { Heat and Smoke Detectors } \\
\text { Installed Below Large Unobstructed } \\
\text { Ceilings (Evans, Stroup) }\end{array}$ & N/A \\
\hline
\end{tabular}


Subsystem 4 - fire suppression

\begin{tabular}{|c|c|c|c|c|c|}
\hline & IFEG & BS 7974 & SFPE & ISO 13387 & Comments \\
\hline Sprinklers & $\begin{array}{l}\text { Madrzykowski and Vittori } \\
\text { (1992) relationship for heat } \\
\text { release after sprinkler } \\
\text { initiation. Evans (1993) NIST } \\
\text { relationship between spray } \\
\text { density and heat release. An } \\
\text { extended radius is } \\
\text { recommended to incorporate } \\
\text { a degree of conservatism in } \\
\text { the detection time equations. }\end{array}$ & $\begin{array}{l}\text { General discussion on the } \\
\text { subject. Reference to NFPA } \\
750 \text { for more information. }\end{array}$ & $\begin{array}{l}\text { Adjustment to HRR curve are } \\
\text { discussed in } 9.5 .3\end{array}$ & $\begin{array}{l}\text { Water: Details on how to design a wet system } \\
\text { references } \\
\text { - Hydraulics(SFPE Handbook) } \\
\text { - Automatic Sprinkler System Calculations (SFPE } \\
\text { Handbook) } \\
\text { - Suppression (FP Handbook) } \\
\text { Dry: Activation time is equal to the time it takes } \\
\text { to expel system air. It should be equal to the } \\
\text { longest time for suppression agent to expel air } \\
\text { through the agent outlet at the furthest point } \\
\text { from the system control valve. }\end{array}$ & $\begin{array}{l}\text { IFEG and } 7974 \text { are similar. } \\
\text { SFPE discusses how the } \\
\text { HRR curve may change }\end{array}$ \\
\hline Water Mist & $\begin{array}{l}\text { Referred to applicable } \\
\text { national standard. }\end{array}$ & $\begin{array}{l}\text { General discussion on the } \\
\text { subject. Reference to NFPA } \\
750 \text { for more information. }\end{array}$ & $\begin{array}{l}\text { Delay time for discharge on } \\
\text { wet pipe systems can be } \\
\text { ignored. But for dry pipe } \\
\text { systems the discharge delays } \\
\text { need to be evaluated either } \\
\text { through the SFPE Handbook } \\
\text { or software }\end{array}$ & $\begin{array}{l}\text { Activation time is equal to the time it takes for } \\
\text { suppression agent to expel air in system } \\
\text { pipework through the agent outlet in the furthest } \\
\text { point from the system control valve }\end{array}$ & $\begin{array}{l}\text { N/A- } 7974 \text { provides more } \\
\text { information, mostly } \\
\text { qualitative but with some } \\
\text { guidance on high, low, or } \\
\text { medium pressure systems. }\end{array}$ \\
\hline $\begin{array}{l}\text { Gaseous } \\
\text { Suppression } \\
\text { System }\end{array}$ & $\begin{array}{l}\text { Referred to applicable } \\
\text { national standard. }\end{array}$ & $\begin{array}{l}\text { General discussion on the } \\
\text { subject. Reference to BS } \\
\text { ISO } 14520 \text { for more } \\
\text { information. }\end{array}$ & & $\begin{array}{l}\text { The literature is referred to for detailed } \\
\text { information on the engineering design of such } \\
\text { systems to minimize activation times } \\
\text { - Halon Design Calculations (SFPE Handbook) } \\
\text { - Halon Replacement Clean Agent Total Flooding } \\
\text { Systems (SFPE Handbook) } \\
\text { - Carbon Dioxide and Application Systems (FP } \\
\text { Handbook) } \\
\text { - Halogenated Agents and Systems (FP } \\
\text { - Handbook) } \\
\text {-Self-Heating and Spontaneous Combustion" } \\
\text { - Self-heating - Evaluating and Controlling the } \\
\text { - Hazards (Bowes) } \\
\text { "Calorimetry" SFPE Handbook (Janssens) }\end{array}$ & $\begin{array}{l}\text { N/A- } 7974 \text { provides more } \\
\text { information, such as the } \\
\text { impact of fire growth. }\end{array}$ \\
\hline Foam System & No information given. & $\begin{array}{l}\text { General discussion on the } \\
\text { subject. Reference to SFPE } \\
\text { handbook for more } \\
\text { information. }\end{array}$ & & $\begin{array}{l}\text { The literature is referred to for details of the } \\
\text { design process } \\
\text { - Foam Agents and AFFF System Design } \\
\text { Considerations (SFPE Handbook) } \\
\text { - Foam System Calculations (SFPE Handbook) } \\
\text { - Foam Extinguishing Agents and Systems (FP } \\
\text { Handbook) }\end{array}$ & $\begin{array}{l}\text { N/A- } 7974 \text { provides more } \\
\text { information, such as the } \\
\text { impact of fire growth. }\end{array}$ \\
\hline
\end{tabular}


Subsystem 4-smoke management and exhaust systems

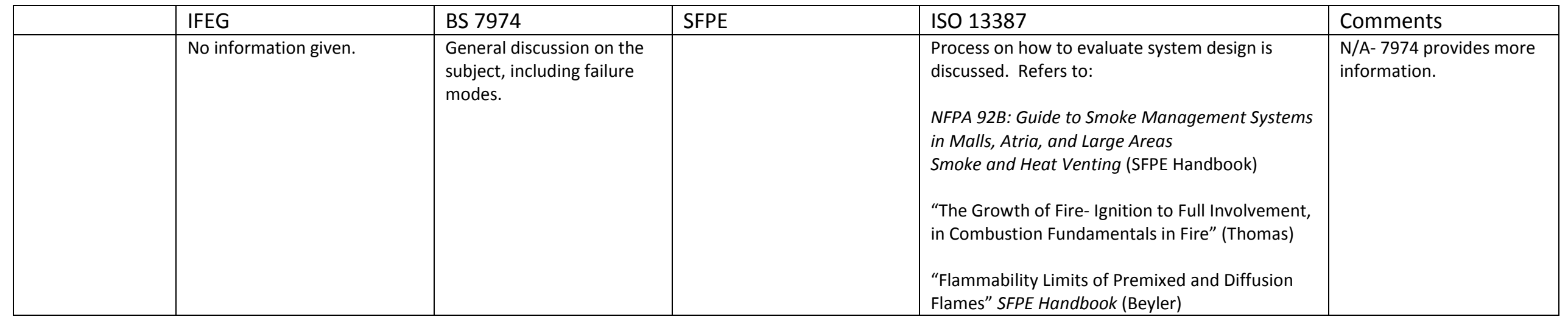


Subsystem $\mathbf{5}$ - fire service intervention

\begin{tabular}{|c|c|c|c|c|c|}
\hline & IFEG & BS 7974 & SFPE & ISO 13387 & Comments \\
\hline \multirow[t]{4}{*}{$\begin{array}{l}\text { Fire Service } \\
\text { Intervention }\end{array}$} & $\begin{array}{l}\text { The Australian FBIM (Fire } \\
\text { Brigade Intervention Model) } \\
\text { is presented as an appropriate } \\
\text { method for quantification of } \\
\text { fire service intervention. }\end{array}$ & $\begin{array}{l}\text { The time for fire service } \\
\text { attendance is referenced to } \\
\text { the Home Office, and a table } \\
\text { of recommended time limits is } \\
\text { shown for different areas } \\
\text { depending on the areas risk } \\
\text { classification. }\end{array}$ & \multirow[t]{4}{*}{ No information given. } & \multirow[t]{4}{*}{ No information given. } & \multirow[t]{4}{*}{$\begin{array}{l}\text { NA- IFEG provides a model or a } \\
\text { framework for fire service } \\
\text { intervention. } 7974 \text { provides } \\
\text { more information, but this is } \\
\text { qualitative to a great extent. }\end{array}$} \\
\hline & $\begin{array}{l}\text { The FBIM employs a } \\
\text { structured decision-based } \\
\text { framework necessary both to } \\
\text { determine and measure fire } \\
\text { service activities on a time } \\
\text { line basis. }\end{array}$ & $\begin{array}{l}\text { The only details to support a } \\
\text { quantified analysis are the } \\
\text { recommended time limits and } \\
\text { a notation that the initiation of } \\
\text { fire tackling will take "upwards } \\
10 \text { minutes from the time of } \\
\text { arrival". }\end{array}$ & & & \\
\hline & $\begin{array}{l}\text { The fire service operation is } \\
\text { split up into } 16 \text { flowcharts. }\end{array}$ & $\begin{array}{l}\text { A detailed description of what } \\
\text { is expected of fire service } \\
\text { provisions installed in a } \\
\text { building, but their respective } \\
\text { relation to fire service } \\
\text { operations is not thoroughly } \\
\text { explained. }\end{array}$ & & & \\
\hline & $\begin{array}{l}\text { The description of the FBIM is } \\
\text { very much an overview, and } \\
\text { the IFEG does not cover any } \\
\text { technical details of fire service } \\
\text { provisions and operations. } \\
\text { The FBIM (2004) is referenced } \\
\text { for quantified estimates for } \\
\text { each flowchart. }\end{array}$ & $\begin{array}{l}\text { Very little information on } \\
\text { where the reader can find } \\
\text { more information about } \\
\text { quantified analysis of fire } \\
\text { service operations. }\end{array}$ & & & \\
\hline Summary & \multicolumn{5}{|c|}{$\begin{array}{l}\text { The IFEG effectively refers all of it recommendations to the FBIM. It also appreciates that the FBIM is a unique document as Australia is the only country that has produced such } \\
\text { an extensive quantified guide. It is also appreciated that the guidance given in FBIM is developed with Australian condition in mind, and that the guidance given in the } \\
\text { document may not be directly applicable to other countries. IT is however suggested that the quantitative guidance in FBIM can be used as a semi-quantitative utility in other } \\
\text { locations. } \\
7974-5 \text { is highly qualitative and does not provide any model for setting up a quantified model for fire service intervention. Some quantified guidance on the likely fire service } \\
\text { response times as a function of the areas UK risk category. }\end{array}$} \\
\hline
\end{tabular}


Subsystem 6 - Occupant safety

\begin{tabular}{|c|c|c|c|c|c|}
\hline & IFEG & BS 7974 & SFPE & ISO 13387 & Comments \\
\hline \multirow[t]{2}{*}{ General } & $\begin{array}{l}\text { The Required Time for } \\
\text { Escape (RSET) is } \\
\text { divided into a } \\
\text { detection phase and a } \\
\text { movement phase. }\end{array}$ & $\begin{array}{l}\text { A description of } \\
\text { Available Safe Escape } \\
\text { Time (ASET) and } \\
\text { Required Safe Escape } \\
\text { Time (RSET). }\end{array}$ & $\begin{array}{l}\text { A design tree for estimating evacuation } \\
\text { time is given in Figure } 10-6\end{array}$ & $\begin{array}{l}\text { Total time consists of } 2 \text { parts: Total Pre-Movement time } \\
\text { (sum of Pre-movement recognition time and Pre- } \\
\text { movement response time) and Movement processes } \\
\text { (estimation of time required for evacuation of } \\
\text { occupants). }\end{array}$ & \multirow{2}{*}{$\begin{array}{l}\text { N/A- The IFEG and } \\
7974 \text { are similar in } \\
\text { such that they both } \\
\text { appreciate the basic } \\
\text { model for evaluating } \\
\text { egress time, but } 7974 \\
\text { provides more } \\
\text { information in regards } \\
\text { to the different } \\
\text { parameters. } \\
\text { SFPE provides a design } \\
\text { tree for estimating } \\
\text { evacuation time and } \\
\text { refers to additional } \\
\text { documents }\end{array}$} \\
\hline & $\begin{array}{l}\text { It is recommended } \\
\text { that Fire engineered } \\
\text { Solutions should be } \\
\text { based on data in } \\
\text { publications such as } \\
\text { the SFPE handbook } \\
\text { and other scientific } \\
\text { publications. }\end{array}$ & $\begin{array}{l}\text { A quantified strategy is } \\
\text { proposed, separating } \\
\text { RSET into sub- } \\
\text { elements, and guidance } \\
\text { is given on quantified } \\
\text { values for the time } \\
\text { needed in the different } \\
\text { sub-elements. }\end{array}$ & 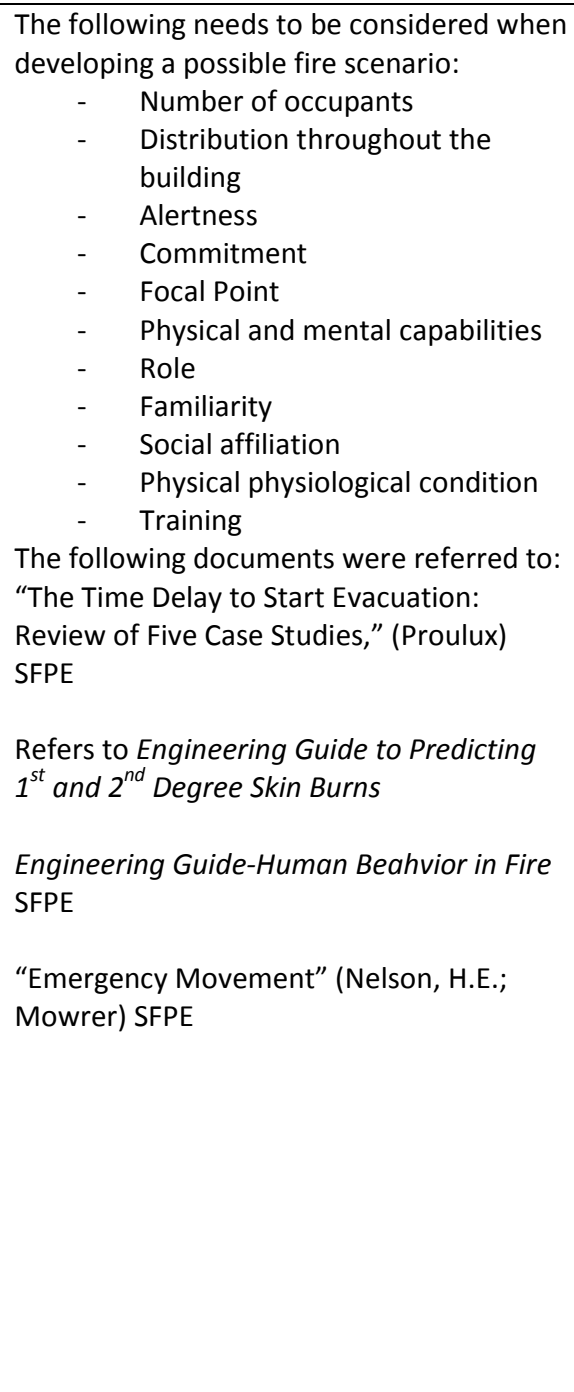 & 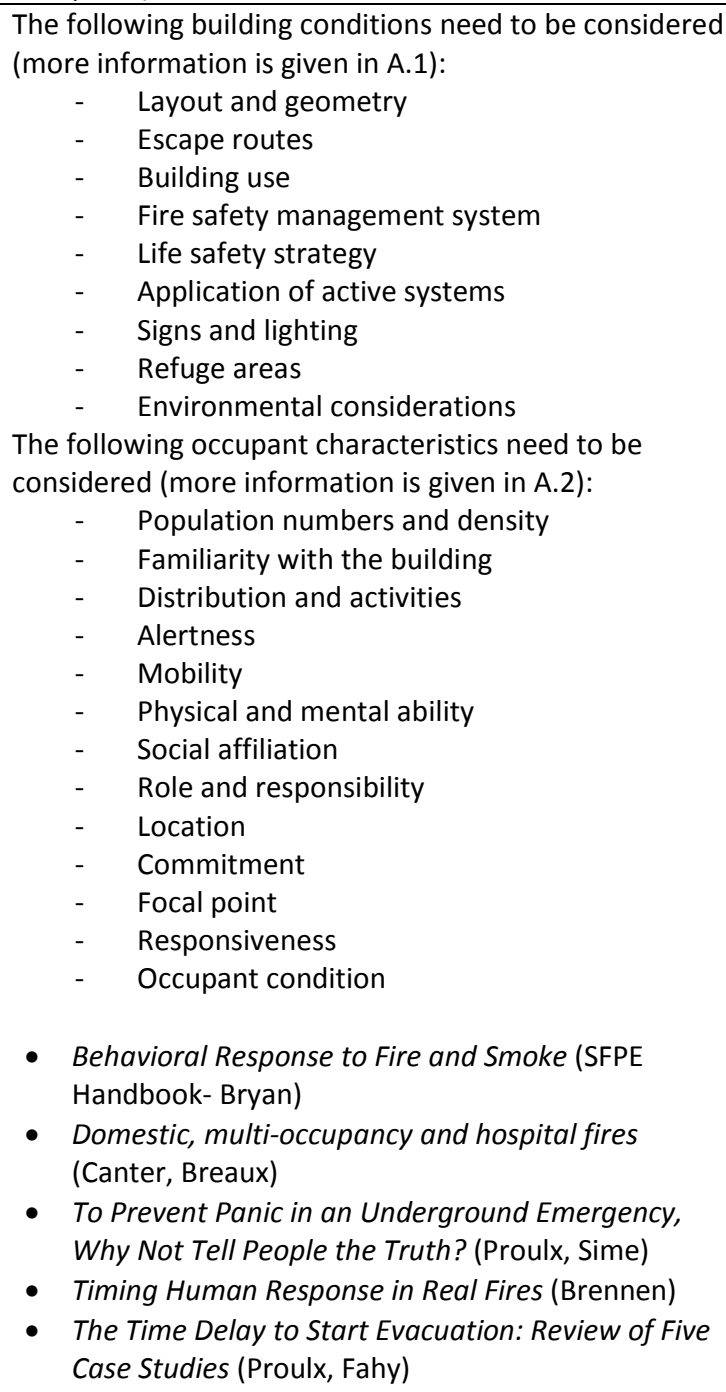 & \\
\hline
\end{tabular}


Subsystem 6 - Occupant safety

\begin{tabular}{|c|c|c|c|c|c|}
\hline & IFEG & BS 7974 & SFPE & ISO 13387 & Comments \\
\hline & $\begin{array}{l}\text { Very little quantitative } \\
\text { guidance on the sub- } \\
\text { elements of the } \\
\text { escape time. A list of } \\
\text { information sources is } \\
\text { however presented. }\end{array}$ & $\begin{array}{l}\text { Extensive quantified } \\
\text { guidance on time to } \\
\text { detection, travel } \\
\text { speeds, evacuation } \\
\text { times etc. given in } \\
\text { appendices. }\end{array}$ & $\begin{array}{l}\text { The following documents were referred to: } \\
\text { "Movement of People: The Evacuation } \\
\text { Timing" (Proulx) SFPE } \\
\text { Combustion Products and Their Effect on } \\
\text { Life Safety (Hartzell) FPH }\end{array}$ & $\begin{array}{l}\text { Also need to consider } \\
\text { - } \quad \text { Fire alarms and cues available to occupants } \\
\text { - } \quad \text { Fire size and extent, smoke density, toxic gas } \\
\text { concentrations, temperature and heat flux in } \\
\text { all building enclosures, activation of } \\
\text { suppression and smoke control systems. }\end{array}$ & \\
\hline & $\begin{array}{l}\text { A model for travel } \\
\text { times is referenced to } \\
\text { Nelson \& Mowrers' } \\
\text { work presented in the } \\
\text { SFPE handbook. }\end{array}$ & $\begin{array}{l}\text { A tenability criterion is } \\
\text { given for zero } \\
\text { exposure. This is given } \\
\text { as a clear layer height } \\
\text { of } 2.5 \mathrm{~m} \text { and a smoke } \\
\text { layer temperature not } \\
\text { exceeding } 200^{\circ} \mathrm{C} \text {. }\end{array}$ & $\begin{array}{l}\text { The following document was referred to: } \\
\text { "Behavioral Response to Fire and Smoke" } \\
\text { (Bryan, J.L.) }\end{array}$ & $\begin{array}{l}\text { A limit for exposure of skin to radiant heat is given as } \\
\text { approximately } 2.5 \mathrm{~kW} / \mathrm{m}^{2} \text {. An expression for } \\
\text { calculating tolerance time is given in ISO } 13571 . \\
\text { Information on exposure to smoke is referenced to } \\
\text { Visibility through Fire Smoke, Part } 5 \text { (Jin) and ISO } 13571 . \\
\text { Evaluation of irritant toxic gases is referenced to } \\
\text { Toxicity Assessment of Combustion Products (Purser) } \\
\text { and ISO } 13571 . \\
\text { Information on asphyxiant toxic gases Toxicity } \\
\text { Assessment of Combustion Products (Purser), } \\
\text { Combustion Products and Their Effects on Life Safety } \\
\text { (Hartzell), Behavioral Impairment in Smoke } \\
\text { Environments (Purser) are referenced and ISO } 13571\end{array}$ & \\
\hline Summary & \multicolumn{5}{|c|}{$\begin{array}{l}\text { The IFEG provides only qualitative guidance and refers extensively to other sources for guidance on several subjects in regards to evacuation. } \\
7974 \text { provides a mainly qualitative commentary on many different aspects of evacuation times and evacuation behavior. Some quantified guidance is provided, most of the figures } \\
\text { originates and relates from the UK. The SFPE provides some design trees for analysis but, like the IFEG, it mainly refers to other documents for additional information }\end{array}$} \\
\hline
\end{tabular}


Subsystem 7 - Risk assessment

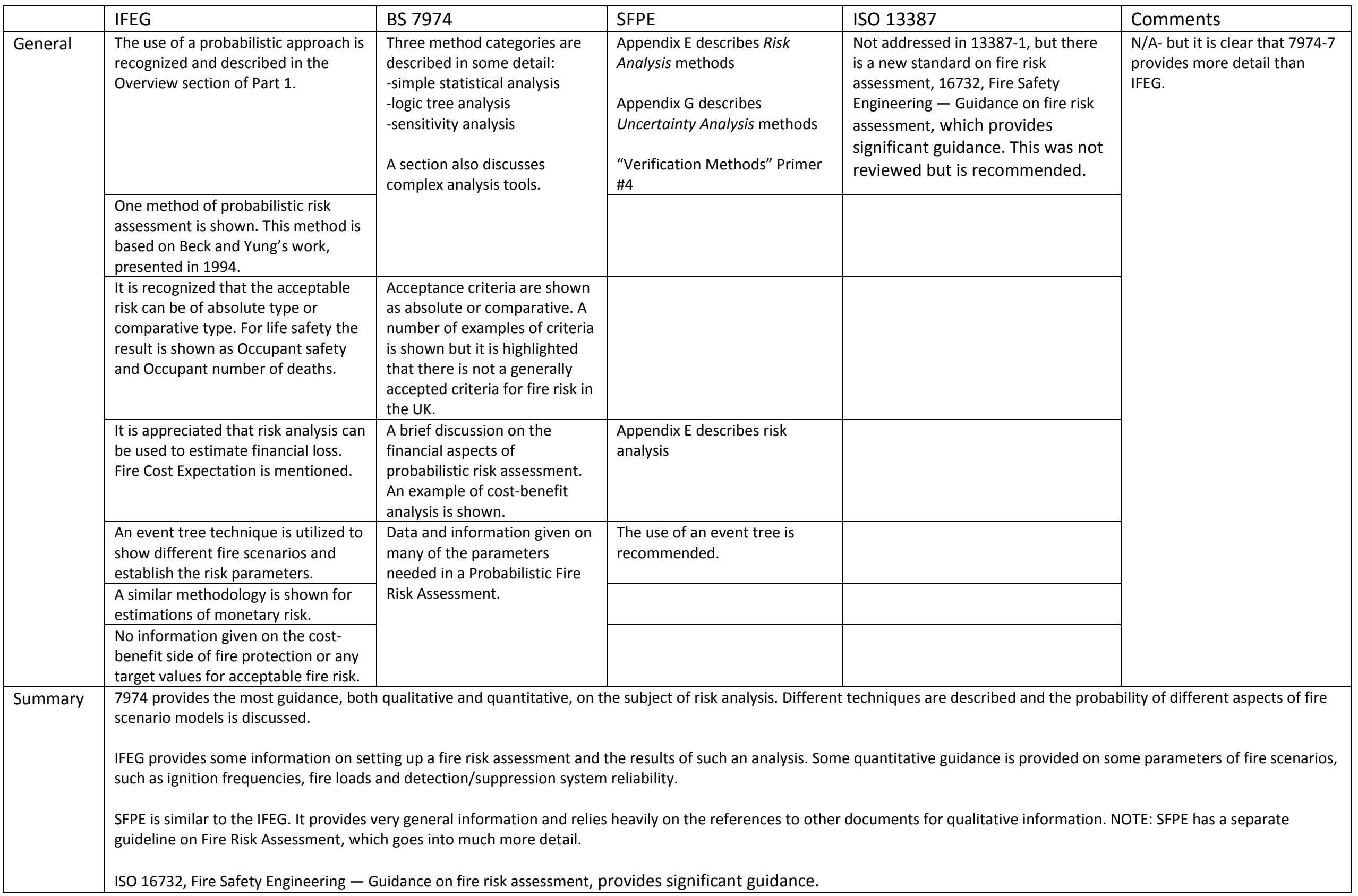




\section{Annex C}

Using A Systems Approach to Assess How Disruptive Events Affect Building Overall Performance 


\title{
Using A Systems Approach to Assess How Disruptive Events Affect Building Overall Performance ${ }^{\text {a }}$
}

\author{
Alvarez-Rodriquez, A. ${ }^{\mathrm{i}, *}$, Meacham, B. J., ${ }^{\text {ii }}$ Dembsey, N.A. ${ }^{\text {ii }}$ Thomas, J.R. ${ }^{\text {iii }}$ \\ ${ }^{\mathrm{i} A O N}$ Fire Protection Engineering, Lincolnshire, IL, USA \\ ${ }^{\mathrm{ii}}$ Department of Protection Engineering, Worcester Polytechnic Institute, Worcester, MA, USA

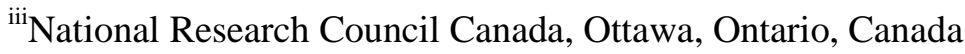 \\ *corresponding author: alberto.alvarez-rodriguez@aon.com
}

\begin{abstract}
A building project implies the participation of different groups of stakeholders, including contractors, building owners and users, architects, engineers, and the authority having jurisdiction which approves the construction and the use of the project. The concept of performance-based design has been used for decades, although it has implied setting different objectives for each of these groups according to their mandates. The overall building performance depends on the interrelations between the different building components such as the architectural system, the interior environment system, and components used for emergency situations. This article focuses on how events such as fires or any other emergency situations can affect the performance of buildings during such events, particularly considering how the actual use of a building might vary from design phase assumptions to post occupancy conditions, and how ignoring such factors may lead eventually to some emergency components being misused by the building occupants or used in unintended ways. To address these concerns, a risk-informed performance-based design process has been developed within a new building performance paradigm, organized around systems formed by the coupling of specific building types, the activities being undertaken in the buildings and the building occupants (building-occupant systems).
\end{abstract}

Keywords: Building performance; performance-based fire protection design; fire safety engineering; systems approach

\section{Introduction}

While a wide range of definitions and criteria exist in the literature, it is suggested that main drivers for application of performance-based design (PBD) include demands from stakeholders for better building performance in use across a wide range of stakeholder expectations, in conjunction with a changes in legislation allow a broader use of engineered options instead of simply fulfilling prescriptive requirements. Within a PBD framework, the demand of the "end users" of the building (i.e. building occupants) become priorities [1] so that PBD provides a more "client" oriented process [2] than the one used when following building code regulations.

\footnotetext{
${ }^{\text {a }}$ Unpublished manuscript, to be submitted for peer review.
} 
Conceptually, a PBD approach can be applied to all the components of a building project, including among others, acoustics, aesthetics, operability, sustainability, and safety. It involves numerous actors, including on one hand the building users who should define the level of performance of the building, and on the other hand, the building industry which should create optimal solutions in order to achieve this level of performance within a regulatory framework established by policy makers.

Because of the complexity of the engineering thinking related to these building components, PBD guidance has been (a) segmented such that each engineering discipline has to consider separately how clients' objectives connected with each of the building components should be achieved, and (b) 'genericized' to accommodate multiple solutions. This applies not only to design of building components dedicated to the normal use of the building (e.g., mechanical components including heating, ventilation, and air conditioning (HVAC) and plumbing) but it also to building components installed to address disruptive events, such as fires, earthquakes, or any type of emergencies susceptible to affect the safety of building occupants or damage the building contents and structure. As such, while PBD guidance has thus far been elaborated to treat discipline-specific 'normal' building performance (e.g., energy, HVAC, etc.) and specific safety objectives (e.g. fire [3] and earthquakes [4]) those conducting analyses must have specialized expertise, and there is little integration across or between disciplines.

However, in practice, the building end users are not really interested in the performance of individual building components and systems, but rather, the performance of the building as a whole [5]. To achieve this, the design team is expected to address the multitude of building components and systems and have them co-operate in order to achieve this seamless daily performance [6] for both normal use and during and after disruptive events. This does not always occur as well as would be hoped.

The research presented in this article originated from a review of decades of worldwide experience of the performance-based option for fire protection design, which identified shortcomings in the interpretation, application and implementation of performance-based fire protection design (PBFPD) processes [7]. It was observed that the aim of these processes is centered on the design of fire protection measures, and not building performance. As a result, the application of current PBFPD processes may lead to the possibility that these measures, deemed appropriate at the building design stage, might be ignored or worse "rejected" by the building end users when needed the most. By looking at performance-based approaches used to deal with earthquakes [4], it was realized that this observation can be generalized to any disruptive event and mitigation strategies. To address these challenges, a new paradigm for building performance was developed around the concept of 'building-occupant' systems, for which a new risk-informed, performance-based analysis and design approach was structured. This paper presents the outcomes of the research, specifically related to the treatment of disruptive events on the overall performance of a building project, using fire as an example:

- First, a system formed by specific building types and their associated occupants is defined, so as to characterize the nature of disruptive events and theirs effects on the overall performance of that system;

- Second, within this system paradigm, a risk informed performance-based design process is established, with the aim that this process would be applicable to any disruptive event and include a step evaluating the integration of the protection measures into the considered system. 


\section{Decrease of the building performance during a disruptive event}

Primary stakeholders in a building project, including the building owner and the potential end users, generally define building performance objectives in terms of the everyday uses of the building. For a hospital, this performance is mainly related to the type of treatments offered, the number of patients who can be treated, the types of equipment and services needed to treat patients. For a school, this performance is primarily related to delivering education to the specific student populations, the number of registered students, the numbers and qualification of teachers or faculty required to deliver education. For a museum, it is mainly related to its exhibits and holdings in terms of circulation and storage, security and controlled environment and then to the number of exhibition attendees who can be accommodated [28]. We call these specific coupling of building use and user performance expectations 'building-occupant' systems (see more detailed discussion later in the paper). Unfortunately, while designing or operating a building, the primary stakeholders of the building do not always think about all the possible, often low frequency events, that may affect the daily performance of the building, either at the level of a specific building-occupant system, or as part of a larger social or economic system.

At a generic level, the nature of disruptive events which could affect the daily performance of a buildingoccupant system on its own or as part of a larger social or economic system can vary significantly, including [8]:

- supplier business disruption leading to operational vulnerabilities,

- fires originated inside or outside a building, earthquakes, severe weather, accidents or terrorism leading to hazard vulnerabilities,

- currency exchange fluctuations leading to financial vulnerabilities,

- new competition leading to strategic vulnerabilities.

We focus here on as specific part of the problem: disruptive events for which building components could be designed so to mitigate the effects of these events, such as natural and technological hazards. Such disruptive events can significantly impact the operation of a building and the mission it supports at the building-occupant system level or at a broader social or economic system level. If the building owner and other key actors are unprepared, the disruptive event can have catastrophic effects on continued operations [9]. Because PBFPD processes have been developed for decades, this article focuses on fires as an example of a class of disruptive events.

\section{Characterization of a disruptive event affecting the performance of a building}

To show the importance of considering potential impacts on a building to be analyzed, as part of a larger social or economic system network, let us describe the events that started with a small fire in a manufacturing plant in USA and ended up with a US\$2.34 billion loss for one of the plant's clients. This example is taken from Sheffi's book "The Resilient Enterprise" [8]. On March 17, 2000, lighting struck the industrial plant of Philips NV, located in Albuquerque, New Mexico, USA. As a consequence a small fire started within the facility but was extinguished by sprinklers and staff in less than 10 minutes. There were no injuries and the fire fighters arrived at the plant just to record a minor blaze. From a fire protection engineering design perspective this could be considered a success, with systems operating as intended. However, due to ensuing activities, the damage to the plant contents and disruption to the plant activity was tremendous. So why was the disruption so significant? 
First, the plant was engaged in manufacturing of semiconductor chips for some 30 clients, including the mobile phones companies Nokia and Ericsson, whose orders accounted for 40 percent of the Albuquerque plant's production. Indeed, a semiconductor manufacturing facility such as this cannot tolerate any dirt or particulate in normal activities, in any of its clean rooms, much less soot in case of a fire. Not only did the fire destroy the chip batches in the furnace (with an equivalent of thousands of mobile phone production) but also smoke, soot and the tramping of staff and fire fighters from the fire scene (in the mix of dirt and water) contaminated chips at every stage of the production, increasing that loss to millions of mobile phone chips. The losses for Philips did not stop at the ones related to property damage. Removing the dirt from the clean rooms implied that the production would be back up after one week. This was the Philips estimation right after the fire, but two weeks later, Philips staff realized that the disruption caused by the fire would take weeks before production could restart. When two of the main clients of Philips, Nokia and Ericsson received the call from Philips on March 20, they each dealt differently with this situation, which ended up with two very different business outcomes. ${ }^{1}$ Figure 1 illustrates the profile of the aforementioned Philips fire, adapted from [8]. Prior to the fire, the plant is performing at a certain level, i.e. it is manufacturing (x) chips for its clients. The disruptive event occurs and the performance of the plant decreases, leading to a full impact of a completely stopped production. In our case, the performance of the plant went down to zero for weeks. The full impact was the sum of the direct consequence of the fire (damage to the furnace and smoke spread) and of the indirect consequence of the fire fighting operations (staff and fire fighters walking all around the plant and contaminating all the remaining furnaces). The recovery time was not the expected one week but several weeks. A long term impact was observed, as Nokia engineers sent to the Philips plant in the recovery phase ended up with increasing the pre-event production rate.

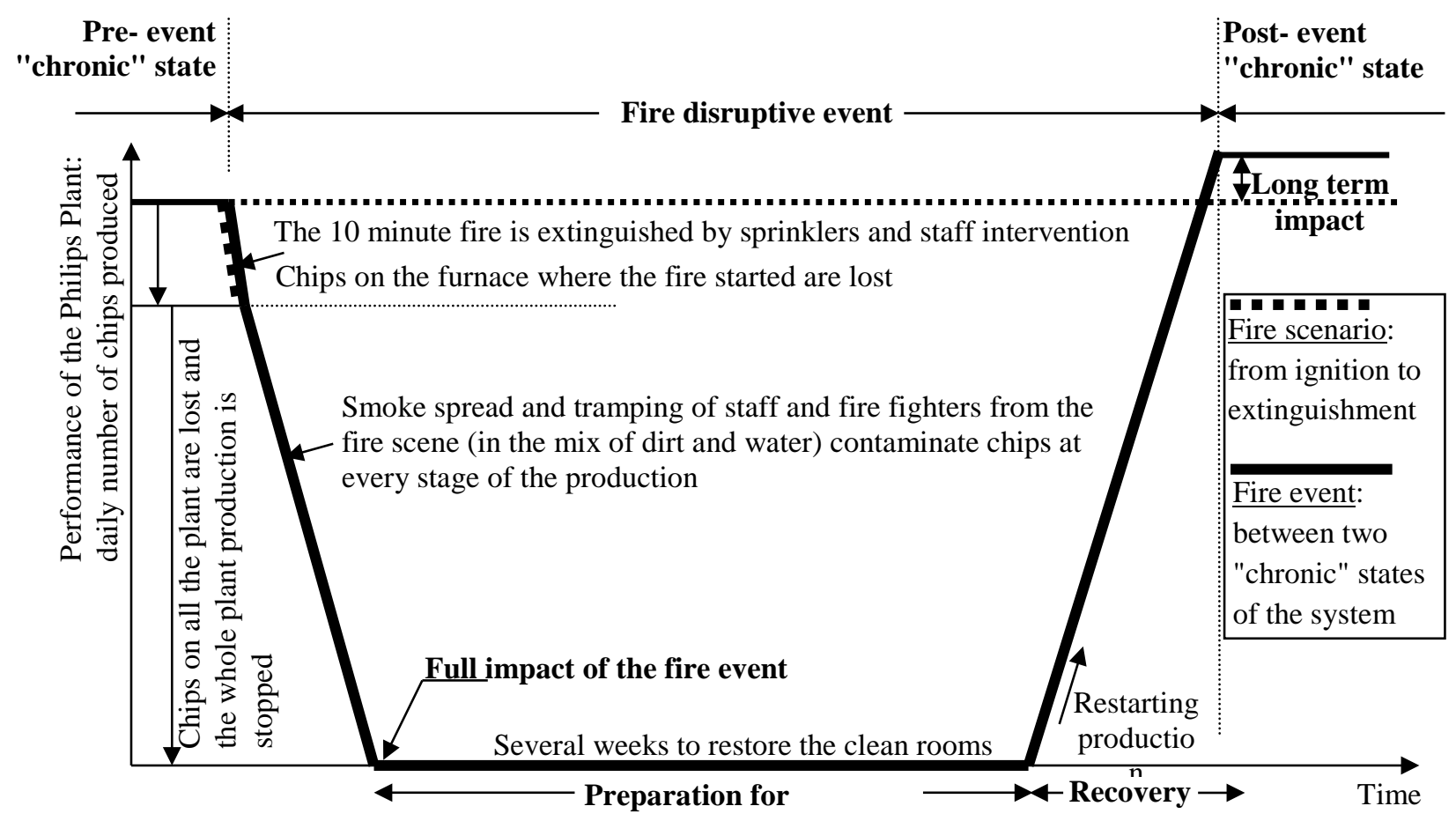

Figure 1 "Disruptive event" profile of the Philips Plant fire, adapted from [8] 
For the authority having jurisdiction (AHJ) approving the use of the plant, the life safety objective was not compromised. Related to fire safety, the plant could have been "code compliant" or designed to perform as well as a building provided with regulatory requirements. With regard to property protection objectives, the fire did not lead to severe damage of the production line in itself, but it contaminated all the production (with the involuntary help of the staff and fire fighters). It should be noted that Philips adopted a risk transfer towards insurance companies and hardly "suffered" from the disruptive event. On the long term, even if its premium may be more expensive, the subsequent boost of production may have compensated for the monetary loss. However, not all entities that suffer such disruptions are so lucky [9]. While currently available PBD guidance for fire suggests that engineers consider impact on mission continuity, they provide no guidance as to how this should be accomplished and at what level the impact should be considered (e.g., building only, raw materials, complete supply chain, etc.). As such, research has shown that this aspect is often ignored or inadequately addressed [7].

\section{Reaching a post event "chronic" state for all building components}

The actions required in the recovery phase need specific documentation to insure that all building components including the ones related to disruptive events, are back in full operational mode. This specific need is illustrated by the fires that successively occurred in a New Orleans warehouse (Louisiana, USA), on March 21, 1996 [7, 27]. A first arson type fire successively started in a low rack section unprotected by in-rack sprinklers, was detected by staff who unsuccessfully tried to extinguish it, activated one over-head sprinkler which action did not extinguish nor control the fire, and eventually was declared out by the fire fighters, about 5 hours after they arrived on site. At that point, "once fire control had been achieved, all of the sprinkler systems in the facility were manually shut down by closing the individual OS\&Y valves on the risers”, as a result of the opening of numerous sprinkler heads throughout the warehouse, causing extensive water damage. Without evaluating the damage to the electrical system caused by water, the electric service of the building was restored, starting the second fire, in a high rack storage area, by ignition of combustible materials with arcing of damage wiring in this area. "As soon as the second fire was discovered, facility personnel began opening the OS\&Y valves on the ceiling and inrack sprinkler systems. However, because these systems were impaired during the initial stages of the second fire, they were overwhelmed". This time, the fire destroyed all the contents of the warehouse and collapsed the structure. The second fire was declared out several days after the fire fighters arrived a second time on site.

This example illustrates the importance of the actions to be performed and the needed documentation (as procedures or check-lists) in the recovery period, after the fire is extinguished. These actions not only concerned the impaired fire protection system but also one utility system to the warehouse, i.e. electricity. The authors of the investigation report [27] advocated for a utility restoration in a "planned and coordinated manner, and only after a complete survey of the damage has been taken" so "that everyone involved with the overhaul and restoration operations be aware of what actions are being taken by the different agencies and services involved". Nevertheless, they "were unable to identify any reference in an NFPA standard, code, or recommended practice that addressed the issue of restoration of utilities and how it should be handled following an emergency". The lack of checking the electrical system after the first fire may be explained by the staff will to go back to production as soon as possible as this business objective trumped the competing objective related to work in a safe environment ${ }^{2}$. 


\section{Identifying the effects of competing objectives related to the usages of a building}

Generally speaking, a building is designed by architects to perform according to "chronic" (every day) objectives. From a societal point of view, a "chronic" objective for hospitals is to cure sick or injured patients, and for schools to educate people. In addition, various societal goals are intrinsically embedded in the design of buildings, such as safeguarding people who use the buildings. While life safety from fire is the focus of most fire protection engineering analyses, a fire is an "acute" event, not often (or ever) expected by users, and competing objectives may exist between such an "acute” objective of fire safety and the "chronic" objectives of a building.

\section{Competing objectives at a design stage}

When looking for the goals and objectives that are relevant for the different stakeholders involved in a building project, a FPE also has to verify that the safety objectives related to the fire risk involving this project are not competing with all the other stakeholders' objectives. Let's see how this point is already considered in the current PBFPD processes. For example, the International Fire Engineering Guidelines (IFEG) [16] indicate that "in addition [to general regulatory objectives], the client may have various nonfire related objectives for the building design that impact on the fire safety of the building. For example, the client may require:

- Increased security

- Extensive natural lighting

- An open plan layout

- The use of new materials

- Measure to improve energy efficiency and sustainability

- Flexibility for future uses

- Low life-cycle cost."

Unfortunately, the IFEG do not provide any guidance on how to consider these additional objectives, which can be competing with the ones related to fire safety. As a result, there is currently no guidance for managing competing objectives in current PBFPD processes during the design stage. If the FPE happens to identify and address such issues through discussion with stakeholders, it is more by experience or chance than by direction.

\section{Adding competing objectives after the design stage}

Building stakeholders may decide to establish additional "chronic" objectives, at some time after the original design phase, when the building is actually operating. For example, as a result of the 11 September 2001 events that occurred in the USA, increased security at airports multiplied check points that may impede safe egress capabilities in the case of an emergency. It should be noted that increased security has now become a "chronic" condition, not only for that type of transportation but also in major crowd gathering events. Besides, adding more security check points concentrate people in certain areas, people that are managed to follow predefined and controlled paths. Not only does this security crowd management condition compete with the conditions employed for dealing with emergency situations (fire or other disruptive event), but it also competes with the original "chronic" objective of the architectural design. For example, Figure 2, which visually translates the ideal vision of the designer to have 
uncongested pedestrian movement in the airport, as well as the aesthetic goal to have passengers walking in a quiet, spacious environment, contrasts with Figure 3, which illustrated the real situations of airports.

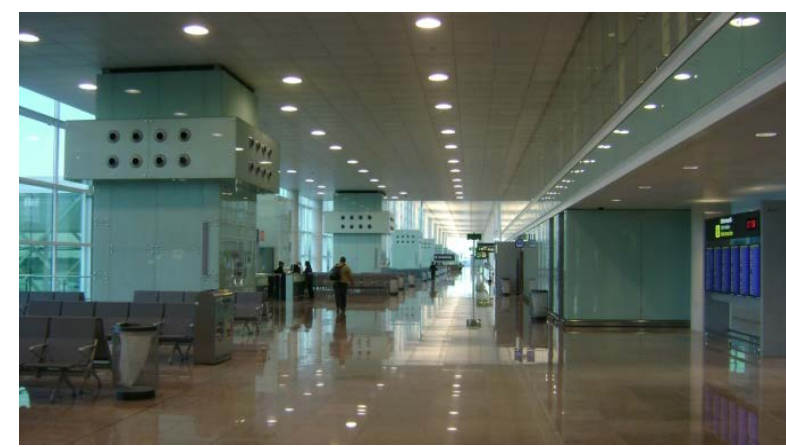

a) Barcelona Airport Terminal 1

source: http://www.flickr.com/photos/francesc_2000/4583309008/, free to share and remix with the attribution of the work to Francesc_2000

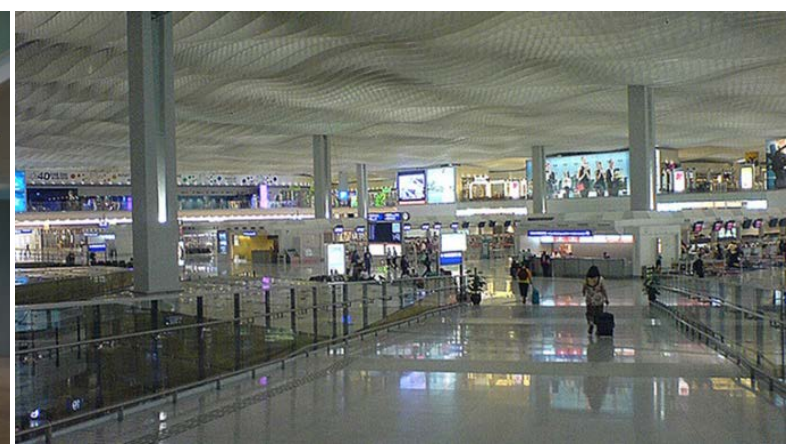

b) Hong Kong Airport Terminal 2

source: http://www.flickr.com/photos/gkpics/953052759/, free to share and remix with the attribution of the work to jgmarcelino

Figure 2 Examples of airport architectural designs

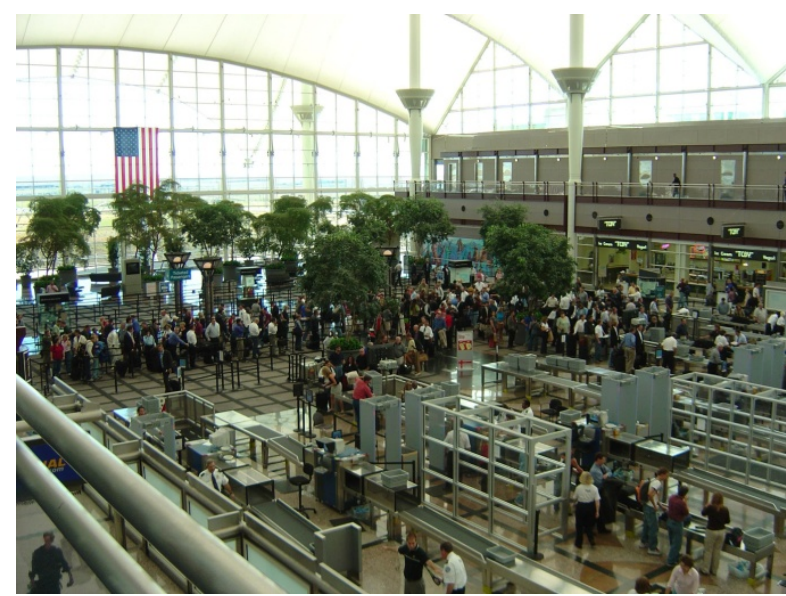

a) source: http://www.public-domain-image.com/full-image/peoplepublic-domain-images-pictures/crowd-public-domain-imagespictures/airport-security-lines.jpg-copyright-friendly-image.html, in the public domain, Author: Kitt Hodsden

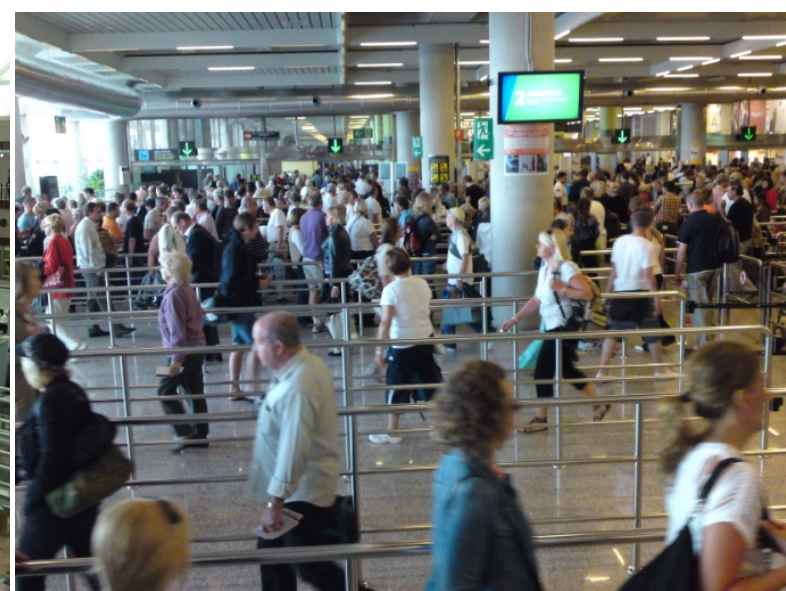

b) Palma de Mallorca Airport

source: http://www.flickr.com/photos/kalleboo/3536493996/, free to share and remix with the attribution of the work to Karl Baron

Figure 3 Examples of impacts of the security "chronic" condition in airports

This is something that does not only concern engineers dealing with disruptive events but also architects, building owners and operators as well as building occupants who have to deal with changes between the original conceptual design of the building and the subsequent building usages, including changes in the building interior design and attributes in terms of sustainability performance.

\section{Changing objectives and building design}

Starting in the 1850's, based on Florence Nightingales' "Notes on Hospital", hospital wards were designed as large, open, well-lit facilities so that nurses could supervise a lot of patients [17]. As illustrated in Figure 4(a), the "chronic" objective at that time was nurse and staff efficiency. Nowadays, patient privacy and comfort are primary concerns and the "Nightingale" ward design has been replaced by a series of patient rooms (Figure 4 (b)) [18]. 


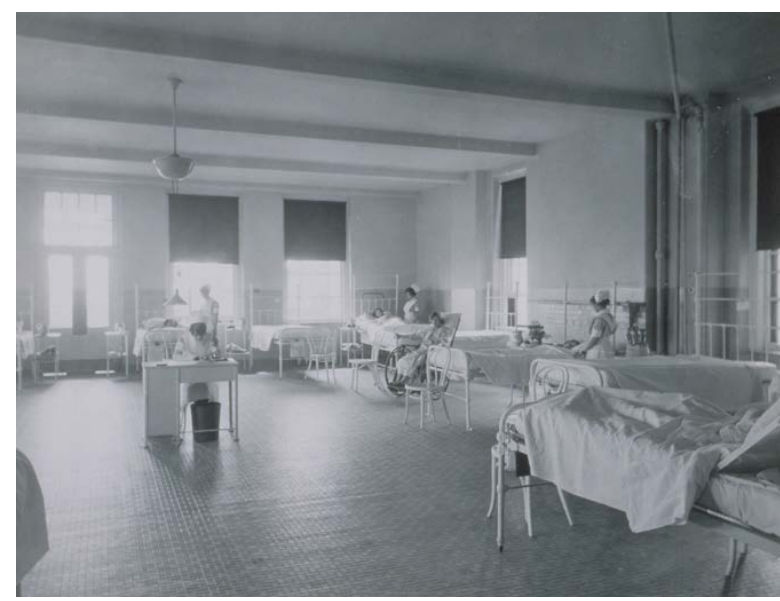

a) source: http://www.flickr.com/photos/vculibraries/4269022763/, free to share and remix with the attribution of the work to Virginia Commonwealth University Libraries

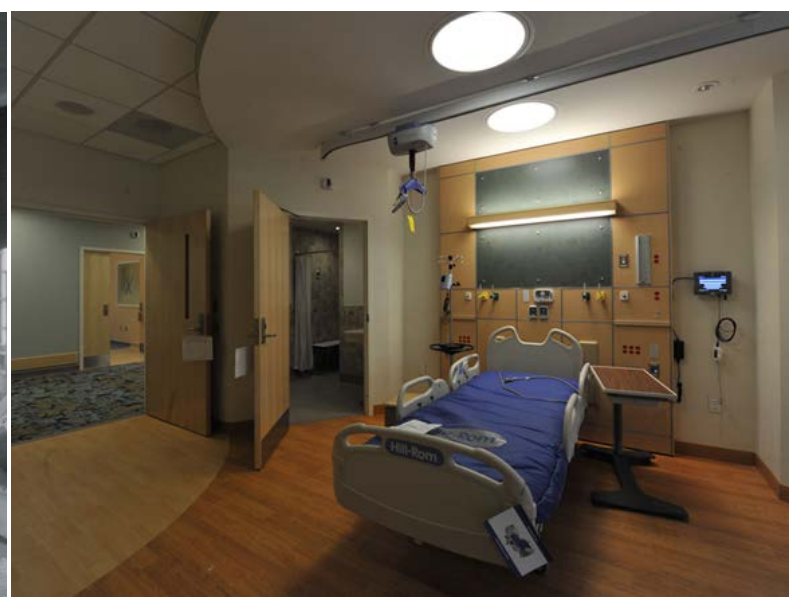

b) source: http://www.flickr.com/photos/usnavy/5913486058/, free to share and remix with the attribution of the work to Official U.S. Navy Imagery

Figure 4 Examples of a) well lit facility ("Nightingale" ward) taken from: b) private patient room in a hospital

Looking at these two configurations from a fire safety point of view, the following comments can be made: in an open patient ward, permanent staff, whose primary objective is to quickly attend an agitated patient, can detect a fire as soon as possible and may extinguish the fire before it spreads away from the $1^{\text {st }}$ burning item. In case the fire is not detected and controlled that quickly, smoke and fire may spread fast and evacuation of all ward patients becomes vital. In the private patient room configuration, fire detection would rely on automatic detection rather than detection by staff who are only briefly present in each patient room. An automatic suppression system could also prevent the patients in the room from being injured and a door closing upon fire detection could limit smoke and fire spread outside of the room of fire origin. This example clearly illustrates that the design of the building is highly dependent of its "chronic" objectives, which design has a strong impact on how the fire protection measures should be selected, installed and maintained as a whole as these measures both include managerial and technical measures, prevention and protection measures. More detailed "chronic" objectives related to hospitals can be found in [19].

\section{Changing objectives and building usage}

Looking at turnover rates of building materials and their impact on the environment, Wærp and Holthe [20] notably conducted surveys and interviews of property managers and architects in Norway. The following paragraph is extracted from their 2009 paper:

"The architects were asked which materials that are often replaced in buildings. This is dependent on type of building and year of construction of the building. In office building interior materials is often changed e.g. flooring materials, ceilings, interior walls and lightening are all changed within 5-15 years. Buildings that are refurbished today are from 1970-80. Solutions and materials are in general poor. There are necessary to change ventilation. After 25 years you are left with façade (when quality is good), stairway and load bearing structure. In building from about 1900 more components are kept: e.g. doors, windows, ceilings, facades and often original interior materials. New buildings from today 
will probably have better quality than in the 1970-80, but there will probably be frequently change in surface materials.”

This information illustrates the fact that even if a building remains an office building during its whole lifespan, the nature and the amount of material (including combustible materials) as well as the exit pathways (interior separation may change or completely disappear with "open space” configurations) have to be reassessed periodically to verify that the performance of the system regarding fire safety has not decreased. It should be noted that building occupant demographics also evolve over long period of times, which may have a significant impact on emergency situations. For example, fire evacuation parameters such as walking speed and crowd density, established from experiments in the late 1980's, should take into consideration population obesity increase. Global ageing population should also be considered [21]. Now that we realized designs may not fulfill every objective defined by all groups involved in a building project, and that building usages, during the building lifespan, may not follow these objectives, the next part of this article concretely presents how this situation impacts the FPEs' analysis of fire protection measures.

\section{Impact of the original design assumptions on actual fire performance}

Knowledge of the "chronic" objectives is important when estimating (a) how long building occupants delay their evacuation after an alarm starts and (b) the state of the building, its systems and its fuel load as modified by users over the course of time. In the case of considering occupant delay times during a fire, the estimation of this "pre-movement" time is related to several factors, and particularly to two called "commitment" and "focus". In Figure 5, people seem quite focus on playing slot machines, inside a Japanese game center. The row of slot machines is itself designed to maximize occupancy time by a single person whom is provided with a chair, has repetitive actions to perform in a very focused vision range, with people in the near proximity, which make it very easy to lose track of time and difficult to be aware of anything happening in the surroundings. People are committed to go on playing as long as they have still money to feed the machines. The "chronic" objective of casinos, related to a high degree of focus and commitment, leads to an increase of the "pre-movement" time, and therefore competes with the life safety objectives to have all these people evacuate as soon as possible in case of emergency.

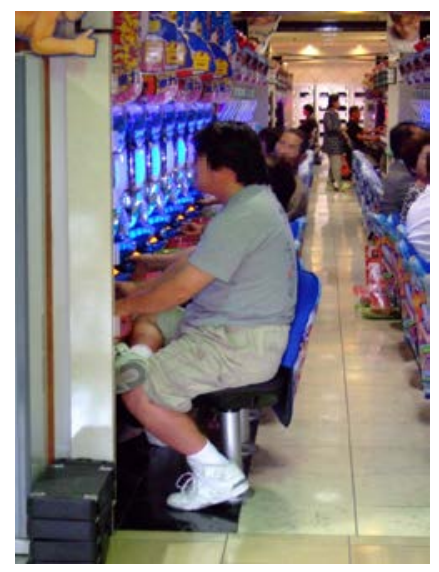

Figure 5 Example of commitment in a Japanese game center (source:

http://www.flickr.com/photos/davidooms/2964039286/, free to share and remix with the attribution of the work to David Ooms) 
From the perspective of the state of the building, its systems and its fuel load, maintenance of systems, fire safety management plans, changing of contents and furnishing, modifying compartmentation (adding or deleting doors, rendering safety measures inoperable), and many other factors can affect the size and spread of fire. Building regulations do not address many of these issues (e.g., contents are not regulated). As such, a 'chronic' building use may negate a fire safety measure (e.g., propping open a smoke door to facilitate unimpeded movement). Where building features are likely to be changed, or fuel loads added, or similar actions taken, such 'chronic' conditions should be considered at the design stage and factored into the design strategy.

\section{Impact of the actual building usages on the treatment of fire events}

It should be noted that in case of an emergency many building users have a strong tendency to try to leave via the route that they entered by rather than using the nearest emergency exit [26]. Displays in department stores and shopping malls are designed to make the potential buyer go from one stand or shop to another: the position of the displays, always changing, can also have some influence on the movement time as people need to find their way out. Estimation of egress paths would be much different when considering design floor layout empty of the movable booths and the real layouts during Sales periods (Figure 6). Besides, lots of additional "Clearance Sale" may also make it more difficult to locate Exit signs. In consequence, during Sales periods, the use of exits other than the one people used to enter the department store might be lower than in regular store usage.

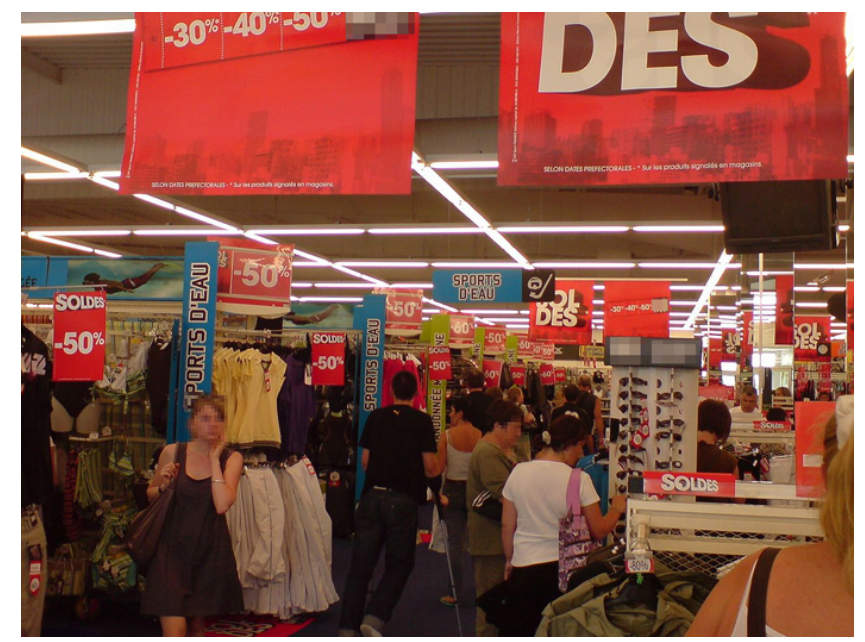

Figure 6 Example of a French department store display during sales (source:

http://fr.wikipedia.org/wiki/Fichier:Ambience_de_solde.jpg, put into public domain by Wikimedia Commons User Medjaï)

A building is dynamically defined with time. For example, the structure of a convention center remains the same in its lifespan but its interior configuration constantly changes as a function of the exhibitions proposed by the convention center owners. From a FPE perspective, nature, amount and location of fire loads are very different for a comic convention, boat show, sport event, etc. Distributions of attendee characteristics (e.g. age, gender) are also relevant and should therefore be gathered and their influences considered in the fire risk evaluation carried out by the FPE. 
Fluctuations can also be seen in the characteristics of a mall concerning the population number and repartitions during the day (food court being more populated around meal times) and days of the week. Transitory combustibles can be located in the common areas (outside the mall shops) for more or less extensive periods of time (such as Christmas decorations in Figure 7). It is necessary to consider of all these fluctuations when assessing fire protection system performance (e.g., sprinkler efficiency and combustible control, for this shopping mall example). In the USA, the day following Thanksgiving (celebrated on the fourth Thursday of November) is becoming the first day of the period during which Christmas decorations are put in place. These decorations are removed in the beginning of January. Are these decorations transitory combustible when they are inside a mall for more than two months?

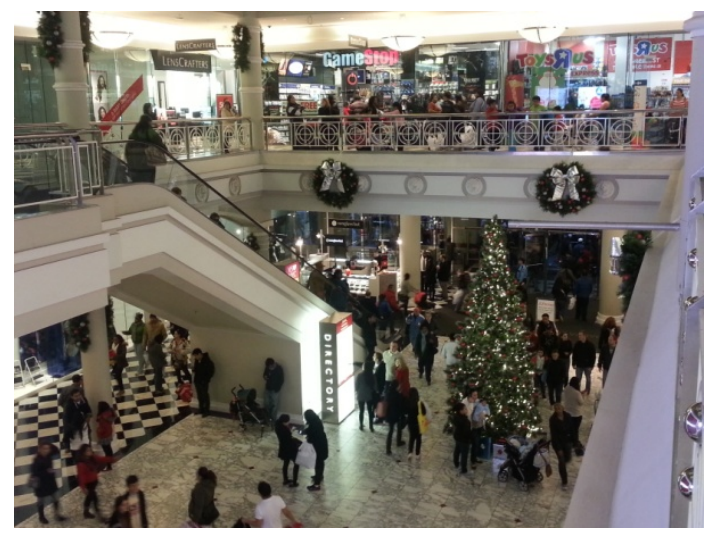

Figure 7 Christmas tree located close to exit routes and main entrance of a shopping mall

The internal structure of a building, designed according specific "chronic" objectives, influences how the building occupants would react in case of a disruptive event (casino example). Arrangement inside the structure of a building, also designed according specific "chronic" objectives, may decrease or negate the efficiency of measures which would help people mitigate the impact of disruptive events (example of department store during sales).

\section{Strong interconnections between people and building components}

Building occupants and building components may have strong interconnections: in a hospital, for example, people can be connected to life supporting machines, so fires impacting these machines (directly or indirectly) can affect the life safety of the people connected to them. Indirect effects of a fire on such patients could result from a fire damaging the distribution of electricity in the building, as well as the backup of this utility.

Also in a hospital, a HVAC/filtration system provides air quality and control of microbe and odor migration between the different functional zones of the hospital. Scott [15] studied a smoldering fire that happened in a storage room in a hospital in New Zealand, in 2008. Smoke generated by this fire traveled via a HVAC duct from the storage room to an operating room. This situation can be qualified as a direct impact of the fire, because the fire effluents directly affect the safety of the patient and of the medical staff (even if the room where the fire was located was not the same room where the targets were located). Keeping the same configuration, the HVAC/filtration system provides microbe migration control by maintaining a pressure differential between different functional zones: this $\Delta \mathrm{P}$ assures that microbes are not going from the examination room towards the operating rooms where people are more vulnerable to 
this threat. A fire damaging the HVAC system ability to maintain this $\Delta \mathrm{P}$ would compromise the safety of the patients most vulnerable to infections. Thus, this last example also illustrates the indirect effects of a fire on targets.

In healthcare facilities, the main safety targets are the patients. Losing a building component from a fire may affect patients. In other terms, the safety of the patient may depend on building components remaining fully functional. The opposite configuration also exists in some building occupancies: a most emblematic example is the nuclear power plant, where staff may be in relative danger in case of a fire but have to remain within the plant in order to maintain the nuclear core within a safety range.

\section{Proposed new treatment of disruptive events affecting the overall building performance}

The review of current PBFPD processes were found to be quite focused on the fire development itself, from ignition to extinguishment so that they ignore the recovery phase, which is essential to consider, as illustrated above by the Philips fire and the New Orleans warehouse consecutive fires. Because engineers dealing with complex disruptive events are too focused on the design of protective measures specific to their own event, they may consider that the integration of these measures is done at a higher level, by the design team who will ultimately synthesize how building users would use and maintain all these different measures. In other terms, the measures against each disruptive event are designed as independent building components and are supposed to be used and maintained by building users as originally designed, without considering competing objectives, minor usage changes and the fact that the building users may ignore or misuse these measures as they do not think every day about events that may or may not occur during the building lifespan. In order to solve these issues, a new treatment of disruptive events affecting the overall building performance is proposed, based on a systems approach.

\section{Introduction of the "building-occupant" system paradigm}

In many countries, building codes can be seen as the first official document providing a taxonomy for buildings. As an example for this paper, healthcare occupancies are examined through the US perspective. The International Building Code (IBC) established by the International Code Council (ICC) includes the Institutional Group (I-2) which gathers detoxification facilities, nursing homes, hospitals, and mental hospitals. Categorized in the same group, these different buildings do need the same requirements. In all these facilities, populations are vulnerable, unable to evacuate without assistance but they are very different and the building systems are also very different, as shown in Figure 8. A classification, such as the one established in ICC IBC, is a "good" start but still necessitates going in a deeper taxonomy level to clearly define a proper "building-occupant" system.

Looking at other building classifications, it was found the one established by the US Bureau of Census [13] more useful than the ones in building codes in defining more precisely the "building-occupant" systems. In this taxonomy a distinction is made between child day care (with the code 624410), general hospitals (with the code 622110), psychiatric and substance abuse hospitals (with the code 62221) and nursing care facilities (with the code 62311). In addition to providing a better "building-occupant" system descriptor, a benefit of using this taxonomy is that the Bureau of Census periodically collects information concerning each of its categorical areas, which can be helpful in the performance assessment. 


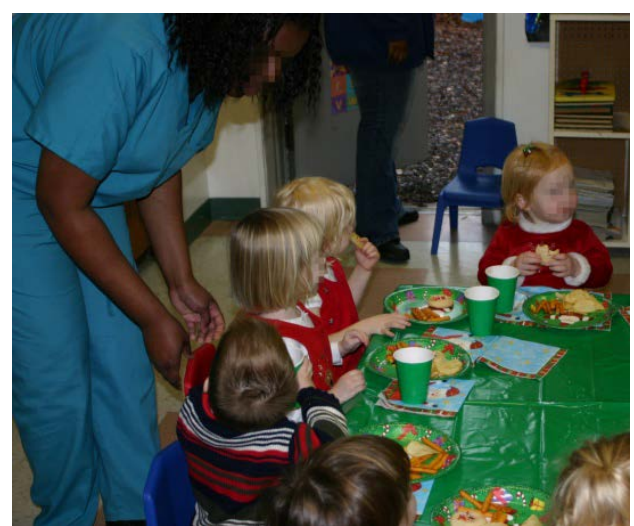

a) Child care facility, source:

http://www.flickr.com/photos/shaggypaul/351385178/, free to share and remix with the attribution of the work to "Shaggy Paul"

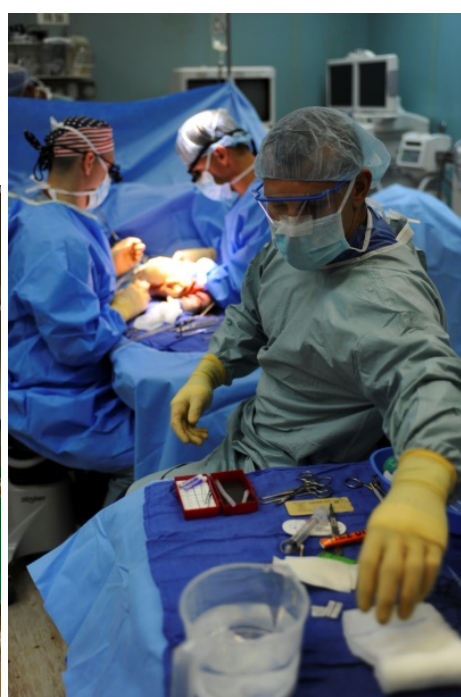

b) Hospital, source:

http://www.flickr.com/photos/usnavy/ 5913202904/sizes/o/in/photostream/, free to share and remix with the attribution of the work to Official U.S. Navy Imagery

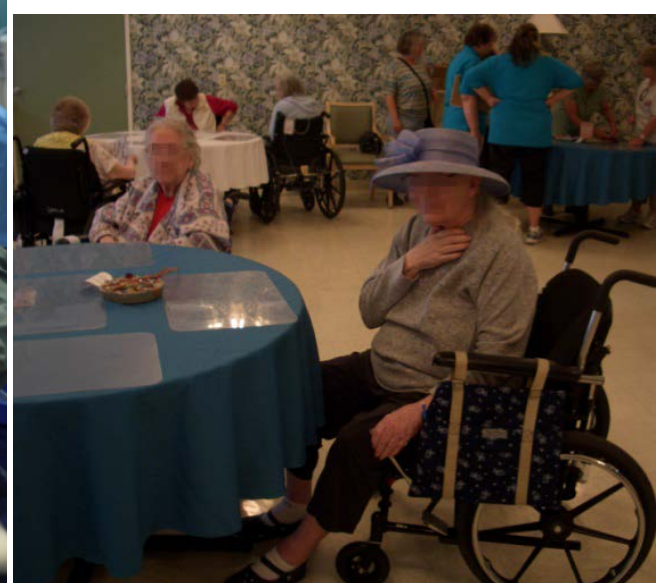

a) Nursing home, source:

http://www.flickr.com/photos/13384589@N00/2780553 $606 /$, free to share and remix with the attribution of the work to by "Robinsan"

Figure 8 Examples of facilities under the ICC IBC Institutional class (I2)

Based on this taxonomy, we defined a "building-occupant" system as a system defined by a structure (i.e. building) inside which occupants are primarily engaged in a specific activity. This activity is quantified (e.g. activity number carried out by day or week) and then the performance of the system is estimated by the level of this activity. Occupants are defined as persons who are physically inside the system, independently of the duration of their stay. Building components are defined in our paradigm as physical portions of the system which can include, for example, spaces dedicated to a particular occupant activity of the system or in support of that activity (e.g. HVAC system).

\section{Introduction of the "functional zone" concept}

A hospital contains different areas which can be identified according to the functions they provide, such as reception areas, emergency rooms, examination rooms, operating rooms, patient rooms and intensive care units. Such areas which can be grouped by function are named "functional" zones, as they are created to fulfill the functions related to the daily objectives of the facility. In addition, there are utility systems and areas which provide support functions, such as power, heating, ventilation and air-conditioning (HVAC), throughout the facility. These utility systems can be located in "utility" zones (mechanical rooms, electrical rooms, cafeteria...) or throughout the building (such as the HVAC system).

For example, Figure 9 illustrates the required level of detail for different functional zones of a hospital, describing the types of population in each of the zones. For example, people located in the reception area are future in-patients, visitors and staff and almost all of them are mobile and conscious. This is important as they would require no or little assistance in case of a hazardous disruptive event such as a fire. Inpatients located in emergency rooms or in operating rooms are undergoing surgery and are connected to life-supporting machines. This is important as extracting them during a fire would require following procedures and requiring time that may not be compatible with a rapidly growing fire [15]. In addition, while a utility zone supporting a reception area may be important to facilitate the comfort of the 
occupants, a utility zone supporting an operating room functional zone is essential. If a fire occurs in the utility zone supporting a reception area the impact in the reception area could be limited to an 'inconvenient' loss of power or lighting. If a fire occurs in the utility zone supporting the operating room, the impact could be life-threatening.

\begin{tabular}{|c|c|c|}
\hline \multicolumn{3}{|l|}{ Hospital } \\
\hline & Reception & Staff + in-patients (mostly mobile) + visitors \\
\hline & Examination rooms & Staff + in-patients (not mobile and mobile) \\
\hline & Emergency rooms & Staff + in-patients (not mobile) \\
\hline & Operating rooms & Staff + in-patients (not mobile) \\
\hline & Intensive care units & In-patients (not mobile) \\
\hline & Patient rooms & In-patients (not mobile and mobile) + visitors \\
\hline
\end{tabular}

Figure 9 People description according different functional zones of a hospital

To summarize, characteristics of occupants within specific locations of a building, as well as the intended function of spaces in a building and contents in those spaces which are essential to achieving the required function needs to be clearly understood, identified and categorized. This constitutes essential information required by the fire protection engineer in order to address stakeholder objectives for "building-occupant" systems when elaborating a fire safety strategy. However, no current PBFPD process directs an FPE to examine a building at such a level of detail, explains the reasons why such a level of detail is important, or provides guidance how to approach the assessment. In large part this is because current PBFPD processes are focused too much on the fire event itself instead of being target-oriented, focusing on the objectives of concern within the specified functional zones or a well-defined "building-occupant" system.

\section{Key-concepts of "building-occupant" systems}

In order to summarize our "building-occupant" system paradigm, we have several key concepts:

- Functional zones: spaces which are directly linked to the performance of the system (e.g. in hospitals, visiting areas where patients are checked in, patient rooms where patients are being prepared for surgery, operating rooms, intensive care units and patient rooms where patients recover before checking out);

- Utility zones: spaces which indirectly contribute to the performance of the system, often providing support to the "functional zones" (e.g. storage rooms, electrical rooms, mechanical rooms);

- Targets: key elements who's performance is of concern within systems (the actors or users of the functional zones). For example, targets can be building occupants (patients including their visiting families and friends and staff in hospitals, pupils and teachers in schools) or building contents 
(important piece of equipment required to contribute to the performance of the system such as a newly developed micro-chip in high tech industry or a priceless artifact in a museum);

- Chronic states of the system: which represent the situations of the system while it is operating as designed or after each modification of its design (e.g. normal use of the system).

- Chronic objectives: objectives the system is designed or subsequently modified, to attain during its chronic states;

- Disruptive events: every possible event (technological events, natural events, socio-economical events) having an effect on the performance of the system. A disruptive event lasts between two chronic states of the system.

- Acute objectives: objectives the system is designed or subsequently modified, to attain during disruptive events;

- Event effects: damaging effects of a disruptive event on a target. These can be 'direct effects' or 'indirect effect.' With respect to fire as a disruptive event, "direct effects" reflect fire-induced damage upon targets, such as heat, toxic, corrosive, irritant effects. "Indirect effects" reflect loss of building components which are vital for the targets to perform in the system. For example, a fire can through 'direct fire effects' such as heat directly damage power cables to a life supporting equipment, which then has an indirect effect on the safety of people connected to this equipment.

\section{A new performance-based design process structured as a systems approach}

Within this "building-occupant" system paradigm, a risk-informed performance-based process was established, as illustrated in Figure 10. Its application is aimed to quantify the effects of any type of disruptive events affecting the overall performance of a specific system.

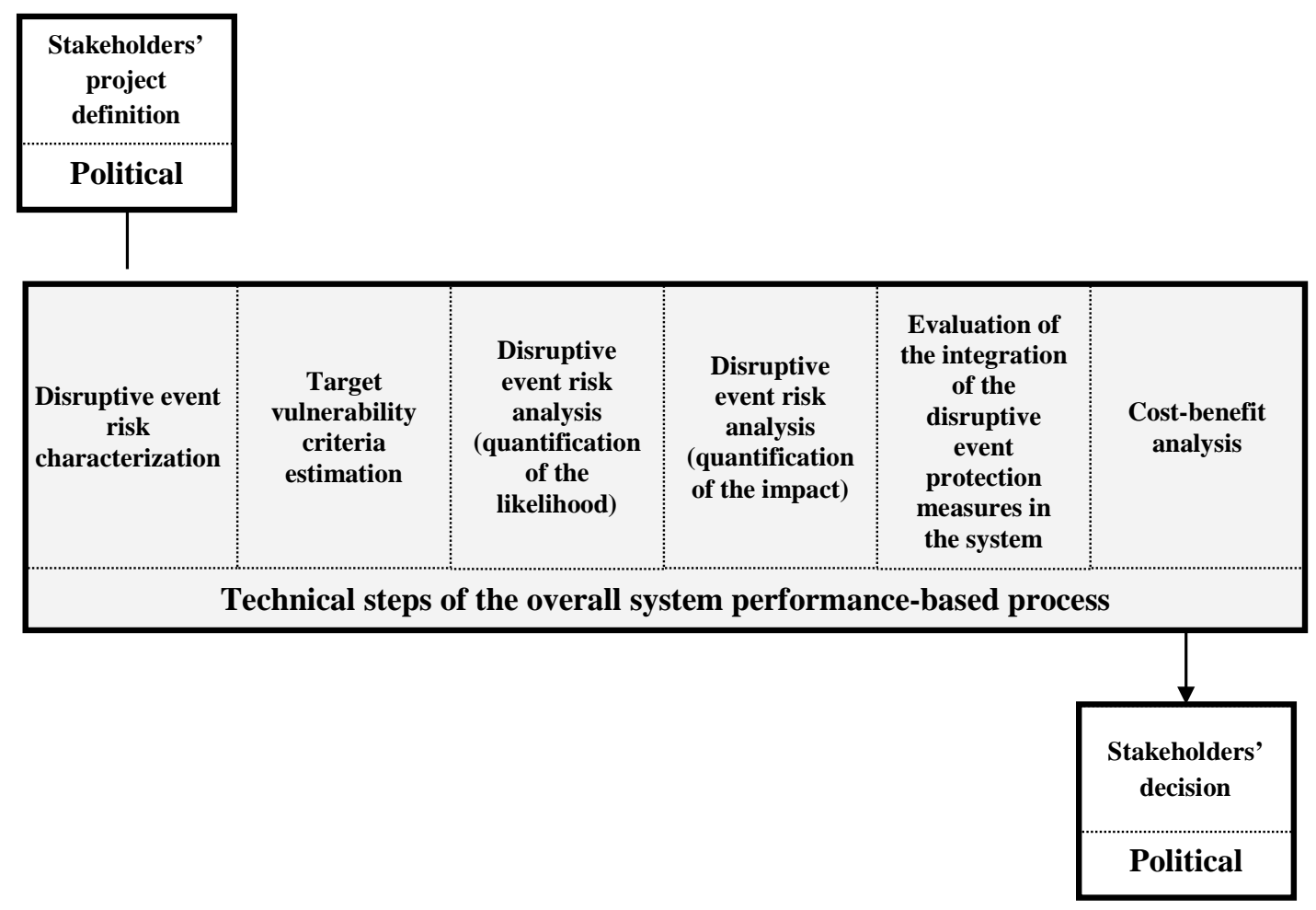

Figure 10 Political and technical steps of the system specific risk-informed performance-based process 
At the initial step of the process the stakeholders of a "building-occupant" system under consideration clearly indicate the nature and the characteristics of the system in terms of "chronic" objectives. This step is essential as it specifies the parameters of the "building-occupant" system to be examined in terms of building components, occupants and functional/support zones used by the system in order to achieve the "chronic" objectives. This initial step is also a "political" step of the risk-informed performance-based process as the system stakeholders need to come to an agreement on the system main goals and decide whether the system will possess specific building attributes such as an atrium or a high rise configuration, which are of special importance when dealing with fire risk for buildings containing these attributes.

All the information gathered by the stakeholders is then transmitted to the engineer in charge of evaluating the impact of a certain type of disruptive event on the overall performance of the system: FPEs to deal with fires, structural engineers for earthquakes, etc. Since the system targets are the components which contribute to the overall performance of the "building-occupant" system, it is imperative that the stakeholders list in this step of the process all the system targets so that the engineer take them into consideration while performing the technical steps of the process. At this point, the corresponding engineer carries out the "technical" part of the process, which mainly consists of a target oriented risk analysis well integrated in a systems approach, by performing the steps as follows:

- Selecting risk acceptance metrics that are representative of the considered system in relation to the stakeholders' listed targets during the chronic use of the building. The aim of the "risk characterization" step is to correlate the likelihood of the disruptive events which occur during chronic operation with vulnerability criteria for each of the listed target (e.g. assessing how often the disruptive event causes injuries or casualties when the target is the building occupant, based on statistics and past events) - Step 1;

- Quantifying the vulnerability criteria for each target in case of the disruptive event (e.g. evaluating the mechanisms by which the disruptive event can have direct and indirect effects on each listed target while taking into consideration the capacity/incapacity of the target to absorb the damage from the disruptive event and still be functional/loses its functionality) - Step 2;

- Carrying out a risk analysis of the direct and indirect effects of the disruptive event on the overall performance of the system, via the characterization of both the likelihood - Step 3 and the impact Step 4 of the disruptive event on each of the listed targets;

- Evaluating the integration of the protection measures against the disruptive event, analyzed in the risk analysis, so to verify that these measures, once installed, would not be ignored or misused by the system end users - Step 5;

- Performing a cost-benefit analysis of the protection measures against the disruptive event, analyzed in the risk analysis - Step 6.

At the end of the technical steps of the performance-based process, the engineer dealing with a certain type of disruptive event will transmit three important documents (or three components of a consolidated document) back to the system stakeholders:

- One document containing the results of the disruptive event risk analysis (from technical Step 3 and Step 4) including a risk matrix or risk curves and explaining how the engineer's proposed protection measures reduce the risk of the disruptive event affecting the performance of the studied system, 
- One document describing the possible interactions of the protection measures designed by the engineer against the disruptive event and the other components of the studied system,

- One document estimating the costs and the benefits to install and maintain the proposed protection measures.

Based on the results thus collected, the stakeholders finally decide on the set of protection measures they want to be installed in the system, knowing how well these protections would help the system to mitigate the impact of the disruptive events on the performance of the "building-occupant" system in its chronic state, how well these protections would be integrated in the system and how much they would cost to install and maintain. It was realized that the concerns related to building usages fluctuating according to building changes may be addressed by incorporating, into a performance-based process, a mechanism for not only looking at expected normal operations (chronic use) but for triggering reassessment if certain operational schemes are modified by building usages (using in Step 5 of the new process, a feedback loop as defined in a systems approach). In case the performance-based process is simultaneously conducted on several disruptive events, the different engineers involved in proposing protection measures against their respective disruptive events have to generate a common additional document since it is important to verify that all their additional protection measures are not counterproductive (Figure 11). It should be noted that the initial political step is identical for the stakeholders as they only need to provide once, in their own terms, the specifics of their "building-occupant" system. The "translation", in terms of solving the right problem for each disruptive event, is made by the corresponding engineer in the technical step related to risk characterization.

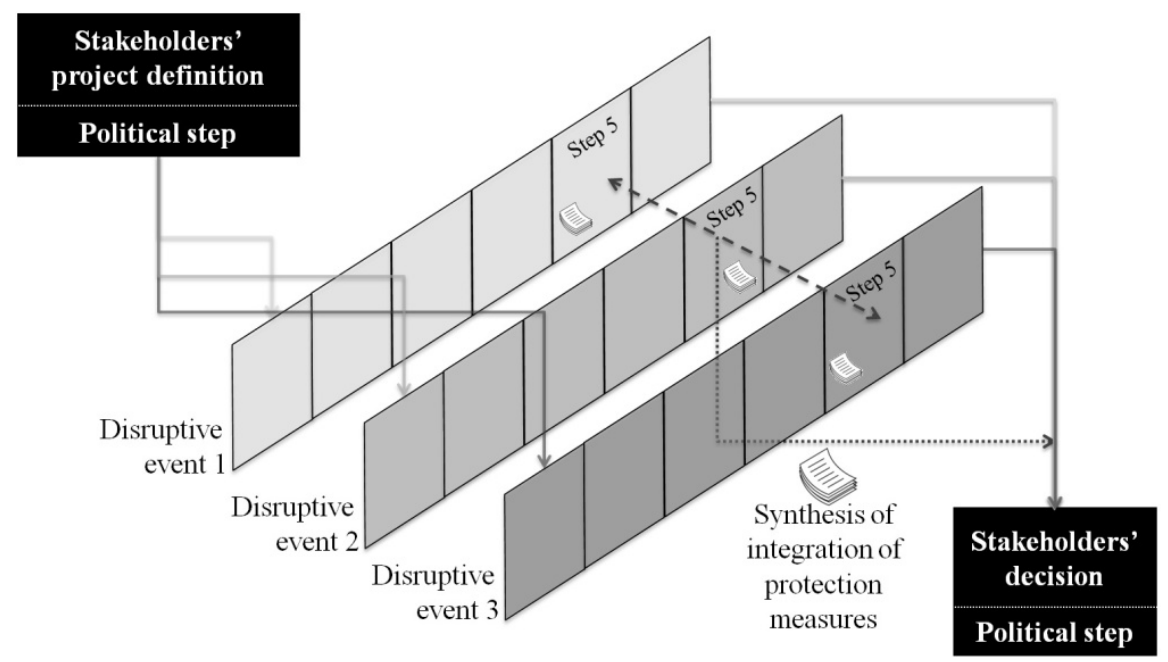

Figure 11 Practical treatment of multiple disruptive events

\section{Conclusions}

Designing a building project is a complex enterprise involving project stakeholders who are the main drivers of the project concept and professional groups who are the main drivers of the actual realization of the project. In addition to this complexity, differences arise between the building project at its design phase and when the building is actually exploited by its end users. 
The performance of a building depends on the interrelations between the different components of the building which are separately designed by specific engineers, having their own objectives to fulfill, so the final integration of all the building components may not be optimal. When these components concern disruptive events, i.e. events affecting the daily performance of the building such as fires, it was found that the end users might misuse or ignore the protection measures against the disruptive events, because these measures were not integrated well enough by the end users.

This paper presented the outcomes of research carried out in order to:

- define a paradigm of study organized around systems formed by specific building types and their associated occupants so to clearly determine how hazardous disruptive events such as fires affect these system daily performance,

- introduce a corresponding system specific risk-informed performance-based design process, which could take into consideration the complexity of such systems and their evolution during disruptive events.

\section{Acknowledgments}

The authors would like to thank the US National Institute of Standards and Technology (NIST) for supporting the research on which this present paper is based, under grant 60NANB10D228.

\section{References}

1. Zalejska-Jonsson, A. (2012) Evaluation of low-energy and conventional residential buildings from occupants' perspective. Building and Environment 58, 135-144.

2. International Council for Research and Innovation in Buildings and Construction. (2004) Performance Criteria of Buildings for Heath and Comfort. Report CIB number 292, prepared by ISIAZ-CIB Task Group TG 42.

3. SFPE (2007) Engineering guide to Performance-Based Fire Protection - Second Edition

4. SEAOC (1995) Performance-Based Seismic Engineering of Buildings, Volume I, Structural Engineers Association of California

5. Ornstein, S.W., Ono, R., Lopes, P.A., Franca, A.J.G.L, Kawakita, C.Y., Machado, M.D., Robles, L.V.L., Tamashiro, S.H., Fernandes, P.R. (2008) Performance evaluation of a psychiatric facility in Sao Paulo. Facilities, 27, 3/4, 152-167.

6. Spekkink D. Performance Based Design of Buildings - PeBBu Domain 3 - Final Domain Report Performance Based Buidling Network (PeBBu) October 2005 (availabe at: http://www.pebbu.nl/resources/allreports/downloads/07_D3_FinalReport.pdf, checked 10/31/2012)

7. Alvarez, A., Meacham, B.J., Dembsey, N.A. and Thomas, J.R. (2013) 20 Years of PerformanceBased Fire Protection Design: Challenges Faced and a Look Ahead. Journal of Fire Protection Engineering, submitted Aug, 12th 2012, submission number: JFE-12-0035, accepted for publication by SAGE

8. Sheffi, Y. (2005) The Resilient Enterprise, Massachusetts: Institute of Technology Press.

9. Knight RF and Pretty DJ. The Impact of Catastrophes on Shareholder Value, The Oxford Executive Research Briefings. Templeton College, University of Oxford, England

10. International Code Council (ICC) International Building Code, 2012 
11. Lataille, J.I. (2008) Factors in Performance-Based Design of Facility Fire Protection. Fire Protection Engineering, 2nd quarter 2008, Society of Fire Protection Engineers (available at: http://magazine.sfpe.org/fire-protection-design/factors-performance-based-design-facility-fireprotection, checked 10/31/2012)

12. International Code Council (ICC). (2012) Performance Code

13. US Department of Commerce, Bureau of Census, North American Industry Classification System (NAICS) Definitions. 2007 at: http://www.census.gov/eos/www/naics/2007NAICS/2007_Definition_File.pdf, checked 10/31/2012)

14. Chow, C.L. and Chow, W.K. (2010) Heat release rate of accidental fire in a supertall building residential flat. Building and Environment, 45, 1632-1640.

15. Scott D. (2009) Fire in an operating Theatre - What really Happened? - A Case Study of a Fire in a Private Hospital in Hamilton, New Zealand. In Proceedings of the 4th International Symposium on Human Behaviour in Fire (Robinson College, Cambridge, UK, July 2009), pp. 313-322

16. (ABCB) Australian Building Codes Board. (2005) International Fire Engineering Guidelines, 2005 edition

17. Richardson R. (2010) Florence Nightingale and hospital design. King's College, London. (available at: http://www.kingscollections.org/exhibitions/specialcollections/nightingale-and-hospitaldesign/florence-nightingale-and-hospital-design, checked 10/31/2012)

18. Tolley M. Institutional Buildings, the Built Environment - Public Spaces. 2011 (available at: http://martintolley.com/environment/BuiltEnv2EnvPsy6.html, checked 10/31/2012)

19. Alvarez A. and Meacham BJ, Towards an Integrated Performance-Based Design Approach for Life Safety Across Different Building Use Groups, in: Proceedings of the 12th International Interflam Conference, Nottingham, UK, 2010

20. Wærp S. and Holthe K. Turnover Rate and Environmental Load for Building Materials - Checkpoints in Design Process. CIB14251, SINTEF. 2009 (available at: http://www.sintef.info/upload/Byggforsk/Bibliotek/Publikasjonsdatabasen/CIB14251.pdf, checked 10/31/2012)

21. Spearpoint, M. and MacLennan, H.A. (2012) The effect of an ageing and less fit population on the ability of people to egress buildings. Safety Science, 50, 8, 1675-1684.

22. (NFPA) National Fire Protection Association (2009) NFPA 101 Life Safety Code ${ }^{\circledR}$ Handbook, eleventh edition, edited by R. Coté and G. E. Harrington, NFPA, pp.667-669.

23. Flynn, J.D. (2009) Structure Fires in Medical, Mental Health, and Substance Abuse Facilities, February 2009, National Fire Protection Association.

24. (NFPA) National Fire Protection Association. NFPA 101 Life Safety Code ${ }^{\circledR} 2009$ edition, NFPA. 2009

25. O’Connor DJ. Health care occupancies, chapter 15, section 20 of the 20th edition of the Fire Protection Handbook, National Fire Protection Association, 2008

26. Kobes, M. et al. (2010) Way finding during fire evacuation; an analysis of unannounced fire drills in a hotel at night. Building and Environment, 45, 537-548.

27. Comeau, E. and Puchovsky, M. (1996) NFPA Fire investigation report, Warehouse fire, New Orleans, Louisiana, March 21, 1996, National Fire Protection Association.

28. Bachman, L. (2002) Integrated Buildings: The Systems Basis of Architecture, Wiley, 1st edition 


\section{Endnotes}

${ }^{1}$ As soon as it received the call, Nokia started to work closely with Philips and other of its providers so to maintain its own production of mobile phones and satisfy its customers in a period of time when demand for this type of product was booming worldwide. Ericsson's reaction was different: they treated the fire incident at the Philips plant as a "technical matter" which would result as a chip production disruption of one week only, which is something that could easily be taken care of. Unfortunately for Ericsson, the disruption lasted longer and by the time it realized the size of the disruption, it was too late and Ericsson failed to deliver mobile phones to its customers.

As a result of the small fire that occurred in 2000 at the Philips Albuquerque plant, Philips's chip sale loss, estimated to a US $\$ 40$ million, was almost covered by a 39 million Euro settlement with its insurance company; this loss only accounted for 0.6 percent of the US\$ 6.8 billion semiconductor global benefits of Philips for 2000. Having failed to deliver its new generation of mobile phones, Ericsson reported losses between US \$ 430 million and US \$ 570 million in the first disruption-affected quarter, due to a lack of parts, that is to say more than ten times Philips' losses. In addition to the fire disruption effects, incorrect product mix and marketing problems are to be blamed for Ericsson's US \$ 2.34 billion losses in the mobile phone division by the end of 2000. This situation led to a SonyEricsson merging for designing, producing and marketing mobile phones, in April 2001. In addition to its competitor economic situation, Nokia's fire disruption treatment helped to increase its percentage of the mobile phone market.

${ }^{2}$ Speeding up activities in hazardous environments have shown dramatic results. 


\section{Annex D}

A Simple Probabilistic Fire Safety Risk Model for Room and Corridor Configurations in Different Building Uses 


\title{
A Simple Probabilistic Fire Safety Risk Model for Room and Corridor Configurations in Different Building Uses
}

\author{
Cornelius Albrecht and Brian Meacham*
}

\begin{abstract}
Performance-based codes and fire safety design methods are in use worldwide. However, most performance building codes lack quantitative risk, safety or performance criteria, and the decision regarding acceptance criteria often rests with the fire protection engineer and design team, with no benchmarking against other buildings. As a result, there is a high degree of variability in fire engineered building design solutions and in the review and approval of these solutions, and therefore in the levels of fire safety provided in buildings that have been designed using performance methods. Although there have been no significant fire-related failures that can be attributed to "unacceptable" fire safety performance being delivered under the current system, performance failures in other regulated areas, perceived quality concerns, and a desire to be more transparent has motivated several countries to try and better understand and quantify the level of fire safety and performance being provided in deemed-tosatisfy solutions (acceptable solutions, approved documents) and to establish quantitative measures for use in next generation performance-based building codes.

To help facilitate progress on quantifying the level of fire risk, safety and performance in buildings, and the development of data, tools and methods for risk-informed performance-based design, research has been conducted in these areas under Award 60NANB10D228 from the U.S. National Institute of Standards and Technology (NIST). In this work, a simple probabilistic risk analysis model, using Monte Carlo and event tree analyses techniques, is developed for room and corridor geometries to assess life safety levels based on different occupant and fire protection system characteristics. The development of model is briefly described along with the input parameters and the simplifications made. The model runs 100,000 simulations for each fire scenario, giving a good impression of the annual failure probabilities of the fire life safety design in such buildings. In addition, the assumed probabilities for the various decision gates within the event-tree are analyzed for their impact on the system reliability using a simplified sensitivity analysis. To quantify the impact of the various fire protection systems assumed, analyses with and without these systems are performed. Furthermore, an occupancy-specific analysis with respective variation of the input parameters provides a comparison between different building uses for a similar geometry. The results are analyzed, discussed and recommendations for future performance-based fire life safety codes are made.
\end{abstract}

*Department of Fire Protection Engineering, Worcester Polytechnic Institute, Worcester MA, USA 


\section{Introduction}

The model developed herein is in accordance with the quantitative risk assessment studies on the 140 Williams Street building conducted by Thomas et al. [25] and incorporates elements from the study by Olsson [21] and Frantzich $[10,11]$. The stochastic model for the various times herein was also adapted from the above sources and was validated with deterministic state-of-the-art numerical fire protection engineering tools, namely computational fluid dynamics (CFD) and microscopic egress simulations. The deterministic evaluations were found the be in the range of the input parameter distributions, so that the validity of the model is given.

The probabilities for the fire ignition, spread, and the barrier probabilities are varied in a parameter study to quantify their sensitivity with regards to the overall failure probability. The results are visualized in a so-called tornado diagram. In addition, comparative analyses are conducted where the fire protection systems, assumed to be installed and operational with their respective failure probability, are compared to a case without the respective system installed in order to quantify the impact of those systems.

Based on the results, the most sensitive parameters are derived for various building occupancies in order to allow for a quantitative comparison of the fire risk. This could lead to a more risk-informed design since it directly incorporates occupancy-specific input data and thus provides the basis for a future code framework.

\section{Model description}

The model utilized herein in a simple event-tree based simulation model similar to the models used by Thomas et al. [25] or Olsson [21] that utilizes crude Monte Carlo simulation [17] in order to compute failure probabilities for the various scenarios. The system analysis is subsequently performed using simplified event-tree analysis in order to compute the overall annual failure probabilities of in-room and corridor fires for a standard office-type fire compartment geometry. The models along with the input parameters are discussed in the following.

\subsection{In-room modeling}

The in-room model computes the failure probability of a successful self-rescue from the room of fire origin based on a simple comparison of the available time until untenable conditions are reached (ASET) and the total required time to respond to a fire cue and subsequent egress into the corridor (RSET). The egress is obviously successful if ASET is greater than RSET and the failure domain is defined

$$
\Omega_{f}=A S E T \leq R S E T .
$$

Probabilistic analysis with $n=100,000$ simulations is performed for each scenario with crude Monte Carlo analysis where random numbers are drawn from the stochastic model for ASET and 
RSET. The failure probability $p_{f}$ can then simply computed by dividing the number of failed simulations by the total number of simulations

$$
p_{f}=\frac{\sum_{i}^{n} I\left(\Omega_{f}\right)_{i}}{n}
$$

with $I\left(\Omega_{f}\right)$ being an indicator function that either yields 0 for successful or 1 for failed simulations.

For the event-tree model, it was assumed that the annual ignition frequency for fire in standard type buildings can be assumed to be around $p_{i g} .=1 E-2[8,9]$. The probability for the fire develop into a severe and hostile fire was assumed to be $20 \%$ according to Thomas et al. [25]. This is similar to the numbers given in, for example $[4,20]$. For the fire to threaten the occupants, the room of fire ignition has to be occupied, which was assumed to be the case in $80 \%$ of the time. In case of a hostile fire, the time to untenability (ASET) can be assumed to be between 4 and 10 minutes. This is assumed to be uniform distributed in accordance with the assumptions made in the analysis of the 140 William St building [25]. A deterministic CFD simulation for a room of similar proportions using commonly chosen input source terms yielded untenability within this range. This is also in accordance with various fire tests conducted $[18,24,15,7,14]$.

The effect of a sprinkler system for the room of fire origin was omitted since the system will most likely actuate when untenable conditions are reached or are about to be reached. Nevertheless, he sprinkler will be considered in the corridor spread model.

As for the RSET, three different scenarios were considered: the first scenario assumes a fast manual detection of the fire by the occupants within the development phase by visual, auditory or olfactory means. This is considered to occur with a probability of $70 \%$. The detection time is rather fast since the occupant is in the same room as the fire. In accordance with [25], the times to perceive the fire cue is uniform distributed between 0 and 2 minutes. In addition, a response time has to be considered which includes an attempt to extinguish the fire and the escape from the room. Since the rooms are comparatively small, a uniform distribution between 0 and 2 minutes was assumed. A brief deterministic numerical simulation and self-conducted tests showed these times to be reasonable assumptions.

In a second scenario is is assumed that the occupant in the room will not manually detect the fire (the remaining 30\%). It is assumed that a smoke detection system is installed that will detect the fire and alarm the occupant with a success probability of $85 \%$. This number includes various subscenarios, i.e. for example the failure of the system to detect the fire, the occupants ignoring or overhearing the alarm and even the incapacitation of the occupants before the alarm. The time for the detection system to detect the fire and alarm the occupant is given with a uniform distribution between 3 and 15 minutes. Since the alarm occurs at a later time during the fire development and will make the occupants aware of the danger faster, the reaction time is modeled here as a uniform distribution between 0.1 and 0.5 minutes (immediate escape from the small room after the alarm).

In both of the above scenarios, $n$ samples will be drawn from the distributions and $\mathrm{ASET}_{i}$ and $\operatorname{RSET}_{i}\left(=\sum \Delta t_{j}\right)$ will be compared for success or failure of each case $i$. 


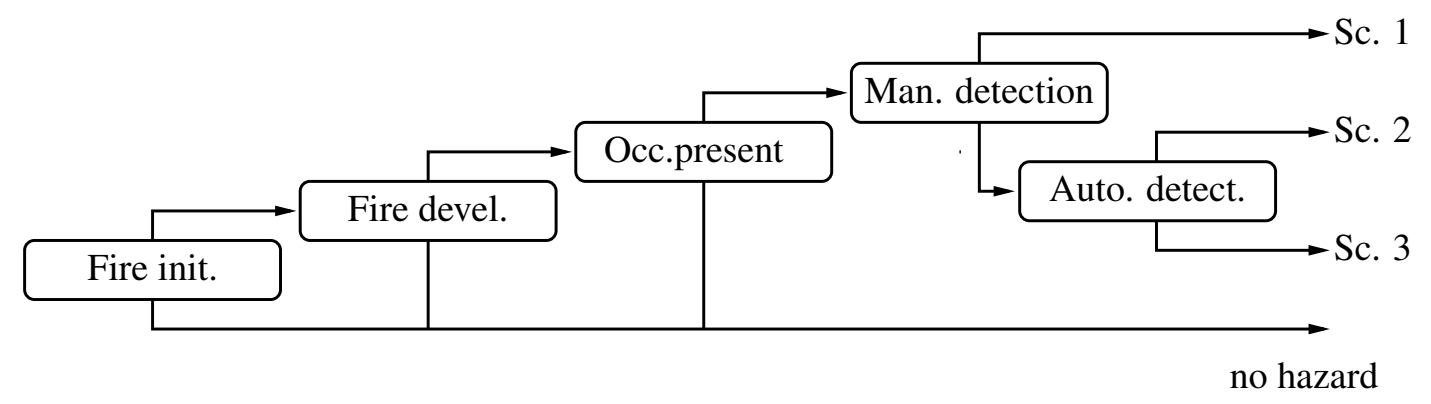

Figure 1: Event-tree of the in-room model.

The third scenario considered in this in-room model is the failure of the manual and the automatic detection, leading to a certain fatal outcome, so that the scenario failure probability is $100 \%$. Looking at the event-tree, the probability of this scenario to occur is fortunately very low.

All the scenarios can be compiled into an event-tree tree with each branch representing one of the above scenarios. The probabilities can then be computed by multiplying each branch horizontally under the assumption that the decision gates are not correlated [16]. This leads to individual annual failure probabilities for each scenario as shown in figure 1. In order to compute the overall annual failure probability of the event tree, the annual scenario probabilities $p_{i}$ can be summed up as a simplification, since each scenarios occurrence is purely stochastic and thus it implies a series system. Hence, the simplification [16] can be made to

$$
p_{f, s y s .} \leq 1-\prod\left(1-p_{i}\right) \approx \sum p_{i} .
$$

The overall annual failure probability for the event-tree was computed to $p_{f, s y s .}=3.54 E-4$.

\subsection{Corridor modeling}

The corridor model is similar to the in-room model, but more complex due to the advanced stage of the fire and more possible scenarios. In order for the fire to spread to the corridor, further probabilities have to be introduced to the system. As mentioned above, if a sprinkler system is installed, it will not have any effect on the tenability in the room of fire origin, but it will have a large effect on the fire spread. It is assumed that a successful sprinkler actuation will control the fire and confine it to the room of origin, so that no fire spread will occur. The sprinkler system is assumed to be successful in $98 \%$ of the cases, in accordance with the numbers given in [8,9]. This number includes not only the failure of the system to actuate, but also the failure of controlling the fire and hence it was chosen lower than the assumed probability of $99.9999 \%$ for the system to control the fire given the sprinkler system works, which was comprehensively derived in Thomas et al. [25].

The probability of the fire to spread beyond the room of origin is given in Thomas et al. [25] with $90 \%$ if the door to the room of origin is open. The times for the fire to spread are modeled with a uniform distribution between 0 and 20 minutes after reaching untenable conditions in the room of 
origin. For the analysis herein it was additionally assumed that fire spread can also occur when the door is closed with a probability of $60 \%$. Thomas et al. [25] even assume the spread probability with a closed door to be $85 \%$. An in-depth analysis of the sensitivity of the various probabilities assumed herein in given in section 3 . The time for the fire to spread given a closed door are modeled with a uniform distribution between 20 and 40 minutes according to the original model.

After having spread with the according spread probability and time distribution it will take some time for the more voluminous corridor to develop untenable conditions. This is assumed to be uniform distributed between 5 and 20 minutes after the fire has spread. Untenability in the corridor herein was assumed to preclude safe egress from all the other rooms so that the occupants therein are in immediate danger.

In order for the fire spreading into the corridor to be detected manually, occupants must be present in the corridor, which is assumed to be less likely then in the rooms and thus was chosen to be only $30 \%$. Given that occupants are present, the same probabilities and times for manual detection were assumed as for the in-room model. If no occupants are present in the corridor, the occupants in the other rooms must rely on the detection system, which has the same probability and time properties as for the in-room model above. Should the detection system fail also, it is assumed that this scenarios leads to the entrapment of the occupants in their room since they will not become aware of the fire until untenability in the corridor prevents them from a safe egress $(R S E T=\infty)$ with a scenario probability of $100 \%$. It should be noted here, that this not necessarily means for fatalities to happen, since the occupants could defend in place in their rooms until they are rescued by the fire department. More in-depths models for the fire spread and fire department responses are given in $[25,12,26]$.

The above assumptions can also be structured and systematically assessed with an event tree which would lead to six scenarios after the fire develops in a room and the sprinkler is not able to contain it:

1. door closed, people present, manual detection successful,

2. door closed, people not present, auto detection successful,

3. door closed, people not present, auto detection fail (worst case 1),

4. door open, people present, manual detection successful,

5. door open, people not present, auto detection successful,

6. door open, people not present, auto detection fail (worst case 2),

The time spans $\Delta t$ for ASET were sampled $n$ times and compared to the sum of the time spans for RSET in a crude Monte Carlo simulation in order to produce the scenarios failure probabilities for the above scenarios 1,2 and 4,5. The worst case scenarios are assumed to have a 100\% failure probability given their occurrence as mentioned above.

The overall annual system failure probability for the corridor becoming untenable before the safe egress from the other rooms is completed was calculated to be $p_{f, s y s .}=1.57 E-05$, which is approximately times 20 lower than the in-room failure probability. Hypothesizing that the common definition of risk $(\mathrm{R})$ as the sum of all scenario probabilities $(\mathrm{P})$ multiplied with their respective 
effect (E) The overall annual system failure probability for the corridor becoming untenable before the safe egress from the other rooms is completed was calculated to be $p_{f, s y s .}=1.57 E-05$, which is approximately times 20 lower than the in-room failure probability. Hypothesizing that the common definition of risk $(\mathrm{R})$ as the sum of all scenario probabilities $(\mathrm{P})$ multiplied with their respective effect $(\mathrm{E})$

$$
R=\sum P_{i} \cdot E_{i}
$$

applies herein, it could be, for example, recommended based on this outcome that no more than 20 units/rooms shall be located within a protected fire compartment in order to keep the risk constant.

\section{Parameter study and system sensitivity analysis}

While the time spans used above are chosen and modeled as distributions to account for uncertainty within the data, the assumed probabilities for the fire protection systems, the fire spread, etc. are chosen based on available data, experience and educated best practice guesses. Being probability data, there is no obvious way to validate the data, especially since comprehensive fire statistics are still missing. In the following a sensitivity analysis is conducted to gain insight into the overall system behavior should some of the assumed values be too optimistic. Also, a sensitivity analysis shows the most critical components of the system and thus it is easier to detect missing redundancies and short-cuts that could potentially jeopardize the life safety concept.

For the analyses herein, a simple approach was chosen to identify the effect of one parameter on the system performance [6]. In this approach, a reasonable range was chosen for each probability. While holding all other parameters fixed at their original value, the system is evaluated at the minimum and the maximum value of the chosen range. The resulting system probability range is plotted as a probability band. This analysis is repeated for every parameter. Subsequently, the resulting bands will be sorted by the size of their interval producing the so-called tornado plot in figure 2 showing the parameters in order of their sensitivity. The input and resulting intervals are shown in table 1 .

Obviously, the fire ignition frequency and the probability of a full fire to develop have the highest sensitivities within the system for both, the in-room and the corridor risk assessment. This can be attributed to the early stage within the event tree and the ultimate nature ${ }^{1}$ of these decision gates. Without ignition or fire development, respectively, there cannot be a hazard situation for the occupants. This is rather unfortunate, since these parameters are those which can not or only slightly be influenced and very little information is known about the accuracy of these numbers, since only a few comprehensive fire statistics exist in the literature, for example [13].

For the in-room case, the highest sensitivities to the input ranges can be seen for the manual detection followed by the probability of occupants being present. While the latter can be attributed to the ultimate gate nature within the event tree, the manual detection has such a strong influence on the overall probability, since the detection can occur very early during the fire development $(0-2$

\footnotetext{
${ }^{1}$ A decision gate that directly leads to failure or safety without any further elements within the regarded branch of the event-tree is considered an "ultimate" gate herein.
} 
Table 1: System sensitivity analysis and results. The component probabilities are given in percent, the system failure probabilities in absolute numbers.

\begin{tabular}{lrrr|rrrr}
\hline \hline & \multicolumn{3}{c}{ Component } & \multicolumn{2}{c}{ In-room } & \multicolumn{2}{c}{ Corridor } \\
& org. [\%] & $\min [\%]$ & $\max [\%]$ & $\min$ & $\max$ & $\min$ & $\max$ \\
\hline \hline Fire ignition & 1 & $0.0445^{\dagger}$ & 10 & $1.58 \mathrm{E}-5$ & $1.80 \mathrm{E}-3$ & $6.94 \mathrm{E}-7$ & $7.78 \mathrm{E}-5$ \\
Fire development & 20 & 10 & 50 & $1.77 \mathrm{E}-4$ & $1.10 \mathrm{E}-3$ & $7.83 \mathrm{E}-6$ & $4.7 \mathrm{E}-5$ \\
Occupants in room & 80 & 60 & 99 & $2.66 \mathrm{E}-4$ & $4.38 \mathrm{E}-4$ & - & - \\
Manual detection & 70 & 30 & 90 & $8.28 \mathrm{E}-4$ & $1.18 \mathrm{E}-4$ & $1.57 \mathrm{E}-5$ & $1.56 \mathrm{E}-5$ \\
Automatic detection & 85 & 75 & 99 & $3.69 \mathrm{E}-4$ & $3.33 \mathrm{E}-4$ & $1.65 \mathrm{E}-5$ & $1.43 \mathrm{E}-5$ \\
\hline Sprinkler success & 98 & 90 & 99.9999 & - & - & $7.81 \mathrm{E}-5$ & $7.81 \mathrm{E}-10$ \\
Occupants in corridor & 30 & 10 & 60 & - & - & $2.00-5$ & $8.89 \mathrm{E}-6$ \\
Door open & 80 & 20 & 90 & - & - & $1.10 \mathrm{E}-5$ & $1.63 \mathrm{E}-5$ \\
Spread via closed door & 60 & 20 & 70 & - & - & $1.54 \mathrm{E}-5$ & $1.56 \mathrm{E}-5$ \\
Spread via open door & 90 & 75 & 99 & - & - & $1.42 \mathrm{E}-5$ & $1.65 \mathrm{E}-5$ \\
\hline
\end{tabular}

Annual system failure probability

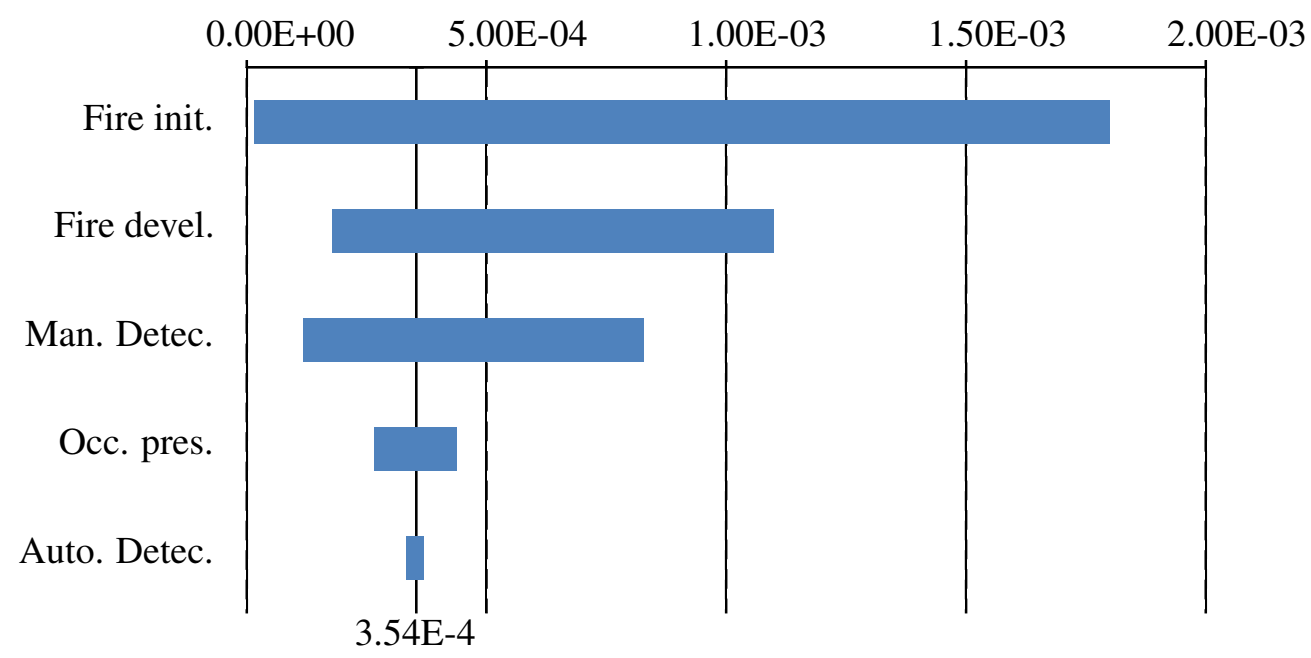

Figure 2: Tornado sensitivity diagram for the in-room model. 


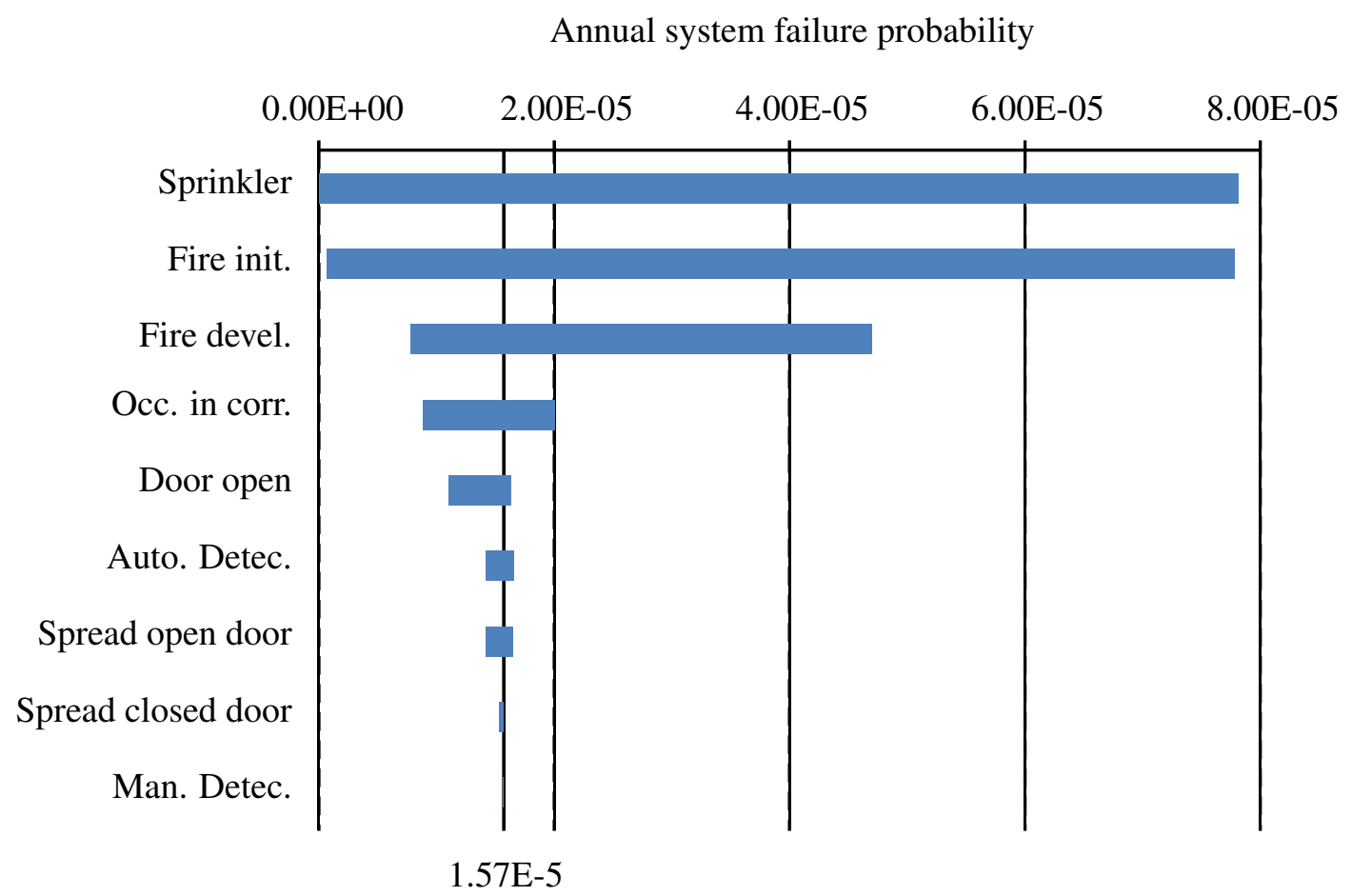

Figure 3: Tornado sensitivity diagram for the corridor model.

minutes after ignition). The automatic detection will actuate later within the fire course between 3 and 15 minutes while the tenability limit can already be reached after 4 minutes. This essentially means, that if the fire is manually detected the occupants are always able to escape, making the manual detection an ultimate decision gate, whereas the automatic detection is not. Changing automatic detection time to an earlier time span would significantly increase its sensitivity, as an additional Monte Carlo simulation of the system showed.

For the corridor model, the highest sensitivity (along with the aforementioned ignition frequency and fire development) can be seen for the sprinkler system as shown in figure 3 . While not playing a significant role within the room of fire ignition due to the comparatively late actuation with respect to the time to the development of untenable conditions [1], it can be seen here, that the sprinkler is ea strong barrier for the fire spread beyond the room of origin and for the structural fire protection $[9,3]$. This is also amplified by the modeling herein, where the sprinkler acts as an ultimate gate and a successful containment will not endanger any occupants in adjacent room. This, of course, could and should be investigated in more detail in further studies with numerical tools, such as proposed by Albrecht $[4,1]$.

Furthermore, the presence of occupants in the corridor and the state of the door (open/close) has some impact. Occurring later within the event tree, the fire spread probabilities only have a minor impact on the system reliability.The manual detection is directly dependent on the presence of occupants in the corridor and, therefore, the influence on the system is only minor. 
Table 2: Quantification of the impact of fire protection systems.

\begin{tabular}{l|rrrr}
\hline \hline & \multicolumn{2}{|c}{$\mathbf{P}_{f, \text { sys }}$} & \multicolumn{2}{c}{ Normalized [\%] } \\
System & In-room & Corridor & In-room & Corridor \\
\hline Baseline (all systems) & $3.54 \mathrm{E}-4$ & $1.57 \mathrm{E}-5$ & 100 & 100 \\
No Sprinkler & $3.54 \mathrm{E}-4$ & $6.40 \mathrm{E}-4$ & 100 & 2 \\
No auto. detection & $4.80 \mathrm{E}-4$ & $2.35 \mathrm{E}-5$ & 74 & 67 \\
No Fire doors & $3.54 \mathrm{E}-4$ & $1.75 \mathrm{E}-5$ & 100 & 90 \\
None & $4.80 \mathrm{E}-4$ & $1.30 \mathrm{E}-3$ & 74 & 1 \\
\hline \hline
\end{tabular}

\section{Influence of fire protection systems}

For all the examples above, including the sensitivity analysis, it was assumed that all the fire protection systems considered were operational with a certain probability of failure. The impact might be larger for this analysis than what was found in the previous section since the probability bounds in table 1 are rather narrow for some of the systems. For example, the lowest sprinkler reliability was chosen to be $90 \%$ which is still more favorable than the complete absence of such a system.

In order to assess the overall quantitative impact of a fire protection system, probabilistic analysis have to be performed for the system not being present. This can be easily modeled by setting the failure probability to $100 \%$, or the reliability to $0 \%$, respectively, implying that the system will always fail and thus is disregarded within the system analysis. The resulting system failure probability for the in-room and the corridor model can then be compared to the case in with the system is present with its assumed failure probability as described in section 2.

For the analysis herein, the following three systems were analyzed and compared to the above base case: sprinkler, automatic fire detection system, and fire doors. The results are shown in table 2. In addition, the system is analyzed with none of the fire protection systems present. The right-most columns for in-room and corridor are normalized against base case (100\%) and show the percentage of remaining safety in comparison to the base case which has all systems present and operational with their respective failure probability from section 2 .

The results again show the strong influence of the sprinkler system which can be, as mentioned above, attributed to the ultimate gate nature within the model. Other than that, the fire door have a marginal influence. This rather slight influence might be due to the fact that the original model above already accounted for open doors in $90 \%$ of the cases. The automatic detection system was identified to be the only system that has an impact within the room of fire origin. While this a due to the modeling it implicitly shows that most systems target directly at the fire spread, which is in accordance with the code objectives in, for example NFPA 101 [19, Section 4.11] that primarily requires protection for "occupants not intimate with the initial fire development".

For further analysis, the interaction between fire protection system could be analyzed as well as the influence of the various systems on the various occupancies shown in the next section in order to determine which system is most favorable for which occupancy. This could also contribute to a more risk-informed and performance-based allocation of assets for fire protection, which currently are as high as $10 \%$ of the total building cost [23]. 


\section{Occupancy-specific risk analysis}

Based on the findings above and incorporating the results of the sensitivity analysis, further studies can be conducted considering occupancy-specific input data in order to compare the emanating risks directly. For the analysis herein, the following occupancies were analyzed considering the same or a very similar underlying building geometry with multiple units connected with a corridor within a fire compartment:

Office occupancy considers the occupants to be awake and familiar with the surroundings as well as capable of self-egress within a comparatively short time frame. Since this was the data used for the original analysis herein, it constitutes the baseline case.

Residential occupancy is very similar to the office occupancy with the difference that the occupants might be asleep and thus the manual detection probability is reduced. In addition, the manual detection and response times are chosen to be slightly longer than for the office occupancy.

Hotel occupancy accounts for the occupants to be generally asleep and unfamiliar with the surroundings. Yet, general capability of self-egress after a prolonged pre-movement time (depending on the fire cue or alarm received) can be assumed.

Educational/School occupancy assumes that the teachers and students are awake and familiar with the surroundings but are subjected to higher stress and thus potentially irrational behavior during a fire emergency. Regular fire drills can improve the egress performance. It is generally assumed that the occupants are capable of self-egress (younger children possibly with the teacher's assistance), but might require additional time, which can be reflected within the RSET model.

Hospital/Nursing occupancy has the occupants most likely to be bed-ridden without the capability of self-egress. Horizontal evacuation with the assistance of the attending personnel can be assumed, but would most likely take a very long period of time. In addition, no means or data to model this situation are know to the author, so that for simplicity it is assumed herein that $\mathrm{RSET}=\infty$ for this occupancy so that the failure probability is solely based on the probability of fire spread ${ }^{2}$.

The models chosen for the occupancy-specific values for RSET, herein the manual detection times and the response time after a manual and automatic detection, respectively, are assumed to be uniform distributed (for the lack of better models) with the parameters shown in table 3 .

While it can be assumed that at least some of the input probabilities, such as presence of occupants, doors open/closed, etc. will differ among the various occupancies, the sensitivity analysis in section 3 showed that their impact on the overall safety is rather low so that their variation was omitted. The only exception is the manual detection in the in-room model, which-for the lack of better

\footnotetext{
${ }^{2}$ Enhanced models could consider a defend-in-place scenario, where the spread from the corridor or the room of origin into another room could be analyzed with the respective structural barriers (another door or wall rating, etc.) and ultimately the fire departments capability to control the fire before the spread as it is proposed by Thomas et al. [25]
} 
Table 3: Occupancy-specific stochastic models (in minutes) for manual detection and response time to manual and automatic detection, annual fire ignition frequency, and manual detection probability for an in-room fire.

\begin{tabular}{|c|c|c|c|c|c|c|c|c|}
\hline \multirow[b]{2}{*}{ Occupancy } & \multicolumn{2}{|c|}{ Man. detec. } & \multicolumn{2}{|c|}{ Resp. $\mathbf{m} / \mathbf{a}$} & \multirow{2}{*}{$\begin{array}{l}\text { Ign. prob. } \\
\text { [per annum] }\end{array}$} & \multirow{2}{*}{$\begin{array}{c}\mathbf{P}(\mathbf{m} \text { det }) \\
{[\%]}\end{array}$} & \multicolumn{2}{|c|}{$\mathbf{P}_{f, s y s .}}$. \\
\hline & Min. & Max. & Min. & Max. & & & In-room & Corridor \\
\hline Office & 0 & 2 & $0 / 0.1$ & $2 / 0.5$ & 0.01 & 70 & 0.000354 & $1.57 \mathrm{E}-5$ \\
\hline Residential & 0.5 & 2.5 & $0.5 / 0.1$ & $2.5 / 1$ & 0.03 & 50 & 0.0018 & $3.99 \mathrm{E}-5$ \\
\hline Hotel & 2 & 5 & 1/0.1 & $6 / 4$ & 0.037 & 20 & 0.0046 & $6.12 \mathrm{E}-5$ \\
\hline Educational & 1 & 4 & $3 / 1.5$ & $5 / 4$ & 0.04 & 50 & 0.0042 & 7.27E-5 \\
\hline Hospital & - & - & $\infty / \infty$ & $\infty / \infty$ & 0.3 & 0 & 0.0048 & $1.05 \mathrm{E}-4$ \\
\hline
\end{tabular}

data-has to be assumed for each occupancy herein and are shown in table 3 . The highly sensitive fire ignition probabilities are also given in table 3 which is based on the findings by Rahikainen and Keski-Rahkonen [22] and the data given in BS 7974 [8] and the German Eurocode Annex [9]. It should be noted, that the data has a large variability of up to one magnitude depending on the reference used.

The results based on the data used herein show that various occupancies can be simply assessed by using their respective annual fire ignition frequency and some simple, but reasonable assumptions about the occupants' response by variation of the stochastic model. For the analysis herein, the occupancy was only considered based on the RSET, while more complex models could also incorporate different models for the ASET. Nevertheless, the results show that all the occupancies produce results within the same order of magnitude with the exception of the office-occupancy which, besides having the most favorable parameter constellation, also has a comparatively low annual ignition frequency.

The other outlier is the risk beyond the room of ignition for the hospital occupancy. This can obviously be attributed to the model assumption, but also shows the vulnerability of occupants without the means of self-escape. This should definitely be considered in additional requirements (i.e. sprinkler systems, compartmentalization, fire rating of walls and doors) if a defend-in-place strategy is chosen.

\section{Summary and conclusions}

The study within this report showed the capability of a rather simple model in order to show the annual reliability levels of standard-type buildings with a rather straight-forward geometry. Such buildings would currently only be regraded with prescriptive codes, since performance-based fire protection engineering is usually only applied to complex and voluminous buildings that require special attention due to shortcomings to the current codes. Within this study, a simplified Monte Carlo and event-tree-based model was developed that is able to compute approximate probabilistic safety levels for the room of fire origin and the adjacent rooms within a fire compartment. While the assumptions are rather simple, they could be easily amended with more complex models using an 
approach as outlined in [20,2] oder even CFD-based risk analysis [5]. This would allow for a more in-depth understanding of the underlying processes and it would allow risk-informed, performancebased occupancy-specific source term values for the fire effects and input parameters for the egress modeling, as outlined by Albrecht [1].

Varying the probabilities of various decision gates within the system not only shows their impact on the system reliability, but unveils potential weak points within the system design. In addition, it shows which fire protection systems have a large impact and which do not. In the example above it was clearly shown that a sprinkler system might not have a significant impact on the tenability within the room of fire origin, but it significantly mitigates the hazard emanating form fire spread beyond the room of origin.

Furthermore, cases with and without the respective fire protection systems showed the quantitative impact of the systems with respect to the in-room and the corridor model. It was shown that especially the sprinkler system herein has a significant impact due to the modeling as an ultimate gate for the fire spread. While the systems only have a slight impact on the safety within the room of fire origin, a large influence can be seen for the corridor model. In further analyses, the underlying models, especially for fire spread, could be refined in order to derive more accurate results.

An occupancy-specific analysis yielded some information of the fire risk with respect to the occupancy. While it was difficult to find accurate data, especially for the fire ignition frequencies, some general conclusions can be drawn which are coherent with state-of-the-art risk assessment techniques. The event-tree-based approach shown herein can provide a basis for the future structuring of risk-informed and performance-based life safety codes by providing a systematic and quantitative basis for occupancy-specific risk assessment.

In further analyses, it is anticipated to significantly improve the data basis along with a more suitable stochastic model. The hard-bounded uniform distributions should be replaced with better models that also account for (physically reasonable) values beyond these bounds. In other studies by the author, normal, log-normal, or extreme value distributions were used with the appropriate caution with respect to the physical limits.

\section{Acknowledgments}

This study was conducted during a post-doctoral fellowship at the Department of Fire Protection Engineering at Worcester Polytechnic Institute (WPI) under the supervision of Prof. Brian Meacham. The work was generously supported by the National Institute of Standards and Technologies (NIST) under the grant "Characterization of Risk and Quantification of Design Fires" (Award 60NANB10D228). 


\section{References}

[1] Cornelius Albrecht. A risk-informed and performance-based life safety concept in case of fire. $\mathrm{PhD}$ thesis, Technical University of Braunschweig, Institute for Building Materials, Concrete Construction and Fire Protection (iBMB), May 2012. URL http://www.digibib.tu-bs . $\mathrm{de} /$ ?docid=00043585.

[2] Cornelius Albrecht and Dietmar Hosser. Probabilistic Assessment of Performance Criteria for Egress Design. In Van Gelder, Prokse, and Vrijling, editors, Proceedings of the 7th International Probabilistic Workshop, 2009.

[3] Cornelius Albrecht and Dietmar Hosser. A risk-informed framework for performance-based structural fire protection according to the Eurocode fire parts. In Proceedings of the 12th International Conference on Fire Science and Engineering (InterFlam9), 2010.

[4] Cornelius Albrecht and Dietmar Hosser. A Response Surface Methodology for Probabilistic Life Safety Analysis using Advanced Fire Engineering Tools. Fire Safety Science, 10:10591072, 2011. doi: http://dx.doi.org/10.3801/IAFSS.FSS.10-1059.

[5] Cornelius Albrecht and Dietmar Hosser. Probabilistic CFD and Evacuation Simulation for Fire Life Safety Assessment. In Proceedings of the first FEMTC (Fire and Evacuation Modeling Technical Conference), Baltimore, MD, USA, August 2011. Thunderhead Engineering.

[6] Cornelius Albrecht, Matthias Siemon, and Dietmar Hosser. Application of sensitivity analysis to specific problems in Fire Protection Engineering to identify the most critical parameters and to reduce dimensionality. In Lucjan Gucma, Dirk Proske, and Pieter van Gelder, editors, Proceedings of the 8th International Probabilistic Workshop in Szczecin, pages 13-26, November 2010.

[7] N. P. Bryner, D. Madrzykowski, and W. L. Grosshandler. Reconstructing the Station Nightclub Fire: Computer Modeling of the Fire Growth and Spread. In Proccedings of the 11th International Interflam Conference (INTERFLAM 2007), volume 2, pages 1181-1192. interScience Communications, September 2007.

[8] BS 7974. Application of fire safety engineering principles to the design of buildings. Code of practice. Technical report, British Standards Institution (BSI), 2001.

[9] DIN EN 1991-1-2/NA. National Annex - Nationally determined parameters - Eurocode 1 - Actions on structures - Part 1-2/NA: General actions - Actions on structures exposed to fire. Technical report, Normenausschuss Bauwesen (NABau) im DIN Deutsches Institut für Normung e.V., 2010.

[10] Hakan Frantzich. Uncertainty and Risk Analysis in Fire Safety Engineering. PhD thesis, Lund University Sweden, Department of Fire Safety Engineering, 1998.

[11] Hakan Frantzich. Risk analysis and fire safety engineering. Fire Safety Journal, 31:313-329, 1998. doi: http://dx.doi.org/10.1016/S0379-7112(98)00021-6.

[12] A. M. Hasofer, V. R. Beck, and I. D. Bennets. Risk Analysis in Building Fire Safety Engineering. Butterworth-Heinemann (Elsevier Science), Burlington, MA, 1. edition, 2007. 
[13] P. G. Holborn, P.F. Nolan, and J. Golt. An analysis of fire sizes, fire grwoth rates and times between events using data from fire investigations. Fire Safety Journal, 39:481-524, 2004.

[14] D. Madrzykowski, N.P.Bryner, and S. Kerber. The NIST Station Nightclub Fire Investigation: Physical Simulation of the Fire. Fire Protection Engineering, 31:34-46, 2006.

[15] Daniel Madrzykowski. Impact of a Residential Sprinkler on the Heat Release Rate of a Christmas Tree Fire, NISTIR 7506. Technical report, Department of Homeland Security, Washington, DC, 2008.

[16] Robert E. Melchers. Structural Reliability Analysis and Prediction. John Wiley \& Sons Ltd., Chichester, UK, 2. edition, 1999.

[17] N. Metropolis and S. Ulam. The Monte Carlo method. Journal of the American Statistical Association, 44:335-341, 1949. doi: http://dx.doi.org/10.1080/01621459.1949.10483310.

[18] Henri Mitler. Input Data for Fire Modeling. In13th Meeting of the UJNR Panel on Fire Research and Safety, 1996. URL http://fire.nist.gov/bfrlpubs/fire97/PDF/f97128. pdf.

[19] NFPA 101. NFPA 101: Life Safety Code. National Fire Protection Association (NFPA), 2008.

[20] Kathy A. Notarianni. The Role of Uncertainty in Improving Fire Protection Regulation. PhD thesis, Carnegie Mellon University, Pennsylvania, 2000.

[21] Fredrik Olsson. Tolerable Fire Risk Criteria for Hospitals. Master's thesis, Department of Fire Safety Engineering Lund University, Sweden, 1999. URL http://www4.lu. se/o. o. i.s?id=12972\&postid=605500. Report 3101.

[22] J. Rahikainen and O. Keski-Rahkonen. Statistical Determination of Ignition Frequency of Structural Fires in Different Premises in Finland. Fire Technology, 40:335-353, 2004.

[23] Ganapathy Ramachandran. The economics of Fire Protection. E \& FN Spon, London, UK and Routledge, New York, NY, 1998.

[24] Guillermo Rein, Cecilia Abecassis, and Richard Carvel, editors. The Dalmarnock Fire Tests: Experiments and Modelling. School of Engineering and Electronics, University of Edinburgh, November 2007.

[25] Ian R. Thomas, Ian D Bennetts, S. Leong Poon, and Julie A. Sims. The Effect of Fire in the Building at 140 William Street - A Risk Assessment. Technical Report BHPR/ENG/R/92/044/SG2C, BHP Research - The Broken Hill Proprietary Company Ltd. A.C.N. 004028 077, February 1992.

[26] David Yung. Principles of Fire Risk Assessment in Buildings. John Wiley \& Sons, Ltd., West Sussex (UK), 2008. 


\section{Annex E}

Risk-Informed and Performance-Based Life Safety Design in Atrium-Type Buildings 


\title{
Risk-informed and performance-based life safety design in atrium-type buildings
}

\author{
Cornelius Albrecht ${ }^{1}$ and Brian Meacham ${ }^{2}$ \\ ${ }^{1}$ Simpson, Gumpertz and Heger, New York, NY, USA \\ ${ }^{2}$ Dept. of Fire Protection Engineering, Worcester Polytechnic Institute, Worcester, MA, USA
}

\begin{abstract}
Performance-based fire protection design is often applied, where a traditional, prescriptive design is not feasible or is cost-prohibitive. However, the relative risk of the performance-based option is often not compared with the relative risk of the prescriptive solution. In this paper, a risk-informed approach based on probabilistic risk analysis is shown in order to quantify the risk emanating from various possible fire scenarios. In order to handle the high computational costs for the proposed analyses, a cloud computing-based non-linear response surface method is employed which enables the utilization of state-of-the-art numerical fire engineering tools, such as computational fluid dynamics (CFD) and complex egress simulation. The probability of failure of the scenarios as well as other considerations will be assessed in order to derive conclusions and recommendations for a more risk-informed and thus ultimately cost-optimized fire protection design.
\end{abstract}

\section{INTRODUCTION}

With modern, open architecture and a general movement towards an optimized and performancebased building design, the traditional approach to fire protection with prescriptive requirements and compartmentalization specifications is not applicable in many cases. Instead, numerical simulation of the fire and smoke propagation, occupant egress behavior and structural response is conducted in order to tailor a cost-benefit optimized fire safety concept for the particular building. In order to get these alternative, performance-based design options approved by the authorities having jurisdiction (AHJs), usually a proof of equivalency to the existing, prescriptive fire codes is required, which constitute a "deemed-to-satisfy" solution, i.e. they are considered safe by definition.

Currently, this proof of equivalency can only be shown qualitatively, for example for life safety by showing that the time of a fire to develop untenable conditions within the compartment of interest (available safe egress time, ASET) is longer than the time for the occupants to safely escape from that compartment (required safe egress time, RSET). Input parameters, fire scenarios, threshold values, etc. within this analysis are chosen by the fire protection designer and are agreed upon with the AHJs. In order to provide some form of implicit safety, these values are chosen to be deterministic and conservative, whereas an analysis of the uncertainty is usuallz omitted. Additionally, rather arbitrary safety factors $(\kappa)$ between 1.5 and 3.0 [1-6] are used, so that

$\operatorname{ASET} \stackrel{!}{\geq} \kappa \cdot \operatorname{RSET}$ 
in order to prove that a life safety design is safe. Obviously, ASET and RSET are highly dependent of the deterministic input parameters, scenarios, etc. chosen, so that different fire protection designers will ultimately have different solutions [7]. This uncertainty is even amplified if Eq. 1 is regarded as pass-fail option without looking at the margin of safety $\Delta t$ between ASET and RSET [8].

\section{PROBABILISTIC TREATMENT}

To address these shortcomings of the current analysis process, the input parameters $\left(x_{i}\right)$ which can be, for example, the maximum heat release rate $\left(\mathrm{HRR}_{\max }\right)$, fire growth rate, number of occupants, pre-movement times, etc., can be assumed uncertain. Probabilistic analysis can be conducted in order to quantify the probability of a proposed design solution to fail $\left(p_{f}\right)$, i.e. ASET $\leq$ RSET, so that under cosideration of Eq. 1

$p_{f} \equiv \operatorname{Pr}\left(\Omega_{f}\right)=\operatorname{Pr}\left(\operatorname{ASET}\left(x_{1 \ldots j}\right)-\operatorname{RSET}\left(x_{k \ldots n}\right) \leq 0\right)$

where $\Omega_{f}$ is the so-called failure domain of the limit state. The uncertain parameters $\left(x_{i}\right)$ can be considered to follow statistical distributions, and can (and should) be defined using available data and statistics.

In order to solve Eq. 2 and to compute $p_{f}$, the resulting joint distribution function $f(\mathbf{x})$ of all variables $x_{i}$ has to be integrated over $\Omega_{f}$, so that Eq. 2 can be solved

$p_{f}=\int \ldots \int f(\mathbf{x}) d \mathbf{x}$.

Despite this straightforward formulation it can be impossible to analytically find $f(\mathbf{x})$, since the evaluation of Eq. 2 required the utilization of numerical models, such as CFD and egress simulation tools. A common and robust method to solve the problem is the Monte Carlo simulation [9-11], which constitutes a numerical integration scheme. Herein, Eq. 3 is reformulated to

$p_{f}=\int \ldots \int I\left(\Omega_{f}\right) \cdot f(\mathbf{x}) d \mathbf{x}$

where $I\left(\Omega_{f}\right)$ is a so-called indicator function ${ }^{1}$. This formulation from Eq. 4 can be discretized for computational implementation to

$\hat{p}_{f}=\frac{1}{n} \sum_{i=1}^{n} I\left(\Omega_{f}\right)_{i}$,

$$
{ }^{1} I\left(\Omega_{f}\right)= \begin{cases}1 & \text { if } \in \Omega_{f} \\ 0 & \text { if } \notin \Omega_{f}\end{cases}
$$


where $n$ is a finite number of independent simulations. In order to achieve accurate results, a large number $n$ of simulations have to be performed, since $n \rightarrow \infty$ yields exact results due to the law of large numbers [12]. The big drawback of this method is obviously the high numerical costs, that are implied within the numerous required simulation runs.

\subsection{Response surface approach}

In order to reduce the numerical cost, an adaptive response surface method using a varianceoptimized Monte Carlo simulation was developed [13] which bypasses the high number of required simulations runs by replacing them with an approximative mathematical formulation that can be exploited at low numerical costs. The fitting of the surrogate or response surface model only requires a limited number of support points (i.e. actual simulation runs). To maximize the accuracy of fit of the surrogate models, the traditional approach using linear least-square regression models [14] was replaced with a moving least square formulation [15]. For an interpolative fit at the support points, the weighting function was chosen accordingly as outlined in $[13,16]$. The methodology is described in detail in [17] and thus is not reproduced in details here.

\subsection{Load distribution with cloud-based on-demand IaaS-HTC systems}

Despite the reduction of required simulation runs, still a rather significant numerical workload has to be dealt with, especially when it comes to analyses where multiple scenarios or complex geometries have to be evaluated. This workload can even exceed the computational resources that are available locally or would be too time-consuming if processed sequentially. For that reason, an cloud-computing interface was developed that uses the Infrastructure as a Service (IaaS) service model [18] in order to build on-demand high throughput computing (HTC) systems [19] in the Amazon Elastic Compute Cloud [20]. This is particularly applicable, as the various simulations are non-interacting and thus the problem can be deemed "embarrassingly parallel" [21] and can be distributed to loosely coupled computing instances. The computing instances are added and removed dynamically depending on the current workload and/or availability. This has the sideeffect of optimized resource utilization which is an ultimate driver for the cost-effectiveness. In previous studies, it was shown by the author that a 250 core HTC system could be build within 30 minutes [20], while other sources allegedly even built systems up to 50,000 cores [22].

Such scalable systems or even hybrid systems to extend the local in-house capacities with cloudinstances could provide sufficient computational resources at reasonable cost for most problems in fire protection engineering, even beyond the scope of probabilistic risk analysis. Other potential areas of application along with more details on the methodology developed can be found in [20].

\section{SCENARIOS AND PARAMETERS FOR AN ATRIUM-TYPE GEOMETRY}

In order to demonstrate the applicability of the developed methodology for generic examples beyond the scope of rather small geometries such as in $[13,17]$, an atrium-type building was chosen 


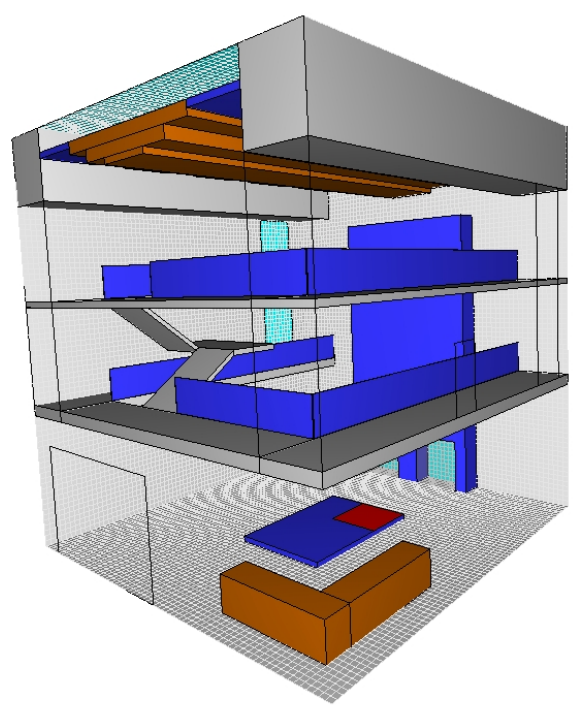

Fig. 1. The numerical model of the atrium geometry used within this work.

as depicted in Fig. 1. This type of building is usually subject to performance-based fire protection design since prescriptive fire codes are usually not sufficiently detailed or not applicable altogether [1]. Atria can be used for various purposes and thus occupancy and fire risk can differ significantly throughout even the course of one year. This will be accounted for within the various fire scenarios considered.

\subsection{Building description and analysis objectives}

The atrium shown in Fig. 1 is a generic example of an entrance to a medium-size office building and is supposed to create a welcoming and representative first impression to the occupants. The atrium contains space for a centrally located product display and a reception area for visitors. Offices are located on all levels (1-3) and are connected to the atrium or in corridors off the atrium. The corridors are separated from the atrium space with smoke-tight doors which automatically close upon actuation of the fire detection system and thus were deemed omissible within the fire simulation but will be considered within the egress analysis. Emergency stairs exist at the ends of each corridor, yet the offices are usually accessed through the atrium and the free stairs (and an elevator) within the atrium.

The main objective of the analysis is showing a safe egress case of a fire within the atrium. Despite the additional emergency stairs, it has to be assumed that a significant number of occupants will try to escape the building through the atrium since it constitutes the primary means of egress. Additionally, it has to be considered that the atrium can be used for special high-occupancy occasions such as receptions or seasonal events. This will be included in the risk analysis. 
Table 1. Stochastic model for the "standard" scenario.

\begin{tabular}{lc|lrrr}
\hline Parameter & Unit & Distribution & Mean & Std.-Dev. & Cov.-Var. \\
\hline $\mathrm{HRR}_{\max }$ & $\mathrm{MW}$ & Normal & 4 & 0.8 & $20 \%$ \\
$t_{g}$ & $\mathrm{~s}$ & Gumbel (min) & 250 & 30 & $12 \%$ \\
$y_{\mathrm{CO}}$ & $\mathrm{g} / \mathrm{g}$ & Normal & 0.090 & 0.030 & $33 \%$ \\
$y_{\mathrm{HCN}}$ & $\mathrm{g} / \mathrm{g}$ & Normal & 0.006 & 0.002 & $33 \%$ \\
$y_{\text {Soot }}$ & $\mathrm{g} / \mathrm{g}$ & Normal & 0.120 & 0.040 & $33 \%$ \\
\hline
\end{tabular}

\subsection{Fire and egress scenarios}

Three fire scenarios were identified to be of particular interest within the context of quantitative risk analysis, namely a "standard" fire which is based on the t-squared fire [23] with a linear incubation phase [24], a fire in the reception desk area based on the NIST kiosk fire tests [25], and a Christmas tree fire centrally located within the atrium, based on DHS fire tests [26].

\subsection{Standard fire scenario}

The "standard" fire scenario is analyzed herein, because it is based on the t-squared fire growth which is a common and generally accepted approach for the quantification of fire scenarios. The fire is assumed to increase the HRR quadratic over time until a maximum HRR is reached. The growth rate is usually given as the time $t_{g}$ in seconds until $1 \mathrm{MW}$ is reached or as $\alpha$ in $\mathrm{kW} / \mathrm{s}^{2}$, respectively. Based on the findings in [24] and looking the HRR courses of various fire tests [27], a linear phase of $t_{g}$ seconds was added in order to account for a fire incubation phase. The same scenario was also used in $[17,28]$ and thus yields a quantitative comparison between the atrium and the assembly building. The fire is placed centrally within the atrium, implying some form of product display (e.g. show car display). The stochastic model for the source terms was also adopted from the sources above and is given in Tab. 1.

\subsection{Kiosk}

In order to create a occupancy-specific scenario for the atrium space, a fire was assumed to develop within the reception area. The fire was assumed to behave similar to the NIST kiosk fire tests [25], and hence the stochastic model was developed based on the results of those tests. To conservatively envelop the fire, a t-squared fire with linear incubation was chosen (s. above and fig. 2). The uncertain fire source term parameters along with their distributions are shown in Tab. 2. 
Table 2. Stochastic model for the kiosk scenario.

\begin{tabular}{lc|lrrr}
\hline Parameter & Unit & Distribution & Mean & Std.-Dev. & Cov.-Var. \\
\hline $\mathrm{HRR}_{\max }$ & $\mathrm{MW}$ & Normal & 1.645 & 0.2 & $12 \%$ \\
$t_{g}$ & $\mathrm{~s}$ & Gumbel (min) & 400 & 100 & $25 \%$ \\
$y_{\mathrm{CO}}$ & $\mathrm{g} / \mathrm{g}$ & Normal & 0.050 & 0.0125 & $25 \%$ \\
$y_{\mathrm{HCN}}$ & $\mathrm{g} / \mathrm{g}$ & Normal & 0.003 & 0.0008 & $27 \%$ \\
$y_{\text {Soot }}$ & $\mathrm{g} / \mathrm{g}$ & Normal & 0.100 & 0.030 & $30 \%$ \\
\hline
\end{tabular}

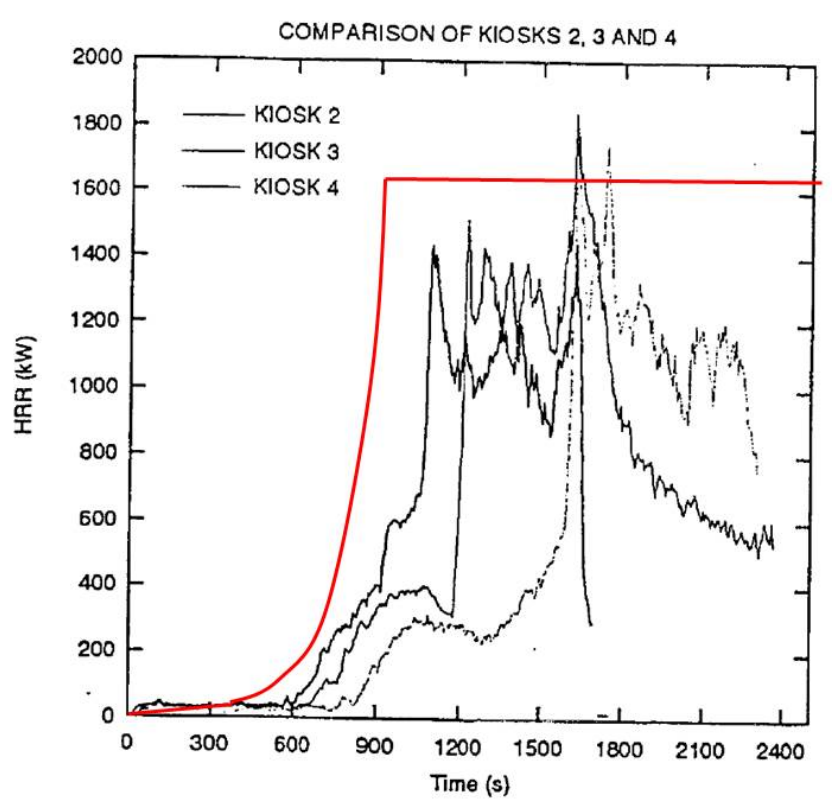

Fig. 2. Conservative derivation of the kiosk scenario. The red line shows the course of the enveloping mean scenario according to tab. 2. Not to scale. Adopted from [25].

\subsection{Christmas tree}

A third fire scenario of particular interest was an ultra-fast developing fire. Therefore, a fire of a large Christmas tree was assumed, which is placed in the atrium during the holiday season. In order to quantify the scenario, the Christmas tree fire data from the DHS [26] was used and extrapolated to a larger tree that would be assumed in the atrium. One of the main risks emanating from Christmas trees is the extremely fast fire growth to high maximum HRRs. In order to account for this in a conservative manner, a t-squared fire spread without incubation was assumed. Since the tree will burn out very quickly, approximately $70 \%$ of the fire load is assumed to be consumed after only 150 seconds and thereafter the fire will decay linearly and will burn out after 200 seconds. These assumptions are approximately coherent with the experimental data [26]. The uncertain parameters and their stochastic model for the reliability analysis is given in Tab. 3 . 
Table 3. Stochastic model for the Christmas tree scenario.

\begin{tabular}{lc|lrrr}
\hline Parameter & Unit & Distribution & Mean & Std.-Dev. & Cov.-Var. \\
\hline $\mathrm{HRR}_{\max }$ & $\mathrm{MW}$ & Normal & 3.05 & 1.3 & $43 \%$ \\
$t_{g}$ & $\mathrm{~s}$ & Gumbel (min) & 40 & 16.3 & $41 \%$ \\
$y_{\mathrm{CO}}$ & $\mathrm{g} / \mathrm{g}$ & Normal & 0.005 & 0.001 & $20 \%$ \\
$y_{\mathrm{HCN}}$ & $\mathrm{g} / \mathrm{g}$ & Normal & 0.001 & 0.0003 & $30 \%$ \\
$y_{\text {Soot }}$ & $\mathrm{g} / \mathrm{g}$ & Normal & 0.02 & 0.002 & $10 \%$ \\
\hline
\end{tabular}

Table 4. Stochastic model for the egress scenario.

\begin{tabular}{lc|lrrr}
\hline Parameter & Unit & Distribution & Mean & Std.-Dev. & Cov.-Var. \\
\hline Warning time & $\mathrm{s}$ & Normal & 60 & 15 & $25 \%$ \\
Pre-move. time & $\mathrm{s}$ & Gumbel (max) & $90 / 180$ & $25 / 45$ & $28 / 25 \%$ \\
Occ. density & occ./m² & Gumbel (max) & 1.5 & 0.5 & $33 \%$ \\
Velocity & $\mathrm{m} / \mathrm{s}$ & Normal & 1.25 & 0.3 & $24 \%$ \\
\hline
\end{tabular}

\subsection{Egress scenario}

The egress scenario analyzed herein is a high-occupancy scenario. It is assumed that the atrium is used to host a reception or gathering for, for example, a seasonal event. Hence, the atrium is assumed to have an occupant density usually found in assembly buildings. The balconies of the atrium are also highly occupied, whereas the office tracts (adjacent corridors and offices) have a normal office specific occupancy. The occupants are assumed to be both, unfamiliar and familiar with the building, as they could be guests/costumers and employees. Hence, around $70 \%$ of the occupants will try to exit the atrium through the main entrance. The stochastic models for both scenarios are given in tab. 4.

This scenario can be deemed rather conservative, since such an occupancy will realistically only occur infrequently. Yet, for the purpose of this study, it sufficiently envelopes all possible scenarios on the safe side. For further analyses, also a normal occupancy should be analyzed in order to assess the average safety levels. This could also be integrated in a multi-step system approach, where fire and egress scenarios can be linked according to their respective probability.

\section{PROBABILISTIC ANALYSIS}

The probabilistic analyses were conducted using the methodology described above with the stochastic models for the defined scenarios. In addition to the probabilities of a safe evacuation to fail $p_{f}$, sensitivities $\alpha_{i}$ can be derived for the input parameters in order to quantify the influence on the limit state variance.

While RSET is defined as the point in time when the last occupant reached a point of relative safety (i.e. left the atrium through the main exist or evacuated into an emergency stairwell), the definition of ASET largely depends on the threshold criterion chosen. Herein, two criteria were 
considered: a rather conservative momentary visibility criterion expressed by an optical density of $0.15 / \mathrm{m}$, which approximately corresponds to a visibility of $20 \mathrm{~m}[29,30]$, and a time-cumulative fractional effective dose model $[31,32]$ which considers asphyxiant fire effluents and heat (radiation and convection). For FED, values of 1.0 and 0.3 were chosen to determine untenability. The data required to determine ASET was recorded at every floor at $2 \mathrm{~m}$ above the floor level. This allows for a more detailed analysis on a floor-by-floor basis and to incorporate local phenomena, such as balcony spill plumes, etc. Additionally, the simulations were evaluated for smoke detector and sprinkler actuation times in order to develop appropriate stochastic models for future use.

\subsection{Standard scenario}

A first analysis for the standard scenario with the visibility threshold yielded a failure probability $p_{f}$ of $98.5 \%$. While this number is extremely high, this can be assumed extremely conservative since the comparison of ASET and RSET is based on under-running the visibility threshold at the third floor to the last person existing to a relative place of safety at a very high occupancy. In reality, the third floor balconies could be evacuated via the stairs and the adjacent corridors before the visibility threshold is reached. Occupants coming from the office tracts trying to evacuate through the atrium would be likely to turn around once they see the smoke when approaching the atrium. The closing of the smoke-proof doors between office corridors and atrium adds an additional safety margin for safe egress via the emergency stairs.

Looking at the sensitivities, the fire growth time to $1 \mathrm{MW} t_{g}$, the pre-movement time and the number of occupants have the highest sensitivities, with $\alpha_{t_{g}}=0.57, \alpha_{\text {pre }}=-0.58$, and $\alpha_{\# \text { occ }}=$ -0.58 , respectively. In total, these three parameters can explain $99 \%$ of the overall variance.

The same analysis with the FED values as threshold to determine ASET yielded the following results: none of the (support point) simulations returned a FED-value of 1.0 within the simulated time frame of 20 minutes, in which the egress was completed. Therefore, it can be assumed that for the chosen fire scenario, a FED of less than 1.0 can be defended-in-place. For a FED threshold of 0.3 which is sometimes conservatively used to account for vulnerable parts of the population $[1,3]$ yielded a $p_{f}$ of only $5.44 \%$, whereas the mean safety margin between ASET and RSET was $411 \mathrm{~s}(>6 \mathrm{~min})$.

For the latter FED analysis, the sensitivities for the most relevant parameters were $\alpha_{t_{g}}=0.87$, $\alpha_{\text {pre }}=-0.37$, and $\alpha_{\# \text { occ }}=-0.31$, respectively. In this case, the fire growth is the most relevant parameter, explaining $75 \%$ of the variability. All three parameters combined explain $98 \%$ of the variance.

A comparative analysis was performed where the threshold times for ASET with the visibility criterion were only determined for the first and second floor (at $2 \mathrm{~m}$ above floor level) while assuming that people will rather quickly move to the corridors or the lower levels at fire start ${ }^{2}$. Again, this time was compared to the conservative RSET that the left occupant left the compartment. In this approach, the failure probability $p_{f}$ significantly reduced from $98.5 \%$ to only $6.36 \%$, a more than factor 15 increase of the safety.

\footnotetext{
${ }^{2}$ The last occupant leaving the third floor balcony was at a mean of $30 \mathrm{~s}$.
} 
Obviously, the findings are due to the smoke-filling of the atrium, but is shows clearly that unreasonable assumptions (i.e. upper floor threshold vs. last person out of entire atrium) lead to biased numbers that do not reflect the actual level of safety within the compartment. An additional, yet deterministic analysis of the critical scenario identified (third floor visibility vs. evacuation from the third floor balconies) with conservative input parameters above showed that a safe egress will be possible.

As for the simulated fire protection systems, the smoke detectors (located centrally on the ceiling of the atrium) actuated at a mean of $49 \mathrm{~s}$, while the sprinklers above the fire and within the plume actuated at around $600 \mathrm{~s}$. As found in previous studies [17] sprinkler actuation can be directly correlated to the fire growth $\left(t_{g}\right)$ with an $R^{2}$ of greater than $99 \%$.

\subsection{Kiosk fire scenario}

While the standard scenario gives a good estimate of the safety level of a rather conservative scenario, the kiosk fire was chosen to have a occupancy-specific scenario. The thresholds for visibility and FED were assessed in the same manner as stated above in order to retain comparability. The probability of the visibility criterion to be under-run on the third floor before the last occupant has exited the fire compartment was calculated to be $p_{f}=43 \%$. While still being rather high, within this scenario, the probability of failure is only half as high as it was for the standard scenario due to the less conservative, but more occupancy-specific parameter set.

The highest sensitivities were, again, found for $t_{g}\left(\alpha_{t_{g}}=0.76\right)$, the pre-movement time ( $\alpha_{\text {pre }}=$ $-0.46)$ and the number of occupants $\left(\alpha_{\# \text { occ }}=-0.43\right)$, accounting for more than $97 \%$ of the variance, while $t_{g}$ is the dominating parameter accounting for about $57 \%$ of the variance.

Looking at the FED criterion in order to determine the conservative ultimate threshold, again none of the support point simulations yielded FED values of 1.0 for the simulated 20 minutes. Contrary to the standard scenarios, also none of the simulation reached a reduced FED value of 0.3 . The maximum values found for the FED when using high percentiles of the input distributions were around 0.15 at at a height of $2 \mathrm{~m}$ above the third floor level. Hence, further analyses with even more conservative FED values were omitted herein as the number of occupants and warming/premovement times are already assumed to be on the conservative side. Hence, for this scenario and set of input parameters the atrium can be assumed to provide a sufficient level of life safety.

The mean time to smoke detector actuation was $124 \mathrm{~s}$. This is due to the prolonged linear incubation phase with a low HRR at fire start. Also due the location of the fire partially underneath the balconies, the smoke has a longer travel distance and greater potential for dispersion before reaching the detectors. The sprinklers in the atrium ceiling did not activate during the simulated time of 20 minutes. This is most likely due to the fact that the fire is not powerful enough and the resulting balcony spill plume does not produce sufficient temperatures to actuate the system. Additional detectors and/or sprinkler underneath the balconies will most likely actuate significantly earlier so that the systems would be more effective. Unfortunately, this was omitted during the setup of the simulation model. 
This scenario based on the NIST kiosk fire is more specific for the anticipated occupancy of the atrium, but it is less conservative when it comes to the severity of the impact. Since performancebased design is also targeted at providing the most cost-effective design, the specific selection of scenarios (in addition of prescribed scenarios from the codes) should be an essential part of the engineering analysis.

\subsection{Christmas tree fire}

While this scenario is less severe when it comes to effluent production rates (see Tab. 3), it is an extremely fast developing fire without any incubation phase, so it could potentially over-run the protection systems. In addition to the fast fire growth, a comparably high peak HRR of the tree is reached rather early during the course of the fire. This is reflected in the results for the visibility threshold which yielded a failure probability $p_{f}$ of more than $99 \%$, implying that the visibility criterion will almost always be reached ( $2 \mathrm{~m}$ above the third floor balcony) before the last occupant has left the atrium compartment. Yet it should be noted, that at the same time as the $0.15 / \mathrm{m}$ optical density threshold was nearly always reached, the highest values of the optical density from the support point simulations were around $0.25 / \mathrm{m}$ for the high percentile input parameter sets. Since these values imply a visibility of around $4-5 \mathrm{~m}$, it should not be seen as critical. In addition, since the fire load of the Christmas tree is consumed rather fast with the fire ending after around four minutes, a subsequent increase of the visibility can be expected as well.

This can also be seen for the FED analysis, which is a time-integrated criterion as stated above. Herein, the maximum FED values reached in the support point simulation were only around 0.1 , denoting that occupants on the third floor might me affected by the fast developing fire, but are unlikely to be severely harmed or even incapacitated. In addition, the warning and pre-movement times were conservatively not reduced for this scenario, but it is highly likely that the occupants would begin the egress when a certain fire cue is recognized (i.e. a fire size that is deemed threatening, etc.).

As for the fire protection systems, the smoke detectors would actuate with a mean of $23 \mathrm{~s}$, while the sprinklers either actuated within a maximum of $120 \mathrm{~s}$ of fire start or the fire did not generate enough heat to actuate the sprinkler at all. This highly depended on the input parameter set of the support point simulation and the maximum HRR can be directly correlated to the actuation state as well as the time in case of actuation.

Despite the fast fire development and the severity of this scenario, the atrium can be deemed safe under the premise that, for severe scenarios, it should be allowed to expose the occupants to small amounts of smoke that barely affect but never prevents safe egress entirely [33,34]. Yet, this is currently usually not the case in nearly all legislations or fire-specific codes. For that reason, a more hierarchical approach would be highly desirable.

\subsection{System analysis}

Even though the calculated failure probabilities are partially rather high, they have to be regarded in the context of the safety levels of other safety concepts, for example the structural Eurocode 
safety concept [35], where the requirements are stated in terms of acceptable failure probabilities. Those failure probabilities are referenced for a one-year-period. Since a hostile building fire is not a permanent, but an exceptional event, the fire frequency has to be taken into account. According to [36,37] and in analogy to [13], the annual frequency of a fire could be chosen to be, for example,

$p_{f i}=2 E^{-2} / y$ which is then multiplied with $p_{f}$. In the perspective of annual failure probabilities, the numbers can then be compared to other annual probabilities or annual reliability requirements. Additional information on system analysis within a probabilistic analysis can be found in other publications by the authors.

\section{SUMMARY, CONCLUSIONS \& OUTLOOK}

The preliminary results of the probabilistic analyses showed a broad variety of results, yet some general conclusions can be drawn. Besides the known fact, that the selection of the scenarios and input parameters is absolutely crucial for the design process, the analyses clearly showed that the fire growth rate $t_{g}$, the pre-movement time, and the number of occupants are the most crucial parameters for the life safety process when t-squared or modified t-squared fire development curves are assumed [17]. Knowing about these parameters and their implications allows fire protection engineers to focus on the choice of the relevant inputs.

In addition to the scenarios and parameters, the choice of the threshold criteria is also an important step in the design process. While there are obvious differences between momentary visibility criteria like the optical density and the time-integrated dose models like FED, the choice of the "correct" threshold values might not be as obvious. Using the traditional pass/fail approach to determine ASET potentially leads to a bias, as it can be seen above for the Christmas tree scenario: even though the threshold of around $20 \mathrm{~m}$ visibility will be under-run in $99 \%$ of the cases, visibilities of less than around 4-5 $\mathrm{m}$ are not expected either. The choice of only one criterion therefore could lead to overly conservative or too optimistic solutions.

Besides these considerations, a more structured approach should be undertaken as to where (location, height, etc.) and how (criterion, model, etc.) to assess the tenability in order to define ASET. The same applies to the determination of RSET from the egress simulation, which is usually simply defined as the last occupant leaving the simulated compartment. In the applied example herein, the last occupant will exit the atrium through the main exit door at the ground level of the atrium, while the criteria are reached at the third floor balconies. A comparison of these particular values implies a margin of safety which completely remains unquantified despite the probabilistic efforts herein.

Compared to the quantified example from [13], it is obvious that the results are in same range of magnitude and especially the parameters with the highest sensitivities proved to be the same. This is a significant first step towards the development of a safety concept that is based on a more risk-informed approach by looking at a quantitative metric, i.e. the failure probabilities of a life safety design in case of fire, instead of using (only) qualitative educated guesses and engineering assumptions. 
Also, further analysis should be performed by the fire engineer when it comes to the utilization of the classical ASET/RSET approach. In addition to the remarks in [8], in such analysis it is crucial to structure how exactly ASET and RSET are determined. This could include, but is not limited to, a possible multi-step approach, i.e. for the atrium this could be the analysis of local performance on the third floor and an additional analysis of the entire atrium and/or, for example, an in-depth analysis of the underlying uncertainties and minimum/maximum values of the threshold criteria instead of the current pass/fail approach.

Linking the various fire and egress scenarios with a corresponding performance criterion could also yield some further knowledge about the total risk to life safety. For example, worst case fire scenarios can be linked with less severe egress scenarios and vice versa considering the probability of each scenario to occur.

Conservative criteria such as the FED could, in addition, be linked to more severe scenarios, so that the validation is similar to the "ultimate limit" states within the structural codes [38], while less severe scenarios should be analyzed with, for example, visibility criteria, constituting an equivalent to the "serviceability limits" in structural codes. Thus, the solution would be reasonable and not overly conservative, but the worst-case scenario would still be considered in the analysis process.

\subsection{Recommendations for a risk-informed, performance-based life safety design framework}

Figure 3 shows the various elements of a proposed risk-informed and performance-based life safety concept. Within the framework of such a concept, various elements would have to be defined. These elements can be categorized into basic elements and performance elements. While the former include basic requirements and definitions, validation problems for the numerical models, and a hierarchy that regulates the models and the required competencies of the designers, the latter are more focused on the performance part, including, but not limited to, threshold criteria and their treatment, a (semi-) probabilistic safety concept and/or at least an uncertainty assessment framework, and concise specifications for modeling, input data, and effects of fire protection systems.

As stated in [17], a safety concept could be anticipated that uses semi-probabilistic partial safety factors $\gamma_{i}$ which are based on the respective sensitivities $\alpha_{i}$ for the most relevant input parameters derived above. The partial safety factors could, in analogy to the Eurocode approach [35], be calculated considering their input distribution and their 90-percentiles, so that for a normal distributed parameter

$\gamma_{i}=\frac{1+\alpha_{i} \cdot \Phi^{-1}\left(p_{f, r e q .}\right) \cdot V_{i}}{1+1.28 \cdot V_{i}}$

where $\alpha_{i}$ is the sensitivity and $V_{i}$ the variance of the underlying normal distributed parameter, $\Phi^{-1}(\cdot)$ is the inverse normal distribution, and $p_{f, r e q}$. is the acceptable failure probability. Equation 6 has to be changed to account for other distributions accordingly [39]. 
This, in conjunction with acceptable safety levels in a form of reliability requirements $p_{f, r e q}$. embedded within a framework would lead to a more comprehensive and objective, and thus riskinformed and performance-based life safety design that replaces the traditional "black box"-approach when it comes to achieved safety.

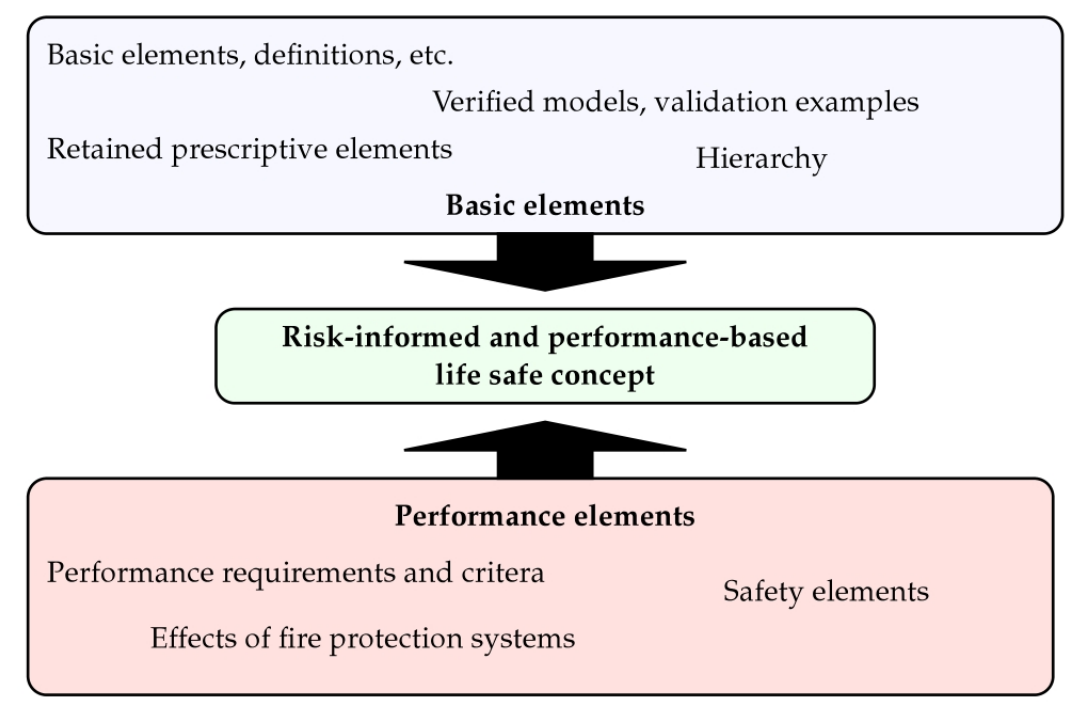

Fig. 3. Various aspects and elements of a framework for a more comprehensive risk-informed and performance-based life safety code.

\section{ACKNOWLEDGEMENTS}

This work was supported by a fellowship within the Postdoc-Program of the German Academic Exchange Service (DAAD) and grant \#219810 from the US National Institute of Standards and Technology (NIST).

\section{REFERENCES}

[1] Friedrich Mehl. Richtlinien für die Erstellung und Prüfung von Brandschutzkonzepten. In Dietmar Hosser, editor, Praxisseminar Brandschutz bei Sonderbauten, volume 178. Institut für Baustoffe, Massivbau und Brandschutz, TU Braunschweig, 2004.

[2] BS 7974. Application of fire safety engineering principles to the design of buildings. Code of practice. Technical report, British Standards Institution (BSI), 2001.

[3] Jeffrey S. Tubbs and Brian J. Meacham. Egress Design Solutions - A guide to Evacuation and Crowd Management Planning. John Wiley \& Sons, Inc., Hoboken, NJ, 1. edition, 2007.

[4] R. Johnson and G. Timms. Performance-based Design of Shopping Center Fire Safety. In Proceedings of the First International ASIAFLAM Conference 1995, Hong-Kong, March 1995. Inter-Science Communications Ltd. 
[5] G. Deakin and G. Cooke. Future Codes for Fire Safety Design. Fire Safety Journal, 23(2): 193-218, 1994. doi: http://dx.doi.org/10.1016/0379-7112(94)90026-4.

[6] vfdb-Leitfaden. Leitfaden Ingenieurmethoden des Brandschutzes, Technischer Bericht TB 04/01, 2. Auflage. Dietmar Hosser (Hrsg.), Verein zur Förderung des deutschen Brandschutzes e.V. (vfdb), Altenberge, Braunschweig, Mai 2009.

[7] Society of Fire Protection Engineers (SFPE). 8th International Conference on PerformanceBased Codes and Fire Safety Design Methods - Proceedings \& Case Studies. 2010.

[8] Vytenis Babrauskas, Joseph M. Fleming, and B. Don Russell. REST/ASET, a flawed concept for fire safety assessment. Fire and Materials, 34:341-355, 2010. doi: http://dx.doi.org/10. 1002/fam.1025.

[9] N. Metropolis and S. Ulam. The Monte Carlo method. Journal of the American Statistical Association, 44:335-341, 1949. doi: http://dx.doi.org/10.1080/01621459.1949.10483310.

[10] Reuven Y. Rubinstein. Simulation and the Monte Carlo Method. John Wiley \& Sons, Inc., Hoboken, NJ, 1981.

[11] George S. Fishman. Monte Carlo - Concepts, Algorithms and Applications. Springer-Verlag New York, Inc., NY, 1995.

[12] I. N. Bronstein, K. A. Semendjajew, G. Musiol, and H. Mühlig. Taschenbuch der Mathematik. Wissenschatflicher Verlag Harri Deutsch GmbH, Frankfurt/Main, 7. edition, 2008.

[13] Cornelius Albrecht and Dietmar Hosser. A Response Surface Methodology for Probabilistic Life Safety Analysis using Advanced Fire Engineering Tools. Fire Safety Science, 10:10591072, 2011. doi: http://dx.doi.org/10.3801/IAFSS.FSS.10-1059.

[14] Christian G. Bucher and U. Bourgund. A Fast and Efficient Response Surface Approach for Structural Reliability Analysis. Structural Safety, 7(1):57-66, 1990. doi: http://dx.doi.org/ 10.1016/0167-4730(90)90012-E.

[15] P. Lancaster and K. Salkauskas. Surfaces generated by moving least squares methods. Mathematics of Computation, 37(155):141-158, 1981. doi: http://dx.doi.org/10.1090/ S0025-5718-1981-0616367-1.

[16] Thomas Most and Christian Bucher. A Moving Least Squares weighting function for the Element-free Galerkin Method which almost fulfills the essential boundary conditions. Structural Engineering and Mechanics, 21(3):315-332, 2005.

[17] Cornelius Albrecht. A risk-informed and performance-based life safety concept in case of fire. PhD thesis, Technical University of Braunschweig, Institute for Building Materials, Concrete Construction and Fire Protection (iBMB), May 2012. URL http://www.digibib. tu-bs.de/?docid=00043585.

[18] Peter Mell and Timothy Grance. The NIST Definition of Cloud Computing, Special Publication 800-145. Technical report, National Institute for Standards and Technology, 2001. 
[19] Frédéric Magoulès, Jie Pan, Kiat-An Tan, and Abhinit Kumar. Introduction to Grid Computing. CRC Press, Taylor and Francis Group, Boca Raton, FL, 2009.

[20] Cornelius Albrecht. Cloud Computing for High-Throughput Problems in Fire Protection Engineering. Submitted to Automation in Construction, Manuscript Number AUTCON-D13-00037, January 2013.

[21] Ian Foster. Designing and Building Parallel Programs: Concepts and Tools for Parallel Software Engineering. Addison Wesley, 1995.

[22] Cycle Computing LLC. CycleCloud Achieves Ludicrous Speed! (Utility Supercomputing with 50,000-cores). http://blog.cyclecomputing.com/2012/04/ cyclecloud-50000-core-utility-supercomputing.html, 2012. [Online; accessed 12-19-2012].

[23] Gunnar Heskestad. Engineering Relations for Fire Plumes. Fire Safety Journal, 7(1):25-32, 1984. doi: http://dx.doi.org/10.1016/0379-7112(84)90005-5.

[24] Dieter Brein and Thomas Hegger. Innenraumluftqualitit im Brandfall. Bauphysik, 27(4): 234-240, 2005. doi: http://dx.doi.org/10.1002/bapi.200590058.

[25] Henri Mitler. Input Data for Fire Modeling. In 13th Meeting of the UJNR Panel on Fire Research and Safety, 1996. URL http://fire.nist.gov/bfrlpubs/fire97/PDF/f97128.pdf.

[26] Daniel Madrzykowski. Impact of a Residential Sprinkler on the Heat Release Rate of a Christmas Tree Fire, NISTIR 7506. Technical report, Department of Homeland Security, Washington, DC, 2008.

[27] R. Peacock, R. Portier, and P. Reneke. FastDATA 1.0, NIST Standard Reference Database Number 75, Online Preview Release, January 1999. URL http://fire.nist.gov/fastdata/. accessed Oct 28, 2010.

[28] Cornelius Albrecht and Dietmar Hosser. Probabilistic CFD and Evacuation Simulation for Fire Life Safety Assessment. In Proceedings of the first FEMTC (Fire and Evacuation Modeling Technical Conference), Baltimore, MD, USA, August 2011. Thunderhead Engineering.

[29] Tadahisa Jin. Visibility and Human Behavior in Fire Smoke, volume 1, chapter 2-6, pages 2-42-2-53. National Fire Protection Association (NFPA), Quincy, MA, 3rd edition, 2002.

[30] David A. Purser. Toxicity Assessment of Combustion Products, chapter 2-6, pages 2-83-2171. National Fire Protection Association (NFPA), 3 edition, 2002.

[31] David A. Purser. Assessment of Hazards to Occupants from Smoke, Toxic Gases, and Heat, chapter 2-6, pages 2-96-2-193. National Fire Protection Association (NFPA), 4 edition, 2008.

[32] Louise C. Speitel. Fractional effective dose model for post-crash aircraft survivability. Toxicology, 115:167-177, 1996. doi: http://dx.doi.org/10.1016/S0300-483X(96)03505-6. 
[33] Matthias Siemon, Cornelius Albrecht, and Dietmar Hosser. Considerations for the development of a quantitative life safety design concept using performance based fire engineering methods. In Proceedings of the 9th SFPE International Conference on Performance-Based Codes and Fire Safety Design Methods, 2012.

[34] Matthias Siemon, Cornelius Albrecht, and Dietmar Hosser. Reliability assessment of safe egress in case of a fire incident using Adaptive Importance Sampling. In 11th International Probabilistic Safety Assessment and Management Conference and the Annual European Safety and Reliability Conference 2012 (PSAM11 ESREL 2012). Curran Associates, Inc., 2012.

[35] DIN EN 1991-1-2/NA. National Annex - Nationally determined parameters - Eurocode 1 - Actions on structures - Part 1-2/NA: General actions - Actions on structures exposed to fire. Technical report, Normenausschuss Bauwesen (NABau) im DIN Deutsches Institut für Normung e.V., 2010.

[36] Cornelius Albrecht and Dietmar Hosser. A risk-informed framework for performance-based structural fire protection according to the Eurocode fire parts. In Proceedings of the 12th International Conference on Fire Science and Engineering (InterFlam9), 2010.

[37] Cornelius Albrecht and Dietmar Hosser. Probabilistic Assessment of Performance Criteria for Egress Design. In Van Gelder, Prokse, and Vrijling, editors, Proceedings of the 7th International Probabilistic Workshop, 2009.

[38] DIN EN 1990. Eurocode: Grundlagen der Tragwerksplanung, German Edition. Technical report, Normenausschuss Bauwesen (NABau) im DIN Deutsches Institut für Normung e.V., 2002.

[39] Dietmar Hosser, Astrid Weilert, Christoph Klinzmann, Ralf Schnetgöke, and Cornelius Albrecht. Abschlussbericht zum Forschungsvorhaben "Erarbeitung eines Sicherheitskonzeptes für die brandschutztechnische Bemessung unter Anwendung von Ingenieurmethoden gemäß Eurocode 1 Teil 1-2 (Sicherheitskonzept zur Brandschutzbemessung)". Technical report, Institut für Baustoffe, Massivbau und Brandschutz (iBMB), TU Braunschweig, November 2008. 
Annex F

HRR_Catalog: Database on Heat Release Rates of Real Products 


\title{
The Vulcan Initiative
}

\author{
Step 5: Fire Risk Analysis (Impact)
}

Fire Effects Tool Databases

\section{HRR_Catalog: Database on Heat Release Rates of Real Products Rev. 0}

Alberto Alvarez Rodriguez and Manuel Hurtado AON Fire Protection Engineering 4 Overlook Point, Lincolnshire, IL 60069 (USA)

\author{
Brian J. Meacham \\ Department of Fire Protection Engineering \\ Worcester Polytechnic Institute, Worcester, MA 01609 (USA)
}

June 28, 2014 


\section{How to use the "HRR_catalog”" spreadsheet}

The "HRR_catalog” has been established to be a free repository of information about one of the major components of Fire Protection Engineering: the Heat Release Rate (HRR). One of the main sources of HRR consists of the eponym chapter by Vytenis Babrauskas in the SFPE Handbook of Fire Protection Engineering (Section 3, Chapter 1 for the $4^{\text {th }}$ edition). The "HRR_catalog" objective is to collect heat release rates of "real products" or items that could be considered in an engineering analysis requiring fire modeling. Thus, the "HRR_catalog” contains HRR evolution with time (called "HRR curves") of mattresses and wardrobes or of office worker cubicles that could be used to assess the consequences of a fire in a hotel guestroom or an office open space, respectively.

The origin of the "HRR_catalog" came after noticing that even if the aforementioned source is unmatched in terms of contents (as it includes real products alphabetically ranging from beddings to windows made of plastics), its printed format could be improved in the era of information technology. For instance, publication restrictions of the SFPE Handbook generate updates every few years ( $3^{\text {rd }}$ edition: 2002, $4^{\text {th }}$ edition: 2008) and it is not practicable to devote hundreds of pages on this particular but essential topic in a single book covering all the aspects of fire protection engineering.

As a consequence, it was thought that providing information on the Internet would remove these restrictions in terms of space and content update. Attempts were made and webpages can be found but, unfortunately, instead of expanding the paper format, these webpages condensed even more the information presented in the SFPE Handbook under the form of tables. Besides, these attempts were proposed by individuals who could not maintain or update their webpages.

Within the Vulcan Initiative, participants would have the opportunity to help implementing a database or catalog for heat release rates. A more pragmatic approach than a webpage configuration has been taken so that the information would not be contained (and therefore restricted) to the limits of webpage visualization but expended, as needed in separated and self-supported files.

By its own nature, the heat release rate data is graphic and consists of the evolution of the HRR with time. Other information related to the test performed to obtain the HRR data can be associated with parameters such as the nature of the test, time to the maximum HRR or if additional measurements were made during the test (soot, CO...). As a consequence, it was decided to use a Microsoft Excel spreadsheet to gather all the information regarding heat release rates of real products. Excel presents the advantage to be relatively easy to use, widely known in Academia and work environment and with the latest version, it is possible to share the same document "on the Cloud" so that a single document is used and can be updated by multiple participants of the Vulcan Initiative.

This present document explains the organization of the contents of the "HRR_catalog" spreadsheet, and then how a participant to the Vulcan Initiative can help implementing it for the benefits of the Fire Protection Engineering community. 


\section{1. “HRR_catalog” spreadsheet Overview}

The "HRR_catalog" information for each "real product" is located in two different sheets:

- the "Overview" sheet ( $1^{\text {st }}$ sheet, at the left of the sheet tabs) which serves as a table of contents. Each collected item in the Overview sheet will have a unique item number that is hyperlinked to the following sheet.

- the "item" sheet which contains all the detailed information of the test conducted to obtain the heat release rate curve of the corresponding item.

\section{Instructions on how to create a new "Item" sheet}

The "HRR_catalog” will open at the "Item template” sheet, presented in Figure 1.

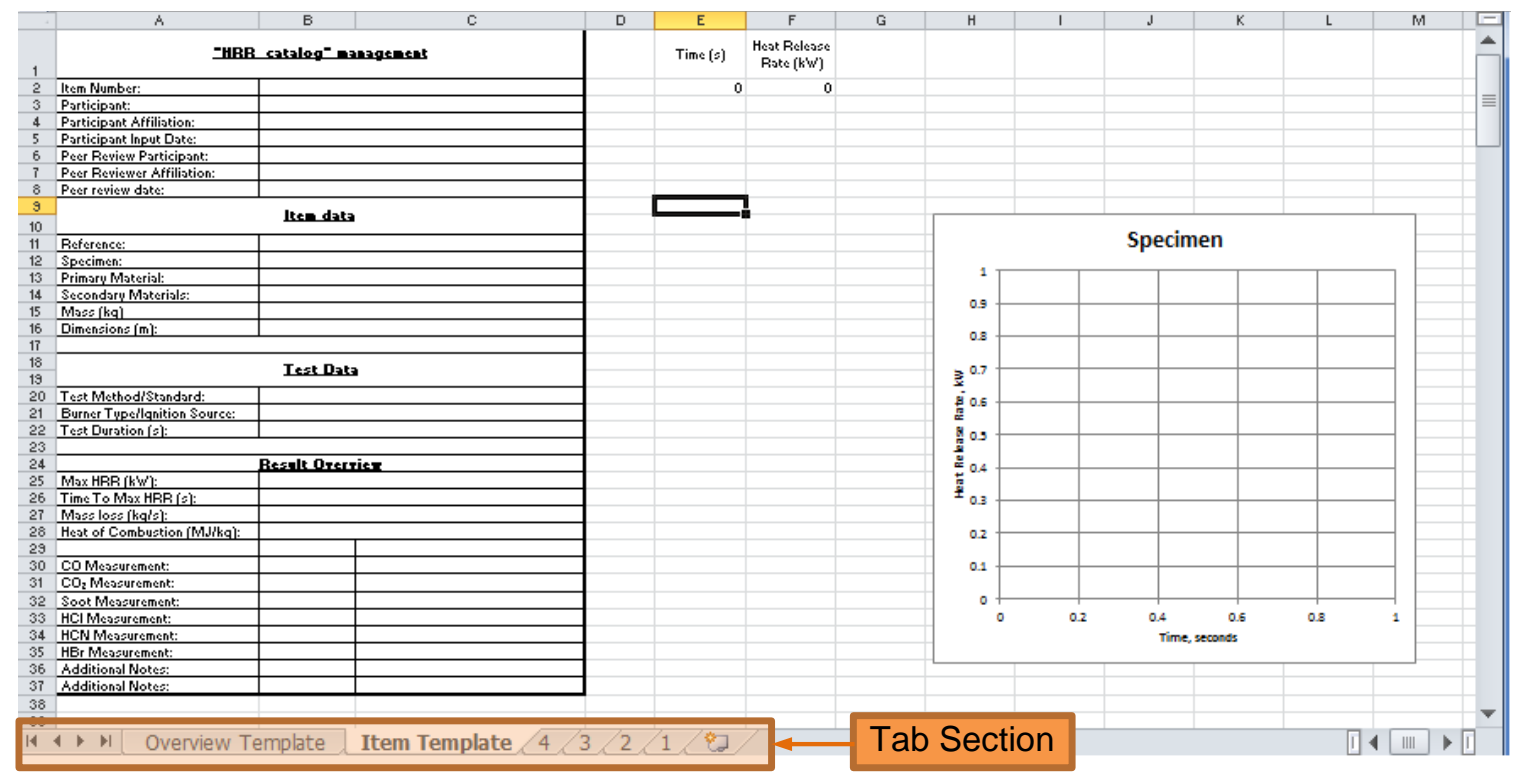

Figure 1. View of the "Item template” sheet of the "HRR_catalog” spreadsheet

In the "tab" section at the bottom left of the Excel window, the following sheets would appear, from Left to Right:

- The "Overview Template" sheet,

- The "item Template" sheet,

- "Items" sheets, named with a specific number, in decreasing order. In Figure 1, the HRR_catalog only contains 4 items.

The first task is to "copy" the "Item template" and rename it with the Item number immediately at the right of the "Item Template" sheet, incremented of " 1 ”.

- Right click on the "Item Template" Tab,

- Select "Move or Copy" in the menu, and in the corresponding window, select the number immediately below "Item Template" (it should be the highest number in the list), 


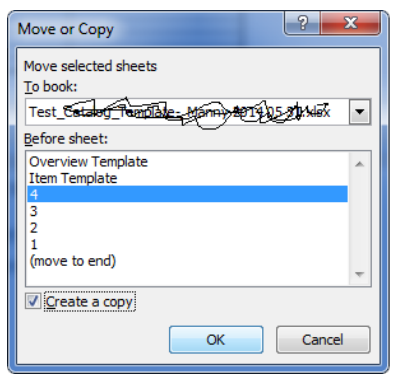

- The sheet "Item Template (2)" is created. It needs to be immediately renamed with the Item number immediately at its right, incremented of " 1 ” (In our case, “5”).

You are now ready to fill up a new “item”.

\section{Instructions on how to fill up a new "Item" sheet}

You start a new "Item" sheet with a sheet identical to the one presented in Figure 2.

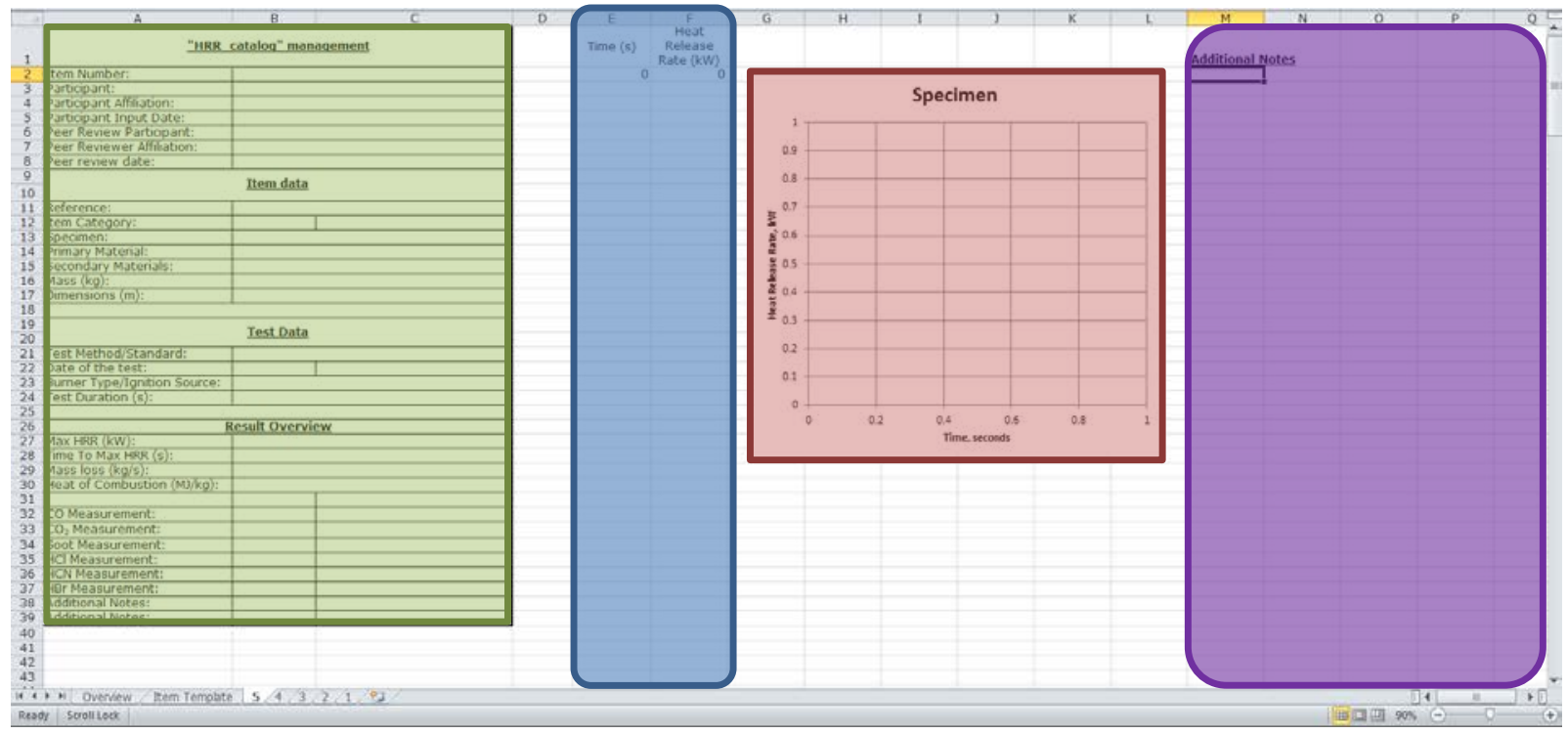

Figure 2. View of the different parts of an "Item" sheet newly created (here "5") of the "HRR_catalog" spreadsheet and ready to be filled up by a participant

The "Item" sheet is composed of four parts:

- Parameters of the "Item" which do not only include data about the tested item and the test measurements but also the "item" management, which is an important part of the peer review process required by the management of the Vulcan Initiative,

- Columns of values so that the participant can describe the evolution with time of the heat release rate,

- The corresponding graph of the HRR curve,

- Additional notes about the test and comments from the participant about the test. 


\subsection{Filling up the "Item" parameter part}

Table 1 (in 5 parts a) to e) ) explains all the parameters, as well as gives some examples of acceptable and unacceptable inputs.

Table 1. Content description of the "Item" parameter part

\begin{tabular}{|c|c|c|c|}
\hline Parameter & Parameter Explanation & Acceptable Inputs & Unacceptable Inputs \\
\hline \multicolumn{4}{|c|}{ "HRR_catalog" management } \\
\hline Item Number & $\begin{array}{l}\text { Sequential order from the last } \\
\text { Item Number. See Section } 2 \text { to } \\
\text { see how an item number is } \\
\text { attributed }\end{array}$ & Integers & \\
\hline Participant & $\begin{array}{l}\text { Name of the participant filling } \\
\text { up the new "Item" sheet }\end{array}$ & & \\
\hline Participant Affiliation & $\begin{array}{l}\text { Affiliation of the participant } \\
\text { filling up the new "Item" } \\
\text { sheet }\end{array}$ & & \\
\hline Participant Input Date & $\begin{array}{l}\text { Date of the "Item" sheet } \\
\text { completion and submittal to } \\
\text { the Vulcan Initiative }\end{array}$ & $\begin{array}{l}\mathrm{dd} / \mathrm{mm} / \text { yyyy } \\
\text { (day, month, year) }\end{array}$ & \\
\hline Peer Review Participant & $\begin{array}{l}\text { Name of the peer-reviewer } \\
\text { checking the "Item" sheet }\end{array}$ & & \\
\hline Peer Reviewer Affiliation & $\begin{array}{l}\text { Affiliation of peer-reviewer } \\
\text { checking the "Item" sheet }\end{array}$ & & \\
\hline Peer review date & $\begin{array}{l}\text { Date of the completion of the } \\
\text { "Item" sheet peer review }\end{array}$ & $\begin{array}{l}\mathrm{dd} / \mathrm{mm} / \text { yyyy } \\
\text { (day, month, year) }\end{array}$ & \\
\hline
\end{tabular}

a) "HRR_catalog" management Parameters 


\begin{tabular}{|c|c|c|c|}
\hline Parameter & Parameter Explanation & Acceptable Inputs & Unacceptable Inputs \\
\hline \multicolumn{4}{|c|}{ Item Data } \\
\hline Reference & $\begin{array}{l}\text { Reference the source using } \\
\text { APA (American } \\
\text { Psychological Association) } \\
\text { format. Examples of the APA } \\
\text { format are provided below this } \\
\text { table. }\end{array}$ & $\begin{array}{l}\text { The authors and title of } \\
\text { the source should be } \\
\text { provided at a minimum. }\end{array}$ & $\begin{array}{l}\text { URL links to } \\
\text { websites, authors } \\
\text { only, title only. }\end{array}$ \\
\hline Item Category & $\begin{array}{l}\text { Category characterizing the } \\
\text { group of the tested item }\end{array}$ & Furniture & \\
\hline Specimen & $\begin{array}{l}\text { Common name of the tested } \\
\text { item }\end{array}$ & Chair, couch & $\begin{array}{l}\text { Do not use the name } \\
\text { of the item from the } \\
\text { reference ("Chair } \\
\text { F21" does not } \\
\text { describe an } \\
\text { upholstered armchair } \\
\text { and "Chair F31" } \\
\text { does not describe a } \\
\text { loveseat. }\end{array}$ \\
\hline Primary Material & $\begin{array}{l}\text { The largest construction } \\
\text { component. }\end{array}$ & $\begin{array}{l}\text { Descriptive words such } \\
\text { as wood, cotton, } \\
\text { polyester }\end{array}$ & $\begin{array}{l}\text { Vague words such as } \\
\text { "blends," "several”" }\end{array}$ \\
\hline Secondary Material & $\begin{array}{l}\text { The second largest } \\
\text { construction component }\end{array}$ & $\begin{array}{l}\text { Descriptive words such } \\
\text { as wood, cotton, } \\
\text { polyester }\end{array}$ & $\begin{array}{l}\text { Vague words such as } \\
\text { "blends," "several." }\end{array}$ \\
\hline Mass (kg) & $\begin{array}{l}\text { Mass of the test specimen in } \\
\text { kilograms }\end{array}$ & $\begin{array}{l}\text { Mass of the combustible } \\
\text { portion of the specimen if } \\
\text { possible. Comments } \\
\text { under "Additional Notes" } \\
\text { should be made if a } \\
\text { significant portion of the } \\
\text { mass is not combustible. }\end{array}$ & - \\
\hline Dimensions (m) & $\begin{array}{l}\text { Dimensions in meters } \\
\text { describing the specimen in a } \\
\text { simplified fashion }\end{array}$ & $\begin{array}{l}\text { Shapes such as cubes, } \\
\text { cuboids, cones, and } \\
\text { cylinders should be } \\
\text { described as a simplified } \\
\text { representation of the } \\
\text { specimen. }\end{array}$ & Single dimensions \\
\hline
\end{tabular}

b) Item Data Parameters 


\begin{tabular}{|c|c|c|c|}
\hline Parameter & Parameter Explanation & Acceptable Inputs & Unacceptable Inputs \\
\hline \multicolumn{4}{|c|}{ Test Data } \\
\hline Test type & $\begin{array}{l}\text { Standardized test or method } \\
\text { used to measure the heat } \\
\text { release rate }\end{array}$ & $\begin{array}{l}\text { Furniture Calorimeter or } \\
\text { internationally } \\
\text { recognized standards } \\
\text { such as ISO, ASTM, EN, } \\
\text { UL and Factory Mutual } \\
\end{array}$ & $\begin{array}{l}\text { This cell should not } \\
\text { be left blank. }\end{array}$ \\
\hline Date of the test & $\begin{array}{l}\text { The date of the test is useful to } \\
\text { indicate how relevant the test } \\
\text { could be in regards to the } \\
\text { evolution with time of the } \\
\text { item. }\end{array}$ & $\begin{array}{l}\text { The year seems the most } \\
\text { appropriate input as any } \\
\text { more precise date does } \\
\text { not really matter. }\end{array}$ & \\
\hline $\begin{array}{llll}\begin{array}{l}\text { Burner } \\
\text { Source }\end{array} & \text { Type } / & \text { Ignition } \\
\end{array}$ & $\begin{array}{l}\text { The method of ignition and/or } \\
\text { burner }\end{array}$ & $\begin{array}{l}\text { Typically a cigarette, } \\
\text { sand burners, irradiance } \\
\text { is used to ignite and/or } \\
\text { maintain the fire. Notes } \\
\text { should be made if the } \\
\text { ignition source or burner } \\
\text { contributes significantly } \\
\text { to the measured heat } \\
\text { release rate }\end{array}$ & - \\
\hline Test Duration (s) & $\begin{array}{l}\text { The time of the test from } \\
\text { beginning to end. This time } \\
\text { does not necessarily mean the } \\
\text { specimen was consumed. It } \\
\text { might mean that the test was } \\
\text { stopped at the point. }\end{array}$ & - & \\
\hline
\end{tabular}

c) Test Data Parameters 


\begin{tabular}{|l|l|l|l|l|}
\hline \multicolumn{1}{|c|}{ Parameter } & \multicolumn{1}{|c|}{ Parameter Explanation } & Acceptable Inputs & Unacceptable Inputs \\
\hline Max HRR (kW) & $\begin{array}{l}\text { Value of the peak heat release } \\
\text { rate measured during the test. } \\
\text { This value gives an indication } \\
\text { of the order of magnitude of } \\
\text { the item HRR. }\end{array}$ & Integers (in $\mathrm{kW})$ & - \\
\hline Time to Max HRR (s) & $\begin{array}{l}\text { Time to maximum heat } \\
\text { release rate }\end{array}$ & Integers (in s) & \\
\hline
\end{tabular}

d) Test Results Parameters 


\begin{tabular}{|c|c|c|c|}
\hline Parameter & Parameter Explanation & Acceptable Inputs & Unacceptable Inputs \\
\hline \multicolumn{4}{|c|}{ Additional Results } \\
\hline Mass Loss (kg/s) & Mass loss during the test. & $\begin{array}{l}\text { It is preferred to have the } \\
\text { mass loss in } \mathrm{kg} / \mathrm{s} \text { but it is } \\
\text { also acceptable to have } \\
\text { the mass at the beginning } \\
\text { and at the end if that is all } \\
\text { the information that was } \\
\text { provided. }\end{array}$ & - \\
\hline Heat of Combustion (MJ/kg) & $\begin{array}{l}\text { Heat of combustion. Verify } \\
\text { that the units are in entered in } \\
\mathrm{MJ} / \mathrm{kg}\end{array}$ & - & - \\
\hline CO Measurement & Carbon Monoxide & $\begin{array}{l}\text { Both the value and the } \\
\text { units must both be } \\
\text { entered as shown in the } \\
\text { filled out example if the } \\
\text { measurement was taken } \\
\text { during the test. }\end{array}$ & $\begin{array}{l}\text { The value alone is } \\
\text { not sufficient. }\end{array}$ \\
\hline $\mathrm{CO}_{2}$ Measurement & Carbon Dioxide & $\begin{array}{l}\text { Both the value and the } \\
\text { units must both be } \\
\text { entered as shown in the } \\
\text { filled out example if the } \\
\text { measurement was taken } \\
\text { during the test. }\end{array}$ & $\begin{array}{l}\text { The value alone is } \\
\text { not sufficient. }\end{array}$ \\
\hline Soot Measurement & $\begin{array}{l}\text { Solid carbon that burns at } \\
\text { approximately } 4000^{\circ} \mathrm{K}\end{array}$ & $\begin{array}{l}\text { Both the value and the } \\
\text { units must both be } \\
\text { entered as shown in the } \\
\text { filled out example if the } \\
\text { measurement was taken } \\
\text { during the test. }\end{array}$ & $\begin{array}{l}\text { The value alone is } \\
\text { not sufficient. }\end{array}$ \\
\hline HCI Measurement & Hydrogen Chloride & $\begin{array}{l}\text { Both the value and the } \\
\text { units must both be } \\
\text { entered as shown in the } \\
\text { filled out example if the } \\
\text { measurement was taken } \\
\text { during the test. }\end{array}$ & $\begin{array}{l}\text { The value alone is } \\
\text { not sufficient. }\end{array}$ \\
\hline HCN Measurement & Hydrogen cyanide & $\begin{array}{l}\text { Both the value and the } \\
\text { units must both be } \\
\text { entered as shown in the } \\
\text { filled out example if the } \\
\text { measurement was taken } \\
\text { during the test. }\end{array}$ & $\begin{array}{l}\text { The value alone is } \\
\text { not sufficient. }\end{array}$ \\
\hline HBr Measurement & Hydrogen Bromide & $\begin{array}{l}\text { Both the value and the } \\
\text { units must both be } \\
\text { entered as shown in the } \\
\text { filled out example if the } \\
\text { measurement was taken } \\
\text { during the test. }\end{array}$ & $\begin{array}{l}\text { The value alone is } \\
\text { not sufficient. }\end{array}$ \\
\hline
\end{tabular}

e) Additional Test Results Parameters 
For these results, two Excel cells have to be filled up: the first one indicates the value of the measurement and the second one the unit in [ ] and the specification of the measurement. For example, during a test, a measure of the CO yield was established at the peak of the Heat Release Rate and it was 0.05. Thus, the "Item" cells would be filled as follows:

\begin{tabular}{|c|c|c|}
\hline CO Measurement: & 0.05 & [-] CO yield at peak HRR \\
\hline CO Measurement: & 57 & [ppm] CO volume fraction at peak HRR \\
\hline CO Measurement: & & $\begin{array}{l}\text { Evolution with time of the CO fraction in } \\
\text { the air (see additional notes) }\end{array}$ \\
\hline
\end{tabular}

It should be noted that in the case no additional information was provided in the test, the letters "N/A" should be used to indicate that the information was looked for in the reference report and it was not found.

\subsection{Filling up the Columns of values describing the evolution with time of the heat release rate}

Columns (E) and (F) are filled up by the participant to the Vulcan Initiative, with respectively:

- the time, after the test start, at which the HRR measurements were made, in seconds,

- the corresponding Heat Release Rate, in kilowatts.

The cells have been formatted so that the values inputted in these two columns appear as integers and with the comma indicating a 1000 separator.

The participant has to verify that the values of column (E) are always increasing.

There are many ways to abstract this information from a graph if the numerical data is not provided. One way is to use Engauge Digitizer Software which is an open source program that allows you to trace over the image of a graph (available at: http://digitizer.sourceforge.net/).

Participants must remember that only one HRR curve is permitted per template. In consequence, test replicates will have their own Item Number and will be on its own Item sheet.

\subsection{Auto-creating the corresponding HRR curve}

The graph of the HRR curve will automatically be created when the participants fills up cells in the Columns (E) and (F). The tile of the graph has to be manually changed from "Specimen" to the name of the tested item.

\subsection{Presenting additional notes and comments}

The "Additional Notes" is located at the upper right part of the template. It can be used for any other comment such as another parameter that is not part of the template. Also, it can be used to indicate if replicates tests were conducted. It should be clear that replicate tests consist of the exact test repeated. Any changes to the test sample, such as conditioning, or the testing method is not considered a replicate. 
This part can include photos, video links of the test, as well as comments from the participant concerning the test.

\section{Instructions on how to fill up the "Overview" sheet}

Once the "Item" sheet has been completed, the participant needs to enter the corresponding information to the "Overview" sheet and create a hyperlink to his newly created "Item" sheet.

A peer reviewer having verified an "Item" sheet should also complete the corresponding cells in the "Overview” sheet.

\section{Instructions for a peer-reviewer of the HRR_Catalog}

The HRR_Catalog contains information about the participant who kindly provides data for the Fire Protection Engineering community. Another important action is asked for another participant to the Vulcan Initiative, who would act as a peer-reviewer of the "Item" submitted by the initial participant.

In that case, it is asked from the peer reviewer to complete the corresponding cells in the "Item" sheet(s) the peer-review was done as well in the "Overview” sheet.

THANK YOU FOR YOUR PARTICIPATION TO THE VULCAN INITIATIVE 


\section{Additional Reference Examples:}

Basic Format for Books

Author, A. A. (Year of publication). Title of work: Capital letter also for subtitle. Location: Publisher.

Babrauskas, V; Lawson, J.R.; Twilley, WH (1982)

\section{Two Authors}

List by their last names and initials. Use the ampersand instead of "and."

\section{Three to Seven Authors}

List by last names and initials; commas separate author names, while the last author name is preceded again by ampersand.

\section{Article from an Online Periodical}

Online articles follow the same guidelines for printed articles. Include all information the online host makes available, including an issue number in parentheses.

Author, A. A., \& Author, B. B. (Date of publication). Title of article.Title of Online Periodical, volume number (issue number if available). Retrieved from http://www.someaddress.com/full/url/ 


\begin{abstract}
Annex G
The VULCAN INITIATIVE: a web platform for the next generation of performance-based fire protection design
\end{abstract}




\title{
THE VULCAN INITIATIVE: A WEB PLATFORM FOR THE NEXT GENERATION OF PERFORMANCE- BASED FIRE PROTECTION DESIGN*
}

\author{
Alberto ALVAREZ, Ph.D., Matthew A. FERREIRA \& Brian J. MEACHAM, Ph.D., P.E. \\ Worcester Polytechnic Institute, USA
}

\begin{abstract}
For decades, various building regulations around the world have allowed fire safety design of buildings to be based on expected performance (e.g., allow occupants adequate time to escape in the event of fire) rather than prescriptive requirements (e.g., maximum travel distance to an exit shall not exceed $100 \mathrm{~m}$ ). Although this performance-based approach concedes more flexibility and innovation for intricate buildings, its application and acceptance has varied widely due to the complexity of the process and lack of widely accepted values for key parameters, such as level of performance or risk. Current versions presented in various codes, guides and guidelines intrinsically link the technical issues with political issues, making it difficult for stakeholders to decide on the acceptability of the proposed engineering solutions. This observation has led to a new conceptual design procedure for fire protection design that basically separates, as much as possible, the technical aspect from the political aspect of the current performance-based fire protection processes.

It has been further observed in such processes the reliability of the fire protection measures is often not taken into consideration, at least explicitly, since there is nothing in the benchmark requirements about reliability and is therefore not addressed in performance-based solutions. This observation has led to the need to characterize the fire risk of building use groups based on fire statistics collected for existing buildings of a same building occupancy class. Fire risk characterization of a new project, designed with the performance-based option, should then be compared with this baseline to assess its acceptability.

A third observation is that the current approach to performance-based design often neglects the lifecycle of the building and the affect that may have on fire safety performance. This observation has led to the need to consider a fire protection engineering study as one component of an overall safety study of the building in use, with fire to be viewed as a possible acute event which perturbs the otherwise chronic operation of a system (building-occupants-use interaction).

The final observation relates to the use of tools when assessing the consequences of the fire design scenarios. Independently of the validation of tools, user effects are numerous and their influence needs to be weighed in the overall performance-based design process, as part of uncertainties in the quantification of design fire scenario consequences. This requires better guidance on selecting tools for a specific application, data for use in the tools, and a better understanding of the complexities of the tool-application-justification decision.
\end{abstract}

\section{RESULTS}

As a result of these observations, the first part of this paper presents the framework for a new riskinformed performance-based approach which has been developed. It illustrates how collection of better data can assist in risk characterization, scenario development and design fire quantification using examples for different building occupancy types.

A web platform called the Vulcan Initiative for data collection and dissemination, and for facilitating broad stakeholder involvement in the development and refinement of work started in this effort, will be introduced and discussed in the second part of this paper.

* Unformatted manuscript for paper: Alvarez, A., Ferreira, M.A. and Meacham, B.J., “The VULCAN INITIATIVE: a web platform for the next generation of performance-based fire protection design,” Proceedings, Interflam 2013, Interscience Communication, Ltd., London, June 2013. 
The corresponding overall research project aims to produce more specific design guidance, and potential modifications to building codes, to advance the application, implementation and acceptance of risk-informed performance-based fire protection analysis and design options for the built environment. It will help engineers better identify, characterize and assess critical fire risk and hazard mitigation issues based on differences in building occupancy types, to introduce a new framework for identifying and clustering risk-significant fire scenarios, to more appropriately select fire analysis and modeling tools to match the specific application, and to take more account of lifecycle operation and maintenance aspects of building use. The associated web platform will also result in tools and methods for better managing engineering data needed for analysis and design, as well as providing a forum to enhance links between the fire engineering community and the broader group of interested and affected stakeholders in the building design and operation process.

\section{FRAMEWORK FOR A NEW RISK-INFORMED PERFORMANCE-BASED APPROACH}

A review ${ }^{1,2}$ of the last two decades of application of the performance-based fire protection design (PBFPD) option concluded that challenges still need to be overcome in order to expand this option as an alternative to prescriptive requirements. The main challenge fire protection engineers (FPEs) still meet is related to the generic aspect of the current PBFPD processes presented in codes, standards, guides and guidelines; thus requiring FPEs to spend significant time and resources when applying these generic processes to specific projects. Besides, technical challenges are identified when FPEs need to specify process parameters such as performance criteria, select and quantify design fire scenarios, and select appropriate tools and corresponding data in order to perform the analysis of trial designs. Political challenges related to the decision making framework in which the PBFPD processes are used, are also identified and concern the relative roles and objectives of all the different involved stakeholders.

Shortcomings are also identified from the fact that the FPEs are focused on the assessment and design of fire protection measures related to a list of design fire scenarios the involved stakeholders agreed upon. In other terms, the sets of fire protection measures established after applying current PBFPD processes correspond more to "idealized" independent design features than "real life" installed, running features, integrated as a component of a global system formed upon building components and occupant characteristics. This situation led to cases where fire protection measures were ignored, or even rejected by the system in which they were installed due to incompatibilities between the real usage of the system and the conceptual design of the fire protection measures, as occupants are focused on their activities and do not think about how these activities may compromise the efficiency of fire protection measures. Examples of such cases are given elsewhere ${ }^{1,2,3}$ and are observed during inspections (fire doors maintained opened and blocked emergency exits).

Besides, stakeholders are focused on the performance of their building on a daily basis. Design fire scenarios defined in current PBFPD processes only consider fires between ignition and extinguishment. Nevertheless, recovery period should also be considered between fire extinguishment and the time when the building is back in full operative mode, as this recovery period could be significant for the stakeholders in terms of business continuity objective ${ }^{4}$. In consequence, FPEs need to consider fires as disruptive events of a "building occupant" system formed by a building and its occupants, between two "chronic" states of this system, not only taking into consideration the fire itself between ignition and extinguishment, but also the recovery period leading to a "chronic" state or state corresponding to a normal daily basis system operation ${ }^{5}$.

Addressing these shortcomings requires that FPEs shift their current study paradigm focused on the design of fire protection measures based on the analysis of design fire scenarios to a paradigm for which building performance metrics are evaluated in the case of fire events so that sets of fire protection measures could be fully integrated and compatible with the building usages. The characteristics of a "building occupant" system are detailed elsewhere ${ }^{2,5}$.

Along with this "building-occupant" system paradigm, a risk performance-based process has been established and focused on assessing the overall performance of the system in case of any type of event affecting its performance ${ }^{2,5}$. Then, this process has been detailed for the treatment of fire 
events and compared with current PBFPD processes. Figure 1 presents the new PBFPD process, showing, by comparison with a current PBFPD process, that:

- a new technical step dedicated on the evaluation of the integration into the system of the fire protection measures, selected after the fire risk analysis,

- a technical step dedicated to a required cost-benefit analysis.

- a complete separation between the "political" decision-making process and the "technical" resolution of the engineering fire problem, operated once in a straightforward manner. Indeed, at the start of the process, project stakeholders define the characteristics of their system and establish the "targets" (defined as actors of the global system performance) and the current "chronic" state of the system. At the end of this technical part of the new process, FPEs have elaborated three documents detailing the results of the target-oriented fire risk analysis, of the evaluation of the integration of the fire protection measures into the system and of the cost-benefit analysis. Based upon these documents, the stakeholders decide which fire protection measures they would have installed in their system.

Although the proof of concept $\mathrm{t}^{2,5}$ was established for the new PBFPD process, specific guidelines related to the application of each process step to different types of systems (e.g., schools, hospitals) are yet to be established. Each specific guidance is planned to describe the different actions for the FPE to perform, a list of most appropriate tools to use (and the way to use them so to reduce the user effects and its corresponding uncertainties), and the system specificities to look at. This guidance will be associated with databases for input data needed to use the tools for the different technical steps of the new PBFPD process.

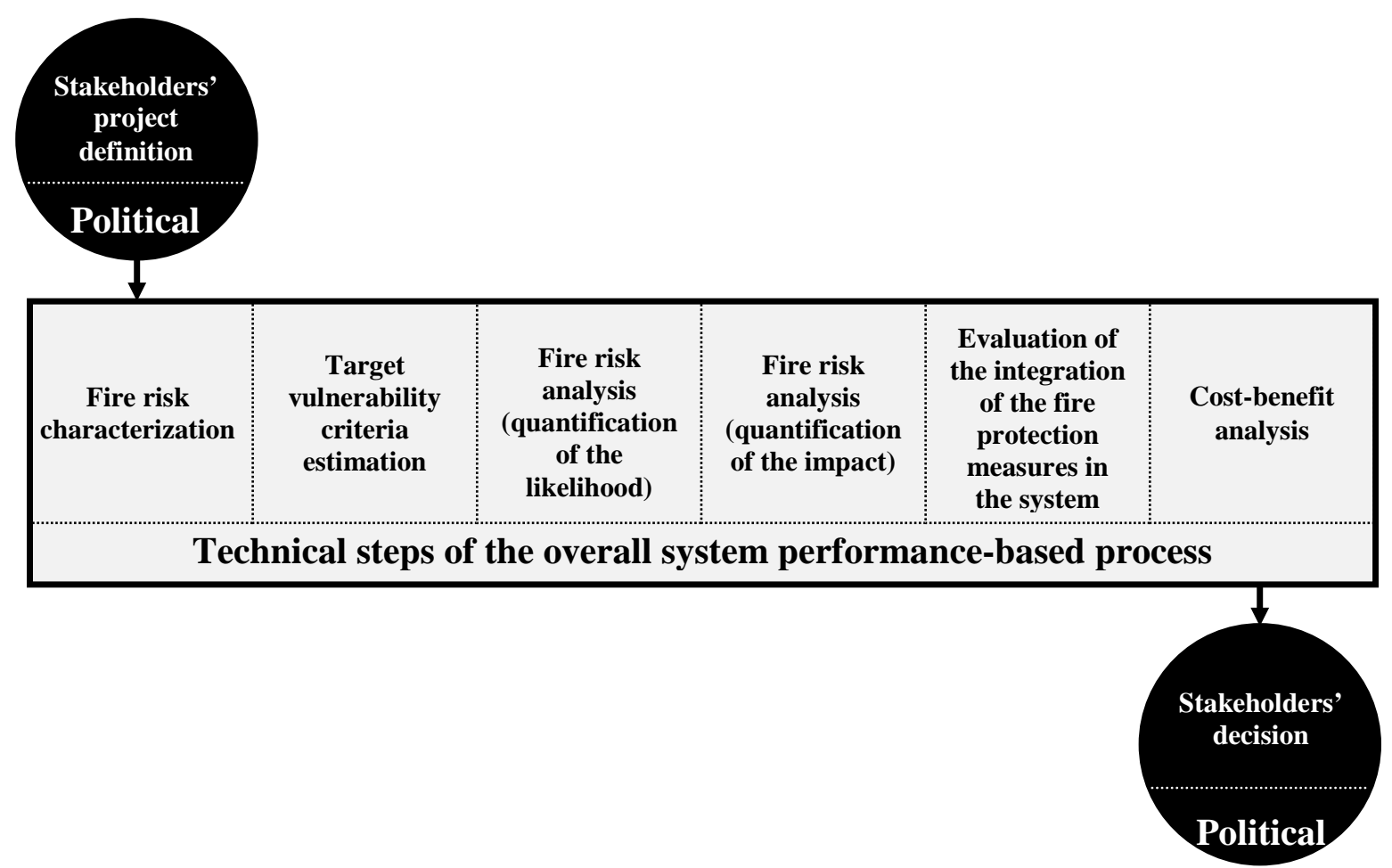

Figure 1. New Performance-Based Fire Protection Engineering Design (PBFPD) process

\section{THE VULCAN INITIATIVE}

\section{Origin and objectives of the Vulcan Initiative}

Actions FPEs would be required to perform for each of the six technical steps of the new riskinformed PBFPD process, are detailed elsewhere ${ }^{2}$. It should be noticed that these actions can be 
similar to or different from the ones performed in the current PBFPD processes. For each step of the process, a plan of action has been proposed in order to describe the nature of the information that would be inscribed in the future guidance, and how this information would become a part of future guidelines and standards. First useful elements of information extracted from past and current research involving experts from a large spectrum of competencies and systems stakeholders, as well as information from standardization efforts were also gathered for each step ${ }^{2}$.

This plan of action is assumed to be impossible to be supported by a single entity of the Fire Protection Engineering community. Not only the research would be too costly in terms of time and resources but it also has to involve stakeholders (as they are the ones who can define the targets of their system and know how their system operates on a daily basis), engineers from other fields than fire protection engineering (e.g., psychologists, structural engineers, economists), as well as policymakers and authorities having jurisdiction. Thus, there is a need of an environment which is flexible enough to allow all these kind of people to communicate and exchange information, for extended periods of time. Besides, research related to the different technical steps of the new PBFPD process develops at a different pace and may vary of interest for different people within the Fire Protection Engineering community (practitioners, researchers, tool developers, academia) and people dealing with building projects (design team, fire services, authorities having jurisdiction). Thus, there is a need of an environment which is flexible and adaptable enough to allow the dissemination of results from research conducted on the technical steps of the new PBFPD process.

It appears that a web platform environment would be the best way to implement the two points above, in conjunction with the ultimate objective to facilitate and speed up the establishment of the guidelines related to each step of the new PBFPD process. This web-platform environment is named the Vulcan Initiative. It is accessible through the web address: http://vulcan-initiative.net. It is organized mainly through 'test bed' environments, the implementation of tool input databases and projects related to the use of the new PBFPD process.

\section{'Test bed' environments}

\section{Origin and characteristics of 'test bed' environments}

While solving real-life problems, engineers are used to quantifying parameters that are relevant for the analysis they are undertaking. In order to do so, they use tools for which they apply input data that is representative of the examined problem. Because real-life solutions require the approval of authorities having jurisdiction, tools are required to be validated for the considered problems. Besides, concerning fire protection engineering problems, the analyzed phenomena are complex and still nowadays necessitate a lot more research not only in the evaluation of fire effects itself but also in the evaluations of building evacuation and structural response. Having models and research tools used appropriately when analyzing trial designs in a performance-based design framework is even more difficult due to the complexity of building geometries influencing fire effluent spread, the diversity of human behaviour patterns, and the intricacies of diverse structural elements. To these research difficulties, are added engineering difficulties due to the fact that FPEs still need to mix all the results provided by these different research tools to perform their analysis and that these complex tools require FPEs to be able to use them (user effect ${ }^{6}$ ).

It should be noted that even if technical guidance has recently been published for fire effects tools ${ }^{7}$, this guidance is still too generic and therefore implies FPEs to figure out how it could be applied to a specific project. Besides, there is still a need for the same kind of guides for evacuation tools and structural response tools, as well as the additional layer when mixing all the results for these tools. In order to attenuate these difficulties and overcome these challenges and needs, it was decided to concentrate our efforts on well-defined engineering problems called 'test bed' environments.

If one positions all the possible building configurations in the y-axis and all the possible building occupant distributions in the z-axis, one can see distinctive domains appear on such a representation. If keeping the building configurations in the y-axis and adding a z-axis for the fires that are susceptible to occur in these different building configurations, one can also see distinctive domains appear as different buildings configurations differ in terms of geometry, size and structure, and from the nature of the combustibles located in these configurations; all influencing the fires 
susceptible to occur in these configurations. At last, by looking at populations (z-axis) and fires affecting these populations (x-axis), one can see domains where fire effects (and the means of evacuation) are based according to occupant characteristics, and more particularly according to defined classes of vulnerable populations (see Figure 2). Within this three dimensional representation involving all the possible buildings, occupants and fires, discrete domains appear which clusters the characteristics of well defined environments that we define as domains of interest or 'test bed' environments.

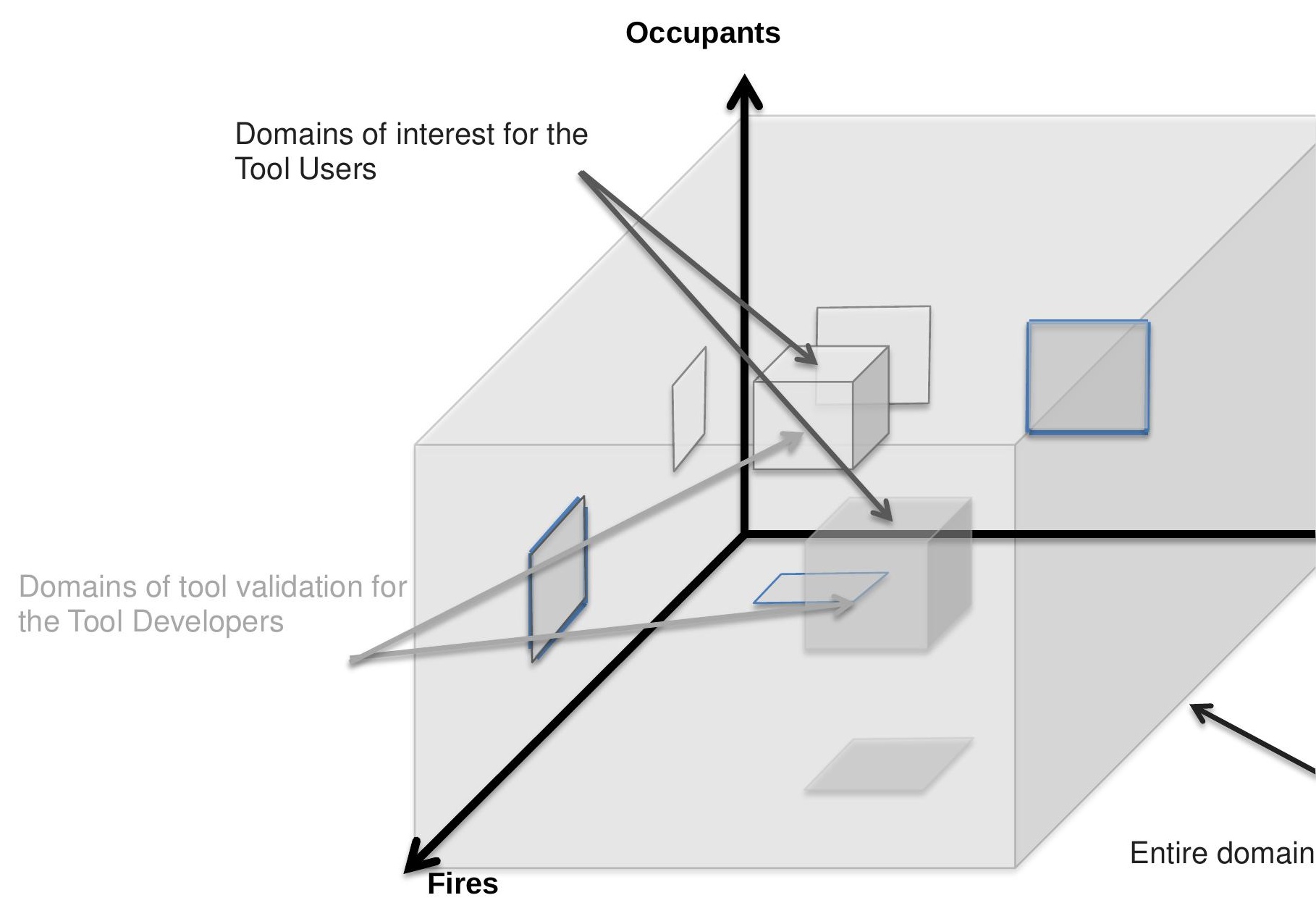

Figure 2. Schematic representation of all the different possible domains linking buildings, occupants

\section{Quantifying domains of interest for 'test bed' environments}

As explained in the previous paragraph and illustrated in Figure 2, domains of interest potentially defining 'test bed' environments can be delimited by different types of buildings, or "building occupant" systems if following the system paradigm defined in the first part of this conference paper. Data characterizing these domains have to be gathered so that:

- FPEs (tool users) can quantify the input data for the tools they would use to conduct their engineering analysis, whatever the tools are used for assessing consequences of fire effects, fire scenario probabilities, cost-benefits of sets of fire protection measures or integration of these measures into an examined system (Step 5 of the new PBFPD process).

- Tool developers are aware of the needs for validation of their tools around these domains and concentrate their efforts for these domains in terms of tool validation and model development. In that matter, it should be noted that the EXODUS suite of software tools designed to simulate the evacuation of large numbers of people from a variety of enclosures, contains 
buildingExodus, maritimeExodus, airExodus and railExodus (under development) are an example on how tools, based on the same generic principles, have to be specialized according the specificities of the enclosure.

Considering building evacuation process, occupants characteristics can be defined according to the building use, so data characteristics for different sets of (building-occupants) domains should be determined so to anchor the needs for the engineer to solve problems related to these sets and help the evacuation tool developer to increase the analytical power of their tools for these sets.

For example, in the USA, statistics and data on population distributions can be found at the Center for Disease Control (http://www.cdc.org) website for population distribution in short stay patient in hospitals. For the period 1968 - 2010 (see Figure 3), the distribution of short stay patients in hospitals saw the decrease of the percentage for children and young adults (up to 34 years old), the increase of the percentage for older adults and the large increase of the percentage for elderly population (75 years old and older). Without this type of data and other associated data (e.g., distribution of these patients in the different areas of the hospital, how many people are connected to life-supporting machines?), FPEs cannot really estimate the evacuation process of hospital patients (how long will it take to prepare a patient for evacuation? How fast is the "walking speed" of a group composed of the evacuated patient and his/her nurse(s)?) and what incidence would this population distribution have on the evacuation management plan of hospitals? For evacuation tool developers, how do they model such a group where the patient is on a wheelchair or carried in a litter? For business continuity objectives, other useful information regarding lengths, reasons and costs of hospital stays can also be found on the Internet ${ }^{8}$.

Data concerning buildings can be found, for example, at the US Energy Information Administration ${ }^{9}$. This data can be used to describe the building stock according to their occupancy types and functions ${ }^{10}$ (e.g., offices and all different kinds of hospitals - general hospitals, psychiatric hospitals). This kind of data was already used within a risk-informed perspective, to quantify fire risk for different types of buildings ${ }^{11}$. More data of this type needs to be gathered and analyzed. In a similar manner, building characteristics including geometry and types of combustibles that can influence fire ignition and spread should be studied so that (fires-buildings) data sets could be established for different building types. Fire loads have been established by building occupancy types ${ }^{12}$ but there is still a need to standardize the way of collecting the data, as well as a more detailed description of the combustible contents in the different areas of a considered building ${ }^{13}$.

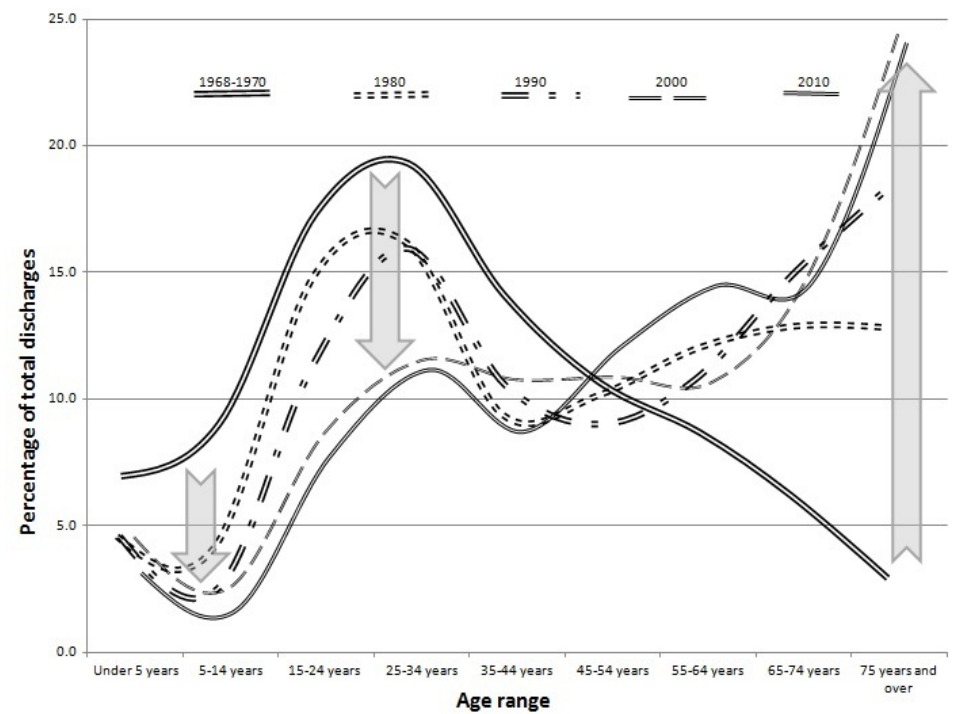

Figure 3. Evolution of the population distribution in short stay patients in hospitals between 1968 and 2010 (source: compiled from data US Centers For Disease Control and Prevention / National Center for Health Statistics)

At last, effects of fires on occupants should also be determined for different domains, since untenable conditions may vary according to occupants characteristics and FPEs analysis would need 
to emphasize on the vulnerable occupants. It should be noted that one component of the data can be gathered by FPEs as presented above for population distributions in hospitals while the other component of the data still require the contributions of toxicologists and psychologists to model the effects of fires on building occupants, so that ultimately tool developers could implement their respective fire effects and evacuation tools with the corresponding models.

In conclusion, in the previously defined "building occupant" system paradigm, tools and databases for tool input data are necessary to perform every technical step of the new PBFPD process, as they are usually needed in order to solve any engineering problem. Nevertheless, it is unpractical to look for validated tools and associated databases that could be applied to all possible domains where the tools could be used. Thus, 'test bed' environments are set up around specific domains defined by specific "building occupant" systems. These domains need to be quantified so that FPEs are able to evaluate how these values would impact their engineering analysis and so that tool developers concentrate their model validation and development efforts on these domains.

\section{'Test bed' environment studies: solving fire protection engineering issues}

Now that the procedure related to the definition and the quantification of 'test bed' environments is established, all this information still need to be processed so they can be used for the establishment of guidelines related to each technical step of the new PBFPD process. In order to do so, real "problem solving" engineering studies have to be associated with 'test bed' environments. Indeed, it is required to have usable tools and corresponding input data, but still it is necessary to guide FPEs in the selection of appropriate tools and data to be used to solve well defined issues and how to conduct the analysis to solve the issues. 'Test bed' environments studies were primarily focused on the use of tools for assessing fire consequences ${ }^{14}$, as this assessment is one key element of the PBD approach:

- Dynamic way to evaluate fire effects vs. evacuation process for a hospital horizontal evacuation. As previously indicated, no guidance is given concerning the global quantification of the evacuation process. For a L-shape or T-shape hospital, a zone model may be appropriate to assess fire effects along with simple hydraulic calculations to assess the evacuation process. For other more complex hospital layouts, a CFD model may be more appropriate. If not providing the FPE with the same exact answer, would the use of the two fire effects tools make the FPE conclude with the same engineering solution? How are assessed the interacting key events of fire spread (e.g., exit pathways being untenable, activations of fire detection and suppression) and of evacuation (e.g., pre-movement time, successive patient preparation for evacuation, nurse travel back and from the horizontal safe place)?

- Description level of details needed for a near field analysis and a far field analysis. 3-D fire simulations are costly in time and computing resources. For some engineering problems, it may be necessary to know precisely how the fire is spreading in the near field of fire start (i.e., to describe ignition of subsequent burning items), while in the far field, the concern is fire effluent transport and temperature elevation. Different computational meshes along with different levels of detailed geometry may be used to solve this type of problems at once but there is no guidance for the FPEs to know how to do that.

The answer to these questions (and many more) can come from parametric studies performed by students in Academia, engineers all around the world, as multiple independent ways to look at these problems, as well as different "ways of doing". The web-platform is a good way to coordinate all the study results, flexible without constraints of usual meetings and document management. Phases to establish and conduct a 'test bed' environment related to the quantification of fire consequences are described elsewhere, as well as the different roles of all the actors involved in the corresponding issues $^{14,15}$.

\section{Tool input databases}

The need to get databases that are relevant and easily accessible 
The Internet already makes accessible numerous reports related to fire experiments and other resources that are relevant for fire engineering purposes. Nevertheless, in many countries, lots of reports still remain unused because they are not searchable in English. Agencies such as INERIS in France, SP in Sweden, and VTT in Finland, which publish a large quantity of reports in their respective websites but mainly in their native language, are not known as they should be. Through its forum, the Vulcan Initiative will try to encourage the dissemination of knowledge from non-English speaking countries. Attempts to make data available have been made concerning the heat release rate parameter but unfortunately they remain not fruitful because of a lack of maintenance (resources were allocated for a short period of time) and flexibility (it is almost impossible for someone else than the website owner to upload new data). The Vulcan Initiative will provide links to existing databases and will include its own database related to combustion experiments.

\section{Many databases are needed not only for HRR}

Data is required for different types of analysis FPEs may have to perform, including fire risk analysis in a PBD framework (looking for data on probabilities and consequences of design fire scenarios), code change analysis, product evaluation analysis, or major fire reconstruction ${ }^{16}$. Data types and sources, organized around incident data, field observation, usage or exposure data, and laboratory test results have been discussed in terms of availability, representativeness, applicability limitations and discrepancies between databases of the same type ${ }^{16}$. Even if important precautions are already associated with the use of such databases, we observe there is still a lot to do in terms of helping FPEs with being aware such databases exit, knowing what the data really represent, and using the data appropriately for their engineering analysis.

Besides, even if data such as heat release rates could "speak" a lot to FPEs because of their academic background, it is less sure than statistical data on fire ignition probabilities are correctly perceived by FPEs. As FPEs get more and more involved in risk-informed PBD analysis, they will look for more and more information related to the characterization of fire risk. For example, concerning fire risk curves linking the probability of a fire with damage areas, the lumped results presented in the late 1970's from UK have seen some diversified attempts in Japan, Finland, Sweden and more recently in Slovenia ${ }^{17}$, with the inclusion of parameters such as daily work operation period and number of employees. We conclude that FPEs should get more involved in the definition of the data that could be treated via statistical methods (or statisticians) as they are the end users of all this data. Some parameters such as the one considered in the Slovenian study may or may not be relevant for other types of "building occupant" system than the studied one. Without that action, the data that is really needed would never be collected and the FPEs would have to use "engineering judgment" to fill the gap between currently available data and really needed data.

\section{Projects related to the new risk-informed PBFPD process}

As the Vulcan Initiative was created as a way to facilitate the establishment of guidelines for each technical step of the new PBFPD process, it already contains the structure with which one can upload a "project". A project contains the characteristics ${ }^{2,5}$ of a "building occupant" systems, such as the building layout, the list of stakeholder targets.

In the Vulcan Initiative, one participant willing to apply the new PBFPD process for a particular project will successively go through the following components: fire risk characterization will include databases on fire statistics and on the census of specific systems, fire damage criteria will include databases on how fire can affect people and building contents that are relevant to stakeholders for property protection or business continuity objectives. Fire risk analysis will include tools to assess the likelihood and the consequences of fires, as well as their corresponding databases relative to fire ignition frequencies, reliability of fire protection measures, production of heat and fire effluents from combustible packages, human behavior and structural response. Cost-benefit analysis will include tools to assess the cost of installing and maintaining fire protection measures in specific systems. 
Participants to the Vulcan Initiative are welcome to upload the projects of their choice, at the present time even if there is still a lot of research to be undertaken to complete the guidelines. By doing so, they will provide needed input data which could be used for 'test bed' environment studies described above. By sharing the characteristics of their system and presenting the issues related to their project, these "project owners" could be joined, in the short term, by others in the Fire Protection Engineering community having the same issues. On the long term, they will ultimately benefit from the results of the studies as these results will be applied to their own project or similar projects (see Figure 4).

Examples of projects to be uploaded to the Vulcan Initiative site include a hospital, a highrise hotel and a mall, created in Academia, from the Worcester Polytechnic Institute (WPI), USA. The 5-story hospital was based on an actual building design, modified with specific features such as a 'function space,' so as to allow students experience in assessing different fire scenarios and evacuation, protect in place and relocation scenarios. The 30-story high-rise hotel with associated convention space was developed at WPI to provide an environment within which to have students assess such factors as fire scenarios, evacuation schemes and mitigation measures (such as smoke exhaust in atria and meeting spaces). The 3-story shopping mall was likewise developed at WPI to have students assess such factors as fire scenarios, evacuation schemes and mitigation measures (such as smoke exhaust and material control). These projects can serve as examples for future students, and new projects could be added to the Vulcan Initiative using these configurations and associated data. WPI hopes to be joined by other institutions around the world, as well as tool developers, architects, code officials and others, from whom advice could be requested and interaction in the virtual environment can help address 'real world' issues and facilitate development of new detailed guidelines as outlined above.

Figure 4. Organization of a "project" in the Vulcan Initiative

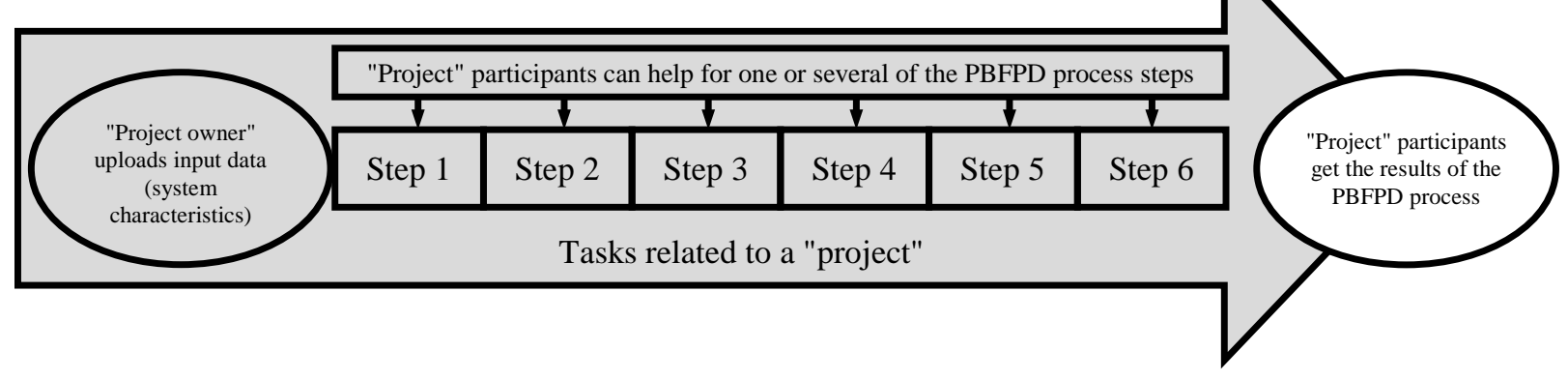

\section{CONCLUSION}

To address shortcomings with the current performance-based approach, a research project is developing detailed guidance for the fire protection engineer to assist in the development of riskinformed fire safety options that could be implemented and maintained during a building life span.

In order to support the establishment of this detailed guidance, a web platform, called the Vulcan Initiative, has been created around the technical steps of the new conceptual procedure for fire protection design. Each of these steps is related to the quantification of engineering parameters, which requires the use of appropriate tools and associated input databases. Since our aim is not sciencefocused but engineering-focused, specific domains that are relevant to building projects called 'test bed' environments are created for each fire issue to be solved for a specific system (buildingoccupants-use interaction) so to speed up the current and future validation domains of engineering tools around these environments, instead of waiting to have these tools validated for all the possible physical domain.

One ultimate goal of the Vulcan Initiative where information and knowledge are exchanged among tool users and stakeholders is to create new guidelines on the appropriateness of tools for a given application, all along the new risk-informed performance-based process steps. In order to do so, participants are welcome to upload "projects" containing the characteristics of "building-occupant" systems of their choice. Projects involving a hospital, a high-rise hotel and a mall, created by WPI as part of courses in the Fire Protection Engineering program, will be posted to the Vulcan Initiative site 
as a model for others and to stimulate specific analyses, discussions and development of data and information needed for the ongoing development of PBFPD and required guidance.

Even if they are not interested in applying the new PBFPD process, participants in the Vulcan Initiative can find benefits in contributing to any 'test bed' environment studies as some of these studies reflect concerns of the current PBFPD processes (e.g., concerns related to the quantification of fire scenario consequences), as well as using and providing data useful to perform any of these studies.

Participants from all the spectrum of the Fire Protection Engineering community (Academia, research agencies, industry, authorities) are welcome as they can all contribute and benefit from the Vulcan Initiative.

\section{ACKNOWLEDGEMENTS}

The authors would like to gratefully acknowledge the financial support provided by the National Institute of Standards and Technology (NIST) under award 60NANB10D228 which facilitated the research and outcomes as described herein. This award was used to support a large number of graduate students in the Department of Fire Protection Engineering who contributed to this effort.

\section{REFERENCES}

${ }^{1}$ Alvarez, A., Meacham, B.J., Dembsey, N.A. and Thomas, J.R., 20 Years of Performance-Based Fire Protection Design: Challenges Faced and a Look Ahead, Journal of Fire Protection Engineers, submitted Aug. 12 ${ }^{\text {th }}$, 2012, submission number: JFE-12-0035

2 Alvarez, A., An integrated framework for the next generation of risk-informed performance-based design approach used in fire safety engineering, Ph.D. thesis, Fire Protection Engineering Department, Worcester Polytechnic Institute, December 2012

3 Alvarez, A., Meacham, B.J., Dembsey, N.A. and Thomas, J.R., A framework for risk-informed performance-based fire protection design for the built environment, Journal of Fire Protection Engineers, submitted April $8^{\text {th }}$, 2013, submission number: JFE-13-0016

${ }^{4}$ Sheffi Y., The Resilient Enterprise, Massachusetts Institute of Technology Press. 2005

${ }^{5}$ Alvarez, A., Meacham, B.J., Dembsey, N.A. and Thomas, J.R., Using a Systems Approach to Holistically Assess Building Performance during disruptive events, to be submitted in May 2013 to Building Research and Information

${ }^{6}$ SFPE, The SFPE Code Official's Guide to Performance-Based Design Review, 2004

${ }^{7}$ SFPE, SFPE guidelines for substantiating a fire model for a given application, SFPE G.06 2011, Society of Fire Protection Engineers, 2011

${ }^{8}$ HCUP Facts and Figures: Statistics on Hospital-Based Care in the United States, 2007, available at (http://www.ncbi.nlm.nih.gov/books/NBK53001/), last checked April 23rd, 2013

${ }^{9}$ US Energy Information Administration (EIA) - 2003 Commercial Buildings Energy Consumption Survey (CBECS) Detailed Tables - most recent available, released: September 2008 (http://www.eia.doe.gov/emeu/cbecs/cbecs2003/detailed_tables_2003/detailed_tables_2003.html\# enduse03)

${ }^{10}$ Alvarez, A. and Meacham, B.J., Towards an Integrated Performance-Based Design Approach for Life Safety Across Different Building Use Groups, in: Proceedings of the 12th International Interflam Conference, Nottingham, UK, 5-7 July 2010, Interscience Communications Ltd, London, UK, p1259-1270, 2010

${ }^{11}$ Kobayashi, Y. and Nozaki, H., A Statistical Method to Evaluate Fire Risks in Non-Residential Buildings in Japan," in: Fire Safety Science: Proceedings of the Eight International Symposium, China, International Association for Fire Safety Science, pp. 341-352, 2005 
${ }^{12}$ Bukowski, R.W., Determining Design Fires for Design-level and Extreme Events, in: Proceedings of SFPE 6th International Conference on Performance-Based Codes and Fire Safety Design Methods, June 14-16, 2006, Tokyo, Society of Fire Protection Engineers, 2006

${ }^{13}$ Department of Veterans Affairs, Structural Design Manual for Hospital Projects, 2009

${ }^{14}$ Alvarez, A. and Meacham, B.J., Ready-to-use" Building Layouts and Combustible Packages for 3D simulations. In: proceedings of the Fire and Evacuation Modeling Technical Conference, 2011

${ }^{15}$ Alvarez, A. and Meacham, B.J., 'Test bed' environment process for assessing the appropriateness of engineering tools to be used in performance-based design applications, in: Proceedings of the 9th International Conference on Performance-Based Codes and Fire Safety Design Methods, Hong Kong. 20-22 June 2012

${ }^{16}$ Ahrens, M. and Hall, J.R., Data for Engineering Analysis, Chapter 5, Section 5 of the 4th edition of the SFPE Handbook of Fire Protection Engineering, SFPE, 2008

${ }^{17}$ Šrekl, J. and Golob, J., Impact of The Buildings Areas on the Fire Incidence, Acta Chim. Slov., 57, 118-122, 2010 
Annex $\mathbf{H}$

The VULCAN INITIATIVE: Beta Version Web Pages 


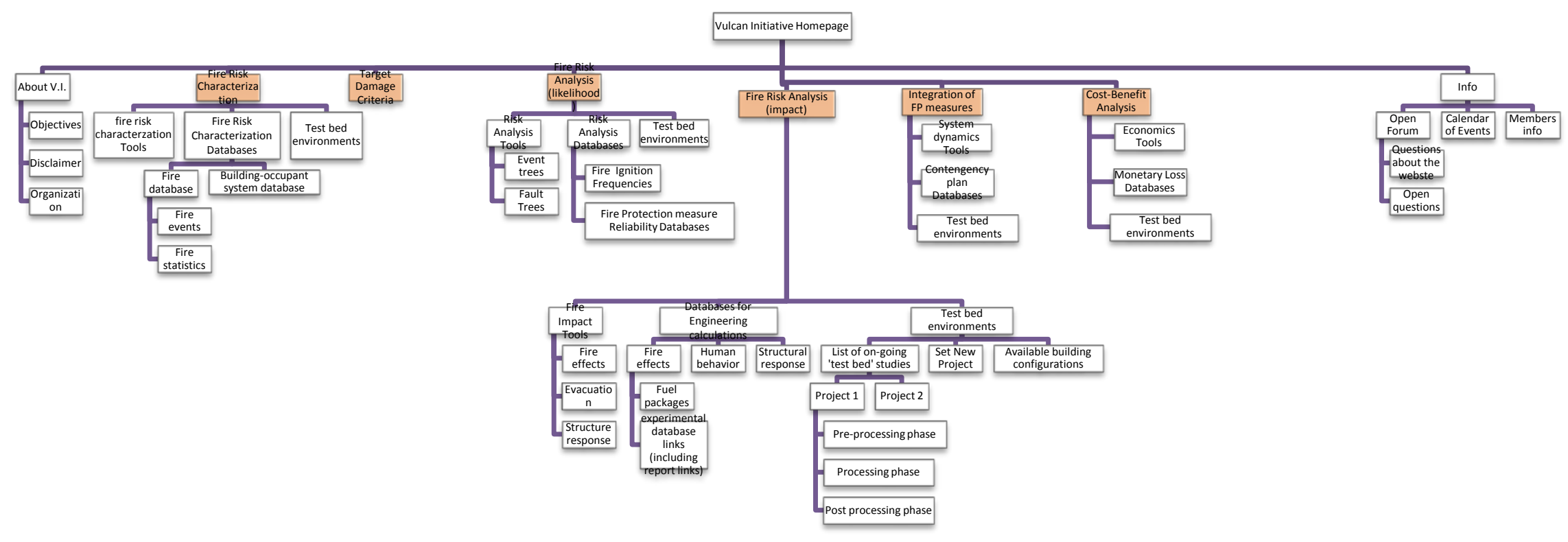


This is the website banner, at the top of every page

Banner

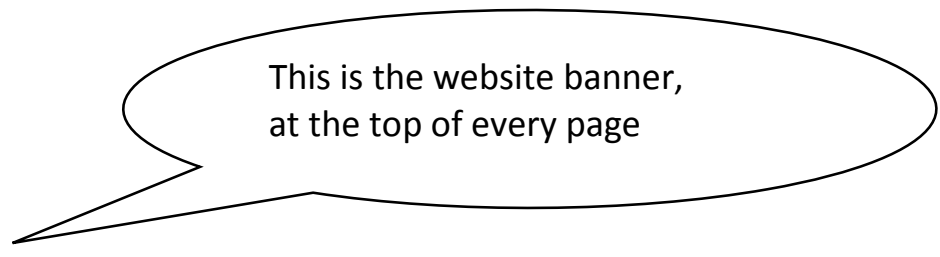

Performance-Based Fire Protection Design Process Technical Steps

\begin{tabular}{|c|c|c|c|c|c|c|c|}
\hline HOME & $\begin{array}{c}\text { Risk } \\
\text { characterization }\end{array}$ & $\begin{array}{c}\text { Damage } \\
\text { criteria } \\
\text { estimation }\end{array}$ & $\begin{array}{c}\text { Fire risk } \\
\text { analysis } \\
\text { (quantification } \\
\text { of the } \\
\text { likelihood) }\end{array}$ & $\begin{array}{c}\text { Fire risk } \\
\text { analysis } \\
\text { (quantification } \\
\text { of the impact) }\end{array}$ & $\begin{array}{l}\text { Evaluation of } \\
\text { the integration } \\
\text { of the fire } \\
\text { protection } \\
\text { measures in } \\
\text { the system }\end{array}$ & $\begin{array}{l}\text { Cost-benefit } \\
\text { analysis }\end{array}$ & INFO \\
\hline
\end{tabular}
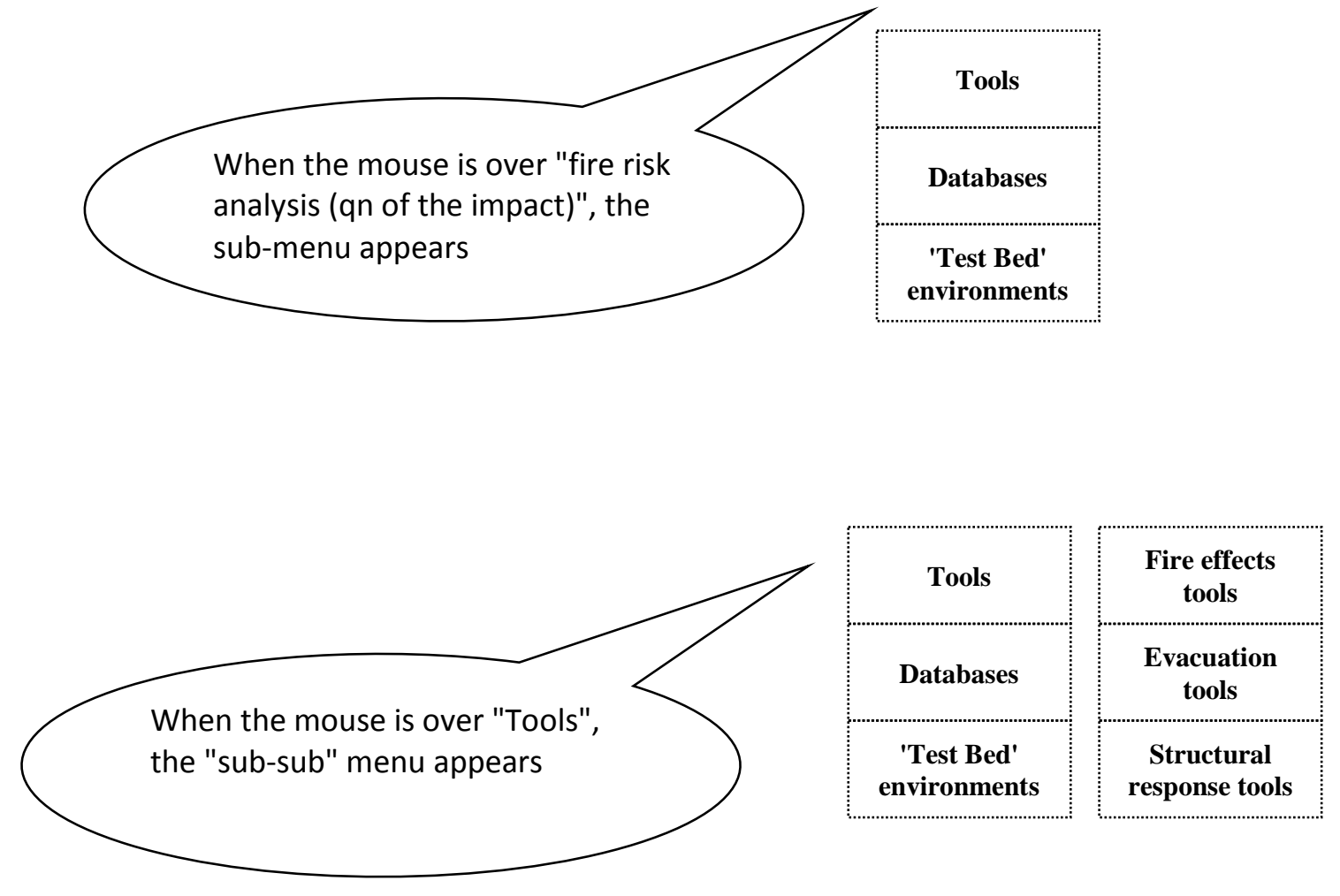

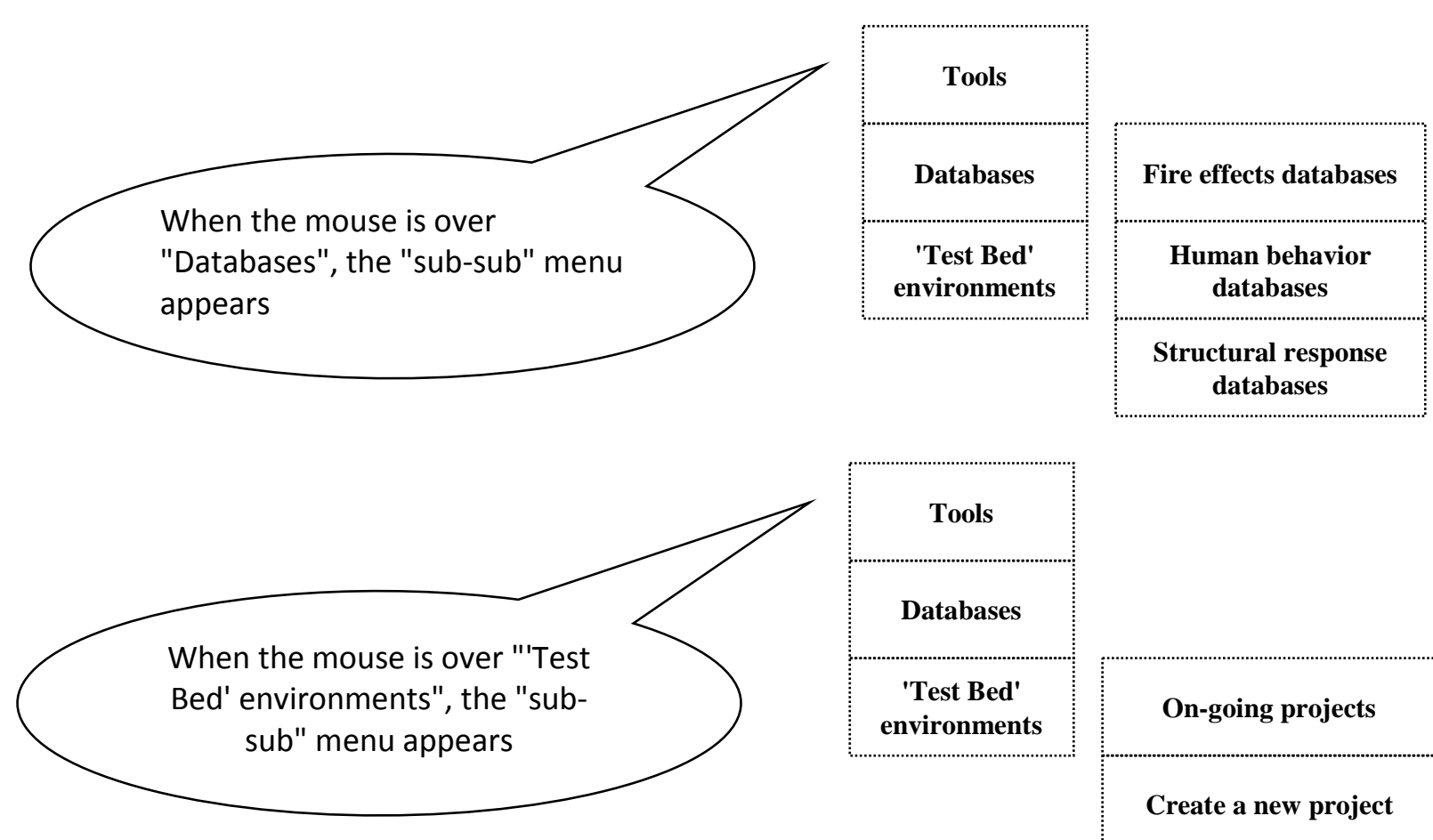

\begin{tabular}{|c} 
On-going projects \\
Create a new project \\
Select /upload a \\
building configuration
\end{tabular}



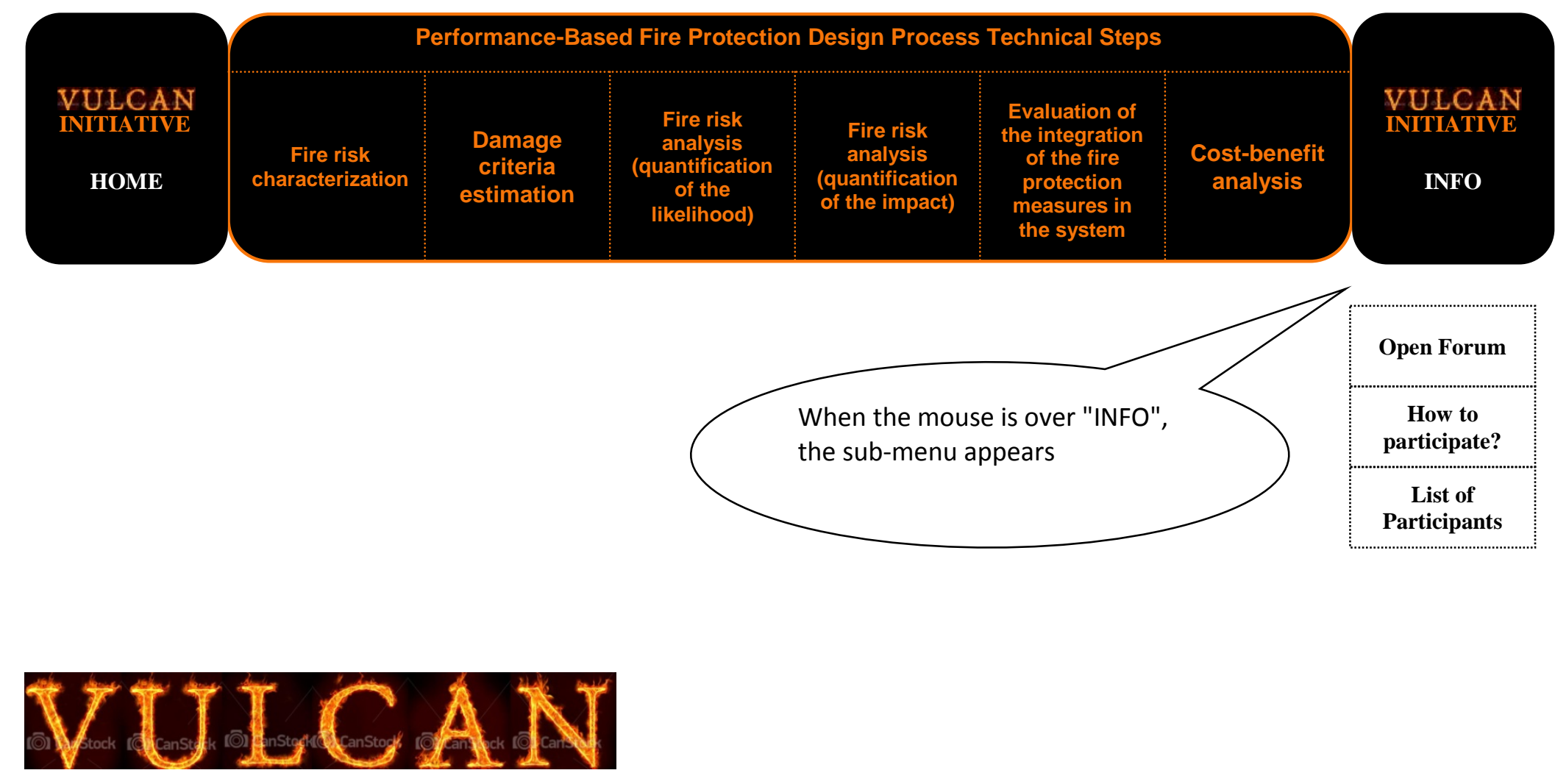
The Vulcan Initiative is a website dedicated to help the Fire Protection Engineering community with the application of Performance-Based Fire Protection Design (PBFPD) option.

This website was set up around a new risk-informed PBFPD process, which aim is to assess how fire events affect the overall performance of a system formed by specific building types and their associated occupants (called "building-occupant" systems). This new process contains technical steps that are separated from the ones where project oriented decisions are taken by the considered stakeholders. This separation allows Fire Protection Engineers (FPEs) after gathering the characteristics of the system to study, to independently treat fire events in a straightforward manner and propose their fire protection feature sets to the stakeholders for their final approval. The approval is based on documents showing the results of a fire risk analysis, the evaluation of the fire protection features in the system and a cost-benefit analysis of these features.

Guidelines associated with each technical step of the new PBFPD process have to be developed for specific "building-occupant" systems. Generic guidance was necessary to present the PBFPD approach when it was originally proposed to the FPEs and the code policy makers. Nevertheless, this generic attribute turned to be a challenge for the application of the PBFPD option, and it led to the need for more specific guidance.

The Vulcan Initiative has been created in order to be the repository of all the information gathered, from the needed research to the establishment of the guidelines elaborated for specific "building-occupant" systems.

The Vulcan Initiative is aimed to facilitate the exchange of information between the different actions of the PBFPD process: Fire Protection Engineers (FPEs), stakeholders, decision policy makers, and researchers. Participation of Academia is also welcome as teachers can use the information provided here as a technical resource and course projects and the students can upload their reports in an active effort to improve database contents or the use of models.

The Vulcan Initiative is organized according to the PBFPD process. Except the step related to the evaluation of the integration of the fire protection measures in the system, each step of the process requires the quantification of information. This information is estimated using dedicated tools which output is the requited information. Input data is necessary for the use of tools and therefore this requires the establishment of relevant databases. Validation of tools is a concern across the FPE community. The extension of validation domains is often associated with costly experiments. It would be time consuming to increase the current validation domains up to their application domains. Since the PBFPD process is an engineering one, the validation domains need to encompass the engineering domain limited by the specific systems characteristics and their associated issues, i.e. engineering problems related to fire events affecting these systems. Within the Vulcan Initiative, 'test bed' environments are then created in order to ultimately create guidelines related to the appropriateness of tools and their associated databases to be used to solve specific issues concerning specific "building-occupant" systems.

Clicking on each of the technical step in the banner will send you to a page describing the corresponding step.

Clicking on "Info" will open a sub-menu composed of a "forum" where you can post and review threads associated with the Vulcan Initiative, of a "how to participate" and of the lists of participants and their current actions.

Alberto Alvarez - W³PI (2012-09-28) 


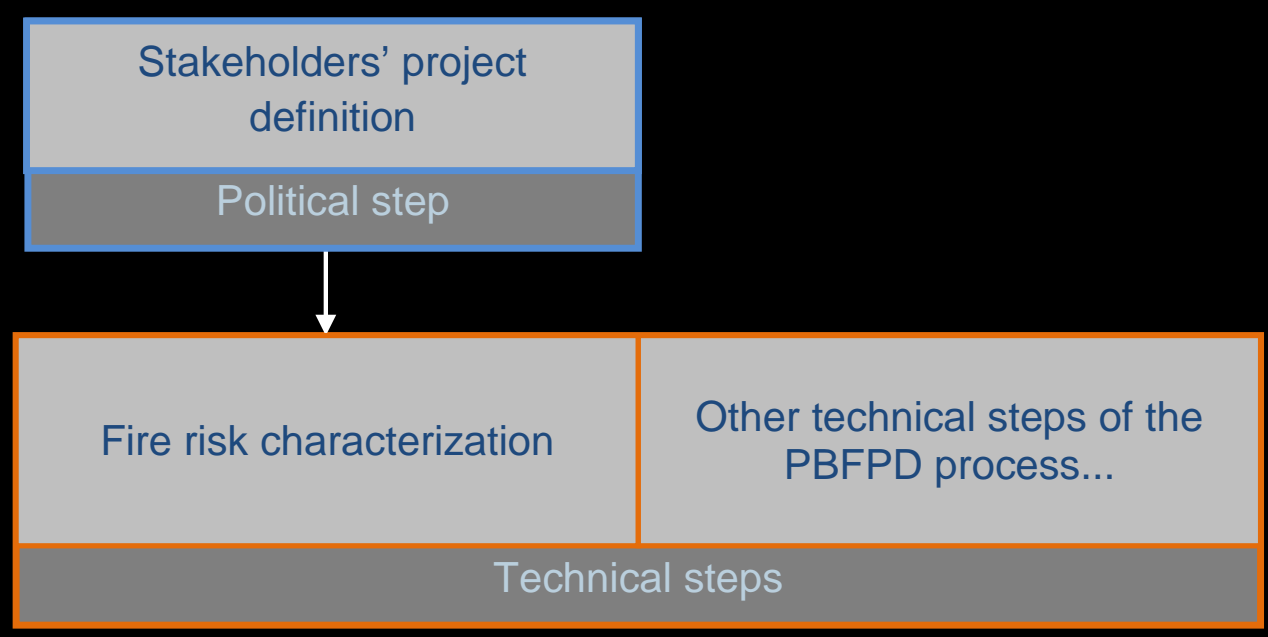

The stakeholders of a specific "building-occupant" system are mainly interested in the daily performance of their system. In the building-occupant system paradigm associated with the new PBFPD process, "targets" are defined as the actors of this performance. For example, targets can be building occupants (patients including their visiting families and friends and staff in hospitals, pupils and teachers in schools) or building contents (important piece of equipment required to contribute to the performance of the system such as a newly developed micro-chip in high tech industry or a priceless artifact in a museum).

The fire risk characterization step is about translating the fire safety engineering problem from a stakeholders' perspective to a FPE perspective.

During the project definition step at the start of the PBFPD process, the project stakeholders have to agree on the main goals and objectives related to the considered "building-occupant" system and precisely what specific building attributes are of concern (e.g., atrium, high rise configuration). These are considered political aspects of the problem, as decisions are required by others than the FPE alone.

Once decided, all of this information is transmitted to the FPE who starts the technical aspect of the PBFPD process by selecting fire risk acceptance metrics that correspond to the considered project.

Tools that FPEs can potentially use to assess the information relative to the fire risk characterization step are fire risk matrixes or fire risk curves, as illustrated.

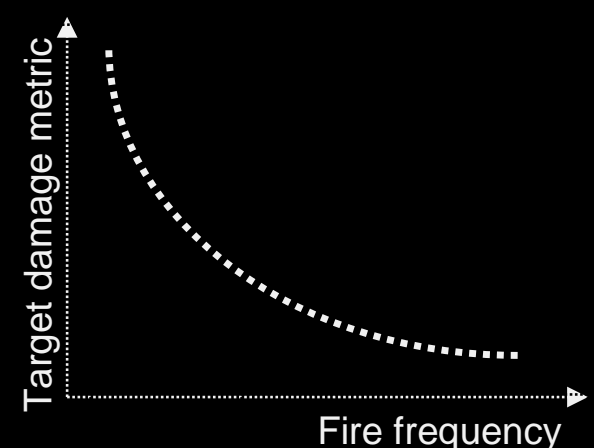


Tool Input databases are then related to the assessment of two different types of information:

- fire statistics which would help to quantify the frequency of fire events with their associated impact of the system targets,

- system statistics which would help to quantify the number of systems upon which fire statistics are applied.

In consequence, 'test bed' environments will be set up for specific "building-occupant" systems according to their characteristics. Issues related to a particular 'test bed' environments will be treated in relation to the different natures of targets a specific system contains.

Alberto Alvarez - W³PI (2012-09-28) 
In the "fire risk characterization" step of the new PBFPD process, fire protection engineers (FPEs) collected the system targets (i.e. elements of the system which contribute to its overall performance). Then, in the "damage criteria estimation" step, for each considered targets, FPEs have to quantify how these targets are affected by direct and indirect effects of fire events, events involving a fire and defined between two "chronic" states of the system.

After reviewing the two decades of worldwide experience using standards, codes and guidelines related to PBPFD for buildings [1], we concluded that the performance criteria gathered in the current codes, standards and guides and guidelines:

- should be called "damage criteria" as they quantify more a threshold value at which building occupants (and contents) are damaged than the performance of the considered project to withstand fires,

- only include the direct effects of a fire (people and building contents are affected by high temperatures, high toxic fire effluents and low visibility preventing occupant evacuation or rescue).

As the new engineering process is target oriented, it is essential to get the metrics allowing the estimation of the potential damage to the targets. Damage criteria metrics would have to include:

- typical criteria related to fire effects to humans (due to thermal threat, toxic threat and loss of visibility which impedes evacuation),

- damage criteria related to stampede,

- damage criteria related to indirect fire threat to people,

- damage criteria related to safety equipment, building contents (e.g. for heritage preservation) and - damage criteria related to the use of fire protection measures (sprinkler, fire fighting) on building contents and systems.

These damage criteria have to be collected and the process by which the damage is assessed has to be a result of an agreement within the scientific community not only involving fire protection engineers but also:

- toxicologists, psychologists, etc. when the targets are related to the life safety objective,

- operators, electronics engineers, etc. when the targets are related to the business continuity objective,

- Structural engineers, etc. when the targets are related to the property protection objective.

[1] A. Alvarez, B.J. Meacham, N.A. Dembsey, J.R. Thomas, 20 Years of Performance-Based Fire Protection Design: Challenges Faced and a Look Ahead, Journal of Fire Protection Engineers, submitted Aug, 12th 2012, submission number: JFE-12-0035

Alberto Alvarez - W³P (2012-10-02) 
For each system targets considered in the "fire risk characterization" step of the new PBFPD process, fire protection engineers (FPEs) have to quantify how these targets are affected by direct and indirect effects of fire events. Fire events differ from the current notion of fire scenarios: a fire event does not only consider the time frame between the iginition and the extinguishment of a fire but it also involves the recovery period follwing a fire until the considered system has reach a new "chronic" state, where it can perform again in a daily basis.

Fire risk analysis has then to be conducted in order to characterize the likelihood and the consequences of fire events on the targets. The FPE work is then to propose fire protection measures in order to minimize the occurrence of the damaging fires and mitigate the impact of these fire events on the system performance (i.e. the consequences of the fires events affecting system targets).

In a deterministic approach, the current PBFPD processes do not specify detailed procedures on how to select fire design scenarios or they provide a list from where the FPE and the stakeholders can "pick up" and finally agree on the ones to use. Thus, the resulting fire design scenarios fell to consider the chronic use of a building, are focused on the fire event instead of being target oriented and miss the importance of the recovery phase.

In this step of the proposed PBFPD process, event trees are elaborated in order to describe quantitatively the different fire events. Fault trees are also established in order to characterize all the different scenarios leading to target damage, so to capture the indirect threats to the targets. Fire risk models are used in this process step to help calculate the scenario likelihoods.

Tools related to the quantification of the likelihood of fire events may include fault trees, event trees, what-if analysis, bayesian networks and "ready-to-use" tools such as FiRECAM ${ }^{\mathrm{TM}}$ [1], CRISP [2] and FIERAsystem [3].
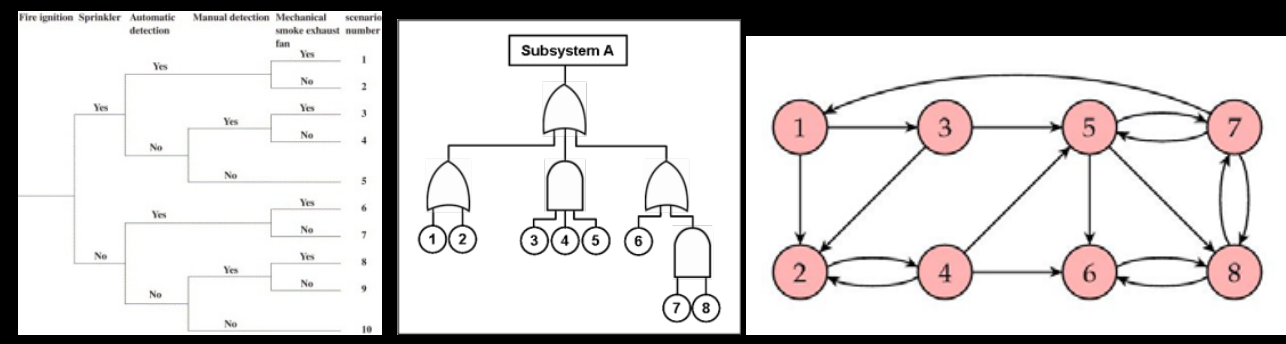

\section{Event tree - Fault tree - Markov chain}

Databases related to the quantification of the likelihood of fire events may include fire statistics with an emphasis on fire ignition frequencies and data on fire protection measure reliability.

'Test bed' environments will be set up for assessing the appropriateness of tools to quantify the likelihood of fire events for specific "building-occupant" systems, along with the corresponding data needed to use the tools.

[1] http://www.firemodelsurvey.com/pdf/FiRECAM_2001.pdf

[2] http://www.firemodelsurvey.com/pdf/CRISP_2001.pdf

[3] http://www.firemodelsurvey.com/pdf/FIERAsystem_2001.pdf

Alberto Alvarez - W³ PI (2012-10-04) 
Following the new PBFPD process step dedicated to the assessment of the likelihood of fire events susceptible to occur in defined "building-occupant" systems, the fire protection engineers (FPEs) have to assess the consequences of these fire events, and more precisely the impact these events would have on the system targets which define its performance.

While assessing the consequences of fire events susceptible to occur in the built environment (including buildings, structures such as airport terminal or underground subway station or tunnels), the fire protection engineers (FPEs) use different types of tools. These tools can be characterized by the phenomena they model (fire effects including temperature profiles, smoke movement, evacuation of occupants and structure response to a fire) and by their level of complexity (e.g. for fire effects calculations: algebraic equation gathered in a procedural set, zone models, and computational fluid dynamics).

In order to help the FPEs "substantiate a fire model for a given application", the Society of Fire Protection Engineers (SFPE) published a guide [1] in 2011, in complement of the SFPE guidelines that help the engineer understand the performance-based design process [ ] and the SFPE guidelines which assist code officials in the review of performance-based designs [ ].

Solving a fire related problem within the engineering context of performance-based fire protection design requires most of the time using tools characterizing the fire effects on one hand and the occupant evacuation process on the other hand. Due to the complexity of these phenomena, the past decades of research have been dedicated by scientists to model 3-D effects of fires while other scientists concentrated their efforts on building occupant evacuation tools. In consequence, no major effort was made by the community to provide guidance for FPEs to use these tools in conjunction.

Thus, the 'test bed' environment studies seem the best opportunity for the FPE community to share their savoir-faire in terms of how the simultaneous processes of fire spreading and occupant evacuation are dealt for specific systems formed by building configurations and their occupants.

Databases for all these types of tools dedicated to the quantification of the impact of fire events are also required in order to provide data applicable to specific "building-occupant" systems, in order to reduce the uncertainities related to the input data on the tool results.

[1] SFPE, Guidelines for Substantiating a Fire Model for a Given Application, 2011

[2] SFPE, SFPE Engineering Guide to Performance-Based Fire Protection, 2007

[3] SFPE/ICC, Code Official's Guide to Performance-Based Design Review (chapter 11), Society of Fire Protection Engineers and International Code Council, 2004

Alberto Alvarez - W³I (2012-10-03) 
Tools quantifying the impact of fire events have been developed separately as each of the following phenomena has required its own extensive research:

- fire effects,

- evacuation of building occupants,

- response of the building structures.

Fire effects tools gather:

- algebraic equation sets, dedicated to the specifics of the fire phenomena such as the temperature on the centerline of a fire plume, temperature profiles in the ceiling jet, time before flashover in a room, activation time of a heat detector.

- fire zone models, which usually divide an orthogonal space into two control volumes (i.e. a lower zone and an upper zone) where the temperature and the species concentrations are considered homogeneous. Additional zones may be considered like a plume or a ciling jet.

- Computational Fluid Dynamics (CFD) fire models, which divide complex geometries in a large number of control volumes where usually a set of governing equations for conservation of energy, total mass, momentum and chemical species.

\section{Evacuation tools gather [1]:}

- movement models based on algebraic equation sets that describes the movement of people with hydraulic models,

- partial behavioral models,

- behavioral models,

- behavioral models with risk assessment capabilities,

- behavioral models with artificial intelligence capabilities.

Structural response tools gather:

- algebraic equation sets, which were established for the design of fire resistance of structures [2],

- $2 \mathrm{D}$ or $3 \mathrm{D}$ models, which calculate the evolution of the temperature in the structural elements in a fire introduced as the evolution of the gas temperature or a net flux on the surface of the structure.

[1] Erica D. Kuligowski, Computer Evacuation Models for Buildings, Section 3, Chapter 17 of the 4th edition of the SFPE Handbook of Fire Protection Engineering, Society of Fire Protection Engineering, National Fire Protection Association, 2008 
[2] Ulf Wickstrom, Methods for Predicting Temperatures in Fire-Exposed Structures, Section 4, Chapter 9 of the 4th edition of the SFPE Handbook of Fire Protection Engineering, Society of Fire Protection Engineering, National Fire Protection Association, 2008

Alberto Alvarez - W³ $\mathrm{PI}(2012-10-05)$ 


\section{Objectives of the 'test bed' environment studies.}

The 'test bed' environment studies are designed to ultimately provide guidelines for the FPEs to use the appropriate set of tools while solving a fire safety related issue in the built environment.

Guidelines would be established at the conclusion of each 'test bed' environment, gathering information of the different tools used to solve the common engineering questions, how the engineers manage to mix the results from different

As a by-product of the 'test bed' environments, feedback may be given to the tool developers (who we hope will be an active part of the 'test bed' environment studies) in order to develop new models or improve the current ones so to increase the validation domains of their tools to include the ones considered in the 'test bed' environment studies.

\section{The organization of 'Test bed' environments}

Each 'test bed' environment is organized in three phases:

- $\quad$ the pre-processing phase,

- $\quad$ the processing phase

- $\quad$ and the post-processing phase.

You can help the community by either joining already defined 'test bed' environments (by looking at the list of ongoing projects) or setting up a new project. By clicking on either one of these links, you will be given information about the different phases of a 'test bed' environment.

Besides, you can look at the different building configurations that are available for a possible new project, create a new project with one of these configurations or propose new building configurations so other engineers can use and set up new 'test bed' environment projects.

\section{Important related texts}

The concept behind the 'test bed environments was first introduced by Alberto Alvarez at the 2011 Fire and Evacuation Modeling Technical Conference, hosted by the company Thunderhead Engineering. The paper prepared for this conference is available with this link.

In 2002, Prof. Brian J. Meacham presented the 'test bed' environment during the 9th International Conference on Performance-Based Codes and Fire Safety Design Methods organized by the Society of Fire Protection Engineers. 


\section{Pre-processing phase page for a New Project}

The pre-processing phase introduces the 'test bed' environment study and therefore includes the following information someone designed as the Project Leader needs to provide to start a new project. Feel free to submit the information described below. The information will be sent to the moderator of the website in order to assess the completeness of the information and consequently design a specific page in the ongoing project section of this website. All the provided information would be made available there, and a corresponding forum will be created so that the project participants could exchange information on the subsequent phases of the project.

Please fill up the different information below and upload the building layout files.

\begin{tabular}{|c|c|}
\hline $\begin{array}{l}\text { Name of the Project Leader } \\
\text { If you are interested in submitting a new topic for a 'test bed' } \\
\text { environment, you are encouraged to fill up the form and submit to the } \\
\text { moderator of the site for assessment and configuration of the new project } \\
\text { page }\end{array}$ & \\
\hline $\begin{array}{l}\text { Classification of the studied system } \\
\text { Specify the building-occupant type related to the main purpose of the } \\
\text { building (e.g. hospital, nursing home), along with the design features } \\
\text { which have an influence on the fire event (e.g. high rise configuration and } \\
\text { atrium space) }\end{array}$ & \\
\hline $\begin{array}{l}\text { Object of the Study } \\
\text { Specify here the objective of the 'test bed' environment study related to } \\
\text { the considered system described above }(*) \\
\text { (e.g. horizontal evacuation of a patient room floor in a hospital) }\end{array}$ & \\
\hline $\begin{array}{l}\text { Building layout } \\
\text { For the time being, building layouts provided here for use in the } \\
\text { subsequent processing phase will contain all the data architects establish } \\
\text { in the design phase of a project }(* *) \text {. } \\
\text { Please, upload here all the files related to architectural design. Common } \\
\text { formats are from the software AutoCad }{ }^{\odot} \text { and } \operatorname{Revit}^{\odot}\left({ }^{* * *} \text { read the }\right. \\
\text { important disclaimer) }\end{array}$ & \\
\hline
\end{tabular}

$\left.{ }^{*}\right)$ Fire events susceptible to occur in the system and damage directly or indirectly system targets which define the metrics of the system performance.

Within a single complex building configuration, it would be possible to study numerous fire events including: - the fire events themselves (e.g. study of the characteristics of a single or several fire protection measures and their effects on the fire event) in that case, the 'test bed' study only deals with fire effects tools,

- building occupant evacuation strategies (e.g. the study of the evacuation process using elevators in high rise buildings). In that case, the 'test bed' study deals with evacuation tools alone or combined with fire effects tools, - structural response (e.g the study of partial or total collapse of a building in fire).

$(* *)$ The focus of the 'test bed' studies is related to the capabilities of the tools to describe the phenomena, with knowing the maximum of information as given after the design phase of a project, so that each tool, from the simple procedures found in standards to the most complex, such as computational Fluid Dynamics and evacuation tools simulating human behavior, can be used at their own full potential in order to the comparison to be complete. Studies have been performed to compare results from tools, but for specific scenarios with the aim of determining and increasing the domain of validation of these tools. Studies were conducted on certain types of tools, fire effects tools or evacuation tools (Lord et al. 2006). No study has been undertaken for comparing tools for specific engineering topics for specific systems: for example, and then(but not as engineering responses)

$\left({ }^{* * *}\right)$ By submitting these files, you make sure that the files are not copyright protected, and legally available for the FPE community to use. 
Name of the Project Leader:

Prof. Brian J. Meacham - Worcester Polytechnic Institute (USA)

e-mail address: place email address here

Please contact the Project leader if you wish to participate

Classification of the studied system: 6 story High-rise Hospital, with an atrium

Object of the Study:

horizontal evacuation of a patient room floor in a hospital

Building layout files:

Link to the CAD and PDF files

Project Initiation Date: October 1st, 2012

Project Participants: Alberto Alvarez (Worcester Polytechnic Institute - USA, place email address here) Majed Almejmaj (Worcester Polytechnic Institute - USA, place email address here)

\section{Description of the object of the 'test bed' study}

Project 1 concerns the optimization of horizontal evacuation of a patient room floor in a high-rise general hospital, in case of a fire starting in a corridor of that floor.

The objectives related to Project 1 are to:

- insure the safe displacement of the patients susceptible to be affected by the effects of the fire originating in the corridor,

- minimize the number of patients affected by any fire originating in the corridor as well as limit the damages to the patient room floor.

Alberto Alvarez - W³PI (2012-10-01) 
Databases for tools quantifying the impact of fire events include:

1) databases associated with fire effects tools, containing useful information from

o fire experiments involving combustible materials located in the considered system, describing how these materials release heat and fire effluents with time,

o characteristics of combustible materials, in terms of physical properties to absorb heat and ignite (e.g. thermal conductivity, density, heat capacity, thermal response parameter).

When looking for heat release rates for building contents, from furniture to curtains, from appliances to even cars, a primary source of information is the SFPE Handbook chapter dedicated to heat release rates, written by Babrauskas [1]. This chapter contains numerous references that can lead to a significant amount of data from furniture calorimeters, including heat release rates evolution with time, soot and toxic component yields. In addition, by reviewing NIST publications alone, some fifty different experiments have already been included in a database, along with the available snapshots and videos. This number will be expanded by looking at more NIST studies, as well as tapping into test data from around the world. Before the end of the year 2012, it is planned to include this database in the Vulcan Intiative to get some feedback and possible contribution to the database from engineers across the world.

Radiation transfer is avery important phenomenon to consider when assessing fire spread from the first burning item to the rest of the combustibles located nearby. 3-D fire simulators are able to model radiative heat transfer, which requires a refined characterisation of the flame, in terms of location and height. In consequence, creating Fuel Packages for 3-D simulations seems a useful task to perform so that FPE could directly use them in calculations using the Fire Dynamics Simulator at first.

The fire experiment database could be found here.

The Fuel Packages for 3-D simulations are introduced here.

2) databases associated with the evacuation of building occupants, containing useful information from

o experiments related with occupant movement in the built environment,

o experiments related with human behavioral response to fire and smoke.

3) databases associated with structural response of the building in case of fire events, containing useful information from

o fire experiments related with the partial collapse of a ,

o characteristics of non combustible building materials, in terms of physical properties to absorb heat.

[1] Vytenis Babrauskas, Heat Release Rates, Section 3, Chapter 1 of the 4th edition of the SFPE Handbook of Fire Protection Engineering, Society of Fire Protection Engineering, National Fire Protection Association, 2008

Alberto Alvarez - W³PI (2012-10-09) 
3-D fire simulators that are used as engineering tools for safety purposes, still require the user to input data such as the evolution with time of the heat release rate (HRR), which describes the fire from its ignition to its extinguishment, as well as the evolution with time of the species produced by the combustion of the different flammable building contents. The HRR history is assumed to be determined from single HRR curves established with furniture calorimeter tests and translated in time when the ignition of the subsequent building contents is estimated, according to a pre-established fire scenario. This project aims to create a comprehensive database of HRR curves for a range of combustible building contents so that the fire protection engineer can select the data which is the most appropriate to a fire protection engineer project.

Fuel packages for 3-D fire simulators include:

- a 3-D geometry, which represents the spatial configuration of the combustible package, as its external envelope,

- the description of the evolution with time of the burning surfaces of the 3-D geometry.

The characteristics of the burning surfaces will determine the HRR history as well as the production of fire effluents.

The final product of this project is intended to create "fuel packages" to be used in the Fire Dynamics Simulator (FDS) developed by the US National Institute of Standards and Technology (NIST) since this computational Fluid Dynamics is available for free and largely used by the Fire Protection Engineering community. Nevertheless, it is expected that the 'fuel packages" will be described with enough details that they could be used for other CFD fire simulators.

The advantage of having discrete "fuel packages" for 3-D simulations is to be used by Fire Protection Engineers to estimate the ignition of secondary fuel sources located nearby the 'fuel package' on fire. Ignition of secondary fuels is mainly dependent on the thermal radiation received by these fuels. The received radiation is a function of the distance between the two types of fuel sources and the power of the radiative "fuel package" emitter.

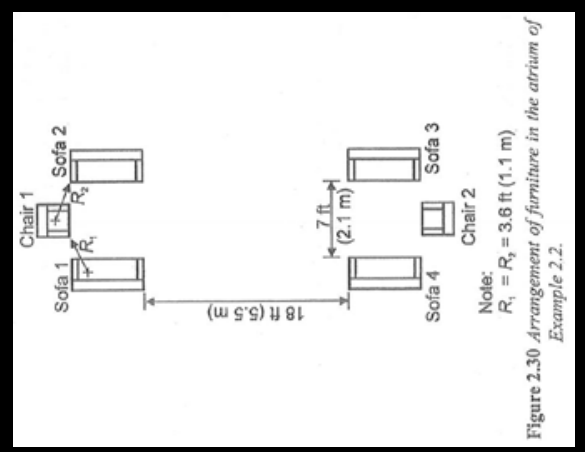

Insert new figure here (when it is available).

The figures below present an example of the process followed in order to implement the 'combustible package' database, for a mattress ignited at its center. The 3-D Fire Dynamics Simulator (FDS) from NIST has been used to recreate this experiment. 

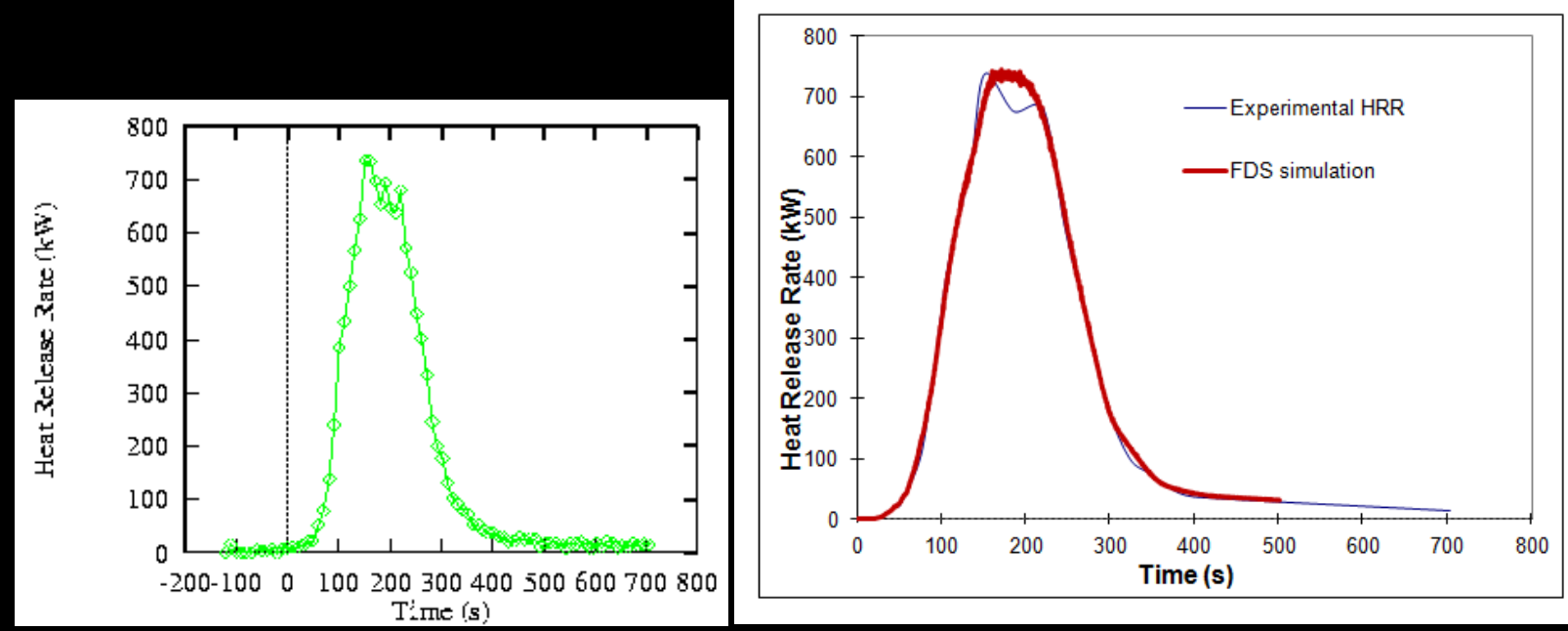

Evolution with time of the Heat Release Rate of a mattress with central ignition On the left: experimental data extracted from a NIST resource

On the right: comparison between the experimental data and a FDS simulation

In addition to the HRR curve, the database gathers information related to the dimensions of the 'combustible package', the applied ignition source, videos or snapshots of the experiment showing flame spread, evolution with time of the fire effluents.
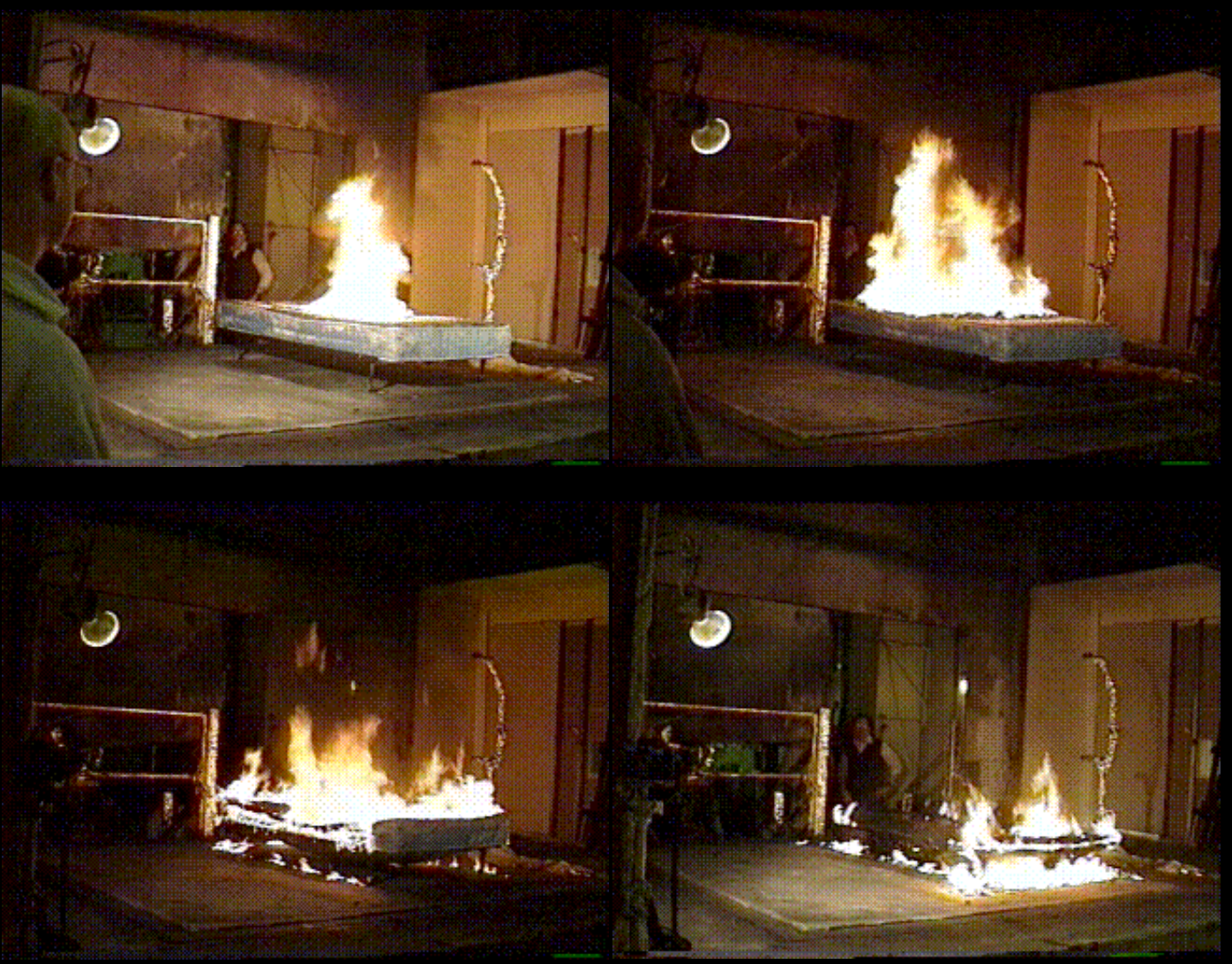
Snapshots of an experiment involving the combustion of a mattress with central ignition (source: NIST) From left to right: at 90 seconds, at 120 seconds, at 210 seconds, at 300 seconds

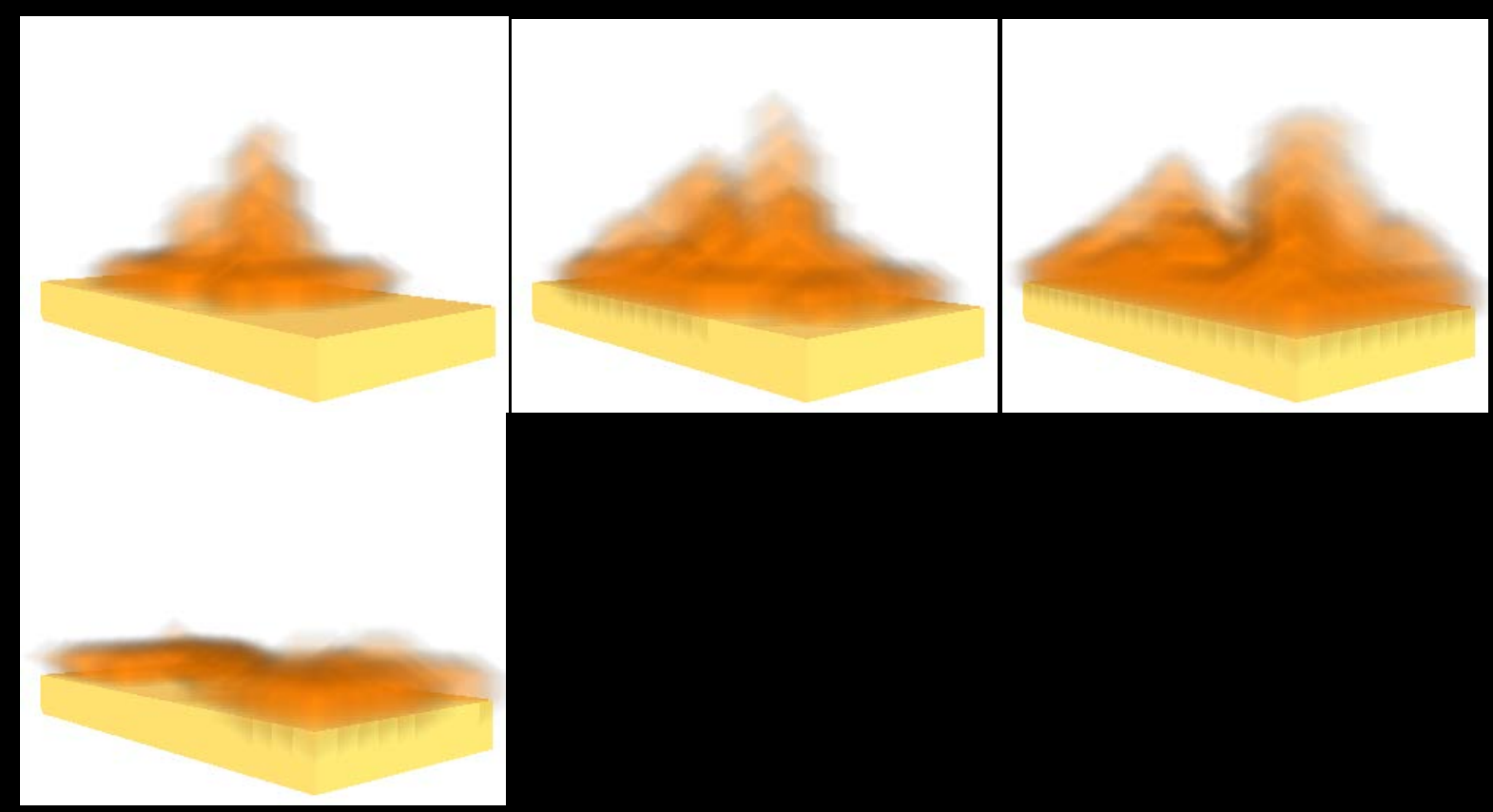

Snapshots of the corresponding FDS simulation at the same moments (200 kW.m-3)

Productions of fire effluents (toxic and irritant products) as well as soot are data required for assessing toxicity and loss of visibility during fire events. FDS allows the use of 'burners' which can also emit species such as $\mathrm{HCN}, \mathrm{CO}_{2}, \mathrm{CO}, \mathrm{HCl}$ and soot, as a function of time, specified by the user. Some of the furniture calorimeter experiments contain this data. For these 'combustible packages', the data will include fire effluent productions (in over-ventilated conditions and under-ventilated conditions when available) as well as the HRR curve.

Nevertheless, it should be noted that the data related to fire effluent production is sparse. It is often given as a global mass yield (i.e. mass of a considered fire effluent produced, divided by the mass of fuel consumed), or as a global $\mathrm{CO} / \mathrm{CO}_{2}$ ratio as this parameter is an indicator of the ventilation conditions.

In absence of fire effluent data for a 'combustible package' from furniture calorimeter tests, data gathered from cone calorimeter tests or other laboratory-scale tests may be considered.

A list of collected experiments that could be used to set up packages is located here. 
"List of collected furniture test experiments" page

Twin Size Bunk Bed

Twin Size Mattress

Twin Size Mattress

Kiosk

Small Dresser

Workstation

Workstation

Sofa NIST Fire test

Loveseat NIST Fire Test

Wooden Pallet NIST Fire test

Chair

Chair

Chair

Chair

Loveseat

Sofa

Chair

Chair

Chair

Chair

Chair

Chair

Loveseat

Sofa

Sofa

Sofa

Sofa

Sofa

Sofa

Sofa

Sofa

Bookshelf

Bookshelf

Bookshelf

Bookshelf

Wires

Wires

Wires

Wires

TV Cabinet housing (NFR)

TV Cabinet Housing(FR)

Business Maching Housing (NFR)

Business Maching Housing(FR)

Kiosk-open shelved

Kiosk-closed shelved

Metal Wardrobe

Metal Wardrobe 
Plywood Wardrobe Plywood Wardrobe

Plywood Wardrobe

Particleboard Wardrobe

Plywood Bookcase

Mattress

Mattress

Mattress and box spring

Mattress, no box spring

Mattress, Twin size

Mattress, Queen size

Mattress, King size 


\section{Building Configurations Homepage}

This page contains building configurations that have been collected independently of any 'test bed' studies but could be used for future projects as they are free from any copyright and as they represent potential interesting buildings of interest.

In case you have building configurations you would like to share with the Fire Protection Engineering community for future 'test bed' studies, feel free to fill up the form at the bottom of this page.

\begin{tabular}{|l|l|}
\hline \multicolumn{1}{|c|}{ Building configurations } & Image(s) \\
\hline High Rise Historic building (Hall of Justice) & \\
\hline High-rise office building & \\
\hline Science Building & \\
\hline Dormitory (2 wards with a common space at the junction) & \\
\hline & \\
\hline & \\
\hline
\end{tabular}


The fire protection measures considered in the fire risk analysis steps for their benefits in reducing the effects of fire events upon the overall performance of a "building-occupant" system.

Fire Protection Engineers (FPEs) need to evaluate how these fire protection measures are integrated in the system, so because of the challenges related to the maintenance and the possible changes of the building use once the design phase and the construction phase are done. This 5th important step of the new PBFPD process is performed in order minimize the incompatibility of the fire protection measures with the components used in an everyday basis. In other terms, this step assesses the fire protection measures, which are the most efficient according to the fire risk analysis, are not counter-productive and therefore ignored or worse rejected by the system, ultimately rendering them inoperative during an actual fire event. This step goes beyond the documentation on how the fire protection measures are designed, installed and maintained in the current PBFPD processes.

Tools such as the ones elaborated for system dynamics could be valuable to perform this new PBFPD process.

Databases are required to gather elements of the system functionality including contingency plans established to deal with emergency situations.

'Test bed" environments are built so to consider the specificities of "building-occupant" systems and their related fire event issues.

Alberto Alvarez - W³ PI (2012-10-03) 
To be completed

Tools such as the ones elaborated for establishing a cost-benefit analysis of system components could be valuable to perform this new PBFPD process.

Databases are required to gather.

'Test bed" environments are built so to consider the specificities of "building-occupant" systems and their related fire event issues.

Alberto Alvarez $-\mathrm{W}^{3} \mathrm{PI}(2012-10-03)$ 